\title{
PURChASING SKILLS
}

\section{LEADING TO}

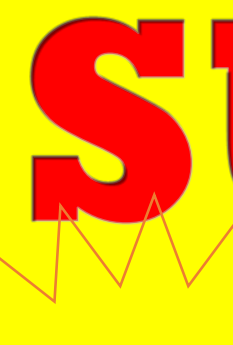

U
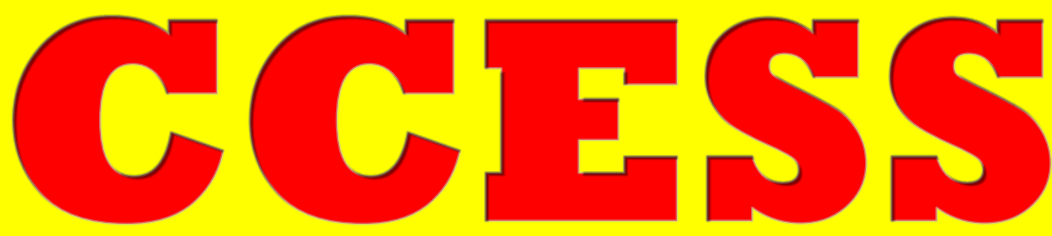

BEST

BUYER
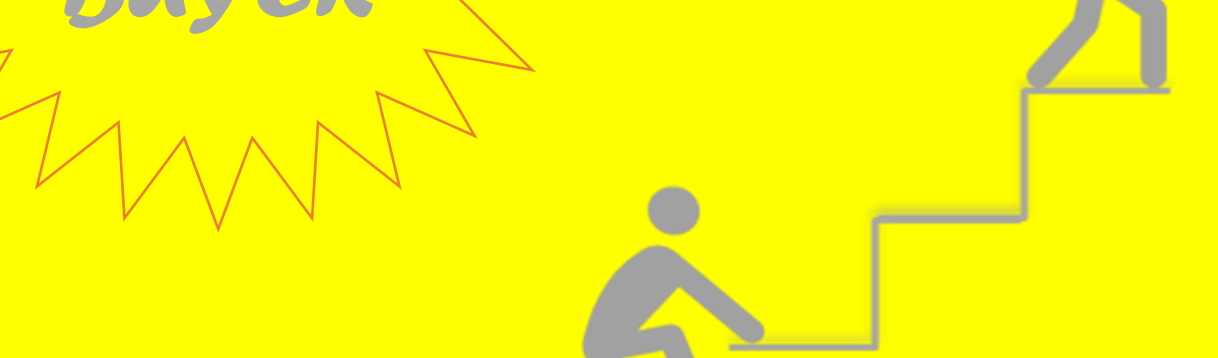

\section{INCLUDING}

ROADMAP TO

IMPROVE YOUR

PROCUREMENT

SKILLS 



\section{PURCHASING SKILLS LEADING TO SUCCESS}

HOW TO SUCCEED IN INNOVATION SOURCING 


\title{
PURCHASING SKILLS LEADING TO SUCCESS HOW TO SUCCEED IN INNOVATION SOURCING
}

\section{DISSERTATION}

\author{
to obtain \\ the degree of doctor at the University of Twente \\ on the authority of the rector magnificus, \\ prof. dr. ir. A. Veldkamp \\ on account of the decision of the Doctorate Board \\ to be publicly defended \\ on Friday 11 June 2021 at 14.45 hrs \\ by \\ Klaas Peter Martin Stek
}

born on the $3^{\text {rd }}$ of July, 1967

in Meppel, The Netherlands 


\section{This dissertation has been approved by:}

\section{Supervisor}

prof. dr. habil. H. Schiele

Cover design: Klaas Stek

Printed by: Ipskamp Printing

Lay-out: Klaas Stek

ISBN: 978-94-6421-364-5

DOI: $10.3990 / 1.9789464213645$

(c) Klaas Stek, The Netherlands. All rights reserved. No part of this dissertation may be reproduced, stored in a database or retrieval system, or published in any form or in any way, electronically, mechanically, by print, photo print, microfilm, or any other means without prior written permission by the author.

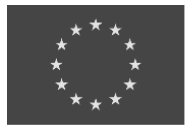

\section{Co-funded by the}

Erasmus+ Programme of the European Union

Acknowledgements: This research is a part of Project PERFECT (Purchasing Education and Research for European Competence Transfer), Project PERSIST (Purchasing Education Research Syndicate: Industry 4.0 Skills Transfer), and Project PERISCOPE (Purchasing Education Research with an Innovative Sustainability Scope) set up and funded by the European Union to become the first worldwide region to establish an empirically validated pan-European PSM higher education curriculum. The project is embedded into the ERASMUS+ 2015 KA2 programme (Cooperation for Innovation and the Exchange of Good Practices Strategic Partnerships for Higher Education) with the project numbers 2015-1-DE01-KA203-002174 (PERFECT); 2019-1-NL01KA203-060501 (PERSIST); and 2019-1-FR01-KA203-062990 (PERISCOPE). 


\section{GRADUATION COMMITTEE}

Chair / Secretary:

prof. dr. T.A.J. Toonen

University of Twente

Supervisor:

prof. dr. habil. H. Schiele

University of Twente

Committee Members:

prof. dr. L.C. Giunipero

Florida State University

prof. dr. J. Hallikas

Lappeenranta University of Technology

prof. dr. U. Bauer

Graz University of Technology

prof. dr. T. Bondarouk

University of Twente

prof. dr. L.A. Knight

University of Twente 


\section{Preface, \\ Tables of Content and Glossary}




\section{PREFACE}

\section{Procurement and purchasing - skills and competences - plus success}

Ideally, the title of a dissertation serves as the proverbial standard that covers the load. Here the title is short - PURCHASING SKILLS LEADING TO SUCCESS - which might raise questions on what is meant with 'purchasing', 'skills' or 'success' and especially, as the subtitle suggests, on How to SUCCEED IN INNOVATION SOURCING. This research aims to present those necessary skills for success in the purchasing profession and innovation sourcing, and answers are given on how higher education institutions should address these in purchasing or procurement courses. However, the first issue is determining 'purchasing' or 'procurement'.

Interestingly, the etymology of "to procure" stems from the old French (procurer) and means "care for, be occupied with; bring about, cause; acquire, provide". "Procurer" is associated with the late Latin "procuro", which means "to manage"; "take care of" or "carrying out responsibilities for others" (Wageningen \& Muller, 1929, p. 766; own translation). In a more modern sense, it has the meaning to "obtain" or to "recruit" and got in the late Middle Ages the connotation "to obtain (women) for sexual gratification" (Etymonline, 2020). According to the modern dictionary, it still has this meaning besides obtaining possession by particular care and effort. ${ }^{1}$ In this dissertation, procuring will be used in the meaning of purchasing.

Alike "to procure," the term "to purchase" also has an old French origin: "porchacier" or the modern French variant "pourchasser", meaning to "run after", "to hunt (or) chase (for)". Modern meanings are to "acquire, obtain; get, receive; procure, provide," and also to "accomplish or bring about; instigate; cause, contrive, plot; recruit, hire" (Etymonline, 2020). Currently, the meaning of purchasing is obtaining by "paying

\footnotetext{
${ }^{1}$ See: www.merriam-webster.com/dictionary/procuring
} 
money or its equivalent ${ }^{\prime 2}{ }^{2}$ Concluding, purchasing or procurement are now synonyms for professional, organisational buying activities, although they had other meanings in the past.

As hereafter will be shown, in the scientific literature, the term 'skill' is often briefly but wrongly used for the broader construct of a so-called 'competence'. The term 'skill' is used in everyday language for a construct of cognition, professional and personal skills, traits and behaviour (Delamare-Le Deist \& Winterton, 2005) or knowledge, skills, abilities and other characteristics (KSAO) (Campion et al., 2011). Further in this dissertation, more refined definitions of 'purchasing', 'skills' and 'success' will be provided. However, the concept of success is harder to define since it depends on context and perception.

\section{Projects PERFECT, PERSIST and PERISCOPE}

The idea to study purchasing skills in terms of success arose in a scholars' and educators' meeting in Germany in 2014. It was unclear how a purchasing and supply management (PSM) curriculum in higher education should be designed; research in this field was lacking. A year later, this led to a research proposal submitted to apply for an Erasmus+ project entitled Project PERFECT to design learning objectives for a PSM curriculum.

Project PERFECT (Purchasing Education and Research for European Competence Transfer) was financed by the German national agency DAAD as a so-called Erasmus+ strategic partnership in higher education from September 2015 to August 2018. Besides the German coordinator TU Dortmund and the University of Twente in the Netherlands, PERFECT consisted of Lappeenranta University of Technology (LUT) in Finland, Mainz University of Applied Sciences in Germany and Staffordshire University / Edge Hill University in the United Kingdom.

In February 2016, I joined PERFECT by attending the first transnational project meeting, still being a master student of the PSM track and a future PhD candidate at the University of Twente. In August that year, I graduated on the comparison of requirements in an international set of job advertisements for purchasers, which was part of Project PERFECT's first intellectual output. The master thesis formed the basis of Chapter 4. The possibility to graduate within Project PERFECT came with the invitation to work on this dissertation. From September 2016, the University of Twente employed me as a researcher and assigned me to the project.

\footnotetext{
${ }^{2}$ See: www.merriam-webster.com/dictionary/purchasing
} 
In August 2018, when PERFECT was finalised, six outputs were delivered. The first three outputs were (1) an exploration into the topic and consisted of literature studies and a comparison of requirements international job advertisements and learning objectives; (2) expert interviews; and (3) a European survey amongst purchasers. The following three stages were aimed to contribute to educational development: (4) the design of the set of learning objectives; (5) the production of a massive open online course (MOOC); and (6) the production of a benchmark tool for purchasers' competences.

Early 2018, before Project PERFECT came to an end, plans were made for a successor on purchasing skills in the era of the Internet-of-Things. The Project PERSIST application (Purchasing Education and Research Syndicate for Industry 4.0 Skills Transfer) was handed in with the Dutch national agency in March 2018. In 2019, the project plan was finally awarded after the second attempt with almost the same constellation as PERFECT: TU Dortmund (D), LUT (FIN), Edge Hill University (UK) and the University of Twente (NL). PERSIST is complemented with the Economic University of Bratislava with a seat in Košice, Slovakia.

Meanwhile, in 2018, more colleagues from higher education institutions had shown their interest in cooperating in an Erasmus+ strategic partnership project regarding purchasing skills in acquiring suppliers' innovations. The focus was set to the context of the circular economy, sustainable development and corporate social responsibility. In the slipstream of PERSIST, this project entitled PERISCOPE (Purchasing Education and Research with an Innovative and Sustainable Scope) was handed in with the French national agency and also got awarded. PERISCOPE consists of the French business schools Audencia in Nantes and coordinator ESSCA in Angers, Copenhagen Business School in Denmark, the Graz University of Technology in Austria and the University of Twente.

Therefore, this research is financed by ERASMUS+ KA2 programs (Cooperation for Innovation and the Exchange of Good Practices Strategic Partnerships for Higher Education) entitled Project PERFECT, Project PERSIST and Project PERISCOPE. Chapters 3,5 and 6 are based upon the European purchasing skills survey organised within Project PERFECT. Ethical approval to carry out the survey was provided by the Ethics Committee of the Faculty of Behavioural, Management and Social Sciences of the University of Twente under the numbers 17067 and 17108. 


\section{TABLE OF CONTENTS}

GRADUATION COMMITTEE iii

PREFACE vii

Procurement and purchasing - skills and competences - plus success vii

Projects PERFECT, PERSIST and PERISCOPE viii

TABLE OF CONTENTS $\quad X$

LIST OF TABLES, FIGURES AND APPENDICES $\quad$ xiii

GLOSSARY $x$

1. INTRODUCTION TO PURCHASING AND SUPPLY MANAGEMENT, TO COMPETENCES AND EDUCATION AND AN OUTLINE OF THE RESEARCH STRUCTURE $\mathbf{2}$

1.1. A brief history of purchasing and supply management 2

1.2. A brief outline of the PSM competences literature 10

1.3. A brief history of competence development and education 23

1.4. Introduction to the EU-funded Project PERFECT 51

1.5. Research design, the research objectives and the red thread 54

1.6. Addressing the research design, research objectives, and red thread 56

2. PURCHASING AND SUPPLY MANAGEMENT (PSM) COMPETENCES: CURRENT AND FUTURE REQUIREMENTS

2.1. Introduction 60

2.2. Conceptual background 61

2.3. Methodology 65

2.4. Findings and Discussion 72

2.5. Conclusions 78

3. PUBLIC PROCUREMENT OF INNOVATION - SKILLS REQUIREMENTS 88

3.1. Introduction - Public procurement in a new era 88

3.2. Theoretical framework - Stimulating innovations with procurement 91

3.3. Methodology - a qualitative approach with the World Café method 94

3.4. Results - future competences profiles for the strategic innovation procurer $\quad 99$

3.5. Discussion of the entrepreneurial competence set for public procurers 103

3.6. Conclusions - public procurement needs communicative and strategic entrepreneurs 106

3.7. Limitations, managerial implications and further research 109

4. CULTURE'S CONSEQUENCES FOR PURCHASING COMPARING PURCHASING JOB AD REQUIREMENTS FROM DIFFERENT EUROPEAN COUNTRIES WITH CULTURAL MODELS 
4.1. Introduction - the assumption of a standard profile for a universal purchaser

4.2. Theoretical background - results of a literature review on culture, culture models, PSM skills requirements and research in job advertisements

4.3. Method and data: cultural clusters and mapping skills and competences 127

4.4. Results: research questions and testing the proposition and hypotheses 129

4.5. Discussion - Explaining the differences between job ads: structural and cultural reasons

4.5. Limitations and further research: representability of job ads 138

5. THE PURCHASER FOR INNOVATION

5.1. Introduction - skills and organisational influences on innovation sourcing success

5.2. Literature-Absence of innovation sourcing competences in the scientific literature

5.3. Methodology - t-test, stepwise OLS regression, NCA and polynomial regression with composite-based structural equation modelling used to answer three research questions

5.4. Model testing - combing the results of polynomial regression with response surface analyses with necessary condition analysis

5.5. Discussion - The innovation purchaser being the future CPO

5.6. Conclusion - focus on proper organisational conditions and skills training to increase innovation levels

\section{HOW TO TRAIN SUPPLY MANAGERS - NECESSARY AND SUFFICIENT PURCHASING} SKILLS LEADING TO SUCCESS

6.1. Introduction - lack of clarity on the importance and selection of purchasing skills

6.2. The literature on purchasing skills as drivers for organisational performance

6.3. Methodology-deriving of purchasing competences leading to success surveying European purchasers

6.4. Findings: target-specific purchasing competences - Purchasing skills summarised in 15 factors

6.5. Discussion, deepening and implications for theory and practice 199

6.6. Limitations and future research 209

7. DEVELOPING SOFT SKILLS OF PSM GRADUATES 214

7.1. Introduction - soft skills gap in higher education 214

7.2. Theory on soft skills development and student-centred learning 217

7.3. Methodology-quasi-experiment with intrapersonal skills in a PSM course 
7.4. Results - an increase of levels of interpersonal skills and intrapersonal traits

7.5. Discussion - contextual fundament for attitudes and intrapersonal traits development

7.6. Conclusions and recommendations for practice in PSM higher education 235

$\begin{array}{ll}\text { 7.7. Limitations and further research } & 238\end{array}$

8. DISCUSSION - FINDINGS AND IMPLICATIONS

8.1. Summary of key findings and contributions to the literature and practice 244

8.2. Reply to the overarching research objective 269

10. FUTURE RESEARCH FOR PSM

10.1. Project PERSIST - towards PSM competences in the era of Industry 4.0342

10.2. Project PERISCOPE - towards PSM competences in the era of the circular economy

10.3. Future projects for academic and lifelong learning in PSM

11. PUBLICATIONS COMING FORTH FROM THIS DISSERTATION 348

11.1. Academic output per chapter 348

11.2. Other peer-reviewed publications coming forth from the dissertation 349

11.3. Non-peer-reviewed publications 350

12. SUMMARY AND RED THREAD 354

12.1. Summary in English 354

12.2. The red thread of the dissertation 356

12.3. Samenvatting (Summary in Dutch) 358

12.4. Rode draad in het proefschrift 359

12.5. Zusammenfassung in deutscher Sprache 361

12.6. Der rote Faden der Dissertation 362

12.7. Roadmap for Practitioners - How to use the outcomes of this dissertation in the Human Resources practice 363

12.8. Routekaart voor professionals - Hoe de resultaten van dit proefschrift te gebruiken in de Human Resources-praktijk 365

12.9. Roadmap für Praktiker - Verwendung der Ergebnisse dieser Dissertation in der Personalpraxis $\quad 366$

$\begin{array}{ll}\text { 12.10. Propositions } & 367\end{array}$ 


\section{LIST OF TABLES, FIGURES AND APPENDICES}

\section{TABLES}

Table 1.1 - Skills required of a world-class purchaser

Table 1.2 - Competences matching with Tassabehji \& Moorhouse (2008) and additional competences gathered in interviews 18

Table 1.3 - items of the factor 'Team creativity climate' in PSM ................................21

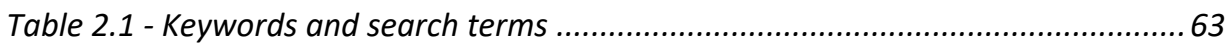

Table 2.2 - Company Demographics ......................................................................... 68

Table 2.3 - Interviewees' Demographic Data for Focal Buying Company Participants. 69

Table 2.4 - Interviewees' Demographic Data for Supplier Participants ........................69

Table 2.5 - Top 10 current and future competences for PSM, in alphabetical order.... 73

Table 2.6 - Competences Analysed by Clusters ............................................................. 75

Table 2.7 - Competences matching with Tassabehji \& Moorhouse (2008) and

additional competences gathered in interviews and the IFPSM Golden Standard ....... 79

Table 3.1 - Analysis of the populations in the three different World Café sessions ......97

Table 3.2 - Years of work experience and current place of employment of population 97

Table 3.3 - Employment (workplaces) of the research population.............................. 98

Table 3.4 - Results of the Independent samples $t$-test ...............................................99

Table 3.5 - Results of the Stepwise regression analyses................................................ 100

Table 3.6 - Top-15 competence sets per World Café question, order of importance.. 102

Table 4.1 - Matrix combining the GLOBE and the Hofstede cultural clusters ............. 118

Table 4.2 - PSM requirements mentioned at least once per article in the scientific PSM

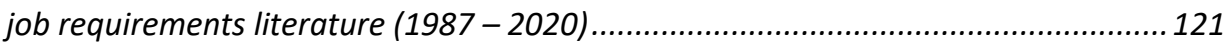

Table 4.3 - Sample and the division of working experience ..................................... 127

Table 4.4 - Common grounds found in the 300 PSM job advertisements .................... 130

Table 4.5 - National differences - additional requirements per country ..................... 131

Table 4.6 - Hofstede's Cultural Dimension for Austria, Belgium and the Netherlands on

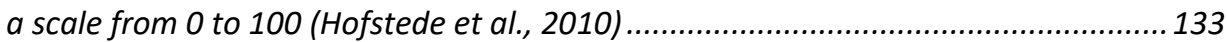

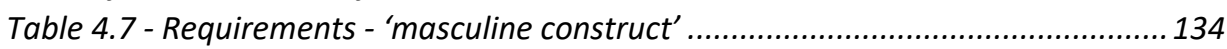

Table 4.8 - Feminine Requirements (Masculinity-Femininity dimension)..................... 134

Table 4.9 - Individualistic Requirements (Individualism-Collectivism Dimension)....... 135

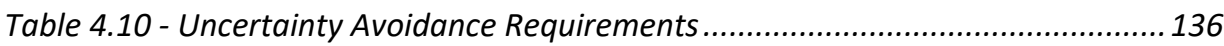

Table 5.1 - Results of necessary condition analyses....................................................... 162

Table 5.2 - Results of the composite-based Structural Equation Modelling on

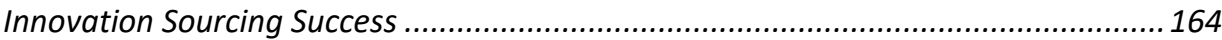

Table 5.3 - Polynomial analysis of slopes and curvatures for effects of innovation

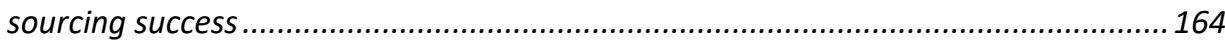


Table 5.4 - data points of polynomial analysis with response surface modelling as shown in Figure 5.2

Table 6.1 - summary of PSM skills in the literature - extended from Tassabehji and Moorhouse (2008) and Bals et al. (2019), i.e. Chapter 2 ......................................... 185

Table 6.2 - Outcomes of the factor analysis - A new PSM skills taxonomy ................. 197

Table 6.3 - Regression and NCA outcomes for the seven objectives and 15 factors ... 198

Table 6.4 - Matrix showing the significant effect sizes of the direct, necessary conditions for each PSM objective .......................................................................... 201

Table 6.5 - Training and education focus according to objective..............................205

Table 7.1 - Effect sizes of significant differences of interpersonal and intrapersonal skills levels between $\mathrm{O}_{1}$ and $\mathrm{O}_{2}$ in a Paired-Samples or Dependent $t$-test....................229

Table 7.2 - Regression output belonging to Figure 7.3 .............................................2. 232

Table 8.1 - Overview of purchasing types and success competences..........................264

Table 8.2 - Three management recommendations coming forth from Chapter 6 ...... 265

Table 8.3 - Schematic overview of the competences found in chapters $2-6 \ldots \ldots \ldots . . .270$

Table 8.4 - Schematic overview of the competences for innovation sourcing found in chapters 3, 5 and 6 .

Table 8.5 - Competence factors positively related to innovation sourcing objectives 274

\section{FIGURES}

Figure 1.1 - PERFECT intellectual outputs .52

Figure 1.2 - Project PERFECT overview of the project leads ........................................53

Figure 2.1 - Development of a set of competences for the modern PSM professional . 66

Figure 2.2 - Purchasing and Supply Management processes .................................... 70

Figure 3.1 - Competences of public procurers of innovation ...................................... 108

Figure 5.1 - Procurement effectiveness matrix .......................................................... 154

Figure 5.2 - Effect of the innovation sourcing competences construct and the level and organisational conditions for innovation sourcing on Innovation Sourcing Success... 166 Figure 5.3 - Effect of Innovation Sourcing ("SKILLS") on Innovation Sourcing Success ("SUCCESS") and the moderation of Innovation Organisation ("SUPPORT"). 167

Figure 5.4 - Effect of Innovation Organisation ("SUPPORT") on Innovation Sourcing Success ("SUCCESS") and the moderation of Innovation Sourcing ("SKILLS") .............. 167 Figure 6.1 - Surface graph of the effect sizes of the interrelated factors....................203 Figure 7.1 - Neurological activity of a student in long-term in situ electrodermal activity (EDA) recordings, recorded for seven days in a natural home environment............... 221

Exhibit 7.2 - Case kick-off: 'talking with real people' and 'social distancing' ..............227 Figure 7.3 - Graph displaying the Relationship between perceived competence levels in $O_{1}$ and the significance of the progress of the personal skills in the course (t-values) 231 Figure 12.1 - Red thread in the thesis: soft skills are key factors in PSM success......... 357 Figure 12.2 - Graphical outline: the organisation of PSM competence development 365 


\section{APPENDICES}

Appendix 9.1 - PSM competences literature 1987-2020 (all chapters) 309

Appendix 9.2 - PSM requirements mentioned in the scientific PSM job requirements literature (1987-2020) 309

Appendix 9.3 - IFPSM Golden Standard

Appendix 9.4 - Introduction of a new taxonomy of procurement skills, adapted from Tassabehji and Moorhouse (2008)

Appendix 9.5 - Previous literature with competence clusters, adapted from Tassabehji and Moorhouse (2008, p. 58)

Appendix 9.6 - Subjects cited from Tassabehji and Moorhouse (2008) by others....... 313 Appendix 9.7 - Relation of PSM skills articles not citing Tassabehji and Moorhouse (2008)

Appendix 9.8 - Research Quality Assurance

314

Appendix 9.9 - Interview Guide Main Parts and Introductory Texts .......................... 315 Appendix 9.10 - Additional competences to the competence clusters of Tassabehji and Moorhouse (2008)

Appendix 9.11 - PSM job requirements in the total set of the 300 Austrian, Belgian and Dutch PSM job advertisements

Appendix 9.12 - Significant distinct competences of innovation-focused purchasing professionals

Appendix 9.13 - Significant distinct absent competences of innovation-focused purchasing professionals (t-test).

Appendix 9.14 - Factors in the questionnaire of competence items.....

Appendix 9.15 - Result of exploratory factor analysis on the 17 competences

significantly associated with PSM professionals with an innovation focus.

Appendix 9.16 - Constructs of the three axes in the polynomial regression ................ 325

Appendix 9.17 - Level of agreement in z-value levels of the independent variables... 325

Appendix 9.18 - Tests of normality

Appendix 9.19 - Necessary condition analyses outcomes per factor 326 Appendix 9.20 - Necessary condition analyses outcomes: effect sizes per factor on each factor

Appendix 9.21 - Invitation to the purchasing skills survey of Project PERFECT ........... 330

Appendix 9.22 - Results of the Paired-Samples or Dependent $T$-Test $\mathrm{O}_{1}$ and $\mathrm{O}_{2} \ldots \ldots . . .331$

Appendix 9.23 - Rankings of the items in the two student surveys..............................333

Appendix 9.24 - Summary of the competences found in chapters $2-6$......................334

Appendix 9.25 - Schematic overview of the competences found in chapters 2-6.... 336

Appendix 9.26 - Effectiveness statements on seven PSM objectives. 338 


\section{GLOSSARY}

Al - Artificial Intelligence

Ausbildung - Acquiring skills needed for a profession (vocational training)

Bildung - Personality development and self-cultivation

CPO - Chief Purchasing Officer

CSR - Corporate and Social Responsibility

DAAD - Deutscher Akademischer Austauschdienst (German Academic Exchange Service)

ECSC - European Coal and Steel Community

ECTS - European Credit Transfer System (standard for comparing academic credits)

ENQA - European Association for Quality Assurance in Higher Education

EPI - Early Procurement Involvement

Erasmus+ project - E.U. funded project

ERP - Enterprise Resource Planning

ESG - European Standards and Guidelines (Higher Education)

ESI - Early Supplier Involvement

ESU - European Students' Union

EUA - European University Association

EURASHE - European Association of Institutions in Higher Education

GDP - Gross Domestic Product

GLOBE project - Global Leadership \& Organisational Behaviour Effectiveness

H.R. (M) - Human Resources (Management)

IEM - Industrial Engineering Management

IFPSM - International Federation of Purchasing and Supply Management

INTED - International Technology, Education and Development Conference

I.O. - intellectual output (in the projects PERFECT, PERSIST, and PERISCOPE)

IPSERA - International Purchasing and Supply Education and Research Association

Industry 4.0 (I4.0) - Fourth Industrial Revolution

JPSM - Journal of Purchasing and Supply Management

KBV - Knowledge-Based View

KSAO - knowledge, skills, abilities, and other characteristics

MOOC - Massive Online Open Course

NCA - Necessary Condition Analysis

NVivo - Qualitative data analysis software

PERFECT - Purchasing Education and Research for European Competence Transfer

PERISCOPE - Purchasing Education Research with an Innovative Sustainability Scope

PERSIST - Purchasing Education Research Syndicate: Industry 4.0 Skills Transfer

PSM - Purchasing and Supply (Chain) Management

R\&D - Research and Development

RBV - Resource-Based View

R.Q. - Research Question

SCM - Supply Chain Management

SEL - Social and Emotional Learning

SME - Small and medium-sized enterprises

UNIDO - United Nation Industry Development Organisation

WEF - World Economic Forum

World Café method - Form of a participatory workshop dialogue 


\section{Chapter 1}

Introduction to Purchasing and Supply Management, to Competences and Education and an Outline of the Research 


\section{INTRODUCTION TO PURCHASING AND SUPPLY MANAGEMENT, TO COMPETENCES AND EDUCATION AND AN OUTLINE OF THE RESEARCH STRUCTURE}

\subsection{A brief history of purchasing and supply management}

\subsubsection{Introduction to purchasing skills leading to success}

As explained in the preface, this dissertation's focus is on those competences in PSM and especially in innovation sourcing that would lead to success. The aim is to apply those in academia to learning objectives or human resource management in private and public organisations to recruit, train, and develop. In section 1.1, PSM is introduced within the context of the Industrial Revolutions. Next, in section 1.2, the literature on the required competences in PSM is discussed, and 1.3 elaborates on the literature on education, teaching, and learning of competences in PSM in times of an Industrial Revolution.

In the following sections, the history of PSM, the result of a literature review on PSM competences, and the theoretical framework are presented to grasp these topics entirely. Furthermore, the history of the philosophy and the application of competence development and (management) education are described. The purpose of the underlying Erasmus+ funded Project PERFECT (Purchasing Education and Research for European Competence Transfer) is explained in the subsequent section. This first chapter ends with the overarching research objectives, an explanation of the research design, and its red thread.

After this introductory chapter, the successive chapters are elaborating on the current and future PSM job requirements in European industry (chapter 2); competences in public procurement of innovation (chapter 3); cultural differences in PSM job advertisements (chapter 4); organisational conditions combined with individual competence levels and success in innovation sourcing (chapter 5); and necessary competences leading to success regarding different objectives in PSM from 
transactional, reducing cost to strategic, innovation sourcing (chapter 6). Chapter 7 uses this dissertation's outcomes in an experiment to test adequate methods to learn and teach PSM competences and exceedingly soft skills in an academic course. In Chapter 8, the research is discussed, and the research objectives are addressed. Finally, Chapter 12 summarises the red thread and provides a practitioners' roadmap to improve PSM skills. Chapter 12 is written in English, Dutch and German.

\subsubsection{Purchasing and supply management in the $19^{\text {th }}$ century}

The emergence of PSM is often placed on the timeline somewhere in the $20^{\text {th }}$ century. Many scholars refer to the work of Peter Kraljic, who in 1983 pleaded in the Harvard Business Review article that 'purchasing must become supply management' (Kraljic, 1983). Yet, PSM is rooted deeper in history than in the early 1980s. Nevertheless, a trend in outsourcing and global sourcing is visible in the past decades; PSM is shifting increasingly from a transactional towards a strategic role (Tassabehji \& Moorhouse, 2008).

Early attention to purchasing and supply is given by Babbage (1832), who in his work On the Economy of Machinery and Manufactures frequently mentions the importance of the purchasing function, in combination with terms like 'quality,' 'delivery' and 'cost control,' however, the work is focused on economics and in line with the title the author emphases on economic principals like the cause of price fluctuations and dealing with those:

"The frequent speculations in oil, tallow, and other commodities, which must occur to the memory of most of my readers, were always founded on the principle of purchasing up all the stock on hand, and agreeing for the purchase of the expected arrivals; thus proving the opinion of capitalists to be, that a larger average price may be procured by the stock being held by few persons" (Babbage, 1832, p. 146).

In the second half of the $19^{\text {th }}$ century, the purchasing function is formed as a separate corporate function starting with U.S. railroad companies; "the purchasing function was such a major contributor to the performance of the organization that the chief purchasing manager had a top managerial status" (Monczka, Handfield, Giunipero, \& Patterson, 2016, pp. 24-28). In 1866, the Pennsylvania Railroad company's purchasing function had been given departmental status under the title of Supplying Department (Kaufmann, 2002).

Early forms of dedicated purchasing departments started to appear with the U.S. inter-state railways. In that context, "the first book exclusively about the purchasing function" was published (Monczka et al., 2016, pp. 25-26), titled The Handling of Railway Supplies Their Purchase and Disposition and was written by Marshall Monroe Kirkman (1887), "the controller of the Chicago and North-western Railroad" (Kaufmann, 2002, p. 6). 
The book addressed still up-to-date vital issues like the necessary technical expertise for purchasing agents, the need for command under one purchasing manager or chief purchasing officer (CPO), and skilled purchasing personnel. Sporadically, calls for professional purchasing followed, such as in the German article of Redtmann, who back in 1910 recommended:

"It should be regarded as a big mistake to neglect the significant advantages of a wellorganised purchasing department. Experience shows that this negatively impacts organisational success. Every experienced businessman will establish a purchasing department" (translated from German; Redtmann, 1910, p. 55).

\subsubsection{Purchasing and supply management in the $20^{\text {th }}$ century - $1900-1950$}

In the first half of the $20^{\text {th }}$ century, the industrial purchasing function gained attention. "In 1905, the second book devoted to purchasing - and the first non-railroad purchasing book - was published. The Book on Buying contained 18 chapters; each written by different authors" (Monczka et al., 2016, p. 25). "The Book on Buying was published (...) to introduce the principles of buying. Nevertheless, purchasing was regarded as a clerical job" (Ling, 2007, p. 59). Kaufmann (2002, p. 6) adds: "The Book on Buying' described fundamental guidelines and gave evidence of the forms and procedures of purchasing used in different industries". During World War I, the purchasing function gained importance for obtaining war materials and semi-finished goods (Monczka et al., 2016).

A century ago, Thomas (1919) was the first addressing public procurement with his work titled 'Principles of Governmental Purchasing'. It compared public procurement with private purchasing practices from the point of view that public procurement, or 'governmental purchasing', could benefit from private purchasing insights (Gries, 1919; Thai, 2001). In the past century, public procurement law and practices have developed as a mature function (Thai, 2001). However, at that time, Thomas (1919) characterised public procurement as unsuccessful, unreliable, and nepotistic. Thomas (1919) stated about the public procurement function of the 1910s:

" (...) governments have in the past, with few exceptions, notoriously failed as purchasers. [...] Dealers complain of red tape, which hampers them in bidding, in delivering goods, and in securing the payment of bills. Government executives themselves complain of delays between the issue of purchase acquisitions and the availability of goods for use. Citizens generally are prone to assert that graft and political favoritism taint a large part of government purchasing" (Thomas, 1919, p. 5).

During the 1920s and the 1930s, the increase of knowledge in PSM manifested in the book entitled Scientific Purchasing (Gushée \& Boffey, 1928) that was written: "in the tradition of Frederick Taylor's work" (Kaufmann, 2002, p. 6). Another example is Howard Lewis, who published numerous articles (in the Harvard Business Review) and 
books on purchasing concerning industrial marketing, on (problems in) industrial purchasing and standard purchasing performance (e.g. Lewis, 1932, 1933, 1935a, 1935b, 1936).

The red thread in Lewis's work is the plea for an active role for procurement in which the function would mirror the downstream side of the sales function. Moreover, Lewis underlined the need for purchasing performance measuring (Kaufmann, 2002). "As interesting as these early examples of publications may be, in practice, purchasing was generally not recognized as beneficial to a firm" (Kaufmann, 2002, p. 6).

Alike in World War I, the recognition of the purchasing function appeared instantly during World War II "when the importance of obtaining required material fuelled a growth in purchasing interest" (Kaufmann, 2002, p. 6). The scarcity of goods in World War II increased the attention for purchasing, resulting in a growth in U.S. purchasing associations and universities offering purchasing course (Monczka et al., 2016). The main focus on purchasing and supply issues evaporated more or less after World War II in the USA. However, in post-war Europe, there was political attention for supply chain issues, which lead to the establishment of the European Coal and Steel Community (ECSC), a predecessor of the current European Union.

\subsubsection{Purchasing and supply management in the $20^{\text {th }}$ century $-1950-1990$}

In 1951, in post-war Europe, the Treaty of Paris was signed by the leaders of France, West Germany, Italy, Belgium, the Netherlands, and Luxembourg to officially form the ECSC to create a common market and to regulate the supply chain for natural resources coal and steel between the member states. A year earlier, the French foreign minister Robert Schuman proposed the ECSC (Schuman, 1950). Schuman aimed to prevent another war between France and Germany by proposing solidarity in production so "that any war between France and Germany becomes not merely unthinkable, but materially impossible" (Schuman, 1950, p. 17).

The Treaty of Paris placed the "Franco-German production of coal and steel as a whole (...) under a common High Authority" (Schuman, 1950, p. 17), with the task to secure "in the shortest possible time the modernisation of production and the improvement of its quality; the supply of coal and steel on identical terms to the French and German markets, (...)" (Schuman, 1950, p. 18). The after-war Western European attention for raw materials purchasing and supply chain issues during the reconstruction had a geopolitical and macroeconomic origin, alike in World Wars I and II.

From the interbellum until the 1950s, in the U.S. industry, "there was considerable doubt about the existence of any general recognition of purchasing as important to a company" (Monczka et al., 2016, p. 25). Nevertheless, some companies 
formed exceptions, such as Ford Motor Company that built a system to assist purchasers on product and price analysis and General Electric introduced the value analysis technique (Monczka et al., 2016). To characterise the era from the mid-1940s to the mid-1960s concerning the status of private purchasing generally, Monczka et al. (2016) cite a purchasing professional on the topic:

"For many firms, purchases were simply an inescapable cost of doing business which no one could do much about. (...) Procurement is regarded as a negative function - it can handicap the company if not done well but can make little positive contribution" (Monczka et al., 2016, p. 25).

The increased attention to materials management characterises the era from the mid-1960s until the late 1970s. Worldwide, the Vietnam War and the oil crisis "resulted in upward price and materials availability pressures". As a response, the industry sought to be more "efficient, particularly in the purchase and control of materials leading to the concept of materials management". In this period, the purchasing function "emphasized multiple sourcing through competitive bid pricing and rarely viewed as a value-added partner", although "price competition was the major factor determining supply contracts" (Monczka et al., 2016, pp. 26-27).

In general, in this era, PSM's top management vision is "passive, risk-averse, and a dead-end job". In 1974, the Harvard Business Review article of Davis, Eppen, and Mattsson (1974) pleaded for overcoming this by "active purchasing", "meeting overall company objectives and contributing to bottom-line profitability" (Monczka et al., 2016, p. 27). Nevertheless, during the 1970s, within organisations, the PSM function was more clerical than strategic and had a passive role. "The function operated in an isolated environment, trying to optimize the 'silo', rather than optimizing the enterprise-wide supply chain" (Cousins, Lamming, Lawson, \& Squire, 2008, p. 12).

The period from the late 1970s until the 1990s has been "different from other historical periods": "competition became so intense so quickly"; "global firms increasingly captured market share" using other strategies and management techniques, product life cycles became shorter, resulting in an unprecedented technological change (Monczka et al., 2016, p. 27). In 1980, Michael Porter "emphasized the importance of purchasing in his five forces model of competitive advantage" (Cousins et al., 2008, p. 12).

From the early 1950s, Deming (1986) started lecturing the plan-do-check-actcycle in Japan, which became one of the Toyota Production System's fundaments. "The intense Japanese competition of the 1980s also saw manufacturing firms shift from emphasizing internal operations towards supply chain optimization," and western firms started to recognise PSM's potential contribution to the company's overall result (Cousins et al., 2008, p. 12). 


\subsubsection{Recent developments in purchasing and supply management}

From the 1990s, make-or-buy decisions increasingly became a topic within organisations that started defining their core and non-core activities (Cousins et al., 2008; Luzzini \& Ronchi, 2016) although, make-or-buy decision-making has a long tradition in academic writings (Ammer, 1983; Gross, 1966; Jauch \& Wilson, 1979). As a discipline, PSM practice is affected by political-economic, technological and demographic developments. From the 1980s, the political-economic systems (via the GATT and WTO) have stimulated globalisation (Narlikar, 2003), which led to increased global sourcing activities accelerated by the Chinese economic reform from the late 1970s (Logan, 2011). These are explained by at least four essential academic insights and theories:

(1) the Transaction Costs Economics theory, which is "the most popular theory backing purchasing research" (Schiele, 2019, p. 62) as proposed by Coase (1937) and further developed by Williamson (1981) and, stating that make-orbuy decisions can "be made after assessing the transformation and transaction cost consequences of alternative modes" (Williamson, 1981, p. 557).

(2) by Kraljic' statement that "purchasing must become supply management" (Kraljic, 1983, p. 109);

(3) the focus on core competences of professionals in organisations as underlined by Prahalad and Hamel (1990); and

(4) the Resource-based view (Barney, 1991, 2012) states that a firm's competitive advantage is derived from managing tangible and intangible resources.

Consequently, the importance of supplier management, supply chain management, and strategic decision-making increased (Luzzini \& Ronchi, 2016).

After 2000, the PSM function is characterised as "integrated supply chain management", reflecting a "growing emphasis concerning the importance of suppliers" (Monczka et al., 2016, p. 27). "Supplier relationships are shifting from an adversarial approach to a more cooperative approach with selected suppliers". Value creation in the supply chain is reached via "supplier development, supplier design involvement, the use of full-service suppliers, total cost supplier selection, supplier relationship management, strategic cost management, enterprise-wide systems (enterprise resource planning, or ERP) hosted on the 'cloud' and integrated Internet linkages and shared databases" (Monczka et al., 2016, p. 27).

Currently, PSM is increasingly involved in the "transition and management process of goods and services through the enterprise" to improve the organisation's competitiveness. It involves "not only purchasing goods and services at competitive prices but also focusing on cost reduction techniques, improving cycle times, reducing 
time-to-market, and constantly seeking to exploit actual and potential innovations from within the supply market" (Cousins et al., 2008, p. 14).

However, globalisation led to environmental and social problems upstream in the supply chain: pollution, exploitation, modern slavery, child labour, and waste. Legislators currently react to these problems in supply chains with national, European and other international due diligence supply chain laws (Landman \& Silverman, 2019; Smit et al., 2020; Wieland, 2021; Wijen, Zoeteman, Pieters, \& van Seters, 2012).

\subsubsection{Procurement in history and prehistory}

Here above is shown how PSM mainly developed since the late $20^{\text {th }}$ century. PSM developed towards global sourcing, connecting, for instance, production of parts, modules, and products in Asia and especially China to Western Europe and North America for assemblage and consumption downstream in the value chain (e.g. Schoenherr, 2010; Steinle \& Schiele, 2008; Trent \& Monczka, 2003a). However, trading (semi-finished) products between East and West already existed in 200 B.C. with a trade network known as the 'silk road' or 'silk route' (Hansen, 2012).

Even earlier in the Mesopotamian times (3000 to 1600 B.C.), purchases and sales were subjected to laws. "There are numerous law collection (or 'codes') as legal documents that have survived," showing evidence of early Mesopotamian "commercial law' (VerSteeg, 1998, p. 183). The oldest sales and purchasing contracts are presented by Harper (1904) in his seminal work 'Assyrian and Babylonian Literature: Selected Translations'. Examples are contracts of the sale of a slave (2300 B.C.), of agricultural products: wheat (487 B.C.), dates (490 B.C.), and standing crop (532 B.C.), of real estate (2000 B.C.), and rentals of real estate (earlier than 2000 B.C.). Neumann (1994) shows the existence of ancient Mesopotamian labour contracts and that contracts were made up and signed in taverns, and beer being the means of compensation for the employment (Harper, 1904).

Hence, the written history of purchasing and sale caused by individuals' specialisation goes back more than four millennia. Yet, from another field of science, the evidence is given for the insight that specialisation and consequent sale and purchase is a rudimental human activity or habit of modern human beings (Homo sapiens) that goes back to prehistoric times. Here the term "prehistory refers to the preliterate past" (McCall, 1973, p. 733).

Paleoanthropologists Brooks et al. (2018) researched settlements of early Homo sapiens in several excavations in the Olorgesailie basin in southern Kenya that date back about 300,000 years ago. Their research suggests " $a$ new behavior in the human repertoire: the formation of networks of exchange or procurement over a 
substantial area" (Brooks et al., 2018, p. 93). Brooks et al. (2018, p. 95): "the populations in eastern Africa underwent a technological shift upon procurement of distantly sourced obsidian $^{3}$ for toolmaking, indicating the early development of social exchange".

There is evidence that the extinction of the supposedly stronger, archaic humans, such as Neanderthals (Homo neanderthalensis), has been caused by the success of the Homo sapiens when the latter started spreading around the world about 30,000 to 40,000 years ago (Horan, Bulte, \& Shogren, 2005). The Neanderthals had an advantage over the Homo sapiens. Neanderthals had a larger and more robust skeleton and skull and had a ten per cent larger brain than the Homo sapiens (Horan et al., 2005). The Neanderthals were intelligent and developed tools and weapons. An explanation for the success of the Homo sapiens and the extinction of the Neanderthals is:

"Homo sapiens can create and commit to exchange institutions that promote trade and insurance, and may organize themselves to reap the gains from trade that emerge from the specialization of labor" (Horan et al., 2005, p. 4).

Thus, specialisation and trade (i.e. voluntary exchange) are the traits positively associated with Homo sapiens. "The early Homo sapiens bear the sign of major changes in cognition and culture linked to creativity" (Lumsden, 1999, p. 164). Lumsden (1999) adds that these creative skills supported the early humans in their transcontinental journeys, in harnessing fire, in imitation capabilities, and eventually in being able to reenact, share, and plan. A breakthrough is the development of higher-speed speech skills and the proliferation of vocabularies. Lumsden (1999) defines prehistoric creativity as a planned activity of the self-aware mind. Yuval Noah Harari (2014), in his book entitled Sapiens: A Brief History of Humankind is elaborating on Homo sapiens' specific competence to understand shared 'fictions':

"Trade may seem a very pragmatic activity, one that needs no fictive basis. Yet the fact is that no animal other than Sapiens engages in trade, and all the Sapiens trade networks about which we have detailed evidence were based on fictions. Trade cannot exist without trust, and it is very difficult to trust strangers. The global trade network of today is based on our trust in such fictional entities as the dollar, the Federal Reserve Bank, and the totemic trademarks of corporations. When two strangers in a tribal society want to trade, they will often establish trust by appealing to a common god, mythical ancestor, or totem animal. If archaic Sapiens believing in such fictions traded shells and obsidian, it stands to reason that they could also have traded information, thus creating a much denser and wider knowledge network than the one that served Neanderthals and other archaic humans" (Harari, 2014, p. 36).

Concluding, the purchasing function has evolved rapidly in the past century and secondly, that specialisation of tasks and the subsequent exchanging goods is an ancient old habit of Homo sapiens that might be a built-in genetic system of

\footnotetext{
${ }^{3}$ Obsidian is volcanic glass that has been used for millennia to make cutting tools and spearheads
} 
understanding and sharing 'fictions', which formed the key to the survival of the species over the stronger Neanderthals. Purchasing and trade go back to prehistory, and there is evidence that these come forth from the distinct habits of Homo sapiens, such as creativity, social exchange, improved communication skills, and above all, fictional thinking.

In conclusion, the purchasing function in organisations is currently increasingly complex; therefore, creative PSM personnel is required. Until 30,000 years ago, Homo sapiens co-existed with humans of an archaic origin like Neanderthals and probably caused their extinction (Horan et al., 2005). If Neanderthals had survived and still coexisted, this would have had implications for purchasing departments in organisations searching for creative minds. Homo sapiens candidates would be preferred over applicants with an archaic origin like Neanderthals. As is shown above, Homo sapiens have proven better language proficiency skills, creativity, sellership skills, interpersonal communication and fictional thinking. It is even questionable whether Neanderthals could have applied in vacancy procedures due to their assumed low literacy (Horan et al., 2005). Therefore, in general, creativity is a characteristic of Homo sapiens, implying that creativity competence levels may vary between subjects.

The next and following sections will elaborate on the theoretical framework and definitions of knowledge, skills, competence, et cetera. Further, the literature on PSM competences is deepened systematically and chronologically, and the role of creativeness in innovation sourcing is described.

\subsection{A brief outline of the PSM competences literature}

\subsubsection{Definitions of knowledge and skills}

The literature on organisational knowledge and skills provides different taxonomies. Firstly, there is a body of literature that distinguishes between hard skills and soft skills (e.g. Andrews \& Higson, 2008; Bailly \& Léné, 2013; Heckman \& Kautz, 2012; Laker \& Powell, 2011). Heckman and Kautz (2012, p. 451) define soft skills as: "personality traits, goals, motivations, and preferences". Laker and Powell (2011, p. 113) distinguish "hard-skills or technical training (working with equipment and software) and soft-skills training (interpersonal or intrapersonal focus)".

Andrews and Higson (2008, p. 414) recognise: "Business Specific Issues (Hard business-related knowledge and skills); Interpersonal Competences (Soft businessrelated skills)" and an undefined category: "Work Experience and Work-Based Learning". The differentiation between hard skills and soft skills might not cover all aspects. Andrews and Higson (2008) could have applied the definitions of tacit and explicit knowledge to define the latter, undefined category "Work Experience and Work-Based Learning". 
There are various approaches to manage, classify and share knowledge, but many are based on a fundamental distinction between explicit know-what and tacit 'know-how' (Nonaka \& Takeuchi, 1995; G. Smith, 2002) and mainly the ease of transferability and aggregation of knowledge (Grant, 1996). Polanyi (1966, p. 4) introduced the idea of tacit knowledge by stating, "we can know more than we can tell":

"I shall reconsider human knowledge by starting from the fact that we can know more than we can tell. This fact seems obvious enough, but it is not easy to say exactly what it means. Take an example. We know a person's face and can recognize it among a thousand, indeed among a million. Yet, we usually cannot tell how we recognize a face we know. So most of this knowledge cannot be put into words" (Polanyi, 1966, p. 4).

Tacit knowledge is multidimensional, context-specific, and often embedded within organisational routines (Kothari et al., 2012). Tacit knowledge "can only be observed through its application and acquired through practice" (Grant, 1996; Kogut \& Zander, 1992).

Conversely, explicit knowledge can be articulated in a formal language, like manuals, mathematical expressions, copyright, and patents (E. Smith, 2001) and can be shared more easily between people (Grant, 1996). Explicit knowledge has even "the character of public goods" (Tamer Cavusgil, Calantone, \& Zhao, 2003, p. 7). However, for tacit knowledge, this is not the case; "its transfer between people is slow, costly, and uncertain" (Grant, 1996; Kogut \& Zander, 1992). Therefore, the importance of tacit knowledge is high. There is evidence that approximately 90 per cent of all knowledge in organisations is tacit (E. Smith, 2001). Jasimuddin, Klein, and Connell (2005, p. 109) summarise: "Tacit knowledge is less vulnerable but less accessible by legitimate organisational users, whilst explicit knowledge is more accessible but also more vulnerable to illegitimate exploitation".

Although the distinction between tacit and explicit knowledge can be presented as being a clear cut dichotomy, there is evidence that knowledge exists in the continuum between both ends: between strict tacit and explicit knowledge (Jasimuddin et al., 2005, p. 104; Nonaka \& Von Krogh, 2009, p. 635). Tacit knowledge can shift to explicit knowledge when it is codified (Nonaka \& Takeuchi, 1995). The most common route to transfer tacit knowledge amongst individuals lies in sharing experiences: "Without some form of shared experience, it is extremely difficult to project her- or himself into another individual's thinking process" (Nonaka \& Takeuchi, 1995, pp. 62-63).

Examining the PSM skills literature reviews discussed above, a mix of explicit and tacit knowledge can be distinguished (Giunipero \& Pearcy, 2000; Mulder, Wesselink, \& Bruijstens, 2005; Tassabehji \& Moorhouse, 2008). Within the field of SCM, it has already been clear that supply chain professionals "not only need core entry-level skills, which include inventory, quality control, transportation, and warehousing skills 
but they also need a holistic, cross-functional understanding of value-added systems" (Fawcett \& Rutner, 2014, p. 218). Giunipero, Dawley, and Anthony (1999) have found evidence that decision-making is critical in the purchasing profession. Purchasers use in 50 per cent of the time tacit knowledge in the process of decision-making.

A distinction can be made between hard and soft skills or explicit and tacit knowledge. Both methods are not entirely covering all aspects of the individual's competence, explained by Boyatzis (1982), who can be seen as a founder of competence-based professional education and development (Yeung, 1996). Boyatzis (1982, pp. 20-21) defined 'competence' as "an underlying characteristic of a person which results in the effective and/or superior performance in a job. (...) that may be a motive, trait, skill, aspect of one's self-image, social role, or a body of knowledge) which he or she uses". Boyatzis (1982, p. 21) adds that "The existence and possession of these characteristics may or may not be known to the person" and therefore can be "unconscious aspects of the person", which is matching the idea of tacit knowledge "we can know more than we can tell" by Polanyi (1966, p. 4).

More elaborate definitions, which are building further on the above, are given by Campion et al. (2011) and Delamare-Le Deist and Winterton (2005) on the concept of competence, as a construct of "knowledge, skills, abilities and other characteristics (KSAOs) that are needed for effective performance in the job in question" (Campion et al., 2011, p. 226). Similar is also discussed in other contemporary literature (e.g. Barnes \& Liao, 2012; Flöthmann, Hoberg, \& Wieland, 2018). In this dissertation, this definition will be applied, although a distinction between hard skills and soft skills and between explicit and tacit knowledge will be found in the following chapters:

"The competences required of an occupation include both conceptual (cognitive, knowledge and understanding) and operational (functional, psycho-motoric and applied skill) competences. The competences more associated with individual effectiveness are also both conceptual (meta-competence, including learning to learn) and operational (social competence, including behaviours and attitudes)" (Delamare-Le Deist \& Winterton, 2005, p. 39).

In this section, definitions of knowledge, professional and personal skills and traits are given, which are increasingly crucial intangible resources held by personnel within the organisation (Grant, 1996). However, in PSM, this organisational level of core competences has been expanded and includes external actors, such as suppliers (Dyer, 1996). Although in this dissertation, the focus remains on the organisational level, the capability to manage and achieve value from suppliers, as defended by Pulles, Schiele, Veldman, and Hüttinger (2016), is an essential aspect of organisation-based knowledge. In the next section, the theoretical framework is sketched. The Knowledge-based view built further on the Resource-based view and theorises that employees' competences are intangible resources that characterise a firm's competitiveness. 


\subsubsection{Major theories driving PSM competences}

The preceding sections clarified that the PSM function shifted from an operational, transactional, towards a strategic function. The PSM function developed in this direction probably due to the notion that firms should concentrate on the core business as interpreted by Williamson (1981) in the Transaction Costs Economics Theory (Cousins et al., 2008) and the emphasis on core competences of organisations as suggested by Prahalad and Hamel (1990). The consequence of concentrating on the core business is outsourcing non-core activities and the subsequently increased importance for supplier management, supply chain management and strategic decision-making (G. Walker \& Weber, 1984; Williamson, 1981). The theories driving PSM competences are probably the Resource-based view and the derived Knowledgebased view, as elaborated in this section.

The abovementioned organisation-based knowledge or organisational knowledge is defined as the knowledge distributed by individuals (Nonaka, 1994) and is embedded in the personnel's daily practices and routines throughout an organisation (Lave \& Wenger, 1991; Orlikowski, 2002). Grant (1996) notes that "if the strategically most important resource of the firm is knowledge, and if knowledge resides within individual organisational members, then the essence of organisational capability is the integration of individual's specialized knowledge" (Grant, 1996, p. 375).

Hence, personnel's knowledge, skills, and traits within organisations are probably the most critical sources for competitive advantage since organisations seek to exploit the competences and capabilities dynamically and differentiate themselves from competitors (Grant, 1996). Therefore, organisations are becoming ever more focused on the creation, sharing and application of knowledge, since the added value is revealed of assets other than capital, raw materials and labour, the effective management of which can lead to increases in organisational performance (Jasimuddin et al., 2005; Nonaka \& Takeuchi, 1995; E. Smith, 2001).

This focus shift has "stimulated a vast literature in the area of intellectual capital and intangible assets" (Elias \& Scarbrough, 2004, p. 21) and corresponded with the Knowledge-based view (KBV) within organisations (Grant, 1996), which is the process of "capturing, organizing, and storing information and experiences of workers and groups within an organization and making it available to others" (Girard \& Girard, 2015, p. 4).

The KBV has been derived from the Resource-based view (Barney, 1991, 2012), which theorises that a firm's competitive advantage is derived from the existence and management of tangible and intangible resources. If these tangible and intangible resources are sufficiently distinguished by being valuable, rare, inimitable, and nonsubstitutable, these resources might be considered core competences, resulting in varying levels and duration of competitive advantage (Hitt, Ireland, \& Hoskisson, 2013). 
Not surprisingly, Grant (1996) associates KBV and the subsequent competitive advantage mostly with employees' tacit knowledge, which is more valuable, rare, inimitable and non-substitutable than explicit knowledge that has a 'public goods' character.

Grant (1996, p. 110) notes that the definition of knowledge "has intrigued some of the world's greatest thinkers from Plato to Popper without the emergence of a clear consensus". He addresses the work of Machlup (1980), who identified "13 different 'elements of knowing' including being acquainted with, being familiar with, being aware of, remembering, recollecting, recognizing, distinguishing, understanding, interpreting, being able to explain, being able to demonstrate, being able to talk about, and being able to perform" (Grant, 1996, p. 110).

Knowledge can be perceived as "the understanding, awareness, or familiarity acquired through study, investigation, observation, or experience over the course of time. It is an individual's interpretation of information based on personal experiences, skills, and competencies" (Bollinger \& Smith, 2001, p. 9). Furthermore, Grant (1996) refers to Machlup's five 'classes of knowledge' including: "practical knowledge, intellectual knowledge (embracing scientific, humanistic, and cultural knowledge), pastime knowledge (news, gossip, stories, and the like), spiritual knowledge, and unwanted knowledge" (Grant, 1996, p. 110).

Grant (1996) explains that firms can create value in two ways. Firstly, via the transformation of outputs that has a more excellent value than the inputs. Secondly, by trading or speculation, which is, in fact, "moving a product from one market to another, but without physically transforming it" (Grant, 1996, p. 110). Grant (1996) positions KBV in the first, transformational type of value creation; the "focus is upon the role of knowledge among firms which engage in production, mainly because this is the most important and complex means of value creation" (Grant, 1996, pp. 110-111).

The following two sections are dedicated to the review of the PSM competence literature. The systematic approach is presented, and the literature from the past decades is described.

\subsubsection{Systematic literature review}

Due to the increased importance of strategic purchasing, the PSM function has evolved into a human-centric discipline in which human capital input is of strategic importance for firms (Hohenstein, Feisel, \& Hartmann, 2014). A substantial number of scientific publications confirm the positive relationship of the competence levels of individual purchasers on the success of firms (see: Appendix 9.1) (e.g. Feisel, Hartmann, 
\& Giunipero, 2011; Kaufmann \& Carter, 2006; Patrucco, Luzzini, \& Ronchi, 2017; Schiele, 2007; Tate \& Ellram, 2012).

For this dissertation, a keyword search in Google Scholar and Scopus was performed to conduct a systematic literature review, following Durach, Kembro, and Wieland's (2017) guidelines. The outcomes are used in most of the chapters in this dissertation. The keyword search generated an initial set of 1,007 articles; a list of PSM job requirements was gradually extracted (displayed partly in Appendix 9.2). Articles regarding organisational (i.e., non-individual) competences or capabilities in the described fields and articles that focused on consumer skills of family household purchasing budget use were discarded, likewise minor citations. In the end, from 33 studies published between 1987 and 2020, skills requirements could be extracted (see: Appendix 9.2.).

Appendix 9.1 displays the PSM skills' frequencies of being mentioned at least once in the focal scientific PSM article and shows little unanimity. While a large majority of the studies agree upon the need for 'PSM knowledge' (82 per cent), as well as 'business knowledge' (76 per cent) and 'negotiation skills' (73 per cent), about one-third of the studies introduce skills that the other studies did not consider, such as 'creativity' (33 per cent), 'industry knowledge' (33 per cent) or 'legal knowledge' (30 per cent). Remarkably, whereas the PSM literature has distinguished different objectives within the function, the PSM skills literature has not made this differentiation. Instead, it presents general skillsets for a universal PSM professional type, with Knight, Tu, and Preston (2014) and Schulze and Bals (2020) as exceptions.

The data were subjected to further statistical analyses. Fawcett and Rutner (2014, p. 180) stated that PSM practices in firms have "evolved dramatically over the past generation". Hence, the scientific PSM literature sample was divided into ' $20^{\text {th }}$ century' (1987-2001; $\left.n=16\right)$ and ' $21^{\text {st }}$ century' $(2003-2020 ; n=17)$ sub-samples. Interestingly, no significant differences among the specific requirements were found with a $t$-test, indicating certain academic development stagnation. The advent of the Fourth Industrial Revolution might change the picture, however.

Appendix 9.2 displays PSM job requirements and the percentage of times they occurred for requirements mentioned at least once in a single scientific PSM article in the entire set of articles. The top rankings indicate a profile of a PSM professional who possesses accumulated knowledge (i.e., knowledge and experience) in PSM and business; who can negotiate, network and communicate; who can be both a team leader and member; who can think both analytically and holistically; and who can work with computer systems.

In the next section, the highlights in the PSM competences literature are discussed as they appeared chronologically. 


\subsubsection{The literature on purchasing competences as success factors for organisational performance}

The preceding section shows that the PSM literature is limited to 33 relevant studies, of which ten are (co-) authored by the same researchers (see: Appendix 9.1). This limited number alerts researchers to be aware of the echo chamber effect (Pettigrew, 2001).

The body of PSM skills literature is mainly built upon Larry Giunipero and coauthors' seminal work. The study of Giunipero and Pearcy (2000) is based upon the scientific reports for the longitudinal research of the Center of Advanced Purchasing Studies in 1993 and 2000 (Giunipero, 2000; Kolchin \& Giunipero, 1993) and wraps up the findings in the field in the $20^{\text {th }}$ century and it provides a PSM skills taxonomy that is displayed in Table 1.1.

Additional to the abovementioned taxonomy, Giunipero, Denslow, and Eltantawy (2005, p. 609) defined the overlap between PSM skills and entrepreneurial skills, which is referred to as "flexibility skills" ("planning, influencing, internal motivation, creativity, risk management, decision-making, interpersonal communication"). Giunipero, Handfield, and Eltantawy (2006, p. 835) expected that the traditional, operational role of the buyer "is rapidly disappearing" and that purchasers soon will be assigned to strategic roles. The skills for the strategic role of supply managers of the future (as proclaimed in 2006) are team-building skills ("leadership, decision-making, influencing, and compromising"), strategic planning skills ("project scoping, goal-setting, and execution"), communication skills ("presentation, public speaking, listening and writing"), technical skills ("web-enabled research and sourcing analysis") and broader financial skills ("cost accounting and making the business case") (Giunipero et al., 2006, p. 836).

Hence, the PSM function requires an entrepreneurial profile, according to Giunipero et al. (2005), who underlined the importance of integrating procurement into cross-functional teams. To fulfil an increasingly strategic role, procurers require a flexible and entrepreneurial skillset to be: "a purchaser who is able to plan projects with multiple stakeholders, to influence not only suppliers but also (internal) business partners, and who possess a strong will to contribute to organisational success. This person is not waiting for action to happen but is proactive, creative and decisive" (Feisel, Hartmann, \& Schober, 2007, p. 6).

Tassabehji and Moorhouse (2008) have built further on all research, as mentioned earlier, and conclude that in general, a purchaser needs to master a complete set of skills consisting of: 
- Technical Skills ("product knowledge, computer literacy, total quality management, and government legislation and advanced procurement process skills"),

- Interpersonal Skills ("written and oral communication, conflict resolution, influencing and persuasion, group dynamics, leadership, problem solving and interpersonal and cultural awareness"),

- Internal Enterprise Skills ("effectively conduct market analysis, manage internal relationships, global sourcing evaluation, internal change management and planning, and organisational skills"),

- External Enterprise Skills ("management of external relationships, and stakeholder change management") and

- Strategic Business Skills ("planning and managing strategic partnerships and alliances, risk management, and adding value to the organisation") (Tassabehji \& Moorhouse, 2008, p. 59).

Table 1.1 - Skills required of a world-class purchaser, adapted from Giunipero and Pearcy (2000, p. 11)

SKILLS REQUIRED OF A WORLD-CLASS PURCHASER (DERIVED FACTORS)

Strategic Skills
Strategic thinking
Supply base research
Structuring supplier
relationships
Technology planning
Supplier cost targeting

Interpersonal

communication

Risk-taking/

entrepreneurship

Creativity

Inquisitiveness

Process Management
Skills
Organisation/time
management
Tactfulness in dealing
with others
Written communication
Problem-solving
Conflict resolution

Negotiation Skills
Negotiation
Customer focus
Influencing and
persuasion
Understanding business
conditions

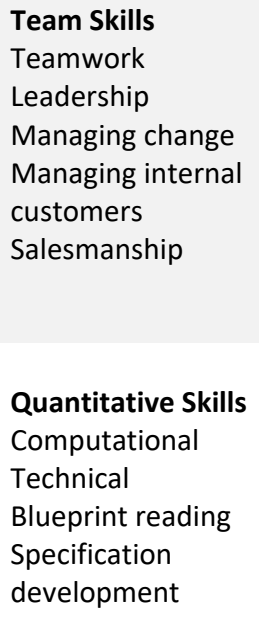

\section{Decision-making}

Skills

Computer

literacy

Ability to make decisions

In their research, Tassabehji and Moorhouse (2008) propose a "new categorisation of skill types required for procurement", "with an increasing emphasis on skills that can be seen as more generic and management-oriented, applied in a procurement context" leading to a more strategic role for PSM (Tassabehji \& Moorhouse, 2008, pp. 59-60). Tassabehji and Moorhouse (2008) conclude that the volume of procurement specific skills compared to generic management skills had diminished "over time as business environments become more dynamic, requiring different skills". 
Table 1.2 - Competences matching with Tassabehji \& Moorhouse (2008) and additional competences gathered in interviews (adapted from Bals, Schulze, Kelly, \& Stek, 2019, p. 7)

\begin{tabular}{|c|c|c|c|}
\hline Technical Skills & Interpersonal Skills & $\begin{array}{l}\text { Internal/ External } \\
\text { Enterprise Skills }\end{array}$ & $\begin{array}{l}\text { Strategic Business } \\
\text { Skills }\end{array}$ \\
\hline \multicolumn{4}{|c|}{$\begin{array}{l}\text { Matching competences - competences identified by Tassabehji and Moorhouse (2008) and } \\
\text { found in the interviews }\end{array}$} \\
\hline $\begin{array}{l}\text { basic knowledge on } \\
\text { PSM role \& } \\
\text { processes; } \\
\text { computer literacy; } \\
\text { contract } \\
\text { management; } \\
\text { cost savings; } \\
\text { eProcurement } \\
\text { technology; } \\
\text { intellectual } \\
\text { property; } \\
\text { KPI reporting design; } \\
\text { languages; } \\
\text { negotiation; } \\
\text { process } \\
\text { optimisation; } \\
\text { product knowledge; } \\
\text { project } \\
\text { management; } \\
\text { quality assurance; } \\
\text { strategic sourcing; } \\
\text { tools and Systems; } \\
\text { implementation }\end{array}$ & $\begin{array}{l}\text { analytical skills; } \\
\text { conflict resolution; } \\
\text { creativity; } \\
\text { decision making; } \\
\text { effective questioning } \\
\text { techniques; } \\
\text { integrity; } \\
\text { interpersonal } \\
\text { communication; } \\
\text { knowledge sharing; } \\
\text { leadership; } \\
\text { learning agility; } \\
\text { prioritisation; } \\
\text { remote virtual } \\
\text { working; } \\
\text { results focus driving } \\
\text { for results; } \\
\text { structured way of } \\
\text { working; } \\
\text { teamwork-working } \\
\text { in teams }\end{array}$ & $\begin{array}{l}\text { change } \\
\text { management; } \\
\text { communication } \\
\text { skills; } \\
\text { cross-functional } \\
\text { abilities \& } \\
\text { knowledge; } \\
\text { cultural awareness; } \\
\text { customer focus; } \\
\text { engineering; } \\
\text { finance; } \\
\text { logistics; } \\
\text { manufacturing \& } \\
\text { production; } \\
\text { marketing; } \\
\text { networking; } \\
\text { quality (QHSE); } \\
\text { R\&D; } \\
\text { supply chain; } \\
\text { sales; } \\
\text { stakeholder } \\
\text { relationship } \\
\text { management; } \\
\text { supplier } \\
\text { management }\end{array}$ & $\begin{array}{l}\text { business acumen; } \\
\text { financial acumen; } \\
\text { PSM best practice } \\
\text { intelligence } \\
\text { scouting; } \\
\text { risk management; } \\
\text { strategic thinking }\end{array}$ \\
\hline \multicolumn{4}{|c|}{$\begin{array}{c}\text { Additional competences - competences NOT identified by Tassabehii and Moorhouse (2008) } \\
\text { and found in the interviews }\end{array}$} \\
\hline $\begin{array}{l}\text { automation; } \\
\text { big data analytics; } \\
\text { innovation sourcing; } \\
\text { innovative sourcing } \\
\text { approaches }\end{array}$ & $\begin{array}{l}\text { curiosity; } \\
\text { deal with ambiguity; } \\
\text { humility; } \\
\text { mobility; } \\
\text { openness, open- } \\
\text { minded; } \\
\text { passion; } \\
\text { resilience; } \\
\text { self-confidence; } \\
\text { self-reflection; } \\
\text { self-reliance }\end{array}$ & & $\begin{array}{l}\text { critical thinking; } \\
\text { holistic supply chain } \\
\text { thinking; } \\
\text { sustainability }\end{array}$ \\
\hline
\end{tabular}


These generic skills are "applicable to other organisational functions", which is also confirmed recently by Bals et al. (2019, i.e. Chapter 2 ) in a replication of the study of Tassabehji and Moorhouse (2008). Based on a PSM competence literature from 1993 to 2008 , Knight et al. $(2014$, p. 278) have found different purchasing roles in their study in which they built further upon Kraljic' matrix (1983). The survey-based study of Knight et al. (2014) ( $n=72$ ) projected strategic, tactical and routine purchasing skills profile on the quadrants of Kraljic' matrix. The most critical strategic skills are "influencing and persuasion", "decision-making skills", "coordinating skills", "ability to work in teams", "managing internal customers", "change management", "strategic thinking", "specification development" and "understanding manufacturing terminology and processes".

The interview-based research ( $n=46$ ) of Schulze, Bals, and Johnsen (2019) elaborates on skills specifically for successful corporate socially responsible and green PSM and concludes that success is reached with strategic rather than with transactional skills. Moreover, in their study, Bals et al. (2019, p. 10, i.e. Chapter 2) are applying the framework of Tassabehji and Moorhouse (2008) and are adding 17 skills or competences to the framework (see: Table 1.2). Bals et al. (2019):

"The combination of the newly identified competencies with others that have already been found in previous research (...), suggests that a new, more modern competency profile for PSM practitioners is needed, that reflects a business context influenced by the latest developments in industry 4.0 and sustainability, such as moving towards a circular economy and circular supply chains" (Bals et al., 2019, p. 10).

Therefore, the PSM skills literature reveals more or less the developments from a transactional to a strategic role over the past decades. Currently, the PSM function is facing the challenges of the Fourth Industrial Revolution or Industry 4.0. Machine-to-machine communication will take over operational tasks, and it is encountering challenges to comply with circular and social responsibility purchasing and supply chain objectives (Bals et al., 2019). The PSM function will deal with complex problems, and therefore other competences will be required (Von der Gracht, Giunipero, \& Schueller, 2016). Whereas in the past PSM professionals required mostly cognition and professional and interpersonal skills, the PSM professional is increasingly selected for intrapersonal skills, traits and behaviour. The competent, future-proof purchaser masters knowledge, professional skills, interpersonal skills and intrapersonal traits (Bals et al., 2019). Remarkably, a listing of distinct innovation sourcing competences appears to be absent in the literature, despite the assumed importance. Next, the literature on the role of creativity in the PSM function and innovation sourcing is presented. 


\subsubsection{The role of creativity in business and PSM}

The research of Kiratli, Rozemeijer, Hilken, de Ruyter, and de Jong (2016) is an atypical PSM competence literature paper, as it is concentrating solely on the support for a creativity climate in sourcing. However, the question is how to define creativity and how it could be applied. As shown above, creativity and fictional thinking are an ancient concept associated with humans (Homo sapiens) since prehistory (Harari, 2014; Lumsden, 1999).

The literature gave attention to the concept of creativity, leading to innovativeness, which is underlining the importance of both novel and useful idea generation (Perry-Smith \& Mannucci, 2017). Hence, "innovation can be conceptualized as encompassing two different activities: the development of novel, useful ideas and their implementation" (Baer, 2012, p. 1102). PSM's key role in innovative creativity occurs typically during the process of NPD. Parts of this innovation process are "idea generation, idea screening, concept testing, development, and launch" (Roy, Sivakumar, \& Wilkinson, 2004, p. 62) or "idea generation, idea elaboration, idea championing, and idea implementation" (Perry-Smith \& Mannucci, 2017, p. 53).

In creativity research, there are two directions: "everyday creativity (also called "little-c"), which can be found in nearly all people, and eminent creativity (also called "Big-C"), which is reserved for the great" (Kaufman \& Beghetto, 2009, p. 1). Examples of little-c given are: "creative activities in which the average person may participate each day," such as "coming up with a creative solution to a complex scheduling problem at work" (Kaufman \& Beghetto, 2009, p. 1) or active participation "in innovation projects or heads cross-functional sourcing teams" (Kiratli et al., 2016, p. 202).

Kaufman and Beghetto (2009) found that most research that studied students' or children's behaviour focus on everyday creativity, i.e. little-c. Big-C is focused on eminent creativity, creative genius, and creative greatness of well-known creators who excel at high levels on creativity measures. Kaufman and Beghetto $(2009$, p. 2$)$ provide even further differentiation and present a broader distinction. They recognise, besides little-C and Big-C, a lower and a higher form of creativity: mini-c and Pro-c. Minicreativity or mini-c is the individual learning of creative expression, and Pro-c or professional creativity is the creativity reserved for genuine top-level artists (Kaufman \& Beghetto, 2009).

For the PSM function, Kiratli et al. (2016) sees a vital role for creativity in sourcing teams and introduced the concept of a team creativity climate "as a means to address the unique challenges associated with a collective, cross-functional approach to develop value-enhancing sourcing strategies" (Kiratli et al., 2016, p. 196). This creative climate is an organisational atmosphere that enables "the collective sensemaking process that precedes the origination of creative and successful strategies in sourcing teams" (Kiratli et al., 2016, p. 202). To promote creativity, Kiratli et al. (2016, p. 196) 
advise companies "to install sourcing teams that can capitalise on the specialised knowledge and expertise of their employees across the company". Based on a survey ( $n=120$ ), Kiratli et al. (2016) provide the items of the construct that was found by exploratory and confirmatory factor analysis (see: Table 1.3 and Kiratli et al., 2016, p. 200).

Table 1.3 - items of the factor 'Team creativity climate' in PSM (derived from Kiratli et al., 2016, p. 200)

\section{Items that form the factor 'Team creative climate' in PSM}

In our team, we are open to each other's views and ideas.

In our team, we strive to think across departmental boundaries.

In our team, we actively seek out each other for constructive discussions.

In our team, we are encouraged to try new ways of doing things.

In our team, we are comfortable with exploring unfamiliar or unknown ideas and perspectives.

In our team, we openly share our thoughts without fear of rejection.

Building on each other's ideas is an integral part of how we work in our team.

In our team, every team member's contribution is taken seriously.

In our team, we promote behaviours that are conducive towards a trustful environment.

Concluding, creativity or little-c is necessary to invent novel ideas and the subsequent implementation of these innovations. The organisations' management is urged to create a team creative climate to accommodate creativity to stimulate the innovation sourcing process, elaborated in the following section.

\subsubsection{The literature on innovation sourcing}

Innovation creation has to be positioned primarily in the context of capitalism and free-market mechanisms. Capitalism is characterised by private ownership of capital goods and is "by nature a form or method of economic change and not only never is but never can be stationary", as stated by Joseph Schumpeter (1942, p. 147) in his writings about "Creative Destruction":

"The opening up of new markets, foreign or domestic, and the organizational development from the craft shop and factory to such concerns as U.S. Steel illustrate the same process of industrial mutation - if I may use that biological term - that incessantly revolutionizes the economic structure from within, incessantly destroying the old one, incessantly creating a new one. This process of Creative Destruction is the essential fact about capitalism. It is what capitalism consists in and what every capitalist concern has got to live in" (Schumpeter, 1942, pp. 147-148). 
Within the above-described context, innovation creation occurs typically during the involvement of purchasing in the process of new product development. As mentioned above, parts of this process are "idea generation, idea screening, concept testing, development, and launch" (Roy et al., 2004, p. 62). Innovation sourcing requires further "learning orientation, teamwork, and decentralization or autonomy in decisionmaking" because "in learning organizations, decentralized organizational cultures lead to the adaptability required for discontinuous innovation" (Gonzalez-Padron, Hult, \& Calantone, 2008, p. 69).

The literature on innovation sourcing distinguishes different success practices. One practice is to "search for completely new technologies and sources of knowledge and ideas outside existing supply relationships and supply chains" (Johnsen, Calvi, \& Phillips, 2012, p. 12) and "to look beyond immediate requirements and anticipate factors that could provide future competitive advantage" (Legenvre \& Gualandris, 2018, p. 97).

"Purchasing teams need to explore external opportunities beyond first-tier suppliers in order to access or co-develop innovative solutions. Together with their colleagues, they need to: (1) gain a wider understanding of the ecosystem, (2) strengthen their business intelligence, and (3) engage effectively with outsiders and new players" (Legenvre \& Gualandris, 2018, p. 97).

Innovation focused firms need to concentrate on "strategic sourcing (i.e. actively scout and maintain the supply base)" but also need to "promote supplier collaboration (i.e. supplier development as well as involvement into the buying firm's processes)" (Luzzini, Amann, Caniato, Essig, \& Ronchi, 2015, p. 115).

Next, to innovate with other firms, PSM teams must communicate and cooperate "closely with $R \& D$, marketing, operations, and clients" (Legenvre \& Gualandris, 2018, p. 97). Future PSM will "work on a more interdisciplinary level, developing more technical skills, and participating more actively in product development processes" (Von der Gracht et al., 2016, p. 46). Key is early involvement of the PSM function in "the sourcing process, before any specific project has even been formally started" (Johnsen et al., 2012, p. 13).

Thus, in cooperation with internal business partners, purchasers need to grasp the broader ecosystem, increase their business intelligence level, and "engage effectively with outsiders and new players" (Legenvre \& Gualandris, 2018, p. 97). "The purchasing function has clearly emerged as a pivotal interface and process owner of collaborative buyer-supplier relationships" (Luzzini et al., 2015, p. 115). Johnsen et al. (2012, p. 13) advise to "develop short-term supplier relationships, limited to the duration of innovation project" and to "manage these relationships as important but not (initially) strategic partnerships". 
A further challenge for PSM is to balance short-term cost advantages with long-term innovation advantages. Johnsen et al. (2012, p. 13) state that purchasers need to assess suppliers merely on their innovative capabilities than purely on low cost. Legenvre and Gualandris (2018, p. 97) add that the balance between costs and innovations holds that purchasers "need to look beyond risks, cost, and product development to offer further competitive advantages". Schiele (2010, p. 149) emphasises the importance of a long-term scope on the cost-innovation balance by pointing on purchasing's dual role "to support the process of innovation while maintaining cost and integration responsibility for the entire product life cycle for the entire firm".

In conclusion, in this section, the competences that are needed according to the literature are described. A brief history of how the learning, training and transfer of knowledge, skills, and attitudes are described in the literature is presented in the next section.

\subsection{A brief history of competence development and education}

\subsubsection{The education of intrapersonal character traits in ancient Greece}

Institutions for higher education need to anticipate the challenges of the $21^{\text {st }}$ century. A possible answer on how to anticipate may lie in ancient Greek history. The ancient wisdom of the Greek philosophy has been influential over the past centuries or millennia and is commonly seen as one of the most important roots of the European civilisation, and it has influenced, amongst others, the development of the European (classic) academic education system (Crossley, 2018; Cubberley, 1920; Kristeller, 1979).

Ancient educational philosophy is built upon three pillars: the learning of (cognitive) knowledge, (practical) skills and (character) virtues (Bitros \& Karayiannis, 2011). The construct of a 'competence' or of 'being competent' seems, in general, to fit the closest to these ancient educational objectives, and it is mainly defined as a cluster of three elements, knowledge, skills, abilities and other characteristics as defined by Boyatzis (1982), Campion et al. (2011), Delamare-Le Deist and Winterton (2005).

In ancient Athens, the classical education of young Athenians was not primary aimed at preparing students to earn "higher incomes and amass more wealth, but to become better citizens" (Bitros \& Karayiannis, 2011, p. 211). The development of virtues in ancient Greece has subsequently been promoted by Socrates (470-399 BC), his pupil Plato $( \pm 427- \pm 348 \mathrm{BC}$ ), and foremost by Aristotle (384-322 BC), a pupil of the latter. Yet, already four centuries before, the Greek poet Homer ( $\pm 800-750 \mathrm{BC}$ ) in Iliad (or Iliás /

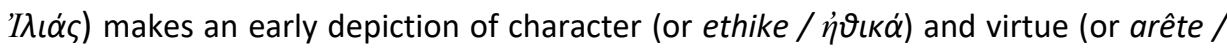

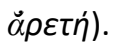


In Homer's lliad, "the heroes of the Trojan War are animated by their quest for virtue or attempts to achieve perfection. Homer used the Greek word 'arête' to describe not only virtue but all characteristics that enable an individual to achieve excellence in the performance of their duties" (Larkin et al., 2009, p. 51).

Around $330 \mathrm{BC}$, Aristotle developed the ancient Greek concept of character and virtue. Aristotle stated in the Nichomachean Ethics (Aristotle, 2013 [350 B.C.]) that the development of virtues leads to a fair and happy life. Virtues not only include doing well but also having good thoughts and good feelings. Virtues represent the golden mean between absence and excess. For instance, courage is described as the mean between recklessness and cowardice (Aristotle, 2013 [350 B.C.]).

Aristotle identified the four cardinal virtues, courage, temperance, justice and prudence and stated these are required for 'excellent' leadership (Hackett \& Wang, 2012). "The struggle for optimal balance in one's life was the struggle for virtue. His concept was that virtue must be practised to find the balance; it must be cultivated for moral behaviour to become a habit" (Larkin et al., 2009, p. 51). The fifteen virtues Aristotle distinguished are:

"courage, justice, prudence, temperance, generosity, magnificence, magnanimity, mildness, truthfulness, wit, friendliness, prone to shame, proper indignation, wisdom and one is pertaining to 'small honour' which essentially remained nameless" (Hackett \& Wang, 2012, p. 870).

The four cardinal virtues have been the subject of countless scientific business journals and are the fundamental virtues of what is promoted in social business networks as 'leaders'. To a certain extent, courage is an essential virtue for the entrepreneur. Courage holds the capacity to "face and to overcome difficult situations" (Arjoon, 2000, p. 163) and is associated with calculated risk-taking, since "entrepreneurs, no matter the type of venture, take some level of risk" (Miller \& Collier, 2010, p. 87). Needless to say that temperance or self-mastery is needed in respect of calculated risk-taking, as it is "the ability to have control over our tendencies" (Arjoon, 2000, p. 163).

The ethical issues are represented in the virtues of prudence and justice. Justice is important for entrepreneurs to "constantly give others what is their due so that they can fulfil their duties and exercise their rights, and at the same time, one also tries to see that others do likewise" (Arjoon, 2000, p. 163). Prudence is the capacity that directs the decision-making process and "that enables us to recognize and choose what is good and right" (Miller \& Collier, 2010, p. 86).

Hence, the ancient Greek educational philosophy was built upon knowledge, skills and virtues (Bitros \& Karayiannis, 2011). Aristotle explains in the Nichomachean Ethics how the learning of knowledge, skills and virtues should be executed. Aristotle emphasises learning-by-doing: 
"the virtues we get by first exercising them, as also happens in the case of the arts as well. For the things we gave to learn before we can do them, we learn by doing them, e.g. men become builders by building and lyre players by playing the lyre; so too we become just by doing just acts, temperate by doing temperate acts, brave by doing brave acts" (Aristotle, 2013 [350 B.C.], p. 20).

Concerning the learning of knowledge, the ancient Greek philosophers underlined that students should build up knowledge by themselves. Socrates is often associated with the unsourced quote: "I cannot teach anybody anything, I only can make them think", that nevertheless has found its way to peer-reviewed literature (e.g. Adelung \& Fitzsimons, 2015, p. 241; McLachlan, Eastwood, \& Friedberg, 2016; Serrat, 2017) although Socrates "did not write anything" (Lacey, 1971, p. 22). For this dissertation, the work of Socrates' pupil Plato is examined, and the conclusion is that the quote is most likely based on Plato, who stated:

"Education is not in reality, what some people proclaim it to be in their profession. What they aver is that they can put true knowledge into a soul that does not possess it, as if they were inserting vision into blind eyes" (Plato, 1992 [375 BC], Book 7, 518b-c).

Four centuries later, Plato's thoughts resound, in the Latin phrase often used in education (Martels, 2011), 'non scholæ sed vitæ discimus' (We do not learn for school, but for life) or 'non scholæ sed vitæ discendum est' (We must learn not for school but for life), which is an inversion of the Roman philosopher Lucius Annaeus Seneca's (4 BC-AD 65) plea for other than cognitive, theoretical lectures in education (on literature at that time):

"Quemadmodum omnium rerum, sic litterarum quoque intemperantia laboramus; non vitæ sed scholæ discimus" (Seneca, 1925 [65 AD], p. 222), meaning: "Just as we suffer from excess in all things, so we suffer from excess in literature; thus we learn our lessons, not for life, but for the lecture-room "(Seneca, 1925 [65 AD], p. 223),

The ancient Greek society was distinct from contemporary societies, and the main criticism on ancient Greek education, from a modern perspective, is that it "sought to mold the individual in the hard and inflexible matrix of a dominant society" (Meyer, 1939, p. 1). Meyer (1939) refers to the Renaissance Humanists who accelerated the idea of educating individuals for the sake of their own 'precious self' in the late Middle Ages and Renaissance.

\subsubsection{The education of intrapersonal character traits from the Middle Ages to the Enlightenment}

A widespread misconception reflected in the name Renaissance, i.e. the 'rebirth' of the achievements of classical antiquity, is that there was no attention for classical antiquity in the Middle Ages (Huizinga, 1924). However, in the $16^{\text {th }}$ century, the 
term Renaissance would not have been recognised because it is a $19^{\text {th }}$-century conception. "The first person to use the term was the French historian Jules Michelet ${ }^{4}$, a French nationalist deeply committed to the egalitarian principles of the French Revolution" (Brotton, 2006, p. 10). Although in the $16^{\text {th }}$ century, there was a revival of attention for the classical culture that was addressed with the Italian word 'rinascita' (rebirth), Michelet was mistaking. There was indeed medieval attention for the ancient Greek achievements. In fact, in the late Middle Ages, the Greek philosophers were rediscovered not only by Christians but also by Jews and Muslims (Rubenstein, 2004).

In the Middle Ages, Aristotle's work, the Nichomachean Ethics, has been retranslated by the Toledo School of Translators in 1240 and came in the hands of the medieval philosopher and theologian Saint Thomas Aquinas (1225-1274, hereafter 'Aquinas') (Kretzmann, Kenny, Pinborg, \& Stump, 1988). Probably due to this translation, Aquinas got inspired to combine the four cardinal virtues of Aristotle (courage, temperance, justice and prudence) with the virtues of Christianity (faith, hope, and charity) (Larkin et al., 2009).

Moreover, Aquinas was also focused on the learning process. In his most important work, Summa Theologiae (in 1274), he states in line with the abovementioned quote of Plato (1992 [375 BC], Book 7, 518b-c):

"Now wonder is a kind of desire for knowledge; a desire which comes to man when he sees an effect of which the cause either is unknown to him or surpasses his knowledge or faculty of understanding. Consequently, wonder is a cause of pleasure, in so far as it includes a hope of getting the knowledge, which one desires to have. For this reason, whatever is wonderful is pleasing, for instance, things that are scarce" (Saint Thomas Aquinas, [1274] 1989, Part I-II, Q. 32, Art. 8).

Thus, in the 'dark' Middle Ages, Aquinas referred to learning processes and, on the question, 'how to learn', inspired by the Nichomachean Ethics of Aristotle and which seems to be a surprisingly modern view that would fit in the discourse of individualism in education from the Enlightenment to the present time.

Modern philosophers have been questioning the promotion of good habits by the Aristotelian philosophy. Wootton (2018) gives a philosophical, historical overview of the conception of 'good habits'. Around 1600 A.D., two conceptions existed, the biblical explanation (piety, demur, goodness and self-engaging) and the Aristotelian tradition (courage, justice, prudence, and temperance). Wootton (2018) sketches the Enlightenment along the line via the philosophers Machiavelli, Hobbes and Locke, and demonstrates that Enlightenment is based on the idea that humans are egocentric and self-indulgent by nature. In that light, humans can do well to others only if they profit from that good deed. The Aristotelian conception of virtues to become 'better citizens'

\footnotetext{
${ }^{4}$ Jules Michelet (1798-1874) was a French historian.
} 
seem to have been transformed into another conception after the Enlightenment (Wootton, 2018).

As mentioned above, Meyer (1939) referred to the Renaissance Humanists (e.g. Desiderius Erasmus, 1466-1536 or Giovanni Boccaccio, 1313-1375) and drew a direct line to the most influential advocate of individualism in education, the philosopher Jean-Jacques Rousseau (1712-1778). In his work Émile, ou De l'Éducation (Emile, or On Education), Rousseau (1762) "brushed aside almost every form of social control" for the sake of learning (Meyer, 1939, p. 1).

Rousseau's three basic principles are (1) the individual and its capacities are the starting point in all education without any adult constraint; (2) the learning process has to come from the individual's experimental investigation of his surroundings without any political or theological constraints, and (3) education comes with actual living and not so much via book knowledge. "Though Rousseau was an educational theorist and not a practical school teacher, his 'Emile' definitely left its mark on the educational world," according to Meyer (1939, p. 2).

Rousseau died before the French Revolution that lasted from May 1789 to November 1799; however, Rousseau's influence was felt. His work Du Contrat Social; ou, Principes du Droit Politique (On the Social Contract; or, Principles of Political Rights) influenced the new French constitution of 1793 and the Déclaration des droits de I'homme et du citoyen de 1789 (Declaration of the Rights of Man and the Citizen, 1789) (Baker, 2012). Interestingly, in the literature, France and the French Revolution, and Great Britain and the Industrial Revolution are subject to comparison, as shown in the next section.

\subsubsection{The education of intrapersonal character traits around the First Industrial Revolution}

Parallel to the French Revolution with its' ideals of individual liberty and equality arose in Britain, the First Industrial Revolution from about 1750 until 1810 (Von Tunzelmann, 2003). The First Industrial Revolution cannot be seen without the context of the so-called British Agricultural Revolution that took place from 1650 to 1780, and that was caused by a combination of "climate recovery and agrarian efforts (the increase in nitrogen stock) and the increase in population within a favourable institutional framework led to a significant increase in production and yield during the first half of the 18th century" (Martínes-González, 2015, p. 18).

The "climate recovery" means that the Little Ice Age and especially the socalled Maunder Minimum (1645-1715) was left behind (A. Koch, Brierley, Maslin, \& Lewis, 2019; Martínes-González, 2015). The "agrarian efforts" regarded more efficient agricultural techniques that led to a chain reaction from increasing food supplies to 
rapid growth in population and urbanisation in Britain (Mingay, 1977). In the first part of the $19^{\text {th }}$ century the agricultural employment decreased "from about one-half to onequarter of employment, and there was a significant increase in factory employment," and there "was the shift to towns and cities, and to industrial occupations. Large and middle-sized urban centres in Britain took a steadily rising share of the population between 1770 and 1850" (Clark, Huberman, \& Lindert, 1995, p. 225). The diet shifted from homemade bread in the agricultural society towards outdoor cooked potato meals in the urbanised society. Potatoes were nutritious and cheap 'fuel' (Horrell \& Oxley, 2012).

The First Industrial Revolution is characterised by using steam power to mechanise production and was the first to impact societies, organisations, and business. In his time during the First Industrial Revolution, the Scottish philosopher and author Adam Smith (1723-1790) published his seminal work An Inquiry into the Nature and Causes of the Wealth of Nations (A. Smith, 1776), for which he has been addressed as "the philosopher of the capitalist revolution" (Koebner, 1959, p. 382). Smith had an eye for "the innovations in technique and the organisation of business" (Koebner, 1959, p. 382) but merely concentrated on the abstract part, the economic theory. Nevertheless, he visited enterprises from 1767 to 1775, when he worked on The Wealth of Nations. Later, when he was working on further editions, "he was in a position to take account not only of new inventions but also of the increasing application of modern machinery to practical uses, as witnessed by new spinning mills" (Koebner, 1959, p. 383).

Remarkably, the expression 'Industrial Revolution' is a French 'invention' and is attributed to "Europe's first historian of political thought, author of the preface to The Wealth of Nations, and also the first figure to acquire a business school in his lifetime and become its dean, Jérôme-Adolphe Blanqui (1798-1854)" (Deslandes, 2019, p. 1). Jérôme-Adolphe Blanqui was a French liberal economist and an economic historian, and he was indeed the author of the preface and the editor of Recherches sur la Nature et les Causes de la Richesse des Nations (A. Smith, 1843), the French translation of The Wealth of Nations.

Jérôme-Adolphe Blanqui could easily be confused with his younger brother Louis Auguste Blanqui (1805-1881). Louis-Auguste Blanqui was a socialist and political activist and known for the revolutionary theory: Blanquism. Karl Marx (1818-1883) referred to Louis-Auguste Blanqui as the "man whom I have always regarded as the brains and inspiration of the proletarian party in France" (Marx \& Engels, 2010, p. 326). Hereafter, the older Blanqui or in his own words 'Blanqui année', Jérôme-Adolphe Blanqui will be referred to as 'Blanqui'.

Blanqui (1837) praised Great Britain's efforts, which were made possible by the steam engine's invention and the spinning machine, which reversed the old trading system and generated similarly material products and unprecedented social issues. "It 
looked like England had discovered new mines and had suddenly been enriched with unexpected treasures", while "the French Revolution was doing its large social experiments on a volcano" (own translation; Blanqui, 1837, p. 166).

"Cependant, à peine éclose du cerveau de ces deux hommes de génie, Watt et Arkwright, la révolution industrielle se mit en possession de l'Angleterre. A la fin du dixhuitième siècle, il ne se consommait pas en Europe une seule pièce de coton qui ne nous vint de l'Inde, et vingt-cinq ans après, l'Angleterre en envoyait au pays même d'où elle avait tiré jusque-là tous les produits semblables. "Le fleuve, dit J.-B. Say, était remonté vers sa source "."

"However, barely hatched from the brains of these two men of genius, Watt ${ }^{5}$ and Arkwright ${ }^{6}$, the industrial revolution took possession of England. At the end of the eighteenth century, a single piece of cotton was not consumed in Europe, which did not come to us from India, and twenty-five years later, England sent it to the very country from which it had so far pulled all similar products. 'The river,' says J.-B. Say', 'went back up to its source'”' (own translation; Blanqui, 1837, p. 167).

Blanqui was highly interested in the developments in the British industry and the efforts in British education. Blanqui spoke English and followed the British press. Moreover, he often travelled to Britain. "He urged his audience not to shrink from debating and thinking about the big questions facing contemporary France" (Deslandes, 2019 , p. 6). Blanqui praised the British education of that time because throughout Britain, political economy was lectured, while it was taught practically nowhere in France. Further, "the UK boasted a network of around sixty 'mechanics institutions' offering evening classes, which aimed to explain the technical workings of industry to a wider audience" (Deslandes, 2019, p. 6).

Blanqui (1837) praised the British inventors on the one hand, and on the other hand, he emphasised that the Industrial Revolution caused social issues. He criticised the British entrepreneurs of his time for being more occupied with collecting the profits than looking for the social embarrassments they dragged after them. Blanqui emphasised that the inventors, Arkwright and Watt, could not have foreseen that the machines would bring "so much power and so many worries" such as "pauperism" (own translation; Blanqui, 1837, p. 167).

Eight years after Blanqui (1837) used the phrase 'Industrial Revolution' in a liberal economic setting, the communist philosopher Friedrich Engels (1820-1895) adopted and translated it into the German language, although the term was still not common parlance. It lasted until the 1880s when the English translation of Blanqui's

\footnotetext{
${ }^{5}$ James Watt (1736-1812) presented an improved version of Thomas Newcomen's steam engine in 1776.

${ }^{6}$ Sir Richard Arkwright (1732-1792) in 1769 patented a spinning frame that was initially water powered and later steam powered.

${ }^{7}$ Jean-Baptiste Say (1767-1832) was a French liberal economist that is known of Say's law, that says that the production creates the demand and is the source of the demand. Moreover, Say was Blanqui's lecturer.
} 
work came out that 'Industrial Revolution' became a common term (Blanqui, 1880; Tribe, 1981). Similar to Blanqui, Engels compared the British Industrial Revolution with the French Revolution and added the German philosophical revolution:

"The industrial revolution has the same meaning for England as the political revolution for France and the philosophical revolution for Germany, and the distance between England from 1760 and 1844 is at least as great as that between France of the ancien régime and that of the July Revolution. The fruit of this industrial upheaval is the English proletariat" (own translation; Engels, 1845, p. 28).

As mentioned above, Blanqui acquired a business school. The school's history started in 1819 with the liberal economist Jean-Baptiste Say (1767-1832). Say participated with his pupil Blanqui and the Lyonnais industrialist Vital-Roux in the foundation of a 'seminar' of executives of liberal and entrepreneurial industrialism titled École Spéciale de Commerce (ESC), now known as École Supérieure de Commerce de Paris or ESCP Europe (Nemo, 2006). This institution "remains the oldest business school in the Western world still in existence today" (Deslandes, 2019, p. 1; Kaplan, 2014). Blanqui was the chair of History and Industrial Economy, and in 1830 he took over the role of director at ESC after Say.

For Blanqui, "management studies could in no way be reduced to an accumulation of technical capacities, however necessary they may have been. In his view, proper management education was an exercise, which enabled future economic decisionmakers to develop the crosscutting know-how and skills needed to reformulate problems and identify solutions in complex organisational situations" (Deslandes, 2019, p. 8).

According to Blanqui, management education also needed to cover "the moral lesson of freedom, leaving room for the apparently useless (...) as well as the strictly utilitarian" (Deslandes, 2019, p. 8). Deslandes (2019, p. 8) concludes that eventually, "learning for learning's sake' (...) must remain a central priority of Europe's management schools" Deslandes $(2019$, p. 8). Blanqui notes that this principle "is more important now than ever, in a world where the majority of the posts, which our students will occupy in their careers do not yet exist" (Deslandes, 2019, p. 8). Here the Latin phrase resounds that was referred to earlier: 'non scholæ sed vitæ discimus' (not for school, but for life we study), which in general is seen as Seneca's plea for other than cognitive, theoretical lectures in education (on literature at that time) (see: Seneca, 1925 [65 AD], p. 223 for the original quote). 


\subsubsection{Von Humboldt and the Bildung ideal}

Blanqui's contemporary, the Prussian philosopher, linguist, government functionary, diplomat, introducer of Bildung in the Prussian school system and cofounder of the current Humboldt University of Berlin, Wilhelm von Humboldt (1767 1835), in 1809 wrote similar ideas to the Prussian king:

"People obviously cannot be good craftworkers, merchants, soldiers or businessmen unless, regardless of their occupation, they are good, upstanding and - according to their condition - well-informed human beings and citizens. If this basis is laid through schooling, vocational skills are easily acquired later on, and a person is always free to move from one occupation to another, as so often happens in life" (Günther, 1988, p. 132).

Von Humboldt distinguishes between two philosophical academic education streams, referred to with the Germanic terms Bildung and Ausbildung, commonly used in Anglophone literature. Bildung refers to the personality development and selfcultivation ideal, and it has often been linked to the Humboldtian model of higher education (Bruford, 1975), meaning that this approach intends to create graduates with developed abilities to be formed for a career or life and not only for a particular (first) job (Schaffar \& Uljens, 2015).

Ausbildung, in contrast, is related to acquiring the skills needed for a specific profession. It could thus be described as 'vocational training', i.e. Ausbildung takes a professional profile approach of teaching (cognitive) knowledge and (practical) skills and aims to create graduates ready to enter a specific job function at the labour market. The German physics Nobel price winner Werner Heisenberg (1901-1976) defined the difference between Bildung and Ausbildung: "Bildung ist das, was übrig bleibt, wenn man alles vergessen hat, was man gelernt hat" or "Bildung is that what is left over when all is forgotten what one has learned" (own translation; Heisenberg, 1973, p. 105).

Rousseau's pedagogical writings inspired von Humboldt's Bildung concept. Central to Bildung is that individuals indeed develop their personality. The purpose of Bildung does not lie outside the individual: it is not about preparing to perform specific functions or tasks in society. Bildung is a process without a fixed end goal, a continuous development of capabilities. Therefore, Bildung is never completed: it presupposes lifelong, continuous and interacting working with the outside world on one's personal development (De Hert, Kinneging, \& Colette, 2015). In 1789, Von Humboldt advocated a reorientation of political thinking inspired by the reorientation of pedagogical thinking by Rousseau:

"When will man finally cease to regard the outward consequences of action with greater esteem than the inward spiritual flame of mind from which they flow; when will someone appear who will be for legislation what Rousseau was for education, who will 
withdraw the point of vantage from the outward physical results to the inward cultivation (Bildung) of men?" (Sorkin, 1983, p. 58).

Von Humboldt defined 'civilisation', 'culture' and 'Bildung' (here translated as cultivation) as follows:

"Civilization is the humanization of peoples in their outward institutions and customs and the inner attitude pertaining thereto. Culture adds science and art to this refinement of the social order. But when we speak in our language of cultivation (Bildung), we mean by this something at the same time higher and more inward, namely the disposition that, from the knowledge and feeling of the entire mental and moral endeavour, pours out harmoniously upon temperament and character" (Von Humboldt, 1999, pp. 34-35).

Inspired by Greek philosophy, Von Humboldt compared the ancient Greek citystate's political constitution with the $19^{\text {th }}$-century Prussian state. In the ancient Greek city-states, the direct influence on private lives was minimal. However, the influence was indirectly applied by expanding politics into private life through an education aimed at generating loyal citizens (Sorkin, 1983). The ancient Greek education "sought to mold the individual in the hard and inflexible matrix of a dominant society" (Meyer, 1939, p. 1). In line with Von Humboldt's ideas, this political fashioning of private life must have had a harmful effect, because by manipulating human's "inneres Dasein" (or: "inmost being"), it must have irrevocably distorted the inhabitants of the ancient Greek citystates (Sorkin, 1983, p. 60). Paradoxically, the opposite occurred, Von Humboldt notes, since the city-states endorsed happiness via the development of virtues, it promoted harmonious, individual development. In an attempt to in aiming to develop "kraftvolle" (i.e. temperate and energetic) citizens, the city-state gave "higher impulse to their whole spirit and character" (Sorkin, 1983, p. 60).

Von Humboldt states that the promotion of individual virtues in the ancient Greek city-states cannot be copied into the Prussian state "for the sake of since its aim is too eudaemonistic," i.e. the ethical theory promoting happiness and personal wellbeing as highest goals (Sorkin, 1983).

"By attending to man's well-being and his property, his ease and comfort, the modern state suppresses man's energies; it thwarts man's personal growth in favor of obtaining a productive and obedient citizen. The modern state must, therefore, be restricted to a negative function, providing merely the outward conditions of freedom for individual development" (Sorkin, 1983, p. 60).

Or as Von Humboldt noted:

"The State must wholly refrain from every attempt to operate directly or indirectly on the morals and character of the nation otherwise than as such a policy may become inevitable as a natural consequence of its other absolutely necessary measures; and that 
everything calculated to promote such a design, and particularly all special supervision of education, religion, sumptuary laws, etc., lies wholly outside the limits of its legitimate activity" (Von Humboldt, 1854, p. 113)

Alves (2019) underlines that to grasp the Bildung ideal understanding is needed for the German society, its development and response to the modernisation process in the $18^{\text {th }}$ century. Von Humboldt (1767-1835) lived in a Germany that consisted of a "patchwork of small autonomous principalities, marked by a rigid social stratification and by the small despotism that left no room for individual initiative and stifled cultural creation" (Alves, 2019, p. 7). However, after the Seven Years War (17561763), "Prussia emerged as a European power" (Alves, 2019, p. 7).

"In this modernizing society, where the development of sciences and techniques and the increasing division of labour lead to an increasing specialization of knowledge, new forms of integration and social distinction were necessary" (Alves, 2019, p. 7).

From 1770 to 1815, Bildung was seen in Germany "as a cosmopolitan and universalist ideal that was associated with the ideas of individual autonomy and selfdetermination and with the image of an integral individual endowed with an aesthetically harmonious personality" (Alves, 2019, p. 9). This educational view reflected the ideals of genuine and objective understanding instead of external reasons and utilitarian purposes. After Napoleon defeated Prussia in 1807, the Bildung ideal found a favourable opportunity to realise a series of reforms (Alves, 2019).

"Under the influence of liberalism and that of the revolutionary ideal of civil equality, measures were taken, such as the liberation of the peasantry from servitude and the emancipation of the Jews. Humboldt and the neo-humanists were called by Ministers Stein and Hardenberg to reform the Prussian educational system according to their ideal of humanity (Humanitätsideal). In primary schools, the pedagogy of Pestalozzi was adopted, taking into account the needs and specificities of the child. At the secondary level, the Gymnasien (Gymnasia, KS) were instituted based on the study of the Greek classics and the ideal of harmonious individuality. In 1810, the University of Berlin was founded, based on the principles of freedom of research and teaching; it would serve as a model for the reorganization of all the other German universities. (...) The task of education was not to adapt the individual to the world, to train him with useful knowledge and skills, but to awaken the inner forces, creativity, and critical judgment to transform the world and to realize within itself the ideal of humanity" (Alves, 2019, pp. 9-10).

As shown in ancient Greek philosophy, the development of students' intrapersonal traits is crucial for good citizenship. Or as the liberal economist, John Stuart Mill (1806-1873) in his inaugural speech at the University of St. Andrews, Scotland in February 1867, expressed the Anglo-Saxon character-education ideal:

"At least there is a tolerably general agreement about what an (sic!) University is not. It is not a place of professional education. Universities are not intended to teach the 
knowledge required to fit men for some special mode of gaining their livelihood. Their object is not to make skilful lawyers, or physicians, or engineers, but capable and cultivated human beings" (Mill, 1867, p. 4).

Mill was inspired by Von Humboldt's work Ideen zu einem Versuch, die Gränzen der Wirksamkeit des Staates zu bestimmen (Von Humboldt, 1851). Von Humboldt wrote this work already in 1791. Since of difficulties with the Berlin censorship, Von Humboldt decided to withdraw the manuscript. However, individual sections were published in 1792 in the "Berlinische Monatsschrift" and Schiller's "Neuer Thalia". Eventually, the book was published in full posthumously in 1851, shortly after the revolution year 1848 . At that time, state power was on the rise in Europe (see: preface of Von Humboldt, 1854).

The Enlightenment inspired von Humboldt's thoughts. In the summer of 1789, when he visited Paris, Von Humboldt witnessed the French Revolution (see the preface of Von Humboldt, 1999). Inspired by the French revolutionary "Liberté", Von Humboldt's message of freedom fitted the atmosphere after 1848 and was therefore not limited to Prussia. His book Ideen zu einem Versuch, die Gränzen der Wirksamkeit des Staates zu bestimmen (Von Humboldt, 1851) was translated in English, entitled "Sphere and Duties of Government (The Limits of State Action)" (Von Humboldt, 1854). Mill took up Von Humboldt's ideas and quoted Von Humboldt at the beginning of his book entitled "On Liberty":

"The grand, leading principle, towards which every argument unfolded in these pages directly converges, is the absolute and essential importance of human development in its richest diversity" (Mill, 1859, p. 4).

Mill builds up his case for individual freedom from a development perspective. Freedom is crucial for civilisation and development. Instruments for this development are free speech, experimenting with different life forms, and the clash of ideas to become better citizens and society. Mill reasons that freedom aims to serve development. Mill adds a subtle shift in meaning to the Humboldtian "development concept" (De Hert et al., 2015). This shift is best illustrated with Mill's metaphor of a tree:

"Human nature is not a machine to be built after a model, and set to do exactly the work prescribed for it, but a tree, which requires to grow and develop itself on all sides, according to the tendency of the inward forces which make it a living thing" (Mill, 1859, p. 107).

The comparison to a tree has two crucial implications. Firstly, the development lies in humans' nature and slowing down that development would be unnatural. Secondly, Mill reasons further than Von Humboldt that individual development's objective is to realise human nature (De Hert et al., 2015). 


\subsubsection{Criticism on governmental misuse of the Bildung ideal}

As introduced in the Prussian 19th-century school system by Von Humboldt, the Bildung education led to criticism in the second half of the $19^{\text {th }}$ century, philosophically articulated by Friedrich Nietzsche (1844-1900) (Sanderse, 2019).

Von Humboldt's ideal of Bildung referred to personality development and selfcultivation (Bruford, 1975) and was initially "intended as a progressive and cosmopolitan project, but was used by German governments in the $19^{\text {th }}$ century to fashion the nation-state" (Sanderse, 2019, p. 399). Indeed, the Bildung underwent "an important change in the semantic structure of the ideal of self-cultivation occurs after the Restoration period (1815-1848)" (Alves, 2019, p. 10). Von Humboldt's measures were used during the Restoration to expand the state influence on the school system to control society and to curb political expression against the government (Alves, 2019).

"In 1819, the so-called Carlsbad decrees restricted the civil freedoms of press, association and expression in response to socialist and nationalist agitation, especially in student leagues (Burschenschaften). In fact, the Prussian reformers, as opposed to Humboldt, never relinquished State dominance over the school system, which controlled all its aspects: internal organization, curriculum, finance, examinations, and teachers. This is what enabled the system to be functionalized by later Prussian nationalism" (Alves, 2019, pp. 10-11).

Nietzsche "criticized the German system of public education for having relinquished the Bildung ideal, having replaced it with preparing students to serve the German nation station and war machine" (Sanderse, 2019, p. 406). Von Humboldt greatly influenced Nietzsche's thoughts regarding Bildung (Zauli, 2019): "It is clear from innumerable references in Nietzsche's works that the idea of 'Bildung' was one of his principal preoccupations at all stages in his life" (Bruford, 1975, p. 164). In Nietzsche's work, the word Bildung refers to the academic training of a particular individual. However, Humboldt's definition is "closely linked to the question of language, which he considers as 'the organ of inner being' or even 'this being itself'" (Zauli, 2019, p. 126).

The Bildung ideal of the early $19^{\text {th }}$ century had, according to Nietzsche, alienated from the initial idea of experimenting "with classical ideas to spur a people's cultural development" and "called people that pride themselves of their high German culture, 'Bildungfilister'" (Sanderse, 2019, p. 408). Here, the German word Filister or Philister should be translated or interpreted as a name for a narrow-minded petitebourgeoisie member. Nietzsche's criticism focused on education, being under the control of the 'national-economic dogma', meaning that schooling was aimed to increase knowledge and culture, leading to more production and consumption, more money, and subsequent happiness, and eventually an increased competitive advantage related to other nations (Sanderse, 2019). Nietzsche: 
"I think I know where the loudest and clearest call for the maximum expansion of education is coming from. Expansion is one of the favorite national-economic dogmas of the day. As much knowledge and education as possible-leading to the greatest possible production and demand-leading to the greatest happiness: that is the formula. Here we have Utility as the goal and purpose of education, or more precisely Gain: the highest possible income. From this point of view, education essentially means acquiring the discernment that keeps a person 'up to date,' tells him all the ways to most easily make money, gives him power over the various channels along which individuals and peoples conduct their business" (Nietzsche, [1872] 2016, p. 16).

According to Nietzsche, the Bildung ideal was falsely employed for 'utility' and 'gain' to turn students into 'currency' to let them 'circulate' in the national economy (Sanderse, 2019), or as Nietzsche in 1872 articulated in his work entitled Über die Zukunft unserer Bildungsanstalten, which is translated as Anti-Education - On the Future of our Educational Institutions:

"The true task of education, in this view, is to form people who are, as the French say, 'au courant'-the same way a coin is 'courant', valid currency. The more of these 'circulating' people there are, the happier the nation is as a whole. And that is the goal of the modern educational institution: to make everyone as 'current' as it lies in his nature to be, to train everyone to convert his innate capacity for knowledge and wisdom, whatever it might be, into as much happiness and income as possible. Everyone has to be able to give an exact appraisal of himself, has to determine exactly how much he has a right to demand from life. The 'link between intelligence and property' that this view alleges is practically an ethical demand" (Nietzsche, [1872] 2016, p. 16).

Nietzsche's criticism of Bildung was that it was used as a vehicle to fashion the German nation-state. Indeed, Bildung or every other form of character education is susceptible to governmental influence. Needless to say that after Nietzsche launched his criticism in 1872, some examples of governmental misuse of the Bildung ideal or character education can be pointed out. Lansing (2010) explicitly describes the continuation of the Bildung activities under the $20^{\text {th }}$ century totalitarian regimes in Germany in his book entitled From Nazism to Communism: German schoolteachers under two dictatorships.

These authoritarian and totalitarian regimes had the objective to influence and shape (young) people, which violates the liberty concept proposed by Von Humboldt and Mill. Von Humboldt argues that it is not a task for governments to promote citizens' development but maintain order and safety and guarantee the freedom of conscience. Imposed Bildung would obstruct conscious self-development. A government that aims to develop society will, if that society is not prepared to develop, just reap conformity and dependence, as is illustrated with the abovementioned German examples by Lansing (2010). The government must, therefore, exercise restraint and allow citizens to develop as they like. Von Humboldt pleaded for a relatively small, neutral, and 
tolerant government as a precondition to developing citizens and society (De Hert et al., 2015).

However, if, according to Mill, development is the goal of man and society, inevitably, the question arises whether forms of development are a task of the government to promote these actively. Indeed, Mill distinguishes activities of a higher and lower order and clarifies that pursuing higher forms is preferable, both for the individual and society. Unlike Von Humboldt, Mill is convinced that the government can at least support individuals' self-development process. In his work, the Principles of Political Economy, Mill states that the government can start that development process through targeted policy. Mill has a more positive view of the state than Von Humboldt, who mainly pleaded to increase the individuals' free space. Mill sees more room to manoeuvre for the public sector. However, Mill does not see a role for governments to provide education. It should be left for private initiatives (De Hert et al., 2015). Here the issue of positive and negative freedom, as proposed by Isaiah Berlin (1958), comes to the forefront. In the next section, the context of the two liberties is briefly described.

\subsubsection{Liberalism and two conceptions of liberty: positive and negative freedom}

The concept of liberalism first emerged in the early decades of the $19^{\text {th }}$ century. The term then referred to those who, after the French Revolution, promoted the freedom ideal. In 1812, the term was first used to refer to a specific political group, the Spanish "Liberales". In the same decade, the term became common parlance in France and Great Britain as a collective term for political movements defending rights to extend citizens' freedoms. Remarkably enough, the Swiss and French philosopher, politician and essayist Benjamin Constant (1767-1830) used the term Liberalism already in 1797, as a description from his middle position, between the extremes (De Hert et al., 2015; Vincent, 2000).

Freedom is the core value for Constant. He emphasised that a part of the human existence is necessarily individual and independent, which part needs to stay out of the government's reach. The government's power has to be delineated and limited based on a constitution and institutions established for that purpose, transparent laws and procedures, independent courts, the separation of powers, direct elections of authorities, and a responsive policy (De Hert et al., 2015).

In 1819, Constant made a distinction between two conceptions of freedom: the "ancients" and the "moderns". Modern freedoms are mainly private: privacy and individual freedom are modern concepts. It concerns freedoms such as those of expression, property, choice of profession and residence, association, religion, right to vote and the right not to arbitrary deprivation of liberty or be subject to abuse. Ancient 
liberty was lying in the possibility of participation and representation in politics (De Hert et al., 2015).

"One is the liberty that the ancient peoples valued so much; the other is the liberty that is especially precious to the modern nations. I think that this investigation matters to us, for two different reasons. (1) The failure to distinguish these two kinds of liberty was the cause of many evils during the famous - all too famous! - days of our revolution. France found itself exhausted by useless experiments, and the authors of these, angered by their failures, tried to force France to enjoy the benefits that it did not want and denied it the ones it did want. (2) We are called by our happy revolution to enjoy the benefits of representative government, and we could not find freedom and peace today except under the shelter of that form of government, yet it was totally unknown to the free nations of antiquity, and it would be interesting and useful to look into why that is so" (Constant, 1988 [1819], p. 1).

Constant is here referring to the French Revolution and especially to Reign of Terror (or: la Terreur) that was led by Maximilien de Robespierre (1758-1794), an eminent member of the French revolutionary Committee of Public Safety and responsible for signing hundreds of arrests (Walter, 1961). The French Revolution did not lead to 'modern freedom'. Constant stated that during the French Revolution, a new, up till then, an unknown excuse was found for warfare, liberating peoples from their governments' yoke (De Hert et al., 2015). Berlin (1958, p. 2) reminded the audience of his inaugural speech of the German poet Heinrich Heine, who called "the works of Rousseau the bloodstained weapon (...) in the hands of Robespierre". In 1834, Heine indeed suggested that Rousseau foresaw that making his thoughts come to life would demand a certain kind of "bloody" delivery:

"Maximilian Robespierre was merely the hand of Jean Jacques Rousseau, the bloody hand that drew from the womb of time the body whose soul Rousseau had created. May not the restless anxiety that troubled the life of Jean Jacques have caused such stirrings within him that he already foreboded the kind of accoucheur ${ }^{8}$ that was needed to bring his thought living into the world?" (Heine, 1986 [1834], p. 106).

With the distinction of the two liberties, Constant is the founder of modern freedom (De Hert et al., 2015) that inspired amongst others Mill (Lachs, 1992) and the British political philosopher Isaiah Berlin (1909-1997), who further developed the idea of two freedoms. In 1958, Berlin presented before the University of Oxford his inaugural lecture "Two Concepts of Liberty", the negative and the positive concept. In the negative view, individuals are freer when the space in which an individual can act unhindered by others is larger:

\footnotetext{
${ }^{8} \mathrm{An}$ accoucheur is an obstetrician, i.e. a person that assists during childbirth.
} 
"The negative concept: I am said to be free to the degree to which no human being interferes with my activity. This is the classical sense of liberty in which the great English philosophers, Hobbes, Locke, Bentham, Paine, and indeed Mill, used it" (Berlin, 1958, p. 14).

"The desire to be left alone, to live one's life as one chooses, the very sense of privacy, of the area of personal relationships as sacred in its own right; the belief that it is more worthy of a human being to go to the bad in his own way than to the good under the control of a benevolent authority; this, which is almost a defining notion of a large element in Western civilisation, is scarcely older than the Renaissance and the Reformation. Absolute values are not necessarily timeless or eternal, but their death marks the death of an entire civilisation, the end of an entire moral system" (Berlin, 1958, p. 9).

"Another characteristic of this 'negative' conception of liberty is that it is compatible with autocracy, or at any rate the absence of self-government. Liberty, in this sense, is concerned with the area of control, not with its source" (Berlin, 1958, pp. 9-10).

In the positive concept, the individual is free only when being the master of oneself. When the individual cannot use positive freedom because of poverty or ignorance and cannot master itself, there is no positive freedom and, as a consequence, no negative freedom.

"The 'positive' sense of the word 'liberty' derives from the wish on the part of the individual to be his own master" (Berlin, 1958, p. 14).

"For the 'positive' sense of liberty is an answer to the question: By whom am I governed? Who is to say what I am and what I am not to be or do? And although it seems at first as if there was an intimate connection between individual liberty in the sense of an area free from interference, and democracy in the sense of government not by some outside body but by myself and others like myself with whose interests mine were intertwined, direct government by us of ourselves, or at any rate by our representatives, yet the difference [sc. similarity] is more apparent than real. The desire to be governed by myself, or at any rate to participate in the process whereby my life is to be controlled, is no doubt as basic a wish as that of [sc. for] a free area for action, perhaps more so. But it is not the same; so different, indeed, as to have led in the end to the great clash of ideologies of which I spoke at the beginning. For it is nothing other than the positive conception of liberty which those who believe in the negative concept represent as being at times no better than a disguise for total slavery" (Berlin, 1958, pp. 10-11).

Berlin warns that the positive concept can easily be misused by those who reason about what is right for others, to dictate to others how to live. One could argue that those involved would be misusing their negative freedom because of ignorance and social circumstances and would not be the master of themselves (i.e. positive freedom). Berlin concludes that at best, the positive conception of freedom leads to paternalism and, in the worst case, to despotism (De Hert et al., 2015): 
"This is why paternalism is 'the greatest despotism imaginable', not because it oppresses more than naked, brutal, unenlightened tyranny, but because it is an insult to my conception of myself as a human being entitled to make my own life in accordance with my own purposes, and above all to be recognised as such by others (...)" (Berlin, 1958, p. 28).

Nevertheless, Berlin did not reject the positive conception of freedom (De Hert et al., 2015). Berlin:

"No doubt every interpretation of the word 'liberty', however unusual, must include the minimum of what I have called 'negative' liberty, that is, an area within which my wishes are not frustrated; for a being who is literally prevented by others from doing anything that he wishes to do is not a moral agent at all, and could not either legally or morally be regarded as a human being in the full sense, even if in a physiological or biological or even psychological sense he is to be included within the human species. But Mill and Constant want more than the minimum: they demand the maximum degree of noninterference compatible with the minimum demands of social life.

It is not clear that this demand for liberty has ever been made by any but a small minority of highly civilised and self-conscious human beings. The bulk of humanity has certainly at most times been prepared to sacrifice this to other goals: security, prosperity, power, virtue, rewards in the next world or indeed justice, equality and many other values which appear wholly or in part incompatible with the attainment of the greatest degree of individual liberty and certainly do not need it as a precondition of their own realisation" (Berlin, 1958, p. 11).

Berlin refers to Prussian philosopher Immanuel Kant (1724-1804) when explaining the concepts of freedom:

"Kant, who was perhaps the most profound secular defender of this point of view, built his concept of freedom upon it. I am free because I am autonomous: I obey laws which I have invented for myself. Freedom is obedience, 'obedience to a law which we prescribe to ourselves' [Rousseau]" (Berlin, 1958, p. 16).

Kant formulated two categorical imperatives that resemble Berlin's concept. The two categorical imperatives are inspired by a Bible text, more precisely a quote from Jesus Christ in the Gospel of Mathew "Therefore whatever you desire for men to do to you, you shall also do to them; for this is the law and the prophets" (Matthew $7: 12)$ :

(1) An action is morally right for a person in a certain situation if and only if the person's reason for carrying out the action is a reason that he or she would be willing to have every person act on, in any similar situation (Velasquez, 1988, p. 91).

(2) An action is morally right for a person if and only if in performing the action, the person does not use others merely as means for advancing his or her interests, but also respects and develops their capacity to choose freely for themselves (Velasquez, 1988, p. 93). 
In conclusion, the concept of maximum negative freedom would conflict with the categorical imperatives of Kant and consequently with the negative freedom of other subjects. Nonetheless, Von Humboldt and Mill served as participants in the discourse on liberties and pleaded for maximum negative freedom. Von Humboldt warned that imposed Bildung would obstruct conscious self-development, and for Mill, negative freedom aims to serve the individuals' development. As elaborated, Rousseau, Von Humboldt and Mill, placed development and learning in the context of (negative) freedom.

Hence, the following section will be elaborated on the educational development theories in the past century. These theories seem to be anchored in the conceptions mentioned earlier, such as the impact of industrialisation and societal change increased the demand for an educated workforce. Consequently, the emphasis on the research on the concept of learning increased in the $20^{\text {th }}$ century dramatically:

"Learning has been a central topic in psychological research virtually since the inception of psychology as an independent science. (...) During the largest part of the previous century, it was even the most intensely studied topic in psychology" (De Houwer, Barnes-Holmes, \& Moors, 2013, p. 631).

Therefore, the approach to pupils and students in the $20^{\text {th }}$-century-pedagogy is briefly described in the following section.

\subsubsection{A brief overview of the educational theories in the $20^{\text {th }}$ century}

Rousseau's philosophies are associated with the abovementioned Swiss pedagogue Johan Heinrich Pestalozzi (1746-1827), whose pedagogy was adopted by Von Humboldt to operationalise Bildung (Alves, 2019; Meyer, 1939). Moreover, Rousseau inspired many others such as the Italian pedagogue, medical doctor Maria Montessori (1870-1952), the German pedagogue Friedrich Fröbel (1782-1852), the Dutch teacher and educational innovator Jan Ligthart (1859-1916), the co-founder of the progressive education movement, the Swiss educator Adolphe Ferrière (1879-1960) and the influential US-educational philosopher John Dewey (1859-1952) (Meyer, 1939).

Montessori's philosophy is focused on the pupil: "With Rousseau, she believes that our best cue to the child's education is the child himself. Consequently, she demands complete freedom for the child" (Meyer, 1939, p. 66). In the educational practice, the influence of Montessori, for instance, is up-to-date present. For instance, the Central Bureau for Statistics in the Netherlands reports that almost three per cent of the elementary schools have a Montessori profile, and about five per cent have a Dalton Plan profile. The Dalton Plan is developed by the American educator Helen Parkhurst based on the original ideas of Montessori (Meyer, 1939). 
In 1919, Dewey was the co-founder of The New School (for Social Research) in New York and was known as an advocate of education's social context. Dewey stated: "Knowledge that is worthy of being called knowledge, training of the intellect that is sure to amount to anything, is obtained only by participating in activities in social life", hence in learning by experiencing (Meyer, 1939, p. 63). The New School recommended creative activities to enrich educational development and recognise the individual pupil as a unique person requiring individual treatment, individual instruction, individual initiative and self-education (Meyer, 1939, p. 63).

The Swiss psychologist Jean Piaget (1896-1980) and Russian psychologist Lev Vygotsky (1896-1934) have positively influenced the educational discourse in the $20^{\text {th }}$ century, and their respective constructivist and behaviourist approaches are compared multiple times in the literature (DeVries, 2000). Vygotsky focused on researching children's development; the child is a dependent individual who cannot live in isolation and cannot live without interaction with the social world (DeVries, 2000). Jean Piaget mainly emphasised the interaction of the child with the physical world. Vygotsky presented the behaviourist idea that "the pupil is a reacting apparatus" and "the whole composition of the instrumental act can, without exception, be reduced to a system of stimulus-response connections" (DeVries, 2000, p. 188). The similarities between Vygotsky and Piaget are that "social factors play a central role in child development"; "internalization is not a process of copying material from the environment but is a transformative process"; and "what develops is the individual" (DeVries, 2000, pp. 190-192).

In the 1990s, Biggs (1996, p. 347) introduced "Constructive alignment" in which two ways of thinking are combined: "the first derives from constructivist learning theory and the second from the instructional design literature". Central in constructivism is creating the meaning of the learner's activities, impacting the teaching and assessment methods. The "Instruction design" underlines the alignment between a course's learning objectives and the student's performance assessment methods.

Biggs (1996, p. 347) combines both ways to "Constructive alignment". Constructivism is applied as the instructional design framework to create curriculum objectives "in terms of performances that represent a suitably high cognitive level, in deciding teaching/learning activities judged to elicit those performances, and to assess and summatively report student performance" (Biggs, 1996, p. 347). De Houwer et al. (2013, p. 633) defined learning as "ontogenetic adaption", i.e. "as changes in the behavior of an organism that are the result of regularities in the environment of that organism".

In conclusion, the common ground in the individual educational theory is that learning is a unique reconstruction in each individual's mind within the (social) context. Through Berlin's (1958) lens, the philosophical explanation for individuals' educational 
development would be to ensure positive freedom to prevent governmental paternalism.

In the past sections, the educational approaches since the First Industrial Revolution are described. In the following section, the developments from the First to the Fourth Industrial Revolution will be elaborated. After that, the following section, the Fourth Industrial Revolution competences, will be presented in connection with the sections above. The educational developments are sketched from the introduction of the steam engine, the spinning machines, and the industrial looms in the First Industrial Revolution.

\subsubsection{The development from the steam engine to the Fourth Industrial Revolution}

In the past two centuries, four industrial revolutions took place. In this section, the First, Second, Third and especially Fourth Industrial Revolution are defined and briefly described.

As has been elaborated above, the First Industrial Revolution had a considerable impact on society. Rural areas were abandoned, with urbanisation as a consequence. The characteristics of the First Industrial Revolution are the mechanisation of production with the use of water and steam power (Schwab, 2016b). Equipped with steam-driven complex machinery, the labour force remained the essential resource as machine-assisted labour (Von Tunzelmann, 2003).

The Second Industrial Revolution made use of electric power to generate mass production (Schwab, 2016b) in which "the key characteristic became 'capital process' in Marx's terminology because in this stage of mechanisation and automation it became more appropriate to talk of labour-assisted machinery rather than machine-assisted labour" (Von Tunzelmann, 2003, p. 372), which Charlie Chaplin caricatured in his 1936 moving picture 'Modern Times' (Von Tunzelmann, 2003).

To automate the production, the Third Industrial Revolution used electronics and information technology (Schwab, 2016b). The Third Industrial Revolution is "the digital revolution that has been occurring since the middle of the last century. It is characterized by a fusion of technologies that is blurring the lines between the physical, digital, and biological spheres" (Schwab, 2016b, p. 1). Information processes were "partly linked to this automation of control appear in turn to be supplanting capital processes, stemming of course from the launchpad of initial technological breakthroughs in information and communication technologies" (Von Tunzelmann, 2003, p. 372).

The Fourth Industrial Revolution is associated with the term Industry 4.0 and at first with the German term "Industrie 4.0" that was first introduced in an outlook on 
how the German manufacturing industry could maintain competitive advantages and sustain their leading position in future at the Hannover Messe (Fair) in Germany in 2011 (Kagermann, Wahlster, \& Helbig, 2013). The Fourth Industrial Revolution affects PSM, which is referred to as "Procurement 4.0," i.e. a set of factors "influencing the digitisation of procurement and supply chains" (Bienhaus \& Haddud, 2018, p. 965). The expectations in 2011 were that business models would be transformed by Industry 4.0 to a merely dynamic, networked manufacturing environment (Kagermann et al., 2013).

Kagermann et al. (2013) urge standardisation of the term Industry 4.0 and especially the alignment of the crucial vocabulary of Industry 4.0, since other words for the latest industrial revolution are used, such as "Advanced Manufacturing", "Integrated Industry", "Smart Industry" or "Smart Manufacturing (Hermann, Pentek, \& Otto, 2016, p. 6). Industry 4.0 is described by the Boston Consulting Group as the "fourth wave of technological advancement: the rise of new digital industrial technology known as Industry 4.0, ad transformation that is powered by nine foundational technology advances" (Rüßmann et al., 2015, p. 3). These nine technologies are "autonomous robots"; "simulation"; "horizontal and vertical system integration"; "the industrial Internet of Things"; "cybersecurity"; "the cloud"; "additive manufacturing"; "augmented reality"; and "big data and analytics" (Rüßmann et al., 2015, p. 3). Hermann et al. (2016) define Industrie 4.0 as follows:

"Industrie 4.0 is a collective term for technologies and concepts of value chain organization. Within the modular structured Smart Factories of Industrie 4.0, CPS monitor physical processes, create a virtual copy of the physical world and make decentralized decisions" (Hermann et al., 2016, p. 11).

The definition of Industry 4.0 is under great debate among researchers. As pointed out by Culot, Nassimbeni, Orzes, and Sartor (2020):

"Although a clear-cut definition of the Industry 4.0 would be expected against the dramatic growth in the number of studies in the last few years, recent research papers show instead a clear omission in the conceptualization of the phenomenon. The ongoing confusion between Industry 4.0 and similar concepts is still perceived as a major hindrance for the scope and theoretical foundations of academic investigations" (Culot et al., 2020, p. 1).

The Fourth Industrial Revolution is a term used by the World Economic Forum (Schwab, 2016a). It is building further on the digitisation and robotisation from the 1960s of the Third Industrial Revolution, and "it is characterized by a fusion of technologies that is blurring the lines between the physical, digital, and biological spheres" (Schwab, 2016b, pp. 1-2).

The World Economic Forum formulated the definition mentioned above for the Fourth Industrial Revolution and proposed a set of necessary competences for a new era: the $21^{\text {st }}$-century-skills on which will be elaborated in the following section. 


\subsubsection{The emphasis on intrapersonal character traits in the Fourth Industrial Revolution}

Considering the requirements for the current and future job environment in combination with the fast change due to the shift of eras, the World Economic Forum (WEF, 2015) formulated a range of sixteen necessary skills, which students should possess. This $21^{\text {st }}$-century-skill-set consists of six cognitive skills ("literacy/ability to read and write, numeracy, scientific literacy, ICT literacy, financial literacy, and cultural and civic literacy"), three interpersonal skills ("communication, collaboration and leadership") and seven character traits or virtues, which also can be defined as 'intrapersonal traits' ("critical thinking/problem-solving, creativity, curiosity, initiative, persistence, adaptability, and social and cultural awareness") (WEF, 2015, p. 3). Remarkably, the majority of these sixteen skills consist of (three) interpersonal skills and (seven) intrapersonal traits.

The World Economic Forum seems to be inspired by the ancient Greek construct of cognition, skills and traits that is also found in contemporary literature (Boyatzis, 2008; Campion et al., 2011; Delamare-Le Deist \& Winterton, 2005), which construct is the key to future success:

"To thrive in the $21^{\text {st }}$ century, students need more than traditional academic learning. They must be adept at collaboration, communication and problem solving, which are some of the skills developed through social and emotional learning (SEL). Coupled with mastery of traditional skills, social and emotional proficiency will equip students to succeed in the swiftly evolving digital economy" (WEF, 2016, p. 4).

The World Economic Forum's emphasis on the teaching of mostly soft skills has led to criticism. Literacy and numeral literacy are declining in primary and secondary education (Howie et al., 2017), and the World Economic Forum's focus on soft skills does not turn the decline. However, most criticism is focused on whether 'critical thinking' is a skill in itself. The discourse is led by Willingham (2008), who states:

"If you remind a student to 'look at an issue from multiple perspectives' often enough, he will learn that he ought to do so, but if he doesn't know much about an issue, he can't think about it from multiple perspectives," and: "critical thinking (as well as scientific thinking and other domain-based thinking) is not a skill. There is not a set of critical thinking skills that can be acquired and deployed regardless of context" (Willingham, 2008, p. 21 and 29).

Hence, the content matters as much as acquiring knowledge to grasp the context when applying the World Economic Forum's $21^{\text {st }}$-century-skills in a balanced manner. This balance between hard skills and soft skills is also found in the work of Giunipero (see: Table 1.1. in Section 1.2.4.). Giunipero (2000, p. 8) emphasises on PSM knowledge and skills, but also at intrapersonal traits in PSM: the "world-class purchaser" is "continuously improving his/her skills; (...) is focused on professional 
development and education; (...) is willing to change and adapt; is a problem solver seeking the best solution; is flexible; (...) is ethical; (...)" and "adapts well to change", hence within the PSM context as suggested by Willingham (2008), which would also be in line with the ideas of Piaget and Vygotsky (see: DeVries, 2000).

Additionally, Giunipero and Pearcy (2000) mention the ability to make decisions, influence and persuade, strategic thinking, problem-solving, inquisitiveness, and risk-taking/being entrepreneurial. The intrapersonal skills stated by Knight et al. (2014) are decision-making skills, problem-solving skills, and strategic thinking, whereas Kiratli et al. (2016) promote a team creativity climate within the strategic PSM function.

Furthermore, a similar contextual construct of knowledge, skills and traits is seen with the International Federation of Purchasing and Supply Management (IFPSM), the international umbrella organisation of national PSM associations. The IFPSM listed eleven cognitive skills, eight interpersonal and thirteen intrapersonal traits in its Global Standard for Professional Competence in Purchasing and Supply Management (see: Appendix 9.3).

The thirteen intrapersonal traits are problem identification and analysis, problem-solving, critical analysis, personal responsibility, global awareness, exercising of judgement, decision making, initiative, integrative skills, prioritisation, reflection/reflective learning, social and ethical awareness in PSM, and student skills development by mentoring and coaching. This Golden Standard is eligible for professional PSM training and academic teaching PSM programs, reflecting the employers' requirements for purchasing graduates (Brennan \& Crowe, 2012).

These $21^{\text {st }}$-century skills can be regarded as a future skillset. Not many studies have focused on future competences. An exception is an outlook on the status of PSM in the year 2035 by order of consultancy firm KPMG (hence, non-peer-reviewed research) of Von der Gracht et al. (2016), who introduced a new critical competence, which is called dynaxibility, which is a composition of the terms 'dynamic', 'complex' and 'ability'.

"Because of this increasing development of changes, structural breaks and complexity, the need arises for procurement and supply chain managers to acquire a new key competence: 'dynaxibility'. It is the ability to competently manage dynamic and complex (dynaxic) developments - in other words, to manage our near and distant future" (Von der Gracht et al., 2016, p. 6).

Guided by the text of the definition of Delamare-Le Deist and Winterton (2005), the conclusion is that in history, educators have undertaken not only efforts towards the learning of "the competences required of an occupation (that) include both conceptual (cognitive, knowledge and understanding) and operational (functional, psycho-motoric and applied skill) competences," but also "the competences more associated with individual effectiveness (that) are also both conceptual (meta- 
competence, including learning to learn)" and the "operational (social competence, including behaviours and attitudes)" (Delamare-Le Deist \& Winterton, 2005, p. 39)

Thus, educators aim to learn knowledge, skills and traits. Knowledge and skills are utilisable for professional use. The latter, i.e. the "operational (social competence, including behaviours and attitudes)" (Delamare-Le Deist \& Winterton, 2005, p. 39), is the subject of discussion. In many cases, the ideal was personal development and creating 'better citizens'. The Bildung movement initially achieved success. However, Sanderse (2019, p. 411) warns that the "history of the Bildung idea offers an all too potent reminder of the fact that such ideals are vulnerable within a strong education system that focuses on turning young people into 'currency', to use Nietzsche's phrase," although the Bildung ideal is often initiated with the best intentions.

Those best intentions are also visible in the $21^{\text {st }}$ century in the current structure for higher education in Europe. The Bologna Process declaration issued at the meeting of the European ministers of education in Leuven and Louvain-la-Neuve, Belgium on April 28 and 29, 2009, is entirely in line with the Germanic Bildung ideal and Anglo-Saxon character-education. The Leuven/Louvain-la-Neuve Declaration (2009, p. 1) of the European ministers stated that students need to "develop the competences they need in a changing labour market and empower them to become active and responsible citizens in the future".

Here, the Aristotelian conception of virtues to become 'better citizens' is gaining importance. However, Nietzsche's alerting resounds and raises the question of whether governments are applying Bildung again to turn students into a form of 'currency'. It is questionable whether Von Humboldt would have supported this kind of declaration. Imposed Bildung would obstruct conscious self-development (De Hert et al., 2015). Mill states, "Human nature is not a machine to be built after a model, and set to do exactly the work prescribed for it, (...)" (Mill, 1859, p. 107). The development lies in humans' nature, and slowing down that development would be unnatural (De Hert et al., 2015). When applying the two concepts of liberties, as explained by Berlin (1958), the Leuven/Louvain-la-Neuve Declaration $(2009$, p. 1 ) is an example of limiting positive freedom when stating that students need "to become active and responsible citizens in the future", which leads in the best case to paternalism and the worst case to despotism (De Hert et al., 2015).

However, currently, at the advent of the Fourth Industrial Revolution and the environmental and social challenges, it is questionable whether positive and negative freedoms can be guaranteed. The World Economic Forum states in the pamphlet entitled "The Fourth Industrial Revolution: what it means, how to respond": 
"We stand on the brink of a technological revolution that will fundamentally alter the way we live, work, and relate to one another. In its scale, scope, and complexity, the transformation will be unlike anything humankind has experienced before. We do not yet know just how it will unfold, but one thing is clear: the response to it must be integrated and comprehensive, involving all stakeholders of the global polity, from the public and private sectors to academia and civil society" (Schwab, 2016b, p. 1).

Deslandes (2019) points at the Fourth Industrial Revolution's challenges and sees comparisons with the First Industrial Revolution. Based upon the ideas that Adolphe Blanqui's formed during the First Industrial Revolution, Deslandes (2019) emphasises that management schools currently should offer students the political, technical, artistic, philosophical and literary contemporary context to understand the future better:

"The large proportion of top managers with a background in humanities serves as a reminder that certain intangible qualities cannot be understood strictly in terms of organisational utility: personal identity, interpersonal skills, shared cultural values, and even the 'economic' intelligence we carry more or less unconsciously' (Deslandes, 2019, p. 8).

Hence, managers need a broad education. According to Blanqui, management education also needed to cover "the moral lesson of freedom, leaving room for the apparently useless (...) as well as the strictly utilitarian" (Deslandes, 2019, p. 8).

Since it is unclear whether PSM in higher education offers this broad education, the literature on PSM education and its challenges is presented in the following section.

\subsubsection{The state of the art and challenges in PSM higher education}

As explained, the ancient educational philosophy is built upon three pillars: the learning of (cognitive) knowledge, (practical) skills and (character) virtues (Bitros \& Karayiannis, 2011). When analysing PSM curricula in academia in literature, often one and, in some cases, two of the three pillars seem to be present. Traditionally, lecturers at European universities are focused on just the transfer of knowledge and theory (Hoidn, 2017). It also counts for universities in the USA as concluded by Birou, Lutz, and Zsidisin (2016) and universities in the UK as found by Wong, Grant, Allan, and Jasiuvian (2014), whom both analysed learning objectives in logistics and SCM curricula. As part of Project PERFECT, Stinenbosch (2017) found similar outcomes for Dutch academic PSM and SCM courses.

The learning and teaching of knowledge, professional skills and interpersonal skills are recognised, whereas interpersonal skills development is mainly limited to presenting, communication and teamwork. However, most academic purchasing, 
logistics and supply (chain) management courses and tracks have been evaluated for not or almost not learning and developing intrapersonal skills (Birou et al., 2016; Wong et al., 2014).

Nevertheless, such abilities seem to be as important as cognitive skills or are even more essential for gaining professional success. Universities are primarily focused on learning and developing knowledge and professional skills and a lower extent of developing interpersonal skills. Employers notably value intrapersonal abilities, but they seldom explicitly emerge in academic curricula (Hoidn, 2017).

To apply knowledge and cognitive skills in daily practice, interpersonal skills and intrapersonal traits have an essential role (Ahmed, Fernando Capretz, Bouktif, \& Campbell, 2012). Literature states that interpersonal skills and intrapersonal traits are as critical or even more important than cognitive skills for a professional (Ahmed et al., 2012). The presence of interpersonal skills and intrapersonal traits is an excellent forecaster to success in life, and an absence of interpersonal skills and intrapersonal traits appears to be causing the ending of a labour relationship rather than a lack of cognitive skills (Ahmed et al., 2012; Heckman \& Kautz, 2012; Zunk \& Sadei, 2015).

The PSM function will be affected by an increase of changes, structural breaks and complexity soon. The consequence is that PSM professionals' requirements will change radically to handle "dynamic and complex developments" (Deloitte, 2013; Prajogo \& Sohal, 2013; Von der Gracht et al., 2016, p. 6). Presumably, the future PSM professional will work in a highly automated environment of machine-to-machine communication. In such an environment, intrapersonal skills will make a difference. "Skills such as social intelligence, creativity and perception/manipulation are lacking in computerization and can be provided by a skilled buyer. In this scenario, the algorithm is then actually an indirect job upgrade" (Von der Gracht et al., 2016, p. 9).

These ongoing changes also occur outside of the PSM discipline; the World Economic Forum concluded that in the past 50 years, the developed economies in general "have witnessed a steady decline in jobs that involve routine manual and cognitive skills while experiencing a corresponding increase in jobs that require nonroutine analytical and interpersonal skills" (WEF, 2015, p. 2). At present, there is an agreement that students will have jobs in careers that do not exist when they graduate (Deslandes, 2019). Von der Gracht et al. (2016) agreed on that and stated that 50 per cent of the current jobs in the USA did not exist 25 years ago.

This development of ever-shifting job careers might seem to be a contemporary, $21^{\text {st }}$-century-issue that the Third and Fourth Industrial Revolution induces or has induced. However, as shown above, two centuries ago, in the early nineteenth century, students and young professionals were not always aware of what future job they would fulfil. In 1809, Von Humboldt already alerted the Prussian king that individuals are "free to move from one occupation to another, as so often happens 
in life" (Günther, 1988, p. 132). In the same period in France, Blanqui noted that "the majority of the posts, which our students will occupy in their careers do not yet exist" (Deslandes, 2019, p. 8). Concluding, in the subsequent Industrial Revolutions, the same need for flexibility and competences occurs. New attention for intrapersonal skills development at universities is needed to prepare PSM students for future careers.

The question arises which intrapersonal skills or abilities of bachelor and master PSM students at European universities would benefit the PSM function. It reflects the third, ancient Greek educational pillar, the development of character virtues, as the third element of competence: character traits, intrapersonal skill, traits, behaviours, abilities or attitudes. Another question is how to train and develop academic students' competences with learning and teaching methods. As elaborated on above, in the literature, a distinction has been made between Bildung and Ausbildung.

The Bildung-Ausbildung discourse also applies to PSM as one of the strategic disciplines in business. There is evidence in the literature that intrapersonal skills are important for the PSM function and skills levels of PSM and relate positively to the innovation implementation success (Feisel et al., 2011). PSM professionals require several individual skills to ensure access to suppliers' innovative resources and implement those in their process or product (e.g. Giunipero \& Pearcy, 2000; Knight et al., 2014).

In the contemporary business context, innovation developments are the most critical competitive priorities: "Companies increasingly rely on their supply base to support their innovation potential. As a consequence, the purchasing department might dramatically affect the firm's innovation capability" (Luzzini \& Ronchi, 2011, p. 14). Birou et al. (2016) therefore emphasise that: because of the impact of PSM's contribution "on the overall competitive position of a firm, it is imperative that the course content and curriculum be relevant and rigorous enough to meet industry needs" (Birou et al., 2016, p. 83).

Sinha, Millhiser, and He (2016) recommend that academia review the learning objectives and embed the strong industry demand for interpersonal and intrapersonal skills throughout PSM curricula. This recommendation is based on the evidence Sinha et al. (2016) found for an intrapersonal skills gap in the demand and supply of supply chain management (SCM) in businesses with and learning objectives in SCM courses of top- 50 business schools in the U.S.

The advent of the Fourth Industrial Revolution and PSM's role in that or 'Procurement 4.0' on PSM education in academia is centred around the question of which competences might be required in the future in the PSM function. This point was discussed during a meeting of members of the International Purchasing and Supply Education and Research Association (IPSERA) in Spring 2014. It appeared that the 
gathered scholars in their roles could not address this vital question as academic lecturers in PSM or SCM.

Efforts were taken to find possible answers, and in Autumn 2015, the Erasmus+ EU-financed project PERFECT was established around the theme of what and how to educate students in higher PSM education, which is described in the following section. The formulated research assignment and the project objectives of the Project PERFECT have been an inspiration and a handhold for this dissertation. Project PERFECT consisted of two stages; research and a design phase, both reflected in this dissertation.

Therefore, as will be explained in $\S 1.5$, this research aims to determine which competences lead to success in the PSM function, and the eventual focus is on the most specific strategic activity in purchasing, which is innovation sourcing. A further aim is to test whether it is feasible to train intrapersonal skills. Chapter 7 further elaborates on the results of an experiment in an introductory procurement course for master students of Industrial Engineering Management and Business Administration in which the insights of this dissertation are applied.

\subsection{Introduction to the EU-funded Project PERFECT}

Project PERFECT was conceptualised in 2014 and was set up in 2015. The initial rationale to set up this research project was the question of what an appropriate PSM curriculum in higher education should contain. From 2015 until 2018, the project was funded by the European Committee and has been formed as an international research group that exists of researchers from universities in different European countries: TU Dortmund (Technische Universität Dortmund) in Dortmund (D); University of Applied Sciences Mainz (Hochschule Mainz) in Mainz (D); LUT University (LappeenrannanLahden Teknillinen Yliopisto) in Lappeenranta (FIN); Staffordshire University, Stoke-onTrent, UK and University of Twente (Universiteit Twente), Enschede, the Netherlands.

The project was aimed to solve current and future challenges for PSM in practice and academia. As mentioned, the PSM function in any organisation is a pivotal contributor to firm performance (Drake, 2012), as more than half of the total turnover of a modern firm in Europe is directly transferred to suppliers (Bals et al., 2019; Van Weele, 2009). Furthermore, most supplies are no longer of domestic origin but of a European and international nature and depend on international suppliers (Horn, Schiele, \& Werner, 2013). This recent phenomenon has emerged in the last two, three decades. However, companies seem to struggle to find effective and efficient ways to cope with these circumstances (Van Weele \& Van Raaij, 2014). It underlines the need and request for employees to possess the necessary skills and competences in this field.

Although the PSM profession is progressively more mature, understanding what a PSM curriculum in higher education must contain is missing. Project PERFECT's 
most desired impact was an increase in the number of highly qualified graduates suitable for entering the workplace in PSM related jobs. Learning objectives in bachelor's and master's programme modules in PSM are developed to achieve this goal. It intended to bring PSM education to an improved level for needs in the professional field. On the research side, it empowered the participating institutions to anticipate future requirements for PSM professionals to start educating the future's workforce today.

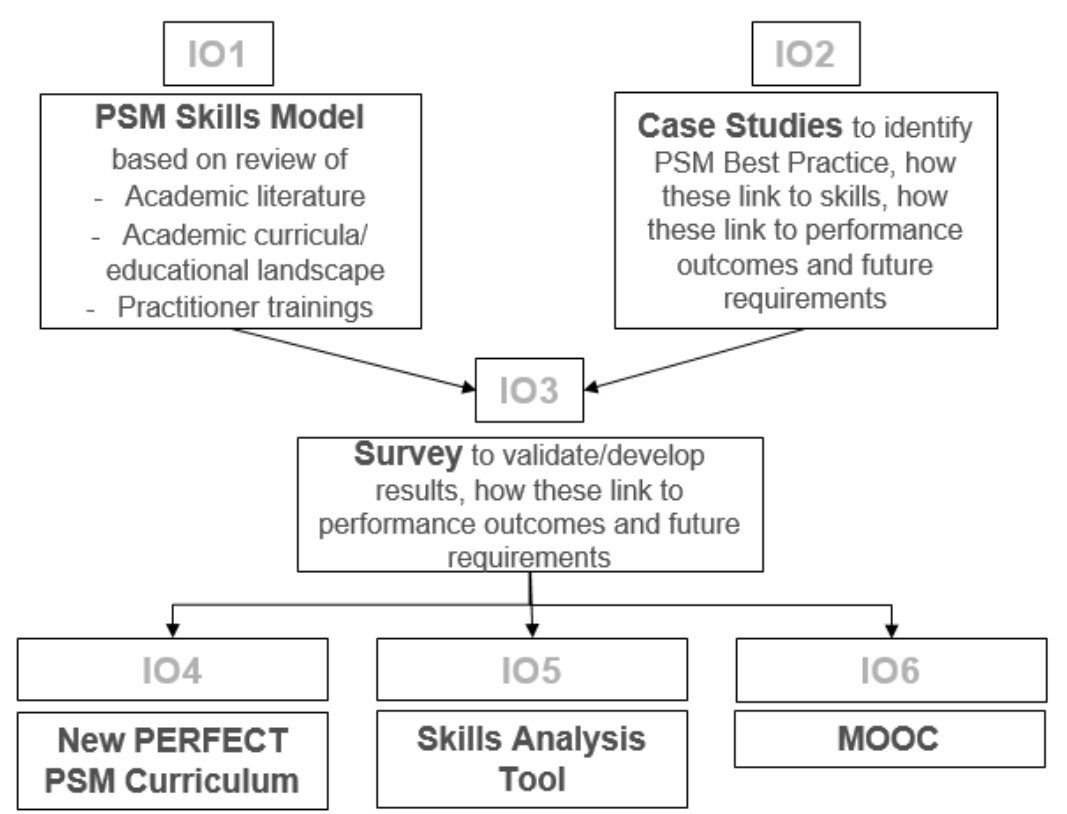

Figure 1.1 - PERFECT intellectual outputs (illustration by Project PERFECT)

The Project PERFECT included the following milestones: The project started with an in-depth theoretical analysis of PSM reviewing different sources, such as examining academic and practitioner literature dealing with PSM skills (e.g. Karttunen, Hallikas, \& Stek, 2017); the European PSM educational landscape (e.g. Berger, Kelly, Stek, \& Zunk, 2018; Stek, Zunk, Berg, et al., 2018; Stinenbosch \& Stek, 2017a, 2017b); the requirements in PSM job advertisements (e.g. Chapter 4; Stek, 2016; Stek, Koch, Zunk, \& Schiele, 2017; Stek, Zhang, Koch, Zunk, \& Schiele, 2018; Stek, Zunk, Koch, \& Schiele, 2021; Zunk \& Stek, 2018); and performing studies on trends and future requirements for PSM (e.g. Bapeer, Stek, \& Schiele, 2018; Bijl, Stek, \& Sigurđardóttir, 2020; Hoorn \& Stek, 2018; Kelly, Bals, Schulze, \& Stek, 2020; Kelly, Vangorp, Stek, \& Delke, 2020; Stek, 2017a; Stek, 2017b, 2017c, 2017d, 2018a, 2018b; Stek, Hoorn, \& 
Schiele, 2019; Stek \& Wieland, 2019; Stek, Wisniewski, van Dun, \& Schiele, 2020; Tkáč, Kelly, \& Stek, 2020).

In addition to the theoretical analysis, the project conducted case study interviews with industry PSM best practice to identify required skills and competences with current requirements and future trends (Chapter 2, i.e. Bals et al., 2019). Project PERFECT aimed to develop learning objectives for modules and courses in a PSM curriculum based on this first comprehensive compass assessment project. Furthermore, to promote fast and broad dissemination, PERFECT developed a selfassessment tool for PSM skill evaluation and prepared an introductory Massive Online Open Course (MOOC) for elementary PSM skills. Students and organisations can measure the levels of the PSM competences (see: Figures 1.1 and 1.2).

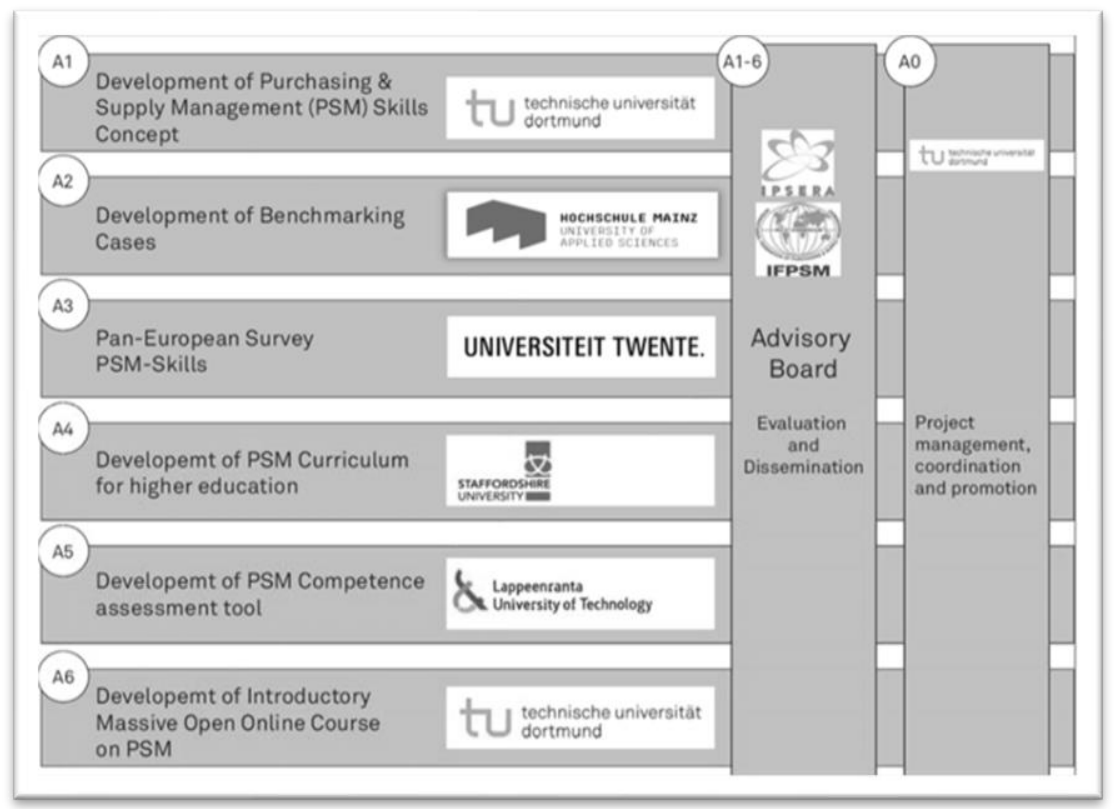

Figure 1.2 - Project PERFECT overview of the project leads (illustration by Project PERFECT)

To ensure that Project PERFECT met the PSM function's current and future needs in organisations, the project team conducted interviews with PSM professionals in selected companies to identify skills and competences for successful, effective and efficient PSM. The European Survey on Purchasing Skills has built further on earlier research outcomes by asking a broad audience $(n=581)$ about the level and importance of PSM competences, the focus the level of success in PSM. 


\subsection{Research design, the research objectives and the red thread}

Innovation is one of the most important competitive priorities in business (e.g. Hauser, Tellis, \& Griffin, 2006; Luzzini \& Ronchi, 2011; Sorescu, 2017). It is accomplished by a process comprising "idea generation, idea elaboration, idea championing, and idea implementation" (Perry-Smith \& Mannucci, 2017, p. 53). Traditionally, a more mechanistic picture of innovation, carried out entirely in a single firm's R\&D laboratory, was the dominant view (Freeman \& Soete, 1997). In recent years, however, two important changes in perspective have been initiated and started to spread: disruptive or radical innovation is seen as a social process and an open process involving not a single lab but on several organisations' collaboration (Sivasubramaniam, Liebowitz, \& Lackman, 2012). Innovation sourcing requires "learning orientation, teamwork, and decentralization or autonomy in decision-making" because "in learning organizations, decentralized organizational, cultures lead to the adaptability required for discontinuous innovation" (Gonzalez-Padron et al., 2008, p. 69).

The literature differentiates between incremental and radical or disruptive innovations. Simultaneously, companies earlier were aligned to innovating wellfunctioning recipes, and they are currently dealing with discontinuous innovations (e.g. Nambisan, Lyytinen, Majchrzak, \& Song, 2017; O’Connor \& McDermott, 2004; PicaudBello, Johnsen, Calvi, \& Giannakis, 2019). In this thesis, innovations are considered to be "discontinuous". Discontinuous innovations are "the regenerative dynamic capability that allows the firm to move away from previous change practices towards new dynamic capabilities" (Picaud-Bello et al., 2019, p. 3). Best practices for discontinuous innovation management are to "search for completely new technologies and sources of knowledge and ideas outside existing supply relationships and supply chains" (Johnsen et al., 2012, p. 12); "to look beyond immediate requirements and anticipate factors that could provide future competitive advantage" (Legenvre \& Gualandris, 2018, p. 97); and to move "beyond the zone of comfort" (Phillips, Noke, Bessant, \& Lamming, 2006, p. 15). In this context, PSM teams "need to explore external opportunities beyond first-tier suppliers to access or co-develop innovative solutions" (Legenvre \& Gualandris, 2018, p. 97).

As a consequence, competence levels of human innovation actors come into focus of management attention. For a corporate function such as PSM, which was not in the centre of attention in the past but has gained an increasing role in the new interorganisational innovation process, challenges arise since innovation sourcing is the most strategic PSM activity (Luzzini et al., 2015). However, it remains unclear which particular competences are needed for innovation sourcing, i.e. innovation co-creation in a buyers-supplier relation and innovation implementation. The innovation sourcing function as a boundary spanner in the buyer-supplier relation has a growing strategic role in a company's innovation capability and competitiveness (Johnsen et al., 2012; Legenvre \& Gualandris, 2018; Luzzini \& Ronchi, 2011; Schiele, 2012). 
Given the importance of the human aspect in innovation management, it is not surprising that not only the success of innovation generation but also the success of innovation sourcing is considered to be primarily dependent on individual PSM professionals and their competences, i.e. knowledge, professional and interpersonal skills together with the character traits and attitudes needed for effective performance (Campion et al., 2011; Delamare-Le Deist \& Winterton, 2005; Feisel et al., 2011).

The PSM function needs competent personnel to ensure access to the innovative resources of suppliers, to arrange early supplier involvement to co-create innovations and to implement those innovations in the own product or process (e.g. Bals et al., 2019; Giunipero \& Pearcy, 2000; Hauser et al., 2006; Johnsen et al., 2012; Knight et al., 2014; Legenvre \& Gualandris, 2018; Luzzini et al., 2015; Schiele, 2012; Slowinski, Hummel, Gupta, \& Gilmont, 2009).

Remarkably, (1) despite the assumed importance, a listing of distinct competences associated with innovation sourcing is absent in the literature as is shown in Section 1.2, and (2) the literature is referring solely to PSM competences in the private sector and presents standard skillsets for all PSM activities. Moreover, the literature has neglected public procurement competences, let alone the competences needed for the public procurement of innovation.

The rationale for this dissertation is to find those critical competences associated with successful individuals working in PSM in firms and public organisations. The central research aim of this thesis is, therefore, formulated as follows:

- This dissertation's overarching research objective is to determine which competences lead to success in the PSM function and the eventual focus is on the most specific strategic activity in purchasing, which is innovation sourcing.

The overarching research objective has been split up into four different research objectives to come to an answer.

1) Research objective 1 is (1) to analyse the literature regarding the described PSM competences, (2) to find out which future PSM skills requirements for PSM personnel are perceived in the public and private sector and (3) to compare both; current and future requirements.

2) Research objective 2 is to determine whether and which cultural and structural differences exist in PSM job requirements across Europe.

3) Research objective 3 is to determine which competences and which organisational conditions lead to PSM success in innovation sourcing.

4) Research objective 4 is to find out how to develop the PSM knowledge, professional and interpersonal skills and intrapersonal traits. 


\subsection{Addressing the research design, research objectives, and red thread}

Chapters 2 and 3 are addressing the first research objective. With qualitative methods based on primary data, both chapters are investigating future competences. Chapter 2 is interview-based and focuses on industry, and uses a word-mining program to analyse the outcomes. Chapter 3 is aimed at public procurement and is based upon survey results and a World Café or mini-Delphi project in cooperation with an interim management agency. Both chapters compare the current competences as described in the literature and compare those with the outcomes of interviews investigating future competences.

The second research question is the subject of Chapter 4, which is using secondary data. It compares the job requirements found in 300 PSM job advertisements. The chapter presents what employers require from purchasers in three different European countries and cultural clusters. Determining cultural or international differences is of importance when designing job requirements or learning objectives in higher education.

Chapter 5 and 6 are both quantitative, survey-based studies. Whereas former research appeared to be one-dimensional by measuring the 'importance' of competence and assuming that 'important' competences are automatically leading to 'success', this dissertation combines competence levels with success levels in a threedimensional way. Chapter 5 is therefore using another relatively newly developed method, the polynomial regression with response surface analysis combined with composite-based structural equation modelling and is presenting a three-dimensional projection of (1) innovation sourcing competence levels and (2) organisational conditions for innovation sourcing leading to (3) individual success in innovation sourcing. Chapter 6 is a study into which competences can be distinguished as a necessary condition and predictors for success in different purchasing objectives. It compares the necessary competence sets of the operational, transactional purchaser type, involved with delivery and quality improvements, sustainable purchasing and cost-reducing with the strategic purchaser that aim for competitive advantage and acquire access as preferred customers to the innovative solutions in the hands of suppliers.

Chapter 7 focuses on translating the findings in the previous education of PSM knowledge, professional and interpersonal skills, and intrapersonal traits. The literature and this dissertation show that higher education institutions are focused on the transfer of explicit knowledge, professional skills, and to a lesser extent on interpersonal skills. Intrapersonal traits, however, are valued by employers but are absent in learning objectives in PSM curricula. The set of success competences found in the preceding chapters are mostly intrapersonal traits. This chapter provides evidence that intrapersonal traits can be developed. For this study, a quasi-experiment is performed 
with three cohorts of master students in Industrial Engineering Management and Business Administration.

Chapter 8 addresses and discusses the outcomes of the research objectives; each chapter is summarised and compared with the literature review sections in Chapter 1 . Moreover, the implications of the dissertation are revealed. Whereas Chapter 8 is summarising the research in detail, Chapter 12 is added to provide the practitioner guidance via a summary, the 'red thread' and a roadmap to improve procurement skills as promised on the cover. Chapter 12 is trilingual and addresses procurement professionals in English, Dutch and German. 


\section{Chapter 2}

Purchasing and Supply Management (PSIM) Competences Current and Future Requirements 


\title{
2. PURCHASING AND SUPPLY MANAGEMENT (PSM) COMPETENCES
}

\author{
CURRENT AND FUTURE REQUIREMENTS
}

\subsection{Introduction}

Purchasing and supply management (PSM) plays a pivotal role in increasing overall organisational competitiveness. Between 60 and 80 per cent of total costs (Monczka et al., 2016; Van Weele, 2009) are external to the organisation, i.e. being paid to suppliers, and so PSM's role in spanning organisational boundaries and managing these external networks has become increasingly important (Van Weele \& Van Raaij, 2014). In this chapter is referred to the PSM discipline as being focused on the upstream supply network. In the broader supply chain management (SCM) context, the so-called unionist perspective, positioning PSM as a sub-area within SCM, is followed (Larson \& Halldórsson, 2002; Spina, Caniato, Luzzini, \& Ronchi, 2013) and focus on these, rather than broader SCM competences.

While there exists a robust trajectory of research on the skills, competences and knowledge required in PSM (Faes, Knight, \& Matthyssens, 2001; Giunipero et al., 1999; Giunipero et al., 2005; Giunipero et al., 2006; Giunipero \& Pearcy, 2000; Kern, Moser, Sundaresan, \& Hartmann, 2011; Knight et al., 2014), there are recent developments that require taking stock of current and future competence requirements. Developments such as sourcing innovation (Luzzini et al., 2015; Schiele, 2010, 2012), handling potential supplier disruptions (Wieland, Handfield, \& Durach, 2016), ensuring sustainability in the supplier network (Montabon, Pagell, \& Wu, 2016; Schneider \& Wallenburg, 2012; Wilding, Wagner, Miemczyk, Johnsen, \& Macquet, 2012) and the implications of technology-based workplace changes due to increased digitisation are challenging previous assumptions about what competences the modern PSM professional will require. For example, with increasing automation, is it now sufficient to prepare students for a future career in PSM by conveying the textbook basics of purchase order processing or should teaching include project-oriented learning on how to design processes and have them executed digitally with an advanced understanding of the role of Information Technology? 
In light of these developments and the need for generating further insights for research and practice, this study addresses the following research questions:

$$
\begin{aligned}
& \text { RQ1 - Which current and future competences do PSM professionals require? } \\
& \text { RQ2 - How have these PSM competences changed in the } 21^{\text {st }} \text { century? }
\end{aligned}
$$

\subsection{Conceptual background}

\subsubsection{Terms and definitions: Competences, skills and knowledge}

It is beyond this chapter's scope to reconcile the conceptual ambiguity around the terminology of skills, competences, knowledge and the interrelationships between them (e.g. Delamare-Le Deist \& Winterton, 2005). This conceptual ambiguity and lack of consensus have been noted in other related SCM studies (e.g. Derwik and Hellström (2017, p. 200). Therefore, building on similar studies in PSM, SCM and the broader Human Resource Management (HRM) fields (e.g. Bollinger \& Smith, 2001; Boyatzis, 2008; Giunipero et al., 2006; Mirabile, 1997) and the terms 'competence' (singular) and 'competences' (plural) are adopted through the work to ensure consistency but note that this encompasses the broad spread of PSM job requirements and therefore includes knowledge and skills.

The holistic view is followed as advocated by Tassabehji and Moorhouse (2008), Derwik and Hellström (2017, p. 210) and essential works from the HRM literature (e.g. Delamare-Le Deist \& Winterton, 2005). They propose broader typologies of competences to obtain the broadest possible view of competences and enhance the understanding of what PSM professionals need to do their jobs. These differentiate specific clusters but include conceptual (cognitive, knowledge and understanding) and occupational (technical and functional knowledge, psychomotor and applied skills) aspects.

It reflects work from an earlier stage, e.g. Hayes (1979), who described competences as encompassing knowledge, motives, traits and skills. This holistic approach is also consistent with the United Nation Industry Development Organisation (UNIDO, 2017) and the European Commission (see: e.g. the customs competence framework: European Commission, 2014) frameworks and also reflects how competences have been defined in several similar papers in other, but related, areas such as SCM (e.g. Briscoe, Dainty, \& Millett, 2001; Derwik \& Hellström, 2017; Flöthmann, Hoberg, \& Gammelgaard, 2018; Flöthmann, Hoberg, \& Wieland, 2018; Gammelgaard \& Larson, 2001; Giunipero et al., 2005; Giunipero et al., 2006; Kotzab, Teller, Bourlakis, \& Wünsche, 2018; Mangan \& Christopher, 2005; Prajogo \& Sohal, 2013). 
This study focuses on Tassabehji and Moorhouse's (2008) work and complements it with competence clusters based on Delamare-Le Deist and Winterton (2005) to develop the current and future understanding of PSM competences in a structured and consistent manner.

This holistic approach provides valuable inputs for industry/practice to perform their competence mapping exercises. In particular, the work conforms to some of the characteristics of the approach advocated by Campion et al. (2011, p. 226), in which: "Competency models refer to collections of knowledge, skills, abilities, and other characteristics (KSAOs) that are needed for effective performance in the jobs in question". Specifically, a more deductive approach is adopted (e.g. starting with the outcomes and backing into the tasks and KSAOs), in that is asked what participants need to do their jobs effectively now and in future. Based on the participants' input, an overview of current and future PSM competences has been provided.

Moreover, the work is presented in a manner that facilitates use and includes the utilisation of practice-specific language. Coding at a more general level, the work is not overly adapted to any specific organisational context and therefore allows practitioners to adopt aspects of the results in their competence mapping activities and the alignment of their HRM systems. The approach also reflects some of the steps of focused competence mapping papers such as Yuvaraj (2011). This study has identified specific organisations and the individuals within them, conducted semi-structured interviews, collected and analysed relevant data and then classified pertinent competences.

\subsubsection{PSM Competences - Literature Review}

To address RQ1: What current and future competences are required by PSM professionals and identify what PSM professionals need to do effectively and efficiently in their jobs, via www.scholar.google.com and www.scopus.com a systematic literature search is conducted, following the guidelines of Durach, Kembro, and Wieland (2017). This literature review also revealed how different studies over the last decade interrelate (J. Shaw, 1995). The key search terms used were: 'buyer', 'purchase', 'purchaser', 'purchasing', 'procurement', 'skill', 'skills', 'competence', 'competency' and 'competencies' and led to the combinations shown in Table 2.1: buyer OR purchas* OR procurement AND competenc* OR skill*.

All 1,007 articles identified in the initial search were evaluated. Any duplicates were discarded, as were those that looked at organisational (i.e. non-individual) competences in the described fields and those that focused on the consumer-related skills of purchasing budget use. Similarly, those that only briefly mentioned the term 'skill', 'competence' or 'competency' concerning the PSM profession, but did not focus 
on them, were also discarded. This search and review generated an extensive list of competences found in thirty articles published in the PSM field from 1987 to 2020, as shown in Appendix 9.1 resulted in a list of competences (see: Appendix 9.2).

Table 2.1 - Keywords and search terms

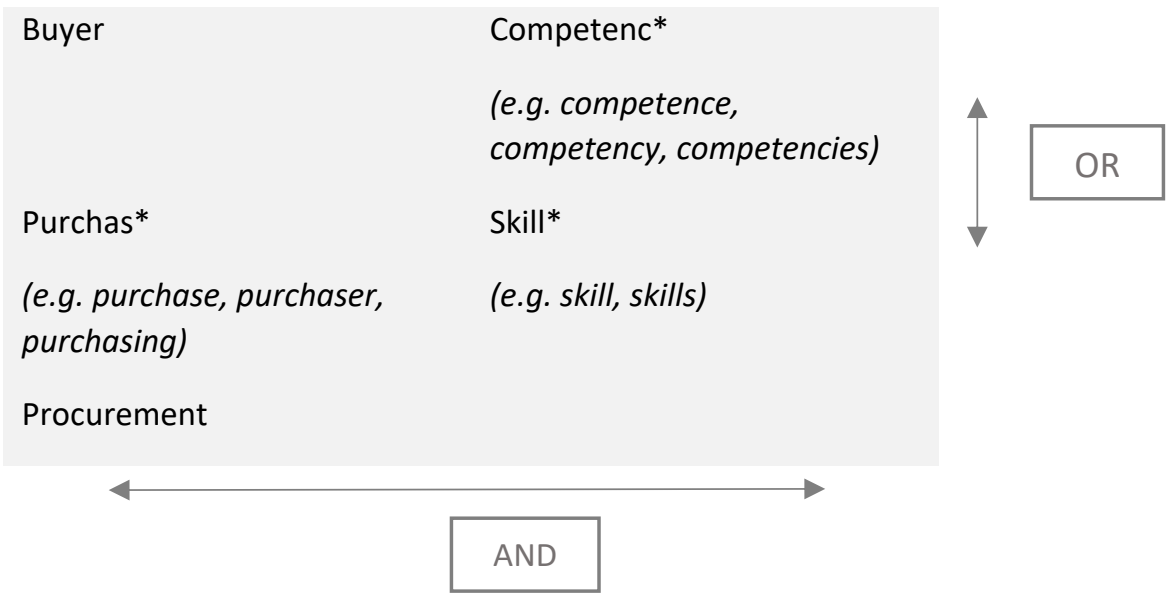

Tassabehji and Moorhouse (2008) have been chosen as the basis for the comparative analysis in this study, as it is the most elaborately categorised model and is in line with other research in the area, for example, Tatham, Wu, Kovács, and Butcher (2017) and Killen and Kamauff (1995). Tassabehji and Moorhouse (2008) use in-depth interviews with Chief Procurement Officers (CPOs) and the subsequent PSM competence/skills studies: Kolchin and Giunipero (1993), Giunipero and Pearcy (2000), Carr and Smeltzer (2000), Giunipero et al. (2005), Cousins, Lawson, and Squire (2006), Giunipero et al. (2006) and Large and Giménez (2006). A robust and underlying element in Tassabehji and Moorhouse (2008) are longitudinal study reports from Purchasing Education Training (1993) and Purchasing Education Training-2 (2000) (i.e. Giunipero, 2000; Kolchin \& Giunipero, 1993), both initiated by the Centre of Advanced Purchasing Studies (CAPS).

Tassabehji and Moorhouse (2008) differentiate between Technical skills, Interpersonal skills, Internal and External enterprise skills and Strategic business skills (as shown in Appendix 9.4.) and categorise procurement skills as 1) procurement 
specific skills and 2) generic management skills. This distinction is also seen in the works of Killen and Kamauff (1995), Shou and Wang (2015) and Tatham et al. (2017). ${ }^{9}$

Tassabehji and Moorhouse (2008) state that PSM reaches strategic maturity when PSM professionals possess both 'basic' procurement specific competences and 'advanced' generic management skills as long as the PSM function has top management support. The different papers' specific categorisations depend on the different methodologies, and the studies' research focuses. However, there is a distinction between PSM-related, general management and interpersonal and intrapersonal competences. In Appendix 9.5, Tassabehji and Moorhouse's (2008) original table has been extended to encompass relevant research.

During the past decade, Tassabehji and Moorhouse (2008) have been cited in 41 peer-reviewed journal articles (based on www.scopus.com, October 2018), which can be distilled into five main topics (see: Appendix 9.6). Most of the articles referenced in the introductions to Tassabehji and Moorhouse (2008) emphasising that the PSM function is strategic or is evolving in that direction. Second, articles refer to it about its main finding(s), in that the development of PSM competences in individuals, combined with top management support for the PSM function, will lead to strategic advantage.

Surprisingly, five articles do not adopt Tassabehji and Moorhouse's (2008) full findings and use neither 'top management support' nor the 'development of individual PSM skills' in their work. Further, six articles state that, based on Tassabehji and Moorhouse (2008), intra-organisational communication skills development leads to excellence in the PSM function. Another six articles refer to the PSM skills taxonomy, and five articles cite the article to support the notion that the PSM function faces an "internal politico-cultural glass ceiling" (Tassabehji \& Moorhouse, 2008, p. 63).

As the number of scholars that study PSM competences is limited, there may be a risk of self-referencing in the PSM literature because of an apparent small group of authors citing each other and/or who are co-authoring journal papers. To establish this, the search terms 'purchasing', 'supply' and 'skills' were entered in www.scopus.com (October 2018) and the search scope limited to 'business, management \& accounting' journals, in the period 2008-2018, and those authors not mentioned in Appendix 9.6 were excluded. It resulted in nineteen articles, of which seven are (co-) authored by the same scholars (see: Appendix 9.6).

The remaining twelve articles were analysed based on their titles and abstracts to establish if the chapter's core subject is PSM competences. It resulted in seven

\footnotetext{
${ }^{9}$ The paper of Shou and Wang (2015) collected requirements from 900 online SCM job ads in Canada, China, India, Malaysia, and Singapore, UK, USA and 'other' countries. The work of Tatham et al. (2017) is a literature review and Killen and Kamauff (1995) is a handbook titled 'Managing Purchasing: Making the Supply Team Work'.
} 
papers, which do not cite Tassabehji and Moorhouse (2008), and these are displayed in Appendix 9.7 (in combination with the related citations). Since the research is based upon Tassabehji and Moorhouse (2008), this self-referencing has been identified as a potential limitation of this chapter; however, the work's empirical nature ensured that additional competences would be identified and categorised.

In addition to the academic literature, there are two recent practitioner publications by consultancy firms KPMG and Deloitte that identify PSM professionals' characteristics, particularly intrapersonal traits combined with cross-functional competences. In their outlook on the future of PSM for the consultancy firm KPMG, Von der Gracht et al. (2016, p. 6) introduce 'dynaxibility', which is a composition of 'dynamic', 'complex' and 'ability' as "the ability to competently manage dynamic and complex (dynaxic) developments - in other words, to manage our near and distant future". Deloitte (2013, p. 14), in their 2020 outlook for the PSM field, state that: "(...) one of the most important roles of procurement leadership is to embrace diverse skills, capabilities and background for the appropriate positions". Moreover, cross-functional skills are needed to "engage and interact with constituents across legal, IT, HR, marketing, engineering/design, customer service/support, supply chain, manufacturing, etc.". Also, Deloitte (2013) identify a commonality between the skills needed in finance departments in 2013 and those in PSM in 2020:

"Analytical skills and a data-driven orientation will be the ante but will not stand alone in assembling the right team members. Overall, how organizations conceive of talent will transcend just identifying 'A-players' at all ranks and levels" (Deloitte, 2013, p. 14 ).

\subsection{Methodology}

\subsubsection{Research Design}

As discussed in the introduction, this research provides an updated perspective on current and future PSM competences by building on and then extending Tassabehji and Moorhouse (2008). In the development of the research design, a qualitative data collection approach, with theoretical elaboration, was considered most suitable for the emergence of competences beyond a predefined list, based on previous research. This exploratory research design facilitated a contemporary practice perspective on current and future competences.

The assurance of research quality criteria, such as 1) credibility/internal validity, 2) transferability and generalisability/external validity, 3) dependability/reliability and 4) confirmability/objectivity was addressed in the case study research by the use of several techniques (based on Lincoln \& Guba, 1985; Riege, 2009; Salzberger \& Sinkovics, 2006; Salzberger, Sinkovics, \& Schlegelmilch, 1999; 
Welch, Marschan-Piekkari, Penttinen, \& Tahvanainen, 2002; Yin, 2018). The details of how each particular research quality requirement was addressed in every project phase are in Appendix 9.8. For each primary project phase, i.e. preparation, implementation, follow-up and dissemination, the specific measures to be applied were defined during March/April 2016 and then continuously reviewed and refined throughout the data collection.

The preparation phase included developing the methodology, the development of the interview guide and company selection. For example, project implementation included participant communication, conducting interviews and generating relevant documentation. The semi-structured interview guide helped enhance reliability in the data collection phase (Maxwell, 1997; Yin, 2018). Finally, four researchers' coding, consistent peer discussion and evaluation of the results ensured credibility and objectivity in the interview analysis phase. Figure 2.1 systematically draws together the development steps for the updated PSM competences set.

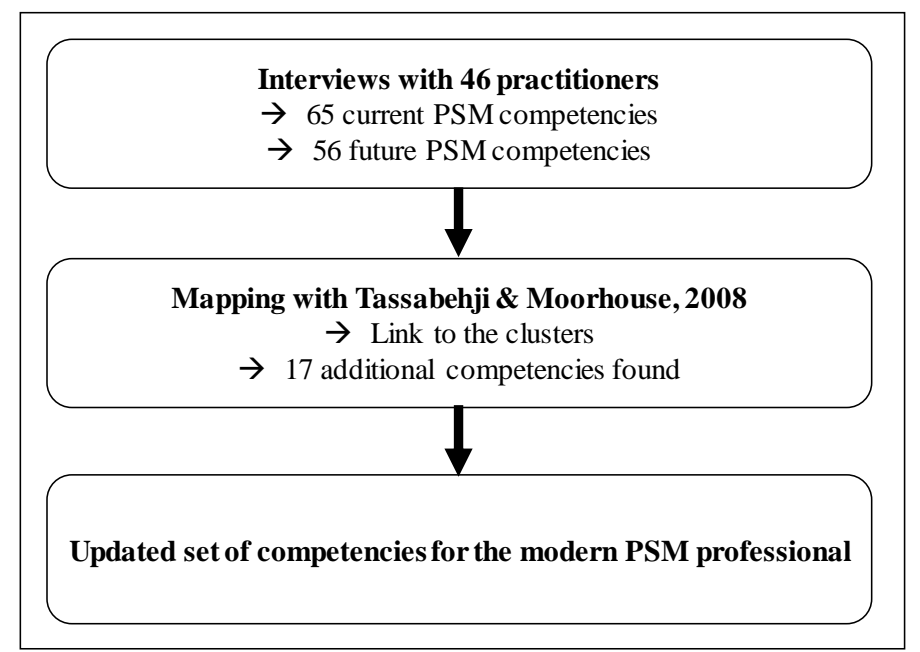

Figure 2.1 - Development of a set of competences for the modern PSM professional

First, the range of various competences identified from the primary data from this research have been taken and linked to the Tassabehji and Moorhouse (2008) model categories. Second, the research identifies 17 additional new competence areas that reflect PSM professionals' current needs and requirements and complements the Tassabehji and Moorhouse (2008) research.

Finally, as a third step, this has allowed us to look at changes to PSM competences over the last decade and derive an updated set of competences for PSM professionals that reflect current and future requirements. 


\subsubsection{Empirical Research: Company Selection, Data Collection, and Analysis}

Collecting qualitative data using semi-structured interviews ensured that a deep understanding of the phenomenon could be obtained. A robust selection strategy for the companies was used, encompassing a range of organisational characteristics: Industries with lower and higher external value-added; two major consultancies to obtain their views on PSM's current and future competence requirements across their client base, geographical spread (to not overemphasise one particular national culture), and conventional (i.e. commercial) business models alongside social businesses (to challenge current PSM conventions). Although not aiming for statistical representativeness, the breadth of organisational types did facilitate the broadest possible perspective of different requirements. It led to a final selection of twelve buying companies, described in Table 2.2, all of which had some international scope in their operations.

Within each of these companies, the interviewee target sample included the Chief Procurement Officer (CPO) or a senior-level PSM representative, a PSM employee responsible for strategic sourcing, as well as a PSM training/HR representative. These different hierarchical and functional roles were included to ensure a more holistic view of the research topic. Besides, some companies provided access to an even broader interviewee base, which followed the intention to cover the entire procure-to-pay process (a process description was discussed with potential interviewees before scheduling the interviews, shown in Figure 2.1).

Some of the smaller companies nominated a single interviewee, who, because of the role he/she had and the nature of the organisation, was able to cover all PSM areas. In four cases, access was also given to interview a supplier, providing another perspective on the competences required to facilitate a successful business relationship. In total, this resulted in 16 companies (12 buying companies and four suppliers) and 46 separate interviews (Table 2.2). The coverage of those involved in the operational aspects of the PSM process (shown in Figure 2.2 and referred to as 'operational roles'), as well as those assisting in the recruitment process (e.g. HR), complements and extends Tassabehji and Moorhouse (2008), whose study focused on managerial roles only. The core interviewee demographics are shown in Tables 2.3 and 2.4 .

Tailored interview guides were prepared for each of the three interviewee groups: Companies, Suppliers and Consultants. Appendix 9.9 provides an overview of the main headings, showing that the Company interview guide had 59 questions. The interview guide focused on what competences individual PSM professionals needed to do their job well (i.e. effectively and efficiently). The initial idea to focus on understanding the activities related to specific job titles were discarded, as companies have numerous job titles. There was a risk that there would be a misunderstanding in 
the scope between the interviewers and the interviewees. Instead, a comprehensive PSM process overview, showing the strategic (Source-to-Contract) and operational (Purchase-to-Pay) processes (Monczka et al., 2016; Van Weele \& Van Raaij, 2014), plus typical competence centre responsibilities (e.g. data and systems), was integrated into the interview guide and the interviewers were asked about the competences needed to perform activities within these processes, both currently and in the future. The process overview (see: Figure 2.2) was sent to all interviewees in advance.

\section{Table 2.2 - Company Demographics}

\begin{tabular}{|c|c|c|c|c|c|}
\hline Case & $\begin{array}{l}\text { Sector/ } \\
\text { Industry }\end{array}$ & $\begin{array}{l}\text { Inter- } \\
\text { viewees }\end{array}$ & $\begin{array}{l}\text { Business } \\
\text { Model }\end{array}$ & $\begin{array}{c}\text { No. of } \\
\text { Employees }\end{array}$ & Turnover in $€^{*}$ \\
\hline AUTO1 & Automotive & 10 & Commercial & $>300000^{1}$ & $>70$ billion $^{1}$ \\
\hline $\begin{array}{l}\text { AUTO1 } \\
\text { Supplier }\end{array}$ & Automotive & 2 & Commercial & $\begin{array}{c}10000- \\
49999^{1}\end{array}$ & $>1$ billion \\
\hline AUTO2 & Automotive & 1 & Commercial & $\begin{array}{c}80000- \\
99999\end{array}$ & $>10$ billion $^{1}$ \\
\hline CHEM1 & Chemicals & 2 & Commercial & $\begin{array}{l}10000- \\
49999^{1}\end{array}$ & $>5$ billion ${ }^{1}$ \\
\hline $\begin{array}{l}\text { CHEM1 } \\
\text { Supplier }\end{array}$ & Training \& Consulting & 1 & Commercial & $<999$ & n.a. \\
\hline CHEM2 & Chemicals & 6 & Commercial & $\begin{array}{l}10000- \\
49999^{1}\end{array}$ & $>10$ billion $^{1}$ \\
\hline CONSU1 & Consulting & 2 & Commercial & > $300000^{1}$ & $>20$ billion $^{1}$ \\
\hline CONSU2 & Consulting & 1 & Commercial & $\begin{array}{l}1000- \\
9999^{2}\end{array}$ & $>1$ billion ${ }^{2}$ \\
\hline TECH1 & Technology, Electronics & 1 & $\begin{array}{c}\text { Social } \\
\text { Business }\end{array}$ & $<999$ & n.a. \\
\hline $\mathrm{TECH} 2$ & Technology, Electronics & 1 & Commercial & $<999^{4}$ & $>10$ million $^{4}$ \\
\hline CONST1 & Construction & 3 & Commercial & $\begin{array}{l}10000- \\
49999^{3}\end{array}$ & $>1$ billion ${ }^{3}$ \\
\hline $\begin{array}{l}\text { CONST1 } \\
\text { supplier }\end{array}$ & Construction & 1 & Commercial & $\begin{array}{l}1000- \\
9999^{2}\end{array}$ & n.a. \\
\hline FOOD1 & Food & 9 & Commercial & $\begin{array}{c}80000 \text { - } \\
99999\end{array}$ & $>20$ billion $^{5}$ \\
\hline $\begin{array}{l}\text { FOOD1 } \\
\text { supplier }\end{array}$ & Food & 1 & Commercial & $\begin{array}{l}1000- \\
9999^{2}\end{array}$ & \\
\hline PHARM1 & Pharma & 3 & Commercial & $\begin{array}{l}50000- \\
79999^{1}\end{array}$ & $>10$ billion ${ }^{1}$ \\
\hline SOCSER1 & Social Service & 2 & $\begin{array}{c}\text { Social } \\
\text { Business }\end{array}$ & $<999^{4}$ & $>2$ million ${ }^{4}$ \\
\hline
\end{tabular}


Table 2.3 - Interviewees' Demographic Data for Focal Buying Company Participants

Interviewees' Demographic Data Focal Companies

\begin{tabular}{|c|c|c|c|c|}
\hline \multicolumn{5}{|c|}{$\Sigma$} \\
\hline \multirow[t]{2}{*}{ Gender } & & Male & \multicolumn{2}{|c|}{ Female } \\
\hline & 41 & 28 & \multicolumn{2}{|c|}{13} \\
\hline \multirow[t]{2}{*}{ Job role } & & HR-Representative & Operational & Management \\
\hline & 41 & 4 & 5 & 32 \\
\hline Job title & 41 & \multicolumn{3}{|c|}{$\begin{array}{c}\text { CEO (1); CPO (6); Commercial director (2); HR manager (4); } \\
\text { Operations manager/director (4); Process manager ( } 3 \text { ); } \\
\text { Procurement manager/director (21); }\end{array}$} \\
\hline \multirow{2}{*}{$\begin{array}{l}\text { Cross-functional } \\
\text { experience }\end{array}$} & & Yes & No & Unassigned \\
\hline & 41 & 20 & 13 & 9 \\
\hline \multirow[t]{2}{*}{ Business Model } & & Commercial & \multicolumn{2}{|c|}{ Social Business } \\
\hline & 41 & 38 & \multicolumn{2}{|c|}{3} \\
\hline \multicolumn{2}{|l|}{ Statistics } & Mean & \multicolumn{2}{|c|}{ Standard Deviation } \\
\hline \multicolumn{2}{|c|}{ Total Working Experience (in years) } & 17 & \multicolumn{2}{|c|}{8.51} \\
\hline \multicolumn{2}{|c|}{ Company Turnover (in billion $€$ ) } & 16.1 & \multicolumn{2}{|c|}{21} \\
\hline
\end{tabular}

Table 2.4 - Interviewees' Demographic Data for Supplier Participants

\begin{tabular}{|c|c|c|c|}
\hline \multicolumn{4}{|c|}{ Interviewees' Demographic Data Suppliers } \\
\hline \multicolumn{4}{|l|}{$\Sigma$} \\
\hline Gender & Male & \multirow{2}{*}{\multicolumn{2}{|c|}{$\begin{array}{c}\text { Female } \\
1\end{array}$}} \\
\hline 5 & 4 & & \\
\hline \multirow[t]{2}{*}{ Job role } & HR-Representative & Operational & Management \\
\hline & 0 & 1 & 4 \\
\hline Job title & \multicolumn{3}{|c|}{$\begin{array}{l}\text { Vice-President (2); Commercial Director (1); } \\
\text { Account Manager (1); Consultant (1) }\end{array}$} \\
\hline \multirow{2}{*}{$\begin{array}{l}\text { Cross-functional } \\
\text { experience }\end{array}$} & Yes & No & Unassigned \\
\hline & 1 & 3 & 1 \\
\hline \multirow[t]{2}{*}{ Business Model } & Commercial & \multicolumn{2}{|c|}{ Social Business } \\
\hline & 5 & \multicolumn{2}{|c|}{0} \\
\hline Statistics & Mean & \multicolumn{2}{|c|}{ Standard Deviation } \\
\hline Total Working Experience (in years) & 22 & \multicolumn{2}{|c|}{8.79} \\
\hline Company Turnover (in billion $€$ ) & 4 & \multicolumn{2}{|c|}{5.1} \\
\hline
\end{tabular}

The interviewees were asked: 'Which roles are differentiated in your organisation to cover the process steps?' and 'How would you describe your role regarding these process steps?' Interviewees were then asked to describe important competences they need to perform their job, which required them to describe competences at an abstract level. A spider diagram is used to support the discussion, which was partly pre-filled with seven competences from a study by Giunipero and Pearcy (2000), but with space to allow the interviewees to add other competences as necessary. 


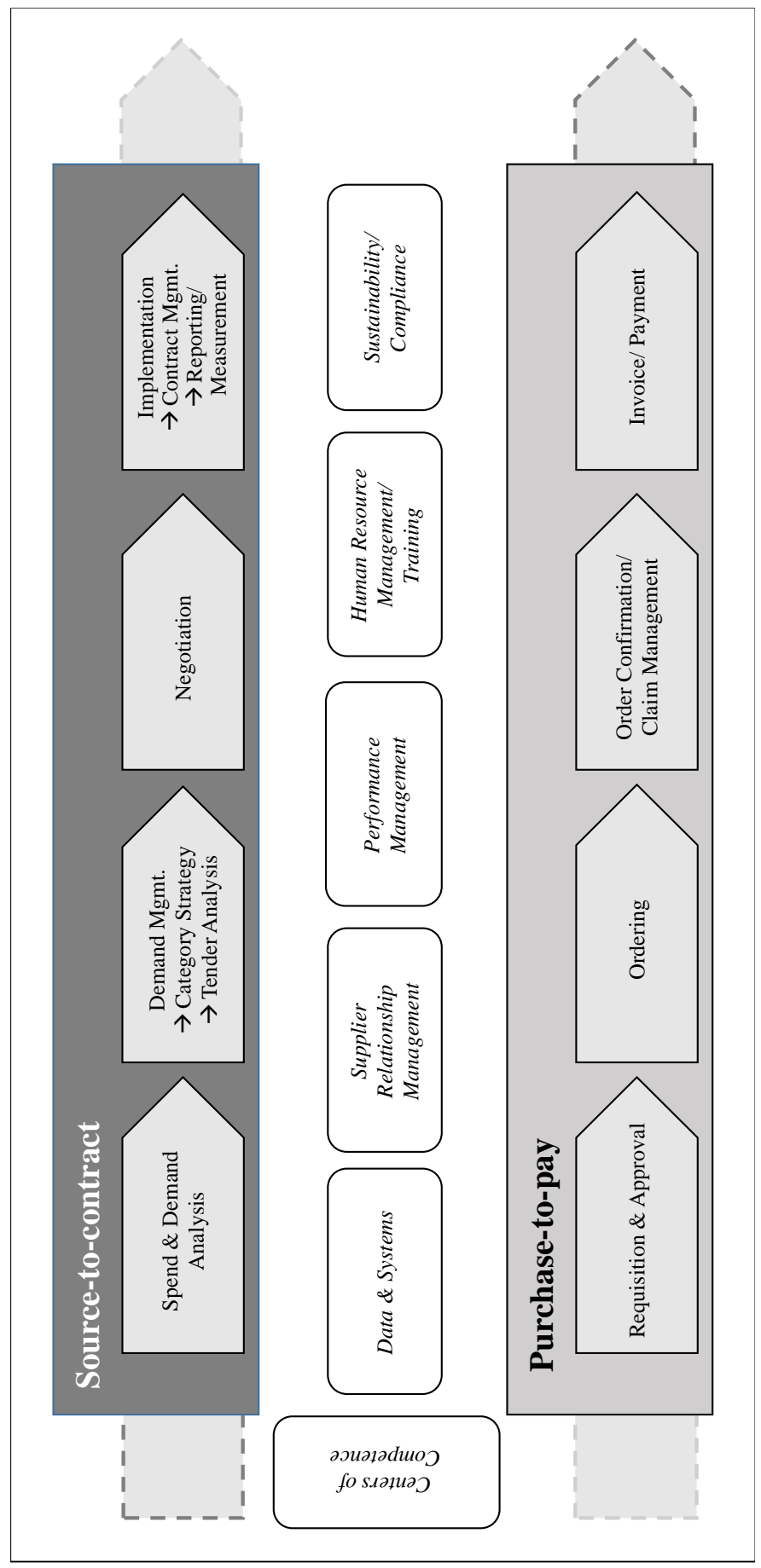

Figure 2.2 - Purchasing and Supply Management processes, adapted from Van Weele (2009) and Monczka et al. (2016) 
The interviewer initially asked interviewees to rank the seven competences based on their importance and then broadened the discussion by encouraging them to add their thoughts and suggestions. The intention was not to say that these are the seven most essential competences but to foster a discussion around the importance of competences and complement this list during the interviews. The spider diagram was sent to the interviewees in advance to make sure they had it available during the interview.

A pre-test was performed at one of the case companies (CONST1), where the first three interviews were conducted to obtain feedback on the interviewees' questions and interview process. This feedback mainly focused on explaining the context and the background of the interview, but not on the questions themselves, and therefore a short briefing document was developed. However, the complete interview guide was not shared with the interviewees to ensure that the order of questions was still flexible, and different aspects could be elaborated on, depending on the interviewee responses. All interviews were conducted within a six-month timeframe, and they were all recorded and transcribed.

The initial coding protocol planned to use a pre-defined coding tree based on existing literature. However, a subsequent review suggested that an in vivo or indigenous coding (Bazeley \& Jackson, 2013) was more suitable to prevent overly fixation on specific categories of competences. To ensure open coding consistency and reliability, the coding team had regular discussion meetings and created a standard reference document that captured an agreed consensus on approaching individual nodes in a standardised manner. To ensure and increase the inter-coder reliability in NVivo 11, all the researchers coded the same interview to be accustomed to the approach.

A detailed review meeting of this transcript allowed the group to become aware of any individual differences, therefore ensuring consistency and develop a standardised approach to the use of individual nodes in the coding process, for example, by showing that an individual had coded 'willingness to work' under 'passion'. Also, it helped to ensure a transparent and traceable qualitative data analysis approach (e.g. Bazeley, 2013). Two researchers coded all the other interviews to ensure broad node coverage and enhance the coding process reliability. Each coder continuously updated the standard reference document and passed it on to the next coder, thus facilitating inter-coder consistency.

The coding team also agreed that they would not necessarily code every instance of a competence multiple times in an interview if it had been coded already, and it was only if the text yielded an additional insight on what was behind a particular competence, was it coded to a node. A mere repetition of a specific word (e.g. sustainability) was not coded at every instance. This process was followed because the 
qualitative research approach only has limited power to make exact inferences from frequencies to importance. Instead, the complexity of the phenomenon and the breadth of competences were the focus of this research.

\subsection{Findings and Discussion}

\subsubsection{Current and Future Competences identified by practitioners}

The first research question investigates the competences required by PSM professionals. It begins by looking at which current competences are necessary for PSM professionals before considering the same question concerning future competences.

To identify which competences PSM professionals consider as being currently necessary to meet their organisational objectives, the researchers asked dedicated questions in the interview guide's respective section. These questions asked participants to discuss the goals they had in their jobs, which they were rewarded for, the competences that helped them to be successful in their job and circumstances that prevented them from being more successful. PSM professionals identified 65 competences, which they felt were currently necessary for them to meet their organisational objectives. The number of instances ranked these. They were coded in the various interviews, and the top-10 of the 65 current competences are shown in Table 2.5 in the left column.

'Negotiation' was coded with the highest number of instances. After grouping competences into those that share similar characteristics, the remaining competences in this list reflect those related to communication and relationship ('Communication skills', 'Interpersonal communication', 'Stakeholder relationship management'), to strategic and analytical ('Strategic thinking', 'Analytical thinking', 'Strategic sourcing'), or professional knowledge requirements ('Basic knowledge on PSM role \& processes', 'Cross-functional knowledge'). It shows a mix of competences required to be successful in a PSM role, and there are links between some of these competences, as shown in interviewee statements such as:

"... interpersonal, which I think comes into negotiation as well. Negotiation is quite specific, but it's that building of a relationship." (Interviewee, SOCSER1);

"Naturally, you mentioned negotiations, this is not negotiable for me, so they have to be able to negotiate on an external level with suppliers on a price and contract, but also on an internal level; how are they positioning and selling themselves and their ideas." (Interviewee, FOOD1).

The section on future competence requirements in the semi-structured interview guide contained questions evaluating future PSM trends, with a clear focus on the developments and challenges that the interviewees were already starting to see 
in their work environments. After discussing trends and upcoming changes ("What are the current trends in PSM in general?"), the researchers asked how these might influence the interviewee's current activities and which competences will be required in the future ("What do you think will change specifically in your job in the future due to these trends?"). The interviewees emphasised new competences that will change or add to the current profile, and so many different future priorities, as compared to the current ones, should not be interpreted as a replacement of current competence requirements, but as a shift towards competences required for coping with new challenges in PSM.

PSM professionals identified 56 competences, which they felt would be necessary for them to meet their organisational objectives in the future. The number of instances ranked these that they were coded in the various interviews and the top-10 of the 56 future competences are shown in Table 2.5 in the right column.

Table 2.5 - Top 10 current and future competences for PSM, in alphabetical order

\begin{tabular}{ll} 
Current Competences & Future Competences \\
\hline Analytical skills & Analytical Skills \\
Basic knowledge of PSM role \& processes & Automation \\
Communication skills & Big Data Analytics \\
Cross-functional abilities \& knowledge & Computer Literacy \\
Interpersonal Communication & eProcurement Technology \\
Negotiation & Holistic supply chain thinking \\
Stakeholder Relationship Management & Process optimisation \\
Strategic sourcing & Strategic Sourcing \\
Strategic thinking & Strategic thinking \\
Sustainability & Sustainability \\
\hline
\end{tabular}

These competences reflect areas of growing interest and concern for PSM professionals and across the wider organisational context. Some competences relate to the broader digitisation agenda (e.g. 'eProcurement Technology', 'Automation', 'Big Data Analytics' and 'Computer Literacy'), and the high ranking of 'Sustainability' emphasises its increasing importance in the modern industrial context. The following statements demonstrate what these competences mean to PSM practitioners within their organisational and broader environments.

"This is giving a kind of requirement of their way of working and solving process. The massive amount of data that you are getting today is so large. Given that you do completely understand the equipment that you are buying for your organisation might 
be helpful in some part. However, how do you merge these tons of information into something meaningful and make the right decision? This is important, and not everybody is capable of doing that, and that is where we all have to learn and develop." (Interviewee, PHARM1)

"From a sustainability point of view, of course, where products come from and transparency around that it's the trend we see now. Not only for a company like ours but any company; the need to integrate that into purchasing behaviour and not only from a compliance perspective but also from a driving value and partnership perspective that is the trend to come or already there." (Interviewee, TECH1)

If digitisation and sustainability were not mentioned proactively, the interview guide was prepared to ask whether the interviewees considered these relevant future trends specifically. Digitisation was discussed pro-actively in all interviews, whereas some interviewees identified sustainability but did not mention it before being asked explicitly about it. All of the interviewees considered the two competences, or at least one of the two, as relevant future trends.

Competences in these areas were rated with a high priority, complementing those traditionally connected to PSM, such as 'Negotiation'. However, interviewees expressed uncertainty on exactly what specific competences would need to be developed in PSM professionals and students to meet these requirements. Although the correlation with competences that were also given a high priority in future PSM, such as 'Holistic Supply Chain Thinking' or 'Strategic Thinking', might indicate how these areas can be further broken down into manageable areas is recognised that further investigation is needed.

Four competences were shared in both current and future views (as shown in Table 2.5. in alphabetical order): 'Analytical Skills', 'Strategic Sourcing', 'Strategic Thinking' and 'Sustainability'. The grey colour indicates commonality between current and future competences.

\subsubsection{Comparison of the findings to the Tassabehji \& Moorhouse framework}

To answer the second research question, "How have PSM competences changed over the last ten years?" the interviews' findings are now discussed with the framework of Tassabehji and Moorhouse (2008).

\subsubsection{Clustering Process and Aggregated Results}

The coded current and future competences were grouped thematically into the cluster categories based on Tassabehji and Moorhouse (2008). At an aggregated 
level, competences in the Technical skills cluster are by far the most frequently coded ones, followed by competences related to Interpersonal skills. The clusters Internal/ External enterprise skills and Strategic business skills were coded less frequently. Table 2.6 shows the mapping of the competences to these clusters.

Many of the nodes were the same as, or very similar to, those identified in Tassabehji and Moorhouse (2008) and were, therefore, easy to allocate. However, based on a careful review and agreed-upon decision-making process, the research team clustered those remaining. The team discussed whether competences related to category management would also fit within the External Enterprise skills cluster or Strategic Business skills but kept the format as it is, adding the competences regarding category management to the Technical Skills cluster. A close relationship between Internal Enterprise skills and External Enterprise skills is also identified, and so the two categories were grouped in Table 2.6.

Table 2.6 - Competences Analysed by Clusters

\section{Cluster}

$\begin{array}{lr}\text { Technical Skills } & 1,012 \\ \text { Interpersonal Skills } & 739 \\ \text { Internal and External Enterprise Skills } & 632 \\ \text { Strategic Business Skills } & 593\end{array}$

Therefore, this work's essential contribution is updating the PSM competences and clusters identified by Tassabehji and Moorhouse (2008) to reflect current and future challenges and requirements. This study confirms that the competences are still valid, but the clustering of the coded competences revealed 17 competence areas that have not been identified in previous research. The most prominent new competence areas are related to digitisation (e.g. 'Automation'), innovation (e.g. 'Innovative sourcing') and 'Sustainability'. In addition, interestingly, practitioners added 11 new competences to the interpersonal skills cluster, most of them in the intersection of competences and traits (e.g. 'Passion').

Table 1.2 in Section 1.2.4 (chapter 1) combines all current and future competences coded in the interviews. In the Technical skills cluster, 'Innovation Sourcing' and 'Innovative Sourcing Approaches' complement the list of Advanced Procurement Process skills (APP), which is defined as a sub-cluster by Tassabehji \& Moorhouse (2008), as shown in Appendix 9.4. Additionally, 'Automation' and 'Big Data Analytics' are added to the technical cluster. They can be considered technical knowledge required to cope with future challenges, specifically as 'Big Data Analysis' was coded as one of the most important future competence requirements. 
Practitioners also mentioned 'Self-Confidence', 'Self-Reliance' and 'Self-Reflection' as being important Interpersonal skills for PSM professionals, together with the ability to 'Deal with Ambiguity' and 'Integrity'.

It is questionable why Tassabehji and Moorhouse (2008) left out 'Integrity' when analysing Giunipero and Pearcy (2000), as 'Integrity' and 'Honesty' are items referred to by Killen and Kamauff (1995), who refer to 'Integrity'; and Mulder et al. (2005) and Giunipero and Handfield (2004) who use the term 'Ethics'. Statements covering 'Curiosity', 'Openness' and 'Passion', although considered personal traits rather than skills or competences, were also coded and added to the Interpersonal skills cluster. For the cluster Internal/external enterprise skills, no additional competences were identified in the interviews. In the context of Strategic business skills, 'Critical Thinking' 'Holistic Supply Chain Thinking' and 'Sustainability' complement the list of Tassabehji and Moorhouse (2008), with the latter two competences being in the list of the top-10 future key competences resulting out of the interviews. Appendix 9.10 displays supporting quotations for the newly added competences.

\subsubsection{Differences by Sample Demographics}

A more detailed analysis by industry reveals that the ranking in terms of the competence clusters (Table 2.6) is valid for the automotive, chemical, construction and pharmaceutical sectors. However, the consultancy companies emphasised Technical skills over the other three competence clusters, whereas representatives of the electronics industry, although still prioritising Technical skills, were more equally balanced across the four competence clusters. Interestingly, Strategic business skills were identified as second on the food sector and social services priority list. Regarding differences in the individual competences by industry, 'Creativity' was in the top-10 future competences for Construction and Social Services industries.

Additionally, several future competences were only mentioned by a single or small number of industries, with the key ones being: 'Creativity' (construction and social services), 'Customer Focus', 'Innovation Sourcing' and 'Leadership' (all emphasised by consulting), 'Cross-Functional Abilities \& Knowledge' (construction), 'Cultural Awareness' (automotive), 'Passion' and 'Integrity' (both only electronics), 'Learning Agility' (pharma). The emphasis on 'Creativity' and 'Cross-Functional Abilities \& Knowledge' seems to relate mainly to those industries that are more service-dominated (construction and social services), in which cross-functional value creation seemed a particular focus.

The consulting interviewees, when asked what they would regard as the most important competences for PSM at their clients (as they work across many industries simultaneously and overtime in their consulting engagements), were the only industry area to emphasise 'Customer Focus', 'Innovation Sourcing' and 'Leadership'. It might be 
interpreted that both of the first two of these have a PSM department external orientation, i.e. 'Customer Focus', requiring PSM professionals to engage with both internal and external customers and therefore emphasises PSM's boundary-spanning role. 'Leadership' may be seen as inherently internally focused, but consultants often rely on strong leadership at their clients' organisations to drive projects successfully forward. Due to the nature of their business, consultants may see both 'good' and 'bad' cases more frequently over time, as they move from project to project/client to client, more so than someone based in a single organisation for a longer time and they might therefore be more cognisant of the 'Leadership' competence of being important.

Comparing the results between traditional (profit-focused) and social businesses in the study, 'Sustainability' as a future competence was highly prioritised by both types of organisation. Although 'Automation', 'Computer Literacy' and 'Big Data Analytics' were all very important for traditional businesses, the PSM professionals from social businesses did not emphasise them at an equal level. Potentially, skills in the digitisation context, such as 'Automation' might not be so important for social businesses, e.g. offering a specific product or service in the social welfare sector. Second, social businesses tend to be smaller, younger companies that may well have anticipated digitisation aspects from their inception/founding and, therefore, may not feel the need to mention explicitly this as a future challenge. Besides, the competences related to digitisation might be more challenging for established, more prominent companies, in which widespread organisational change is more difficult to engender. It might be an area of future research, specifically looking at this area in more depth and across a broader empirical base.

Comparing the interview results from a supplier and buying company representatives, both agreed about the current importance of 'Interpersonal Communication' and 'Communication Skills', as well as 'Negotiation', 'Sustainability' and 'Analytical Skills'. However, suppliers emphasised 'Product Knowledge' and 'Holistic Supply Chain Thinking', which are part of the ten most often coded current competences for suppliers, but not for those in buying roles. It might indicate the suppliers' wish or hope that buyers who more fully understand the products they buy and the supply chain of these products are more competent business partners. It may make them more 'reasonable' in negotiations and ensure a more balanced buyersupplier relationship. The ranking also differs for 'Cultural Awareness' and 'Passion', as these are in the ten most often coded future competences for suppliers only. Supplier representatives' future competence priorities confirm those from buying interviewees in the areas of 'Sustainability' (highest number of codings for both groups) and for 'eProcurement Technology' (second-highest number of codings for both groups).

The analysis of the codings related to the study participants' total work experience revealed another critical difference. The competences related to Interpersonal skills were much less often coded for interviewees with only three to five 
years of working experience than those who were more experienced. Interpersonal skills for this less experienced group are the least relevant, and Technical skills are by far mentioned the most. For interpersonal skills, "Conflict resolution" and "Communication" stand out as being less important for interviewees with only three to five years of working experience, although "Conflict resolution" was also emphasised by all other groups. This finding can be an indication of how recent PSM professionals have been educated and trained for their job, although it could be that they did not get an understanding of the importance of Interpersonal skills during their academic education, or they lack the Technical skills that they need in their first PSM professional role. Therefore, this finding would need further data and investigation to develop a fuller understanding. Conversely, 'Integrity', the PSM professionals with the least work experience only focused on 'Prioritisation' and 'Cultural awareness'.

There were also differences based on the buying companies' interviewee demographics in terms of their cross-functional experience, as interviewees with crossfunctional experience emphasised 'Openness', 'Process Optimisation', 'Strategic Sourcing' and 'Supplier Management' when talking about future requirements. It may be interpreted that their cross-functional background lets them see how these competences (would in the future) improve their effectiveness and the competences of 'Openness' and 'Process Optimisation' stand out as being connected to upcoming technological advances, with which end-to-end process optimisation will require more outstanding cross-functional efforts. This 'Openness' can be interpreted as being open to new solutions and technologies and the points of view and other functions' requirements.

Regarding differences across roles, HR/Training representatives did not identify the 'eProcurement' competence as being of current importance, yet the other roles did. It may indicate that PSM, as a function, needs to highlight the importance of eProcurement to the rest of the organisation, or there is a risk that it is not seen as a priority. 'Supplier Management' was not listed as a current competence in the management role but was explicitly operational. It is not necessarily surprising, as it is more of operational buyers' day-to-day task to focus on direct dealings with their suppliers.

\subsection{Conclusions}

The two research questions " 1 . Which current competences are required by PSM professionals?" and "2. How have these PSM competences changed over the last ten years?" were addressed through interviews with 46 practitioners representing either a managerial, operational or Training/HR role in PSM, in 12 buying companies 
across a broad range of industries, located in different countries and also from four supplier organisations.

\section{Table 2.7 - Competences matching with Tassabehji \& Moorhouse (2008) and additional competences gathered in interviews (compared with the IFPSM Golden Standard)}

$\begin{array}{llll} & & \text { Internal / External } & \text { Strategic Business } \\ \text { Technical Skills } & \text { Interpersonal Skills } & \text { Enterprise Skills } & \text { Skills }\end{array}$

Matching competences - competences mentioned by Tassabehji and Moorhouse (2008) and found in the interviews

\begin{tabular}{|c|c|c|c|}
\hline $\begin{array}{l}\text { Basic knowledge on } \\
\text { PSM role \& processes; } \\
\text { Computer Literacy; } \\
\text { Contract Management; } \\
\text { Cost savings; } \\
\text { eProcurement } \\
\text { Technology; } \\
\text { Intellectual Property; } \\
\text { KPI Reporting Design; } \\
\text { Languages; } \\
\text { Negotiation; } \\
\text { Process optimisation; } \\
\text { Product knowledge; } \\
\text { Project Management; } \\
\text { Quality assurance; } \\
\text { Strategic sourcing; } \\
\text { Tools and Systems } \\
\text { Implementation }\end{array}$ & $\begin{array}{l}\text { Analytical skills; } \\
\text { Conflict Resolution; } \\
\text { Creativity; Decision } \\
\text { making; Effective } \\
\text { questioning } \\
\text { techniques; Integrity; } \\
\text { Interpersonal } \\
\text { Communication; } \\
\text { Knowledge sharing; } \\
\text { Leadership; Learning } \\
\text { agility; Prioritisation; } \\
\text { Remote Virtual } \\
\text { Working; Results focus } \\
\text { driving for results; } \\
\text { Structured way of } \\
\text { working; Teamwork- } \\
\text { working in teams }\end{array}$ & $\begin{array}{l}\text { Change Management; } \\
\text { Communication skills; } \\
\text { Cross-functional } \\
\text { abilities \& knowledge; } \\
\text { Engineering; Finance; } \\
\text { Logistics; } \\
\text { Manufacturing/ } \\
\text { Production; Marketing; } \\
\text { Quality; R\&D; Supply } \\
\text { Chain; Sales; Cultural } \\
\text { awareness; Customer } \\
\text { Focus; Networking; } \\
\text { Stakeholder } \\
\text { Relationship } \\
\text { Management; Supplier } \\
\text { management }\end{array}$ & $\begin{array}{l}\text { Business Acumen; } \\
\text { Financial acumen; PSM } \\
\text { Best Practice } \\
\text { Intelligence Scouting; } \\
\text { Risk management; } \\
\text { Strategic thinking; }\end{array}$ \\
\hline
\end{tabular}

Additional competences - competences not mentioned by Tassabehji and Moorhouse (2008) and found in the interviews

$\begin{array}{ll}\text { Automation; } & \text { Curiosity; Deal with } \\ \text { Big Data Analytics; } & \text { ambiguity; Mobility; } \\ \text { Innovation sourcing; } & \text { Humbleness; } \\ \text { Innovative sourcing } & \text { Openness; Open- } \\ \text { approaches } & \text { minded; Passion; } \\ & \text { Resilience; Self- } \\ & \text { confidence Self- } \\ & \text { reflection; Self-reliance }\end{array}$

Critical thinking;

Holistic Supply Chain

Thinking;

Sustainability

Additional competences from the IFPSM Golden Standard - competences not mentioned by Tassabehji and Moorhouse (2008) and not found in the interviews

$\begin{array}{ll}\text { Commercial writing; } & \text { Exercising of } \\ \text { Time management; } & \text { Judgement; Problem } \\ \text { Identify, analyse, } & \text { identification; Problem- } \\ \text { formulate and solving } & \text { solving } \\ \text { PSM problems; } & \end{array}$

Note: in bold font, the IFPSM Golden Standard competences are displayed (see: Appendix 9.3). The lower part of the table contains those competences mentioned in the IFPSM Golden Standard but not in Tassabehji and Moorhouse (2008) and the interviews in this research. 
Based on a combination of a systematic literature review and rich empirical data, that the current competence profile for PSM encompasses a range of competences are found, such as 'Negotiation', those that relate to communication and relationship management (e.g. 'Interpersonal communication'), strategy and analytics (e.g. 'Strategic thinking'), as well as professional knowledge requirements (e.g. 'Basic knowledge on PSM role \& processes). From a future perspective, particularly 'Digitisation' and 'Sustainability' were identified as upcoming competence areas.

This study identified an additional 17 competences to those previously established in the Tassabehji and Moorhouse (2008) framework to provide a more solid platform for staff development (Table 2.7). These additional competences relate to digitisation (e.g. 'eProcurement Technology', 'Automation'), 'Sustainability', or the need to adopt a more holistic perspective, specifically around supply chain management and innovation (e.g. 'Holistic supply chain thinking', 'Innovative sourcing approaches').

Moreover, a range of new competences are identified in the interpersonal area (e.g. 'Deal with ambiguity', 'Self-confidence', 'Curiosity'), many of which are closely connected to personal traits. These additions reflect the requirements of modern PSM and complement the findings of previous research. The combination of the newly identified competences with others that have already been found in previous research (see: Table 2.7 and Appendix 9.10) suggests that a new, more modern competence profile for PSM practitioners is needed that reflects a business context influenced by the latest developments in industry 4.0 and sustainability, such as moving towards a circular economy and circular supply chains (De Angelis et al., 2018).

Table 2.7 displays in bold font the similarities with the Golden Standard of the IFPSM (see: Appendix 9.3). The lower part of the table contains those competences mentioned in the IFPSM Golden Standard but not in Tassabehji and Moorhouse (2008) and the interviews in this research. Remarkably, Tassabehji and Moorhouse (2008) and this study did not identify problem identifying, problem analysis and problem-solving competences, although analytical skills are acknowledged. Further, the IFPSM mentions commercial writing, time management and exercising of judgements.

Surprisingly, the IFPSM has overlooked more than 60 per cent of the competences identified in this study. These are displayed in regular font in the upper two parts of Table 2.7. The IFPSM Golden Standard is missing about three dozen of competence items, mainly personal skills and traits, such as conflict resolution, creativity, a holistic and a strategic manner of thinking; curiosity; deal with ambiguity; mobility; humbleness; openness and being open-minded; passion; resilience; selfconfidence; self-reflection and self-reliance. Also, product knowledge and financial 
acumen and PSM professional skills as standard negotiation, contract management, process optimisation; Quality assurance; strategic sourcing; tools and systems implementation, establishing cost savings are overlooked, PSM best practice intelligence scouting and risk management.

\subsubsection{Implications for Research}

The academic literature's primary contribution is providing a listing of current and future individual competences required for PSM, identifying differences and similarities from work done more than a decade ago. Specifically, the study is a timely refresh of the Tassabehji and Moorhouse (2008) framework, with the addition of competences that reflect changes in the PSM environment over the last decade and take a forward-looking view establishing what future requirements may be. As far as known, this research is the first to add specific, empirically grounded competences to the PSM literature since Tassabehji and Moorhouse (2008).

Moreover a holistic view is taken of the complete competence requirements set of individuals who work in a variety of PSM roles in different industrial sectors and complements other research that focuses on the competences needed in particular categories, such as: sustainable purchasing (Liu, Srai, \& Evans, 2016; Yu, Chavez, \& Feng, 2017); how to manage "enablers of building supply chain skills" (Dubey, Gunasekaran, Childe, \& Papadopoulos, 2018, p. 143); varying competence sets in the Kraljic portfolio quadrants (Knight et al., 2014); the distinct difference between explicit and tacit knowledge as mediators between supply chain knowledge management capability and supply chain performance (Schoenherr, Griffith, \& Chandra, 2014); the role of strategic skills on supplier integration (Eltantawy, Giunipero, \& Fox, 2009); the identification of "current trends, skills and knowledge areas for PSM professionals" that "PSM focus on purchasing cost reduction, the skills focus on negotiation and communication, and the knowledge on supply analysis and relationship management" (Lau, 2010, p. 400); on specific intrapersonal/entrepreneurial abilities "which incorporates creativity, innovation, problem-solving, risk-taking, directing resources, and taking initiative" (Steward, Wu, \& Hartley, 2010, pp. 127-128).

Future research could further investigate why the 17 newly defined competences have gained importance and how such changing competences shape PSM departments' daily work. For example, how will an improved competence level in "big data analytics" influence the PSM process? Are there industries in which these are particularly relevant and may offer cross-training opportunities with other departments, such as marketing (e.g. in the pharmaceutical industry)? Apart from collecting and analysing primary data for such a purpose, another helpful exercise could be to analyse secondary data from grey literature such as trade journals, consultancy 
and think-tank reports. Due to such sources' nature, they could be analysed for additional competences, and then primary data collection and validation could be used to validate this extended list.

The findings reflect the consultant reports on the expected future competences in PSM, in which both Deloitte (2013) and Von der Gracht et al. (2016) (i.e. KPMG) see an increasingly strategic role for PSM in firms and highlight the importance of analytical skills, data-driven orientation and cross-functional abilities. Moreover, Deloitte and KPMG both agree that the PSM function has an essential role in environmental and sustainability compliance, and Deloitte notes the need for PSM involvement with stakeholder engagement (Deloitte, 2013). KPMG and Deloitte foresee an increasing need for creative and inventive skills to facilitate innovation sourcing and refer to out-of-the-box thinking. (Deloitte, 2013, p. 13) is more focused and calls it "thinking outside of the standard procurement transformational box", aligning with identifying the 'Holistic supply chain thinking' competence.

The empirically-based list of competences put forward in this research provides an opportunity for future work to further develop the research stream on individual PSM competences to cover the future role of PSM as an organisation, e.g. by further developing a PSM competence model. It might lead to a revision of Tassabehji \& Moorhouse's (2008) taxonomy, adding or changing the clusters to reflect the new findings.

Investigating the link between competences and the purchasing maturity of organisations, resulting in higher firm performance levels, is a field for future research. A case-study-based approach with a dedicated inter-case comparison could be an appropriate methodological setting in this context.

Using frameworks and competence cluster models from organisational psychology would be an innovative way of further investigating how they could be applied in the PSM context. For example, the competence typology of Delamare-Le Deist and Winterton (2005), which differentiates between cognitive, social, functional and meta-competences, provides a comprehensive framework to build a current and future competence model for PSM professionals. Cognitive competences are general knowledge and understanding, social competences are focused on individual behaviour, and functional competences cover skills and knowledge in a professional context. Meta-competences are described as being "concerned with facilitating the acquisition of the other substantive competences" (Delamare-Le Deist \& Winterton, 2005, p. 39).

The latter might be a competence category added to Tassabehji and Moorhouse's (2008) clusters, reflecting the new findings based on the research. Such meta-oriented competences may help to keep competences up to date in an 
increasingly dynamic business environment. Looking at the competences added to the interpersonal skills cluster (see: Table 2.7), they would fit more closely into a metaoriented category. For example, 'Curiosity', 'Deal with ambiguity', 'Integrity' or 'Openness' all fit within the category of facilitating the acquisition of other competences. The discussion of the results in light of the four competence clusters by Delamare-Le Deist and Winterton (2005) also emphasises the need to think beyond functional skills and embrace the meta-oriented competence area, becoming increasingly relevant for modern PSM professionals.

\subsubsection{Implications for Practice}

From a managerial perspective, these findings' implications are to set out a list of all current and future competences that could form part of personnel selection and any staff development processes. The findings can be used as an input into organisational competence models or mapping activities (as per Campion, 2011) and inform the alignment of relevant HR systems. The results also have implications for the educational and managerial training and knowledge management context, as a broader range of required competences has been identified and may necessitate changes in teaching methods and content. For instance, the 11 intrapersonal competences added to the framework need to be reflected in curricula and training programs. There is evidence in the peer-reviewed literature that PSM bachelor and master courses do not, with limited exceptions, cover intrapersonal learning objectives (Birou et al., 2016; Wong et al., 2014).

Additionally, competences needed in the critical areas of sustainability and digitisation should be more fully integrated into higher and professional education and professional/industrial training programs, as is shown in Table 2.7, where the differences with the IFPSM Golden Standard (see: Appendix 9.3) are displayed. This Golden Standard of the international federation of purchasing and supply management associations is missing 60 per cent of the competences identified in this research. Further, the type of competence needs to be considered, as current training and teaching methods are not necessarily suitable for developing all types of competences, and the pedagogy needs to be adapted to reflect these requirements.

Specifically, different training methods are needed when developing competences in the technical skills cluster compared to those in other clusters. Fostering shared experiences highlights the potential of in-class training formats such as role-plays and online courses and more interactive formats, e.g. blended learning or flipped classroom approaches. The meta-oriented competence cluster reasoning presented in this study suggests that finding and training employees to develop and 
apply these kinds of competences might be the key to sustaining performance over time, under rapidly changing contextual factors.

\subsubsection{Limitations}

As with all research, there are limitations. First, Tassabehji and Moorhouse's (2008) study as the basis for the comparative analysis might contribute to the selfreferencing mentioned in section 2.2. On the other hand, the literature review and results promote future research that should consider all studies and avoid the disparities shown in Appendix 9.7.

Second, the interviewees might be over-reported based on identifying seven of the competences pre-defined in the spider diagram, as outlined in the methodology section. Similarly, the future competences section of the interview guide explicitly asked for digitisation and sustainability as likely trends, which might have partly influenced the number of codings. However, if companies did not see these as important, no text generated would have been coded later (interview questions were not coded nor mentioned without the appropriate context ${ }^{10}$ ). Nevertheless, when looking at the list of the top-10 future competences, the interviewees did not just refer to the seven pre-defined competences but also discussed their competence descriptions, e.g. only 'Interpersonal Communication' appeared in the top-10 future competence list.

Third, as with much qualitative research, this research's main limitation lies in the restricted number of interviewees and companies. Moreover, regarding the results, around half of all interviewees (22 of 46) are from the Automotive and Food industries. Therefore, some care needs to be exercised in interpreting the results. The intention was not to generate statistically measurable numbers of instances, as obtained via survey data, but to generate insights into the competences' breadth and relevancy and develop and update an overall competences framework for PSM.

\footnotetext{
${ }^{10}$ E.g. if someone would mention "Sustainability is currently not a priority, instead we focus on..." that would not have been coded as a mention of sustainability-related competences
} 


\section{Chapter 3}

\section{Public Procurement of Innovations}

Skills Requirements 


\section{PUBLIC PROCUREMENT OF INNOVATION}

\section{SKILLS REQUIREMENTS}

\subsection{Introduction - Public procurement in a new era}

The expenditures on public procurement (e.g. the purchasing of services, goods and works by governmental organisations and public companies) are considered to have a substantial macro-economic impact (Obwegeser \& Müller, 2018); the last decade, the share of public procurement expenditures in OECD countries has been on average about 12 per cent of GDP (OECD, 2017a) and even 17 per cent in the countries of the European Union (Yeow \& Edler, 2016), representing a total expenditure of over $€ 2$ trillion per year (Alvarez \& Rubio, 2015).

Moreover, public procurement not only has a crucial macro-economic influence. Public procurement policies are increasingly applied to stimulate and to promote innovations in private-owned companies in the market (e.g. Amann \& Essig, 2015; European Commission, 2018a; Harland, Telgen, \& Callender, 2013; Knutsson \& Thomasson, 2014; Nijboer, Senden, \& Telgen, 2017; Obwegeser \& Müller, 2018; Rolfstam, 2015; Yeow \& Edler, 2016) and have been evaluated as such as a successful policy tool (Czarnitzki, Huenermund, \& Moshgbar, 2018).

This research is focused on the public procurement of acquiring innovations, which are "purchasing activities carried out by public agencies that lead to innovation" (Amann \& Essig, 2015, p. 282; Rolfstam, 2012, p. 303), and a distinction can be made between two types of public procurement of innovation:

"(1) responsive procurement of a novel service or product that is offered by suppliers to the market and (2) procurement that triggers the development of a new product or service, necessitating a clear definition of functional specificities to spur innovation creation by suppliers" (Yeow \& Edler, 2012, p. 475).

In this study, the latter definition is applied. Prompted by the governmental policies to stimulate and encourage innovations in the markets, the public procurement 
function is shifting from its more traditional, transactional and administrative role towards a more strategic role (McKevitt et al., 2012; Patrucco, Luzzini, \& Ronchi, 2017). An effect of this transition is that the new role of the function requires other public procurement personnel's competences (Yeow \& Edler, 2012). Effective public procurement is dependent mainly on the competence levels of its employees (Lau, 2010; Ogden, Rossetti, \& Hendrick, 2007), and the shift towards the procurement of innovative products, services and works have implications for the competences required for personnel in the public procurement function, since the process of purchasing innovation differs from the procurement of a predetermined, transactional supply (Yeow \& Edler, 2016). "Relative little competence is needed when procuring offthe-shelf goods for the lowest possible price, greater competence (of procurers) is required to encourage the supplier to innovate" (Yeow \& Edler, 2012, p. 478).

A possible barrier for the public procurement of innovation is the discrepancy between the competences held by public procurement professionals and the required competences (Yeow \& Edler, 2016). In contrast, competences are defined as a construct of knowledge, experience, skills, capabilities and abilities, following the definition of Delamare-Le Deist and Winterton (2005). Hereafter, 'competence' and 'competences' are used for each of the competence construct elements. The challenge for public procurement agents is to handle both the role of translating the inside organisational needs and policies and stimulating innovative potential developments in the outside market (Yeow \& Edler, 2016). Hence, the public procurement function is balancing between challenges in the internal organisation and external market.

Moreover, the public procurement function is in a transition and moves towards new future roles and developments. Regarding future competences, McKevitt et al. (2012, pp. 351-352) see "a distinction between positive ('what is') and normative ('what should be') public procurement practice (...). Practitioners should also be encouraged to move beyond identifying competencies that describe current tasks. In this regard, research ought to 'future proof' tactical competencies". Concerning the future development of innovations (Brimhall, 2019, p. 2) calls for more research "on how non-profit leaders create human resource and management systems that leverage employee human capital (unique talents and perspectives) for innovation". These calls are picked up in the research.

A systematic keyword search in Google Scholar and Scopus is performed to yield procurement competences. It reveals a set of 33 relevant studies on general purchasing skills and competences published between 1987 and 2020 (see: Appendices 9.2 and 9.3). Remarkably, (1) a listing of distinct competences associated with innovation sourcing is absent in the literature, despite the assumed importance and (2) the 33 studies are referring solely to purchasing in the private sector and seem to have neglected competences needed for public procurement; let alone the competences 
needed for the public procurement of innovation. The gap found in the literature is in line with the finding of Mogre, Lindgreen, and Hingley (2017).

This study aims to provide insight into which specific competences public procurement professionals need to fill the scientific literature gap. It is acting on the cutting edge of the external and internal intertwined areas during a transition, (1) to identify the needs in the internal organisation and (2) to transform from a traditional, transactional public procurement agent into a strategic procurement partner that interacts between the internal organisation and external market parties and (3) to identify and to stimulate the innovative developments in the market and to acquire innovations from the market within the framework of public procurement regulations. Moreover, since the discipline is in transition, this study aims to identify the future competences required in the public procurement of innovations. This leads to the following research questions:

Which competences are currently and soon required for public procurement personnel to be successful in:

$R Q 1$ - identifying the internal need for innovations in the internal organisation

$R Q 2$ - acting in the intermediating role between the internal organisation and the external market parties

$R Q 3$ - identifying possible supplier and stimulating innovative developments in the market to acquire innovations from the market

This research contributes to the current literature by addressing these issues by providing a specialised competence set for public procurement personnel responsible for innovation sourcing. The competence set identified within this research can be used for human resource management purposes to design job profiles, the education and training of public procurement personnel by institutions for higher education, or (in-house) training programs.

This mixed-method study is organised as follows: in the second section, the public procurement of innovation is introduced. The following methods section explains how the quantitative data was collected with the use of a European survey on public procurement competences $(n=215)$ and how the data was analysed and applied as an input for the qualitative research to validate and interpret the quantitative outcomes of the empirical outcomes, which approach is proposed in the seminal work of Schwandt (1994). Next is described how the qualitative data were collected using a World Café or mini-Delphi study, analysed and combined with the survey outcomes. The results of the quantitative and qualitative research are presented in the fourth section. The final sections include the conclusions, a discussion on the implications of the findings, the study's limitations, and further research. 


\subsection{Theoretical framework - Stimulating innovations with procurement}

\subsubsection{The context of stimulating innovation in the markets with public procurement}

Essential for the public procurement agent for the internal organisation is to understand the needs within the organisation and the possible impact on the organisation through innovation; to facilitate a risk-reward incentive structure to mitigate efficiency or reputational risks associated with innovation to "overcome risk aversion through risk management approaches"; and "to implement the innovation and change organisational procedures, routines and capacities needed to do so" (Yeow \& Edler, 2016, p. 417). The procurement function needs to "act as a value-adding function, as a consequence of several factors, including recognition from other departments, the position in the organisation hierarchy, and the involvement in strategic planning" (Patrucco, Luzzini, \& Ronchi, 2016, p. 745).

Ideally, the public procurement function cooperates and interacts with other departments to achieve organisational goals and increase public procurement performance. Cross-functional integration, alignment between public procurement decisions and other departments' strategies are essential in improving procurement performance. Increasing the procurement department's status is crucial to be perceived as an equal partner for other departments (Harland et al., 2013; Patrucco, Luzzini, \& Ronchi, 2017). Regarding the internal organisation, Yeow and Edler (2016, p. 415) underline that within public organisations, "needs are often novel and ill-defined," and that there is "a multitude of different functions within public organisations (that) produce different expectations and incentives to demand innovation", however, the public procurement function also has an external role in stimulating innovations in the market.

The public sector is a prominent market player whose power stimulates private investments in research and innovation (Mazzucato, 2018). Therefore public procurement of innovation faces also challenges in encountering the market (Amann \& Essig, 2015; Yeow \& Edler, 2016). External, at the side of the suppliers, "markets for innovation are (...) not established," and "the business case of new solutions offered to organizations is ill-defined at best" (Yeow \& Edler, 2016, p. 415). According to Yeow and Edler (2016), "the most important challenges for the public procurement of innovation are related to understanding and assessing the market and its opportunities, both in terms of what is already offered and in terms of what the market could deliver if asked for by the public buyer".

The public procurement of innovations has gotten attention in several reports and publications of the European Committee (e.g. European Commission, 2014, 2017, 2018a; European Commission, 2018b); the OECD (e.g. OECD, 2017b); the UN (e.g. United Nations Capacity Development Centre, 2010); and other governmental 
organisations in several countries that exploit websites that give guidance to the process of public procurement of innovation (see the website of IPP, in the references).

For example, the OECD (2017b) suggest some key success factors and potential pitfalls: (1) establish a "clear picture of upcoming innovation needs", (2) "build a "business case'" to make an economic justification, (3) "First scan the market for available solutions", (4) "Stimulate innovation with functional performance requirements", (5) "Avoid overly-stringent requirements", (6) "Apply the correct legal framework", (7) "Collaborate with the innovation agency or technology specialists", (8) "Adopt an experimental mindset", (9) "Share and exchange best practice/create a community of practice", and (10) "Provide incentives and support to contracting authorities".

Mazzucato (2018) studied public procurement missions to stimulate innovations in the market. Based "on the broader lessons from mission-oriented programs for innovation policy-and indeed policies aimed at investment-led growth," Mazzucato (2018, p. 803) states firstly about the organisational implications that: "While much has been written about case studies on missions, this has not resulted in an alternative policy making toolkit. Missions-in the least-require those tools to be just as much about market cocreating and market shaping, as they are about market fixing". Regarding the attitude of public procurement, Mazzucato $(2018$, p. 811 ) notes that " $A$ culture of experimentation and risk-taking is a crucial element in the philosophy of missions. There must be incentives to "think outside the box" to come up with new solutions to address the mission objective".

Hence, the literature shows that public procurement professionals responsible for innovation sourcing need to acting and interacting as a strategic business partner between internal, public, and market parties. This leads to the following hypothesis:

Hypothesis: public procurers for innovation require a role as a strategic business partner.

The kind of roadmaps as the one in the above example from the OECD is also found at national websites (IPP); however, these roadmaps hardly reveal competence sets or job requirements for stimulating innovation in the market with public procurement policy tool. Therefore, in the next section, the neighbouring discipline analysis is considered: innovation sourcing in private companies. As abovementioned, the purchasing competence literature is general and is not specified to innovation sourcing competences. However, innovation sourcing literature suggests the required behaviour. 


\subsubsection{The context of stimulating innovation in the markets with private purchasing}

Peer-reviewed literature on developing innovations with suppliers in private companies' purchasing departments exhibits some similarities with public procurement of innovations literature. On forehand, the main differences in consideration that public procurement distinct from private purchasing (Telgen, Harland, \& Knight, 2007; Thai, 2001): whereas purchasing in private firms are subject to measurements like return on investment of earnings per share, the procurement in public organisations is viewed as a policy instrument (Telgen et al., 2007).

Moreover, public procurement professionals need to be able to purchase within the governmental and (EU) regulations, deal with the broad scope of public procurement; and support secondary goals and policy initiatives through their purchasing activities (Telgen et al., 2007). Nevertheless, the literature on comparing private purchasing and public procurement has a long history. A century ago, Thomas (1919) compared both and explained that 'governmental purchasing' can benefit from private purchasing practices (Gries, 1919; Thai, 2001). More recently, Stentoft Arlbjørn and Vagn Freytag (2012) conclude that public procurement can learn from private purchasing despite the differences. In the peer-reviewed literature on industrial innovation sourcing, there is a body of knowledge and subsequent understanding that possibly serves the public procurement "that triggers the development of a new product or service, necessitating a clear definition of functional specificities to spur innovation creation by suppliers" (Yeow \& Edler, 2012, p. 475).

A first possible lesson from private purchasing for the innovation sourcing in public procurement might be to "search for completely new technologies and sources of knowledge and ideas outside existing supply relationships and supply chains" (Johnsen et al., 2012, p. 12) and "to look beyond immediate requirements" (Legenvre \& Gualandris, 2018, p. 97). Secondly, to stimulate innovations with other organisations, it is necessary that the purchaser communicates and cooperates closely with operational departments and internal clients (Legenvre \& Gualandris, 2018, p. 97).

The purchaser of the future will "work on a more interdisciplinary level, developing more technical skills, and participating more actively in product development processes", as predicted by Von der Gracht et al. (2016, p. 46) in their scientific outlook report. Moreover, suppliers' early involvement in the purchasing function is vital in "the sourcing process, before any specific project has even been formally started" (Johnsen et al., 2012, p. 13). Together with internal partners, purchasers need to understand the broader ecosystem to enlarge their knowledge level and "engage effectively with outsiders and new players" (Legenvre \& Gualandris, 2018, p. 97). Luzzini et al. (2015, p. $115)$ summarise, "The purchasing function has clearly emerged as a pivotal interface and process owner of collaborative buyer-supplier relationships". The importance of the 
early involvement of suppliers in the procurement of innovations in the industry is evident.

Another challenge for industrial purchasing is to balance short-term cost advantages with long-term innovation advantages. Johnsen et al. (2012, p. 13) underline that purchasers in firms need to avoid that suppliers will be assessed purely on low costs and their innovative capabilities. The balance between costs and innovations holds that purchasers "need to look beyond risks, cost, and product development to offer further competitive advantages" (Legenvre \& Gualandris, 2018, p. 97). Schiele (2010, p. 149) elaborates on the importance of a long-term scope on the cost-innovation balance by highlighting the purchasing's dual role "to support the process of innovation while maintaining cost and integration responsibility for the entire product life cycle for the entire firm".

The following section will elaborate on how the quantitative and qualitative research was carried out with an extensive European survey and World Café of miniDelphi study with public procurement experts that a private agency deployed to work as interim procurement managers at ministries, provinces in health care, water boards or municipalities.

\subsection{Methodology - a qualitative approach with the World Café method}

\subsubsection{The research design of the online European purchasing competences survey}

For this purpose, the quantitative data was collected with an online European purchasing competences survey that was part of a larger European project. This European project's main objective was to design new academic learning objectives based on the competences associated with successful purchasers. About 3,200 European purchasers were personally invited via Linkedln.com to participate in an online survey ( $n=581$; response rate $>18$ per cent). The respondents are in 63 per cent of the cases working in the private sector $(n=366)$ and 37 per cent in public procurement $(n=215)$. For this research, the respondents from public procurement were isolated. There is a normal spread over the ages in the sample, about one-quarter of the respondents is female, and three quarter is male. The respondents are primarily Western European, predominantly Dutch. About 80 per cent of the respondents have Dutch nationality, seven per cent have French nationality, and four per cent are German or Austrian.

The survey consisted of three different kinds of items. First, the participants' professional purchasing focus on the procurement of innovations was determined. The public procurement professionals with an innovative focus $(n=52)$ were isolated from the total number of participants in public procurement $(n=215)$, i.e. the participants 
who placed 'having the focus on innovation' on rank $1(n=13)$ and rank $2(n=39)$ are selected for this study. In total, five ranks were amongst the possible choices (lowering costs and improving delivery, quality, competitive advantage and the sourcing of innovations).

Second, the participants rated their levels on 88 competence items (see: Appendix 9.14). All items were measured on a 5-point Likert scale (fully disagree to fully agree). The pre-test of the survey has been performed with six purchasers in the chemical industry, pharmacy wholesale, and the technology industry in Germany and the Netherlands. The pre-test clarified the items' texts, and it led to the introduction of missing items.

The third step was to measure the level of success regarding the procurement of innovations individually and in combination with their teams on the topic of detecting innovations in the hands of suppliers, which resulted in four items derived from Azadegan and Dooley (2010), Schiele, Horn, and Vos (2011) and Terpend, Krause, and Dooley (2011). The four items are: (1) Due to my actions, product and process improvements have been implemented; (2) Due to my actions, we achieved more product and process improvements than average; (3) Due to my actions, we identified more ideas that are useful with suppliers than the benchmark; (4) The product and process improvements achieved in my department/company are considerably better than expected (see: Appendix 9.26 - Statements focussed on innovation).

The next step in this study was to identify the competences and the organisational conditions for innovation sourcing that belong significantly to public procurers with an innovation sourcing focus. First, with a $t$-test, the significant differences in the innovation sourcing professionals' perceived competences level $(n=52)$ and those with a non-innovation sourcing focus $(n=163)$ are identified. Secondly, with four different stepwise regression analyses $(n=215)$, the 88 competences as independent variables are combined with the four-abovementioned success items as dependent variables. The survey outcomes were used as the basis and starting point of the qualitative study in the World Café sessions to validate and extend the results.

Hence, with the empirical and sociological positivist approach, a set of competences was expected to be found that would reflect a profile for the public procurement of innovations as it currently is as a starting point for the constructivist interpretation of the consequences for the future competences in the public procurement of innovations, which approach is advocated by Schwandt (1994). 


\subsubsection{The research design of the World Café or mini-Delphi study}

In the second stage of this study, the World Café or mini-Delphi study method is applied (Brown \& Isaacs, 2005). The World Café method strives "to recreate an informal environment within a structured conversation that focuses on key questions that are relevant to the participants" (Estacio \& Karic, 2016, p. 733). Von der Gracht and Darkow (2013, p. 410) add that the World Café method is "an innovative form of participatory workshop dialog", which "is based on the principle that the best ideas and solutions often occur outside of formal structures (e.g. in coffee and tea breaks, over dinner, at the bus stop)". A World Café harnesses small group discussions' energy to develop shared learning and new insights regarding a topic of interest.

The collaboration was found with a Dutch agency for interim procurement management focused on public procurement professionals' secondment to attract participants. All participants $(n=55)$ are experts in public procurement. All responded to an invitation from the interim management agency (which in most cases was to be the current intermediary of the participants) to participate in a network session to discuss competences needed in the public procurement function. Three different World Café sessions took place over time in the three different cities spread over the Netherlands.

This World Café session was organised as follows. The participants were informed about the empirical outcomes of the quantitative research in a plenary presentation. Moreover, the participants filled out a questionnaire with personal and professional related items. Information about the participants was collected in two categories: (1) personal information and (2) work experience and current function. Next, the World Café rounds took place. Each World Café session comprised three rounds of respectively 25,20 and 15 minutes. The participants moved according to a prescribed personalised 'road map' from a discussion table to the other tables to ensure that every participant contributed to the discussion around all the three research questions in heterogeneous groups, i.e. that the participants were distributed in such a manner that individuals would (almost) not encounter the same fellow participants in the next round(s) as in the previous.

During the subsequent rounds, the discussion points and statements were noted with coloured markers on large paper sheets per table. Eventually, the paper sheets with the discussion per research question's outcomes were presented in a plenary session. After the presentations, each participant used 25 small, coloured stickers to 'vote' for the 'most important' discussion points written down on large paper sheets. Herewith, the most important topics, according to the participants, were retrieved with the final 'voting' round. The sheets with stickers were the basis for further analysis as the result of the three discussion rounds. It deviated from the original 
outline for World Cafés as proposed by Brown and Isaacs (2005) by adding a validation by identifying the most critical issues.

Table 3.1 - Analysis of the populations in the three different World Café sessions

\section{Pearson Chi-Square}

\begin{tabular}{lccc} 
& Value & $p$-value & $\mathrm{N}$ \\
\hline Gender & 4.235 & 0.120 & 55 \\
Highest completed educational level & 7.469 & 0.487 & 55 \\
Education Specialisation & 44.930 & 0.273 & $46^{2}$ \\
Place of deployment & 49.711 & $0.040^{*}$ & 55 \\
Success level in lowering costs & 9.616 & 0.293 & $54^{2}$ \\
Success level in improving quality & 8.489 & 0.387 & $54^{2}$ \\
Success level in improving delivery times & 6.506 & 0.591 & $53^{2}$ \\
Success level in sustainability & 7.721 & 0.461 & $54^{2}$ \\
Success level in purchasing innovations & 4.360 & 0.823 & $54^{2}$ \\
Success level in supplier satisfaction & 4.370 & 0.822 & $54^{2}$ \\
\hline${ }^{1}$ variable for which the conditions for the Chi-square test were met / ${ }^{2}$ missing data / *significant difference: \\
$p<.05$ \\
\end{tabular}

Table 3.2 - Years of work experience and current place of employment of the research population

\begin{tabular}{lllll}
\hline & & $\begin{array}{l}\text { Utrecht } \\
(\boldsymbol{n}=\mathbf{1 5})\end{array}$ & $\begin{array}{l}\text { Apeldoorn } \\
(\boldsymbol{n}=\mathbf{2 1})\end{array}$ & $\begin{array}{l}\text { Groningen } \\
(\boldsymbol{n}=\mathbf{1 9 )}\end{array}$ \\
Total years of work & Min. & 6 & 6 & 3 \\
experience & Max. & 50 & 37 & 40 \\
& Mean & 25 & 22,14 & 19,37 \\
& Std. dev. & 12,82 & 8,82 & 10,84 \\
Years of work & Min. & 0 & 0 & 0 \\
experience purchasing & Max. & 35 & 20 & 38 \\
private sector & Mean & 8,33 & 8,19 & 5,21 \\
Years of work & Std. dev. & 11,45 & 7,2 & 9,25 \\
experience purchasing & Min. & 0 & 0 & 0 \\
public sector & Max. & 35 & 20 & 20 \\
& Mean & 10,66 & 8,09 & 8,55 \\
Current place of & Std. dev. & 10,15 & 6,31 & 5,86 \\
employment & Municipality & 0 & 3 & 7 \\
& Government & 9 & 2 & 1 \\
& Education & 1 & 2 & 3 \\
& Province & 1 & 0 & 0 \\
& Healthcare & 1 & 5 & 0 \\
& Business & 2 & 1 & 3 \\
& Water authority & 0 & 1 & 1 \\
& other & 1 & 7 & 4
\end{tabular}


Between the World Café sessions, differences in the research population were found, however only the character of working place the interim management showed a significant difference $(p<.05)$, i.e. the kind of organisation that hired the interim procurement manager (see: Table 3.1). In the first World Café session, most participants worked in central governmental organisations, like ministries. In the second session, the most prominent part consisted of participants working in health-care-related organisations, and an influential group in the last session was working in decentral governmental organisations, like municipalities, water boards and provinces.

Table 3.3 - Employment (workplaces) of the research population

\begin{tabular}{|c|c|c|c|}
\hline & $\begin{array}{l}\text { Utrecht } \\
(n=15)\end{array}$ & $\begin{array}{l}\text { Apeldoorn } \\
(n=21)\end{array}$ & $\begin{array}{l}\text { Groningen } \\
(n=19)\end{array}$ \\
\hline Municipality & 0 & 3 & 7 \\
\hline Government & 9 & 2 & 1 \\
\hline Education & 1 & 2 & 3 \\
\hline Province & 1 & 0 & 0 \\
\hline Healthcare & 1 & 5 & 0 \\
\hline Business & 2 & 1 & 3 \\
\hline Water authority & 0 & 1 & 1 \\
\hline Other; independent & 0 & 1 & 0 \\
\hline Other; semi-government & 0 & 1 & 0 \\
\hline Other; housing corporation & 0 & 1 & 0 \\
\hline Other; public sector & 0 & 1 & 0 \\
\hline Other; decentralized government & 0 & 1 & 0 \\
\hline $\begin{array}{l}\text { Other; municipality, government, } \\
\text { education, and healthcare }\end{array}$ & 0 & 0 & 1 \\
\hline Other; healthcare and education & 0 & 0 & 1 \\
\hline Other; province and business & 0 & 0 & 1 \\
\hline Other; ZBO RDW & 0 & 0 & 1 \\
\hline Other; municipality and government & 0 & 0 & 1 \\
\hline Other; municipality and education & 1 & 1 & 0 \\
\hline Other; healthcare and business & 0 & 1 & 0 \\
\hline
\end{tabular}

Job titles: procurement manager (20); consultant - procurement advisor (16); contract manager (7); tender project manager (6); entrepreneur (1); controller (1); trainer (1)

The total number of stickers over the discussion points was added up, and the three World Café sessions' results are further analysed. For the results of every question in the World Café sessions, coding was used to group similar discussion points into one discussion point or statement. Coding took place per research question to limit the different table hosts' influence $(n=11)$ on the different discussion points. Variation in the terminology used by the different table hosts and participants was discussed during the final plenary presentations, and subsequent discussions top rankings with 
discussion points that received the most votes across the three World Cafés were determined to provide answers to the three research questions. The participants' related information derived from the filled-out questionnaires was analysed using SPSS and used to identify whether differences in the research population could explain differences in the top-ranking competences per location. Tables 3.2 and 3.3 reveal the years of experience and the employment of the population.

\subsection{Results - future competences profiles for the strategic innovation procurer}

\subsubsection{Quantitative results based on the survey outcomes}

Table 3.4 displays those competences identified with independent samples $t$-tests as significant and positively related to public procurers with an innovation focus. It might not be surprising that 'innovation' and corporate social responsibility (CSR) related roles are found. Public policy is often used to stimulate innovations combined with encouraging sustainable, durable solution. The finding is not surprising. Besides the daily topics of public procurers regarding innovations and CSR, procurement laws, regulations, and tender procedures are essential, shown in the competences cooperation with the legal department, having legal knowledge and developing customised contracts.

Table 3.4 - Results of the Independent samples t-test

\begin{tabular}{|c|c|c|}
\hline & & Sign. \\
\hline PLa_100_InnoSourc & $\begin{array}{l}\text { Innovation Sourcing - External scan. This requires a systematic } \\
\text { scan of the solutions available on the supply market }\end{array}$ & .039 \\
\hline PLa_110_Innolmpl & $\begin{array}{l}\text { Innovation Implementation - Implementing suppliers innovations } \\
\text { in the own organisation }\end{array}$ & .001 \\
\hline POa_70_CSR & $\begin{array}{l}\text { Corporate Social Responsibility - A business model that requires } \\
\text { active compliance with the spirit of the law, ethical standards and } \\
\text { national or international norms }\end{array}$ & .040 \\
\hline POa_100_ContrDevelopm & $\begin{array}{l}\text { Contract Development - Designing of contracts, application of } \\
\text { standard vs customised contracts }\end{array}$ & .023 \\
\hline POa_170_ESI_c & $\begin{array}{l}\text { Early Supplier Involvement - Inviting the supplier in the new } \\
\text { product development process from a very early stage }\end{array}$ & .005 \\
\hline POa_180_StratBusPartn & $\begin{array}{l}\text { Strategic Business Partner - The process of becoming a strategic } \\
\text { (business) partner with your supplier }\end{array}$ & .015 \\
\hline PSa_50_Loyalty_c & Loyalty - Being loyal to the employing organisation & .010 \\
\hline SOa_40_AddValue2Org & $\begin{array}{l}\text { Add Value to the Organisation - Knowledge on the added value of } \\
\text { the purchasing function to the organisation }\end{array}$ & .053 \\
\hline SOa_60_CorpGov_c & $\begin{array}{l}\text { Corporate Governance - Knowledge of how organisations are } \\
\text { governed, including board, the advisory board's role, stakeholders } \\
\text { etc. }\end{array}$ & .020 \\
\hline SOa_140_CoopLegal & $\begin{array}{l}\text { Working together with the Legal department - Knowing basics } \\
\text { about legal aspects, like contracts, compliance and legal } \\
\text { consequences and knowing how to establish/maintain the } \\
\text { relationship }\end{array}$ & .044 \\
\hline
\end{tabular}


Beta Sign.

DV_Innovation_1 Due to my actions, product and process improvements have been implemented

$\begin{array}{llll}\text { HRa_70_ChangeMngt } & \begin{array}{l}\text { Managing to change processes - The ability to lead a team or } \\ \text { group through a change process }\end{array} & .216 & .007 \\ \text { PLa_60_SupMarkAnalys } & \begin{array}{l}\text { Supply Market Analysis - Analysis of the supply market, i.e. } \\ \text { the suppliers of a good and their properties/relationships to } \\ \text { each other }\end{array} & .254 & .002 \\ \text { PSa_120_Inventiveness } & \begin{array}{l}\text { Inventiveness - Being imaginativeness } \\ \text { SOa_120_CoopRD }\end{array} & \begin{array}{l}\text { Working together with the department Research and } \\ \text { Development - Knowing basics about Research \& } \\ \text { Development and knowing how to establish/maintain the } \\ \text { relationship }\end{array} & .436 \\ \end{array}$

DV_Innovation_2 Due to my actions, we achieved more product and process improvements than average

$\begin{array}{llll}\text { COa_40_BigDataAnalys } & \begin{array}{l}\text { Big Data Analysis - Uncovering hidden patterns, correlations } \\ \text { and other insights from large amounts of data using specific } \\ \text { statistical big data analyses methods }\end{array} & .204 & .022 \\ \text { PLa_120_CategStratDev } & \begin{array}{l}\text { Category Strategy Development - Development of the } \\ \text { sourcing strategy for a category or family of purchasing } \\ \text { goods, including strategic analysis and category } \\ \text { classification/portfolio management (e.g. Kraljic) } \\ \text { SOa_50_StratMngt }\end{array} & \begin{array}{l}\text { Strategic Management - Strategic management of } \\ \text { purchasing professionals working as a CPO board member }\end{array} & .006 \\ & .001\end{array}$

DV_Innovation_3 Due to my actions, we identified more useful ideas with suppliers than the benchmark

\begin{tabular}{llll}
\hline POa_180_StratBusPartn & $\begin{array}{l}\text { Strategic Business Partner - The process of becoming a } \\
\text { strategic (business) partner with your supplier }\end{array}$ & .314 & .000 \\
SOa_30_TechKnow & $\begin{array}{l}\text { Technical knowledge of products and production systems - } \\
\text { Understanding the technical aspects of the own products } \\
\text { and production processes }\end{array}$ & .046
\end{tabular}

DV_Innovation_4 The product and process improvements achieved in my department/company are considerably better than expected

\begin{tabular}{|c|c|c|c|}
\hline COa_40_BigDataAnalys & $\begin{array}{l}\text { Big Data Analysis - Uncovering hidden patterns, correlations } \\
\text { and other insights from large amounts of data using specific } \\
\text { statistical big data analyses methods }\end{array}$ & .213 & .006 \\
\hline PLa_120_CategStratDev & $\begin{array}{l}\text { Category Strategy Development - Development of the } \\
\text { sourcing strategy for a category or family of purchasing } \\
\text { goods, including strategic analysis and category } \\
\text { classification/portfolio management (e.g. Kraljic matrix) }\end{array}$ & .369 & .000 \\
\hline PSa_20_HolisticThink & $\begin{array}{l}\text { Holistic Thinking - Holistic thinking involves understanding a } \\
\text { system by sensing its large-scale patterns and reacting to } \\
\text { them }\end{array}$ & .229 & .005 \\
\hline SOa_130_CoopHRM & $\begin{array}{l}\text { Working together with the Department of Human Resources } \\
\text { Management - Knowing basics about Human Resources } \\
\text { Management and knowing how to establish/maintain the } \\
\text { relationship }\end{array}$ & .246 & .004 \\
\hline SOa_140_CoopLegal & $\begin{array}{l}\text { Working together with the Legal department - Knowing } \\
\text { basics about legal aspects, like contracts, compliance and } \\
\text { legal consequences and knowing how to establish/maintain } \\
\text { the relationship }\end{array}$ & .199 & .010 \\
\hline
\end{tabular}


Furthermore, public procurement of innovations is associated with functional role-related knowledge and behaviour: establishing a strategic business partnership with the supplier and inviting the supplier to an early stage of the new product development process. Moreover, the innovation-focused in public procurement has more knowledge of how organisations are governed and have a lower extent of knowledge on the importance of the organisation's procurement $(p=.053)$.

Based on the $t$-test analysis, the evidence is found not to reject the hypothesis that innovation sourcing in public procurement requires a strategic business partner, confirmed with the Stepwise regression analyses (see: Table 3.5). Other important activities are "strategic management"; "category strategy development"; "supply market analysis"; "big data analysis"; and "internal cooperation with the departments Research and Development, Human Resources Management and Legal Affairs". "Technical knowledge" of the own products and processes is of importance. Innovations buying is furthermore related to "change management" and "inventiveness".

\subsubsection{Qualitative results based upon the World Café sessions}

The empirical outcomes of the quantitative analyses in the preceding section are the starting point for the qualitative research to interpret and provide insight into which specific competences public procurement professionals will need. The qualitative part of this study aims to identify the required competences of the procurer to transform from a traditional, transactional public procurement agent into a strategic procurement partner for the internal organisation, as recommended by Patrucco, Luzzini, and Ronchi (2017) and McKevitt et al. (2012). Therefore, the following question for the World Café sessions is formulated:

Q-I: Which competences are required for public procurement personnel to be successful as a strategic business partner?

As shown in the previous section, innovation sourcing, or the systematic scanning of the solutions available on the supply market, is a task of the public procurers of innovation, i.e., to identify and to stimulate the innovative developments in the market and to acquire innovations from the market within the framework of public procurement regulations, as described by Yeow and Edler (2016). This leads to the following question for the World Café sessions:

Q-II: Which competences are required for public procurement personnel to be successful in identifying and stimulating innovative developments in the market, in stimulating and acquiring innovations from the market? 
Moreover, since the discipline is in transition, this study aims to identify the competences required in the public procurement of innovations soon as proposed by McKevitt et al. (2012) and Brimhall (2019). Therefore, the following question is formulated:

\section{Q-III: Which competences are required in the public procurement of innovations in the near future?}

The analysis of outcomes of about 15 hours of (parallel) World Café discussions delivered insight into the most critical competences displayed in Table 3.6.

\section{Table 3.6 - Top-15 competence sets per World Café question, in order of importance}

\begin{tabular}{|c|c|c|c|c|c|}
\hline Procurement of innovation & $\#$ & Strategic business partner & $\#$ & Future success & $\#$ \\
\hline $\begin{array}{l}\text { Having courage and } \\
\text { entrepreneurial skills }\end{array}$ & 53 & $\begin{array}{l}\text { Having a proactive attitude; } \\
\text { showing/taking initiative }\end{array}$ & $\begin{array}{l}3 \\
7\end{array}$ & $\begin{array}{l}\text { Having IT skills and } \\
\text { knowledge }\end{array}$ & 57 \\
\hline $\begin{array}{l}\text { Having an open dialogue with the } \\
\text { market. Being challenging and } \\
\text { experimental towards suppliers }\end{array}$ & 29 & $\begin{array}{l}\text { Being able to distinguish the } \\
\text { 'real need' behind the demand } \\
\text { of the business partner (i.e., the } \\
\text { internal client) }\end{array}$ & $\begin{array}{l}3 \\
0\end{array}$ & $\begin{array}{l}\text { Being able to think about } \\
\text { opportunities }\end{array}$ & 24 \\
\hline $\begin{array}{l}\text { Ability to get involved early in } \\
\text { the procurement process }\end{array}$ & 25 & $\begin{array}{l}\text { Ability to work in } \\
\text { multidisciplinary teams }\end{array}$ & $\begin{array}{l}2 \\
4\end{array}$ & $\begin{array}{l}\text { Being connective and } \\
\text { staying in touch with the } \\
\text { market }\end{array}$ & 24 \\
\hline $\begin{array}{l}\text { Being able to think 'out-of-the- } \\
\text { box' }\end{array}$ & 21 & $\begin{array}{l}\text { Being decisive, being profound } \\
\text { and curious when questioning } \\
\text { the business partner }\end{array}$ & $\begin{array}{l}1 \\
8\end{array}$ & Having analytical skills & 22 \\
\hline Having communicative skills & 21 & $\begin{array}{l}\text { Ability to get involved early in } \\
\text { the procurement process }\end{array}$ & $\begin{array}{l}1 \\
6\end{array}$ & $\begin{array}{l}\text { Having the ability to } \\
\text { transform from risk- } \\
\text { avoiding to risk-controlling }\end{array}$ & 19 \\
\hline $\begin{array}{l}\text { Knowledge about the procurer's } \\
\text { organisation and having } \\
\text { organisational sensitivity }\end{array}$ & 21 & $\begin{array}{l}\text { Being able to think 'out-of-the- } \\
\text { box' and think of alternative } \\
\text { solutions }\end{array}$ & $\begin{array}{l}1 \\
6\end{array}$ & $\begin{array}{l}\text { Being able to translate } \\
\text { vision into practical plans }\end{array}$ & 15 \\
\hline Being creative & 20 & $\begin{array}{l}\text { Being creative, courageous and } \\
\text { entrepreneurial }\end{array}$ & $\begin{array}{l}1 \\
6\end{array}$ & $\begin{array}{l}\text { Having social and } \\
\text { communicative skills }\end{array}$ & 12 \\
\hline $\begin{array}{l}\text { Knowledge about laws and } \\
\text { regulations }\end{array}$ & 19 & $\begin{array}{l}\text { Being a valuable, strategic and } \\
\text { full-fledged discussion partner }\end{array}$ & $\begin{array}{l}1 \\
3\end{array}$ & $\begin{array}{l}\text { Being focused on } \\
\text { sustainability and circular } \\
\text { economy }\end{array}$ & 11 \\
\hline Having networking skills & 16 & $\begin{array}{l}\text { Being willing 'to leave the } \\
\text { office', e.g. frequently visit the } \\
\text { business partner (i.e. the } \\
\text { internal client), to do job } \\
\text { rotations and internship within } \\
\text { the company }\end{array}$ & $\begin{array}{l}1 \\
1\end{array}$ & $\begin{array}{l}\text { Being adaptive and being } \\
\text { able to manage change }\end{array}$ & 11 \\
\hline Being persuasive & 15 & Being persistent & $\begin{array}{l}1 \\
1\end{array}$ & $\begin{array}{l}\text { Having courage, being } \\
\text { entrepreneurial, and being } \\
\text { confident to innovate }\end{array}$ & 10 \\
\hline $\begin{array}{l}\text { Having sellership skills and the } \\
\text { ability 'to sell procurement' }\end{array}$ & 15 & $\begin{array}{l}\text { Asking critical questions to the } \\
\text { business partner }\end{array}$ & $\begin{array}{l}1 \\
0\end{array}$ & $\begin{array}{l}\text { Knowing laws and } \\
\text { regulations }\end{array}$ & 10 \\
\hline $\begin{array}{l}\text { Being able to create } \\
\text { commitment/support for } \\
\text { innovations }\end{array}$ & 13 & Having collaborative skills & $\begin{array}{l}1 \\
0\end{array}$ & $\begin{array}{l}\text { Being able to listen } \\
\text { (listening to needs) }\end{array}$ & 10 \\
\hline Having social skills & 11 & $\begin{array}{l}\text { Able to create and sustain } \\
\text { relationships }\end{array}$ & 9 & $\begin{array}{l}\text { Being able to automatise } \\
\text { decision making }\end{array}$ & 10 \\
\hline Being able to think critically & 11 & $\begin{array}{l}\text { Being visible as procurement } \\
\text { officer to the business partner }\end{array}$ & 9 & $\begin{array}{l}\text { Being able to express } \\
\text { themselves (presentation) }\end{array}$ & 9 \\
\hline Being realistic & 11 & Having emphatic skills & 9 & Being efficient and effective & 8 \\
\hline
\end{tabular}


The participants see the need for the involvement of the procurement function early in the process. Therefore, a procurer needs to be persuasive to 'sell procurement' as an attractive, strategic partner for the internal partner, i.e., the added value that the procurement function in a strategic partner role is made clear to the internal partner. Once the strategic partner's status is achieved, the procurer needs to be physically visible for the internal partner by showing up in regular meetings, project teams, or job rotation. The main challenge is to detect 'the real need behind the firstly expressed need' by being a sparring partner who is listening and can raise relevant questions. The public procurement of innovation needs persuasive skills; the function needs to advocate innovations and create commitment for innovations within organisations. Therefore, the procurer needs to be able to manage change processes.

In general, procurers need knowledge of laws and regulations and communication, presentation and networking skills. In connection with the market, procurers need to establish an open dialogue to challenge suppliers to be experimental. Public procurement of innovations has an interactive role between the internal and innovation suppliers in the market. The central part of the success of innovation buying in the public sector lies in the procurer's entrepreneurial behaviour, who must be courageous, proactive, and persistent to be creative and think out-of-the-box. The future procurer needs to know about digitisation and circular economy issues. Additionally, the procurer conceptualises a clear vision and translates this into realistic (project) plans.

\subsection{Discussion of the entrepreneurial competence set for public procurers}

This research aims to fill the gaps in scientific literature by providing insight into which specific competences public procurers need as professionals, performing their tasks as boundary spanners between the inside organisation and the outside market in times of a transition from a merely operational, transactional to a strategic function.

In the first stage of this study, the quantitative survey-based research contribution that industrial purchasing of innovation, public procurers of innovations, needs to act as a strategic business partner. However, the issue is given the (legal) differences between industrial purchasing and public procurement (Telgen et al., 2007), whether there is a role for early involvement of suppliers for public procurement of innovations. Indeed, public procurers need to work according to rules and regulation. However, for complicated contracts, the competitive dialogue procedure would be applicable in the European Union (Haugbølle, Pihl, \& Gottlieb, 2015; Hoezen, van Rutten, Voordijk, \& Dewulf, 2010). This procedure prevents that "confidential business secrets will fall into the hands of competing tenderers, provided the contracting 
authority ensures that the principles of non-discrimination and confidential treatment of information are applied rigorously" (Hoezen et al., 2010, p. 1180). Hence, early involvement of suppliers in public procurement of innovations is possible.

What is lacking in scientific literature and which is not clear from the survey results is which competences are required for a public procurement agent of innovations to be successful as a strategic business partner (in the future). The participants of the World Café gave answers for this question in four categories: (1) establishing a relationship with the internal partner; (2) establishing a relationship with innovative suppliers in the market; and (3) fulfilling the role of a strategic business partner and bridging the gap between the internal partner and the innovations supplier in the market, which steps are according to Yeow and Edler (2012). Eventually, (4) the competence set for the near future was designed. On each of the four elements will be elaborated hereunder.

Firstly, the World Café participants seemed to develop a precondition for internal procurement success: establishing a stable relationship with the internal organisation partner to ensure early procurement involvement, which is in line with Tassabehji. Procurers need the know-how to get involved early in the procurement process by understanding the own organisation, being persuasive and being able to 'sell procurement', which means that the advantages of cooperating with procurement are made explicit for the internal partner. This is in line with Giunipero and Pearcy (2000, p. 12), who stated (for industrial purchasing) that "Influencing and persuasion skills are required to coordinate and direct supply chain members both within and outside the organization".

Secondly, the question is answered regarding which competences are required for a public procurer to successfully identify and stimulate innovative developments in the market and acquire innovations from the market. Procurers need to be connective and stay in touch with the market by having an open dialogue with the market and establishing relationships with innovative suppliers. The aim is to challenge potential suppliers to be experimental and to come up with innovative solutions.

Thirdly, competences needed for a successful strategic partnership are characterised by an intensive dialogue. The procurer needs to listen carefully to the internal partner and to raise critical questions to distinguish the 'real need' behind the demand, which topic is also addressed in industrial buying by Giunipero and Pearcy (2000), who emphasise 'listening' and 'understanding the need of the internal partner'. In the plenary discussions, the World Café participants stressed the need to ask supplementary questions since internal partners may use technical specifications instead of describing the functional outcome. This is in line with Uyarra, Edler, GarciaEstevez, Georghiou, and Yeow (2014, p. 631) that "The main barriers reported by suppliers refer to the lack of interaction with procuring organisations, the use of over- 
specified tenders as opposed to outcome-based specifications, low competences of procurers and poor management of risk during the procurement process".

Moreover, as a strategic partner, the procurer knows procurement laws and stays visible to the internal partner. To be visible and to understand the organisation better, the participants suggested job rotations. This would be in line with Feisel et al. (2011), who emphasise the importance of job-rotation and cross-functional workshops in increasing the procurement department's internal effectiveness in an industrial setting. Integrating procurement with internal business functions increases the linkage among the organisation, improves internal relationships and "results in quicker problem solving, better information exchange, and successful performance" (Feisel et al., 2011, p. 61).

Our study shows the need for procurers to show entrepreneurial behaviour by thinking 'out-of-the-box' and having courage. Further, the procurer needs to be confident to innovate and create commitment for innovations to advocate innovations in the internal organisation. The procurer is creative, proactive and persistent and has excellent communication, presentation and networking abilities. This is in line with industrial purchasing competences literature, as shown in the following sections.

For industrial purchasing, Giunipero et al. (2005) note the importance of integrating procurement into cross-functional teams and emphasising that only adopting a flexible and entrepreneurial competence set enables procurers to fulfil an increasingly strategic role. The procurer needs to be "a purchaser who is able to plan projects with multiple stakeholders, to influence not only suppliers but also (internal) business partners, and who possess a strong will to contribute to organizational success. This person is not waiting for action to happen but is proactive, creative and decisive" (Feisel et al., 2007, p. 6).

In industrial supply chain management, Sohal (2013) underlines the importance of communication skills, teamwork skills and technology skills for a supply chain manager to successfully integrate different businesses along a supply chain and be effective in their role. Communication, coordination, and problem-solving skills are essential skills for strategic and tactical industrial purchasers identified by Knight et al. (2014).

Giunipero and Pearcy (2000) identified a seven-factor skillset, including strategic skills, team skills and behavioural skills. Especially behavioural skills, including interpersonal communication, entrepreneurship, creativity, and inquisitiveness, correspond to this research's findings as essential competences for public procurement professionals to be successful. Furthermore, in industry, strategic purchasers "are closely aligned with internal business needs, highly regarded by top management and possess high skill levels and knowledge" (Giunipero et al., 2006, p. 787). 
Individual purchasers require creative competences; however, "developing creative sourcing strategies is a social endeavour" (Kiratli et al., 2016, p. 202). For strategic procurement, such as innovation sourcing, Kiratli et al. (2016, p. 202) emphasises the need for sourcing team leaders to understand "the soft or social factors that underlie team performance," "to encourage and fuel creative behaviour among sourcing teams," to change focus from costs to value-driven sourcing.

Finally and fourth, the public procurement competences for innovations for the near future are addressed. The participants of the World Cafés identified sustainable, circular procurement and digitisation as essential themes of the future. Therefore, the procurer's focus needs to contribute to circular economy solutions and acquiring IT skills and knowledge. The participants' answers on future requirements partly overlapped the answers of the first two research questions on current requirements. The distinct future competences are being able to conceptualise vision, translate it into a practical plan, have analytical skills, and manage change processes.

These results are in line with the findings of Von der Gracht et al. (2016) in the KPMG-outlook on the private purchasing function in the year 2035 state that industrial purchasers of the future need competences to function as a spider-in-the-web to manage the increasingly complex tasks of digitisation of processes and the challenges on sustainability. "As a result of this increasing development of changes, structural breaks and complexity, the need arises for procurement and supply chain managers to acquire (...) the ability to competently manage dynamic and complex (...) developments - in other words, to manage our near and distant future" Von der Gracht et al. (2016, p. 6).

The outcomes of Mazzucato's (2018) study on stimulating innovations in the market with public procurement missions show that notes that " $A$ culture of experimentation and risk-taking is a crucial element in the philosophy of missions. There must be incentives to "think outside the box" to come up with new solutions to address the mission objective" (Mazzucato, 2018, p. 811).

\subsection{Conclusions - public procurement needs communicative and strategic entrepreneurs}

The main contribution of this research is the development of a profile for the public procurement of innovations: an entrepreneurial, courageous, communicative and strategic public procurement professional that resembles the requirements addressed in industrial purchasing literature (e.g. Giunipero \& Pearcy, 2000; Knight et al., 2014; Tassabehji \& Moorhouse, 2008). Tassabehji and Moorhouse (2008) state that increasing competence levels must be accompanied by top-management support as an organisational precondition for increasing competence levels. Chapter 5 supports 
Tassabehji and Moorhouse (2008) with quantitative evidence. Moreover, the outcomes of Mazzucato's (2018) study on stimulating innovations in the market with public procurement missions show that " $A$ culture of experimentation and risk-taking is a crucial element in the philosophy of missions. There must be incentives to "think outside the box" to come up with new solutions to address the mission objective" (Mazzucato, 2018, p. 811).

The outcomes of this study are in line with Knight et al. (2014), who stated that communication skills, influencing and persuasion, strategic thinking, managing internal customers, and working in teams are critical skills for strategic, industrial purchasers. Moreover, Tassabehji and Moorhouse (2008, p. 65) "suggest that today's private purchasing professional must be a dynamic relationship manager creating and developing cross-functional strategies and must possess internal selling, change management, supplier relationship and partnership management skills".

The purpose of this study is to explore which competences public procurement professionals require to face specific challenges concerning the public procurement of innovation, transforming from an operational buyer to a strategic business partner and future success, and providing a list of required competences of public procurement professionals. This study is built upon a quantitative and a qualitative pillar. The surveybased quantitative part empirically confirmed an essential role for the procurer of innovations as a strategic business partner, which might seem counterintuitive as a role for a public procurement agent; however, as shown, the competitive dialogue procedure is an applicable EU procedure for the procurement of innovations in the public field. The competences were derived from three World Cafés or mini-Delphi studies that provided rich insights into the importance of different competences for the professionals facing public procurement challenges.

In Figure 3.1, the outcomes of this study are summarised. When combining the competences sets, there are three roles for the public procurement of innovations (see: Figure 3.1). (1) The first role is to establish relationships with the internal organisation and the possible suppliers of innovations in the market. (2) The second challenge for public procurers of innovations is to bridge both and connect the internal partner's needs with the external partner's innovative capacities. (3) The third role is to challenge and encourage suppliers to innovate. It requires entrepreneurial behaviour, which may seem contraindicative and belong at first sight to a private purchasing profile. However, 'entrepreneurial' has to be understood as considering 'risk-taking', having the 'courage' and being 'confident' to innovate, to create 'out-of-the-box' solutions, being persistent and not in the sense of being able to establish an enterprise and gain certain profits or a high return on investments, like in the private sector. 


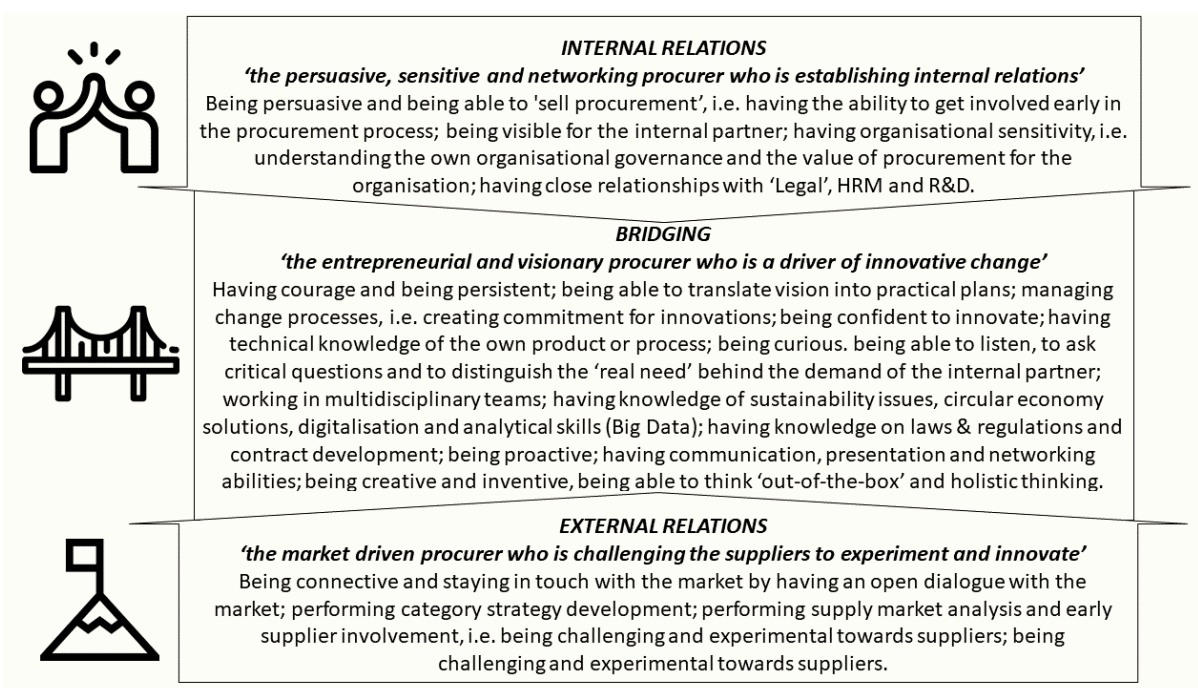

Figure 3.1 - Competences of public procurers of innovation (own illustration/icons: www.flaticon.com)

The subsequent requirements categories of an innovation buyer in public procurement are interpersonal human-to-human skills (e.g. persuasiveness, communication, challenging, listening), intrapersonal character traits or attitude (e.g. 'out-of-the-box' thinking, curiosity, sensitivity, persistence), professional skills (e.g. team working skills, contract development, data analysis, interview skills, category strategy development) and knowledge (e.g. knowledge of the own organisation and the market, legal and technical knowledge, knowledge on circularity and digitisation ).

While private purchasing and public procurement may have many differences regarding laws and regulations (Harland et al., 2013), it seems that the competences that procurement professionals need to be successful in their sector might be more similar than expected. Therefore, the supposed significant difference between the public and the private sector (Telgen et al., 2007) seems not to apply to the interpersonal, behavioural, and intrapersonal character traits in this research profile.

Public procurement is often used as a lever of governmental policy where core objectives are set by politicians limiting public procurement professionals' input in the procurement process (Gordon, 2009; Patrucco, Luzzini, Ronchi, et al., 2017; Telgen et al., 2007). Public procurement laws and political pressure that public procurement professionals are urging them to make responsible, accountable economic decisions may have caused public procurement to be risk-averse (Knutsson \& Thomasson, 2014; Obwegeser \& Müller, 2018; Thai, 2008). However, it seems that not only public organisations are characterised as risk-averse. Giunipero and Pearcy (2000, p. 11) 
detected risk aversion in industrial organisations when they concluded, "Being successful means having an entrepreneurial spirit despite pressure in many organisations to maintain the status quo".

Our research questions regarded the competences required by procurers. However, the participants seemed to urge to raise these organisational conditions by addressing early procurement involvement. It is in line with the private purchasing and the public procurement literature (e.g. Giunipero \& Pearcy, 2000; Patrucco, Luzzini, \& Ronchi, 2017). Communication with different organisational units and the (early) involvement with the specification of demand enables the procurement department to significantly influence what is purchased, leading to lower governmental expenditure (Patrucco, Luzzini, \& Ronchi, 2017).

This research deliberately has been performed with a sample of interim managers in public procurement specialists to overcome the risk of describing the status quo and listing competences for traditional, transactional public procurement. These specialists are employees of a private-owned, interim management agency and are operating at ministries, provinces, municipalities, water boards, health care organisations and other public institutions. Therefore, the participants do not have civil servants status and work temporarily in different jobs or projects at diverse public organisations. This study intentionally aimed participants with this signature to benefit from their inside view as relative outsiders at public procurement departments to focus on this research on future public procurement's strategic role with the different competences.

\subsection{Limitations, managerial implications and further research}

\subsubsection{Limitations}

For this research, collaboration was found with an interim management agency in the Netherlands. The agency sent out invitations to the interim procurement managers in its portfolio. The inclusion of only Dutch professionals interested in public procurement competences selected by a Dutch interim management agency suggests the influence of selection bias within this research, which might be a limitation. Moreover, the respondents were apparently interested and intrinsically motivated in public procurement competences development. Therefore, the group of participants might be considered as a convenience sample, which is a limitation.

Next, about 80 per cent of the survey population and the entire World Café population consisted of Dutch professionals in procurement and contract management in the public domain, which could have caused a cultural bias. Moreover, the results derived from the three World Café sessions differed, probably caused by the significant 
distinct populations from ministries, local governments and health care. Additionally, this study is limited because it does not specify competences profiles within the public procurement function, such as requirements for a central or decentral governmental organisation or other tender obligated institutions related to health care.

Across all three World Cafés, eleven different table hosts lead the discussion around one of the three research questions. Even though instructed not to, the table hosts may have influenced this research's outcomes in various ways due to the discussion leading style, formulating and writing down the participants' competences. During this presentation, the table hosts provided small summaries of the points discussed at this table, and some could have added an opinion on which competences are the most important for the public procurement professional.

\subsubsection{Managerial implications}

One of this research's managerial implications is the high importance of an entrepreneurial mindset and developing a vision, and translating a vision into concrete plans. Evidence is found that an entrepreneurial mindset could break the risk-averse public sector procurement culture, stimulate innovation in the development of new technology or services, and innovation in management and work processes, creating more collaboration between and within public organisations defended by Knutsson and Thomasson (2014).

The public procurement function is facing several structural challenges. One of them is the low status of the procurement department in the public sector (Harland et al., 2013; Patrucco, Luzzini, Ronchi, et al., 2017). When the public procurement function can act as a strategic partner for the internal organisation, the status is expected to increase over time by assigning competent, entrepreneurial public procurers. An adequate solution for increasing the public procurement function's entrepreneurial competences may seem to hire purchasing experts from the private sector. However, Telgen et al. (2007, pp. 465-466) warn that the public sector's challenges despite a "seemingly unceasing flow of private sector business magnates brought in by politicians and civil servants to sort out public sector spending" are not solved.

The organisational capability that leads to purchasing effectiveness is caused by individual competences and an increased level of management support and organisational conditions, such as stimulating creative idea generation, the alignment of goals between the procurement and other organisational departments, and with top management support, as shown in industrial purchasing literature (Feisel et al., 2011; Kiratli et al., 2016; Tassabehji \& Moorhouse, 2008). Hence, increasing the staff's competence levels on itself is not sufficient; internal recognition and organisational support for the public procurement of innovation are as much of importance. 
Unlike in private-owned organisations, longer-term contracts might be obstructed in public procurement, especially by laws and regulations (Harland et al., 2013). Whereas purchasing in private firms are subject to measurements like return on investment of earnings per share, procurement in public organisations is viewed as a policy instrument (Telgen et al., 2007). Governments and public authorities using public procurement as a policy tool to promote the developments of innovations by market parties are often risk-averse (Czarnitzki et al., 2018; Yeow \& Edler, 2016).

\subsubsection{Further research}

The public procurement function is facing challenges in reaching innovation and sustainability policy goals of the near future. However, research in the field of (future) competences in public procurement is lacking. This study is contributing to the public procurement competences research with an explorative method. Further research is essential to investigate and replicate which competences are crucial for future tasks in the (different disciplines in the) public procurement function. Preferably, a more extensive, quantitative method like multiple international, cross-continental surveys or a larger scale, qualitative method, such as an international Delphi study, could be applied. It would be worth investigating whether the complete competence set (1) should be obtained by every single procurer or (2) could be shared amongst individuals within a public procurement team.

This research identified an entrepreneurial, communicative and strategic profile for the public procurement professional. However, public procurement is subject to political objectives and goals, limiting the degree to which the procurer can influence the procurement process and use the entrepreneurial mindset. Further research should investigate the influence of political decisions on the public procurement function to define how skilled public procurement professional maximally can contribute.

Moreover, this study does not specify competences profiles within the public procurement function. Competence profiles derived from this research cannot be seen in isolation from its context. The competences public procurement professionals will need are dependent on the challenges in public procurement and the concrete organisational context, such as the size and type of organisation.

Next, this study focuses on which (future) competences are required and not on how procurers of innovations should acquire those competences. In general, there are two measurements: training personnel or firing senior staff and hiring new ones. Feisel et al. (2011) noted for industrial purchasing that while training is "an adequate measure to develop technical, interpersonal, internal and external enterprise skills, but not to achieve an ultimate shift in mindset. To achieve the appropriate mindset, 
recruiting new employees was the only measure perceived to be effective in developing strategic business skills of individual performance" (Feisel et al., 2011, p. 64). Feisel et al. (2011) have added a third measurement to increase the team's competences. Additionally, training, firing, and hiring is assigning a new chief purchasing officer with a distinct strategic profile (Feisel et al., 2011).

Further research could investigate the influence of the organisation's context on the competences crucial for public procurement professionals. Additionally, for public procurement of innovations, further research is applauded that combines the effects of training programs for existing staff and the introduction of appropriate organisational conditions and top management support.

\section{Acknowledgements}

This research is made possible by YACHT Supply Chain Management \& Procurement, the Netherlands, to cooperate in the World Café sessions' organisation. 


\section{Chapter 4}

\section{Culture's Consequences for Purchasing}

Comparing Purchasing Job Ad Requirements from Different European Countries with Cultural
Models 


\section{CULTURE'S CONSEQUENCES FOR PURCHASING COMPARING PURCHASING \\ JOB AD REQUIREMENTS FROM DIFFERENT EUROPEAN COUNTRIES WITH CULTURAL MODELS}

4.1. Introduction - the assumption of a standard profile for a universal purchaser

Researchers broadly agree that the individual skills levels of purchasing and supply management (PSM) professionals have a significant influence on their organisational capabilities and are positively related to organisational success (e.g. Feisel et al., 2011; Giunipero et al., 1999; Giunipero \& Pearcy, 2000; Knight et al., 2014; Legenvre \& Gualandris, 2018; Schiele, 2007; Tassabehji \& Moorhouse, 2008; Tate \& Ellram, 2012). Hence, organisations require a well-educated workforce, and standardised skills models are needed for these individuals' education and training.

However, in the comparative management literature, researchers generally agree that business structures and practices vary across different countries and cultures (e.g. Hofstede, 2001; House, Hanges, Javidan, Dorfman, \& Gupta, 2004; Inglehart \& Welzel, 2010; Ogden et al., 2007; Schwartz, 2008; Terlutter, Diehl, \& Mueller, 2006). In this research, the term 'skill' is briefly used for items that form the broader construct of cognition, professional and interpersonal skills, intrapersonal traits and behaviour (Delamare-Le Deist \& Winterton, 2005).

Cultural differences have been reported in the areas of outsourcing (Horn et al., 2013; Schoenherr, 2010), PSM decision-making (e.g. Pagell \& Sheu, 2001; Roth, Money, \& Madden, 2004), and buyer-supplier relationships (e.g. Cannon, Doney, Mullen, \& Petersen, 2010; Homburg, Cannon, Krohmer, \& Kiedaisch, 2009; Kibbeling, Gelderman, Ulijn, Van Weele, \& Calvi, 2009). For instance, Horn et al. (2013, p. 27) investigated "the operational and financial implications and real effects of cost-oriented sourcing from China, based on the specific example of a European automotive OEM". They found that "more than three-quarters of the analyzed China-sourcing projects do not reap the expected benefits" due to "differences in cultural distance and the development level of the countries" (Horn et al., 2013, p. 35). Pagell and Sheu (2001, p. 2783) suggest that "any theory that links buyer behaviours to supplier performance will 
need to consider a firm location," since the outcomes of their study "vary by region of the world". Kibbeling et al. (2009, p. 354) found "that the cultural background of purchasers does affect their perceptions of trust, commitment and dependence in supplier relationships". Another example is Cannon et al. (2010, p. 506). They found "that a buyer's trust of a supplier and the supplier's performance affect the buyer's longterm orientation toward the relationship," and add the finding "that the relative effects of trust and performance on long-term orientation are moderated by culture" and more precisely Hofstede's dimension of individualism vs collectivism (which will be explained in the theory section).

Nevertheless, as described more extensively in the theoretical background section, the literature review results show no attention has been given to cultural deviations in PSM competences. Moreover, universalism also seems to apply to practitioner assumptions, such as those made by the overarching union of national PSM associations, the International Federation of Purchasing and Supply Management (IFPSM). The IFPSM has published a Global Standard in Purchasing and Supply Management (GSPSM) for professional education, which, as the name already indicates, rests on an assumption of universal validity (Brennan \& Crowe, 2012). The GSPSM does serve as a standard in higher education and is "awarded to programmes of learning, which are of Bachelor degree level or equivalent and which are typically of three to four years duration" (Brennan \& Crowe, 2012, p. 1).

Concluding that scholars and PSM practitioners' associations have overlooked the influence of cultural differences, the question arises whether industrial actors in their human resources (HR) practice take cross-cultural differences into account in the design of the descriptions of required skills for purchasing managers. These descriptions are typically expressed in job advertisements.

Several studies in the peer-reviewed literature have been carried out to examine the requirements cited in online job postings in the field of supply chain management. However, these studies have thus far been geographically limited to the USA (Radovilsky \& Hegde, 2012; Radovilsky, Hegde, \& Kandasamy, 2007; Rossetti \& Dooley, 2010; Sodhi, Son, \& Tang, 2008), Anglophone (Canada, UK, and USA), and Asian countries (China, India, Malaysia, and Singapore) (Shou \& Wang, 2015), although a single country study has been conducted in Europe (Serbia) (Cvetić, Vasiljević, \& Danilović, 2017).

Researchers have ignored international or cultural differences in these studies (Birou et al., 2016; Shou \& Wang, 2015). Only the research of Shou and Wang (2015) included a multi-country comparison. Although it was not the focus of research, differences were identified by Shou and Wang (2015, p. 11). They speculated that "culture may be an underlying reason for the (...) differences. More in-depth studies are still necessary to explore these differences further", referring to Hofstede (1984) as a suggestion for further research to address this literature gap. 
Table 4.1 - Matrix combining the GLOBE and the Hofstede cultural clusters

Hofstede's clusters in Europe based upon Kale

(1995)

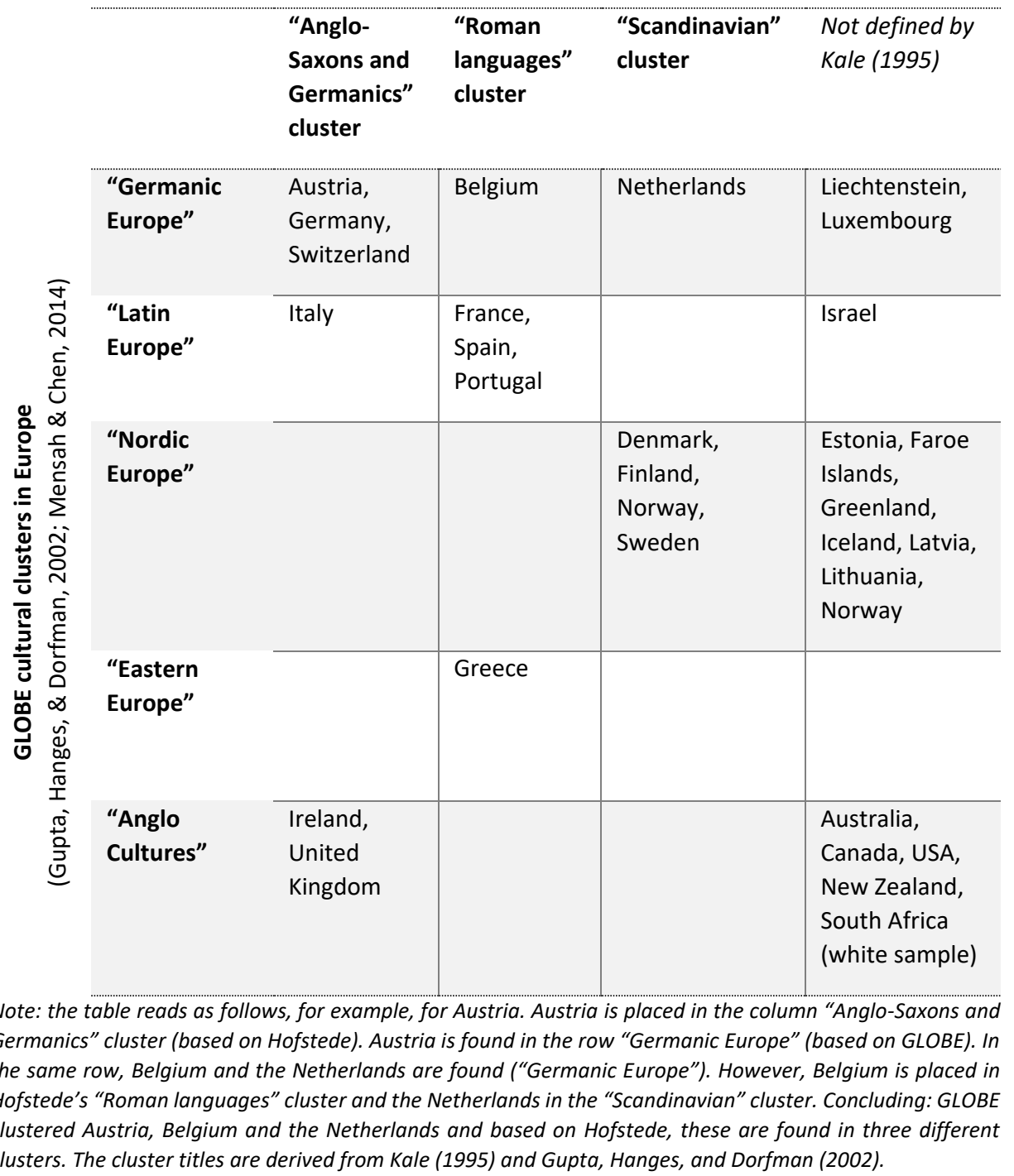

This study was conducted to close this gap. Previous researchers did not conclusively test the generalist assumption made in the available skills models, although it was often implicit. Previous research has also generally applied to specifically supply chain management, which often translates as "logistics" rather than as "purchasing management". This study was carried out to identify cultural differences 
or similarities in job requirements in PSM. As an object of analysis, the focus is on European job requirements.

The discourse in the literature on cultural comparisons appears to be dominated by Hofstede and the GLOBE project (e.g. Hofstede, 2006, 2010; Hofstede, Hofstede, \& Minkov, 2010; House et al., 2004; House et al., 1999; P. B. Smith, 2006), and a watershed seems to have formed between the two groups of adherents as will be explained. Although the GLOBE model is rooted in Hofstede's model, the outcomes of applying these two models deviate strikingly from one another, especially in the approach taken to cluster European countries.

The GLOBE research group (House et al., 1999; Mensah \& Chen, 2014) distinguishes different European cultural clusters: "Germanic Europe", "Latin Europe", "Nordic Europe", "Eastern Europe", and "Anglo Cultures" (see: Table 4.1). On the other hand, Hofstede characterised the European continent in general and these three countries in particular as culturally diverse (Hofstede et al., 2010). Referring to the Cultural Dimensions of Hofstede, three different European cultural clusters are presented by Kale (1995, p. 40), who labelled the clusters as follows: an "Anglo-Saxons and Germanics" cluster, a "Roman language countries" cluster, and a "Scandinavian" cluster (see: Table 4.1). "This classification yields two outliers: Italy in Cluster 1, and the Netherlands in Cluster 3" (Kale, 1995, p. 40).

Kale (1995, p. 40) continues: "Italy, as a Roman-language speaking country, would be expected to fit better in Cluster 2. However, if Italy were divided into north and south, it would be perfectly adapted to the existing classification". The south part of Italy would belong to Cluster 2, and the north of Italy would fit Cluster 1. "The Netherlands, based on geographic proximity, would appear to fit better with Cluster 1, but its centroid's distance to Norway is almost the same as Belgium's is to France". Therefore, "the Netherlands was assigned to the 'Scandinavian' cluster" (Kale, 1995, p. 40).

Table 4.1 shows disagreement regarding European cultural clusters and the specific clusters' positions; the two different cultural models' outcomes deviate. The GLOBE research placed Austria, Belgium, Germany, Liechtenstein, Luxemburg, the Netherlands and Switzerland in one "Germanic Europe" cluster (House et al., 2004). Thus, according to the GLOBE model, a universal profile would exist among these countries. Based upon Hofstede's dimensions, Kale (1995) distinguished three European clusters that found Austria in the "Anglo-Saxons and Germanics" cluster, Belgium in the "Roman languages" cluster and the Netherlands in the "Scandinavian" cluster.

Therefore, in this study, Austria, Belgium, and the Netherlands were taken as objects of analysis because these three countries were assigned to three different clusters based on Hofstede's cultural dimensions (Kale, 1995). More precisely, 100 Austrian PSM job ads, 100 Belgian, and 100 Dutch are compared. 
Moreover, these three countries' choice is justified due to their similar GDP per capita (OECD, 2020) and structural characteristics (Banai, 2010). Furthermore, all three are members of the European Union (EU), unlike Switzerland, which could have served as an alternative country for Austria in this study. Austria, Belgium, and the Netherlands are comparable, 'smaller' EU countries with similar populations, as opposed to, for instance, Germany or France.

Indeed, Germany ("Anglo-Saxons and Germanics" cluster) and France ("Roman languages" cluster) could have been compared. However, all other larger countries with a similar population and GDP belong to the same clusters, such as the UK and (Northern) Italy ("Anglo-Saxons and Germanics" Hofstede cluster) or Spain and (Southern) Italy ("Roman language" Hofstede cluster and "Latin Europe" GLOBE cluster). Therefore, next to Germany and France, a third comparable, larger country would not be available in the European context.

The contradiction between the cultural clusters led to the development of the following research questions:

RQ1: Does a universal, shared, ideal job profile exist for a purchaser?

Moreover, if differences between the countries would be detected:

RQ2: Which differences exist in the employers' PSM job requirements?

RQ3: How can these differences in PSM job requirements be explained?

This research contributes to PSM practice in that it provides a list of the most commonly required skills that differ among the diverse countries and cultural areas. It contributes in practical terms to practitioners' work involved in designing PSM curricula in higher education and company training sessions. The empirical detection of substantial differences among the countries in job skills requirements is a crucial PSM research contribution in that it makes PSM scholars aware that the prevailing universalistic approach may be overly simplistic and not entirely realistic. Instead, PSM (skills) researchers would benefit in the future from leading discussions on how this approach is culturally embedded and pro-actively conducting research on cultural influences.

This research also contributes to the comparative management literature in that it is the first to compare the needs of European employers in the field of PSM and - in its empirical content - to reveal cultural differences. The findings suggest that the Hofstede model is still relevant and could be more effectively used to explain the detected differences than the GLOBE model.

This chapter is organised as follows: in the second section, PSM skills requirements are discussed, and the literature on culture and culture models is reviewed to establish a basis for international comparison. In the subsequent methods section, a description in detail is given on how job advertisements were used as 
empirical input and explain how the sample of 300 online job advertisements was collected and processed. From each of the three countries, 100 PSM job ads have been analysed. The results are presented in the fourth section. The final sections include the conclusions, a discussion on further research, the implications of the findings, and the study's limitations.

\subsection{Theoretical background - results of a literature review on culture, culture models, PSM skills requirements and research in job advertisements}

\subsubsection{The literature on PSM job requirements seems to indicate cultural unity}

A keyword search was performed in Scopus ('buyer', 'purchase', 'purchaser', 'purchasing', 'procurement', 'skill', 'skills', 'competence', 'competency' and 'competencies'), which generated an initial set of 1,007 articles. Articles that focused on organisational (i.e. non-individual) competences or capabilities in the described fields or on consumer skills of family household purchasing budget use were discarded, as were minor citations. A total of 33 relevant studies were identified, published from 1987 to 2020. From these articles, skills requirements were extracted (see: Appendix 9.1), and a list of PSM job requirements was gradually extracted (see: Appendix 9.2), and a list of PSM job requirements was derived (displayed partly in Table 4.2).

Table 4.2 - PSM requirements mentioned at least once per article in the scientific PSM job requirements literature (1987 - 2020)

\begin{tabular}{llll}
\hline PSM knowledge & $82 \%$ & Problem-solving skills & $58 \%$ \\
Negotiation skills & $76 \%$ & Decisiveness/capacity to make & $52 \%$ \\
Business knowledge and & $73 \%$ & Organisational skills & $49 \%$ \\
Leadership skills / personnel & $73 \%$ & Risk management & $42 \%$ \\
Relationship management & $67 \%$ & Persuasive skills & $42 \%$ \\
Holistic thinking / having an & $67 \%$ & Conflict resolution & $42 \%$ \\
Analytical thinking & $64 \%$ & Customer orientation & $42 \%$ \\
Communication skills & $61 \%$ & Curiosity / will to learn / learning & $33 \%$ \\
Strategic thinking & $58 \%$ & Creativity & $33 \%$ \\
Computer literacy & $58 \%$ & Legal knowledge & $33 \%$ \\
Team ability & $55 \%$ & Industry knowledge & $33 \%$
\end{tabular}

(based upon the requirements mentioned in: Anderson \& Katz, 1998; Baily, Farmer, Crocker, Jessop, \& Jones, 2008; Bals et al., 2019; Burt, Dobler, \& Starling, 2003; Carr \& Smeltzer, 2000; J. R. Carter \& Narasimhan, 1996; Cavinato, 1987; Cousins \& Spekman, 2003; Cruz \& Murphy, 1996; Dowd \& Liedtka, 1994; Eltantawy et al., 2009; Faes et al., 2001; Flöthmann, Hoberg, \& Gammelgaard, 2018; Giunipero, 2000; Giunipero et al., 2005; Giunipero \& Handfield, 2004; Giunipero et al., 2006; Giunipero \& Pearcy, 2000; Keough, 1993; Kern et al., 2011; Killen \& Kamauff, 1995; Knight et al., 2014; Kolchin \& Giunipero, 1993; McKeefry, 1998; Mulder et al., 2005; Muller, 2001; Murphy, 1995; Pagell, Das, Curkovic, \& Easton, 1996; Schulze et al., 2019; Tassabehji \& Moorhouse, 2008; Tatham et al., 2017; Trent \& Monczka, 2003b; Zawawi et al., 2014) 
The data were subjected to further statistical analyses. Fawcett and Rutner (2014, p. 180) stated that PSM practices in firms have "evolved dramatically over the past generation". Hence, the scientific PSM literature sample was divided into ' $20^{\text {th }}$ century' $(1987-2001 ; n=16)$ and ' $21^{\text {st }}$ century' $(2003-2020 ; n=17)$ sub-samples. It was interesting to note that no significant differences could be found among the specific requirements by applying a $t$-test, indicating a certain stagnation in academic development.

Table 4.2 displays PSM job requirements and how often these were mentioned at least once in a single scientific PSM article from the entire set of articles. The top rankings indicate a profile of a PSM professional who has accumulated knowledge (i.e. displays knowledge and experience) in PSM and business; who can negotiate, network, and communicate; who can be both a team leader and member; who can think both analytically and holistically; and who can work with computer systems.

Interestingly, international or (cross-) cultural awareness was mentioned as a requirement for purchasers in only nine of the 33 articles (i.e. Bals et al., 2019; Faes et al., 2001; Gammelgaard \& Larson, 2001; Giunipero, 2000; Giunipero \& Handfield, 2004; Pagell et al., 1996; Tassabehji \& Moorhouse, 2008; Tatham et al., 2017; Trent \& Monczka, 2003b). Most authors seemed to assume that those job requirements would not be different in separate cultural settings.

Faes et al. (2001), for instance, recognises that interest in different cultures is vital and groups this skill in a category together with "self-discipline", "environmental awareness", and "extroversion". Tassabehji and Moorhouse (2008) and Pagell et al. (1996) leave the "cultural awareness" ability undiscussed and rank it as an item in an "interpersonal skills" category. Giunipero (2000, p. 24), however, quotes two CEOs on global sourcing and different cultures: "I don't think most people really understand what global really is. It's not taking your culture and transplanting it someplace else, " and "I believe we are going to have to understand cultures in much more depth". According to Giunipero and Handfield (2004, p. 51 \& 57), it is essential "to have some sense of the different cultures" and "supply managers should be fully debriefed on cultural norms in various international markets as well as the culture of organizations in other countries". Bals et al. (2019, p. 9) associate "cultural awareness" with "a more balanced buyersupplier relationship", which makes purchasers "more 'reasonable' in negotiations".

This outcome is remarkable: on the one hand, cultural differences are recognised in studies on PSM job requirements because purchaser should be aware of cultural differences. On the other hand, however, it is not concluded that this concept would lead to deviating PSM skillsets in various countries under different cultural circumstances.

In the next section, a description of the cultural models of Hofstede and GLOBE and international differences is given to establish a basis for comparing different international samples. 


\subsubsection{Culture as a collective level construct}

PSM skills requirements are for this study, combined with the concept of culture. Culture is an intangible concept that Hofstede (1980a, p. 15) explained as a social system: "Social systems can exist only because human behavior is not random, but to some extent, predictable". The prediction of a person's behaviour in a situation assumes "that each person carries a certain amount of mental programming that is stable over time and causes that person to display more or less the same behavior in similar situations" (Hofstede, 1980a, p. 15). Cultural sciences observe human behaviour inferred from "the presence of stable mental programs" (Hofstede, 1980a, p. 15).

In the GLOBE research, House et al. (1999, pp. 13-14) defined culture as the agreement among members of collectives concerning psychological attributes (i.e. "motives, values, beliefs, identities, and interpretations or meanings of significant events that result from common experiences of members of collectives and are transmitted across age generations") and the agreement regarding "commonality of observed and reported practices of entities such as families, schools, work organizations, economic and legal systems, and political institutions".

Hofstede (1980a) distinguishes three levels of uniqueness in mental programs: the universal, the collective and the individual level. "The universal level of mental programming, which is shared by all, or almost all, mankind. This is the biological 'operating system' of the human body. (...) The collective level of mental programming is shared with some but not all other people". This level belongs to people in a specific category or group and can deviate from the programming of those that belong to other categories or groups. Finally, the individual level of social programming is defined as the genuinely distinctive part: "no two people are programmed exactly alike, even if they are identical twins reared together. This is the level of individual personality; it provides for a wide range of alternative behaviors within the same collective culture" (Hofstede, 1980a, pp. 18-19).

Hence, culture is a social system regarding the collective programming of the mind. A well-known definition of culture stems from Hofstede that culture is the "collective programming of the mind that distinguishes the members of one group or category of people from others" (Hofstede, 2001, p. 9). More specified, Geertz (1973, p. 89) defined the concept of culture as "a historically transmitted pattern of meanings embodied in symbols, a system of inherited conceptions expressed in symbolic forms by means of which men communicate, perpetuate, and develop their knowledge about and attitudes toward life", while House et al. (1999) made a distinction between societal culture ("commonly experienced language, ideological belief systems (including religion and political belief systems), ethnic heritage, and history") and organisational culture ("commonly used nomenclature within an organisation, shared organisational values, and organisational history") (House et al., 1999, p. 14). 
In all these definitions, (national) culture is seen as "an important regulator of both the quality and the aggregate rates of entrepreneurial entries across countries" (Autio, Pathak, \& Wennberg, 2013, p. 334). However, Baskerville (2003, p. 6) alerts that "cultures do not equate with nations". In the Middle East, 35 different cultures are identified in 14 nations; 98 different cultures in 48 African countries; and 81 cultures in 32 Western European countries. Moreover, "in North America, 147 Native American cultures and nine North American folk cultures are detailed" (Baskerville, 2003, p. 6).

Nevertheless, evidence exists that national culture causes distinct behaviours and business (Autio et al., 2013; Cagliano, Caniato, Golini, Longoni, \& Micelotta, 2011; Pemer, Sieweke, Werr, Birkner, \& Mohe, 2014). Pemer et al. (2014) found that different aspects of national culture influence the steps in the purchasing process and refers to Hofstede's Dimensions "Uncertainty Avoidance" that it "influences the early steps in the purchasing process (specify, select and contract)" and "Masculinity-Femininity" that affects "the later steps (order, expedite and evaluate)" (Hofstede, 1980b, p. 43; Pemer et al., 2014, p. 11). Pemer et al. (2014, p. 11) conclude that these outcomes imply "further attention to the complex nature of organizational culture and how its' different dimensions interplay with different stages and aspects of the purchasing process".

Thus, culture is defined as a social system (e.g. Hofstede, 1980a). However, to understand social systems, models are used as "lower-level systems that we can better understand and that we substitute for what we cannot understand. We simplify because we have no other choice. It is in this simplification that our subjectivity enters the process" (Hofstede, 1980a, p. 16). Hence, to understand culture and cultural difference, models are used to define and detect specific cultural differences. In comparative management, several models have been proposed for this purpose, with the most popular models (Banai, 2010) including those of Hofstede (e.g. Hofstede, 1980a, 1994; Hofstede et al., 2010), Schwartz (e.g. Schwartz, 1992, 1994, 2014), Trompenaars and Hampten-Turner (e.g. Hampden-Turner \& Trompenaars, 2006; Trompenaars, 1996), and GLOBE (e.g. House, 1998; House et al., 2004; Javidan \& House, 2002).

Cagliano et al. (2011) proposed using two cultural models simultaneously: the cultural dimensions of Hofstede and the GLOBE project. These two models have also been referred to as 'fighting elephants' by P. B. Smith (2006), as Hofstede's cultural model was considered the leading model until the GLOBE study extended and updated it (House et al., 2004). Although GLOBE was inspired by Hofstede's (1980a) work, the outcomes differ and provide a broad explanatory valuable framework in this research.

\subsubsection{Sketching Hofstede's cultural model and the GLOBE project}

Hofstede's original model can be used to distinguish four cultural dimensions: "Individualism-Collectivism", "Power Distance", "Uncertainty Avoidance", and "Masculinity-Femininity". Hofstede later added, "Long-term Orientation" and 
"Indulgence" (Hofstede, 1980b, 1983a, 1983b; Hofstede et al., 2010). The "Individualism-Collectivism" dimension refers to the sense of belonging and being loyal to a group or being individualistic (Hofstede, 1983b). "Power Distance" refers to accepting the spread of power within a society (Hofstede, 1983b).

A high score on the "Masculinity-Femininity" dimension is a characteristic of a competition-driven, 'masculine' culture. In a 'masculine' society, another way of describing success is 'being the best', whereas 'seeking quality of life' and 'doing the things one likes' are phrases synonymous with success in a 'feminine' society, which is characterised by a low score on the "Masculinity-Femininity" dimension (Hofstede, 1984).

Hofstede defined 'Uncertainty Avoidance' as: "the extent to which the members of a culture feel threatened by ambiguous or unknown situations and have created beliefs and institutions that try to avoid these" (Hofstede, 1980b, p. 45). Hofstede extended the model with a 'Long-term Orientation' that describes the societies' preferences for traditions (Hofstede, 2001) and 'Indulgence' that "stands for a society that allows relatively free gratification of basic and natural human drives related to enjoying life and having fun" (Hofstede et al., 2010, p. 281).

The GLOBE project implemented Hofstede's dimensional paradigm of national cultures and extended the first five dimensions of Hofstede to nine. GLOBE did not change "Power Distance" or "Uncertainty Avoidance", but Hofstede's "Long-term Orientation" was renamed as a "Future Orientation" (i.e. the degree to which behaviours are performed in an attempt to control the future, such as investing, planning, and postponing gratification). GLOBE split up Hofstede's "IndividualismCollectivism" into "In-group Collectivism" (i.e. the degree to which pride, loyalty, and cohesiveness are expressed in families, groups, or organisations), on the one hand, and "Institutional Collectivism" (i.e. the degree to which collective distribution of resources is encouraged and rewarded in contrast to individual distribution), on the other hand.

Hofstede's "Masculinity-Femininity" dimension was divided up by GLOBE into four unique dimensions. Firstly, "Assertiveness" refers to the degree of individual assertiveness, confrontation, aggressiveness, and straightforwardness. Secondly, "Performance Orientation" refers to how individuals are encouraged and rewarded for performance improvement and society's excellence. Thirdly, "Gender Egalitarianism" refers to the degree to which gender-role differences are reduced in society. Fourthly, the "Humane Orientation" refers to the degree to which individuals treat each other in fair, altruistic, friendly, and caring ways and are kind to each other (Hofstede, 2010; Terlutter et al., 2006). The GLOBE study surveyed these items twice: firstly, by asking respondents to describe their own (organisational) culture "as it is", and, secondly, to describe it "as it should be". Whereas Hofstede first collected four and eventually five and even six scores, the GLOBE project presented eighteen scores per country, i.e. per cultural area. 
Although both cultural models share many features, the methods used to cluster the countries differ culturally. These are explained in the next section.

\subsubsection{Differences in the cultural clustering of Western European nations between the GLOBE project and Hofstede's model}

The GLOBE project has divided countries with similar cultures into ten cultural clusters: Confucian Asia, South Asia, Arab, Sub-Sahara Africa, Latin America, Anglo Cultures, Germanic Europe, Latin Europe, Eastern Europe, and Nordic Europe (Gupta et al., 2002; House, Javidan, Hanges, \& Dorfman, 2002; Mensah \& Chen, 2014). According to GLOBE, the countries included in the analysis of the job ads all belong to one cultural cluster (i.e. to Germanic Europe).

Hofstede (1983a, p. 44) detected a "Relationship between national wealth and individualism" by comparing countries by plotting the cultural dimension "Individualism-Collectivism" and GNP per capita of different countries; Hofstede (1983a, p. 44) concludes: "It is evident that wealthy countries are individualist and poor countries are collectivist".

Moreover, Hofstede (1980b) plotted the dimensions "Uncertainty Avoidance" and "Masculinity-Femininity" and found different clusters. One cluster with countries with a high level of "Uncertainty Avoidance" and with lower levels on the "MasculinityFemininity" is formed by the Netherlands, Denmark, Sweden, Norway and Finland. Strong "Masculinity" is found in Austria, Germany, Switzerland, Italy and Great-Britain and Ireland, combined with medium levels of "Uncertainty Avoidance". Strong "Uncertainty Avoidance" is found in Belgium, France, Spain and Greece, combined with medium levels of "Masculinity". However, clustering based upon the total number of cultural dimensions has been performed by other scholars.

Three clusters were found as part of a marketing study conducted on 17 European countries by Kale (1995), who described an "Anglo-Saxon and Germanics" cluster, a "Roman languages" cluster, and a "Scandinavian" cluster. Cagliano et al. (2011) found the same clusters in a study that contained 13 European countries (and eight non-European countries): an "Anglo-Saxon countries and Germany" (e.g. Germany, Ireland, UK; Austria was not included) a "Latin European" (e.g. Belgium), and a "North European" (e.g. the Netherlands) cluster (as well as an "emerging countries" cluster). For this research, Kale's (1995) work is replicated using Squared Euclidean Distance and Ward's Method, resulting in a similar clustering.

In the literature review, it appeared that (1) an assumption of universal validity seems to have been made in the published literature for the purchasing skills identified; (2) practitioner conventions, such as the IFPSM's 'global standard', often seem to apply this universal validity to the design professional education (Brennan \& Crowe, 2012); 
and (3) this assumption can be supported, and at least for the sample of three European countries, by the GLOBE project's identification of a homogenous cultural cluster. Based on these observations, the following hypothesis is developed: There is cultural unity in European PSM job requirements, i.e., the job ads in the compared countries will have the same content, calling for purchasers with the same set of competences.

\subsection{Method and data: cultural clusters and mapping skills and competences}

The analysis of job ads is a well-established form of inquiry in skills research, which is easily replicable, accessible for time-series studies, and may have high validity because the recruiting firms themselves present their requirements (Kennan, Cole, Willard, Wilson, \& Marion, 2006). As part of this research, in total, 300 PSM job ads were collected via online platforms and sorted in the random ranking order in which the online platforms presented these ads when the search key 'purchaser' was entered (in the Dutch, English, French, and German languages). The online platforms accessed were: karriere.at (www.karriere.at) for the 100 Austrian job ads; Indeed (be.indeed.com), StepStone (www.stepstone.be), Monster (jobview.monster.be), Michael Page (www.michaelpage.be), and Hudson (jobs-eu.hudson.com) for the 100 Belgian job ads; and NEVI (www.nevi.nl), Monsterboard (www.monsterboard.nl) and Intermediair (www.intermediair.nl/vacature) for 100 job ads in the Netherlands. Because the same sites have been visited over the study period, and the same job ads were placed on different platforms, duplicates were identified and subsequently discarded. Most advertisements were published by SMEs searching for purchasers who had experience levels ranging from no experience to two years and from three to up to ten years of experience, coded in this research as 'beginners' and 'advanced' (see: Table 4.3).

Table 4.3 - Sample and the division of working experience

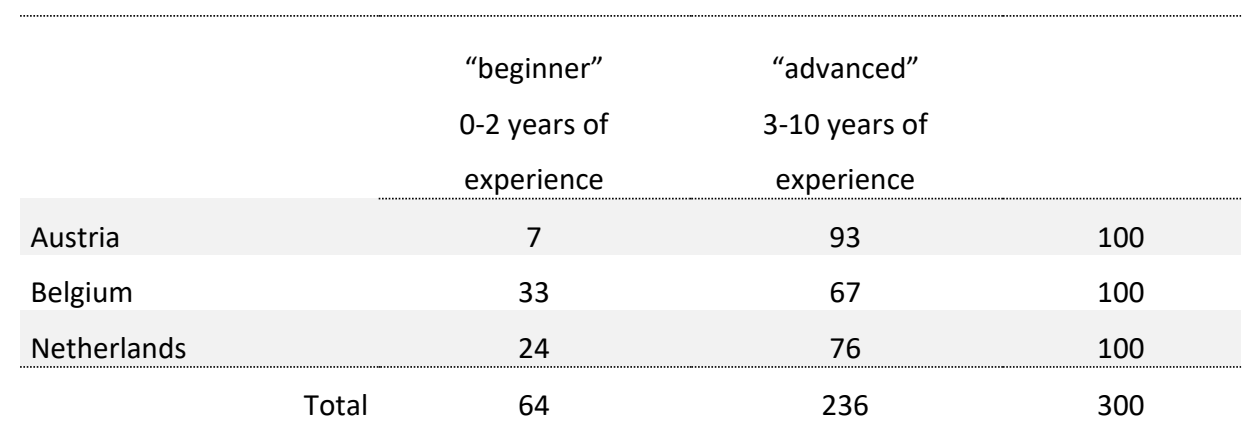


Two multilingual researchers from Austria and the Netherlands collected the job ads written in the English, Dutch, French, and German languages. The researchers translated Dutch, German, and French job requirements into English. The 300 collected job ads contained an average of about 12 requirements, resulting in a comprehensive list of about 3,600 requirements that were matched with the best possible solution extracted from scientific PSM job requirement literature (see: Appendix 9.2). However, most PSM job requirements listed in the advertisements did not resemble any requirements listed in the scientific PSM skills literature. In these cases, the requirements were matched with the 64 descriptions and about 180 underlying synonyms proposed by the HR competence model, as suggested by Heyse, Erpenbeck, and Max (2004), and Erpenbeck and Scharnhorst (2005).

Fereday and Muir-Cochrane (2006, p. 91) distinguish "deductive coding (derived from the philosophical framework) and inductive coding (themes emerging from participant's discussions)". Therefore, the conclusion is that initially, a deductive coding approach has been taken in this study. However, the listing of requirements in PSM job ads is more affluent than the PSM skills literature. Eventually, an inductive coding approach had to be followed.

Some items were discarded, for instance, language proficiency other than English. In the Netherlands, more than half of the ads required Dutch language proficiency. In Belgium, as a bilingual country, both languages were often demanded. Also, other languages were occasionally mentioned as Italian, Spanish, and Turkish. These were discarded. English as the lingua franca was considered to be 'foreign language proficiency'.

Moreover, some items were not discarded but could not match the PSM skills literature or the HR skills model. These were items as the willingness to travel and have a bachelor's or master's degree in business administration or engineering. Eventually, about 3,400 requirements were left over, which is 11.3 on average per job ad.

For this research, the model appeared to be suitable for methodologically and systematically categorising the business practice requirements. Since two researchers were involved, both mapped a blind random sample of 30 job ads, which the other researcher then tested this sample to establish the reliability of the mapping method. This test did not reveal significant differences in the mapping results; however, slight differences in interpretation were resolved.

Eventually, next, to compare the 57 different job requirements that were found in the 300 job ads from (1) Austria $(n=100)$, (2) Belgium $(n=100)$, and (3) the Netherlands $(n=100)$, that were mentioned in the 300 job advertisements the Pearson chi-square results were calculated for each of the requirements using SPSS, performing cross-tabulation analyses to analyse the differences and common grounds in the job requirements across the three countries. Based on insignificant and significant Pearson chi-square results, this resulted in a list of common grounds and a list of deviating 
requirements. De Veaux, Velleman, Bock, Vukov, and Wong (2005) note that chi-square analyses are applied for hypothesis testing. The larger the chi-square statistic, the more the observed counts do not match the expected. Hence, the chi-square test outcome is one-sided. In cases that the calculated statistic value shows insignificant $p$-values, the null hypothesis of equality is rejected.

Next, to compare the job requirements that deviated from one another, a cellwise residual contingency analysis was performed by squaring the individual adjusted residual Z-score per cell in the cross-tabulation. Subsequently, the associated $p$-values per country and the experience level for each deviating job requirement were calculated to determine the significant differences. They were divided by three, which represents the number of observations (in this case, the three observations per skill item in each of the three countries) per requirement as described by Beasley and Schumacker (1995) and García-Pérez and Núñez-Antón (2003). The alpha was set at $p<.05$, and for the Pearson chi-square analyses, the null hypothesis $\left(\mathrm{H}_{0}\right)$ was that an equal distribution of averages per skill in the three countries would be expected since the literature gives evidence that universal PSM skills profile would exist. The alternative hypothesis $\left(H_{A}\right)$ was the opposite, i.e. the unequal distribution of averages per skill in the three countries.

\subsection{Results: research questions and testing the proposition and hypotheses}

\subsubsection{RQ1 - Differences between the job advertisements leading to the rejection of the hypothesis that a 'universal purchaser' exists}

The entire list of 57 requirements derived as described above in the 300 job adverts is displayed in Appendix 9.11. As shown in Table 4.4, five common grounds were identified in the observed requirements. Employers in Austria, Belgium, and the Netherlands agreed that having PSM job experience and knowledge and having communication skills are essential, followed by being result-oriented, being a team player (team ability), and being accurate and precise.

The observed 57 job requirements were counted 3,395 times in the 300 job advertisements and the five common grounds requirements 671 times (i.e. 19.8 per cent of 3,395). One striking result of this research is that only 19.8 per cent of the total number of the observed requirements were shared; this means that 80.2 per cent of the observed requirements were unique (i.e. in 2,724 of the cases), and in the other 52 job requirements, they were not.

Based on these findings, RQ1 has to be answered negatively: In this study's sample, no evidence is found that a universal PSM job profile exists. The hypothesis, therefore, also has to be rejected. There is no cultural unity in this study's sample of 
European PSM job requirements, i.e., the compared countries' job ads have different content.

Based upon the PSM job requirements extracted from the scientific literature and based on the practitioners' standards and the GLOBE clustering results, (almost) no significant differences among Austrian, Belgian, and Dutch PSM job ads requirements would have been expected. However, about 80 per cent of the observed requirements were unique. A more detailed description of these cultural differences, which were the second research question's subject, appears in the following section.

Table 4.4 - Common grounds found in the 300 PSM job advertisements

\begin{tabular}{|c|c|c|c|}
\hline Job requirements & $\mathbf{N}$ & Pearson & Sign. \\
\hline PSM job experience and knowledge & 236 & 5.879 & .053 \\
\hline Communication skills: ability to communicate & 142 & 5.803 & .055 \\
\hline Result-orientated: result driven / entrepreneurial & 133 & 1.162 & .559 \\
\hline Team player - having team spirit: the ability to be on a team & 106 & 4.581 & .101 \\
\hline Accuracy and precision & 54 & 4.202 & .122 \\
\hline
\end{tabular}

\subsubsection{RQ 2 - Analysis of the differences in PSM job profiles in Austria, Belgium and the Netherlands}

The importance of one-fifth of the requirements collected from job advertisements was shared, while no agreement was found for about four-fifths of the requirements in the three countries. Firms in each country appear to share a specific country-specific PSM job profile. However, based on the fifteen most commonly mentioned requirements per country, a purchaser, in general, must have (1) English language proficiency and (2) PSM job experience and knowledge, be (3) computer literate, have at least a (4) bachelors' degree, be (5) result-oriented, (6) flexible, (7) persistent, (8) communicative, able to (9) negotiate, be a (10) team player, having (11) analytical skills, (12) discipline, (13 \& 14) business and industry experience and knowledge, and (15) devotedness. The job ad requirements for 'beginners' slightly deviated and asked explicitly for accuracy, independence and persuasiveness, instead of being persistent and devoted and having business experience. 
Austria

\begin{tabular}{lrrrr}
\hline English language proficiency (advanced) & 94 & 80.0 & 24.500 & .000 \\
Flexibility (beginners and advanced) & 71 & 34.7 & 87.451 & .000 \\
Negotiation skills (advanced) & 66 & 46.7 & 23.813 & .000 \\
Devotedness (beginners and advanced) & 65 & 22.7 & 153.613 & .000 \\
Persistence (beginners and advanced) & 62 & 39.0 & 35.057 & .000 \\
Discipline (beginners and advanced) & 61 & 27.0 & 88.382 & .000 \\
Computer literacy - general (advanced) & 56 & 44.0 & 10.065 & .007 \\
Technical education (BSc or MSc degree) (advanced) & 42 & 21.3 & 38.652 & .000 \\
Business and trade knowledge and experience & 36 & 27.3 & 10.606 & .005 \\
Willingness to travel (beginners and advanced) & 34 & 19.0 & 22.222 & .000 \\
Legal knowledge (advanced) & 32 & 19.0 & 20.403 & .000 \\
Responsibility (advanced) & 32 & 15.0 & 34.353 & .000 \\
Technical knowledge and experience (advanced) & 31 & 21.0 & 10.970 & .004 \\
Stress avoidance - handle stress (beginners/advanced) & 29 & 18.3 & 11.532 & .003
\end{tabular}

\section{Belgium}

\begin{tabular}{llrrr}
\hline Analytical skills (advanced) & 49 & 31.0 & 34.035 & .000 \\
Experience in the focal industry (advanced) & 39 & 29.0 & 7.382 & .025 \\
Customer-oriented (advanced) & 30 & 21.0 & 12.417 & .002 \\
Independence - sole-responsibility (advanced) & 27 & 15.7 & 29.720 & .000 \\
Creative, innovative and handling complexity skills & 26 & 18.7 & 34.953 & .000 \\
Problem solving skills (advanced) & 25 & 14.0 & 15.449 & .000 \\
Organisational skills (advanced) & 24 & 16.0 & 14.435 & .001
\end{tabular}

\section{The Netherlands}

$\begin{array}{lllrl}\text { Creative, innovative and handling complexity skills } & 30 & 18.7 & 34.953 & .000 \\ \text { Proactive - taking initiative (beginners and advanced) } & 28 & 19.7 & 8.144 & .017 \\ \text { Energy drive (advanced) } & 27 & 16.7 & 14.448 & .001 \\ \text { Pragmatic - hands-on mentality (advanced) } & 27 & 15.7 & 15.721 & .000 \\ \text { Persuasiveness (advanced) } & 23 & 13.7 & 15.312 & .000 \\ \text { Diplomacy, social manners and political sense } & 21 & 9.0 & 26.374 & .000\end{array}$

Note: from each country, 100 job ads were selected; $n$ stands for the absolute number a requirement is found at least once in a job ad. The mean represents the total number of the requirement in the entire set of 300 job ads divide by three (countries). The table differentiates between requirements found in job ads aimed at beginners and advanced. Behind every requirement is mentioned whether the significant difference is observed for either the 'beginners', the 'advanced' or both.

Statistically significant deviations between countries were noted, even though a widespread agreement on these features' general importance was observed (see: 
Table 4.5). For instance, English language proficiency is mentioned much less frequently in the Netherlands. Negotiation skills and legal knowledge are required more often in Austria. Table 4.5 illustrates whether the 'beginner' applicants, the 'advanced' applicants, or both are the cause of the significant difference. Indeed, the functional level is examined and could distinguish beginners with up to two years of experience from advanced applicants with three up to ten years of experience.

Most of the deviating requirements were identified in job ads that demanded advanced PSM personnel. However, the requests for flexibility, devotedness, persistence, discipline, and stress avoidance were found in the Austrian 'beginners' and 'advanced' ads but rarely appeared in the other countries, which also counts for 'responsibility' in 'advanced' job ads.

Belgian job ads referred more often to having experience in the focal industry, being independent and customer-oriented, and having analytical, organisational, and problem-solving skills. In the Netherlands, employers more often sought proactive, pragmatic, and energetic applicants and had persuasive abilities and a sense of diplomacy, social manners, and organisational-political sense.

Remarkably, employers in Austria often required applicants to have a technical degree and technical knowledge and experience, while this particular feature seemed to be of minor importance to employers in other countries. Here, a different industrial structure may play a role, hinting at Austria's much larger production focus than Belgian and Dutch industries' focus. Hence, to explain the identified differences, (1) structural and (2) cultural aspects are described in more detail in the next section.

\subsection{Discussion - Explaining the differences between job ads: structural and cultural reasons}

\subsubsection{Structurally explained differences: industry structure, associations and ethical composition}

The third research question referred to explanations for the identified differences between the job ads published in the three analysed countries. Firstly, the structural differences between Austria, Belgium, and the Netherlands will be described, potentially contributing to deviations among the PSM job profiles.

Belgium and the Netherlands are trading countries situated along the shore of the North Sea. Both possess significant sea harbours (notably Antwerp in Belgium and Rotterdam in the Netherlands), whereas Austria is an alpine country with an industrial, manufacturing-oriented tradition (CIA, 2019; OECD, 2020). The service sector and industry supply 70.7 and 28.0 per cent of the GDP in Austria, respectively, while the service sector covers 77.0 per cent, and the industry sector, 22.3 per cent, of the GDP in Belgium. In the Netherlands, these sectors represent 79.6 per cent and 18.8 per cent 
of the GDP, respectively (CIA, 2019). The Austrian industry continually adds more value to the Austrian economy, and the demand for technically (schooled) personnel could continually increase as a consequence. Austrian employers required applicants with technical knowledge and a technical degree more often. The contributions from the service sector and industry could explain this higher demand for technically educated personnel in Austria.

English language proficiency was mentioned in 80 per cent of the job ads in all three countries (see: Appendix 9.11, rank 1), but 94 per cent of the Austrian employers emphasised the English-language proficiency requirement. The English language proficiency index rate in all three countries is "very high". However, Austria's was lower than that in the Netherlands but higher than that in Belgium (EF EPI, 2020, p. 6). Belgium, however, is a bilingual country, and Belgian employers required either (mostly) bilingual proficiency in French and Dutch (Flemish) or (in some cases only) English proficiency. In the Netherlands, employers required language proficiency in English in only 56 per cent of the ads.

The Austrian demand for 'willingness to travel' (see: Table 4.2 and Appendix 9.11) might be explained by the fact that Austria's surface is twice that of the Netherlands and 2.5 times that of Belgium.

\subsubsection{Culturally explained deviations: Masculinity vs Femininity}

The sample countries were classified into three European cultural clusters as described by Kale (1995) (i.e. "Anglo-Saxon and Germanics", "Roman languages", and "Scandinavian" clusters), but placed in one cluster in the GLOBE project (i.e. "Germanic Europe"). Analysing the differences between the three countries (which represent their respective cultural clusters, according to Kale), Austria's score of 'Masculinity' in the Hofstede model is much higher than the Belgian and Dutch scores (see: Table 4.6).

Table 4.6 - Hofstede's Cultural Dimension for Austria, Belgium and the Netherlands on a scale from 0 to 100 (Hofstede et al., 2010)

\begin{tabular}{|c|c|c|c|}
\hline & Austria & Belgium & Netherlands \\
\hline Power distance & 11 & 65 & 38 \\
\hline Individualism & 55 & 75 & 80 \\
\hline Masculinity & 79 & 54 & 14 \\
\hline Uncertainty avoidance & 70 & 94 & 53 \\
\hline
\end{tabular}

Hofstede's Dimension of Masculinity-Femininity is measured on a continuous scale that is "related to emotional gender roles" (Hofstede, 2006, p. 883). A high level in this dimension represents a 'masculine' culture, and a lower-level a 'feminine' 
culture. Hofstede described the highly 'masculine' and target-oriented elements in detail, which would significantly characterise the Austrian PSM job ad requirements. Regarding the Austrian requirements, and especially the personal attributes, the distinct 'masculine' requirements that were identified include persistence, flexibility, assertiveness/poise and the most apparent target-oriented skill, 'being result-oriented', as a highly ranked shared skill. Based on Hofstede (2001), the assumption is that these requirements would form the 'masculine' construct from the complete set of requirements (see: Table 4.7).

On the other side, the Netherlands ranks low in 'masculinity' and consequently ranks high in 'femininity' (see: Table 4.6). In feminine societies, the dominant values are interpersonal relation oriented: "not showing off, putting relationships with people before money, caring about the quality of life and the preservation of the environment, helping others, in particular the weak, and believing that small is beautiful" (Hofstede, 1983a, p. 46). Regarding the Dutch requirements, and especially the personal attributes, the distinct 'feminine' requirements identified include building relations, networking skills, diplomacy, social manners and political sensitivity, open communication, openness and being accessible (see: Table 4.8).

Table 4.7 - Requirements - 'masculine construct'

\begin{tabular}{|c|c|c|c|}
\hline & Austria & Belgium & Netherlands \\
\hline Result-orientated: result driven / entrepreneurial & 40 & 47 & 46 \\
\hline Persistence & 62 & 23 & 32 \\
\hline Flexibility & 71 & 16 & 17 \\
\hline Assertiveness/poise & 18 & 11 & 2 \\
\hline & 191 & 97 & 97 \\
\hline
\end{tabular}

Table 4.8 - Feminine Requirements (Masculinity-Femininity dimension)

\begin{tabular}{|c|c|c|c|}
\hline & Austria & Belgium & Netherlands \\
\hline Building Relations/Networking Skills & 0 & 16 & 18 \\
\hline Diplomacy, social manners and political sensitivity & 3 & 3 & 21 \\
\hline Open communication/openness/accessible & 2 & 4 & 13 \\
\hline & 5 & 23 & 52 \\
\hline
\end{tabular}

As shown in Table 4.7, the sum of Austria's frequencies is 191; for Belgium, 97; and for the Netherlands, 97. The scores for these four requirements are about two times higher for Austria compared with Belgium or the Netherlands. Belgium and the Netherlands have equal scores, both of which are significantly lower than the Austrian score. Contrary, as displayed in Table 4.8, the 'femininity' scores for Austria, Belgium and the Netherlands are 5, 23 and 52. The conditions seem to be met, and the conclusion is that (1) Austrian PSM job ads contain significantly more 'masculine' 
elements, such as target-oriented requirements and professional effectiveness skills, and that (2) Dutch job ads contain more 'feminine' elements.

\subsubsection{Culturally explained deviations: Individualism vs Collectivism}

Unlike the scores regarding Masculinity-Femininity, Austria's score on Individualism-Collectivism in the Hofstede model was lower than the Belgian and Dutch scores (see: Table 4.5). Individualism-Collectivism is also measured on a continuous scale and is "related to the problem of interpersonal ties" (Hofstede, 2006, p. 883). A high level in this dimension represents an 'individualistic' culture, and a lower level a 'collectivistic'. Interestingly, the Belgian and Dutch ads contained significantly more requirements related to 'solely responsible/independence'. It is an obviously 'individualistic' feature, and the Belgian and Dutch sets contained significantly more requirements regarding 'creativity/creative talent', the closely related 'innovation propensity', and the 'ability to handle complex situations'; these results indicate that Belgian and Dutch employers assume that handling complex situations and being innovative requires creative ability. For this reason, these requirements are clustered.

Creativity is strongly associated with individualistic cultures. The international research of Rinne, Steel, and Fairweather (2013) showed that cultures with higher 'individualism' rates in the Hofstede model were significantly more frequently associated with a construct of 'creativity' variables. Hofstede's finding that Belgium and the Netherlands have higher levels of 'individualism' seems to support this. The score on the Individualism-Collectivism dimension in the Netherlands is even higher than that in Belgium (see: Table 4.6), which might help explain the Dutch higher score in terms of being 'proactive/taking the initiative' (Hofstede \& Minkov, 2010; Rinne et al., 2013; Saad, Cleveland, \& Ho, 2015; Zha, Walczyk, Griffith-Ross, Tobacyk, \& Walczyk, 2006).

\section{Table 4.9 - Individualistic Requirements (Individualism-Collectivism Dimension)}

\begin{tabular}{lccc} 
& Austria & Belgium & Netherlands \\
\hline Proactive - taking initiative & 19 & 12 & 28 \\
Strategic and holistic thinking & 16 & 14 & 22 \\
Creativity, innovative and complexity skills & 0 & 26 & 30 \\
Independence - sole-responsibility & 0 & 27 & 20 \\
Persuasiveness & 4 & 14 & 23 \\
Will to learn and curiosity & 2 & 11 & 7 \\
\hline
\end{tabular}

Examining the overall list of Dutch and Belgian requirements, especially personal attributes, the distinctly 'individualistic' requirements as having 'independence and sole responsibility' and 'proactive - taking the initiative' can be 
identified. Assuming that the construct of requirements was related to 'individualistic' (and 'non-collectivistic') skills, i.e. those directed toward self-development and creative skills, this construct consists of: having sole responsibility and independence; having creative talent; being innovative; being able to handle complex situations and displaying the will to learn and being curious.

Table 4.9 shows that Belgium (104) and the Netherlands (130) gained significantly higher scores than Austria (41). The online PSM job ads posted in Belgium and the Netherlands contained significantly more individualistic, self-developmentdirected and creative skills and competences than those posted online in Austria. The score in Austria is about 30 to 40 per cent of those in Belgium and the Netherlands.

\subsubsection{Culturally explained deviations: Uncertainty Avoidance}

Hofstede (1980b, p. 55) stated that "for strong Uncertainty Avoidance countries like Austria, working hard is caused by an inner urge - it is a way of relieving stress". "Strong Uncertainty Avoidance" is, according to Hofstede (2006, p. 883), "related to the problem of dealing with the unknown and unfamiliar" or "to the level of stress in a society in the face of an unknown future" (Hofstede, 2011, p. 8) and is associated with experiencing higher levels of anxiety and stress, and "there is an inner urge to work hard" (Hofstede, 1980b, p. 47). Moreover, countries with high levels of Uncertainty Avoidance display "Intolerance of deviant persons and ideas: what is different is dangerous" (Hofstede, 2011, p. 10). "Uncertainty avoiding cultures try to minimize the possibility of such situations by strict behavioral codes, laws and rules, disapproval of deviant opinions" (Hofstede, 2011, p. 10). The higher scores related to Austria on requirements like devotedness, discipline, responsibility and the ability to handle stress are in line with that (see: Table 4.10). The Austrian scores are six times higher than those of Belgium and the Netherlands. Notably, the high Austrian scores are solely responsible for ranking items as devotedness and discipline in the top-15 of the 57 identified skills (see: Appendix 9.2).

Table 4.10 - Uncertainty Avoidance Requirements

\begin{tabular}{|c|c|c|c|}
\hline & Austria & Belgium & Netherlands \\
\hline Devotedness & 65 & 0 & 3 \\
\hline Discipline & 61 & 8 & 12 \\
\hline Responsibility & 32 & 8 & 5 \\
\hline Stress avoidance: the ability to handle stress & 29 & 12 & 14 \\
\hline & 187 & 28 & 34 \\
\hline
\end{tabular}

There is enough evidence to reject the hypothesis of unity derived from the GLOBE model. This research could explain deviations on three of the four Cultural 
Dimensions of Hofstede. The fourth dimension could not be identified: Power Distance which is "related to the different solutions to the basic problem of human inequality" (Hofstede, 2011, p. 10). "Power Distance has been defined as the extent to which the less powerful members of organizations and institutions (...) accept and expect that power is distributed unequally. It represents inequality (more versus less) but defined from below, not from above" (Hofstede, 2011, p. 10). Uncertainty Avoidance in the workplace is characterised by the hierarchy that "reflects existential inequality between higher and lower levels" and a "wide salary range"; "centralisation"; "more supervisory personnel"; reliance on "superiors and on formal rules" (Hofstede et al., 2010, p. 76). Clues that Power Distance influenced job requirements were not found. Power Distance might very well be experienced in practice, but not in wordings of job ads.

The conclusion is that the Hofstede model can be more efficiently used to make forecasts and explain the three countries' cultural differences (Austria, Belgium, and the Netherlands). Herewith the third research question is answered, explaining how differences in PSM job requirements may be due to cultural differences. These culturally explained differences are reflected via personal skills and mostly intrapersonal traits.

\subsubsection{Scientific contributions and managerial implications of this research: taking culture seriously in PSM education and research}

This research provides an up-to-date list of requirements found in European PSM job ads and places these in cultural contexts, which enriches the scientific literature. These findings also contribute in practical terms to the work of practitioners involved in the design of PSM curricula in higher education and company training sessions and the work of those involved in HR management in the field of PSM, individual PSM practitioners, and students.

The study findings contribute to the comparative management literature in that this is the first study to compare the needs of employers in the field of PSM and reveal cultural differences in European PSM job requirements. Previous studies of PSM skills have been conducted only in single countries and have rarely focused purely on purchasing. Instead, previous researchers have more often broadly tried to address supply chain management in general, including logistics.

Regarding the 'fight between the elephants' (P. B. Smith, 2006), the findings support the application of Hofstede's cultural dimensions; these could be effectively used to explain the observed differences, which would not have been possible if the GLOBE model had been used. Also, the Hofstede dimensions seem to be relatively stable over time and are still currently applicable. 
From a methodological perspective, these research findings support the idea that it is essential to distinguish between cultural and structural explanations when examining observed differences between the countries. As in the Dutch case, the observed emphasis on creative requirements, compared to the emphasis on discipline and devotedness in the Austrian case, can be more clearly explained by cultural differences. Meanwhile, the differing emphasis on technical vs non-technical education may explain structural differences that reflect differences in the production and service sectors. Comparative management scholars are encouraged to distinguish between cultural and structural factors that may explain such differences. These findings suggest that country indicators, such as GDP or education levels, need to be considered in comparative management studies (Banai, 2010).

Concerning PSM competences research, this study contributes to the field in that it shows that what generally has been considered one homogenous phenomenon is a series of differentiated phenomena. Herewith the question of why the skills discussed in the literature only partially overlap may also be explained (see: Table 4.2), as do those requested in the analysed job ads (see: Appendix 9.2). Based on the job ads analysis, not a single, ideal, universal purchaser profile could be created. Instead, in each of the analysed countries, employers sought applicants with different profiles.

It is striking that only nine of the relevant 33 articles in the literature review (briefly) detected the need for cross-cultural awareness but overlooked that cultural differences might exist in PSM job requirements between countries. These findings alert future PSM competences researchers that they need to address the comparative dimensions of their findings clearly; these will refer - at least to some extent - to their national cultural and institutional environments and may limit the generalisability of their findings. By considering these dimensions, PSM competences research will gain more applicability and practical relevance. Many practitioners may have already noticed that the current PSM competences research findings do not match their daily experiences because they work in different cultural environments.

\subsection{Limitations and further research: representability of job ads}

In the present study, the compared countries appear to be relatively similar at first glance and have also been classified by some comparative management scholars. Still, substantial differences could be demonstrated. Therefore, it might be expected that such differences are even more pronounced among more distant countries. Future PSM (competences) researchers would benefit from a) acknowledging and discussing how the dimensions considered are culturally embedded and b) purposefully shedding light on the cultural differences that shape purchasing practices in different countries while conducting comparative management studies. 
From a content perspective, this study contributes to the field in that it offers some of the first insights into cultural differences in purchaser's requirements, which, however, raises further questions and calls for more detailed research. In a 'feminine' culture, such as that in the Netherlands, employers are looking for independent purchasers with creative skills. In countries with a more 'masculine' culture, such as Austria, employers emphasised assertiveness and the will to achieve targeted results. On the one hand, it might be interesting to discover how a purchaser recruited by a multinational firm in one of these countries performs when transferred to another country.

There might also be a company-internal dimension involved in the cultural differences observed. For instance, a purchaser who is more prone to use mediation to achieve goals may better be suited to promoting cross-functional collaboration in the firm. These collaborations were expected to be found more often in the Netherlands than in Austria and their respective cultural clusters. A more assertive Austrian purchaser, on the other hand, may place a stronger emphasis on procurement objectives, such as savings.

At the same time, an external dimension should also be considered: In a global sourcing context, how do suppliers react when a 'mediating purchaser' from one company contacts them and, simultaneously, a more 'assertive purchaser' representing another buying organisation in another country competes for the supplier's resource allocation? While some research has been conducted on factors that influence the supplier's prime resource allocation and how preferred customers are chosen (Pulles, Veldman, \& Schiele, 2016), little attention has been directed towards how cultural variables mediate these factors. An exception is Kibbeling et al. (2009, p. 354). They argue that the purchasers' cultural background affects the "perceptions of trust, commitment and dependence in supplier relationships" and found inconsistencies that indicate that the corporate culture might also be an essential factor for explaining differences in buyer-supplier relationships.

Further, job ads as an object of analysis also resulted in some potential study limitations. Using job ads as a source of cross-cultural information on the firms' requirements relies on three assumptions: the assumption is that (1) firms purposefully formulate the ads, rather than merely copying and pasting past ads, (2) employers will be able to recruit individuals who have the required abilities, and (3) once they are active in their job, the recruited purchasers will act accordingly and continue to do so for several years, rather than eventually displaying homogenous behaviour once they are confronted with international sourcing processes.

The comparison of job ads only enabled the detection of the differences in employers' explicitly expressed intentions to recruit purchasers. It was not possible to determine whether candidates who applied for the positions fulfilled the desired job requirements. In the future, a primary data analysis based on survey and interview 
responses could be taken as a preferable approach to analyse PSM requirements. Further research may also be conducted to gather evidence that the culturally expressed intention eventually translates into sustainable, different behaviour during the job.

Another limitation of the job ads method influences the generalisability of the findings: The collected job ads were overwhelmingly aimed toward (younger) PSM professionals with two and up to ten years of working experience. According to the job ads' language, the ideal candidate seemed to have about five years of purchasing job experience. Hence, the databases searched for this research did not typically contain information on CPOs, which might have different (and possibly more homogeneous) requirements.

The results of the analyses of secondary data cited in the literature, such as the requirements mentioned in online job advertisements, may be considered an essential source of highly up-to-date and available information. These results provide readers with a firm understanding of what employers require from employees (e.g. Arcodia \& Barker, 2003; Mathews \& Redman, 2001; Rafaeli \& Oliver, 1998; Shou \& Wang, 2015). Nevertheless, the concise nature of the job advertisement texts sets certain limitations regarding their interpretation. In their demands, the employers listed 12 requirements on average per job advertisement, some of which were 'container terms', such as 'PSM knowledge'. Job ads do not usually specifically describe the exact type of PSM knowledge required. For this reason, a different mapping method, probably involving primary data collection, would need to be applied to examine this data in more depth.

As mentioned, another limitation refers to the object of the analysis. If firms express that they are searching for a purchaser with a specific profile, this does not necessarily mean that an applicant who fits this profile will represent the most empirically successful professional. An isomorphic process might be taking place, whereby HR agents are copying text from previous job advertisements issued by their own company or by peer companies and, in this way, replicating past profiles. Such profiles may no longer be current and applicable to their particular case. The national deviations could also result from such copy-and-paste processes instead of the result of conscious decisions.

Moreover, it was impossible to associate all requirements to the most prominent and elaborate taxonomies as presented in the PSM skills literature (e.g. Bals et al., 2019; Giunipero \& Pearcy, 2000; Schiele, 2007; Tassabehji \& Moorhouse, 2008). Of the 57 requirements, only 27 could be matched. The other 30 were mapped with an HR skills taxonomy (Erpenbeck \& Scharnhorst, 2005; Heyse et al., 2004), and six were newly introduced to the literature. Further research could provide more extensive, validated PSM skills taxonomies.

Further research might need to be conducted to test whether the profiles of successful professionals with specific job experience levels still vary significantly from 
one another, for instance, by conducting surveys. For instance, the more 'feminine' Dutch approach in which purchasers with diplomatic skills are sought may, in practice, not be effective. After spending a few years on the job, only the most assertive purchasers will remain, i.e. those who resemble the type described in the Austrian job ads more closely. It would be interesting to follow the personal development of individual purchasers over time.

On the other hand, this research seemed to replicate and confirm the Hofstede model's usefulness more than the GLOBE model. A significantly higher number of 'masculine' elements are identified in Austrian PSM job ad requirements and a significantly higher number of individualistic elements in Belgian and Dutch PSM job ad requirements. In other words, the analysis of job ads shows that a universal or standard European PSM professional does not exist, at least not from the recruiters' viewpoints. Nevertheless, the study results have to be treated cautiously. Tung and Verbeke (2010, p. 1259) warned, "(...) researchers should never formulate strong conclusions about the impact of cultural dimensions on managerial choice or economic performance based on samples that include only one or a few countries". A more extensive set of samples of PSM job ad requirements from more European countries could be collected to test whether the cultural observations made in this study can be replicated in the field by researching PSM job ad requirements.

Moreover, few of the 52 dissimilarities listed could be explained culturally or structurally. Differences could only be explained by applying Hofstede's cultural dimensions of 'masculinity' and 'individualism'. The influences of differences based on the dimensions 'power distance' and 'uncertainty avoidance' could not be detected.

Hofstede's work has been the subject of serious debate in the scientific literature (Baskerville, 2003; McSweeney, 2002a, 2002b). Authors have questioned whether the Hofstede cultural dimensions test culture rather than personal traits, as Baskerville (2003) stated in her article entitled Hofstede never studied culture. The cultural differences that could be explained in this study are based on personal traits and findings in line with Baskerville's (2003). This study refers to the calculations of Kale (1995), which were based upon the cultural values of Hofstede. However, it is doubtful whether the cultural values of Hofstede can be the subject of further calculations (Tung \& Verbeke, 2010). Furthermore, the question is whether corporate culture might not play a role, as mentioned earlier (i.e. Kibbeling et al., 2009). Dedicated research would need to be carried out in which job ads from multinational companies were compared, attributing the identified differences to either the national culture or the corporate culture of a group of firms.

One of the main concerns regarding the use of Hofstede's model was whether the cultural differences identified among the countries (initially calculated by Hofstede, 1980a) based on surveys made five decades ago (i.e. 1967 to 1971) were still valid in the $21^{\text {st }}$ century. However, Hofstede's Culture's Consequences (Hofstede, 1980b) is still 
among the 25 most frequently cited books in the social sciences (Beugelsdijk, Kostova, \& Roth, 2017). Also, the findings of this study, based on an analysis of the literature, practitioners' standards, and information collected from job ads in Austria, Belgium, and the Netherlands, show that Hofstede's model could still be used to at least partly explain the cultural differences that were identified. In contrast, other models fail to predict such differences.

Regarding the empirical deployment of cultural models, Shi and Wang (2011) underline that scholars have been too focused on values surveys, whereas theories for understanding the connections between cultures are missing. They recommend future research focused on developing theories and focusing on applying Hofstede's and the GLOBE models across different cultures and diverse research fields. They advise using a quantitative method to see which cultural dimensions are vital factors in a crosscultural relationship. 


\section{Chapter 5}

\section{The Purchaser for Innovation}

Innovation, Management and Soft Skills and the Importance of Organisational Support 


\section{THE PURCHASER FOR INNOVATION INNOVATION, MANAGEMENT AND SOFT SKILLS AND THE IMPORTANCE OF ORGANISATIONAL SUPPORT}

\subsection{Introduction - skills and organisational influences on innovation sourcing success}

Innovation is one of the most important competitive priorities in business (e.g. Hauser et al., 2006; Luzzini \& Ronchi, 2011; Sorescu, 2017). It is accomplished by a process comprising "idea generation, idea elaboration, idea championing, and idea implementation" (Perry-Smith \& Mannucci, 2017, p. 53). Traditionally, a more mechanistic picture of innovation, carried out entirely in a single firm's R\&D laboratory, was the dominant view (Freeman \& Soete, 1997). In recent years, however, two important changes in perspective have been initiated and started to spread: radial or disruptive innovation development is seen as a social process and an open process involving not a single lab but on several organisations' collaboration (Sivasubramaniam et al., 2012). Innovation sourcing requires "learning orientation, teamwork, and decentralization or autonomy in decision-making" because "in learning organizations, decentralized organizational, cultures lead to the adaptability required for discontinuous innovation" (Gonzalez-Padron et al., 2008, p. 69).

The literature differentiates between incremental and radical or disruptive innovations. Simultaneously, companies initially were aligned to innovating wellfunctioning recipes, and they are currently increasingly dealing with discontinuous innovations (e.g. Nambisan et al., 2017; O'Connor \& McDermott, 2004; Picaud-Bello et al., 2019). As stated in the introductory chapter, innovations are considered to be "discontinuous" in this thesis. Discontinuous innovations are "the regenerative dynamic capability that allows the firm to move away from previous change practices towards new dynamic capabilities" (Picaud-Bello et al., 2019, p. 3).

Best practices for discontinuous innovation management are to "search for completely new technologies and sources of knowledge and ideas outside existing supply relationships and supply chains" (Johnsen et al., 2012, p. 12); "to look beyond 
immediate requirements and anticipate factors that could provide future competitive advantage" (Legenvre \& Gualandris, 2018, p. 97); and to move "beyond the zone of comfort" (Phillips et al., 2006, p. 15). In this context, PSM teams "need to explore external opportunities beyond first-tier suppliers to access or co-develop innovative solutions" (Legenvre \& Gualandris, 2018, p. 97).

As a consequence, competence levels of human innovation actors come into focus of management attention. For a corporate function such as purchasing and supply management (PSM), which was not in the centre of attention in the past but has gained an increasing role in the new inter-organisational innovation process, challenges arise. However, it remains unclear which particular competences are needed for innovation sourcing, i.e. innovation co-creation in a buyers-supplier relation and innovation implementation.

According to Delamare-Le Deist and Winterton (2005), competence construct items include knowledge, professional skills, interpersonal skills, intrapersonal traits, behaviours and attitudes. How would the purchaser successfully bring innovations from the supply base into the firm and organise their co-development differ from a purchaser who fails to comply with this increasingly important target? The literature has so far failed to provide substantiated guidelines on how to nurture innovation purchasers. This research aims to close this gap by presenting the results of a large-scale survey on innovation skills for purchasers.

Human creativity and inventiveness facilitate idea development for innovations (Baer, 2012; O'Connor \& Veryzer, 2001). Whereas human creativity in the past was considered mainly an individual, innate trait, "the notion that creativity is a social process has increasingly gained prominence" (Perry-Smith \& Mannucci, 2017, p. 53). The creative process is interpreted as " $a$ social endeavor" of innovation teams (Kiratli et al., 2016, p. 202). The social endeavour of developing innovations places purchasers in the role of boundary spanners. Sivasubramaniam et al. (2012, p. 803) underline that for new product development (NPD), "effective boundary spanning within and outside the organization" is necessary to reach success.

The innovation sourcing function as a boundary spanner in the buyer-supplier relation has a growing strategic role in a company's innovation capability and competitiveness (Johnsen et al., 2012; Legenvre \& Gualandris, 2018; Luzzini \& Ronchi, 2011; Schiele, 2012). Given the importance of the human aspect in innovation management, it is not surprising that not only the success of innovation generation but also the success of innovation sourcing is considered to be primarily dependent on individual PSM professionals and their competences, i.e. knowledge, professional and interpersonal skills together with the character traits and attitudes needed for effective performance (Campion et al., 2011; Delamare-Le Deist \& Winterton, 2005; Feisel et al., 2011). The PSM function needs competent personnel to ensure access to the innovative 
resources of suppliers, to arrange early supplier involvement to co-create innovations and to implement those innovations in the own product or process (e.g. Bals et al., 2019; Giunipero \& Pearcy, 2000; Hauser et al., 2006; Johnsen et al., 2012; Knight et al., 2014; Legenvre \& Gualandris, 2018; Luzzini et al., 2015; Schiele, 2012; Slowinski et al., 2009).

A systematic keyword search in Google Scholar and Scopus revealed a set of 33 relevant studies on purchasing skills and competences published between 1987 and 2020 (see: Appendices 9.2 and 9.3). Remarkably, a listing of distinct innovation sourcing competences is absent in the literature, despite the assumed importance. It leads, specifically, to the following research questions for the present enquiry:

(RQ1a) Which individual competences does the purchaser require to achieve innovation sourcing success? And, derived from that:

(RQ1b) How critical are these particular individual competences for leading to innovation sourcing success? Which are the most pivotal skills of this kind?

Advanced individual PSM competence levels are essential but are not sufficient on their own for a successful PSM function accessing the innovation power of their supply base. Cousins et al. (2006) and Tassabehji and Moorhouse (2008) proposed that PSM effectiveness or success is reached by combining higher individual competence levels with increased organisational support and internal recognition for the PSM function. It remains unclear, however, if this hypothesis holds true or whether individual PSM professionals are more successful because of an increased individual competence level, or because of a higher degree of organisational support, or possibly as a result of the complementary and interacting effect from both of these together (e.g. Cousins et al., 2006; Feisel et al., 2011; Johnsen et al., 2012; Luzzini et al., 2015; Slowinski et al., 2009; Tassabehji \& Moorhouse, 2008). The present research includes the following second question to shed light on this area of conflict:

(RQ2) Are individual competences and supportive organisational structures complementary or substitutive to each other? l.e. can a lack of individual competences in a purchaser be substituted by organisational frameworks and vice-versa?

A further question of substantial practical relevance is: should firms, striving to increase their innovative capability, invest more in training their purchasers or would it be better to change the organisational setting, for example, by introducing targets and awarding successful purchasers? The latter case would hold if, in effect, no specific innovation PSM skills existed.

This study builds on an extensive database established in a European project for analysing the skills and success of 581 purchasers to answer these research questions. This research concentrates on quantifying the competence levels of 
innovation sourcing PSM professionals, their perception of support and recognition and the perceived success levels in innovation sourcing.

In its empirical content, this study contributes to answering RQ1a by presenting an empirically backed skills profile consisting of 17 supportive skills. This skills list can be used to select purchasers or train them to achieve a better innovation contribution. Interestingly, personal soft skills and special innovation tool skills are required, and management skills such as change management and project management. One proposition out of this finding is that a competent innovation purchaser would qualify as the future chief purchasing officer (CPO).

Further, the study contributes by answering RQ1b. Stepwise regression and necessary condition analysis (NCA) are performed to differentiate among the 17 skills, identifying those necessary for all successful innovation purchasers and those on top of increasing innovation success beyond the industry standard. Finally, in response to RQ2, a polynomial regression with response surface analysis based on composite-based structural equation modelling is performed, demonstrating the complementary character of organisational backing and individual skills.

This chapter is organised as follows: the following section describes the literature on innovation sourcing success, its organisational conditions, and the interaction between both. The expected outcomes of this research are then hypothesised based on the literature. The subsequent method section elaborates on the outcomes of necessary condition analysis (NCA), followed by an elaboration of the preconditions for polynomial regression with response surface analysis and the calculation towards a three-dimensional plot. The results are presented in the fourth section, followed by the discussion and the conclusion.

\subsection{Literature - Absence of innovation sourcing competences in the scientific literature}

\subsubsection{Innovation sourcing success and organisational factors}

There is a vast body of literature on creativity and innovativeness that underline the importance of both novel and useful idea generation (Perry-Smith \& Mannucci, 2017). Hence, "innovation can be conceptualized as encompassing two different activities: the development of novel, useful ideas and their implementation" (Baer, 2012, p. 1102). In innovation sourcing, PSM's pivotal role in innovation creation occurs typically during the process of NPD. Parts of this innovation process are "idea generation, idea screening, concept testing, development, and launch" (Roy et al., 2004, p. 62) or generating, elaborating, championing and implementing ideas (Perry-Smith \& Mannucci, 2017). Innovation purchasers benefit from a "learning orientation, 
teamwork, and decentralization or autonomy in decision-making" because "in learning organizations, decentralized organizational, cultures lead to the adaptability required for discontinuous innovation" (Gonzalez-Padron et al., 2008, p. 69). Innovation focused companies need to concentrate on "strategic sourcing (i.e. actively scout and maintain the supply base)," but also need to "promote supplier collaboration (i.e. supplier development as well as involvement in the processes of the buyer company)" (Luzzini et al., 2015, p. 115).

A common understanding exists in the literature of the shift from incremental to radical or disruptive innovations in recent decades. Simultaneously, companies earlier were aligned to innovating well-functioning recipes, and they are currently dealing with discontinuous innovations (e.g. Nambisan et al., 2017; O'Connor \& McDermott, 2004; Picaud-Bello et al., 2019). The innovation sourcing literature distinguishes between different success practices in discontinuous innovation management, for instance, to "search for completely new technologies and sources of knowledge and ideas outside existing supply relationships and supply chains" (Johnsen et al., 2012, p. 12); "to look beyond immediate requirements and anticipate factors that could provide future competitive advantage" (Legenvre \& Gualandris, 2018, p. 97); and to move "beyond the zone of comfort" (Phillips et al., 2006, p. 15). In this context, PSM teams "need to explore external opportunities beyond first-tier suppliers to access or codevelop innovative solutions" (Legenvre \& Gualandris, 2018, p. 97).

Innovators require a set of traits consisting of the ability to deal with risks and uncertainty; handling complex information; having deep expertise in at least one field, and having a level of maturity in intelligence, which is result-driven, passionate, empathic and collaborative (Brenton \& Levin, 2012). To effectively co-create innovations with suppliers, PSM teams need to communicate and cooperate internally "closely with R\&D, marketing, operations, and clients" and externally "to involve suppliers in innovation projects that consistently deliver results over time" (Legenvre \& Gualandris, 2018, p. 97). Future PSM is expected to "work on a more interdisciplinary level, developing more technical skills, and participating more actively in product development processes" (Von der Gracht et al., 2016, p. 46). Key is early involvement of the PSM function in "the sourcing process, before any specific project has even been formally started" (Johnsen et al., 2012, p. 13).

In cooperation with internal business partners, purchasers need to grasp the broader ecosystem, increase their business intelligence level, and "engage effectively with outsiders and new players" (Legenvre \& Gualandris, 2018, p. 97). "The purchasing function has clearly emerged as a pivotal interface and process owner of collaborative buyer-supplier relationships" (Luzzini et al., 2015, p. 115). Johnsen et al. (2012, p. 13) provide the advice "develop short-term supplier relationships, limited to the duration of innovation project" and "manage these relationships as important but not (initially) strategic partnerships". 
A further challenge for PSM is to balance short-term cost advantages with longterm innovation advantages. Johnsen et al. $(2012$, p. 13) state that purchasers need to assess suppliers principally on their innovative capabilities rather than purely looking at a low cost. Legenvre and Gualandris (2018, p. 97) add that the balance between costs and innovations holds that purchasers "need to look beyond risks, cost, and product development to offer further competitive advantages". Schiele (2010, p. 149) emphasises the importance of a long-term scope on the cost-innovation balance by pointing on PSM's dual role "to support the process of innovation while maintaining cost and integration responsibility for the entire product life cycle for the entire firm".

The interaction effect of individual PSM competences and organisational conditions that would lead to (innovation) sourcing success will be further elaborated in the following section.

\subsubsection{Literature on PSM competences lacking a set of innovation skills}

In Appendix 9.2, the set of 33 relevant studies on PSM skills and competences published between 1987 and 2020 are presented. Appendix 9.2 shows the result of this literature review. The most frequently mentioned competences in the 33 studies set are listed.

Based upon Fawcett and Rutner (2014, p. 180), who stated that the PSM practices in firms have "evolved dramatically over the past generation," the data were subjected to further statistical analyses and was divided into ' $20^{\text {th }}$ century' (1987-2001; $n=16)$ and ' $21^{\text {st }}$ century' $(2003-2020 ; n=17)$ sub-samples. Remarkably, the $t$-test did not reveal significant differences among the specific requirements, a circumstance that may indicate a certain stagnation in academic development.

Referring to Appendix 9.2, the scientific reports for the longitudinal research of the Center of Advanced Purchasing Studies (CAPS) in both 1993 and 2000 provided a solid foundation for the understanding of current PSM competences (Giunipero, 2000; Kolchin \& Giunipero, 1993) on which the scientific literature has built further. In the following sections, a concise overview is given of the main developments in PSM competences.

Based upon both CAPS reports, Giunipero and Pearcy (2000) propose skills required from a world-class purchaser and distinguish process management skills ("organization/time management, tactfulness, written communication, problemsolving, conflict resolution"); negotiation skills ("negotiation, customer focus, influencing and persuasion, understanding business conditions"); behavioural skills ("interpersonal communication, risk-taking/entrepreneurship, creativity, inquisitiveness"); team skills ("teamwork, leadership, salesmanship, managing change 
and internal customers"); quantitative skills ("computational, technical, blueprint reading, specification development"); decision-making skills ("computer literacy, ability to make decisions"); and strategic skills ("strategic thinking, supply base research, structuring supplier relationships, technology planning, supplier cost targeting") (Giunipero \& Pearcy, 2000, p. 11).

Giunipero et al. (2005, p. 609) then continued this train of thought by defining the overlap between entrepreneurial and PSM competences, an overlap which is referred to as 'flexibility skills' ("planning, influencing, internal motivation, creativity, risk management, decision-making, interpersonal communication"). In 2006, Giunipero et al. (2006, p. 835) speculated that the buyer's traditional operational role would be "rapidly disappearing" in the future, that purchasers will have strategic roles instead. Critical strategic PSM competences, as proclaimed in 2006, are team-building skills ("leadership, decision-making, influencing, and compromising"); strategic planning skills ("project scoping, goal-setting, and execution"); communication skills ("presentation, public speaking, listening and writing"); technical skills ("web-enabled research and sourcing analysis"); and broader financial skills ("cost accounting and making the business case") (Giunipero et al., 2006, p. 836).

Tassabehji and Moorhouse (2008) concluded that a purchaser needs to master a complete set of competences consisting of:

- Technical skills ("product knowledge, computer literacy, total quality management and government legislation and advanced procurement process skills");

- Interpersonal skills ("written and oral communication, conflict resolution, influencing and persuasion, group dynamics, leadership, problem solving and interpersonal and cultural awareness");

- Internal enterprise skills ("effectively conduct market analysis, manage internal relationships, global sourcing evaluation, internal change management and planning and organizational skills");

- External enterprise skills ("management of external relationships, and stakeholder change management"); and

- Strategic business skills ("planning and managing strategic partnerships and alliances, risk management and adding value to the organization") (Tassabehji \& Moorhouse, 2008, p. 59).

Increased PSM competence levels are thus needed to be successful in enabling purchasers to add value in their job and, as a consequence, to be successful in innovation sourcing, the most strategic element of PSM (Feisel et al., 2011; Luzzini \& Ronchi, 2011; Tassabehji \& Moorhouse, 2008). As a result and based on the literature, the following hypothesis emerged: 
(H1a) An increased level of individual innovation sourcing competence leads to innovation sourcing success.

Additionally, the work of Cousins et al. (2006) and Tassabehji and Moorhouse (2008) suggest that individual competences must be supported with organisational conditions to achieve PSM success, which will be elaborated on in the following section.

\subsubsection{The interaction between competences and organisational factors}

Cousins et al. (2006, p. 784 \& 787) found "evidence that purchasing functions can be classified according to their various purchasing characteristics of strategic planning, status, integration and skills" and clustered purchasers into four groups: 'strategic', 'capable', 'celebrity' and 'underdeveloped' purchaser. The 'strategic' purchaser "ranks first in strategic planning, status, internal integration and skills". "Capable purchasers have moderate levels of status, internal integration and involvement in strategic matters" and have "strong capabilities in supplier-related dimensions". "Celebrity purchasers also have low involvement in strategic planning and low-to-moderate integration with the rest of the business" and have a low skill level, which is "due to a 'hands-on' focus for operational issues, rather than higher-level strategic thinking". 'Underdeveloped' purchasers "have the lowest means for all other purchasing characteristics relating to strategic planning, status and internal integration (...) the function is of little concern to top management" (Cousins et al., 2006, p. 784 \& 787).

Tassabehji and Moorhouse (2008) extended the model of Cousins et al. (2006). They conclude that a purchaser needs to master full competences set consisting of technical skills, interpersonal skills, internal and external enterprise skills and strategic business skills. Adding to the findings of Cousins et al. (2006), Tassabehji and Moorhouse (2008) propose that higher competence levels need to be "coupled with a high degree of support and internal recognition" to achieve PSM success (Tassabehji \& Moorhouse, 2008, p. 65). In the field of innovation management, Brenton and Levin (2012, p. 364) confirm this and group innovation teams into those with "high esteem and are viewed as powerful and reliable sources of future growth," and those that are "targets of scorn and ridicule".

Tassabehji and Moorhouse's (2008) model consists of two axes without a precise scale (see: Figure 5.1). The matrix can be interpreted as an illustrative 'two-bytwo' to explain the sum of a high level of different competences (projected on the $x$ axis) plus a high degree of support, and internal recognition (projected on the $y$-axis) leads to strategic elevation. In the two-dimensional model, this strategic elevation is translated in success terms: purchasing professionals with a low level of competences and a low level of 'support and internal recognition' are 'underdeveloped purchasers' 
and 'limited performers'. Those with high levels of competences and low management support levels are 'ineffective', 'disempowered' and 'frustrated'. By contrast, those with low competences levels and enough support are 'constrained' and 'inhibited'. Those with high levels of competences and support are 'strategic purchasers' and 'top performers' that are 'effective', 'recognised', 'value-adding' and 'providing competitive advantage'.

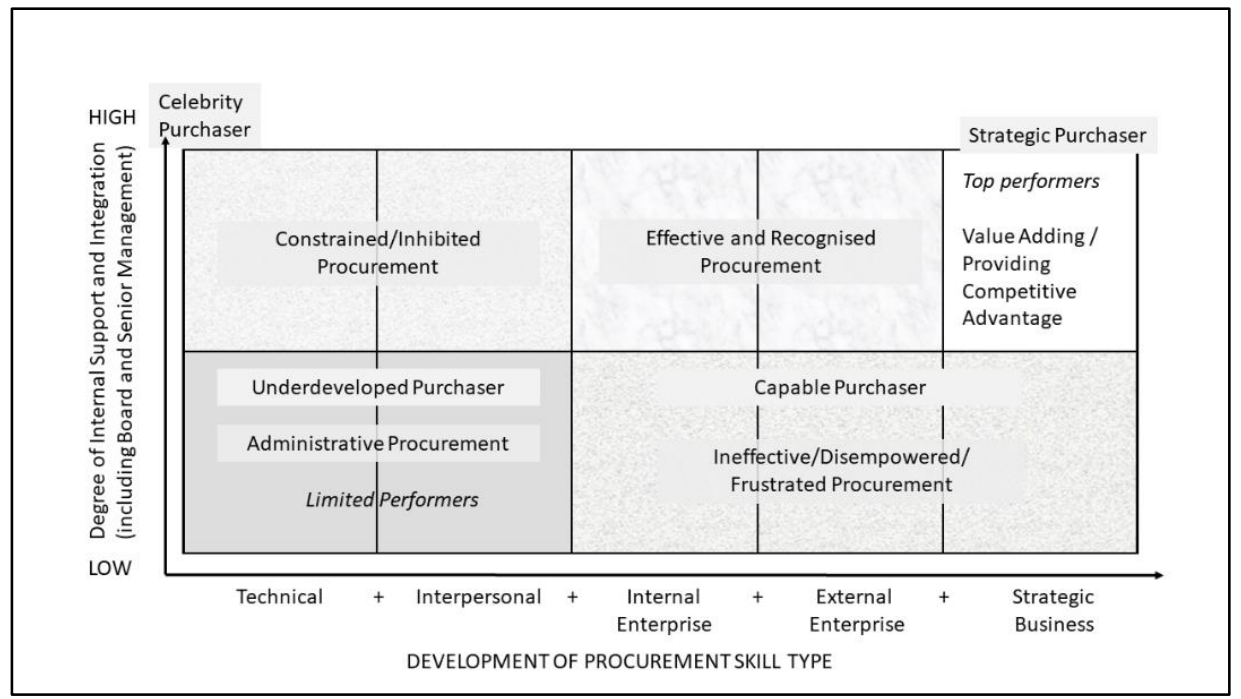

Figure 5.1 - Procurement effectiveness matrix (own illustration, derived from Tassabehji \& Moorhouse, 2008, p. 65)

With the focus on innovation sourcing, this study focuses on the model's top right quadrant (see: Figure 5.1), i.e. high levels of both competences and organisational conditions. In this quadrant, the archetype is the strategic purchaser as a value-adding organisational actor providing competitive advantages to the firm (Tassabehji \& Moorhouse, 2008). In conclusion, Tassabehji and Moorhouse (2008) are projecting three dimensions in a two-dimensional model. Competence levels are projected on the $x$-axis and 'support and internal recognition' on the $y$-axis. Because of their research's qualitative character, the authors do not project evidence for success levels in an (imaginary) third z-axis.

Both an increased level of PSM competences and 'organisational conditions' are needed to succeed in innovation sourcing (Feisel et al., 2011; Luzzini \& Ronchi, 2011; Tassabehji \& Moorhouse, 2008), leading to the following hypotheses: 
(H1b) an increased level of organisational conditions for innovation sourcing leads to innovation sourcing success; and

(H2) a complementary, interacting effect between innovation sourcing competence levels and organisational conditions leading to individual innovation sourcing success will be found, meaning that both are not substitutable; innovation purchasers need both innovation PSM competences and a supportive organisational structure to be successful on the job.

\subsection{Methodology - $t$-test, stepwise OLS regression, NCA and polynomial regression with composite-based structural equation modelling used to answer three research questions}

\subsubsection{Data collection via an extensive European PSM competences survey}

This study uses data collected in an online European PSM competences survey ( $n=581)$, which was carried out as part of a larger European project. This European project's main objective was to align academic learning objectives with successful PSM characteristics. Via LinkedIn.com, about 3,200 European PSM professionals were invited personally to fill out the online survey. In total, 581 professionals filled out the survey. The response rate is thus over 18 per cent. The sample is Western-European, predominantly Dutch: about two-thirds of the respondents have Dutch nationality, eleven per cent are French, and about eight per cent German. A quarter of the respondents work in 'services', 38 per cent in 'industry' and 37 per cent in the 'public sector'. The age spread has a normal distribution. About one-quarter of the respondents are female, and about three quarters are male.

The survey consisted of five different kinds of items. First, the participants' professional PSM focus on innovation sourcing was determined. Second, the participants rated 88 different competence levels. Third, statements on the presence of organisational conditions for innovation sourcing and innovation implementation were rated. Fourth, the participants graded statements on individual and departmental innovation sourcing and innovation implementation successes. Finally, the individual variables 'experience level' ('no experience'; < 5 years; 5-10 years; > 10 years) and 'sector' ('industry'; 'service'; 'public procurement') were part of the survey.

The survey has been pre-tested with six PSM professionals from different industries in Germany and the Netherlands, leading to the clarification of the item texts and the introduction of missing items. All items were measured on a 5-point Likert scale ('fully disagree' to 'fully agree'). After completing the survey, the data was prepared for the NCA and polynomial regression analyses. 


\subsubsection{RQ1a analysed with the help of a t-test: identifying distinctive innovation skills}

The first research question targets identifying a set of particular skills that an innovation purchaser has and which other purchasers do not have. These skillsets are identified with a $t$-test by comparing the innovation purchasers and the others in the sample. The survey asked respondents to rank their priorities to accomplish this separation. Five ranks were amongst the possible choices (costs, delivery, quality, competitive advantage and innovation). Based on their explanation of objectives, the PSM professionals with an innovative focus $(n=103)$ were isolated from the total number of participants $(n=581)$, i.e. the participants who placed 'having the focus on innovation' on rank $1(n=36)$ and rank $2(n=67)$ are compared to those without an innovation priority.

This study's next step was to identify competences and organisational conditions for innovation sourcing that belong significantly to PSM professionals with an innovation sourcing focus. With $t$-tests the means of, firstly, the perceived competence levels and, secondly, the organisational conditions for innovation sourcing of the innovation sourcing professionals $(n=103)$ are compared to those who have a non-innovation sourcing focus $(n=478)$ to identify the significant innovation sourcing competences (hereafter: "Innovation Competences") and organisational conditions for innovation sourcing (hereafter: "Innovation Organisation") (see: Appendix 9.16).

While a comparison of innovation purchasers to those with different priorities allows identifying a set of particular innovation skills, it does not allow differentiation among these skills. Which would be more important and which are necessary? The NCA - necessary condition analysis method is needed to achieve this distinction and answer RQ1b.

\subsubsection{Answering RQ1b with the help of NCA - a method for measuring necessary conditions for performance}

Previous research has typically identified general lists of skills. However, unless the frequency is used as an importance indicator, no differentiation among the skills or competences is identified. The practical difficulty with this is that a long list of skills emerges, which scarcely allows a focus on some of those, which must first be improved and yield the most extensive results. One way of achieving a differentiation could be to perform a regression on 'success'. In this way, those skills which contribute more to the innovation target could be identified by applying a stepwise regression. In Appendix 9.12, the in bold font marked skills are the result of the regression analysis. However, this is not a complete answer to the question since such key success factors may also be misleading in practical terms. If necessary skills for achieving the target could be detected that distinguish successful purchasers from those who are merely doing their 
job, training potential deficits in these necessary skills could first be remedied. Only then, in a second step, would the organisation engage in training the differentiators. Thus, a complete skills development scheme needs to identify the necessary skills for which the NCA has been developed.

Dul (2016b) recently developed the NCA method and argued that sufficient and necessary conditions could be distinguished as two different logical parts of the notion of causality. The outcome $(B)$ will not be achieved when the necessary conditions $(A)$ are absent (no $B$ without $A$ ), whereas other methods, such as polynomial regression, are based upon determining sufficient conditions that lead to the outcome ( $A$ produces B) (Dul, 2016b; Van der Valk, Sumo, Dul, \& Schroeder, 2016). In other words, a sufficient condition will lead to the outcome, and a necessary condition allows the outcome to exist. On the other hand, the absence of the necessary condition will be the reason for the absence of the outcome, regardless of other factors being present (Van der Valk et al., 2016).

While the NCA method is recently developed, notable research results could be presented, of which three examples are given here. Van der Valk et al. (2016, p. 267) performed NCA on different innovation levels in buyer-supplier relations on 'trust' versus 'legal contracts' and their study shows "that successful relationships (...) must necessarily have contracts with at least medium levels of contractual detail, as well as the highest levels of trust". Leischnig et al. (2018, p. 385) analysed "the relationships between service employees' adaptive behaviors and customer satisfaction" and found "that interpersonal adaptive behavior is a necessary condition (...) for high customer satisfaction". Fredrich et al. (2018, p. 862) concluded that "absorptive learning capacity is a necessary condition of interfirm learning, while organizational slack resources and interdependence between firms are important additional conditions".

The NCA method, as described by Dul (2016b), is novel, although it is already applied in various scientific disciplines like PSM (Van der Valk et al., 2016); educational sciences (Fredrich, Bouncken, \& Kraus, 2018; Karwowski, Kaufman, Lebuda, Szumski, \& Firkowska-Mankiewicz, 2017); psychology (Luther et al., 2017; Sorjonen \& Melin, 2019); operations management (Knol, Slomp, Schouteten, \& Lauche, 2018, 2019); hospitality management (W. Lee \& Jeong, 2019); sociology (Vis \& Dul, 2018); and marketing (Leischnig, Kasper-Brauer, \& Thornton, 2018). NCA has been criticised recently, and qualitative comparative analysis (QCA) has been proposed for dealing with the limited potential of NCA for identifying sets of necessary conditions (Dul, Vis, \& Goertz, 2018; Thiem, 2018).

QCA is another method that has been developed by Ragin (1987) for detecting necessary conditions. Thiem (2018) states that QCA would be superior to NCA for the task; however, see how Dul et al. (2018) refuted this. Sorjonen and Melin (2019, pp. 12) have shown that even with skewed predictors, "NCA can give large necessity effects". 
Moreover, NCA uses other methods for the calculation than the analysis of the necessary conditions in QCA. The "ceiling line" in QCA is a static diagonal, whereas this line depends on the NCA calculation: "NCA's reference line is not the diagonal, but the ceiling line drawn on top of all cases (...). This reference line represents all possible combinations of values of $X$ and $Y$ where $X$ is necessary for $Y$ and allows the formulation of many in degree statements of necessity, depending o the levels of $X$ and $Y^{\prime \prime}$ (Dul, 2016a, p. 1517).

Hence, NCA was applied in this research. Dul's (2018b) guidelines are followed to analyse the data, using the statistical functions of the open-source programming language $R$, complemented with the NCA $R$ package provided by Dul (2018a). By using the statistical NCA $R$ package, the effect sizes are calculated and presented. "If the effect size is greater than zero, there is (...) an indication of the presence of a necessary condition". "It ranges from 0 to $1(0 \leq d \leq 1)$. The effect size indicates to what extent the condition is necessary for the outcome. In other words: to what extent the condition constrains the outcome, and the outcome is constrained by the condition" (Dul, 2018b, p. 10).

In the interpretation of the effect size, Dul (2016b, p. 30) states that "An effect size can be valued as either important or not, depending on the context. A given effect size can be small in one context and large in another". Dul (2016b, p. 1518) states that general qualifications for the effect size, such as 'small,' 'medium,' or 'large', are disputable. However, this general benchmark for necessary condition effect size is suggested: " $0<d<0.1$ as a 'small effect,' $0.1 \leq d<0.3$ as a 'medium effect,' $0.3 \leq d<0.5$ as a 'large effect,' and $d \geq 0.5$ as a 'very large effect'". Moreover, the statistical NCA $R$ package provides a $p$-value for determining the significance of the effect size.

Based on the combination of $t$-test, stepwise regression and NCA, a ranked list of skills for the innovation purchaser can eventually be derived. As the literature has suggested, however, individual skills are not enough to guarantee success, as there might well be organisational influence factors to be considered. The polynomial regression is helpful to analyse the interplay between organisational and individual characteristics.

\subsubsection{Answering RQ2 with the help of polynomial regression with response surface analysis}

As a contribution to the literature, this study aims to quantify the interaction effects assumed in the model of Tassabehji and Moorhouse (2008), i.e. the interplay between organisational and individual characteristics enabling a firm to achieve maximum performance in innovation sourcing. One way to analyse this could be by applying a simple regression, including organisational and skills variables. Though, no information on the complementarity or substitute character of the two dimensions can 
be identified in such a design. Polynomial regression with response surface analysis graphing the results in a three-dimensional space (Shanock, Baran, Gentry, Pattison, \& Heggestad, 2010, 2014) is well suited and is applied here.

"Traditional regression analyses of interactions provide a two-dimensional view of the relationship between combinations of two predictor variables" (Shanock et al., 2010, p. 550). It means that in the case of this study, two regression analyses would have been necessary. Polynomial regression with "response surface methodology (...) allows for a three-dimensional examination of this relationship" (Shanock et al., 2010, p. 550) and hence a simultaneous analysis of the interaction of both independent variables (Innovation Competences and Innovation Organisation; see: Appendix 9.16) on the dependent variable (Innovation Sourcing Success; see: Appendix 9.16).

Polynomial regressions support the comprehension of composite constructs' precise impact on dependent variables (K. Lee, Woo, \& Joshi, 2017). The polynomial regression method's main contribution is in testing higher-order, curvilinear effects with the advantage of not losing statistical information (Venkatesh \& Goyal, 2010). When interactions of variables are studied, polynomial regressions combined with response surface modelling can go beyond regular regression or structural equation models (Edwards, 2001; K. Lee et al., 2017; Venkatesh \& Goyal, 2010).

Whereas traditional regressions provide a two-dimensional image of the relation between two predictor variables, the response surface methodology provides a three-dimensional view of the relationship (Shanock et al., 2010, 2014). Polynomial regression analyses are used in many fields, such as innovation management (e.g. Chen, Reilly, \& Lynn, 2012; K. Lee et al., 2017; Stephan, Andries, \& Daou, 2019); psychology (e.g. Caniëls \& Veld, 2016; De Stobbeleir et al., 2018); personnel psychology research (e.g. J. D. Shaw \& Gupta, 2004; Venkatesh \& Goyal, 2010); organisational behaviour (e.g. Hecht \& Allen, 2005; Kristof, 1996); marketing (e.g. Kim \& Hsieh, 2003); and information systems (e.g. Venkatesh \& Goyal, 2010).

A polynomial with the three constructs is modelled, including the items detailed in Appendix 9.16. The dependent variable to be explained is the innovation sourcing success measured by a subjective latent variable focusing on process and product improvements. The variable is not modelled in an absolute manner to ensure comparison among industries, such as counting the number of innovations but asking the respondents to explain if they outperform their competitors. The Innovation Organisation is measured by a construct reflecting whether innovation is an objective of the purchasing function, and the contribution is measured. Likewise, if this approach is extended to the suppliers, who would be requested to make an innovative contribution, this would be reflecting the internal recognition PSM gets for their innovation activities and their support towards third parties, i.e. suppliers. These variables are not influenceable by the individual but are of the organisational level. 
Technically, in the three-dimensional space opened by the polynomial, the latent factor "Innovation Sourcing Success" (dependent) is projected on the z-axis. Both competence levels and organisational conditions were centred on the midpoint of their means by the $R$ software leading to a scale around zero. Next, for the polynomial regression, the Excel spreadsheet supplied by Shanock et al. $(2010,2014)$ is used to generate a three-dimensional view (i.e., surface analysis), including significance testing with a level of .05 (one-tailed) for all analyses. The next step was to find the relationship between the three variables via polynomial regression with response surface analysis (Edwards \& Parry, 1993).

Some conditions had to be satisfied to shape a three-dimensional form with three axes with polynomial regression with response surface analysis (Shanock et al., $2010,2014)$. First, the variables need to share a conceptual domain, which in this study is the topic of innovation sourcing (competences, organisational conditions and success). Second, all variables on the different axes must be measured on the same numeric scale. This condition is met; for the variables on all axes, a 5-point Likert scale is used.

Third, there must be 'agreement' between the latent variables, i.e. that the standard deviations are within half a standard deviation from each other. Half a standard deviation of the $x$-axis variable is .34266 (.68532 / 2), leading to a range from .34266 to 1.02798 . The standard deviations of the variables on the $y$-axis (.87590) and the $z$-axis (.72456) are found within the half standard deviation range. This condition is also satisfied vice versa when calculated from the $y$-axis $(.87590 / 2)$ and the $z$-axis (.72456 / 2).

Fourth, the residuals need to be normally distributed. This condition is met, as shown in Appendix 9.18. The significances of the Kolmogorov-Smirnov and the ShapiroWilk tests are respectively .200 and .693 . A non-significant $p$-value means that the null hypothesis is accepted and thus that the data is distributed normally as a result (Field, 2009). The Durbin-Watson test is 1.934 and is, therefore, close to 2.000 and holds that there is (almost) no autocorrelation detected in the sample (Field, 2009). The sample is checked to be homoscedastic, and the variance of inflation (VIF) of both independent variables is 1.081 , which means there is no multi-collinearity detected between the independent variables (Field, 2009).

Finally, the newly computed $y$-axis and $x$-axis variables' standardised scores are calculated to commence polynomial regression. Both standardised scores are subtracted from each other. These new differences were examined on the spread. It was shown that the discrepant data (that is more than half a standard deviation above or below the standardised score of zero; i.e. the section of $<-0.5$ and the section of $>0.5$ ) is higher than 10 per cent (resp. 32.0 and 32.0 present), which is a condition to perform further polynomial regressions. Herewith the conditions to start polynomial 
regression are satisfied (Shanock et al., 2010). In contrast with Shanock et al.'s (2010) suggestion to calculate constructs into single latent variables in SPSS, an alternative method was found to keep the construct intact for this research. Following the step model proposed by Benitez, Henseler, Castillo, and Schuberth (2019) and Henseler, Hubona, and Ray (2016), the polynomial is modelled with consistent partial least squares, applying the Comprehensive $R$ Archive Network (CRAN) composite-based structural equation modelling software of Rademaker and Schuberth (2020) while relying on Shanock et al.'s (2010) tool for presenting the surface analysis.

\subsection{Model testing - combing the results of polynomial regression with response surface analyses with necessary condition analysis}

\subsubsection{Identifying 17 distinctive innovation purchasing skills}

The survey data fulfil the criteria of normal distribution (see: Appendix 9.17). Hence, the $t$-test comparing innovation purchasers with the total sample was run and resulted in 23 significant competences, 17 with a significant positive sign (see: Appendix 9.12) and six significant competences with a negative sign (see: Appendix 9.13). The six negative-significant competences, i.e. competences not belonging to the profile of innovation sourcing specialist, depict cost reduction profile, which characterises what an innovation purchaser is significantly not.

The 17 positive-significant competences were the subject of exploratory factor analyses to group the variables (see: Appendices 9.12 and 9.14; Principal Component Analysis and Equamax with Kaiser Normalisation). Furthermore, the VIF statistic appeared to be consistently lower than 1.700 , meaning that multicollinearity between the factors was not found. In the end, three factors are found that have been titled:

(1) 'Soft Skills' consists of the following personal skills: creativity; inventiveness; honesty; conflict resolution; willingness to take risks, and comprehension of complexity,

(2) 'Managerial Skills' that are positively related: change management; corporate governance; project management; consultancy skills; and cooperation with the HRM department,

(3) 'Innovation Competences': Early Supplier Involvement in NPD; Innovation Sourcing; Innovation Implementation in the own product or process; cooperation with $R \& D$ department; and cooperation with Marketing.

This analysis provides an answer to RQ1a by presenting an empirically validated list of 17 skills typical for the innovation purchaser. Competence items with an ambiguous outcome are discarded as described by Hair, Black, Babin, and Anderson (2010, p. 138); in Appendix 9.14, these ambiguous items are marked in italics. 


\subsubsection{Necessary condition analysis - the necessity of conditions for competences and competences for success}

This research combines and compares polynomial regression and NCA to verify and justify polynomial regression outcomes and gain new insights by creating more transparency in the outcomes. It is in line with Dul (2016b, p. 6), who "considers NCA as a complement and not a replacement of traditional approaches to analyze causal relations. NCA may provide new insights that are normally not discovered with traditional approaches".

\section{Table 5.1 - Results of necessary condition analyses}

\begin{tabular}{|c|c|c|c|}
\hline $\begin{array}{l}\text { The necessity of the existence of the } \\
\text { independent variable }\end{array}$ & $\begin{array}{l}\text { for the existence of the } \\
\text { dependent variable }\end{array}$ & $\begin{array}{l}\text { Effect } \\
\text { size }(d)\end{array}$ & $\begin{array}{l}\text { Sign. } \\
\text { ( } p \text {-value) }\end{array}$ \\
\hline $\begin{array}{l}\text { (1) Innovation Competences (IC; } \\
\text { construct) }\end{array}$ & $\begin{array}{l}\text { Innovation Sourcing } \\
\text { Success (construct) }\end{array}$ & .125 & .000 \\
\hline $\begin{array}{l}\text { (2a) Innovation Organisation } \\
\text { (construct) }\end{array}$ & $\begin{array}{l}\text { Innovation Sourcing } \\
\text { Success (construct) }\end{array}$ & .107 & .178 \\
\hline $\begin{array}{l}\text { (2b) Innovation Organisation } \\
\text { (construct) }\end{array}$ & $\begin{array}{l}\text { Innovation Competences } \\
\text { (construct) }\end{array}$ & .172 & .049 \\
\hline $\begin{array}{l}\text { (3) Management Competences (MC; } \\
\text { construct) }\end{array}$ & $\begin{array}{l}\text { Innovation Sourcing } \\
\text { Success (construct) }\end{array}$ & .071 & .114 \\
\hline (4) Soft Skills (construct) & $\begin{array}{l}\text { Innovation Sourcing } \\
\text { Success (construct) }\end{array}$ & .097 & .055 \\
\hline $\begin{array}{l}\text { (5) Project Management Skills (item } \\
\text { in the MC construct) }\end{array}$ & $\begin{array}{l}\text { Innovation Sourcing } \\
\text { Success (construct) }\end{array}$ & .161 & .047 \\
\hline $\begin{array}{l}\text { (6) Innovation Sourcing (item in the } \\
\text { IC construct) }\end{array}$ & $\begin{array}{l}\text { Innovation Sourcing } \\
\text { Success (construct) }\end{array}$ & .125 & .000 \\
\hline $\begin{array}{l}\text { (7) Advisory Skills (item in the MC } \\
\text { construct) }\end{array}$ & $\begin{array}{l}\text { Innovation Sourcing } \\
\text { Success (construct) }\end{array}$ & .089 & .026 \\
\hline
\end{tabular}

The necessity for each of the two independent variables (Innovation Competences and Innovation Organisation) are calculated for the dependent variable's existence (Innovation Sourcing Success) (see: Appendices 9.15 and 9.16 for the design of the three constructs). Additionally, to answer RQ1b, the other two competence constructs from the factor analysis (Management Competences and Soft Skills) are tested on the decisiveness of individual competences for Innovation Sourcing Success (see: Appendix 9.12). Moreover, an NCA is conducted of the individual 17 competences 
in the three factors that affect Innovation Success. Table 5.1 also displays the three competences that showed significant effect sizes.

The outcomes of the NCA are shown in Table 5.1. The necessity of (1) Innovation Competences for Innovation Sourcing Success is found ( $d=.125$; $p=.000)$. However, a significant necessity for (2a) Innovation Organisation for Innovation Sourcing Success is not found ( $d=.107 ; p=.178)$, nevertheless a significant necessity is found for (2b) Innovation Organisation for Innovation Competences $(d=.172 ; p=.049)$. The necessity of the constructs based upon the factors (3) Management Competences and (4) Soft Skills is not found either $(d<.100 ; p>.050)$. In other words, based upon NCA, the answer to RQ1a on which individual competences the purchaser requires to achieve innovation sourcing success is that Innovation Competences are a necessary condition for Innovation Sourcing Success, which supports hypotheses 1a: an increased level of individual innovation sourcing competence leads to Innovation Sourcing Success. Moreover, the necessity of three of the 17 items has been found: (5) Project management skills; (6) Innovation sourcing; and (7) Advice skills.

Based upon NCA, hypothesis $\mathrm{H} 1 \mathrm{~b}$ has to be rejected. There is no evidence found that an increased level of organisational conditions for innovation sourcing, on its own, leads to innovation sourcing success.

\subsubsection{Polynomial regression - significant evidence of the interaction innovation sourcing and organisational conditions for Innovation Sourcing Success}

The polynomial regression analysis is applied as described by Shanock et al. $(2010,2014)$ to test Hypothesis 2 . As a preparation for the analysis, in the $R$ application, the composite models were tested in two steps with the composite-based structural equation modelling software provided by Rademaker and Schuberth (2020), resulting in two subsequent models (see: Table 5.2; models 1 and 2). In model 1, the control variables 'experience level' (i.e. 'no experience'; < 5 years; $5-10$ years; >10 years) and 'sector' (i.e. 'industry'; 'service'; 'public procurement') were included in the equation.

The levels of experience and employment sector do not have a significant influence on innovation sourcing success. Based on preliminary examination of the $p$ values and the estimated coefficients of the control variables, the conclusion can be drawn that model 1 is not parsimonious, which is a justifiable reason to discard the control variables because irrelevant variables can mask real effects due to an increase in multicollinearity, although they might not bias estimates of the influential variables (Hair et al., 2010). In model 2, the control variables, which appeared to be nonsignificant, are excluded and are the most parsimonious model of the two (Hair et al., 2010). Parsimony model building is an essential principle to ensure that "the simplest 
possible (model) should be chosen," combined with the principle of model adequacy, i.e. that the model "is considered adequate if it incorporates all relevant information" (Box, Jenkins, \& Reinsel, 1970; McLeod, 1993, p. 388). Moreover, the principle of model parsimony is a precondition for the use of structural equation modelling (Benitez et al., 2019).

Table 5.2 - Results of the composite-based Structural Equation Modelling on Innovation Sourcing Success

Model $1 \quad$ Model 2

\begin{tabular}{|c|c|c|c|c|c|c|c|c|c|c|}
\hline \multirow{3}{*}{$\begin{array}{l}\text { Variables } \\
\text { IC - Innovation } \\
\text { Competencies }\end{array}$} & \multicolumn{5}{|c|}{ Model 1} & \multicolumn{5}{|c|}{ Model 2} \\
\hline & \multirow{2}{*}{$\begin{array}{l}\text { Est. } \\
.3763\end{array}$} & \multirow{2}{*}{ 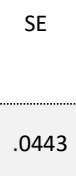 } & \multirow{2}{*}{$\begin{array}{l}\text { Sign } \\
.0000 \\
.0 \ldots \ldots \ldots \ldots\end{array}$} & \multicolumn{2}{|c|}{$\begin{array}{c}\text { Confidence } \\
\text { interval } \\
\text { Percentile 95\% }\end{array}$} & \multirow{2}{*}{$\begin{array}{l}\text { Est. } \\
.3562\end{array}$} & \multirow{2}{*}{$\begin{array}{c}\mathrm{SE} \\
.0413 \\
\ldots \ldots \ldots \ldots \ldots \ldots \\
\ldots \ldots \ldots\end{array}$} & \multirow{2}{*}{$\begin{array}{r}\text { Sign } \\
.0000 \\
\ldots \ldots \ldots \ldots \ldots \ldots \\
\end{array}$} & \multicolumn{2}{|c|}{$\begin{array}{c}\text { Confidence } \\
\text { interval } \\
\text { Percentile 95\% }\end{array}$} \\
\hline & & & & .2902 & .4562 & & & & .2682 & .4318 \\
\hline $\begin{array}{l}\text { IO - Innovation } \\
\text { Organisation }\end{array}$ & .2534 & .0486 & .0000 & .1694 & .3511 & .2565 & .0489 & .0000 & .1698 & .3639 \\
\hline IC * IO & .0209 & .0445 & .6392 & -.0726 & .1109 & .0182 & .0470 & .6988 & -.0814 & .1000 \\
\hline $\mathrm{IC}^{2}$ & -.0518 & .0351 & .1397 & -.1244 & .0134 & -.0518 & .0327 & .1138 & -.1189 & .0091 \\
\hline $10^{2}$ & .0624 & .0287 & .0297 & .0104 & .1209 & .0576 & .0285 & .0429 & .0124 & .1283 \\
\hline Sector & .0393 & .0401 & .3267 & -.0401 & .1142 & & & & & \\
\hline Experience level & -.0483 & .0410 & .2380 & -.1332 & .0268 & & & & & \\
\hline
\end{tabular}

Notes: Est.: Estimate; SE: Standard error; sign: significance; $n=103$.

Above, the hypotheses are tested with NCA, which led to accepting H1a and rejecting $\mathrm{H} 1 \mathrm{~b}$. In the context of the hypotheses testing with composite-based structural equation modelling, for model 2 (and model 1 as well), hypotheses $1 \mathrm{a}$ and $1 \mathrm{~b}$ are both supported. Innovation Competences $(p=.000)$ and Innovation Organisation $(p=.000)$ are significant. As mentioned above, hypothesis 2 will be tested with polynomial regression with response surface analysis in the following step.

Polynomial regression analysis aims to test for curvilinear effects of the interaction of innovation sourcing competence levels and organisational conditions for innovation sourcing (i.e. polynomial analysis and response surface modelling). For that reason, the polynomial terms were inserted in model 2. 
Table 5.3 - Polynomial analysis of slopes and curvatures for effects of innovation sourcing success

\begin{tabular}{|c|c|c|c|c|}
\hline & Innovation & ing suc & cess & \\
\hline & & ndard & $\begin{array}{r}\text { Test } \\
\text { statistic }\end{array}$ & \\
\hline & Coefficient & Error & $(t)$ & Sign \\
\hline Effects along the balanced line & & & & \\
\hline Slope $(\boldsymbol{a} 1=b 1+b 2)$ & .61 & .06 & 9.629 & .000 \\
\hline Curvature $(a 2=b 3+b 4)$ & .02 & .05 & 0.414 & .679 \\
\hline Effects along the balanced line & & & & \\
\hline Slope $(a 3=b 1-b 2)$ & .10 & .06 & 1.681 & .096 \\
\hline Curvature $(a 4=b 3-b 4+b 5)$ & -.01 & .07 & -0.211 & .834 \\
\hline
\end{tabular}

For further analysis of the results, the findings were inserted in the Excel analysis file as provided online via the publisher as described by Shanock et al. (2010) to perform the polynomial regression with response surface modelling. This polynomial regression led to a three-dimensional image, as displayed in figure 5.2, whereas the data points are found in Table 5.4. Table 5.3 shows the significance of the slope $\left(a_{1}\right)$ on the diagonal $x=y$. This significant slope $\left(a_{1}\right)$ is ascending from $(-2,-2,-1.14)$ to $(2,2,1.32)$.

Table 5.4 - data points of polynomial analysis with response surface modelling as shown in Figure 5.2

Points to Plot

\begin{tabular}{|c|c|c|c|c|c|c|c|c|}
\hline \multirow{7}{*}{ 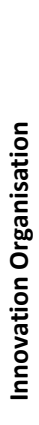 } & \multicolumn{8}{|c|}{ Innovation Competences (X-axis) } \\
\hline & \multirow{6}{*}{ 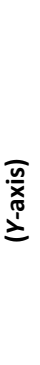 } & & -2 & -1 & 0 & 1 & 2 & \multirow{6}{*}{$\leftarrow$ slope a1 } \\
\hline & & 2 & $-0,25$ & 0,29 & 0,74 & 1,08 & 1,32 & \\
\hline & & 1 & $-0,64$ & $-0,11$ & 0,26 & 0,64 & 0,85 & \\
\hline & & 0 & $-0,92$ & $-0,41$ & 0,00 & 0,30 & 0,51 & \\
\hline & & -1 & $-1,08$ & $-0,59$ & $-0,20$ & 0,09 & 0,27 & \\
\hline & & -2 & & $-0,66$ & $-0,29$ & $-0,02$ & 0,14 & \\
\hline
\end{tabular}

Note: Diagonal is line of congruence $(x=y)$; Below the diagonal $x>y$; Above the diagonal $x<y$ 


\section{Innovation Sourcing Success predicted by Innovation Competences and Innovation Organisation}
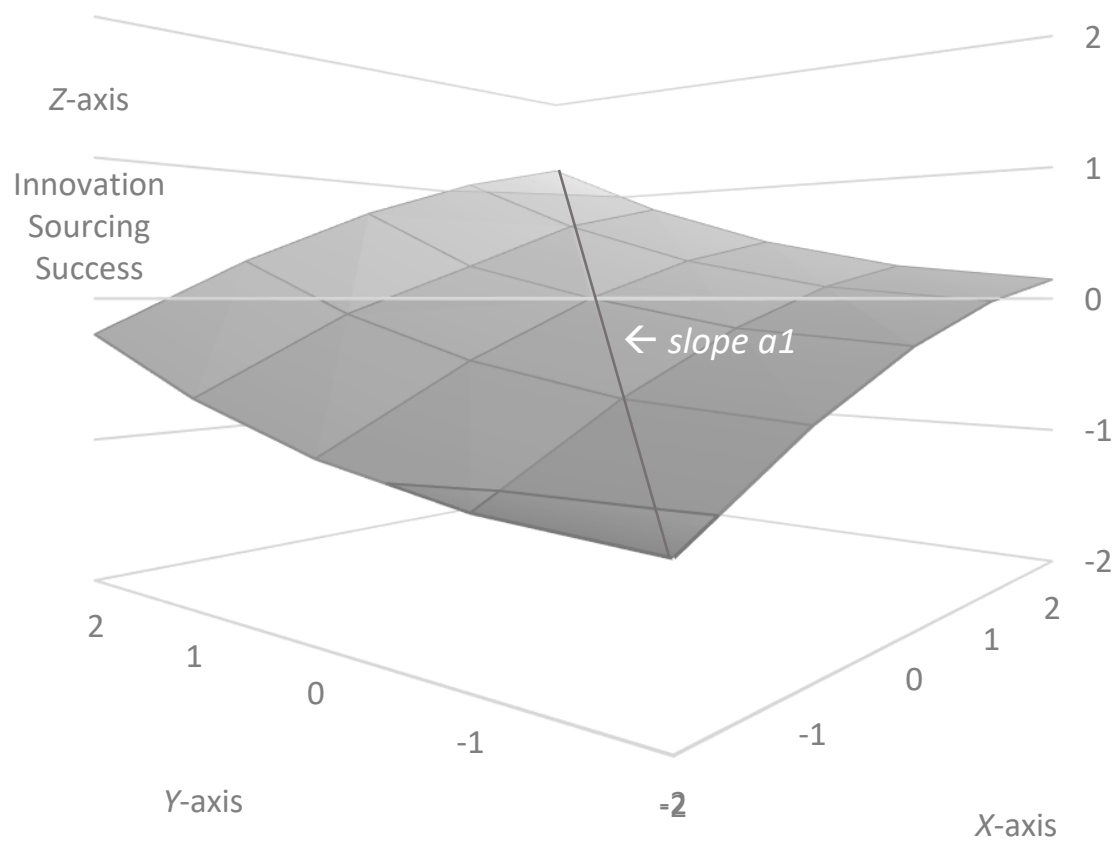

Innovation Organisation

Figure 5.2 - Effect of the innovation sourcing competences construct and the level and organisational conditions for innovation sourcing on Innovation Sourcing Success 


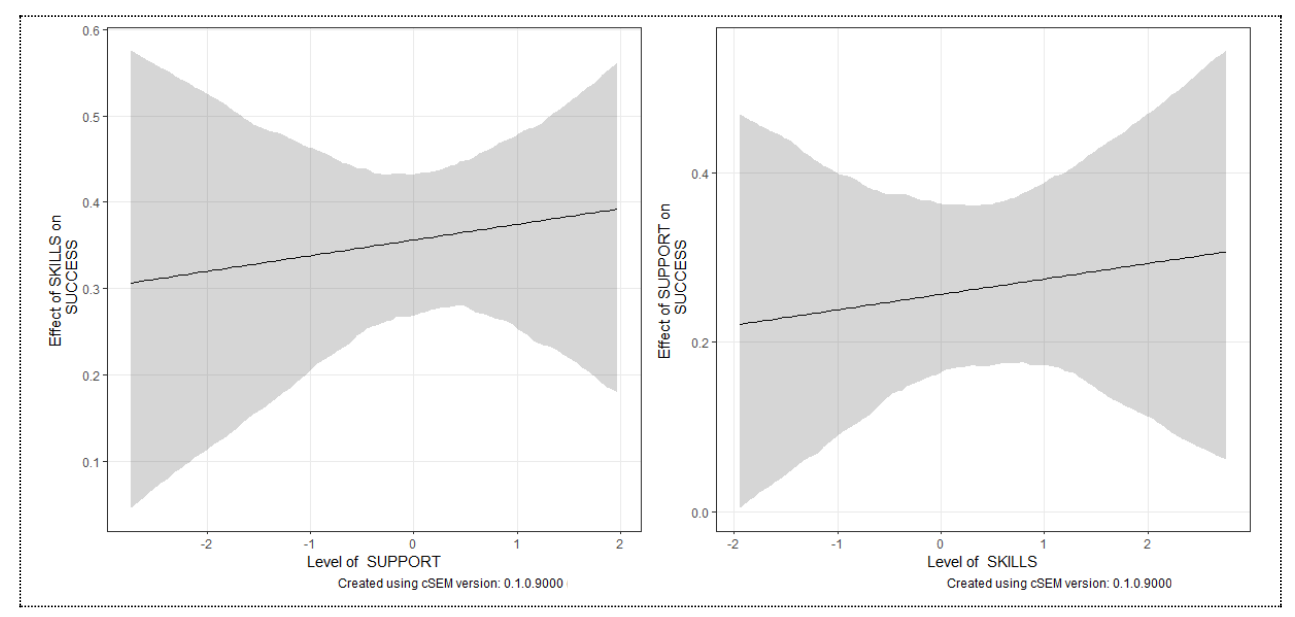

Figure 5.3 - Effect of Innovation Sourcing ("SKILLS") on Innovation Sourcing Success ("SUCCESS") and the moderation of Innovation Organisation ("SUPPORT")

Figure 5.4 - Effect of Innovation Organisation ("SUPPORT") on Innovation Sourcing Success ("SUCCESS") and the moderation of Innovation Sourcing ("SKILLS")

A deficiency of the polynomial regression method (Shanock et al., 2010, 2014) is that the significances are presented as a value for the complete range. Therefore, the question is justified of whether the significance is valid for the full range. As a result, further, so-called floodlights analyses are performed (Spiller, Fitzsimons, Lynch Jr, \& McClelland, 2013) by plotting confidence intervals for both independent variables on the dependent variable (see: Figures $5.3 \mathrm{a}$ and $5.3 \mathrm{~b}$ ) by applying the CRAN software of Rademaker and Schuberth (2020). Figures 3a and 3b display the confidence interval plots of the significant slope $a 1$ in figure 5.2. Neither of the confidence intervals coincides with zero on the vertical axis, meaning that the effect of Innovation Competences and Innovation Organisation on Innovation Sourcing Success is significant for the complete slope $a 1$ (Benitez et al., 2019; Henseler et al., 2016).

Based on the analysis with polynomial regression, the outcome is that Innovation Competences and Innovation Organisation complement each other, meaning that a lack of competences cannot be substituted by organisational support and vice-versa. It means that the independent variable $z$ is reached if and only if the independent variables $x$ and $y$ are combined. It contributes to the answer to research question 2: Are individual competences and supportive organisational structures complementary or substitutive to each other, i.e. can a lack of competences be substituted by organisational conditions and vice-versa? 


\subsection{Discussion - The innovation purchaser being the future $\mathrm{CPO}$}

To answer RQ1a, which skills an innovation purchaser needs to have, survey respondents with an innovation sourcing focus were isolated and secondly, with a $t$-test, 23 significant competences were identified. These 23 significant competences are found in 17 competences with a positive sign (see: Appendix 9.12) and in a set of six competences with a negative sign (see: Appendix 9.13). The discovery of the competences with a negative, significant relation was not preconceived and surprisingly revealed what an innovation purchaser is not.

The 17 competence items have been grouped into three summarising factors, which are titled: Soft Skills, Management Competences, Innovation Competences. Hence, the typical innovation purchaser takes a strategic perspective and does not fit in a transactional, operational role. These findings give empirical evidence for Legenvre and Gualandris' (2018) qualitative research, who stated that it is necessary to communicate and cooperate closely with R\&D, marketing, operations, and clients in the case of innovation sourcing. Further, they emphasised "to look beyond immediate requirements and anticipate factors that could provide future competitive advantage (...) to involve suppliers in innovation projects" and also "to look beyond risks, cost, and product development to offer further competitive advantages" (Legenvre \& Gualandris, 2018, pp. 97-98).

Furthermore, interpersonal skills such as human-to-human communication abilities, advisory skills, conflict resolution, honesty or cross-functional cooperation are essential. The reason is probably that innovation creation is not the work of a single person or a single firm, as concluded by Luzzini et al. (2015), Perry-Smith and Mannucci (2017) and Kiratli et al. (2016). In all cases, low levels of Innovation Competences lead to low Innovation Sourcing Success rates.

Finally, this study provides evidence that Innovation Competences are necessary conditions for Innovation Sourcing Success and that these are a decisive factor, as shown in Table 5.2 (RQ1b). To a certain level of Innovation Organisation conditions, an increase of innovation competence levels leads to higher Innovation Sourcing Success levels. Therefore, it matters whether the Innovation Organisation conditions are met. Organisations with low Innovation Organisation support are unlikely to have success in accessing their supplier's power of innovation. This lack of organisational conditions cannot be compensated with high levels of Innovation Competences that the PSM team members might hold.

Hence, Hypothesis 2, based on Tassabehji and Moorhouse (2008) and Feisel et al. (2011), is supported. It holds that evidence is found for a complementary and interacting effect between Innovation Competence levels and Innovation Organisational conditions for sourcing leading to individual Innovation Sourcing Success 
and the reverse: competent purchasers not equipped with the right Innovation Organisation conditions will end up being inefficient.

Based on the polynomial regression outcomes with response surface analysis combined with composite-based structural equation modelling, Hypotheses $1 \mathrm{a}$ and $1 \mathrm{~b}$ were accepted here. Since Hypothesis 2 is supported, Hypotheses $1 \mathrm{a}$ and $1 \mathrm{~b}$ cannot be accepted entirely. Indeed, on the one hand, it is beneficial to increase the innovation sourcing competence of a purchaser (i.e. $\mathrm{H} 1 \mathrm{a}$ ), and on the other hand, it is beneficial to improve organisational support (i.e. H1b).

Nevertheless, only the combination of the two allows the sizing of the full innovation potential an organisation possesses with its supply base (i.e. H2), which is graphically displayed in figure 5.2. The three hypotheses can be found respectively associated with the three slopes presented on respectively the lines $y=-2(\mathrm{H} 1 \mathrm{a}) ; x=-2$ (H1b); and $y=x$ or a1 $(\mathrm{H} 2)$. The largest level of Innovation Sourcing Success is reached with a combination of $y=x$. This slope increases from $(-2,-2,-1.14)$ to the highest point in the graph $(2,2,1.32)$, followed by $y=-2$ (H1 on Innovation Competences), which slope ascends from $(-2,-2,-1.14)$ to $(2,-2,0.14)$. Finally, the impact of Innovation Organisation leads to the lowest level of success represented by the line $x=-2(\mathrm{H} 2)$ that ranges from $(-2,-2,-1.14)$ to $(-2,2,-0.25)$.

\subsection{Conclusion - focus on proper organisational conditions and skills training to increase innovation levels}

\subsubsection{Contributions to theory: skills-organisation complementarity and the importance of soft skills}

The present study is the first to explicitly look into the skills needed for allowing purchasers to perform in their new role of innovation gatekeepers and facilitators. Almost as a logical consequence, offering a quantitative-empirical test, this research is also the first to provide a basis with some potential for generalisation. Surprisingly, this critical innovation co-creating purchaser has mostly been neglected as an object of study in the PSM competence literature.

The research further highlights the absence of a universal skillset of "the" purchaser. Contrary, these findings strongly support the idea of specialisation. It showed what an innovation purchaser is not; a negative significance is found for the cost analysis, cost reduction technique, soliciting offer, negotiation, and evaluating offers. These skills are de-prioritised by innovation purchasers. This finding suggests evidence for a watershed in PSM. Innovation purchasers have a strategic focus rather than the traditional buyer's transactional perspective focused on cost reductions for the supplies. The fully educated purchasers would, of course, have all skills. However, 
before achieving this status, this research provides a list of the particular skills a purchaser working in a firm with a substantial innovation target should possess.

Support is found for Tassabehji and Moorhouse's (2008) assumption regarding the interactive effects of increased skills levels and organisational conditions leading to innovation sourcing success. Michaelis and Markham (2017, p. 41) warn that while organisational support is necessary, it is not sufficient on its own and that in profitable innovation, human capital is the critical factor (Leiponen, 2005; Michaelis \& Markham, 2017). Michaelis and Markham (2017, p. 41) provided evidence that the development of human capital in companies "is too often neglected in favor of a focus on processes and tools".

This finding is remarkable because it "can lock a company in incrementalism," instead of offering opportunities "to create an innovation-oriented culture and a pool of employees with a deep well of innovation skills and a clear understanding of the company's investment in innovation". Indeed, with NCA, it is shown that Innovation Competences and not Innovation Organisations are necessary for Innovation Sourcing Success. Innovation Organisation is a necessary factor for Innovation Competences (see: Table 5.1) and influences Innovation Sourcing Success via its' necessity for Innovation Competences.

With polynomial regression, the evidence is shown that Innovation Sourcing Success depends on both the individual Innovation Competences of purchasers and the existence of adequate Innovation Organisation sourcing conditions, which were revealed to complement each other, meaning that a lack of skills cannot be substituted with organisational support and vice-versa.

Cousins et al. (2006) and Tassabehji and Moorhouse (2008) suggested that individual PSM competences and organisational backing are related in a complementary form. However, none of the PSM skills models analysed in the literature review provided empirical evidence. Moreover, the complementary effect is established in the innovation literature (e.g. Bresnahan, Brynjolfsson, \& Hitt, 2002; Leiponen, 2005; Michaelis \& Markham, 2017).

This research indicated that future PSM skills research - at least when applied in attempts to identify skills for success - should take the organisational support the responding individual is receiving into account, at least as a control variable. The failure of research might, in fact, actually measure organisational support in a particular firm and mistake the availability of a specific skillset as an antecedent to success. When two equally skilled individuals operate in either a supportive or a non-supportive organisation, the same skillset explains either the existence or the lack of PSM success. It is not the skills themselves that matter, but the ability to apply them so that they thrive and flourish through adequate organisational conditions. 
This study identified organisational support (Innovation Organisation) as a new construct of relevance in skills studies. Future research should include it in skills studies in innovation management research, and it cannot be excluded that organisational support may also influence other skill models. Simultaneously, the modelling of this variable Innovation Organisation has also indicated a limitation in this study. Only visible signals of support in the form of internal and external innovation targets and their measurement were considered. More elements are constituting the organisational setting a corporate actor is embedded into. For instance, the idea has emerged that innovation purchasers should be pooled in a (sub-)department of their own with the label 'procurement engineering' or 'advanced sourcing', rather than remaining a part of the strategic sourcing group (Schiele, 2010; Servajean-Hilst \& Calvi, 2018). Such an organisational setting would again foster the application of skills. Future research would benefit from confirming this assumption and exploring the exact structural and processual requirements that must be met for such departments to succeed.

\subsubsection{Implications for education and training: a hierarchical skillset as a teaching plan}

This research contributes to educational needs by answering the first research question to provide a list of distinct requirements associated with innovation purchasers leading to innovation sourcing success. The significant important skills found in this research have only been shown previously in a fragmented and scattered form in PSM competence literature and not being assigned to the particular target of innovation nor combined in a single list of innovation sourcing competences.

Another crucial and novel contribution of this study refers to the nature of innovation skills. Three factors within the set of competences associated with innovation purchasers have been presented: Soft Skills, Management Competences and Innovation Competences. It comes as no surprise that soft skills such as innovativeness provide help for innovation buyers and that specific tools such as early supplier involvement need to be mastered. Therefore, it is interesting to see that the innovation purchaser also has been titled Management Competences (knowledge of corporate governance, advisory skills, working together with HRM and the necessary conditions shown in Table 5.1: change management and project management). Innovations come into a firm through (NPD) projects, and they need to be defended and promoted within the company. Knowledge of corporate governance and change management skills are required to ensure that this is done. The emergence of awareness about the importance of these general management skills emphasises the increasingly strategic role of PSM in firms (Bals et al., 2019; Tassabehji \& Moorhouse, 2008). 
Moreover, the finding of the importance of Management Competences for innovation purchasers goes along with a recent observation derived from innovation research that gaining access to suppliers' innovations has a substantial strategic component. Buying firms benefit from being more attractive to suppliers than competing buyers to gain collaboration commitment and, by this means, to achieve competitive advantage (Goldberg \& Schiele, 2020; Schiele, 2012).

In designing a master program for PSM, it might well be beneficial to include a course on corporate governance presenting the above-listed Management Competences. This approach is advocated by Birou et al. (2016, p. 83): "Given the level of impact the $P / S M$ function has on the overall competitive position of a firm, the course content and curriculum must be relevant and rigorous enough to meet industry needs". It is not enough to educate in those tools which appear to be immediately applicable as defended by Campion et al. (2011, p. 226) in modelling competences as "collections of knowledge, skills, abilities, and other characteristics (KSAOs) that are needed for effective performance in the jobs in question".

Additionally, Delamare-Le Deist and Winterton (2005) have provided evidence that the proper combination of 'knowledge', 'professional skills', 'personal skills' and 'character traits' will lead to a status of 'being competent'. Thus having Innovation Competences alone and lacking Management Competences will keep the innovation purchaser ineffective. An interesting path for further research elaborating more extensively on these findings is to determine whether the lack of Management Competences is one of the factors preventing purchasing from becoming integrated into the innovation and NPD processes.

With NCA, composite-based structural equation modelling and polynomial regression analysis, the importance is shown of Innovation Competences, consisting of 17 different competence items grouped into three factors. The emphasis is that the factors Innovation Competences and Management Competences are fundamental. However, the conclusion is that (accumulated) knowledge in itself, and the presence in a favourable organisational setting are not sufficient to succeed in a PSM career.

Indeed, the Soft Skills factor plays a role (inventiveness, honesty, creativity, willingness to take risks). This finding would be in line with Bailly and Léné (2013, p. 93), who found that employers show an "increased demand for soft skills" held by employees, whereas the necessity for inventiveness and creativity is widely accepted in the innovation management and the PSM literature (e.g. Baer, 2012; Baer \& Oldham, 2006; Bals et al., 2019; Giunipero \& Pearcy, 2000; Kiratli et al., 2016; Perry-Smith \& Mannucci, 2017)

These findings might have implications for PSM curricula in higher education as well as corporate training plans. Traditionally, lecturers at European universities are 
focused on the transfer of knowledge and theory (Hoidn, 2017). It is also the case for universities in the USA, as concluded by Birou et al. (2016), who found that learning objectives in PSM courses in the USA mainly cover the transfer of knowledge and neglect personal skills development. Michaelis and Markham (2017, p. 41) found that this is also the case in companies; training people in innovation skills "is all too often neglected". A proper mix of competences consisting of knowledge, professional skills, interpersonal skills and intrapersonal and academic soft skills should be introduced. A course on innovation sourcing would benefit from reflecting on all 17 skills identified as contributing. Depending on the course's size, a focus on essential skills would first be considered.

The conclusions align with the Dublin Descriptors (Dublin Descriptors, 2004). These descriptors are part of the Bologna Process, which aims to harmonise higher education's national systems to certify equivalence in the quality and standards of higher-education qualifications in Europe. The Dublin Descriptors are thus intended to be endorsed by all European institutions of higher education. They state that learning objectives in general consists of the full range of competences and hence not exclusively the teaching of knowledge: "(i) knowledge and understanding, (ii) applying knowledge and understanding, (iii) making judgements, (iv) communication skills and (v) learning skills" (Dublin Descriptors, 2004; Leoni, 2014, p. 4), which is a combination of 'knowledge', 'professional skills', 'personal skills' and 'character traits' (Campion et al., 2011; Delamare-Le Deist \& Winterton, 2005) or merely hard skills and soft skills as proposed by Laker and Powell (2011).

A final but highly relevant finding refers to the importance of the intrapersonal characteristics this research identified, e.g. willingness to take risks (i.e. entrepreneurial behaviour), creativity, inventiveness and comprehension of complexity. The increased importance of these intrapersonal character traits is in line with Von der Gracht et al. (2016), who researched future skills of purchasers and who foresees existential threats in organisations when, in the course of a 'talent war' competitors recruit the most "creative and innovative minds" (Von der Gracht et al., 2016, p. 30). This finding is confirmed by Von der Gracht et al. (2018, p. 9), who state that in the future era of machine-to-machine communication, personnel tend to be "creative, productive and innovative".

Moreover, these findings align with Bals et al. (2019, p. 11), who "emphasises the need to think beyond functional skills, and embrace the meta-oriented competence area and this is becoming increasingly relevant for the modern PSM professional". What this research could do, was to identify the importance of these intrapersonal characteristics, which are confirmed in the innovation literature by Brenton and Levin (2012, p. 365), who found traits common to successful innovators to be: "tolerance for risk and uncertainty"; "ability to work with varied and complex information"; "collaborative interpersonal style"; and a "strong drive for results". 
Future research would benefit from developing personality tests to measure the potential innovation purchaser's personality validly and select the most suitable candidates proposed by Keinänen, Ursin, and Nissinen (2018, p. 35). They redeveloped a tool "to measure the development of students' perceptions of Innovation Competences throughout the degree program and measure universities' effectiveness and their pedagogical practices to produce innovative expertise". What could not be tested for is whether these are acquirable skills or personality traits, i.e. characteristics which cannot be trained.

\subsubsection{Implications for management: setting organisational targets and training the future CPO}

For management, the complementarity of organisational support and individual skills cannot be overemphasised. For instance, hiring highly skilled innovation purchasers is unlikely to lead to a substantial increase in suppliers' innovation contribution unless the firm recognises the importance of these people's contribution and communicates this through target setting. Hence, a program for innovation purchasing would firstly define innovation as part of the objective pursued by both purchasers and suppliers, and it would also measure the outcome.

Then, second (but in parallel), the purchasing personnel's current competence level would be assessed, and training plans derived. A gap might appear between the existing competences of individual members of innovation sourcing teams on the one side and the desired competences presented in this study. Feisel et al. (2011) suggest three methods to close such a gap: 1) training staff; 2) laying off current staff and hiring new personnel (selection criteria: soft skills, innovation know-how and management skills); and 3) changing the organisational conditions. Knowledge and professional skills can be trained to a certain extent.

Feisel et al. (2011, p. 65) assumed that: "the implementation of new organizational structures might initially affect organizational performance, but subsequently also affect the process, group or individual performance". In other words, for this model (see: Figure 5.2), it would mean that deviations on the $y$-axis (Innovation Organisation) would influence the (activation of the) Innovation Competences on the $x$-axis. It might mean that underdeveloped or even innate, intrapersonal character traits would be stimulated to 'flourish' by introducing appropriate organisational changes. This effect is probably revealed in this study by the significant necessity of Innovation Organisation for Innovation Competences, as shown in Table 5.1. The people who manage the innovation sourcing managers will need to consider individual competences development and create an appropriate and long-lasting right organisational atmosphere to maximise its benefits. 
This research's contribution, which might well have relevance beyond the innovation purchasing topic, refers to targets' importance. These are often considered ineffective and tiresome by personnel affected by those. However, the findings suggest a contrary, very different view: that is interpreted as the empirical importance of the organisational support targets in terms of these mirroring the firm's commitment towards a specific target or working on achieving the set target as professionals. Given this finding, future research would benefit by revitalising the somewhat stagnating field of purchasing controlling research and identifying suitable KPIs (Dudić, 2015), including innovation-oriented targets such as creativity, inventiveness and innovativeness (Kiratli et al., 2016).

A final (human resource) management implication of this study refers to the management skills a good innovation purchaser requires: change management, corporate governance, advice skills, cross-functional collaboration. These skills are also beneficial for a CPO. CPOs are expected to provide their departments with steering and introduce new tools and methods, for all of which they will need change management skills. The CPO must represent purchasing interests and inputs at the corporate level, closely interacting with the other functions.

The conclusion might be that the right innovation purchaser is acquiring the skills needed to take up a CPO role and - as a logical extension - that of a CEO (in an American setting) or the board's president (in a European governance model). Hence, the pool of innovation purchasers might coincide with the pool of (purchasing) high potentials. Put another way around: the more innovation takes on a central function in a firm, with purchasing having to contribute to this target, the more management talent will develop in this function, and the more this happens, the more likely it will be that purchasing will gain a strategic role in the enterprise.

\subsubsection{Limitations of this research: single respondent and Central European emphasis}

This research has limitations. Firstly, it is based upon a larger survey population ( $n=581)$ and, more precisely, on those focused on innovation purchasing $(n=103)$, a relatively limited sample. Another limitation is that the respondents are predominantly Western European. About two-thirds of the respondents have Dutch nationality, eleven per cent are French, and eight per cent Germanic (e.g. German and Austrian). Even though significant differences in the innovation variables could not be identified, cultural biases cannot be ruled out (Hofstede, 1980b; House et al., 1999; Kale, 1995; Schwartz, 1999, 2014). Hence, future research should test if the findings also hold, for instance, in collectivistic cultures and those with low uncertainty avoidance, which have not been prominent in this Western European sample (Tsao, Behr-Heyder, \& Ma, 2015). 
An additional limitation is that the survey competence items, the organisational conditions for innovation sourcing and the innovation success statements are self-assessed by the participants. An approach with multi-rater feedback is sometimes recommended. The use of self-assessed items in a survey comes with a risk of overstatement and understatement. This phenomenon is known as the Dunning-Kruger effect: unskilled professionals have the tendency "to hold overly favorable views of their abilities in many social and intellectual domains" (Kruger \& Dunning, 1999, p. 1121) and skilled professionals have the tendency "to underestimate their performance relative to their peers" (Kruger \& Dunning, 1999, p. 1126).

Nevertheless, the competence profile for innovation sourcing is positively associated with 17 items and negatively with six. Evidence is provided that innovation sourcing professionals are significantly negatively associated with cost reduction competences (i.e. Making cost analyses; Cost Reduction Techniques; Negotiation of the Specific Terms; Solicit Offers - Request for Quotation (RfQ) / Proposal (RfP) / Information (RfI); Evaluate Offers \& Supplier Selection; Global Sourcing / Supplier Acquisition).

The above would hold that the Dunning-Kruger effect is not strong in this research or is even absent in this substantial sample, which could be caused by the design of this research. It applies a self-perceived rating of the competence items and items regarding effectiveness in innovation sourcing of 581 PSM professionals. Unlike some other research, it does not list the highest-ranked items or factors and is not focused on top-rankings or high scores. As is explained in the chapter, this research is not centred on "important" high ranked competences of a group or an individual. Indeed, if only competence levels were asked, the Dunning-Kruger effect possibly could have been a flaw in the research. Instead, the skills of purchasers with an innovation focus are compared with those with other foci. Next, these innovation-related skills were associated with effectiveness in innovation sourcing in combination with organisational support.

A fourth limitation is that due to the limited number of respondents per sector, differentiation between sectors and different industries could not be made. Innovation sourcing competences and organisational conditions in different industries may deviate. Nevertheless, this research is the first to have identified innovation sourcing competences and conditions in general, and for that reason, it may well serve as a starting point for further research. 


\section{Chapter 6}

\section{How to Train Supply Managers}

\section{Necessary and Sufficient Purchasing Skills Leading to Success}




\section{HOW TO TRAIN SUPPLY MANAGERS \\ NECESSARY AND SUFFICIENT PURCHASING SKILLS LEADING TO SUCCESS}

\subsection{Introduction - lack of clarity on the importance and selection of purchasing skills}

The PSM (purchasing and supply management) function has evolved into a human-centric discipline in which human capital input is of strategic importance to firms (Bals et al., 2019; Hohenstein et al., 2014). Given the importance of the human aspect, it is not surprising that the contributions of PSM to a firm's effectiveness are considered to be primarily dependent on individual PSM professionals' 'skills' (Feisel et al., 2011; Knight et al., 2014; Tassabehji \& Moorhouse, 2008). (In general, the PSM literature mainly uses 'skill' or 'skills' to refer to the separate competence construct items, which, according to Delamare-Le Deist and Winterton (2005), include knowledge, professional skills, interpersonal skills, intrapersonal traits, behaviours and attitudes. For the sake of brevity, this study uses the term 'skill' in all the cases to refer to different items of the competence construct.)

As the field of PSM is evolving and professionalising, it is also differentiating. Depending on the firm's strategy, PSM professionals have different targets, focuses or objectives (hereafter referred to as 'objectives') (Schiele, 2019), such as lowering the costs of supplies, acquiring innovative supplies or improving sustainability (Schulze \& Bals, 2020). A distinction between PSM's objectives in reducing supply costs and creating long-time value by accessing the suppliers' innovations can also be found in other, primarily innovations-directed, PSM literature.

Tracey and Neuhaus (2013) distinguish between innovation-focused ('facilitating') and operational ('regulatory') objectives of PSM professionals. This division is also seen by Johnsen et al. (2012). They have highlighted that the PSM professionals who aim at innovation sourcing and implementation need to assess suppliers' innovative capabilities rather than reduce costs. According to Knight et al. (2014), both PSM types require deviating skills and share only a few common grounds. The recognition that purchasers might have very different objectives depending on 
their companies' strategies might suggest broad support in the literature on PSM skills for differentiated skillsets, at least one for cost and one for differentiation-oriented firms. Remarkably, this is not the case.

The outcome of the systematic review of PSM skills literature (1987-2020) that was performed for this study (see the theory section for further details) shows little unanimity. While a majority of the studies agree upon the need for 'PSM knowledge' (82 per cent), 'business knowledge' (76 per cent) and 'negotiation skills' (73 per cent), one-third of the studies introduce skills that the other studies did not consider, such as 'creativity' (33 per cent), 'industry knowledge' (33 per cent) and 'legal knowledge' (30 per cent).

The possible deviations do not explain the unanimity within the set of PSM skills literature over time. The set of articles was divided into two categories: " $20^{\text {th }}$ century" (1987-2001; 16 articles) and "21 ${ }^{\text {st }}$ century" literature (2003-2020; 17 articles). Contentwise, both sets do not deviate significantly, as shown in the theory section. However, an explanation for the controversial findings could be that these various studies have presented the skillsets of different objectives and labelled them as something like a general skillset for a universal type of PSM professional (e.g. Bals et al., 2019; Giunipero et al., 2006; Giunipero \& Pearcy, 2000; Tassabehji \& Moorhouse, 2008). Nevertheless, as indicated by Knight et al. (2014), this general type might not exist. Depending on the empirical sample composition, different skills could emerge as being more or less important. Therefore, assuming that there is no "one fits all" type of purchaser, but differentiated types, the following research question arises:

(RQ1) Which different skillsets do PSM professionals need in accordance with the different prevailing objectives of their organisation?

Further, are all different skills of equal importance? While the extant PSM literature is not unanimous in the PSM skillset design, the word choice detected in the PSM skills literature does attract attention and, more precisely, the use of the term "necessary" in combination with a particular skill. The PSM skills literature often assumes that "important" skills can be seen as "necessary" (conditions) for performing the PSM function (e.g. Bals et al., 2019; Giunipero \& Pearcy, 2000; Tassabehji \& Moorhouse, 2008; Von der Gracht et al., 2016).

For instance, Bals et al. (2019) have used the term 'necessary' in combination with 'skills' six times, Giunipero and Pearcy (2000) seven times, Tassabehji and Moorhouse (2008) three times and Schulze and Bals (2020) have used it twice. It is nevertheless questionable whether the presented skills are 'sufficient' or 'necessary' conditions for performing the PSM function. In the literature, the distinctions between 'sufficient' or 'necessary' conditions are often made in an implicit manner "using alternative formulations, such as $X$ being critical or a precondition for $Y$ " (Van der Valk et al., 2016, p. 267). 
Indeed, a necessary condition will prevent an outcome from occurring. In the necessary condition logic, there will be "no $Y$ without $X$ " (Van der Valk et al., 2016, p. 267). The sufficient condition logic is that the independent variable $X$ leads to the outcome, i.e. the dependent variable $Y$. Van der Valk et al. (2016), who performed Necessary Condition Analysis (NCA) on 'legal contracts' versus 'trust' on innovation in buyer-supplier relations, concluded the following: "Thus, while a sufficient cause produces the outcome, a necessary cause allows the outcome to exist. Conversely, without the necessary cause, the outcome will not exist despite other factors being present" (Van der Valk et al., 2016, p. 267).

The question of which skills are necessary and which are not is also essential for educators and trainers designing learning objectives, given the limitations of time available for education and hence the request to make choices which skills to teach first. The PSM skills literature does not differentiate between sufficient and necessary conditions. Consequently, it hinders the design of an appropriate set of learning objectives and further professionalising the PSM function. To support the development of learning and training objectives for PSM, this study, therefore, addresses the following research question:

(RQ2) Which skills are necessary and which are sufficient for PSM professionals?

This study aims to overcome these two gaps in the PSM skills literature - the lack of differentiation in purchasers' objectives and the lack of differentiation between important and secondary skills - and followed a quantitative approach in surveying European PSM professionals $(n=366)$. The participants rated a set of 88 skills that were identified in the literature. Eventually, it became possible to condense a statistically relevant set of 15 factors, each representing a particular PSM skill category. As a next step, OLS (ordinary least square) regression was used to identify those skills that explained the results in a particular PSM objective and NCA to distil the primary or necessary conditions for job execution.

This investigation contributes in at least three ways. The first contribution of this study is adding to the literature by presenting an empirically validated PSM skills model and taxonomy, which is the first to be based on a large multi-national sample, identifying 15 empirically backed skill factors. Instead of reporting on the availability of skills, only, this study uses the purchaser's effectiveness or success as the dependent variable. In this way, the importance of soft factors is unveiled, likewise the seldom reported relevance of "sellership", the need for purchasers to have the skill to promote their company and function. The empirical analysis also reveals a different ranking in the importance of purchasing skills than, on average, suggested by previous research.

Second, this research discusses and tests seven PSM objectives (focus on the cost objective, quality, delivery, sustainability, supplier satisfaction, innovation or competitive advantage). For each objective, it is shown that a different, adjusted skillset 
is necessary. This finding questions the validity of the traditional "one size fits all" approach, clearly indicating that there does not seem to be someone like "the" purchaser. Depending on corporate objectives, different skills are needed. By including the objectives, an organisation has, this research contributes by introducing a new analysis level, previously not considered in purchasing skills research. The empirical findings indicate internal inconsistencies in the standard one size fits approach, as some skills have an opposite effect on performance with different targets.

Third, being the first study to distinguish between necessary and sufficient conditions, this research can reposition the soft skill vs hard skill debate. Classical regression analysis identifies the differentiating factors (here: skills), explaining an outcome (here: purchaser's performance). However, the NCA shows that the four identified soft skills, while having minor differentiating character, are essential antecedents to hard skills. Without a minimum level of soft skills - networking, result orientation, imagination and sellership - purchasers are not efficient in employing a series of the identified hard skills.

Finally, the findings challenge some of the common grounds in the literature review, such as alerting about an over-emphasis on negotiation skills and revealing the pivotal importance of supplier relationship management and strategic sourcing management skills. This research also contributes to PSM practice by providing a PSM skills model and taxonomy and by deriving a list of skills differentiating between the PSM objectives. It provides insight into those skills that can be associated with results in PSM. It contributes in practical terms to the practitioners' work regarding the design of PSM curricula in higher education and company training programmes.

This chapter is organised in the following manner. The second section presents the literature on PSM skills and discusses PSM objectives. The subsequent methodology section describes how the literature review was performed, how an extensive European survey was set up, how the survey items were subjected to factor analyses and how the data, i.e. the factors, were analysed with OLS regression and with the newly developed NCA method (Dul, 2016b). The sets of results of this study are presented in the fourth section. The final section includes the conclusions, a discussion on further research, the implications of the findings, and the study's limitations.

\subsection{The literature on purchasing skills as drivers for organisational performance}

\subsubsection{Systematic literature review indicating a lack of consensus over time}

For this study, a keyword search in Scopus was applied, following Durach et al. (2017). It led to an initial set of 1,007 articles. A list of PSM skills was gradually extracted (see: Appendix 9.2). The key search terms that were used were 'buyer', 'purchase', 'purchaser', 'purchasing', 'procurement', 'skill', 'skills', 'competence', 'competency' and 
'competencies' and led to the search string 'buyer OR purchas* OR procurement AND competenc* OR skill*'. Articles regarding non-individual, organisational capabilities and those focused on consumer skills of family household purchasing budget use were discarded. Likewise, the minor citations that mention the search terms as 'PSM skills' only incidentally were discarded. Eventually, only the skillsets referred to in 33 studies published between 1987 and 2020 PSM skills could be extracted (see: Appendix 9.1).

Appendix 9.1 displays the PSM skills' frequencies of being mentioned at least once in the focal scientific PSM article and shows little unanimity. While a large majority of the studies agree upon the need for 'PSM knowledge' (82 per cent), as well as 'business knowledge' (76 per cent) and 'negotiation skills' (73 per cent), about one-third of the studies introduce skills that the other studies did not consider, such as 'creativity' (33 per cent), 'industry knowledge' (33 per cent) or 'legal knowledge' (30 per cent). Remarkably, whereas the PSM literature has distinguished different objectives within the function, the PSM skills literature has not made this differentiation. Instead, it presents general skillsets for a universal PSM professional type, with Knight et al. (2014) and Schulze and Bals (2020) as exceptions.

Appendix 9.2 displays the methods that were used in the researched articles. In approximately 20 per cent of the cases, these were qualitative (case studies or interviews); in 40 per cent of the cases, these were quantitative, survey-based, and in another 40 per cent of the cases, these were based on a mix of quantitative (surveys) and qualitative methods (case studies or interviews). Following Fawcett and Rutner (2014, p. 180), who stated that the PSM practices in firms have "evolved dramatically over the past generation", the data were subjected to further statistical analyses.

Therefore, the scientific PSM literature sample was divided into two categories: from 1987 to 2001 (16 articles) and 2003 to 2020 (17 articles). Next, an independent $t$-test was performed on the skills frequencies. The outcomes revealed insignificant $p$-values $(p>.05)$. Hence, the PSM skillsets, as proposed in the series of ' $20^{\text {th }}$ century' (1987 to 2001 ) and ' $21^{\text {st }}$ century' (2003 to 2020 ) literature, do not deviate significantly, and the non-unanimity within the PSM skills literature (1987-2020) is not explained with possible deviations over time. However, within the complete set of 33 articles, there exists non-unanimity. It could not be explained by the supposedly exploratory character of the research field or by the different objectives that could have been mixed up. The PSM skills literature is briefly described in the following sub-section.

\subsubsection{Purchasing skills in literature: theoretical perspectives, distinguishing between hard and soft skills}

The research on PSM skills has developed over the past three to four decades; based upon the summaries of Tassabehji and Moorhouse (2008) and Bals et al. (2019), an extended summary of PSM skills in the literature is displayed in Table 6.1. Initially, the main focus has been on professional knowledge and skills: computer literacy skills, 
cost reduction and financial skills, quality management, analytical skills and strategic sourcing. Gradually, the attention for personal skills and traits emerged, especially for decision-making, communication, influencing and persuasion, teamwork, creativity and conflict resolution.

Table 6.1 - summary of PSM skills in the literature - extended from Tassabehji and Moorhouse (2008) and Bals et al. (2019), i.e. Chapter 2

\begin{tabular}{|c|c|c|c|}
\hline authors & $\begin{array}{l}\text { Categorisa- } \\
\text { tion of PSM } \\
\text { skills }\end{array}$ & findings & \\
\hline $\begin{array}{l}\text { Cavinato } \\
\text { (1987) }\end{array}$ & $\begin{array}{l}\text { technical; } \\
\text { management; } \\
\text { interpersonal } \\
\text { (group \& } \\
\text { individual) }\end{array}$ & $\begin{array}{l}\text { Professional skills and } \\
\text { knowledge } \\
\text { automated purchasing } \\
\text { systems; computer skills; } \\
\text { costing skills; knowledge of } \\
\text { materials; management } \\
\text { information systems skills; } \\
\text { materials management, } \\
\text { inventory systems and JIT; } \\
\text { production systems and } \\
\text { technologies; quality systems } \\
\text { and options; contract } \\
\text { manufacturing relationships }\end{array}$ & $\frac{\text { Personal skills and traits }}{\text { strong communication skills }}$ \\
\hline $\begin{array}{l}\text { Kolchin } \\
\text { and } \\
\text { Giunipero } \\
\text { (1993) }\end{array}$ & $\begin{array}{l}\text { strategic; } \\
\text { quantitative }\end{array}$ & $\begin{array}{l}\text { Professional skills and } \\
\text { knowledge } \\
\text { analytical skills; computer } \\
\text { literacy }\end{array}$ & $\begin{array}{l}\text { Personal skills and traits } \\
\text { ability to make decisions; } \\
\text { conflict resolution; customer } \\
\text { focus; interpersonal } \\
\text { communication; influencing } \\
\text { and persuasion; managing } \\
\text { change; negotiations; } \\
\text { problem-solving }\end{array}$ \\
\hline $\begin{array}{l}\text { Carr and } \\
\text { Smeltzer } \\
(2000)\end{array}$ & $\begin{array}{l}\text { technical } \\
\text { skills; skills } \\
\text { techniques; } \\
\text { behaviour } \\
\text { skills }\end{array}$ & $\begin{array}{l}\text { Professional skills and } \\
\text { knowledge } \\
\text { analytical skills techniques; } \\
\text { cost analysis; drafting } \\
\text { CAD/computer and maths } \\
\text { skills; technical business } \\
\text { writing, blueprint reading; } \\
\text { forecasting; organisational } \\
\text { (paperwork); programme, } \\
\text { quality, time management; } \\
\text { understanding: tool } \\
\text { capability, manufacturing } \\
\text { processes, MRP; materials; } \\
\text { inventory systems }\end{array}$ & $\begin{array}{l}\text { Personal skills and traits } \\
\text { communication; } \\
\text { presentation; co-ordination; } \\
\text { negotiating (cost) and issues; } \\
\text { problem-solving; people } \\
\text { skills (suppliers); internal } \\
\text { customers and functions; } \\
\text { detail orientation; } \\
\text { proactivity; ability to follow } \\
\text { up; flexibility; stress } \\
\text { management; team working; } \\
\text { patience; multi-tasking }\end{array}$ \\
\hline $\begin{array}{l}\text { Giunipero } \\
\text { and } \\
\text { Pearcy } \\
\text { (2000) }\end{array}$ & $\begin{array}{l}\text { process } \\
\text { management; } \\
\text { team skills; } \\
\text { decision- } \\
\text { making; } \\
\text { behavioural }\end{array}$ & $\begin{array}{l}\text { Professional skills and } \\
\text { knowledge } \\
\text { blueprint reading; } \\
\text { computational skills; } \\
\text { computer literacy; } \\
\text { organisation/time } \\
\text { management; specification }\end{array}$ & $\begin{array}{l}\text { Personal skills and traits } \\
\text { decisions making; conflict } \\
\text { resolution; customer focus; } \\
\text { creativity; influencing, } \\
\text { persuasion; inquisitiveness; } \\
\text { interpersonal communica- } \\
\text { tion; leadership; managing }\end{array}$ \\
\hline
\end{tabular}


development; supply base research; supplier cost targeting; technical skills; technology planning; understanding business conditions

$\begin{array}{lll}\begin{array}{l}\text { Giunipero } \\ \text { et al. }\end{array} & \text { no } & \text { Professional skills and } \\ (2005) & \text { categorisation } & \frac{\text { knowledge }}{\text { planning }}\end{array}$

Giunipero, no Handfield categorisation and Eltantawy (2006)

Cousins et no al. (2006) categorisation

Feisel et no

al. (2007) categorisation

$\begin{array}{ll}\text { Tassabehji } & \text { technical } \\ \text { and } & \text { skills, } \\ \text { Moorhous } & \text { including } \\ \text { e (2008) } & \text { advanced } \\ & \text { procurement } \\ & \text { process skills; } \\ & \text { interpersonal } \\ & \text { skills; internal } \\ & \text { and external } \\ & \text { enterprise } \\ & \text { skills; }\end{array}$

\section{Professional skills and}

\section{knowledge}

technical skills; web-enabled research; sourcing analysis; broader financial skills; cost accounting; strategic planning skills; project scoping, goal-setting, and execution; making business cases Professional skills and

\section{knowledge} supplier/product market monitoring, interpretation; technical skills to improve products and processes; cost analysis to improve total costs with suppliers Professional skills and knowledge strategic objective

\author{
Professional skills and \\ knowledge \\ analytical skills; basic \\ knowledge on PSM role \& \\ processes; business acumen; \\ computer literacy; contract \\ management; cost savings; \\ cross-functional abilities \& \\ knowledge; eProcurement \\ technology; engineering; \\ finance; financial acumen; \\ intellectual-property;
}

change; managing internal customers; negotiation; problem-solving; risk-taking, entrepreneurship; salespersonship; strategic thinking; structuring supplier relationships; tactfulness; teamwork; written communication Personal skills and traits flexibility skills: influencing and persuasion; internal motivation; creativity; risk management; decisionmaking; interpersonal communication Personal skills and traits team-building skills; leadership; decision-making; influencing; compromising; communication skills; presentation; public speaking, listening and writing

\section{Personal skills and traits}

perseverance; imagination; decisiveness; interpersonal skills

Personal skills and traits
flexibility skills;
entrepreneurial skills; plan
projects with multiple
stakeholders; influence
suppliers and (internal)
business partners; a strong
will to contribute to
organisational results;
proactive; creative; decisive
Personal skills and traits
change management;
communication skills;
conflict resolution;
creativity; cultural
awareness; customer focus
decision making; effective
questioning techniques;
integrity; interpersonal
communication; knowledge
sharing; languages;
leadership; learning agility;




\begin{tabular}{|c|c|c|c|}
\hline & $\begin{array}{l}\text { strategic } \\
\text { business skills }\end{array}$ & $\begin{array}{l}\text { KPI reporting design; logistics; } \\
\text { manufacturing/production; } \\
\text { marketing; process } \\
\text { optimisation; product } \\
\text { knowledge; project } \\
\text { management; PSM best } \\
\text { practice intelligence scouting; } \\
\text { quality assurance; quality; } \\
\text { risk management; R\&D; } \\
\text { supply chain; } \\
\text { sales; stakeholder } \\
\text { relationship management; } \\
\text { supplier management; } \\
\text { strategic sourcing; tools and } \\
\text { systems implementation }\end{array}$ & $\begin{array}{l}\text { negotiation; networking; } \\
\text { prioritisation; remote virtual } \\
\text { working; results focus - } \\
\text { driving for results; strategic } \\
\text { thinking; structured way of } \\
\text { working; teamwork-working } \\
\text { in teams }\end{array}$ \\
\hline $\begin{array}{l}\text { Knight, Tu } \\
\text { and } \\
\text { Preston } \\
\text { (2014) }\end{array}$ & $\begin{array}{l}\text { categorisation } \\
\text { based on } \\
\text { Kraljic' (1983) } \\
\text { quadrants: } \\
\text { routine type; } \\
\text { tactical type, } \\
\text { and strategic } \\
\text { type }\end{array}$ & $\begin{array}{l}\text { Professional skills and } \\
\text { knowledge } \\
\text { analytical skills; blueprint } \\
\text { reading; computer literacy; } \\
\text { cost analysis; forecasting } \\
\text { skills; managing strategic } \\
\text { partnerships; mathematical } \\
\text { skills; product knowledge; } \\
\text { quality management; } \\
\text { specification development; } \\
\text { supplier cost targeting; } \\
\text { supplier evaluation; supplier } \\
\text { relationship management; } \\
\text { supply base research; risk } \\
\text { management technical } \\
\text { writing; understanding } \\
\text { business conditions; } \\
\text { understanding manufacturing } \\
\text { terminology; understanding } \\
\text { manufacturing process }\end{array}$ & $\begin{array}{l}\text { Personal skills and traits } \\
\text { ability to work in teams; } \\
\text { change management; } \\
\text { communication skills; } \\
\text { conflict resolution; } \\
\text { coordinating skills; customer } \\
\text { focus; decision-making skills; } \\
\text { influencing and persuasion; } \\
\text { leadership; managing } \\
\text { internal customers; } \\
\text { negotiation skills; problem- } \\
\text { solving skills; project } \\
\text { management; strategic } \\
\text { thinking }\end{array}$ \\
\hline $\begin{array}{l}\text { Bals, } \\
\text { Schulze, } \\
\text { Kelly and } \\
\text { Stek } \\
\text { (2019) }\end{array}$ & $\begin{array}{l}\text { ditto as } \\
\text { Tassabehji } \\
\text { and } \\
\text { Moorhouse } \\
\text { (2008) }\end{array}$ & $\begin{array}{l}\text { Professional skills and } \\
\text { knowledge } \\
\text { see: Tassabehji and } \\
\text { Moorhouse (2008) } \\
\text { automation; big data } \\
\text { analytics; } \\
\text { innovation sourcing; } \\
\text { innovative sourcing } \\
\text { approaches; sustainability }\end{array}$ & $\begin{array}{l}\text { Personal skills and traits } \\
\text { see: Tassabehji and } \\
\text { Moorhouse (2008) } \\
\text { curiosity; critical thinking; } \\
\text { deal with ambiguity; holistic } \\
\text { (supply chain) thinking; } \\
\text { humility; mobility; openness; } \\
\text { open-minded; passion; } \\
\text { resilience; self-confidence; } \\
\text { self-reflection; self-reliance }\end{array}$ \\
\hline $\begin{array}{l}\text { Schulze et } \\
\text { al. (2019) }\end{array}$ & $\begin{array}{l}\text { cognition- } \\
\text { oriented } \\
\text { competences; } \\
\text { social- } \\
\text { oriented } \\
\text { competences; } \\
\text { functional- } \\
\text { oriented } \\
\text { competences; } \\
\text { meta-oriented }\end{array}$ & $\begin{array}{l}\frac{\text { Professional skills and }}{\text { knowledge }} \\
\text { basic individual knowledge of } \\
\text { PSM; basic sustainability } \\
\text { knowledge; contract } \\
\text { management } \\
\text { implementation; } \\
\text { data and systems; demand } \\
\text { management - category } \\
\text { strategy; demand }\end{array}$ & $\begin{array}{l}\text { Personal skills and traits } \\
\text { ability to make decisions; } \\
\text { ability to work in a cross- } \\
\text { functional team; } \\
\text { commitment to change; } \\
\text { communication skills; } \\
\text { communication for } \\
\text { stakeholder management; } \\
\text { communication for supplier } \\
\text { relationship management; }\end{array}$ \\
\hline
\end{tabular}




$\begin{array}{lll}\text { competences } & \text { management - tender } & \text { cooperative attitude for } \\ & \text { analysis; HR management } & \text { supplier relationship } \\ \text { and training; invoice, } & \text { management; creative } \\ \text { payment; ordering, order } & \text { resource combinations; } \\ \text { confirmation, claim } & \text { critical thinking; holistic view } \\ \text { management; performance } & \text { on supplier relationship } \\ \text { management; purchase-to- } & \text { management; negotiation } \\ \text { pay; requisition and approval; } & \text { skills; organisationally and } \\ \text { reporting and measurement } & \text { politically savvy - interaction } \\ \text { implementation; spend and } & \text { and playful attitude; } \\ \text { demand analysis; source-to- } & \text { resourcefulness - } \\ \text { contract; stakeholder } & \text { application of tools; self- } \\ \text { management; supplier } & \text { reflection; systems thinking } \\ \text { relationship management; } & \text { competence } \\ \text { sustainability and compliance } & \end{array}$

Traditionally, procurement was asked to provide the right product, at the right moment, with sufficient quality for the lowest price. However, in the last decades, PSM evolved from such a mainly clerical function to more a strategic one, adding further objectives purchasers have to fulfil. From the 1990s, firms focused on make-or-buy decisions and started to define their core and non-core activities (Luzzini \& Ronchi, 2016). The focus on core competences in organisations, as underlined by Prahalad and Hamel (1990) and the outsourcing of the rest had as a consequence, that the importance of supplier management, supply chain management and strategic decisionmaking increased, and so the scope of purchasing objectives (Luzzini \& Ronchi, 2016).

However, the attention for differentiated purchasing objectives is not reflected in the proposed skillsets as displayed in Table 6.1. These skillsets have a universal character and do not differentiate between purchasing practitioners' objectives. The study by Knight et al. (2014) is an exception. This work was the first to detect different PSM objectives in their sample. Based on a survey in Taiwan $(n=72)$, strategic, tactical and routine purchasing skills profiles were found and were projected on the quadrants of Kraljic (1983). The most critical strategic competences are a mix of personal and professional skills. They are: "influencing and persuasion", "decisionmaking skills", "coordinating skills", "ability to work in teams", "managing internal customers", "change management", "strategic thinking", "specification development", "understanding manufacturing terminology and processes" (Knight et al., 2014, p. 278).

Another exception is the interview-based research $(n=46)$ of Schulze et al. (2019) that elaborated on skills specifically for corporate social responsibility (CSR) and sustainable PSM and concluded that strategic skills are more effective than transactional, operational skills. This study is the first in this series to be dedicated to a particular PSM objective - in this case, sustainability - while the bulk of the traditional literature on PSM skills is qualitative or conceptual and does not differentiate among PSM's diverse objectives might have to fulfil. 
In line with the growing empirical and conceptual importance of the PSM function, the number of PSM objectives has increased, which has made the PSM function more complex. A solution to grasp the complexity comes from Tchokogué, Nollet, and Robineau (2017), who proposed a sequence of organisational objectives based on a systematic PSM literature review (1975-2014). This sequence expands from operational to strategic objectives.

Moreover, the sequence in objectives seems to be hierarchical, i.e. the supply function must first master the operational corporate improvement objectives before it can support strategic competitive advantage objectives. "Therefore, supply professionals should develop their ability to utilise the currently acknowledged strategic contributions better, while being ready to take advantage of the new types of contributions" (Tchokogué, Nollet, et al., 2017, p. 105). Thus, a distinction can be made between operational or tactical activities that involve an emphasis on efficient order placement and price savings and strategic activities "with an emphasis on total cost savings and value-added activities" (Giunipero et al., 2006, p. 824).

A sequence proposed by Tchokogué, Nollet, et al. (2017) at an organisational level has also been seen by Ahmed et al. (2012) to be applicable at an individual level. They have found evidence that soft skills (i.e. interpersonal skills and intrapersonal traits) are as important as professional skills (or hard skills). As is evident, the PSM skills literature also recognises personal and professional skills. In line with this skills literature, the educational literature distinguishes between "soft skills" and "hard skills" (e.g. Andrews \& Higson, 2008; Bailly \& Léné, 2013; Heckman \& Kautz, 2012; Laker \& Powell, 2011). According to Heckman and Kautz (2012, p. 451), soft skills are "personality traits, goals, motivations, and preferences". Laker and Powell (2011, p. 113) have seen "hard-skills or technical training (working with equipment and software) and soft-skills training (interpersonal or intrapersonal focus)".

Ahmed et al. (2012) have underlined that the lack of soft skills is more expected to be the reason for ending a labour relationship than a lack of hard skills, and they add that soft skills not only are highly valued by employers but are also necessary to carry out professional tasks or hard skills (Ahmed et al., 2012). In line with that, Muir (2004, p. 99) has stated that "soft skills are necessary to actually implement-to articulate a vision; to enrol others in possibilities; and to communicate values, standards, and expectations". Socha, Razmov, and Davis (2003, p. 4) have added that "soft skills are necessary to apply the hard skills effectively". 


\subsection{Methodology - deriving of purchasing competences leading to success surveying European purchasers}

\subsubsection{PSM objectives: operational and strategic requirements for PSM reflecting a broad scope of purchasing objectives}

In terms of systematically describing the objectives, Nollet, Ponce, and Campbell (2005) have noted that Doyle (1990) was the first to provide a PSM strategy reflecting five purchasing objectives: "quality improvement (variance reduction), velocity (concept-to-customer cycle time improvement), all-in-cost (total-cost purchasing practices), technology (access and active monitoring) and risk reduction (an activity-managed program approach)" (Nollet et al., 2005, p. 134). Moreover, PSM's task is to provide the most value throughout the value chain to contribute to sustained competitive advantage (Nollet et al., 2005).

Moreover, PSM's task is to provide the most value throughout the value chain to contribute to sustained competitive advantage (Nollet et al., 2005). Schulze et al. (2019) have added to the list of these six objectives, of Nollet et al. (2005), a seventh objective owing to the "increasing resource scarcity challenges, stakeholder expectations and growing legal regulations regarding environmental and social concerns, PSM not only has to manage traditional objectives such as cost, time, quality and flexibility but is also faced with managing innovation and sustainability within supply chains" (Schulze et al., 2019, p. 3). Reflecting the understanding of purchasing as a strategic function, contributing to generating a competitive advantage and caring about the relationship towards suppliers and their satisfaction becomes further objective purchasers have to comply to (Schiele, 2019).

Therefore, the seven objectives separately analysed in this research resume to the following:

(1) Ensuring appropriate costs, i.e. aiming at the lowest costs, probably has the longest tradition in PSM and is a pivotal, hygienic requirement (e.g. Nollet et al., 2005; Schiele, 2007; Schiele, Horn, et al., 2011; Schulze et al., 2019; Shin, Collier, \& Wilson, 2000),

(2) Ensuring timely delivery, i.e., sufficient and safe supply (e.g. Giunipero, 2000; Nollet et al., 2005; Schulze et al., 2019; Shin et al., 2000; Zimmer, 2002),

(3) Ensuring appropriate quality of the supplies (e.g. Fernandes, Sampaio, Sameiro, \& Truong, 2017; Forker, Mendez, \& Hershauer, 1997; Nollet et al., 2005; Schulze et al., 2019; Shin et al., 2000),

(4) Ensuring appropriate sustainability, complying with CSR in a social perspective as well as in green, environmental procurement perspective (e.g. Johnsen, Howard, \& Miemczyk, 2014; Schulze \& Bals, 2020; Schulze et al., 2019; Wilding et al., 2012) 
(5) Striving for sustained competitive advantage for the firm founded on the Resource-based view theory (e.g. Barney, 1991, 2012; Dyer, 1996; Nollet et al., 2005),

(6) Ensuring a relationship characterised by the accomplishment of supplier satisfaction as a precondition for being a preferred customer and guaranteeing privileged access to sources of supply (e.g. Nollet et al., 2005; Pulles, Schiele, et al., 2016; Vos, Schiele, \& Hüttinger, 2016) and

(7) Facilitating innovations from and with suppliers, i.e. the sourcing and implementation of innovative solutions and the creation of new advantages (e.g. Azadegan \& Dooley, 2010; Foerstl, Hartmann, Wynstra, \& Moser, 2013; Hesping \& Schiele, 2015; Johnsen et al., 2012; Krause, Vachon, \& Klassen, 2009; Legenvre \& Gualandris, 2018; Nollet et al., 2005; Schiele, Horn, et al., 2011; Schulze et al., 2019; Terpend et al., 2011).

As mentioned, the PSM function is mainly dependent on PSM professionals' skills that must fulfil differentiated objectives coming forth from the firm targeting an industry or segment with either differentiation or a cost leader strategy (Porter, 1980). The approaches at the one hand in cost reductions and at the other hand in innovation sourcing require fundamentally different approaches, as is referred to by Legenvre and Gualandris (2018, p. 97), who found evidence that PSM professionals responsible for innovation sourcing "need to look beyond risks, cost, and product development to offer further competitive advantages". Hence, the objectives in PSM can differ, and the full PSM skill palette is broad, serving sheer operational objectives, as well as exceptionally strategic ones, leading to potentially contradictory skillsets.

\subsubsection{Research design of the online European PSM skills survey}

This study depended on 366 PSM professionals' responses from the private sector in the PSM skills survey. Initially, about 3,200 European PSM professionals from the public $(n=215)$ and private sector $(n=366)$ were personally invited via Linkedln.com to take part in the online survey ( $n=581$; response rate $>18$ per cent). The survey was pre-tested with six PSM professionals in different industries in both Germany and the Netherlands. The pre-test led to the clarification of the texts of the items and the introduction of missing items.

For this research, the respondents from public procurement were discarded as there was evidence that the procurement in the public sector differs significantly from the private sector (Stentoft Arlbjørn \& Vagn Freytag, 2012; Telgen et al., 2007). Despite the similarities in the demands for supplies in public procurement and private purchasing, both deviate since public procurement is subject to external demands such as 'transparency', 'integrity', 'accountability' and 'exemplary behaviour' and to internal 
demands like serving multiple political goals for many stakeholders. Moreover, public procurement is budget-driven and has to comply with regulations (Telgen et al., 2007).

There was a standard spread across different age groups in the sample, and about one-quarter of the respondents were female, and three-quarters were male. The respondents were primarily Western European, predominantly Dutch. About 58 per cent of the respondents were of Dutch nationality, 14 per cent were French, and about 11 per cent were German. All items were measured on a five-point Likert scale (ranging from 'fully disagree' to 'fully agree'). The survey consisted of different kinds of items. The participants self-rated 88 different competence levels and 22 self-rated statements on individual and organisational effectiveness in the seven objective areas aimed at improving (1) cost levels, (2) delivery performance, (3) quality and (4) sustainability levels, (5) achieving sustained competitive advantage, (6) supplier satisfaction and (7) innovation sourcing and implementation (see: Appendix 9.26 for the formulation of the items and the sources).

The form and wording of the 'cost reduction' and 'innovation' statements were based on the studies by Azadegan and Dooley (2010), Hesping and Schiele (2016), Krause, Pagell, and Curkovic (2001), Schiele, Horn, et al. (2011) and Terpend et al. (2011). The quality, sustainability, delivery, competitive advantage and supplier satisfaction items were based on the literature (see the references in the listing in the theory section) and stated or rephrased in the exact wordings as the 'cost reduction' and 'innovation' statements.

The participants were invited to rate their competence level on 88 skills (see: Appendix 9.14). Next, the participants were asked to rate statements on their effectiveness on the seven PSM objectives. All items were measured on a five-point Likert scale (ranging from 'fully disagree' to 'fully agree'). Self-assessment on a Likert scale is a widely accepted method in the PSM skills literature (e.g. Giunipero, 2000; Giunipero \& Pearcy, 2000; Knight et al., 2014).

The 88 skills items and the 22 statements on individual and organisational targets in the seven objectives were subjected to factor analyses. In both cases, Bartlett's tests of sphericity appeared to be significant, and the Kaiser-Mayer-Olkin measure of sampling adequacy (KMO) was above the threshold (KMO of skills: .963; KMO of statements: .818), and therefore, the factor analyses could be performed (Bartlett, 1950; Kaiser, 1970, 1974).

Confirmatory factor analysis by applying principal component and Direct Oblimin rotation in SPSS was performed for the 22 statement items. The 22 items were found in the expected seven categories. Hence, the factor analysis confirmed that the three 'cost' items belong in the 'cost' factor, etcetera. The factor loadings were all above .625, and the Cronbach's Alpha for the seven constructs was assessed in all cases above .750, which is considered very satisfactory (Cronbach, 1951). Next, for each of 
the seven PSM objectives, the 'effectiveness statements' were computed to a latent PSM effectiveness variable.

Multiple iterations of exploratory factor analyses were performed in SPSS by applying principal component and Equamax rotation. Equamax rotation was applied for this extensive set of 88 skills items of 366 respondents because it "combines Quartimax and Varimax criteria by simplifying both the variables and factors in the factor pattern matrix and spreading variances more equally across the factors" (Sass \& Schmitt, 2010, p. 80). The eigenvalues of the selected factors were set above 1 , which resulted in 16 factors.

The exploratory factor analyses were performed in an iterative process and limited to 12 to 16 factors. The outcomes were analysed and compared. The factor analysis was eventually confined to 15 factors that were selected as the most consistent ones. Increasing the number of factors resulted in "PSM knowledge" emerging as an additional single factor on its own, and the reason for this is difficult to interpret. Reducing the number would have merged soft skills into an undifferentiated, amorphous mega-factor. After that, the 15 factors of skill variables were transformed and computed into a new variable to construct the underlying items to perform OLS regression and NCA.

Moreover, the reliability of the items in the different factors was assessed. In total, 13 factors showed an Alpha of above .800, which is considered very satisfactory (Cronbach, 1951). A lower but satisfactory Alpha was calculated for two factors, i.e. 6 Forecasting skills $(\alpha=.729)$ and 15 Technical skills $(\alpha=.683)$. OLS regression was performed for the 15 PSM skills factors on each of the seven PSM objectives. The variance of inflation factors (VIF) did not exceed 4.2 and with tolerances higher than .2 . Hence, the VIFs are under the maximum level for multicollinearity issues (Hair et al., 2010; Ringle, Wende, \& Becker, 2015).

\subsubsection{NCA - a new method for measuring necessary conditions for performance}

The PSM skills literature often assumed that 'important' skills could be seen as 'necessary' (conditions) for the PSM function's performance. Above, examples have been given of PSM skills studies in which the term 'necessary' was used in combination with the term 'skill', although it is questionable whether the presented skills were 'sufficient' or 'necessary' conditions for performing the PSM function. This finding is in line with Van der Valk et al. (2016, p. 267), who found that distinctions between 'sufficient' or 'necessary' conditions in the literature are often made in an implicit manner "using alternative formulations, such as X being critical or a precondition for $Y$ ". The NCA method has been presented by Dul to systematically and statistically solve issues of this kind (Dul, 2016b, 2018b). 
The idea behind employing the NCA method is that, in general, business research is focused on factors that lead to specific outcomes. However, (underlying) factors being necessary enablers for outcomes to occur are crucial in organisational decision making (Van der Valk et al., 2016). Such an enabling factor is a necessary condition "that must be present to enable a certain outcome; without the condition, the outcome will be absent" (Van der Valk et al., 2016, p. 368). A necessary condition can be seen as a bottleneck that prevents the desired outcome from occurring (Dul, 2016b). According to Dul (2016b), sufficient and necessary conditions can be seen as two different logical parts of the notion of causality. In the case of necessary conditions, the performance will not be achieved in their absence ('no $Y$ without $X$ ') (Dul, 2016b; Van der Valk et al., 2016). In conclusion, a sufficient condition produces the outcome, and a necessary condition allows the outcome to exist. Indeed, the absence of the necessary condition will lead to the absence of the outcome, regardless of other factors being present (Van der Valk et al., 2016).

According to Van der Valk et al. (2016, p. 267), the difference between necessary and sufficient condition logic is that there will be "no $Y$ without $X$ " in the necessary condition logic, and the sufficient condition logic, ' $X$ leads to $Y$ '. Regressionbased methods refer to sufficiency logic in terms of $Y=a+b_{1} X_{1}+b_{2} X_{2} \ldots b_{n} X_{n}+\epsilon$. "In this logic, each input (...) is sufficient to increase the outcome, but not necessary: A lack of an input reduces the outcome, but it will not prevent the outcome if other inputs (...) compensate for it" (Hauff, Guerci, Dul, \& van Rhee, 2019, p. 2). However, NCA is described in terms of $Y=X_{1} * X_{2} * X_{3} \ldots * X_{n}$, in which the effect of a value appearing to be zero is more influential than in the regression-based methods. "The dramatic sudden effect of zero values for necessary conditions fits many everyday experiences. A car stops moving if the fuel tank is empty; financial markets collapse if the trust is gone" (Dul, 2016b, p. 11). Van der Valk et al. (2016) have concluded as follows: "Thus, while a sufficient cause produces the outcome, a necessary cause allows the outcome to exist. Conversely, without the necessary cause, the outcome will not exist despite other factors being present" (Van der Valk et al., 2016, p. 267).

The NCA method has been adopted in multiple scientific disciplines such as PSM (Van der Valk et al., 2016), educational sciences (Fredrich et al., 2018; Karwowski et al., 2017), psychology (Luther et al., 2017; Sorjonen \& Melin, 2019), operations management (Knol et al., 2018, 2019), hospitality management (W. Lee \& Jeong, 2019), sociology (Vis \& Dul, 2018) and marketing (Leischnig et al., 2018). NCA has some similarities with Qualitative Comparative Analysis, which, however, tries to identify combinations of factors (Ragin, 1987) but does not test if individual conditions are necessary for effectiveness, i.e. in whose individual absence the desired outcome is not happening, as per the NCA method (Dul et al., 2018).

Although the NCA method is relatively recently developed, impressive research outcomes could be presented, of which three illustrative examples are given 
here. Van der Valk et al. (2016, p. 267) have performed NCA on 'legal contracts' versus 'trust' on different innovation levels in buyer-supplier relations, and their research shows "that successful relationships (...) must necessarily have contracts with at least medium levels of contractual detail, as well as the highest levels of trust". Leischnig et al. $(2018$, p. 385$)$ have studied "the relationships between service employees' adaptive behaviours and customer satisfaction" and found "that interpersonal adaptive behaviour is a necessary condition (...) for high customer satisfaction". Fredrich et al. (2018, p. 862) have found that "absorptive learning capacity is a necessary condition of interfirm learning, while organisational slack resources and interdependence between firms are important additional conditions".

To analyse the data, Dul's (2018b) manual was followed using the statistical functions of the open-source programming language $R$, complemented with the NCA $R$ package provided by Dul (2018a) and using the $R$ Studio application. The seven dependent variables were combined with the 15 independent variable constructs based on the abovementioned factor analysis. NCA was applied on the entire set for every single factor to find structures and internal logic in the set of 15 independent variable constructs.

The NCA method was performed concerning each of the 15 factors on the other 14 factors to test if soft skills would be necessary conditions to carry out other skills. In the original logic, the 15 factors were projected as the independent $X$ variables being necessary (or not) for the dependent $Y$ variables, i.e. the seven different PSM objectives. However, calculations were made for each of the 15 factors. Each factor fulfilled the role as the dependent $Y$ variable, intending to detect a possible dependency or skills hierarchy, a unicum in (PSM) skills research as far as is known (see: Appendix 9.20).

By using the statistical NCA $R$ package, the effect sizes were calculated and presented. "If the effect size is greater than zero, there is (...) an indication of the presence of a necessary condition. [...] It ranges from 0 to $1(0 \leq d \leq 1)$. The effect size indicates to what extent the condition is necessary for the outcome. In other words: to what extent the condition constrains the outcome, and the outcome is constrained by the condition" (Dul, 2018b, p. 10).

Regarding the interpretation of the effect size, Dul (2016b, p. 30) has stated that "an effect size can be valued as important or not, depending on the context. A given effect size can be small in one context and large in another". Dul has further stated that general qualifications for the effect size such as "small," "medium," or "large" are disputable. However, a general benchmark for necessary condition effect size is suggested as follows: $0<d<0.1$ as a "small effect," $0.1 \leq d<0.3$ as a "medium effect," $0.3 \leq d<0.5$ as a "large effect," and $d \geq 0.5$ as a "very large effect" (Dul, 2016b, p. 30). 


\subsection{Findings: target-specific purchasing competences - Purchasing skills summarised in 15 factors}

Factor analyses were performed at first to answer the research questions. Eventually, after an iterative process, 15 factors were distinguished, which are displayed in Table 6.1. In total, 85 of the 88 initial competence items could be found in one of the 15 factors. Appendix 9.14 shows the factors, the items and the factor loadings, which are PSM skills taxonomy. To recognise the factors, these have been numbered and labelled with a short title that briefly describes the factor content, a standard modus operandi in PSM skills literature (e.g. Giunipero \& Pearcy, 2000; Tassabehji \& Moorhouse, 2008).

The first four factors (1 Networking; 2 Result orientation; 3 Imagination; 4 Sellership) can be classified as mainly containing personal skills, i.e. interpersonal, human-to-human communication skills (e.g. Social Manners; Capacity to be empathetic; Capacity to Advice, Ability to Resolve Conflicts, Power of Persuasion, Building Relations/Networking) and intrapersonal traits (e.g. Loyalty, Conscientiousness, Honesty, Comprehension of Complexity, Creativity, Inventiveness).

The second category of factors is mainly related to the content of PSM (e.g. 6 Forecasting skills; 7 Cost focus; 8 Contracting skills; 9 Supplier relations; 10 Innovation sourcing; 11 Analytics, 13 Organisational insight \& value-adding skills; 14 Automation; 15 Technical skills). The third is a general management category (e.g. 5 Cross-functional cooperation; 12 Leadership and Personnel management).

Table 6.2 displays the sufficient (OLS) and necessary (NCA) conditions for the subsequent PSM objectives. The insignificant values are suppressed and displayed in grey font. Moreover, for the NCA, the significant but "small effects" with an effect size $d$ smaller than .100 are also neglected and displayed in a grey font (Dul, 2018b, p. 10). Hence, Table 6.2 highlights the significant 'medium/high effects' for the NCA and the

significant $p$-values for the positive and negative Betas (the negative Betas are underlined). 
Table 6.2 - Outcomes of the factor analysis - A new PSM skills taxonomy

\begin{tabular}{|c|c|}
\hline Factors & . \\
\hline \multirow[t]{3}{*}{1 Networking } & Capacity to be empathetic; Social Manners; Loyalty; Conscientiousness; \\
\hline & Honesty; Comprehension of Complexity; Building \\
\hline & Relations/Networking; Ability to Solve Problems; Customer-oriented \\
\hline 2 Result orientation & $\begin{array}{l}\text { Self-assurance; Poise; Proactivity; Result-orientated action-taking; } \\
\text { Willingness to take risks; Capacity to Advice; Ability to Resolve } \\
\text { Conflicts; Power of Persuasion }\end{array}$ \\
\hline 3 Imagination & Creativity; Inventiveness; Willingness to Learn; Holistic Thinking \\
\hline 4 Sellership & $\begin{array}{l}\text { Sellership skills; Personality Characteristics Development (e.g. } \\
\text { entrepreneurial); Cross-cultural Awareness; Customer orientation }\end{array}$ \\
\hline $\begin{array}{l}5 \text { Cross-functional } \\
\text { cooperation }\end{array}$ & $\begin{array}{l}\text { Cooperating with the departments such as Marketing Management; } \\
\text { Logistics and Storage; Research \& Development; } \\
\text { Production/Operations; Quality Management }\end{array}$ \\
\hline 6 Forecasting skills & $\begin{array}{l}\text { Forecasting of the demand; Enterprise Resource Planning; Supply Chain } \\
\text { Analysis }\end{array}$ \\
\hline 7 Cost focus & $\begin{array}{l}\text { Cost Reduction Techniques; Solicit offers; Global Sourcing; Making cost } \\
\text { analyses; Negotiation; Purchasing knowledge }\end{array}$ \\
\hline 8 Contracting skills & $\begin{array}{l}\text { Developing specifications for supplies; Contract Development (design } \\
\text { of contracts); Contract Management; Claims Management; Evaluate } \\
\text { Offers \& Supplier Selection; CSR; Working together with the Legal } \\
\text { department }\end{array}$ \\
\hline $\begin{array}{l}9 \text { Supplier } \\
\text { relationship } \\
\text { management }\end{array}$ & $\begin{array}{l}\text { Supplier Relationship Management; Supply Risk management; Supplier } \\
\text { Evaluation; Supplier Development; Early Supplier Involvement; } \\
\text { Strategic Business Partner; Sustainability }\end{array}$ \\
\hline $\begin{array}{l}10 \text { Innovation } \\
\text { sourcing }\end{array}$ & $\begin{array}{l}\text { Innovation Sourcing; Innovation implementation; Category Strategy } \\
\text { Development; Stakeholder Relationship Management; Pooling } \\
\text { Planning \& Demand; Supply Market Analysis }\end{array}$ \\
\hline 11 Analytics & $\begin{array}{l}\text { Set key performance indicators (KPIs); Performance Measurement and } \\
\text { Follow-up; Statistical Analyses; Big Data Analyses; Portfolio Analysis } \\
\text { Support }\end{array}$ \\
\hline $\begin{array}{l}12 \text { Leadership and } \\
\text { Personnel } \\
\text { management }\end{array}$ & $\begin{array}{l}\text { Purchasing Roles and Job Profiles; Personnel Selection Process; } \\
\text { Employee Integration and Development Plan; Employee Performance } \\
\text { Measurement; Leadership/managing personnel; Training personnel; } \\
\text { Managing change processes; Working together with the department } \\
\text { Human Resources Management }\end{array}$ \\
\hline $\begin{array}{l}13 \text { Organisational } \\
\text { insight \& value- } \\
\text { adding skills }\end{array}$ & $\begin{array}{l}\text { (Understanding how to) add value to the organisation; Understanding } \\
\text { Corporate Governance; Understanding the Position of Purchasing in } \\
\text { Organisation Project Management Skills; Team Ability Skills; } \\
\text { Optimisation of Purchasing Processes; Process Management }\end{array}$ \\
\hline 14 Automation & Automation; Procurement IT Systems/e-procurement applications \\
\hline 15 Technical skills & $\begin{array}{l}\text { Technical knowledge of products and production systems; Technology } \\
\text { Planning (knowledge on its own company's technological } \\
\text { requirements); Commodity and Domain-Specific Knowledge. }\end{array}$ \\
\hline
\end{tabular}

Note: See Appendix 9.14 for the complete overview with the descriptions of the skills, the references, the factor loadings and the Alphas 
Table 6.3 - Regression and NCA outcomes for the seven objectives and 15 factors

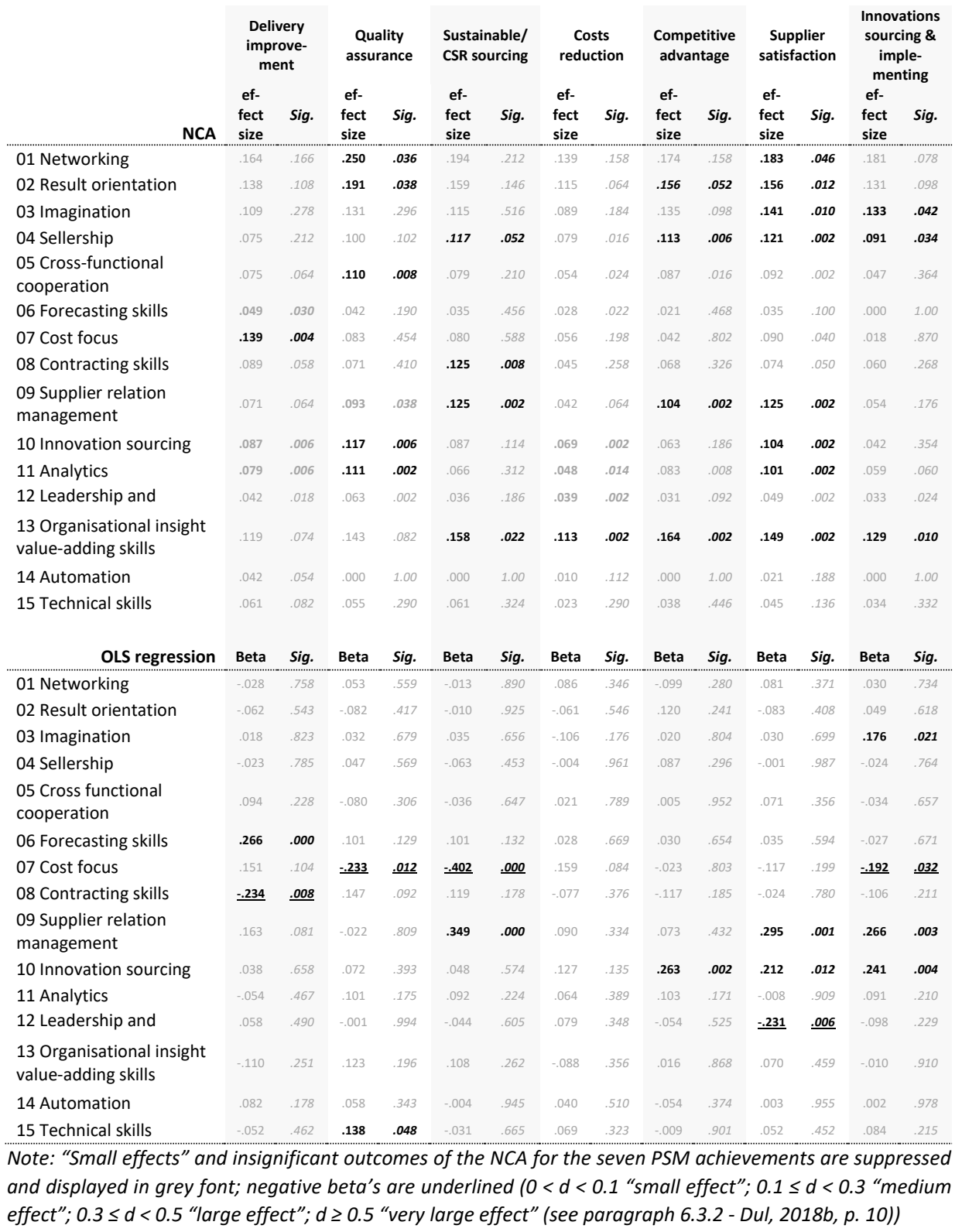


Table 6.2 reads as follows: procurement performing in delivery objectives, cost focus is a necessary skill, while those purchasers with forecasting skills outperformed their colleagues, showing lower competence in this skill. Statistically, it was found that typically delivery specialists had fewer contracting skills, which are more important to fulfil other objectives. In education, delivery specialists would benefit from following cost reduction and forecast improvement training but sending them to contract law classes would not be efficient.

\subsection{Discussion, deepening and implications for theory and practice \\ 6.5.1. Theory implication: distinguishing 15 sufficient and necessary PSM skill factors for seven PSM objectives}

The theoretical contribution is the novel approach in this study. Unlike preceding research on PSM competence, this study does not list the highest-ranked items or factors and is not focused on top-rankings or high scores directly provided by the respondents. This research is not centred on 'important' high ranked competences as seen by a group or an individual. Preceding studies asked individual purchasers to give their view on which skills they considered important. However, they did not at the same time ask which targets these purchasers had to fulfil. In the end, mixing up the responses of someone working in operative procurement with a clear delivery focus and someone responsible for strategic sourcing in a high-tech innovation commodity group may level out the differences.

This study, in contrast, distinguished different PSM objectives and asked the participants to state their effectiveness per PSM objective and associated the independent competence factors with these dependent PSM objective statement factors with OLS regression and NCA. This research aimed to associate necessary and sufficient skills items with different PSM objectives. Moreover, evidence for a skills hierarchy is shown. Results demonstrate that future research would have to take up the different targets and roles purchasers have and deepen the understanding of each of them, but not as a fictitious amalgamate of a single type of purchaser that is not empirically present.

This research analysed which skillsets would support achieving particular purchasing objectives in a firm (RQ1). Further, it distinguished between necessary skills to achieve these objectives and those sufficient for that target (RQ2). Three main contributions strike out: first, an empirically backed 15-factor purchasing skills model emerges. Second, it was shown that depending on the purchasing objective that different skillsets need to be emphasised. It can serve as a blueprint for curriculum and training design and will be discussed as "education implications". Third, this study 
introduces the distinction between necessary and sufficient skills, which re-evaluates the role of soft skills as antecedents to hard skills.

For the seven PSM objectives, a distinction is made between the sufficient skills $\left(X_{s}\right)$ that 'produce' the high effectiveness in a particular PSM objective $(Y)$ and necessary skills $\left(X_{n}\right)$ that 'allow' the effectiveness to existing in a specific PSM objective $(Y)$ (see: Table 6.2). In the sufficient condition logic, ' $X_{s}$ leads to $Y$ ', and in the necessary condition logic, there will be "no $Y$ without $X_{n}$ " (Van der Valk et al., 2016, p. 267). Applying this logic, a series of insights emerge.

Interestingly, the Cost reduction objective strongly shows a necessity for Organisational insight and governance (consisting of: Know how to add value to the organisation; Corporate Governance; Position of Purchasing in Organisation; Process and Project Management Skills; Optimisation of Purchasing Processes; and Team Ability Skills), only. The link between cost reduction and the need to have organisational insight is a remarkable outcome. In the literature, a distinction is often made between reducing supply cost and creating long-time value by accessing the suppliers' innovations. At the same time, cost reduction seems to be a process management issue.

A balance between innovation sourcing and cost reductions is also found in the objectives regarding Innovation sourcing, Quality Improvement and Sustainability. All show negative signs for Factor 7, i.e. Cost focus (e.g. Solicit offers; Making cost analyses; Cost Reduction Techniques). Here, the negative sign for the factor Cost focus could indicate that the innovation, quality, and sustainability objectives have a nontransactional, non-operational, strategic character and Legenvre and Gualandris' (2018) remark to look beyond costs for competitive advantage is applicable. In contrast, a transactional, operational necessity for Cost focus is found in the Delivery improvement objective. This objective operational benefits from performing negotiations, cost analyses and cost reduction techniques.

Factors 9 and 10, i.e. Supplier relationship management and Innovation sourcing, respectively, show similarities. Both are associated with the strategic PSM objectives regarding improving sustainability, supplier satisfaction, competitive advantage innovation sourcing and quality improvements. The soft skills found in Factor 3 Imagination and Factor 4 Sellership skills are necessary conditions for innovation sourcing and achieving supplier satisfaction.

The necessity of skill factors for the seven PSM objectives are presented in Table 6.3. Interestingly, the Supplier satisfaction objective counts eight necessary factors, and the Delivery improvement objective counts only one factor. The difference between both depicts the distance between strategic PSM and operational PSM (e.g. Johnsen et al., 2012; Knight et al., 2014; Legenvre \& Gualandris, 2018; Tracey \& Neuhaus, 2013). The most difficult objective to achieve is supplier satisfaction, as it 
requires a large set of skills. Most other objectives rely on a narrower set of necessary skills.

Altogether, based on an extensive survey conducted amongst 366 PSM professionals, the conclusion is that different skillsets do, indeed, exist in PSM. Further, contradictions between the objectives are primarily found in some objectives showing negative signs for the Factor 7 Cost focus. In contrast, Factor 13 Organisational insight divide the PSM objectives into those with an operational and strategic focus. This division in reducing supply cost and creating long-time value by accessing the suppliers' innovations is found in the literature, as mentioned in the introduction. Tracey and Neuhaus (2013) have distinguished between innovation-focused ('facilitators') and operational ('regulators') objectives of PSM professionals. This division is also noticed by Johnsen et al. (2012), Legenvre and Gualandris (2018) and Knight et al. (2014). Here, a dividing line between PSM strategies focused on either a differentiation or a cost leader strategy, as mentioned by Porter (1980), is seen.

Table 6.4 - Matrix showing the significant effect sizes of the direct, necessary conditions for each PSM objective

Factors

\section{Objectives}

Supplier satisfaction objective

Quality improvement objective

Competitive advantage objective

Sustainability improvement objective

Innovation sourcing objective

Cost reduction objective

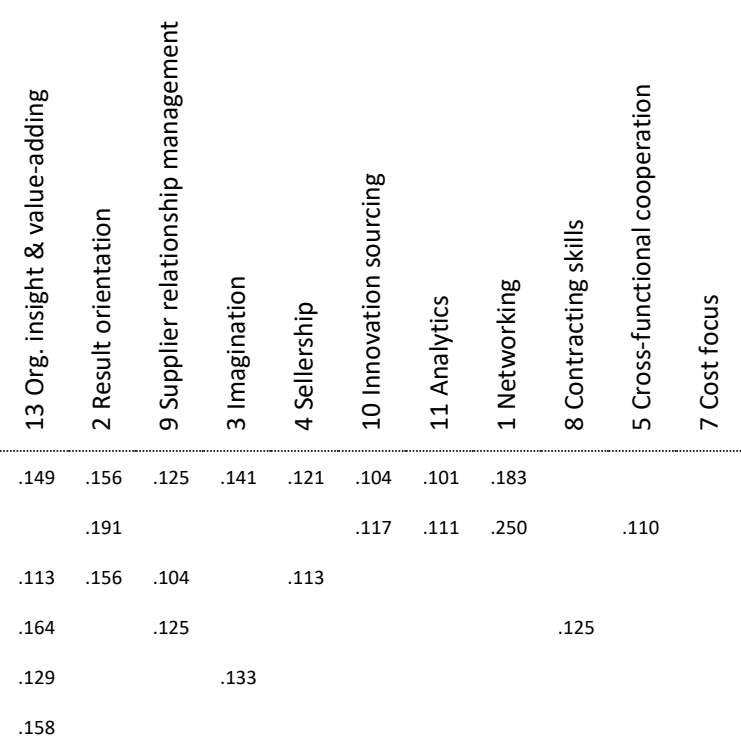

.139 
Table 6.4 presents the necessity of skill factors for the seven PSM objectives. Interestingly, the Supplier satisfaction objective counts eight necessary factors, and the Delivery improvement objective counts only one factor. The difference between both depicts the distance between strategic PSM and operational PSM (e.g. Johnsen et al., 2012; Knight et al., 2014; Legenvre \& Gualandris, 2018; Tracey \& Neuhaus, 2013). Supplier satisfaction is one of the most challenging objectives to achieve, as it requires a large set of skills. Most other objectives rely on a narrower set of necessary skills.

Finally, another remarkable outcome is that the soft skills (factors 1 to 4) are mostly absent in OLS regression but prominently present in the NCA outcomes. NCA shows significant effects $(p<.05)$, while with OLS, only insignificant Betas could be detected (except for imagination's influence on fulfilling the innovation target). Without NCA and just running a classical regression, it could have been concluded that soft skills are not important. However, the above outcomes provide input to conduct a deepening investigation on the assumption that soft skills are necessary conditions to perform hard skills, hence, to analyse the question if some of the 15 skills factors have a necessary influence on the presence of the other skill factors.

\subsubsection{Deepening investigation: quantitative evidence for a skills hierarchy; soft skills are needed for hard skills}

Based on the observation that scarcely any soft skills show up in the regressions, additional analysis is conducted to compare their influence on the other skill factors. Therefore, each of the 15 factors was the subject of NCA on the other 14 factors. In other words, whereas in the primary research, the 15 skill factors' influence on the seven objectives was compared, in the subsequent analysis, the relationship among the 15 factors themselves was analysed. Thus, the rationale is determining whether some of the factors are a necessary condition for others.

NCA provides an output showing the significance by providing $p$-values and showing the effect sizes $d$. In Appendix 9.20, a table of effect sizes is presented, which formed the basis for the surface graph in Figure 6.1, displaying the effect sizes $d$ of the factors as necessary conditions for the other factors. In Figure 6.1, "small effects" $(0<d<0.1)$ are displayed in white colour, "medium effects" $(0.1 \leq d<0.3)$ in grey colour and "large effects" $(0.3 \leq d<0.5)$ in black colour (Dul, 2018b, p. 10). For instance, Factor 1 Networking shows 'black peaks,' i.e., it is necessary for all other factors; this factor shows high significant effect sizes. In contrast, Factor 14 Automation is mostly in the white "lower area" and shows minimal effect sizes on all other factors and is not necessary to carry out the skills in the other factors. This is also quite logical, for purchasing was also working before automation tools were introduced. Hence, the managing of them improves outcome but is not strictly required to buy something. 


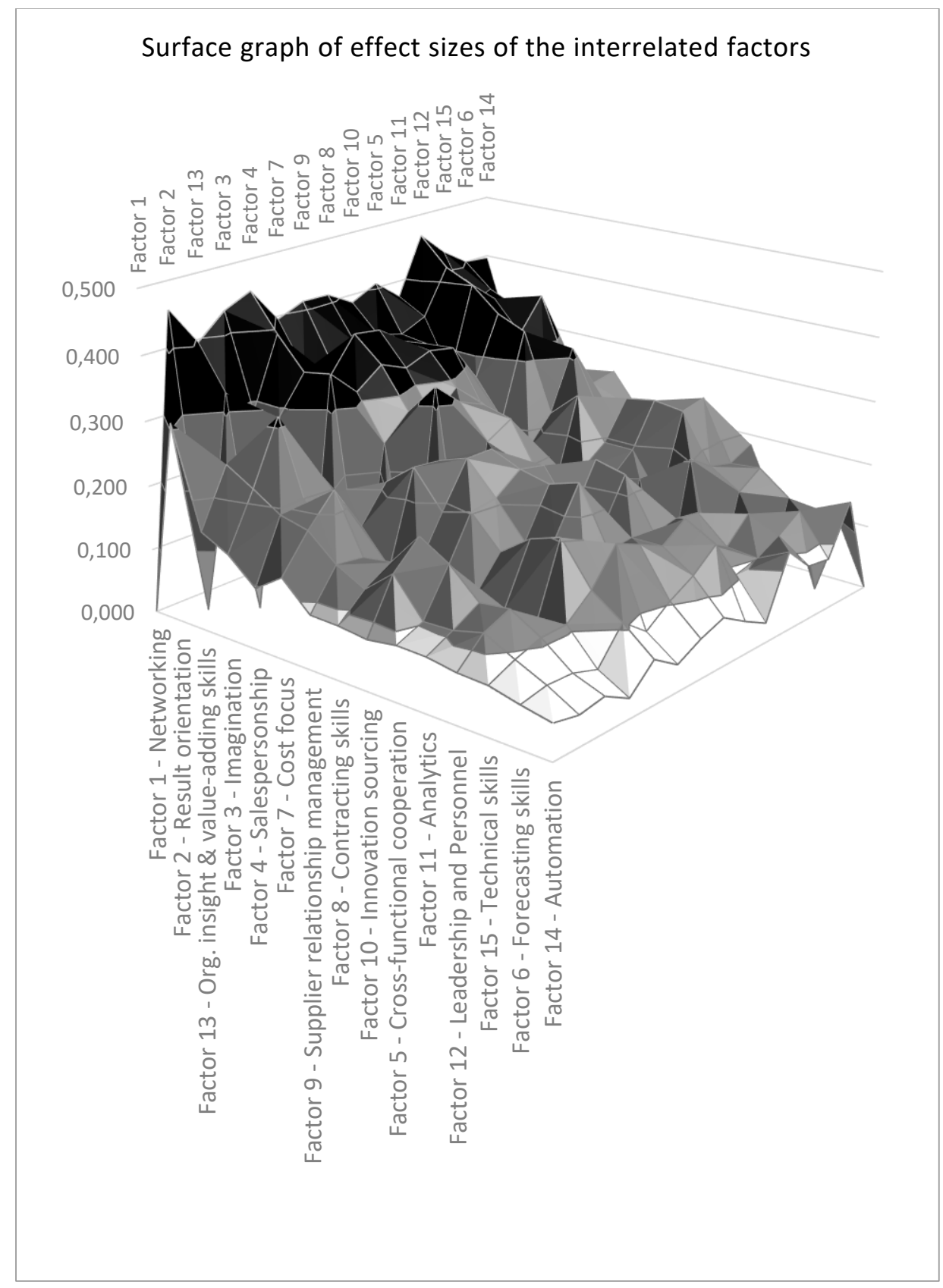

Figure 6.1 - Surface graph of the effect sizes of the interrelated factors

Legend: Displayed in white colour 'small effects' $(0<d<0.1)$; in grey colour 'medium effects' $(0.1 \leq d<0.3)$; and in black colour 'large effects' (0.3 $\leq d<0.5)$; $d$ (Dul, 2018b, p. 10). 
The factors in Figure 6.1 are ranked based on their means, meaning that, for example, Factor 1 Networking has the most significant effect sizes on the other factors (see: Appendix 9.26). The mean of this factor's effect sizes on the other 14 factors is .415 , which is, on average, a 'large effect' (Dul, 2018b, p. 10). Therefore, Factor 1 Networking is a necessary condition for all other skills factors. In contrast, Factor 14 Automation is not a necessary condition for the others as it shows a mean of .069, which is a 'small effect'. The notable outcome is that the "soft" factors networking, resultorientation, imagination and sellership score highest. These soft skills factors are essential to carry out hard skills tasks, while the hard skills factors, as sufficient conditions, make the difference between average and outperforming professionals.

This finding goes in line with the idea introduced by Tchokogué, Nollet, et al. (2017) and Ahmed et al. (2012), Muir (2004) as well as Socha et al. (2003). Tchokogué, Nollet, et al. (2017) that organisational objectives are sequenced and hierarchical. According to them, PSM organisations must first master the operational corporate improvement objectives before strategic competitive advantage objectives can be supported. For individuals, Ahmed et al. (2012), Muir (2004) and Socha et al. (2003) have indicated that soft skills are necessary conditions to execute hard skills, which is exactly what our data support.

These outcomes of this study differ from previous research. The skills found in the literature review (see: Appendix 9.2) were categorised according to the new taxonomy in Table 6.1. In the literature, the most extensive attention was directed to items in Factor 7 Cost focus. On average, 77.2 per cent of the researched literature agrees on Factor 7, followed by Factor 14 Automation (60.1 per cent). The soft skills factors 1 Networking (24.5 per cent), 2 Result orientation (23.5 per cent), 3 Imagination (43.4 per cent) and 4 Sellership skills ( 27.2 per cent) are outside the top- 5 according to the literature. This is in line with this study's 'sufficient' OLS findings where the four factors are absent (with one exception). Nevertheless, with NCA, the necessity and the prominent position of these four are made clear, which is another contribution of this research.

\subsubsection{Implications for education: 15 skills as a blueprint for PSM training}

The outcomes of this study have important implications for the design of PSM curricula in higher education, company training sessions and HRM practice in the field of PSM. The first implication is that sufficient and necessary skills for the seven PSM objectives are revealed. Educators, HRM officials, trainers and individual PSM professionals can benefit from these outcomes by adapting these and adjusting the learning objectives of courses, training and development plans. 
Consequently, firms establishing a purchasing training programme would benefit from, first, clearly establishing the target priorities their purchasing function would follow. Then, a tailor-made training programme could be offered. This programme is different from firm to firm. Likewise, universities or universities of applied sciences that teach purchasing would also have to define the direction of their targeted education and decide for respective course portfolios. It does not imply completely ignoring any of the 15 skills factors. It would be advised to provide a basic skill level in all factors to enable trained persons to switch to organisations with different targets. However, the findings on the difference of effectiveness imply that, depending on the chosen objective, education choices may have to be made, and more emphasis may want to be placed reliant on the chosen objective in education.

In the following, a short proposal based on the empirical findings of this study can be provided. Depending on the requested target, different training plans can be conceived:

\section{Table 6.5 - Training and education focus according to objective}

\section{Objective Skillset / Training}

A particular "generic skill portfolio" and hence training set emerges for the more operationally oriented purchaser, who has to ensure prompt delivery at the right quality and the right sustainability level. The delivery expert adds solid analytical skills, forecasting, cost focus and also automation skills. Surprisingly, contract management shows a negative sign, indicating that, at least for the moment, legally well-trained delivery managers are not more successful.

The only target where technical skills make a significant difference is the quality target. It is an interesting finding supporting the challenge to the often expressed claim that purchasers should have strong technical skills (Cho, Bonn, Giunipero, \& Divers, 2019). If purchasing, respectively the firm, is emphasising quality insurance from the supplier or the quality control is hosted in purchasing and not as a department of its own, technical know-how is required. Cross-functional skills are necessary, as well as SRM and analytical skills. Not surprisingly, a negative relation to cost-cutting skills is evidenced, whereas contracting skills are a weak differentiator.

On the other hand, contracting is a necessary skill for the objective sustainability, reflecting the solid regulation-driven character of sustainability considerations (Schulze \& Bals, 2020; Schulze et al., 2019). Also, in the factor analysis, the item "corporate social responsibility" grouped itself to the contracting cluster, emphasising the solid legal connotation of sustainability. Likewise, sellership skills are necessary (as the sustainability targets are not always complementary to corporates' business requirements). Interestingly, cost skills show a robust and highly negative sign in the regression. Very cost reduction, global sourcing, and negotiation-oriented purchasers, on average, do not achieve sustainability targets better. 
For a purchaser to be successful at cost reduction, an "overlap" target relevant for more strategic or more operationally oriented profiles requires a series of necessary skills. For this objective, soft skills in networking and imagination are unnecessary, neither automation nor technical skills. Interestingly, successfully cost-cutting purchasers did or did not have particular contracting skills. A particular training in cost reduction methods such as, for instance, lever analysis requirement (Schiele, Horn, et al., 2011) is a medium-strong differentiator.

Process and sellership skills are complemented by SRM and, as a differentiator, innovation sourcing skills. Market analysis, category strategy planning and the diverse innovationoriented subskills are grouped. Interestingly, in terms of soft skills being "result driven", i.e. showing self-assurance, poise, proactivity is characteristic to such persons. The training programme for innovation purchasers and strategic purchasers will show considerable overlap. Likewise, the soft skills profile and hence training is similar, though with a slightly different focus on the one hand on imagination and on the other hand on what Hofstede calls "masculinity" (Hofstede, 1983b).

A fascinating skills profile emerges for the target "supplier satisfaction". It is part of the strategic block, as the pre-condition for both innovation and strategic competitive advantage by privileged supplier access, is supplier satisfaction, which may lead to preferred customer status, the ultimate strategic target purchasing can achieve (Pulles, Ellegaard, Schiele, \& Kragh, 2019). With this target, however, 12 out of 15 skills have the character of necessary conditions. A purchaser who achieves satisfied suppliers has a good level in almost all skills. No single target is as demanding. Effectively this means that supplier satisfaction seems to be more a question of the purchaser's maturity level (Schiele, 2007). Put it the other way around: a poorly trained purchaser is likely to generate unsatisfied suppliers.

The innovation purchaser shows a very similar profile as the purchaser can achieve a competitive advantage for its company. Hence, the innovation purchaser may also be the $\mathrm{CPO}$ of the future, as this type can contribute to the entire firm's strategic positioning, thus fulfilling the new strategic role of purchasing. Purchasers successful in the objective "innovation" from and with suppliers typically rely, as necessary conditions, on a proper level of sellership, process \& project skills and the soft skill "imagination", which is also a differentiator. The latter is not surprising, as this skill comprises elements like creativity, inventiveness and holistic thinking. Business innovation is a very project and process-driven activity; firms typically having implemented any variant of a stage-gate model in innovation management (Cooper, 2019). Hence, purchasers need to acquire process \& project skills to succeed in innovation. Another necessary skill is sellership, for any novelty needs to be "sold" in the organisation. The more SRM and innovation sourcing skills a purchaser has, the better this type performs. Part of the advanced skills is innovation sourcing and innovation implementation planning. Interestingly, a negative relation between cost and innovation skills has been found.

Another important implication is that soft skills form the basis for effective performance, which are necessary conditions for many other skills (figure 6.1). Soft skills are appreciated by employers (Ahmed et al., 2012). Nevertheless, explicit soft skills learning objectives are primarily absent in PSM courses in higher education (Birou et al., 2016; Hoidn, 2017). 
The outcomes of this research show the necessity for PSM knowledge, along with hard and soft skills. Institutions of higher education and training benefit from anticipating this in their curricula to facilitate their graduates being able to possess 1 ) knowledge, 2) professional and interpersonal skills, and 3) intrapersonal traits following the definition of Delamare-Le Deist and Winterton (2005) of competence, i.e. 'being competent'. The findings are also in line with the 2009 declaration of the ministers of education from European countries, which states that fostering innovation and creativity in society is a higher education's task (Leuven/Louvain-la-Neuve Declaration, 2009).

An often-heard question is whether entrepreneurial behaviour, creativity, inventiveness and strategic or holistic thinking can be developed. Kiratli et al. (2016) have confirmed and provided evidence that establishing a team creative climate in purchasing departments is supportive. Laker and Powell (2011) also acknowledge that soft skills can be influenced. Yet, they argue that compared with the learning of hard skills, soft skills learning encounters higher resistance levels from both, the trainees and the management. In their study, Feisel et al. (2011) have found that these intrapersonal skills of experienced professionals and their strategic behaviour are difficult to influence.

However, in PSM higher education, Scholten and Dubois (2017) have found evidence that their student-centred method is developing the students' cognitive and professional and interpersonal and intrapersonal skills:

"Our results show that students who are actively involved in the learning process by taking responsibility, engaging in collaborative learning and by taking the chance to learn from practice are able to develop higher-order learning in relation to content as well as skills that are needed in today's job environment" (Scholten \& Dubois, 2017, p. 1696).

Therefore, further (longitudinal) research per industry is suggested on which particular competences are a sufficient or a necessary condition for effectiveness. Research is needed on how the necessary interpersonal skills and intrapersonal traits can be trained within the context of PSM. Hence, empirical research on incorporating benchmark tools and training methods in firms and higher education is commendable.

\subsubsection{Managerial implication: a dedicated purchasing skills management system}

This study's ultimate objective is to ensure that a firm's purchasing establishment becomes effective, resulting in a skilled team of PSM professionals that can achieve the firm's targets. Therefore the following three managerial recommendations are derived: 
Management recommendation 1: Establish a purchasing skills training programme relying on soft skills and hard skills.

This study's first main contribution is the identification of an empiricallybacked skills model comprising 15 skill factors. As a managerial implication, the PSM department's management could establish a training programme, building on these 15 factors. Depending on the firm's size, either a company training programme or an external PSM skills training programme is required. For the latter, the training system would be matched to the skill system developed here in this study and can thus train employees according to the firm's targets. The importance of soft skills also reflects on careful personnel selection, whose soft skills should be tested.

Management recommendation 2: Identify and prioritise the seven PSM targets as input for a training plan.

Another contribution of this research is identifying and empirical verifying the seven different purchasing objectives and their linkages with dedicated skills models. This study provided empirical evidence that a universal PSM professional does not seem to exist. However, whether the PSM professionals' skills profiles match their PSM organisations' objectives or not has substantial implications for firms. The corporate actors need to know which objectives to follow in which order.

The PSM strategy benefits from being aligned with the corporate strategy as suggested, for instance, by Porter (1980). When the PSM department, respectively the entire organisation, does not have a clear strategy, it would be difficult to (1) set requirements for the staff, (2) establish development or learning objectives and (3) train (or recruit) people who can support the achievement of those objectives. Training personnel without having clear objectives means that people acquire skills they cannot all productively employ. In the worst-case such over and wrong qualified persons may become "frustrated purchasers" (Tassabehji \& Moorhouse, 2008).

Further, it also implies that a firm that did not define its objectives and prioritise them lacks the maturity to train its personnel effectively. PSM functions will have to define and reflect a firm's strategy clearly and prioritise and combine the seven possible PSM objectives accordingly even as they break these objectives down to individual positions that may have specific target priorities (Hesping \& Schiele, 2015). It can then serve as an input for the skills development plan.

Management recommendation 3: Establish a purchasing skill controlling system measuring the available training level and the 15 skill factors.

Professional HR has been suggested to monitor its organisation's skill level, measuring it and using this input to plan training and recruiting. To apply such a model to purchasing, a comprehensive purchasing skills model is needed. The present 
research provides the necessary input. The 15 skill factor model can serve as a blueprint for a corporate skills development scheme proposed in the HR literature (Campion et al., 2011; Mansfield, 1996). According to these models, employees' skills are regularly measured, compiled and compared to the strategically derived target skill portfolio, the gap indicating future training needs. Adding up the individual skills level can create a key performance indicator for a firm's total skills development control.

\subsection{Limitations and future research}

This research has its limitations. The NCA's effect sizes on the seven PSM objectives' skills factors are 'medium' (Dul, 2018b). It means that there must be additional factors influencing PSM professionals' effectiveness. None of these skills or the organisational conditions and systems related to them could be covered in this study. Future research would benefit from exploring these relationships and directly control for organisation and management support as suggested, for instance, by Tassabehji and Moorhouse (2008).

Moreover, Kiratli et al. (2016) have shown that creating a team creative climate would help soft skills development. Moreover, although the 15 factors show a consistent picture with reasonable VIFs and Cronbach's Alphas, the decision to not discard items with lower factor loadings led to lower AVEs (Average Variance Extracted). However, similar factor loadings and AVEs are found with the factor analysis of Giunipero and Pearcy (2000). Further research could replicate the outcomes of the factor analysis. Keeping all items in the list allows the reader to choose, for example, in the moment of course design, for instance, prioritising high loading items depending on the depth of the training unit or course.

An additional limitation is that the population that gets covered by this study can be described as predominantly Western European and is based primarily in the Netherlands (58 per cent), France (14 per cent) and German-speaking countries (11 per cent), which may have caused cultural biases. However, literature shows that these countries are representatives of three distinct cultural clusters (Kale, 1995).

Another limitation is that the skills items and achievement statements have been self-assessed by the participants. The participants joined the anonymous survey out of personal interest, and there is little indication of biased results. In self-rated surveys, there is a risk that the participants overstate their skills. Such overstatement is known as the Dunning-Kruger effect, i.e. unskilled professionals have the tendency "to hold overly favourable views of their abilities in many social and intellectual domains" (Kruger \& Dunning, 1999, p. 1121).

On the contrary, skilled professionals tend "to underestimate their performance relative to their peers" (Kruger \& Dunning, 1999, p. 1126). If the possibility 
of this effect applied to PSM professionals, this study would be subject to underestimating the differences in performance. Indeed, negative signs are found in the OLS regression. Using peer assessment or a superior's evaluation could test for the relevance of the Dunning-Kruger effect.

From a methodology perspective, NCA's employment, a relatively young method, has its risks. Recently, there has been some controversy in this regard which suggests that Qualitative Comparative Analysis (QCA) would be more suited to studies like the present one because of NCA's limited ability to identify sets of necessary conditions, i.e. combinations of conditions that need to be tested rather than testing individual conditions (Dul et al., 2018; Thiem, 2018). However, it should be noted that this assertion has been refuted by Dul et al. (2018), advising that the two methods have a different target. This study's target was to test if particular individual skills - and not combinations of skills - are necessary. Therefore, NCA was applied in this research. There is evidence that even with skewed predictors, "NCA can give large necessity effects" (Sorjonen \& Melin, 2019, p. 2).

Employing a QCA that could handle the model's complexity could identify new combinations of effectiveness factors that our method could not distil. QCA is not as applicable for larger sets as in this study. The outcomes of 366 respondents, 15 competence factors and seven objectives on five-point scales would lead to an immense and immeasurable QCA outcome of about 40,000 data points. For larger data sets, NCA is perfectly designed. Moreover, it uses other methods for the calculation than the analysis of the necessary conditions in QCA. The "ceiling line" in QCA is a static diagonal, whereas this line depends on the NCA calculation (Delgosha, Saheb, \& Hajiheydari, 2020; Dul, 2016b). The NCA method is derived from the exact sciences to help social sciences overcome lengthy regression formulas that become increasingly meaningless due to the formulas' complexity (Dul, 2016b). Dul (2016b) advises applying NCA as an additional method to regressions since regressions typically reveal sufficient conditions and NCA necessary conditions.

Another limitation of this study is that it relies on 'as-is'-data and not on 'to$b e^{\prime}$-expectations. Surveying PSM professionals and asking them for the effects they are observing reflects their current effectiveness and not necessarily their expected future effectiveness. For instance, the Fourth Industrial Revolution could have profound impacts on purchasing and would possibly render some skills obsolete and require additional skills currently not relevant for effectiveness (Torn \& Schiele, 2020). Assessing future skills would be an obvious research path. The 'as-is'-situation could also offer some explanatory clues to surprising phenomena in the current data.

Another remarkable finding of this study which has received relatively limited attention in the literature so far, is the objective of sellership. This skill, typically more associated with a marketing or sales objective, reveals to be directly or indirectly a necessary effectiveness condition for all PSM objectives. In future teaching, training, 
and recruiting, it might be beneficial to pay more attention to the respective PSM professionals' ability to 'sell' themselves and their function and present their firm to suppliers. Likewise, upstream or reverse marketing (Leenders \& Blenkhorn, 1988) would be a field for future research. 


\section{Chapter 7}

\section{Developing Soft Skills of PSM Graduates}

An Academic Experiment in Advancing Interpersonal Skills and Intrapersonal Traits 


\title{
7. DEVELOPING SOFT SKILLS OF PSM GRADUATES
}

\author{
AN ACADEMIC EXPERIMENT IN ADVANCING INTERPERSONAL \\ SKILLS AND INTRAPERSONAL TRAITS
}

\subsection{Introduction - soft skills gap in higher education}

Over the past decades, the PSM function has altered. Firstly it shifted from an operational towards a strategic focus (e.g. Bals et al., 2019; Tassabehji \& Moorhouse, 2008). More recently, the attention for sustainability issues and corporate social responsibility (CSR) (e.g. Bals et al., 2019; Schulze \& Bals, 2020; Schulze et al., 2019) and the consequences of the upcoming Fourth Industrial Revolution on PSM (e.g. Bals et al., 2019; Glas \& Kleemann, 2016) affected the PSM function, whereas the Fourth Industrial Revolution or 'Industry 4.0' is described as the "fourth wave of technological advancement: the rise of new digital industrial technology" (Rüßmann et al., 2015, p. 3).

The above led to another palette of required PSM competences (e.g. Bals et al., 2019; Glas \& Kleemann, 2016; Schulze \& Bals, 2020); PSM practitioners increasingly need soft skills, like 'strategic thinking' (e.g. Bals et al., 2019) and 'creativity' (e.g. Kiratli et al., 2016). The growing importance of these soft skills is in line with Von der Gracht et al. (2016), who researched future PSM skills of purchasers and foresaw existential threats in organisations when in a "talent war" competitors recruit the most "creative and innovative minds" (Von der Gracht et al., 2016, p. 30). In a similar study, Von der Gracht et al. (2018, p. 9) warned that personnel need to be "creative, productive and innovative" in the future era of Industry 4.0.

The creative process is understood as "a social endeavor" for innovation sourcing teams (Kiratli et al., 2016, p. 202), which places humans in the role of boundary spanners. Sivasubramaniam et al. (2012, p. 803) state that for new product development (NPD), "effective boundary spanning within and outside the organization" is necessary to reach success. The boundary spanner role in the buyer-supplier relation has a growing strategic role in a company's innovation capability and competitiveness 
(Johnsen et al., 2012; Legenvre \& Gualandris, 2018; Luzzini \& Ronchi, 2011; Schiele, 2012).

Hence, the right soft skills will be decisive in the upcoming era characterised by the Internet-of-Things, machine-to-machine communication, and artificial intelligence (Al) in which the "digital transformation is also transforming our society into a knowledge society" (Von der Gracht et al., 2016, p. 10). The prediction is that the economy changes into "a knowledge economy, or even into a 'human economy', where not only intellect but especially creativity, passion, character and team spirit will make the difference" (Von der Gracht et al., 2016, p. 10).

The emphasis is on soft skills that are defined as human-to-human communication ('interpersonal skills') and character traits ('intrapersonal traits', 'behaviours' and 'attitudes') (Delamare-Le Deist \& Winterton, 2005) or "personality traits, goals, motivations, and preferences" (Heckman \& Kautz, 2012, p. 451). Laker and Powell (2011, p. 113) distinguish "hard-skills or technical training (working with equipment and software) and soft-skills training (interpersonal or intrapersonal focus)". Hard skills, therefore, include cognition (knowledge and theory) and professional skills (Delamare-Le Deist \& Winterton, 2005).

Interestingly, soft skills are crucial as hard skills for professionals (Ahmed et al., 2012). Moreover, the absence of soft skills is more probable to be the reason for ending a labour relationship than an absence of knowledge (Ahmed et al., 2012). Employers highly value soft skills, which are necessary to effectively carry out professional tasks or hard skills (Ahmed et al., 2012; Socha et al., 2003). Moreover, soft skills "are necessary to actually implement-to articulate a vision; to enrol others in possibilities; and to communicate values, standards, and expectations" (Muir, 2004, p. 99). Concluding, to be prepared for PSM in Industry 4.0, i.e. 'Procurement 4.0', PSM professionals need the full palette of competences, including soft skills.

Remarkably, most academic PSM courses and tracks have been evaluated for not or almost not learning and developing soft skills (Birou et al., 2016; Stinenbosch, 2017; Wong et al., 2014). Bals et al. (2019) argue that PSM lecturers in higher education should introduce learning objectives that cover the context of future requirements caused by the challenges of sustainability and the Internet-of-Things. Nonetheless, Fawcett and Rutner (2014) have found that PSM higher education is "not evolving at the pace and in the way expected by professionals" (Fawcett \& Rutner, 2014, p. 181).

Thus, in higher education courses, a significant role is given to the transfer of knowledge and theory, and in parallel, these courses are not equipped or primarily focused on developing soft skills that students need to apply hard skills in practice. Higher education in PSM failed to introduce soft skills learning objectives. Moreover, it is unclear whether individual lecturers in higher education can influence students' soft 
skills levels or that these interpersonal skills and intrapersonal traits are innate character features. If soft skills and, specifically, intrapersonal traits can be actively influenced, the question raises which ones could be developed in higher education. Therefore, this leads to the following research questions:

(RQ1) Can interpersonal skills and intrapersonal traits be actively developed in PSM in higher education?

And if so,

(RQ2) Which interpersonal skills and intrapersonal traits can be actively developed in PSM in higher education?

The PSM competence literature has presented important competences (e.g. Bals et al., 2019; Giunipero \& Pearcy, 2000; Knight et al., 2014; Tassabehji \& Moorhouse, 2008) but has failed to present best practices on how these competences could be taught best. Whereas Feisel et al. (2011) found that these intrapersonal traits of experienced professionals and their strategic behaviour are difficult to influence, the research of Scholten and Dubois (2017) showed, however, the positive outcomes of an educational experiment in cohorts of students in a PSM course as will be elaborated shown in the theory section.

The PSM competence literature hardly provides outcomes of didactical experiments on the topic of how to apply the necessary soft skills and especially intrapersonal character traits in PSM courses in higher education. The question arises whether the prevailing conceptualisation of PSM is capable of comprising the $21^{\text {st }}$ century's complexity since the research community seems not to absorb the suitable instruments to cope with the contemporary and the future challenges in the field (e.g. C. R. Carter, Rogers, \& Choi, 2015; Darby, Fugate, \& Murray, 2019; Knight, Meehan, Tapinos, Menzies, \& Pfeiffer, 2020).

Since the PSM competences literature mainly focuses on listing competences and has neglected to research the testing, experimenting and describing how future PSM education should be organised, this research fills this gap by presenting an educational experiment. The student-centred, learning-by-doing approach of Scholten and Dubois (2017) is adopted as a part of this experiment, and the evidence is given that in a time frame of eight weeks and a study load of 140 hours, specific interpersonal skills and intrapersonal traits could be developed.

Therefore, an experiment was set up in three cohorts of PSM graduates $(n=95)$ in a Master course that took a student-centred approach. The course was built upon three pillars: (1) knowledge and theory; (2) professional skills; and (3) soft skills (including interpersonal skills and intrapersonal traits development). For the first pillar, the teamed-up graduates wrote chapters for a joint book proposed by Scholten and 
Dubois (2017). Introductory (micro) lectures were provided, like academic writing support in tutorial meetings.

The second pillar consisted of solving real-life cases provided by the university's purchasing department. The written case descriptions were kept concise. The student teams were invited to interview the cooperating university staff, such as the purchaser, the contract manager, the contract owner, the project leader, the sustainability officer, or the executive board's vice-president, to acquire further information. Also, here (micro) lectures were provided.

The third pillar was overarching and focused on developing soft skills. For this assignment, two surveys were taken, before and after the course, measuring the selfassessed competence levels on 36 soft skill items. Communication, teamwork, creative problem-solving in the writing and case projects served as the development basis. Furthermore, a Chief Purchasing Officer was invited for a workshop on ethical leadership and sustainability, and workshops on creativity, consultancy skills and negotiation were offered.

The outcomes provided evidence for the effectiveness of a student-centred approach in a course that offers the three pillars' entire competence construct. Most soft skills improved significantly in the three cohorts of graduates in the PSM course. The educational implication is that PSM higher education objectives must contain the three pillars' elements to develop 'competent' graduates for their future PSM jobs.

\subsection{Theory on soft skills development and student-centred learning}

\subsubsection{Soft skills, the distinction between machines and humans}

Due to changing labour market demands, higher education must anticipate and adjust the learning objectives (Hoidn, 2017). Expectations are that in 2025 about 45 per cent of the European jobs will require high-level qualifications, and another 45 per cent will need medium-level qualifications. After graduation, students need the "ability to apply knowledge and skills flexibly in different contexts", and academia has to prepare "students with the subject-based know-how as well as with high-level transversal competences and skills such as joint problem solving, critical thinking, and self-regulated learning" (Hoidn, 2017, p. 2).

In line with that, Bals et al. (2019, p. 11) emphasised the importance of the full integration of all competences needed for the development of the PSM function "into higher and professional education and professional, industrial training programmes", including knowledge, professional and interpersonal skills and a substantial set of intrapersonal traits. Bals et al. (2019) here mention the most influential factor, i.e. the effect of the Fourth Industrial Revolution or "Industry 4.0" on PSM or "Procurement 
4.0," i.e. a set of factors "influencing the digitisation of procurement and supply chains" (Bienhaus \& Haddud, 2018, p. 965). Interestingly, Industry 4.0 transformed business models to a merely dynamic, networked manufacturing environment (Kagermann et al., 2013).

In such a networked manufacturing environment, machine-to-machine communication is more efficient than human-to-human communication. The conclusion is that humans are distinct from machines. Machines are increasingly efficient than humans; however, humans possess creative, inventive skills that machines lack. Whether machines or Al can be 'creative' is countered by Du Sautoy (2019) with the finding that instead of a replacement of human creativity by machines, Al will support and accelerate human creativity (Du Sautoy, 2019). Hence, the creativity and inventiveness of the human workforce will continue to be an essential factor.

\subsubsection{The EU directives on higher education's role in soft skills development}

In line with the above, the European Commission in 2008 already noted that "traditional teaching approaches based on direct instruction or lecturing are no longer adequate" and that they have to be "replaced by more learner-focused models that are based on the learner's active involvement in the process of reflection and interpretation" (Hoidn, 2017, p. 5).

Academia and higher education have to anticipate future competences since fostering innovation and creativity in society is a task for these institutions, according to the European ministers of education (Leuven/Louvain-la-Neuve Declaration, 2009). Moreover, the shift towards student-centred methods is promoted and endorsed by academia and higher education themselves via the European Association of Institutions in Higher Education (EURASHE) and the European University Association (EUA). They co-developed with the European ministers of education the standards and guidelines (ESG) for quality assurance in the European higher education area (ESG Report, 2015). The ESG Report state that:

"Institutions should ensure that the programmes are delivered in a way that encourages students to take an active role in creating the learning process and that the assessment of students reflects this approach (...) Student-centred learning and teaching plays an important role in stimulating students' motivation, self-reflection and engagement in the learning process" ESG Report (2015, p. 12).

Student-centred learning environments are a better alternative to the dominant design of teacher-centred approaches. Based on the findings in the literature (e.g. Hoidn, 2017) and Project PERFECT's observations (e.g. Stinenbosch \& Stek, 2017a), the conclusion is that the didactical methods in European higher education are not in 
line with the ESG Standards and Guidelines (ESG Report, 2015). However, academia and higher education institutions were involved via the EURASHE and the EUA.

\subsubsection{Challenges for the student-centred approach}

Bals et al. (2019) highlighted that the student-centred teaching method should replace traditional teacher-centred methods in PSM courses in higher education to address the challenges of Procurement 4.0. "As current training and teaching methods are not necessarily suitable for developing all types of competencies, and the pedagogy needs to be adapted to reflect these requirements" (Bals et al., 2019, p. 11). They suggested: "in-class training formats such as role-plays and the potential for online courses and more interactive formats, e.g. blended learning or flipped classroom approaches" (Bals et al., 2019, p. 11).

Although student-centred approaches are preferred, especially for the training of soft skills, attitudes or traits (e.g. Bals et al., 2019), the dominant design at (European) universities is (1) teacher-centred, frontal, and classical lecturing for (2) 'transferring' knowledge and theory (Hoidn, 2017). Multiple barriers cause the reason why higher education is dominantly teacher-centred. Firstly, since dozens or even hundreds of students can attend the same lecture, teacher-centred methods are highly efficient, though not as effective as student-centred methods (Hannafin \& Land, 2000).

It raises the question, whether education can be efficient when levels of effectiveness are lower. According to Drucker (1977), it is doubtful that a state of efficiency can be reached before effectiveness is established: "Effectiveness is the foundation of success - efficiency is a minimum condition for survival after success has been achieved. Efficiency is concerned with doing things right. Effectiveness is doing the right things" (Drucker, 1977, p. 33). Therefore, also in higher education, efficiency follows effectiveness. The learning process's effectiveness consists of the reconstruction of bits of knowledge by students themselves. The learning process is not a 'transfer' of information from a lecturer directed towards the student; it is a simple, personal process in the individual student's mind (Land \& Hannafin, 2000).

A second barrier is that a shift from frontal, classical teaching towards studentcentred didactics is a profound change in the working modus (Anthony \& Kadir, 2012). Traditional lecturers who change their didactics to student-centred approaches report "feelings of guilt" because the student-centred method is initially "just guiding and supporting the students in the learning processes," and knowledge is no longer "transferred" in a classical, frontal mode (Anthony \& Kadir, 2012, p. 57). The guiltfeeling is caused by the wrongly expected loss of the lecturers' authority in the classroom when the lecture leaves behind the frontal, classical method (Anthony \& Kadir, 2012). 
Moreover, the learning and teaching of soft skills are more complicated. Laker and Powell (2011, p. 113) found evidence that the soft skills learning process is associated with higher resistance levels from the students/trainees and the management. Most of the time, soft skills training has no direct applicability to the job as hard skills training. Further, soft skill learning results in a lower degree of achieved proficiency and self-efficacy. Also, the preciseness of identifying soft skills training objectives is lower (Laker \& Powell, 2011). This lower level of preciseness might also be the case for the identification of training methods.

Hannafin and Land (2000) found that many lecturers in higher education are convinced that they could transmit the knowledge they possess to the individual students. There is broad agreement that the students have to reconstruct knowledge individually (Hannafin \& Land, 2000). A way to activate students in their learning process to reach a comprehensive learning effect is, for instance, the active involvement in experiments. Active involvement has better learning results than students who passively watch the same similar experiment demonstrated by a lecturer (Bonwell \& Eison, 1991). Contrary, the design of frontal teaching sets students in a passive, listening role, which has the lowest effect on retaining knowledge (Masters, 2013), for which Poh, Swenson, and Picard (2010) even has provided empirical evidence.

\subsubsection{Experimental studies and the student-centred approach}

Poh et al. (2010) measured the student's neurological activity over seven days with a device, a 'wearable sensor for unobtrusive, long-term assessment of electrodermal activity' (see: Figure 7.1). Figure 7.1 shows the "Electrodermal activity (EDA)," which "is a sensitive index of sympathetic nervous system activity" on the $y$-axis over seven days on the $x$-axis (Poh et al., 2010, p. 1243). When examining Figure 7.1, most neurological activity is found with the student during self-study, doing homework, doing laboratory work, exams, and asleep (dreaming).

The nocturnal activities, central in Figure 7.1, are measured during the subject's sleep: "there is a consistent peak between the hours of midnight and 3 am, corresponding to sleep activity" (Poh et al., 2010, p. 1250). "The characteristic peaks occurring during sleep have been associated with slow-wave sleep (SWS) and remain a subject for future studies" (Poh et al., 2010, p. 1250). The literature reports that sleep is "critical in both supporting the overnight consolidation of new memories, and in restoring the next-day encoding capacity of the hippocampus (M. P. Walker, 2009, p. 25). 


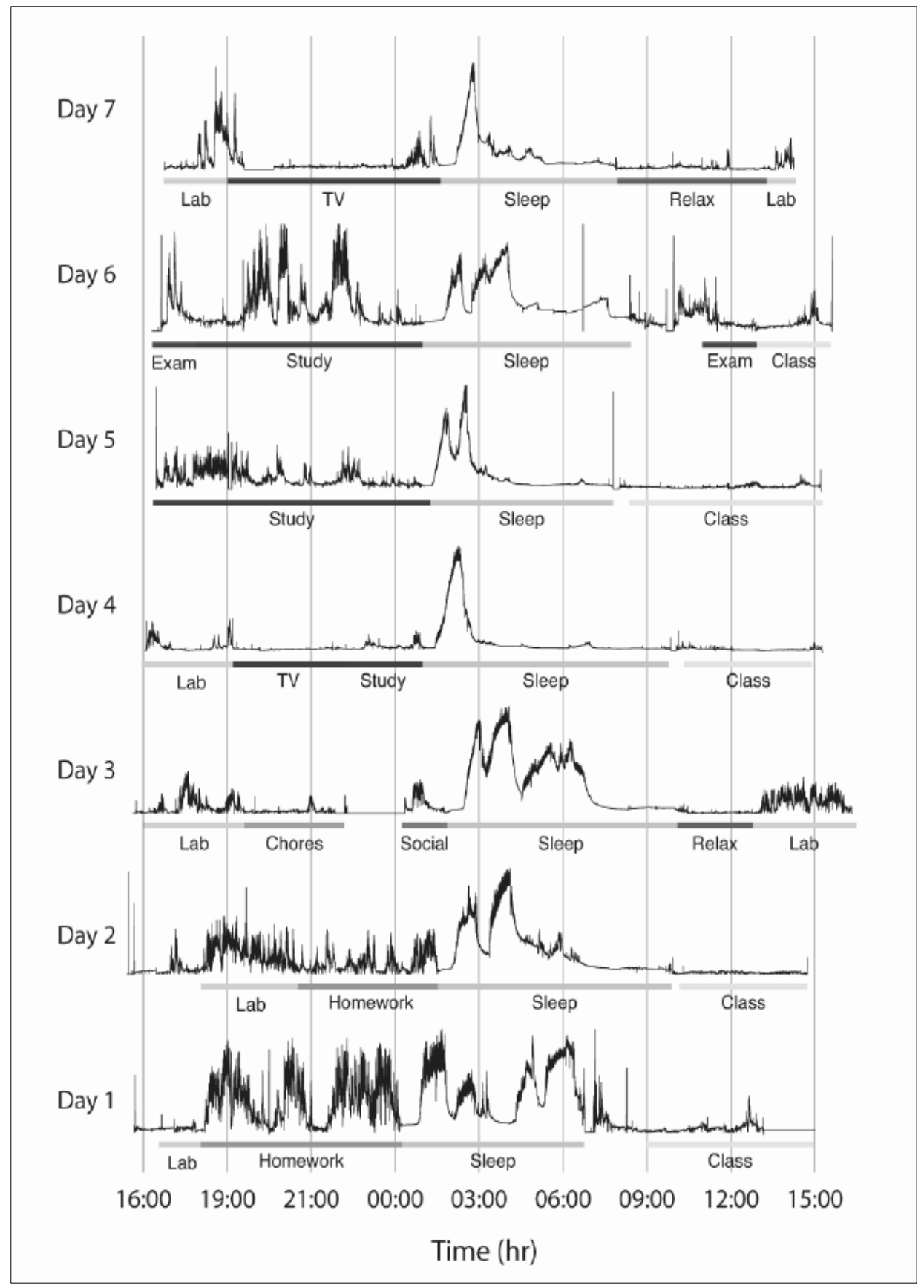

Figure 7.1 - Neurological activity of a student in long-term in situ electrodermal activity (EDA) recordings, recorded for seven days in a natural home environment (Poh et al., 2010, p. 1250). 
Therefore, adequate amounts of sleep are required before learning to prime the brain to form new memories. "Just as important as sleep before learning is the need for adequate sleep (and particularly SWS for nonemotional episodic declarative memory) after learning" (M. P. Walker, 2009, p. 25). The beneficial impact of sleep on memory was already acknowledged by the Ancient Roman rhetorician Quintilian (35100 AD), who noted:

"It is a curious fact, of which the reason is not obvious, that the interval of a single night will greatly increase the strength of the memory. Whatever the cause, things which could not be recalled on the spot are easily coordinated the next day, and time itself, which is generally accounted one of the causes of forgetfulness, actually serves to strengthen the memory" (Quintilian, 1922 [95 AD], p. 6.43)

Poh et al. (2010) report that lesser brain activity is found during watching television, relaxing and remarkably when following lectures in the classroom (see: Figure 7.1). Hence, for the student, having a classical, frontal lecture has, in most cases, the same neurological impact as watching television or remaining in a relaxing state of mind.

The unsourced quote that Socrates is often associated with resounds: "I cannot teach anybody anything, I only can make them think" (Adelung \& Fitzsimons, 2015, p. 241). Plato's original quote is: "Education is not in reality what some people proclaim it to be in their profession. What they aver is that they can put true knowledge into a soul that does not possess it, as if they were inserting vision into blind eyes" (Plato, 1992 [375 BC], Book 7, 518b-c). It means that the learning process consists of reconstructing bits of knowledge by students themselves; the learning process is not a 'transfer' of information from a lecturer directed towards the student (Land \& Hannafin, 2000). De Houwer et al. (2013, p. 633) define learning as 'ontogenetic adaption', i.e. "as changes in the behavior of an organism that are the result of regularities in the environment of that organism".

As mentioned, in PSM, not many experiments with knowledge transfer, interpersonal skills and intrapersonal traits development are described in the academic literature. A rare example is an attempt to train students' competences performed by Scholten and Dubois (2017) from 2008 to 2015. In subsequent cohorts at a Swedish and a Dutch university, case study projects have been performed in which SCM master students were assigned to project groups on writing a joint e-book on PSM.

The main conclusion is that "the teaching context influenced the learning process and the learning outcomes. Active involvement, self-directed learning, collaborative learning and learning from practice enabled by the set-up of the course are identified as key mechanisms for the learning outcomes in relation to skills and content" (Scholten \& Dubois, 2017, p. 1683).

Scholten and Dubois' (2017) approach is a method for developing cognitive, interpersonal and intrapersonal skills of both students and lecturers. Scholten and 
Dubois (2017, p. 1696) conclude that for a student-centred approach, educators need other lecturing skills: "due to students' active involvement in decisions regarding content and process, a lot of flexibility and creativity is required from individual lecturers," and they add:

"Our results show that students who are actively involved in the learning process by taking responsibility, engaging in collaborative learning and by taking the chance to learn from practice are able to develop higher-order learning in relation to content as well as skills that are needed in today's job environment" (Scholten \& Dubois, 2017, p. 1696)

Compared to the traditional, classical way of lecturing methods, the method, as explained by Scholten and Dubois (2017), is in line with the Dublin Descriptors (Dublin Descriptors, 2004). These descriptors are part of the Bologna Process and are supposed to be endorsed by all European institutions of higher education. The Dublin Descriptors state that learning objectives in general consists of both hard and soft skills: "(i) knowledge and understanding, (ii) applying knowledge and understanding, (iii) making judgements, (iv) communication skills and (v) learning skills" (Dublin Descriptors, 2004; Leoni, 2014, p. 4).

In higher education, classical, frontal teacher-centred lecturing is the dominant design, and the teaching is mainly focused on the transfer of knowledge and hard skills (Masters, 2013). When considering this dissertation's outcomes, the conclusion is that the demand for soft skills at the employers' side exceeds the supply side at universities and higher education institutions. Therefore, based upon Scholten and Dubois (2017) and Laker and Powell (2011) describe soft skills developments, and therefore the following is hypothesised:

Hypothesis: soft skills (interpersonal skills and intrapersonal traits) can be developed in PSM courses in higher education with learning-by-doing practices.

\subsection{Methodology - quasi-experiment with intrapersonal skills in a PSM course}

\subsubsection{Research design - one-group pre-test - post-test design}

This chapter pursues an experimental approach, following Pettigrew's (2001) call for a form of 'management research after modernism' to "be prepared for a period of experimentation and learning with all the potential partners out there waiting to engage with us" (Pettigrew, 2001, p. 69). Moreover, Darby et al. (2019, p. 1) calls for an "expanding the methodological toolbox" of PSM and alert not to use just a sheer observative, sociological positivist approaches. This plea of Darby et al. (2019) can be associated with lan Hacking (1984), who stated that:

" (...) no field in the philosophy of science is more systematically neglected than experiment. Our grade school teachers may have told us that scientific method is an 
experimental method, but histories of science have become more histories of theory. Experiments, the philosophers say, are of value only when they test theory. Experimental work, they imply, has no life of its own" (Hacking, 1984, pp. 154-155).

The design of measurement in education usually is a quasi-experimental or pre-experimental design that is "the exposure of a group to an experimental variable or event, the effects of which are to be measured," $(\mathrm{X})$ followed by "some process of observation or measurement" (O) (Campbell \& Stanley, 1966, p. 6). Hence, the typical set-up in education is $\mathrm{X}-\mathrm{O}$, primarily being a series of lectures followed by an assessment, referred to by Campbell and Stanley $(1966$, p. 6) as "the one-shot case study".

For this research, an $\mathrm{O}_{1}-\mathrm{X}-\mathrm{O}_{2}$ design has been set up, or "the one-group pretest - post-test design", which is better than the X-O design and "to be worth doing where nothing better can be done" (Campbell \& Stanley, 1966, p. 6), which is the case, although a design with a control group would have been a better alternative. In that case, the focal group would perform the surveys and follow the lectures $\left(\mathrm{O}_{1}-\mathrm{X}-\mathrm{O}_{2}\right)$, and the control group would only perform the surveys $\left(\mathrm{O}_{1}-\mathrm{O}_{2}\right)$. Since there was no access to a control group, a "pre-test - post-test control group design" could not be performed (Campbell \& Stanley, 1966, p. 6). The $\mathrm{O}_{1}-\mathrm{X}-\mathrm{O}_{2}$ design consisted of two identical surveys $\mathrm{O}_{1}$ and $\mathrm{O}_{2}$, and a 5 ECTS course ( 140 hours of study load) with lectures, workshops, case study, academic writing, and self-study between both surveys.

The used method to assess the difference between $\mathrm{O}_{1}$ and $\mathrm{O}_{2}$ is the PairedSamples or Dependent $t$-test, for which the Confidence Interval Percentage is set at 95 per cent. The missing values are set to be 'excluded by analysis'. The students filled out the first survey before the end of the first week of the ten-week course. The same students filled out the second survey before the end of the last week of the course. The 'mean' results are found by subtracting the different items' outcomes in the second survey from the first survey. Both surveys were measured on a 5-point-Likert scale from 'fully disagree' to 'fully agree'. Moreover, Cohen's $d$ effect sizes are calculated. The effect size are considered to be 'small' $(0.2<d<0.5)$; 'medium' $(0.5<d<0.8)$; or 'large' $(0.8<d<1.2)$ by Cohen $(1988$, pp. $25-26)$.

\subsubsection{Course design in three lines: knowledge, skills and attitudes/traits}

The researched sample consists of business master students of an elective, introductory course, Purchasing Management, at the University of Twente. This course was modified using 'constructive alignment' (Biggs, 2011). According to Biggs (2011), in courses, there should be 'constructive alignment' between 'teaching and learning activities' (TLAs) (i.e. learning content and didactics); 'intended learning outcomes (ILOs) or learning objectives; and 'assessment tasks' (ATs) (i.e. testing and assessing the learning outcomes). Constructive alignment is chosen because it enhances the more in- 
depth learning of students. Wang, Su, Cheung, Wong, and Kwong (2013, p. 477) found that "Students in more 'constructively aligned courses' were more likely to adopt deep learning approaches and less likely to use surface learning approaches in their study of a particular course".

Biggs (1996, p. 347) combined in 'Constructive alignment' two philosophies: "the first derives from constructivist learning theory and the second from the instructional design literature". Central in constructivism is creating the meaning of the learner's activities, impacting the teaching and assessment methods. The 'Instruction design' underlines the alignment between a course's learning objectives and the student's performance assessment methods. Biggs (1996, p. 347) combines both to 'Constructive alignment', i.e. that constructivism is applied as the instructional design framework to create curriculum objectives "in terms of performances that represent a suitably high cognitive level, in deciding teaching/learning activities judged to elicit those performances, and to assess and summatively report student performance" (Biggs, 1996, p. 347).

The master course has been designed in such a way that it offered education (TLAs and ILOs) in (1) knowledge and theory, (2) professional and interpersonal skills, and (3) intrapersonal traits. The didactical construct offered a mix of frontal, classical instructions, practical workshops, storytelling and 'learning-by-doing' in two more extensive projects with tutoring meetings. The students had to produce four outcomes or ATs that were differentiated per TLA and ILO. The academic paper writing assessment was assessed based on a rubric by the lecturer on content, form and the final presentations. The case study reports were assessed based on a rubric by the participating practitioners and the lecturer. The lecturer marginally assessed the soft skills personal development plan report, and eventually, the knowledge and theory ILOs were tested in a written exam.

The course attracted 95 students ( 30 females and 65 males; 82 Dutch students, seven citizens from other EU-countries and four from non-EU countries) in three subsequent cohorts in 2018-2019 (30 students: 8 females and 22 males; average age 23.7, $\delta=1.75$ ); in 2019-2020 (26 students: 12 females and 14 males; average age 23.0, $\delta=1.06$ ); and in 2020-2021 (39 students: 10 females and 29 males; average age 24.3, $\delta=2.52$ ). The students mainly were enrolled at the master track Industrial Engineering Management and Business Administration; however, other business students were also registered. The course consisted of about 16 lectures and workshops of 90 minutes and was divided into three lines: a knowledge line, a skills line and an attitude or intrapersonal traits line.

The knowledge line's practical substance consisted of an assignment to the students to co-author a book entitled 'State of the Art of Purchasing and Supply Management', inspired by Scholten and Dubois (2017). Teams were formed of about three students and were assigned to write a scientific paper, i.e. book chapter on a PSM 
topic. At universities in the Netherlands, lecturers usually leave the (Master) students' initiative to team up in groups. In most cases, this appears to lead to mono-cultural teams of acquainted students, which would not necessarily represent the daily practice in these graduates' future professional lives; usually, professionals cannot choose their fellow team members.

For each book chapter assignment, a topic and guidance were given, such as vital literature and a reminder on performing academic writing. The assignment urged to use the most recent literature and to cite at least 15 peer-reviewed articles. The use of the annotation program EndNote was set obligatory. Each student group was invited at least twice for a meeting of $\mathbf{3 0}$ minutes with the lecturer to structure and to improve the paper writing process. After the deadline and the lecturer's final editing, the book was made available in pdf format via intranet and was handed out in hard copy during the open-book exam. In the final lectures, two weeks before the exam, the student groups presented their chapter in 15-minutes PowerPoint presentations.

For the skills line, the students were again teamed up by the lecturer, however, in other groups than for the book chapter writing assignment. The reason for that is twofold. Firstly, it is unlikely that a professional can form their team in professional life or be consigned to two identical teams. Secondly, teaming up in different team avoided the exchange of tasks between students, leading to freeriding in one of the projects.

The real-life case studies were co-developed with the purchasing department of the University of Twente. The cases regarded the public tender procedure of real-life tender cases at the University of Twente campus that would be carried out a few months later by the university's purchasing department. In the different lectures in the subsequent academic years, workshops were organised with guest speakers, such as chief purchasing officers (CPOs) and purchasing experts.

At the case introduction lectures, the university purchasers, contract-owners and contract managers had a role. The case studies have been designed to be easily explained: e.g. 'the university needs new faculty housing' or 'the contract of the hot beverages vending machine is ending' and 'a tender procedure is upcoming'. Nevertheless, these 'simple' problems were hard to solve due to all the facets, like stakeholders' interest, sustainability issues, et cetera. The case studies were subtitled 'talking with real people'; therefore, the case study assignments' written info was limited.

The students were invited to raise oral questions to obtain more information from the purchasers, contract-owners, contract managers, project managers, and the executive board's vice-president, who are the professionals who would work on the same case in real-life in the following months (see: Exhibit 7.2). These practitioners, who work for the University of Twente, cooperate for different reasons. One reason is the willingness to contribute to the university's educational process and stay connected 
to the employers' core business. Another even more important reason is exchanging ideas with the students, the guest speakers and the lecturers to get insights from a new angle and obtain synergy in the upcoming tender procedures.

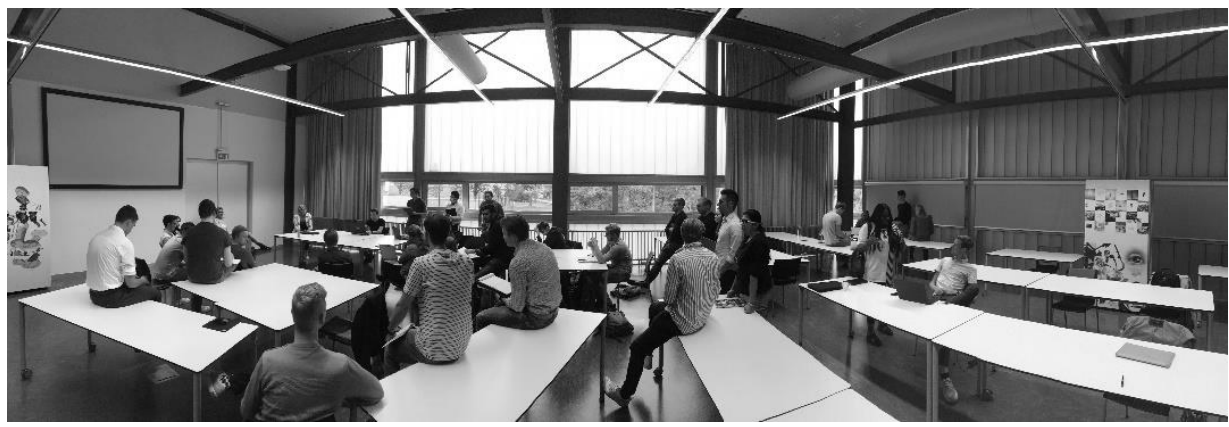

Exhibit 7.2 - Case kick-off: 'talking with real people' and 'social distancing' in September 2020 CKlaas Stek

For both the knowledge and the case line, in 2018 and 2019, classical and in 2020, due to the COVID-19-lockdown, online, frontal instruction lectures were provided on topics like public procurement procedures and the selection and awarding; purchasing management; supplier selection; and innovation sourcing. In the attitudes or intrapersonal traits line, several workshops were provided, such as a CPO's workshop on ethical behaviour and sound leadership; a workshop of an interim management and consultancy agency on consultancy skills and other necessary skills in a purchasing consultancy job; a negotiation lecture and workshop.

The course's third line regarded attitudes or intrapersonal traits. For this line, the one-group pre-test - post-test design experiment is performed in an $\mathrm{O}_{1}-\mathrm{X}-\mathrm{O}_{2}$ design, whereas $\mathrm{O}_{1}$ (observation 1 ) represents the first survey that was held in the first week of the course; $X$ (exposure) represents the exposure to soft skills development and training; and $\mathrm{O}_{2}$ (observation 2) represents the second survey that is identical to the first and was held in the last week of the course.

The survey consisted of 36 interpersonal skills and intrapersonal traits with a five-point Likert scale ('fully disagree' to 'fully agree'). The 36 interpersonal and intrapersonal skills were derived from Giunipero (2000), Giunipero and Pearcy (2000), Knight et al. (2014), Schiele (2007) and Heyse et al. (2004) (see: Appendix 9.22). The first survey in the three cohorts was taken before the second lecture, and the second survey was taken after the final lecture. The first survey's results were kept unrevealed for the individual students until after filling out the second survey. 
Therefore, when filling out the second survey, the individual students were unconscious of their initial scores in the first survey about eight weeks earlier. After the course, students compared their scores and handed in a reflection on the course, including a personal development plan. For the analysis, Paired Samples or Dependent $t$-tests were performed. For the surveys, ethical approval was received from the Ethics Committee of the Faculty of Behavioural, Management and Social Sciences at the University of Twente under numbers 18897 (2018), 191091 (2019) and 201062 (2020), and all students approved the use of anonymised data for scientific use.

\subsection{Results - an increase of levels of interpersonal skills and intrapersonal traits}

The results of both surveys (or observations $\mathrm{O} 1$ and $\mathrm{O} 2$ in terms of Campbell \& Stanley, 1966) were subject to Paired-Samples or Dependent $t$-tests. In total, 26 items showed a significant difference, and ten did not, as is displayed in Table 7.1 (see also Appendix 9.22 for more details). Herewith answers are given on the research questions whether soft skills can be developed in a course (RQ1) and which (RQ2). Moreover, there is enough evidence not to reject the hypothesis; indeed, the evidence is found for a substantial number of soft skills that these can be developed in a relatively short time frame of a ten-week course of 5 ECTS with the described didactics: a mix of frontal, classical instructions, practical workshops, storytelling and 'learning-by-doing' in two larger projects with tutoring meetings.

The course was successful in increasing 'strategic thinking', 'negotiation skills' and 'sellership skills' $(p<.010)$, showing 'medium' Cohen's $d$ effect sizes $(.5<d<.8)$ (Cohen, 1988, pp. 25-26; Sawilowsky, 2009). 'Strategic thinking' has the most substantial effect size, meaning that the progress that the student sample made for this survey item is significant $(p<.000)$ and with a 'medium' effect size (Cohen, 1988, pp. 25-26; Sawilowsky, 2009).

'Strategic thinking' was part of the case study's learning objectives; a lecture and workshop in strategic management were part of the case. In one cohort, the case assignment consisted of forming a vision on higher education development in the next decades to define the building's purpose on the university campus. Another cohort had to form an idea about how to make the coffee and cocoa supply chain sustainable.

'Negotiation skills' improved significantly, and the effect size is 'medium' ( $p=.000 ; d=.636$ ) (Cohen, 1988, pp. 25-26; Sawilowsky, 2009). 'Negotiation skills' are explicitly practised during the negotiation workshop. 'Sellership skills' has a significant outcome with a medium effect size $(p=.000 ; d=.538)$. Probably, sellership skills are associated with negotiation skills by the surveyed students. One part of the students played the buyers' and another the sellers' role in the negotiation workshops. 
Table 7.1 - Effect sizes of significant differences of interpersonal and intrapersonal skills levels between $\mathrm{O}_{1}$ and $\mathrm{O}_{2}$ in a Paired-Samples or Dependent $t$-test

Paired

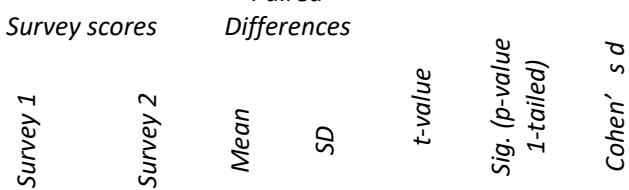

\begin{tabular}{|c|c|c|c|c|c|c|c|c|}
\hline 1 & Strategic thinking & 2,70 & 3,21 & .518 & .713 & 5.433 & .000 & .726 \\
\hline 2 & Negotiation skills & 2,21 & 2,71 & .500 & .786 & 4.759 & .000 & .636 \\
\hline 3 & Sellership skills & 2,36 & 2,80 & .446 & .829 & 4.028 & .000 & .538 \\
\hline 4 & Networking / building relations & 2,49 & 2,86 & .351 & .772 & 4.409 & .000 & .455 \\
\hline 5 & Communication skills & 3,06 & 3,34 & .362 & .914 & 3.837 & .000 & .396 \\
\hline 6 & Decision-making & 2,83 & 3,16 & .309 & .804 & 3.722 & .000 & .384 \\
\hline 7 & Cross-functional management & 2,86 & 3,23 & .391 & .828 & 3.772 & .000 & .472 \\
\hline 8 & Ability to solve problems & 3,13 & 3,38 & .277 & .768 & 3.493 & .000 & .360 \\
\hline 9 & Comprehension of complexity & 2,95 & 3,19 & .245 & .683 & 3.474 & .000 & .358 \\
\hline 10 & Capacity to be empathetic & 3,34 & 3,66 & .339 & .721 & 3.524 & .000 & .470 \\
\hline 11 & Leadership/community management & 2,51 & 2,89 & .359 & .824 & 3.491 & .000 & .436 \\
\hline 12 & Flexibility and agility & 2,79 & 3,07 & .277 & .835 & 3.212 & .001 & .331 \\
\hline 13 & Creativity & 2,60 & 2,83 & .213 & .670 & 3.079 & .001 & .318 \\
\hline 14 & Inventiveness & 2,58 & 2,86 & .277 & .873 & 3.073 & .001 & .318 \\
\hline 15 & Persistence & 2,70 & 3,04 & .339 & .837 & 3.033 & .002 & .405 \\
\hline 16 & Proactivity & 2,87 & 3,10 & .213 & .731 & 2.821 & .003 & .279 \\
\hline 17 & Teamwork & 3,17 & 3,47 & .313 & .889 & 2.813 & .003 & .351 \\
\hline 18 & Cross-cultural awareness & 2,86 & 3,06 & .245 & .876 & 2.708 & .004 & .279 \\
\hline 19 & Willingness to take risks & 2,83 & 3,14 & .191 & .766 & 2.424 & .009 & .250 \\
\hline 20 & Customer-oriented & 3,14 & 3,27 & .191 & .846 & 2.195 & .015 & .226 \\
\hline 21 & Stress management & 2,98 & 3,16 & .297 & 1.122 & 2.116 & .019 & .265 \\
\hline 22 & Willingness to learn & 2,87 & 3,02 & .160 & .780 & 1.983 & .025 & .204 \\
\hline 23 & Capacity to advice & 2,87 & 3,03 & .181 & .904 & 1.941 & .028 & .200 \\
\hline 24 & Holistic thinking & 3,11 & 3,28 & .149 & .747 & 1.933 & .028 & .199 \\
\hline 25 & Poise & 2,66 & 2,80 & .149 & .747 & 1.933 & .028 & .199 \\
\hline 26 & Task management & 3,38 & 3,47 & .219 & .917 & 1.909 & .030 & .239 \\
\hline 27 & Power of persuasion & 2,95 & 3,12 & .143 & .699 & 1.530 & .066 & .204 \\
\hline 28 & Result-orientated action-taking & 2,94 & 3,05 & .128 & .688 & 1.422 & .079 & .147 \\
\hline 29 & Self-assurance & 2,73 & 2,94 & .106 & .809 & 1.274 & .103 & .131 \\
\hline 30 & Inter-generation skills & 2,96 & 3,09 & .156 & .996 & 1.256 & .107 & .156 \\
\hline 31 & Honesty & 3,67 & 3,74 & .096 & .804 & 1.154 & .126 & .119 \\
\hline 32 & Conscientiousness & 3,47 & 3,50 & .125 & .833 & 1.124 & .133 & .150 \\
\hline 33 & Social manners & 3,32 & 3,32 & .096 & .881 & 1.054 & .147 & .108 \\
\hline 34 & Ability to resolve conflicts & 3,21 & 3,27 & .096 & .928 & 1.000 & .160 & .103 \\
\hline 35 & Critical thinking & 3,15 & 3,25 & .107 & .867 & 0.925 & .180 & .124 \\
\hline 36 & Loyalty & 3,69 & 3,77 & .053 & .884 & 0.583 & .281 & .060 \\
\hline
\end{tabular}

See Appendix 9.22 for the item's definitions. The sample consists of Business Administration and Industrial Engineering and Management master students $(n=95)$ in the cohorts 2018-2019 ( $n=30), 2019-2020$ $(n=26)$, and 2020-2021 ( $n=39)$ of the introductory course Purchasing Management at the University of Twente. Used method: Paired t-test; Confidence Interval Percentage: 95 per cent; Missing Values: Exclude cases analysis by analysis (Cohen, 1988, pp. 25-26; Sawilowsky, 2009). 
Furthermore, the course improved networking, teamwork, leadership, problem-solving, cross-functional management, communication skills and the capacity to be empathic to a lower extent, showing lower significances $(.01<p<.05)$ and smaller effect sizes. Cohen's $d$ effect sizes in these cases are 'small' $(.2<d<.5)$ (Cohen, 1988; Sawilowsky, 2009).

\subsection{Discussion - contextual fundament for attitudes and intrapersonal traits development}

\subsubsection{Negative relationship between significance and perceived competence levels}

In the one-group pre-test - post-test, the students filled out identical surveys before and after the course and self-reported their skills levels in 36 skills as displayed in Table 7.1. The research question is: which interpersonal skills and intrapersonal traits can be actively developed in PSM in higher education with learning-by-doing with which didactics?

The course caused a significant difference in 'strategic thinking,' which is a relatively lower-ranked item in the students' sample mean. On a 5-point Likert scale, the students' mean in $\mathrm{O}_{1}$ was 2.70, and it increased in $\mathrm{O}_{2}$ to 3.21. The impact of the course is considerable but should not be exaggerated. The course has played a role in developing this cohort of students from a lower level towards a more average strategic thinking level and certainly not to an excellent level. The listing of 36 competence items 'strategic thinking' was ranked 29 in $\mathrm{O}_{1}$ and $\mathrm{O}_{2}$. It increased to rank 15 (see: Appendix 9.23). 'Sellership skills' and 'negotiation' remained at respectively rank 35 and 36.

Therefore, the initially lower-ranked competences are more likely to be subject to improvement. It is not surprising that the survey items with a higher self-rated competence level cannot be improved as those items with lower self-ratings since the first set of items are developed, and the latter are underdeveloped. In other words, the proverbial low-hanging fruit is found in lower self-rated competences. Figure 7.3 displays the two rankings of the 36 competence items in a scatter plot: the ranking in $t$-values from low to high and the perceived competence level's ranking from low to high on the 5-point Likert scale. The trendline reveals a negative relationship between both. Hence, the lower the initially perceived competence level, the higher the chance of a significant improvement. Table 7.2 shows evidence that the slope of the regression is significant ( $p=.000)$. The $R^{2}$ is .402 .

The negative relationship between the perceived competence in $\mathrm{O}_{1}$ is caused by the use of $t$-values instead of the $p$-values. The $p$-value levels are related to Cohen's $d$ levels, i.e. that items with the highest $p$-values also scored the highest Cohen's $d$ 's (see: Table 7.1). However, the distinction between highly significant $p$-value levels is low since 
these approximate each other $(p<.000)$. Therefore, the $t$-values were used instead. The logic in Figure 7.3 is that lower mean scores of items in $\mathrm{O}_{1}$ are related to higher $t$-value. Hence, the relationship between the mean score of an item in $O_{1}$ and the $t$-values is negative: lower mean scores of items in the first survey $\left(\mathrm{O}_{1}\right)$ are associated with higher $t$ values. Therefore the relationship is negative. The relationship between lower mean scores of items in $\mathrm{O}_{1}$ and the $p$-values is consequently positive. In other words, skills items with lower scores in the first survey are more likely to improve during the course than skills items with higher scores.

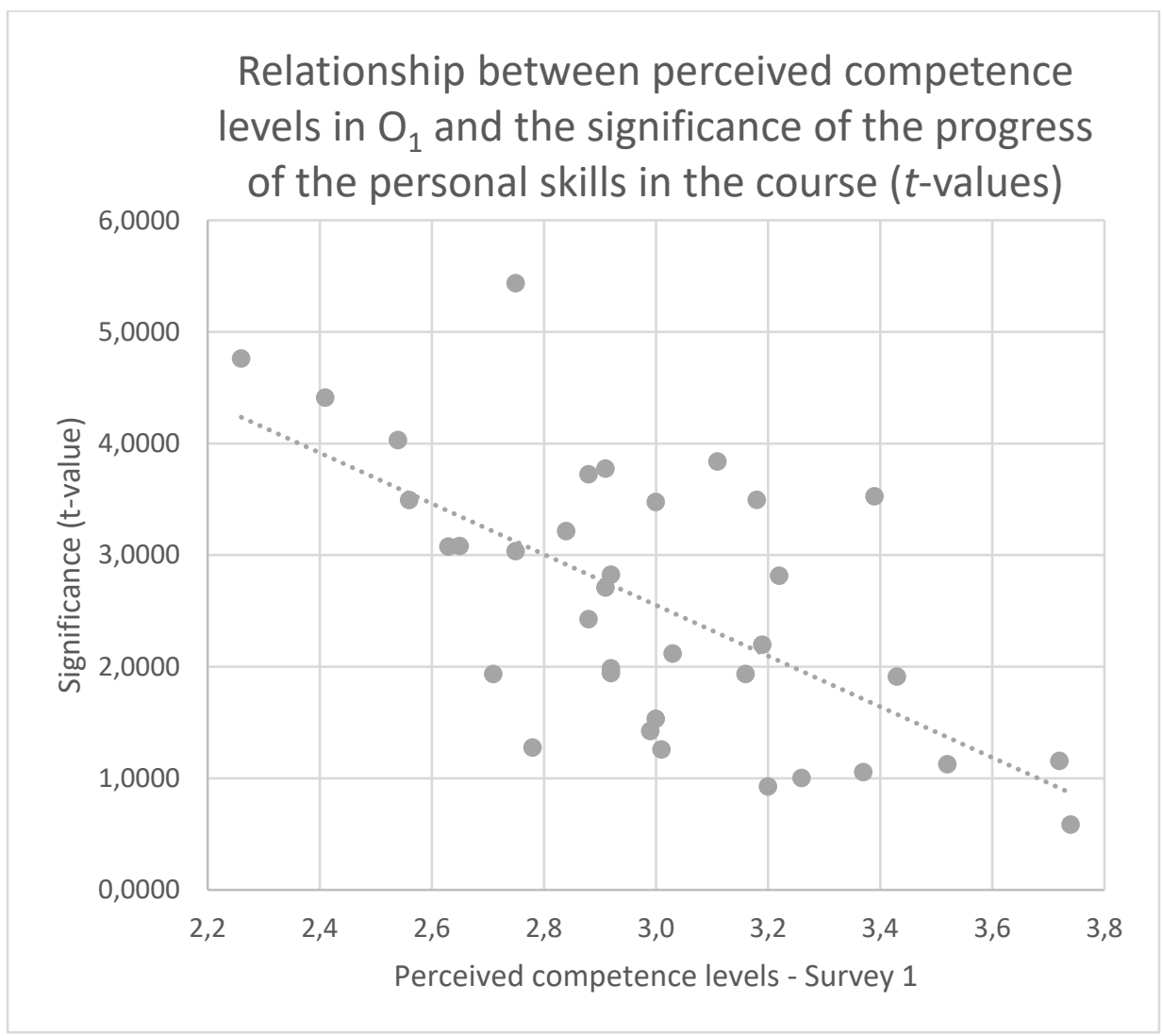

Figure 7.3 - Graph displaying the Relationship between perceived competence levels in $O_{1}$ and the significance of the progress of the personal skills in the course (t-values)

Note: Figure 7.3 displays the relationship between the perceived competence levels in survey 1 $\left(O_{1}\right)$ and the significance of the progress in perceived competence levels from survey $1\left(O_{1}\right)$ to survey $2\left(\mathrm{O}_{2}\right)$ ( $t$-values) $\left(R^{2}\right.$ Linear $\left.=.402\right)$. In other words, skills items with lower scores in the first survey are more likely to improve during the course than skills items with higher scores 


\begin{tabular}{|c|c|c|c|c|c|}
\hline & \multicolumn{3}{|c|}{ Coefficients $^{\text {a }}$} & \multirow[b]{4}{*}{$\mathrm{t}$} & \multirow[b]{4}{*}{ Sig. } \\
\hline & \multirow{2}{*}{\multicolumn{2}{|c|}{$\begin{array}{c}\text { Unstandardised } \\
\text { Coefficients }\end{array}$}} & \multirow{3}{*}{$\begin{array}{c}\text { Standardised } \\
\text { Coefficients } \\
\text { Beta }\end{array}$} & & \\
\hline & & & & & \\
\hline & B & Std. Error & & & \\
\hline (Constant) & 9.265 & 1.410 & & 6.573 & .000 \\
\hline Perceived competence level (survey 1 ) & -2.276 & .476 & -.634 & -4.781 & .000 \\
\hline
\end{tabular}

a. Dependent Variable: Significance of progress (t-values)

\subsubsection{Personal skills and traits development and the competence construct}

Competence items that were not foreseen in the set of learning objectives for the introduction course to Purchasing Management, such as 'sellership skills' and the 'willingness to take risks', are remarkable since these improved without setting corresponding ILOs were defined. However, the modern purchaser needs this kind of entrepreneurial skills, which already was confirmed by Giunipero and Pearcy (2000). Other significant, unintended improvements are detected with 'persistence', 'proactivity', 'teamwork' and 'cross-cultural awareness'. Evidence is provided with the sample consisting of business master students who are used to work in student groups, 'teamwork' skills can be improved significantly when these students are assigned to groups instead of forming groups, i.e. continuing in old structures.

As stated in the introduction, the transfer of knowledge and theory has a significant role in higher education. Indeed, the importance of knowledge and theory is undeniable; however, soft skills (i.e. interpersonal skills and intrapersonal traits) are necessary to carry out professional tasks (Ahmed et al., 2012), as also is shown with qualitative evidence in Chapter 6 . Moreover, employees' soft skills are highly valued by employers, and the lack of soft skills is more likely to be the reason for ending a labour relationship than a lack of knowledge (Ahmed et al., 2012).

For the operationalisation of strategic management knowledge and theory, strategic thinking or strategic handling is needed. In strategic management courses, students are taught strategic management knowledge and theory (which was also done in the described course). However, in most of these courses, the business students are not taken to the next level of carrying out strategic management and lack competences in strategic thinking. In line with Saunders, Mann, and Smith (2008), Delamare-Le Deist and Winterton (2005) show that knowledge, skills and attitudes form an undividable triangle, and Willingham (2008) expresses that attitudes and traits should be developed within a context (of knowledge and theory). 
This balance between hard skills and soft skills is also found in the work of Giunipero (see: Table 1.1. in Section 1.2.4.). Giunipero (2000, p. 8) emphasises on PSM knowledge and skills, but also at intrapersonal traits in PSM: "world-class purchaser" is "continuously improving his/her skills; (...) is focused on professional development and education; (...) is willing to change and adapt; is a problem solver seeking the best solution; is flexible; (...) is ethical; (...)" and "adapts well to change", hence within the PSM context as suggested by Willingham (2008).

\subsubsection{Two forms of thinking - critical thinking and strategic thinking}

Remarkably, two forms of thinking, 'critical thinking' and 'strategic thinking', represent the second lowest and the highest significance and effect size in this study. Moreover, 'critical thinking' is perceived as a top-10 ranked competence with the surveyed students, whereas 'strategic thinking' is ranked amongst the lowest ten. In the four to five years of academic training (and over ten years of elementary and secondary school education), the students stated that they developed critical thinking. Strategic thinking, however, appeared to be underdeveloped.

A possible explanation is that students could be more familiar with the term 'critical thinking' since they might have been primed with the notion that 'critical thinking' is a desirable objective for a student in general. In the literature, there is a discourse on 'thinking'-learning objectives, like 'critical thinking', 'academic thinking' et cetera. The discourse is led by Willingham (2008), who questions whether critical or other kinds of specific thinking are skills on its own: "If you remind a student to look at an issue from multiple perspectives' often enough, he will learn that he ought to do so, but if he doesn't know much about an issue, he can't think about it from multiple perspectives" (Willingham, 2008, p. 21). Willingham (2008) pleads for critical or other specific thinking in a given context, which is in line with Delamare-Le Deist and Winterton's (2005) definition of competence as a construct of three elements, knowledge, skills, abilities and other characteristics. It is also in line with constructive alignment, as proposed by Biggs (2011).

Critical thinking differs from strategic thinking. The critical thinking movement has a longer tradition than strategic thinking. Whereas strategic thinking originates from business management literature (e.g. Mintzberg, 1994), the critical thinking discourse is conducted in the educational science literature (e.g. Ennis, 1993)

"Although critical thinking has often been urged as a goal of education throughout most of this century (for example, John Dewey's How We Think, 1910; and the Educational Policies Commission's 'The Central Purpose of American Education', 1961), not a great deal has been done about it. Since the early 1980s, however, attention to critical thinking instruction has increased significantly-with some spillover to critical thinking 
assessment, an area that has been neglected even more than critical thinking instruction" (Ennis, 1993, p. 179)

Critical thinking is defined mainly with the upper three levels of Bloom's taxonomy of educational objectives, which are "analysis", "synthesis", and "evaluation", and in some cases, the next two levels are included: "comprehension" and "application" (Bloom, 1956; Ennis, 1993). Bloom's taxonomy recognises subsequently (1) (remembering) knowledge; (2) comprehension or understanding; (3) application; (4) analysis; (5) synthesis; and (6) evaluation and is often presented as a pyramid in which the (remembering) knowledge forms the base of the pyramid and evaluation the tip (Bloom, 1956).

This definition of critical thinking based upon Bloom's taxonomy is problematic (Ennis, 1993). Firstly, the levels of Bloom's taxonomy "are not really hierarchical, as suggested by the theory, but rather are interdependent. For example, although synthesis and evaluation generally do require analysis, analysis generally requires synthesis and evaluation" (Ennis, 1993, p. 179). A better definition of critical thinking "is the correct assessing of statements" (Ennis, 1993, p. 179). "Strategic thinking, in contrast, is about synthesis. It involves intuition and creativity. The outcome of strategic thinking is an integrated perspective of the enterprise, a not-too-precisely articulated vision of direction" (Mintzberg, 1994, p. 3).

Strategic thinking is a skill that employers appreciate (Bals et al., 2019). The literature shows that attitudes and intrapersonal traits as strategic thinking are scarcely trained in academia (Birou et al., 2016; Wong et al., 2014). However, this course was directed on the strategic purchasing management theory and urged the students to think about strategic problems in the case assignments. Hence it provided a context to the thinking process. Nevertheless, the literature shows that attitudes and intrapersonal traits as 'strategic thinking' are hardly taught in academia (Birou et al., 2016; Wong et al., 2014). It is also what was found in the Project PERFECT studies: 9599 per cent of the learning objectives of undergraduate and graduate PSM courses in the Netherlands are based upon the transfer of explicit knowledge and for the remainder upon interpersonal skills, i.e. 'communication' and 'teamwork' (Stinenbosch, 2017; Stinenbosch \& Stek, 2017a, 2017b).

For this research, a cohort of students was challenged with a building project on our campus. Since buildings depreciate in 30 years, and hence financial means and resources are involved for 30 years assignment was to formulate a vision on the development of higher education for the next 30 years. This assignment went beyond the level of critical thinking or the correct assessment of statements.

Another case study regarded the tender procedure of hot beverages vending machines on the university's campus. The students were instructed to align with the 
university's overall strategy, which is focused on sustainability. Initially, the students' probably focused on the assignment with their critical thinking abilities and addressed disposable plastic coffee cups. The involved sustainability officer of the university drew attention to sustainability beyond plastic cups. What about energy and water use? What about the sustainability of the supply chain of the main ingredients: coffee and cocoa beans? Sustainability has an environmental (planet) and a social side (people). The students were used to thinking critically about limited problems and not thinking strategically and were initially unable to grasp the larger picture.

\subsection{Conclusions and recommendations for practice in PSM higher education}

The RQ1 is focused on which soft skills 'could' be developed. Like is hypothesised, the evidence is shown that soft skills can be trained, which is confirmed by Laker and Powell (2011) and Scholten and Dubois (2017), although Feisel et al. (2011) doubted the possibility to influence soft skills. Hence, the question of whether soft skills 'could' be taught is answered. Laker and Powell's (2011) findings trigger whether soft skills 'should' be taught in academia. They mention that soft skills training comes with higher levels of resistance.

Nevertheless, employers agree that soft skills 'should' be taught, as shown by Ahmed et al. (2012) and many scholars in the PSM competence field (e.g. Bals et al., 2019; Feisel et al., 2011; Giunipero \& Pearcy, 2000). The European ministers of Education also would agree, according to the statement that: "Higher education should be based at all levels on the state of the art research and development thus fostering innovation and creativity in society" (Leuven/Louvain-la-Neuve Declaration, 2009, p. 4).

Interestingly, the University of Twente's founders were inspired to develop students' interpersonal skills and intrapersonal traits. In the late 1950s and early 1960, a USA-style campus design was proposed for the University of Twente's predecessor, the Technische Hogeschool Twente. Boer and Drukker (2011, p. 31 ) state, "After all, the campus was not just an experiment in intensifying studies, it was also intended to improve the students' general wellbeing". Here the then Minister of Education Jo Cals (1914-1971) indirectly influenced the transfer of other than explicit knowledge or Ausbildung by shaping an American campus, providing studying, sports, social and cultural activities (Boer \& Drukker, 2011).

Hence, many parties would agree that soft skills, more precisely 'intrapersonal traits learning objectives' 'should' be applied in academic courses, most notably the employers, PSM scholars, politicians and policymakers. Nevertheless, academia failed to offer a balanced volume of knowledge and theory, professional and interpersonal skills and intrapersonal traits. This research shows that the proverbial low-hanging fruit is found in lower self-rated competences. Lecturers who replicate this study could use 
the first survey to set or adjust the ILOs and focus on essential soft skills with lowperceived competence levels.

Hence, soft skills 'could' and 'should' be taught in higher education, but they are absent when it comes to learning objectives. It raises the question of whether soft skills 'would' be taught in academia. Soft skills education is less attractive for students, trainees, and management who prefer hard skills over soft skills education (Laker \& Powell, 2011), and lecturers feel guilty when shifting to student-centred methods (Anthony \& Kadir, 2012) necessary for soft skills education (Hoidn, 2017).

The learning of knowledge, skills and traits was facilitated, whereas regular courses focus only on knowledge and theory (Birou et al., 2016). The students revealed in the reflections that they usually would start to study the lecture notes and PowerPoint presentations a week or two before the exams. In this course, the students studied the notes (of the frontal instructions) in an earlier stage because the knowledge formed the context of the case or the book chapter, which is in line with Wang et al. (2013, p. 477), who found that constructive alignment courses offer students "deep learning approaches and less (...) surface learning approaches".

Here, the evidence is provided that the course design followed Willingham's (2008) call for a contextual basis to develop specific thinking forms. Moreover, with the outcomes of Poh et al.'s (2010) research in mind, regarding the intrapersonal traits, the course content seems to have caused 'neurological activity' within the students' brains. Moreover, the conclusion is that frontal instructions that characterise the teachercentred approach nevertheless can be applied as one of the didactical forms in the student-centred approach if it fits the learners' context, which is confirmed by Hoidn (2017).

Student-centred approaches are indispensable for the future of PSM higher education (Bals et al., 2019) and are preferred by employers, politician, policy-makers and student organisations. Moreover, all European universities and universities for applied sciences endorsed ESG Report's content (ESG Report, 2015). The ESG Report urges that higher education institutions "should ensure that the programmes are delivered in a way that encourages students to take an active role in creating the learning process and that the assessment of students reflects this approach". Furthermore, the report underlines the importance of student-centred learning and teaching plays "in stimulating students' motivation, self-reflection and engagement in the learning process" ESG Report (2015, p. 12).

Although student-centred learning environments are a better alternative, the dominant design is based on teacher-centred learning. As is shown in the theory section, the practice is unruly due to two intertwined barriers. Frontal, teacher-centred approaches are assumed to be cost-efficient (but not as effective) and are the 
dominant, traditional form. Nevertheless, this study's focal course is organised within the existing budget of the previous teacher-centred course modified in a studentcentred way. Hence the evidence is shown that a shift towards a student-centred approach can be affected in a budget-neutral manner. This finding contradicts the idea that teacher-centred approaches are more cost-efficient than student-centred.

The overarching associations of European universities and universities of applied sciences endorsed the standards and guidelines (ESG Report, 2015). The European ministers stated in the Bologna Process similar (Leuven/Louvain-laNeuve Declaration, 2009). European higher education institutions were supposed to have changed their teacher-centred approaches in the past 10 to 15 years but mostly failed. The conclusion is that a substantial shift from teacher to student-centred learning is not at hand in many European higher education institutions.

This conclusion does not imply that departments, chairs or individual lecturers cannot start their student-centred approaches and introduce soft skills learning objectives, as is shown in this study. They can offer these learning objectives to cover the full competences' palette. This means that next to the regular learning objectives regarding knowledge, theory and professional skills, also soft skills (i.e. interpersonal skills and intrapersonal traits) learning objectives can be offered. When introducing soft skills learning objectives, some surpassable barriers may arise, as this study has shown.

Firstly, students and other colleagues mainly prefer hard skills learning objectives, as is described above. From the student evaluations, it became clear that the course was mostly positively evaluated and was experienced as 'different from other courses'. Remarkably, the students in the cohort 2020-2021 followed most of the lectures online due to the Covid-measurements have appreciated the course even better than the preceding cohorts.

Nevertheless, the most common asked question by students (and colleagues) was how soft skill development could be evaluated. Knowledge and professional skills can be tested in an exam or assignment. Soft skills ILOs indeed require another evaluation method and didactics. In line with Biggs (2011), when changing the course's ILOs, the content, the didactics, the teaching and learning activities were modified, and subsequently, the assessment tasks and testing of the learning objectives were altered within the 'constructive alignment'.

Thus, introducing soft skills learning outcomes will affect the course's content, didactics, and testing. Concluding, soft skills like strategic thinking, negotiation and sellership skills cannot be assessed with a regular, written exam. Contrary, the strategic management, negotiation and sellership theory and knowledge can be described explicitly and tested in a written exam or an assignment. For the course that served as an example in this study, a mix of assessments was designed. The knowledge and theory 
were tested with multiple-choice, open and essay questions in a regular, written exam. A scientific paper and a case study report formed the assessment of two project outputs that covered professional skills, knowledge and theory. The soft skills development was measured with two surveys on which the individual students reflected with a written personal development plan.

Lecturers that intend to apply the outcomes of this study to modify an existing course are can follow these steps: (1) select a suitable course and create a team of colleagues and practitioners with whom to cooperate and to modify the course; (2) compare the old and new ILOs and assess whether the new ILO would fit in the curriculum; (3) based on the new ILO, design the course content and the case study and define the TLA; (4) align the assessment methods with the ILOs, and the TLAs; (5) communicate the new approach with the students and manage their expectations.

\subsection{Limitations and further research}

The course's new constructive alignment approach might have caused 'neurological activity', i.e. some learning form. The first limitation of this study that it is questionable whether learning as 'ontogenetic adaption' occurred as meant by De Houwer et al. (2013, p. 633), who defined learning "as changes in the behavior of an organism that are the result of regularities in the environment of that organism". It was not possible to measure the students' perceived soft skills levels over a more extended period.

This study's second limitation is the quasi-experimental or pre-experimental character (Campbell \& Stanley, 1966). Campbell and Stanley (1966) note that an $\mathrm{O}_{1}-\mathrm{X}-\mathrm{O}_{2}$ design comes with internal validity problems. Primarily, the 'history' forms a threat to validity. "Between $\mathrm{O}_{1}$ and $\mathrm{O}_{2}$, many other change-producing events may have occurred in addition to the experimenter's X" (Campbell \& Stanley, 1966, p. 6). In this study, a one-group pre-test - post-test design experiment is performed in a cohort of students in an elective, introductory PSM course for the master curriculum Industrial Engineering Management (IEM) in which also master students in the Business Administration (BA) track are enrolled. Parallel to the course, the participating students followed in the same period on average, two other courses that might have affected the second survey outcomes $\left(\mathrm{O}_{2}\right)$.

Consequently, the quasi-experiment was not performed with a parallel group of students in another traditional course that has not incorporated interpersonal skills and intrapersonal traits development in the learning objectives. The results show an increase in some interpersonal and intrapersonal skills. It is uncertain whether this increase was gained due to the course's specific learning objectives and training methods. Thirdly, the increase between survey $\mathrm{O}_{1}$ and $\mathrm{O}_{2}$ could be due to other parallel 
courses in the curriculum or other private life circumstances. Moreover, some students stated that becoming conscious of the competence level caused differences between the two surveys, known as the Dunning-Kruger effect (Kruger \& Dunning, 1999).

Fourth, the course consisted of three cohorts of only 95 students of an elective introduction course to PSM, which is a limited number. It is questionable whether the outcomes are generalisable for larger populations. Fifth, after getting information about the course's first lecture, some students usually sign out for different reasons. In some cases, the required courses' timetables interfered with this elective course, and some students expressed that they did not like the course's design. Hence, after the introduction course, only interested students stayed in the course, which may be seen as a respondent's bias and probable convenience sampling.

Sixth, the majority, 82 of the 95 students ( 86 per cent), has a Dutch nationality, which might have caused cultural bias. Seventh, another potential limitation could be a social-desirability bias, i.e. that (some) students might have anticipated and replied having developed (some) skills in the course and therefore replied differently in the second survey. However, as mentioned, the first survey outcomes were not disclosed before filling out the second survey.

Seventh, interestingly, this course has influenced unintendedly some soft skills significantly. Although these soft skills were not intended as a learning objective, they improved significantly. Indeed, students followed other courses and experienced other events in life. However, eight weeks between the two surveys is a short timeframe, and additionally, this course is described by students as 'different'. Therefore, it cannot be ruled out that lecturers unintendedly influence their students' soft skills levels without defining soft skills learning objectives.

Further research is suggested by replicating this study to test if the same results can be reached in other (cultural) circumstances (Cagliano et al., 2011; Chipulu et al., 2014; Pagell, Katz, \& Sheu, 2005). Moreover, it would be recommendable to distinguish in further research the most critical interpersonal and intrapersonal skills that lead to PSM success and replicate this study with a redesigned course and subsequent learning objectives.

This research shows that soft skills 'could' and 'should' be taught in higher education. Feisel et al. (2011) found that soft skills development with experienced staff is 'difficult'. It aligns with Laker and Powell (2011), who found that trainees and management prefer hard skills over soft skills education but are absent in learning objectives. This study shows that master students are easily influenced in their soft skills development, raising the questions of whether these findings are generalisable and apply to senior PSM or SCM staff. 
Further research is needed to determine the possibility to develop senior staff's soft skills levels as suggested by Kiratli et al. (2016), whereas the 'methodological toolbox' should not be restricted to a sheer observative, positivist research (Chicksand, Watson, Walker, Radnor, \& Johnston, 2012; Darby et al., 2019; Knight et al., 2020; Pettigrew, 2001). PSM and SCM educational research would benefit from active scholarly involvement in the complex challenges the field faces regarding digitisation, circularity and CSR.

With the advent of Industry 4.0, machines will communicate autonomously. Human traits will become even more essential (Von der Gracht et al., 2016). Therefore, strategic thinking will gain importance as a vital trait that deviates from critical thinking, another essential thinking mode. The answer to the question of whether strategic thinking can without critical thinking is probably negative. In this research, a chronological mismatch appeared. During their primary, secondary and academic education, the students in the experiment have appeared to been developed to think critically mainly without seeing the bigger picture nor to think strategically (or even "holistically"?). Further research could focus on the sequence of the training of thinking modes. This research assumes that business students should be trained first to understand the bigger picture and break down problems in bits as they are used to in current education and think critically. 


\section{Chapter 8}

\section{Discussion - Findings and Implications}




\section{DISCUSSION - FINDINGS AND IMPLICATIONS}

\subsection{Summary of key findings and contributions to the literature and practice}

\subsubsection{General remarks on the research objectives}

As mentioned in the Preface, the title of this dissertation thesis - PURCHASING SKILLS LEADING TO SUCCESS - is short, and questions are raised about what "purchasing", "skills", and "success" are. In the first sections of Chapter 1, "purchasing", "skills", and "skills transfer" are elaborated. "Success," however, and especially, as the subtitle suggests, How to SUCCEED IN INNOVATION SOURCING, is more complex. The subsequent Chapters 2 to 6 aim to answer which necessary "skills" would lead to "success", i.e., effectiveness in the purchasing profession. Also, this thesis aims to answer how higher education institutions should implement the "purchasing skills leading to success" in purchasing or procurement courses based on the underlying Project PERFECT.

For this dissertation and the third step in Project PERFECT, an extensive survey was designed, tested and executed. After the survey design and testing, cooperation was found with practitioners' associations (i.e. BMÖ in Austria and NEVI in the Netherlands), with a purchasing platform website (inkopers-café.nl) disseminate the link to the online survey, which lead only to 15 participants in June 2017. In early July, the dissemination strategy was changed, and since then, purchasers were actively contacted via LinkedIn using the platform's algorithm.

In July and August 2017, between 5,000 and 6,000 purchasers were invited via the LinkedIn algorithm to the researcher's profile that revealed being a: 'PhD researcher on purchasing skills at the University of Twente'. It resulted in 3,200 purchasers accepting the invitation to link. Immediately after accepting, the freshly linked 'friend' got a personalised standard message in either English, German, French or Dutch expressing gratitude for accepting the link and for help needed. See Appendix 9.21 for the multilingual invitation texts. Some invited LinkedIn contacts raised questions, which 
have been answered in the same language, although it was clear that the survey was set up in the English language.

Eventually, 581 participants filled out the survey that provided about 250 data points per applicant, leading to a total of about 150.000 data points and a response rate of over 18 per cent. The survey outcomes form the backbone of this thesis. Chapters 3 , 5 and 6 depend on it, and in Section 11.2, papers are listed that used the survey findings to detect the perceived skills levels in gender age groups and found proxies to predict soft skills development during a career.

In Section 8.1, the findings in Chapters 1 to 7 are summarised, and Section 8.2 elaborates on the overarching research objectives and combine the outcomes within Chapter 1 presented literature on "purchasing", "skills", and "skills transfer".

Indeed, this dissertation's overarching research objective is to determine which competences lead to success in the PSM function and the eventual focus is on the most specific strategic activity in purchasing, which is innovation sourcing (Luzzini et al., 2015). This thesis highlighted different facets of the topic in the preceding chapters to answer four research objectives:

1) Research objective 1 is (1) to analyse the literature regarding the described PSM competences, (2) to find out which future PSM skills requirements for PSM personnel are perceived in the public and private sector and (3) to compare both; current and future requirements.

2) Research objective 2 is to determine whether and which cultural and structural differences exist in PSM job requirements across Europe.

3) Research objective 3 is to determine which competences and which organisational conditions lead to PSM success in innovation sourcing.

4) Research objective 4 is to find out how to develop the PSM knowledge, professional and interpersonal skills and intrapersonal traits.

The context in which PSM is situated is characterised by themes like sustainability, circularity, corporate social responsibility, digitisation, machine-tomachine communication or the Internet-of-Things and the advent of the Fourth Industrial Revolution. Therefore, Chapter 1 elaborates on PSM in the historical context towards an Industry 4.0 future, the PSM competences literature, and the discourse on competence development. As elaborated in Chapter 1, the historical context focused on the consequences on skills and skills development during the First Industrial Revolution.

The characteristics of the First Industrial Revolution are the mechanisation of production with the use of water and steam power (Schwab, 2016b). Equipped with 
steam-driven complex machinery, the labour force remained the essential resource as machine-assisted labour (Von Tunzelmann, 2003). The First Industrial Revolution had a considerable impact on society. Rural areas were abandoned, with urbanisation as a consequence. The Second Industrial Revolution used electric power to generate mass production (Schwab, 2016b). The Third Industrial Revolution used electronics and information technology to automate production (Schwab, 2016b).

The Fourth Industrial Revolution is associated with the term Industry 4.0, the Internet-of-Things and machine-to-machine communication. The Fourth Industrial Revolution affects PSM, which is referred to as "Procurement 4.0," i.e. a set of factors "influencing the digitisation of procurement and supply chains" (Bienhaus \& Haddud, 2018 , p. 965). Section 8.1 .2 is discussed how contemporary higher education can benefit from the skills discourse in the $19^{\text {th }}$ century during the First Industrial Revolution. The similarities in skills requirements for professionals in organisations in the two era's is striking. The early $19^{\text {th }}$ century ideas of Blanqui and Von Humboldt are, after 200 years, still current.

For instance, for Blanqui, "management studies could in no way be reduced to an accumulation of technical capacities, however necessary they may have been. In his view, proper management education was an exercise, which enabled future economic decision-makers to develop the crosscutting know-how and skills needed to reformulate problems and identify solutions in complex organisational situations" (Deslandes, 2019, p. 8).

The ideas of Blanqui can be detected in Chapter 2, which is interview-based research on current and future skills and identified an additional 17 competences to those previously established in the Tassabehji and Moorhouse (2008) framework to provide a more solid platform for staff development (Table 2.7). These additional competences are predominantly personal skills and traits that relate to digitisation (e.g. 'eProcurement Technology', 'Automation'), 'Sustainability', or the need to adopt a more holistic perspective, specifically around supply chain management and innovation (e.g. 'Holistic supply chain thinking', 'Innovative sourcing approaches').

Also, in Chapter 3, the ideas of Blanqui can be found. This chapter is a mixedmethods study combining the Project PERFECT survey outcomes with World Café session outcomes. This study is the first that reveals public procurement skills and, more precisely, the (future) competences in the public procurement of innovations. Chapter 3 uncovers requirements categories of an innovation buyer in public procurement, which are interpersonal human-to-human skills (e.g. persuasiveness, communication, challenging, listening), intrapersonal character traits or attitude (e.g. 'out-of-the-box' thinking, curiosity, sensitivity, persistence), professional skills (e.g. team working skills, contract development, data analysis, interview skills, category strategy development) 
and knowledge (e.g. knowledge of the own organisation and the market, legal and technical knowledge, knowledge on circularity and digitisation).

Whereas a monocultural, mostly US-dominated approach characterises the extant literature on PSM skills, Chapter 4 addresses the second research objective and contributes to the literature by presenting evidence that cultural differences in Europe exist, which is based upon the comparing of 300 PSM job ads in three European cultural clusters. The chapter presents what employers require from purchasers in three different European countries and cultural clusters. Determining cultural or international differences is essential when designing job requirements or learning objectives in higher education in different countries or employing purchasers in international settings.

National cultures influence skillsets and job requirements; however, culture does not influence the definition of competence. Hofstede distinguished three levels: the universal, the collective and the individual level. All humanity shares the universal level of mental programming, the biological 'operating system' of eating, drinking, and sleeping. The individual level of social programming is defined as the genuinely distinctive part: "no two people are programmed exactly alike, even if they are identical twins reared together. This is the level of individual personality; it provides for a wide range of alternative behaviors within the same collective culture. In between the biological and the individual level, people share a collective level of mental programming with some but not all others. This level belongs to people in a specific category or group and can deviate from the programming of those that belong to other categories or groups.

Is culture an inseparable part of competences, or should it be incorporated in the definition of competence? Chapter 4 is called Culture's Consequences for Purchasing. In other words, it pictures culture's influence on competence set. Chapter 6 shows that the purchasing focus of innovation sourcing versus cost reduction influences the content of competence set, and Chapter 4 shows that culture has a similar influence. Culture does not change the definition of competence. It affects the content of the competence construct.

Chapters 5 and 6 address the third research objective, and in both chapters, the novel research methodology necessary condition analysis (NCA) is used to find out which competences are necessary for different foci in PSM. Also, other newly developed methods have been used. In Chapter 5, polynomial regression with response surface analysis is applied combined with composite-based structural equation modelling. Organisational conditions and individual skills are combined in a 'threedimensional' approach. 
Chapter 5 adds to the literature the quantitative evidence that organisational support, combined with increased skills levels, will lead to "success". Both are needed, meaning that organisations that train their purchasers also should create organisational conditions to sort effect. In Chapter 6, the competences as a necessary condition for success for different purchasing objectives are revealed. In the existing literature, more or less two archetypes of purchasers are presented: an operational, transactional type focused on delivery, quality and costs and a strategic innovation sourcing expert aiming to be the preferred customer to obtain sustained competitive advantage. Indeed, both profiles were found; however, remarkably, both archetypes share the same necessary skillset.

Since the preceding chapters emphasised the need to incorporate interpersonal skills and intrapersonal traits in higher education learning objectives, developing these is addressed in Chapter 7. The fourth research objective is answered with an experiment or, more precisely, a quasi-experiment (Campbell \& Stanley, 1966) performed with three cohorts of master students in Industrial Engineering Management and Business Administration. In this experiment, this dissertation's findings regarding constructive alignment are applied to formulate the intended learning outcomes and determine the teaching and learning activities and assessment tasks proposed by Biggs (1996) for a real-life case-driven course.

Biggs (1996, p. 347) combined in 'Constructive alignment' two philosophies: "the first derives from constructivist learning theory and the second from the instructional design literature". Central in constructivism is creating the meaning of the learner's activities, impacting the teaching and assessment methods. The 'Instruction design' underlines the alignment between a course's learning objectives and the student's performance assessment methods. Biggs (1996, p. 347) combines both to 'Constructive alignment', i.e. that constructivism is applied as the instructional design framework to create curriculum objectives "in terms of performances that represent a suitably high cognitive level, in deciding teaching/learning activities judged to elicit those performances, and to assess and summatively report student performance" (Biggs, 1996, p. 347).

The quasi-experimental rationale towards constructive alignment lies in the literature's findings and own field research in academic PSM courses in the Netherlands as part of the Project PERFECT. The findings show that higher education institutions are focused on the transfer of explicit knowledge, professional skills, and a much lesser extent on interpersonal skills. Intrapersonal traits, however, are valued by employers but are absent in learning objectives or intended learning outcomes in PSM curricula. The set of success competences found in the preceding chapters are mostly intrapersonal traits. 
This chapter provides evidence with the constructivist learning experiment that a real-life case supports learning objectives regarding (PSM) knowledge, professional and interpersonal skills and intrapersonal traits. The most important finding is that intrapersonal traits not only can be developed in an academic course but need to be developed in the competence triangle of knowledge, skills and attitudes. To put it differently: as a creation of meaning for the learners, strategic management theory is combined with a case-driven exercise in strategic thinking. Employers appreciate graduates knowledgeable in strategic management, but they prefer those that can think strategically. Yet, strategic thinking on itself and without the context of strategic management is meaningless (Willingham, 2008). In the following sections, the findings of the preceding chapters are described and discussed.

\subsubsection{Chapter 1 - presentation of historical overviews on PSM and competence development}

Chapter 1 made clear that PSM is a relatively young discipline that has gotten some interest in the past 100 to 150 years. In the $19^{\text {th }}$ century, railroad companies in the USA focused on PSM and in times of geopolitical turmoil, especially the World Wars and in the Vietnam War, the attention for PSM was temporarily increasing. PSM's development to a more mature discipline dated from the late $20^{\text {th }}$ century when the make-or-buy decisions became a significant topic and organisations started defining their core and non-core (Cousins et al., 2008, p. 12).

The process is accelerated by globalisation due to the GATT's and WTO's attempts to stimulate global trade by decreasing the trade barriers and import tariffs. Moreover, China introduced a new economic politic in the late 1970s. The outsourcing that was caused is explained with the Transaction Costs Economics Theory of Williamson (1981), based upon the theorem of Coase (1937), the emphasis of core competences of organisations by Prahalad and Hamel (1990) and Kraljic (1983), who stated that 'purchasing must become supply management'.

In the past two, three decades, the PSM function is developed into an "integrated supply chain management", reflecting a "growing emphasis concerning the importance of suppliers" and is characterised by cooperative supplier relationships and supplier development (Monczka et al., 2016, p. 27). It involves "not only purchasing goods and services at competitive prices but also focusing on cost reduction techniques, improving cycle times, reducing time-to-market, and constantly seeking to exploit actual and potential innovations from within the supply market" (Cousins et al., 2008, p. 14).

The maturity of PSM might be recent; nonetheless, the specialisation of tasks and subsequent sale and purchase belong to humankind for 300,000 years, which behaviour is distinct to humans (Homo sapiens) since prehistory. Humans possess 
competences like creativity, social exchange, improved communication skills and above all, fictional thinking abilities that the more potent and taller archaic humans, the Neanderthals, lacked. These creative skills supported the early humans in their transcontinental journeys, in harnessing fire, in imitation capabilities and eventually in being able to re-enact, share and plan (Harari, 2014; Lumsden, 1999).

A second pre-historical breakthrough is developing interpersonal skills via higher-speed speech skills and the proliferation of vocabularies. Lumsden (1999) defines prehistoric creativity as a planned activity of the self-aware mind. After elaborating on prehistoric procurement and addressing ancient 'commercial law', insights into the concepts of creativity and of learning are given. Creativity leads to innovativeness, and the importance of both novel and useful idea generation is underlined (Perry-Smith \& Mannucci, 2017).

The second section of the first chapter elaborates the three elements in the construct of competences are knowledge, skills and virtues (traits or attitudes), and attention is given to the philosophy behind training traits. The Aristotelian, ancient Greek idea of virtues to become 'better citizens' seemed to be of less importance after the Enlightenment (Wootton, 2018). However, the idea of creating 'better citizens' appeared to persist. In 1867, John Stuart Mill stated that universities' task is to create "capable and cultivated human beings" instead of delivering professionals (Mill, 1867, p. 4). In the $19^{\text {th }}$ century in France, Blanqui's thoughts on management education included the coverage of "the moral lesson of freedom, leaving room for the apparently useless (...) as well as the strictly utilitarian" (Deslandes, 2019, p. 8).

Earlier in the $19^{\text {th }}$ century in Prussia, in the then German Federation (Deutscher Bund), Wilhelm von Humboldt introduced the Bildung approach in the Prussian educational system. The Bildung ideal is that those students develop their personality, traits or character. The European ministers of education, gathered for the Bologna Process regulations meeting in Leuven and Louvain-la-Neuve in Belgium in 2009, stated that students need to "develop the competences they need in a changing labour market and will empower them to become active and responsible citizens in the future" (Leuven/Louvain-la-Neuve Declaration, 2009, p. 1). Here the influence of Aristotle, Von Humboldt, Blanqui and Mill is felt.

In the first chapter, the notion of freedoms is briefly introduced via Benjamin Constant's distinction between modern and ancient freedom in 1819 and via Isaiah Berlin's 1958 inaugural lecture in Oxford in which he proposed two concepts of liberty, negative and positive freedom. Whereas Von Humboldt and Mill were adepts of what Berlin called negative freedom, i.e. "to be free to the degree to which no human being interferes with my activity" (Berlin, 1958, p. 4), Berlin added the concept of positive freedom, i.e. "the wish on the part of the individual to be his own master" (Berlin, 1958, p. 14). Although Berlin points out that the concept of positive freedom will lead to 
paternalism and even despotism, he does not reject positive freedom. Berlin refers to Kant's two categorical imperatives: "I am free because I am autonomous: I obey laws which I have invented for myself" (Berlin, 1958, p. 16).

Contextual this dissertation is situated in the Fourth Industrial Revolution and comes with the changing requirements for the current and future job environment combined with the fast change due to the eras' shift. The World Economic Forum (WEF, 2015 , p. 3) formulated a range of sixteen necessary skills, which students should possess. Remarkably, the majority of these sixteen skills consist of (three) interpersonal skills and (seven) intrapersonal traits. This so-called $21^{\text {st }}$-century-skillset consists of six cognitive skills (literacy/ability to read and write, numeracy, scientific literacy, ICT literacy, financial literacy, and cultural and civic literacy); three interpersonal skills (communication, collaboration and leadership); and seven character traits or virtues, which also can be defined as 'intrapersonal traits' (creativity, curiosity, initiative, persistence, adaptability, social-cultural awareness and critical thinking/problemsolving), which is in line with the findings in this thesis and the underlying Project PERFECT. Initially, this project was mainly aimed to collect knowledge, theories and professional skills items. In addition to these hard skills, several soft skills were found, such as critical and strategic thinking.

Chapter 1 contains four crucial messages. The first is that competence consists of an indivisible triangle of knowledge, skills and traits. Institutions for higher education overlooked this and scarcely introduced learning objectives regarding personal skills and traits.

The second alert is that intrapersonal characteristic such as 'strategic thinking', 'critical thinking' or 'problem solving' are not skills that stand alone without a clear context (Willingham, 2008). Knowledge, skills and attitudes form an indivisible competence 'triangle', being a construct of these three elements:

"The competences required of an occupation include both conceptual (cognitive, knowledge and understanding) and operational (functional, psycho-motoric and applied skill) competences. The competences more associated with individual effectiveness are also both conceptual (meta-competence, including learning to learn) and operational (social competence, including behaviours and attitudes)" (Delamare-Le Deist \& Winterton, 2005, p. 39).

The third word of warning is on the use of Bildung in education for other than student-centred purposes and violating Berlin's concept of positive freedom. Bildung refers to the personality development and self-cultivation ideal, and it was Wilhelm von Humboldt, who in the early $19^{\text {th }}$ century introduced Bildung in the Prussian school system with the best intentions; Ausbildung prepared students for their first job Bildung for their entire life. Bildung was initially "intended as a progressive and cosmopolitan 
project, but was used by German governments in the $19^{\text {th }}$ century to fashion the nationstate" (Sanderse, 2019, p. 399).

In the 1870s, the philosopher Friedrich Nietzsche led the criticism against Bildung philosophically; he "criticized the German system of public education for having relinquished the Bildung ideal, having replaced it with preparing students to serve the German nation station and war machine" (Sanderse, 2019, p. 406). Thus, when governments interfere with the Bildung, the initial ideal evaporates. This is illustrated with the example of abuse of the Bildung ideal in totalitarian regimes to 'educate' young people ideologically.

Moreover, Nietzsche noted that Bildung had evolved in a tool for utility and gain for governments to compete with other national economies by turning students into 'currency' to let them 'circulate' in the own national economy (Sanderse, 2019). Looking at the Bologna Process declaration, it is clear that history is repeating or at least that Nietzsche's words resound. Higher education institutions are obliged to design job profile competence sets for each of their Bachelor and Master tracks, i.e. that every study track must be in line with a job profile (ESG Report, 2015; Leoni, 2014), which is a perfect example of what is meant with Ausbildung: preparing students for their first jobs. However, as will be demonstrated, Bologna developed towards the Germanic Bildung ideal of Wilhelm von Humboldt and the Anglo-Saxon character-education of John Stuart Mill.

As mentioned, both Von Humboldt and Mill were advocates of what Berlin (1958) distinguished as negative freedom, "to be free to the degree to which no human being interferes with my activity" (Berlin, 1958, p. 4) "The 'positive' sense of the word 'liberty' derives from the wish on the part of the individual to be his own master" (Berlin, 1958 , p. 14). Von Humboldt argues that it is not a task for governments to promote citizens' development but maintain order and safety and guarantee the freedom of conscience. Imposed Bildung would obstruct conscious self-development (De Hert et al., 2015). Unlike Von Humboldt, Mill is convinced that the government can at least support individuals' self-development process. In his work, the Principles of Political Economy Mill states that the government can start that development process through targeted policy. (De Hert et al., 2015).

The declaration that was issued at the end of the Bologna meeting of the European ministers of education in Leuven and Louvain-la-Neuve, Belgium on April 28 and 29, 2009, is entirely in line with the Bildung ideal. The declaration states that students need to "develop the competences they need in a changing labour market and will empower them to become active and responsible citizens in the future" (Leuven/Louvain-la-Neuve Declaration, 2009, p. 1). Here, it is clear that the ministers of education were directly or indirectly inspired by the Aristotelian conception of virtues to become 'better citizens'. However, Nietzsche's alerting resonates and raises the 
question of whether governments are applying Bildung again to turn students into 'currency' for the European economy. Berlin's concept of positive freedom to master oneself might here be on the stake, as described in the first chapter. The contemporary environmental, digital, and societal challenges might threaten individuals' positive freedom, and "paternalistic" measurements might be necessary.

The fourth is a recommendation to hiring creative PSM personnel since the purchasing function in organisations is increasingly complex. Until 30,000 years ago, Homo sapiens co-existed with humans of an archaic origin like Neanderthals and probably caused their extinction (Horan et al., 2005). If Neanderthals had survived and still co-existed, this would have had implications for purchasing departments in organisations searching for creative minds. Homo sapiens candidates would be preferred over applicants with an archaic origin like Neanderthals. As is shown above, Homo sapiens have proven better language proficiency skills, creativity, sellership skills, interpersonal communication and fictional thinking. It is even questionable whether Neanderthals could have applied in vacancy procedures due to their expected low literacy (Horan et al., 2005). This highlights that fictional thinking, creativity, specialisation of tasks and subsequent sale and purchase belong to humans (Homo sapiens) since prehistory. Although, in general, creativity is a characteristic of Homo sapiens, this research showed that creativity competence levels vary between subjects.

\subsubsection{Chapter 2 - finding future PSM competences for the private sector}

Chapters 2 is published in the $25^{\text {th }}$-anniversary edition of JPSM (i.e. Bals et al., 2019) and is a qualitative, interview-based study that investigated the current and the future competences in private purchasing and is addressing research objective 1 , which is (1) to analyse the literature regarding the described PSM competences, (2) to find out which future PSM requirements for PSM personnel are perceived in different sectors and (3) to compare both; current and future requirements.

This chapter is going deeper into PSM competences, which are the individuallevel foundations of organisational PSM performance. In the light of recent developments in the workplace and the external environment, what PSM competences are needed now, and in the future becomes increasingly important. Based on a qualitative approach with 46 interviews with practitioners from 16 companies, this study identifies what PSM professionals require current and future competences categorise PSM competences according to the framework established by Tassabehji and Moorhouse (2008), therefore establishing how these competence requirements have changed over the last ten years.

The most important current competences required by PSM professionals are negotiation, communication and relationship management (e.g. 'Interpersonal 
communication'), strategy and analytics (e.g. 'Strategic thinking'), as well as professional knowledge requirements (e.g. 'Basic knowledge on PSM role \& processes'). The unique competences in sustainability and digitisation were identified as becoming important when looking at future requirements. Overall, 17 competences over and above those identified by Tassabehji and Moorhouse (2008) were identified. The most prominent new competence areas are related to digitisation (e.g. 'eProcurement Technology', 'Automation'), innovation (e.g. 'Innovative sourcing') and sustainability. Interestingly, practitioners added eleven new competences to the interpersonal skills cluster, most of them in the intersection of competences and traits (e.g. 'Deal with Ambiguity', 'Curiosity', 'Passion').

The primary contribution of Chapter 2 to the academic literature is through the analysis of current and future individual competences required for PSM, identifying differences and similarities from work done more than a decade ago. Specifically, this study is a timely refresh of the Tassabehji and Moorhouse (2008) framework, with the addition of 17 competences that reflect changes in the PSM environment over the last decade, as well as taking a forward-looking view to establishing what future requirements may be. This research appears to be the first to add specific, empirically grounded competences to the PSM literature since Tassabehji and Moorhouse (2008).

The findings reflect the consultant reports on the expected future competences in PSM, in which both Deloitte (2013) and Von der Gracht et al. (2016) (i.e. KPMG) see an increasingly strategic role for PSM in firms and highlight the importance of analytical skills, data-driven orientation and cross-functional abilities. Moreover, Deloitte and KPMG both agree that the PSM function has a vital role in environmental and sustainability compliance, and Deloitte notes the need for PSM involvement with stakeholder engagement (Deloitte, 2013). KPMG and Deloitte foresee an increasing need for creative and inventive skills to facilitate innovation sourcing and refer to out-of-the-box thinking. (Deloitte, 2013, p. 13) is more focused and calls it "thinking outside of the standard procurement transformational box", which aligns with identifying the 'Holistic supply chain thinking' competence introduced in Chapter 2.

From a managerial perspective, these findings' implications are to set out a list of all current and future competences that could form part of personnel selection and any staff development processes. The findings can be used as an input into organisational competence models or mapping activities (as per Campion, 2011) and inform the alignment of relevant HR systems. The results also have implications for the educational and managerial training and knowledge management context, as a broader range of required competences has been identified and may necessitate changes in teaching methods and content. For instance, the 11 intrapersonal competences added to the framework need to be reflected in curricula and training programs. There is evidence in the peer-reviewed literature that PSM bachelor and master courses do not 
cover intrapersonal learning objectives with minimal exceptions (Birou et al., 2016; Wong et al., 2014).

Additionally, competences needed in the critical areas of sustainability and digitisation should be more fully integrated "into higher and professional education and professional, industrial training programmes" (Bals et al., 2019, p. 11). Further, the type of competence needs to be considered, as current training and teaching methods are not necessarily suitable for developing all types of competences, and the pedagogy needs to be adapted to reflect these requirements. Specifically, different training methods are needed when developing competences in the technical skills cluster compared to those in other clusters. Fostering shared experiences highlights the potential of in-class training formats such as role-plays and online courses and more interactive formats, e.g. blended learning or flipped classroom approaches. The metaoriented competence cluster reasoning presented in this paper suggests that finding and training employees to develop and apply these kinds of competences might be the key to sustaining performance over time, under rapidly changing contextual factors.

Chapter 2 is emphasising the introduction of personal traits as intended learning outcomes.

\subsubsection{Chapter 3 - finding future PSM competences for the public sector}

Chapter 3 is focused on the public procurement of innovations. The literature reports that public procurement is distinct from private purchasing (Telgen et al., 2007), especially regarding laws and regulations (Harland et al., 2013). Nonetheless, the main contribution is that this does not seem to apply to the interpersonal, behavioural skills and intrapersonal character traits in the profile found in this research regarding the public procurement of innovations, which seem to be similar to industrial purchasing competences as will be explained hereafter.

Public procurement has a critical financial impact on Western economies. The yearly spend in the EU is $€ 2$ trillion per year (Alvarez \& Rubio, 2015). The focus is shifting increasingly from operational buying towards a policy instrument to promote sustainability and innovations at suppliers in the market and is therefore often used as a lever of governmental policy where core objectives are set by politicians limiting the input of public procurement professionals in the procurement process (Gordon, 2009; Patrucco, Luzzini, Ronchi, et al., 2017; Telgen et al., 2007). Public procurement of innovation requires a strategic procurement function, and the question arises which skills public procurement professionals need to fulfil these requirements.

Chapters 3 is a mixed-method study using primary data from the Project PERFECT survey, and the qualitative research outcomes are derived from a World Café 
project in cooperation with the interim management agency YACHT. Hence, this study is built upon a quantitative and a qualitative pillar. The purpose of this study is to explore which future competences public procurement professionals require to face specific challenges concerning the public procurement of innovation and to provide a list of required competences of public procurement professionals transforming from an operational buyer to a strategic business partner role.

This study is investigating the future competences in public procurement as part of research objective 1, which was formulated as: (1) to analyse the literature regarding the described PSM competences, (2) to find out which future PSM skills requirements for PSM personnel are perceived in the public and private sector and (3) to compare both; current and future requirements. The aim of Chapter 3 is to distinguish those competences leading to success in public procurement.

This research has deliberately performed with a sample of interim managers being specialists in public procurement to overcome the risk of describing the status quo and listing competences for traditional, transactional public procurement. These specialists are employees of a private-owned, interim management agency and are operating at ministries, provinces, municipalities, water boards, health care organisations and other public institutions. Therefore, the participants do not have civil servants status and work temporarily in different jobs or projects at diverse public organisations. This study aimed intentionally on participants with this signature to benefit from their inside view as relative outsiders at public procurement departments to focus on this research on future public procurement's strategic role with the following competences.

When combining the competences sets, there are three roles for the public procurement of innovations. (1) The first role is to establish relationships within the internal organisation and the possible suppliers of innovations in the market. (2) The second challenge for public procurers of innovations is to bridge both and connect the internal partner's needs with the external partner's innovative capacities. (3) The third role is to challenge and encourage suppliers to innovate. It requires entrepreneurial behaviour, which may seem contraindicative and belong at first sight to a private purchasing profile. However, 'entrepreneurial' has to be understood as considering 'risk-taking', having the 'courage' and being 'confident' to innovate, to create 'out-ofthe-box' solutions, being persistent and not in the sense of being able to establish an enterprise and gain certain profits or a high return on investments, like in the private sector.

The subsequent requirements categories of an innovation buyer in public procurement are interpersonal human-to-human skills (e.g. persuasiveness, communication, challenging, listening), intrapersonal character traits or attitude (e.g. 'out-of-the-box' thinking, curiosity, sensitivity, persistence), professional skills (e.g. 
team working skills, contract development, data analysis, interview skills, category strategy development) and knowledge (e.g. knowledge of the own organisation and the market, legal and technical knowledge, knowledge on circularity and digitisation ).

The survey-based quantitative part empirically confirmed an essential role for the procurer of innovations as a strategic business partner. This research's main contribution is the development of a profile set for the public procurement of innovations. This research proposes an entrepreneurial, courageous, communicative and strategic public procurement professional that resembles the requirements addressed in industrial purchasing literature (e.g. Giunipero \& Pearcy, 2000; Knight et al., 2014; Tassabehji \& Moorhouse, 2008). The entrepreneurial strategic business partner role for public procurers of innovation might seem counterintuitive; however, as shown in Chapter 3, the competitive dialogue procedure seems to be an applicable EU procedure for the procurement of innovations in the public field.

Concluding, while private purchasing and public procurement may have many differences regarding laws and regulation (Harland et al., 2013), it seems that the competences that procurement professionals need to be successful in their sector might be more similar than expected. Therefore, the public sector's statement is significantly different from the private sector (Telgen et al., 2007) seems not to apply for the interpersonal, behavioural skills and intrapersonal character traits in this research profile.

The qualitative research sample participants are interim managers in public procurement that came to a design of a set of 'entrepreneurial' competences, which align with the public procurement of innovation capabilities literature. The conclusion could be drawn that public procurers of innovation should have an interim management profile. It might be true for competences like 'risk-taking' and having 'courage' and 'confidence' to innovate. However, a public procurement function populated with interim personnel might be costly and not desirable.

Chapter 3 is not digging into organisational circumstances. Nevertheless, based on the literature, a notice is that increasing the personnel's competence level is insufficient. Tassabehji and Moorhouse (2008) state that increasing competence levels must be accompanied by top-management support as an organisational precondition for increasing competence levels. As shown, Chapter 5 supports Tassabehji and Moorhouse (2008) with quantitative evidence. Moreover, the outcomes of Mazzucato's (2018) study on stimulating innovations in the market with public procurement missions show that "A culture of experimentation and risk-taking is a crucial element in the philosophy of missions. There must be incentives to "think outside the box" to come up with new solutions to address the mission objective" (Mazzucato, 2018, p. 811). 


\subsubsection{Chapter 4 - finding cultural differences in PSM job requirements in Europe}

As demonstrated before in this dissertation, organisations require a welleducated workforce, and standardised skills models are needed to educate these individuals. However, in the comparative management literature, researchers generally agree that business structures and practices vary across different countries and cultures (e.g. Hofstede, 2001; House et al., 2004; Inglehart \& Welzel, 2010; Ogden et al., 2007; Schwartz, 2008; Terlutter et al., 2006). Cultural differences have been reported in the areas of outsourcing (Horn et al., 2013; Schoenherr, 2010), PSM decision-making (e.g. Pagell \& Sheu, 2001; Roth et al., 2004), and buyer-supplier relationships (e.g. Cannon et al., 2010; Homburg et al., 2009; Kibbeling et al., 2009).

Nevertheless, as described more extensively in the theoretical background section of Chapter 4, the literature review results show that no attention has been given to cultural deviations in PSM competences. Moreover, universalism also seems to apply to practitioner assumptions, such as those made by the overarching union of national PSM associations IFPSM that has published a 'global standard' for professional education, which, as the name already indicates, rests on an assumption of universal validity (Brennan \& Crowe, 2012). Since scholarly and national practitioners' associations seem to have overlooked the influence of cultural differences, the question arises whether such cross-cultural differences are also present in the descriptions of required skills for purchasing managers and expressed in, for instance, job advertisements.

The research design of Project PERFECT has been an inspiration for this dissertation. Chapter 4 is based upon the first research stage of the project: mapping the landscape. It is built upon secondary data by comparing 300 PSM job advertisements in three European cultural clusters and is measuring what employees in different European countries require from purchasers. Determining cultural differences is of importance when designing job requirements or learning objectives in higher education.

Research objective 2 is to determine whether and which cultural differences exist in PSM job requirements across Europe.

Chapter 4 elaborates on the several models that have been proposed trying to identify the most essential skills supply chain managers would need to have. A common assumption of these models is universal or at least Europe-wide applicability. On the other hand, comparative management studies, often rooted in Hofstede's seminal work, emphasise business-relevant cultural differences among countries. The question arises if there would be one if not universal, so at least 'European Purchaser' or national differences in purchasing need to be considered. This chapter tested the universalism claim based on a comparison of job ads for purchasers from three European countries 
that belong to three culturally distinct areas according to Hofstede based research but would belong to just one cultural area according to the GLOBE model.

Results reveal that about one-fifth of the observed requirements were common among the advertisements, and about four-fifths were dissimilar. While some differences may have structural roots (e.g. industrial vs service predominance), it was also found that Austrian employers emphasised requirements that yield concrete results, which represents Hofstede's 'masculine' dimension. In contrast, Belgian and Dutch employers expected more 'creative' requirements, which would fit Hofstede's 'individualistic' dimension. The conclusion is that cultural differences exist. The failure to confirm the expectation of a standard European profile for PSM personnel has important implications for research and teaching, which may need to overcome this neglect to consider cultural differences to come up with accurate and practically fitting results. The ideal PSM competence set does not exist; it depends on focus (Chapter 6) and culture (Chapter 7).

The findings in Chapter 4 provide an up-to-date list of requirements found in European PSM job ads and places these in cultural contexts, which enriches the scientific literature. These findings also contribute in practical terms to the work of practitioners involved in the design of PSM curricula in higher education and company training sessions and the work of those involved in human resource management in the field of PSM, individual PSM practitioners, and students.

The findings contribute to the comparative management literature in that this is the first study to compare the needs of employers in the field of PSM and reveal cultural differences in European PSM job requirements. Previous studies on PSM skills have been conducted only in single countries and have rarely focused purely on purchasing. Instead, previous researchers have more often broadly tried to address supply chain management in general. Moreover, in the 'fight between the elephants' (P. B. Smith, 2006), the findings support the application of Hofstede's cultural dimensions. These could be effectively used to explain the observed differences, which would not have been possible with the GLOBE model. The Hofstede dimensions seem to be relatively stable over time and are still currently applicable.

From a content perspective, this chapter contributes to the field in that it offers some of the first insights into cultural differences in purchaser's requirements, which, however, raises further questions and calls for more detailed research. It has been shown that, in 'feminine' culture, such as the Dutch, employers are looking for independent purchasers with creative skills. In countries with a more 'masculine' culture, such as Austria, employers emphasised assertiveness and the will to achieve targeted results. Hence, indeed, cultural differences exist in PSM job requirements. This research's outcomes might boost 'Austrian-type' purchasers' international careers since those are primarily associated with a result-driven attitude (Hofstede et al., 2010). 


\subsubsection{Chapter 5 - innovation sourcing success: combining competences and internal support}

Chapter 5 emphasises that contributing to a firm's innovativeness is increasingly a target of purchasing. However, current purchasing skills models do not explain which skills a purchaser for innovation should possess. This chapter utilises $t$-tests, stepwise regressions and novel methodologies like necessary condition analyses and combining composite-based structural equation modelling and polynomial regression with response surface analysis. This study presents a different list of innovation sourcing competences and organisational conditions that lead significantly to innovation sourcing success. Based on an extensive European purchasing competences survey relying on 581 European purchasers' response, this study identified a set of 17 skills characterising a purchaser for innovation. This list can serve as input for skills assessment and training. The skills can be grouped into 'soft skills' (including inventiveness, creativity and willingness to take risks), 'innovation skills' (such as early supplier integration, R\&D collaboration, innovation scouting) and - a novel finding from this study - 'management skills' (such as change management and corporate governance).

Based on a polynomial regression, the importance of organisational support enables the activation of innovation skills. Innovation sourcing success is reached via the combined presence of specific individual skills combined with conditions that secure a firm's supportive atmosphere, expressed through target setting and measurement. These competences consist of different types of items: knowledge, professional and interpersonal skills, and intrapersonal character traits.

The findings in Chapter 5 have implications for skills theory building, arguing that future research should always include organisational support as a control variable. Implications for higher education and PSM training in organisations emphasise the need to redesign PSM curricula, offering dedicated innovation purchaser training, including corporate management training. Finally, management implications advocate that firms striving at better seizing the innovation potential of their supply base would benefit from in parallel (1) including innovation as a target for both purchasers and suppliers, measuring the success via KPIs and (2) identifying and upgrading the skills portfolio of their purchasers. Only one of the two steps, alone, is unlikely to yield benefits. It is, therefore, contributing to the third research objective:

Research objective 3 is to determine which competences and which organisational conditions lead to PSM success in innovation sourcing.

In Chapter 5, the evidence is shown that innovation sourcing success is dependent on both the individual innovation sourcing competences of purchasers and the proper organisational innovation sourcing conditions, which revealed to be 
complementary to each other, meaning that a lack of skills cannot be substituted by organisational support and vice-versa. Individual PSM competences and organisational or top-managerial support and recognition for PSM are related in a complementary form.

The contribution of Chapter 5 is that it empirically shows that what used to be seen as two distinct phenomena - individual PSM competences and organisational backing - have revealed to be related in a complementary form. None of the purchasing skills models analysed in the literature review considers this link, which is nevertheless well established in the innovation literature (e.g. Bresnahan et al., 2002; Leiponen, 2005; Michaelis \& Markham, 2017). This research indicated that future PSM skills research - at least when trying to identify skills for success - should take the organisational support the responding individual is receiving into account, at least as a control variable. Research not doing so could measure organisational support in a particular firm and mistake the availability of a specific skillset as an antecedent to success. If two equally skilled individuals operate, one in a supportive organisation, the other one in an isolated and non-supportive firm, the same skillset may once explain success and, in the other case, it does not. But it is not the skills but the ability to bring them to flourish through adequate organisational conditions that matter.

In this chapter, a new construct of relevance in skills studies is identified: organisational support. Future research should include it in skills studies, not only in innovation management research but also in assuming that organisational support may also influence other skill models. Simultaneously, the modelling of the variable Innovation Organisation is also indicating a limitation of this study. Only visible signals of support in the form of internal and external innovation targets and their measurement are considered. Of course, there are much more elements constituting the organisational setting into a corporate actor is embedded. For instance, the idea has emerged that innovation purchasers should be pooled in a (sub-) department of their own called 'procurement engineering' or 'advanced sourcing', rather than remaining a part of the strategic sourcing group (Schiele, 2010; Servajean-Hilst \& Calvi, 2018). When extending the findings, the hypothesis is that such an organisational setting would again foster the application of skills. Future research would benefit from confirming this assumption and exploring the exact structural and processual requirements for such departments to succeed.

Another significant and novel contribution of this study refers to the nature of innovation skills. It has presented three factors within the competences set associated with innovation purchasers: 'Soft Skills', 'Management Skills' and 'Innovation Skills'. 'Soft Skills' like innovativeness help innovation buyers and specific tools such as early supplier involvement need to be mastered. It is interesting to see that the innovation purchaser also has what is called 'Management Skills' (knowledge of corporate governance, advisory skills, working together with HRM, and the necessary conditions 
change management and project management). Innovations come into a firm by (NPD) projects and need to be defended and promoted in the firm. Therefore, knowledge of corporate governance and change management skills are required. The emergence of these general management skills' importance emphasises the increasingly strategic role of purchasing in firms (Bals et al., 2019; Tassabehji \& Moorhouse, 2008).

A final (human resource) management implication of this study refers to the 'Management Skills' an effective purchaser of innovation requires: change management, corporate governance, advice skills and cross-functional collaboration. These skills are also beneficial for a CPO. CPOs are expected to give steering to their department, introducing new tools and methods, for which they need changemanagement skills. Needless to say, that the CPO has to represent purchasing interests and inputs at the corporate level, closely interacting with the other functions. One might conclude that an effective innovation purchaser is acquiring just the skills needed to take up a CPO role. Therefore the conclusion is that the next CPO is most likely the current innovation buyer.

\subsubsection{Chapter 6 - finding the PSM competences leading to success}

Similar to Chapter 5, Chapter 6 is a quantitative, survey-based study into which competences can be distinguished as predictors for success in different purchasing objectives that address the third research objective, i.e. finding out which competences and organisational conditions lead to PSM success in innovation sourcing. Chapter 6 is entitled 'How to train supply managers - necessary and sufficient purchasing skills leading to success' since it aims to find necessary and sufficient skillsets for different types of purchasers and supply managers. Eventually, this study's outcomes will also support educators in higher education institutions designing PSM courses and curricula.

For this dissertation, the previous PSM skills literature is examined, and, notably, three assumptions have been made without providing empirical evidence. The first assumption is that the perceived 'importance' of competences is a synonym for 'success'. The second assumption is that 'important' job requirements are 'necessary' conditions. The third assumption concerns a watershed between 'operational, transactional' purchasing activities and 'strategic' sourcing and a subsequent distinct set of necessary competences for both archetypes.

This study deliberately has taken another approach by doing two things differently. Eventually, NCA is combined with OLS regression analysis, and a survey was designed with 88 items on competence levels and added 22 statement items on seven purchasing achievements or success levels.

After performing factor analysis on the 88 skills items, the 15 factors have been analysed and calculated whether each of these competence factors would be a 
necessary condition for reaching success for the seven purchasing achievements. Based on this information, it was further possible to answer the first research question by relating the newly formed factors to the responding purchasers' success scores. Therefore, the skills factors could be combined with the success levels of the seven purchasing types.

With NCA, it was possible to identify those skills, which have a necessary character, i.e. in their absence, effectiveness was not reachable. Interpersonal skills and intrapersonal traits are necessary to carry out professional skills. As a second analysis, OLS regressions are performed to identify the sufficient conditions, i.e. those skills that would indicate a more considerable success in the respective factor if more robust present. In sum, this research indicated that 15 skills factors describe the building blocks for a curriculum for a successful purchaser (five soft skills and attitudes, six skills directly supporting the purchasing year cycle, two leadership skills for management and two special skills).

The success of purchasing depends mainly on the quality of skills purchasers have. However, which skills are necessary and which are sufficient for successful purchasers' education (RQ2)? Chapter 6, therefore, presents the results of large-scale empirical research identifying 15 skills factors categorised into soft skills, year-cycle skills, leadership skills and special skills, which can further be differentiated as necessary and sufficient conditions for success.

Further, seven purchasing objectives - costs, delivery, quality, sustainability, strategic competitive advantage, supplier satisfaction and innovation - are identified. Achieving each of these objectives requires a different skillset. Hence, there cannot be just one type of purchaser, but a differentiated skillset is required depending on the intended target. The ideal PSM competence set does not exist; it depends on focus (Chapter 6) and culture (Chapter 7). Based on the proposed skillsets, university educators and firm trainers can draft teaching plans supportive of the intended outcome, while individual purchasers may get an orientation on developing further.

For training and education, the 15 skills factors can be used as input for course descriptions. Except for the three supportive soft skills factors, each skills factor could become one course. However, this research further indicates that training intensity in diverse skills may depend on the organisation's actual target. It gets clear from the answer to the first research question: (RQ1) Do purchasers indeed need different skillsets according to their purchasing organisation's different prevailing objectives? If so, which skills would benefit which objective? 
For the tactically oriented block:

Delivery
quality and the right sustainability level. The delivery expert needs a 'generic skill
portfolio' and is characterised by analytical skills, forecasting, cost focus and
automation skills.
This purchasing type is focused on quality insurance from the supplier or the quality
control and therefore requires technical know-how. Cross-functional skills are
necessary, as well as SRM and analytical skills. Contracting shows a negative sign in
combination with the quality type.

Sustainability Sustainable purchasers require, due to the solid regulation-driven character of sustainability considerations, contracting as a necessary skill. Moreover, sellership skills are necessary since the sustainability targets are not always complementary to corporates' business requirements. Cost reduction skills show a robust and highly negative sign in the regression. On average, global sourcing and negotiationoriented purchasers are cost reduction oriented, and on average, they do not achieve sustainability targets better.

For the overlapping skills requirement:

Costs For a purchaser to be successful at cost reduction, an 'overlap' target relevant for both more strategic or more operationally oriented profiles, a series of necessary skills are present. Not necessary seem to be soft skills in networking and imagination, neither automation nor technical skills. Interestingly, successfully cost-cutting purchasers did or did not have particular contracting skills. A particular training in cost reduction methods is a medium-strong differentiator.

\begin{tabular}{|c|c|}
\hline \multicolumn{2}{|c|}{ For the strategic skills requirement: } \\
\hline $\begin{array}{l}\text { Competitive } \\
\text { advantage }\end{array}$ & $\begin{array}{l}\text { Being 'result-driven', i.e. showing self-assurance, poise, proactivity, is characteristic } \\
\text { of this type. Process and sellership skills complement factor } 9 \text {-supplier relationship } \\
\text { management' and, as a differentiator, 'factor } 10 \text { - innovation sourcing skills'. } \\
\text { Market analysis, category strategy planning and the diverse innovation-oriented } \\
\text { subskills are grouped. The training programme for innovation purchasers and } \\
\text { strategic purchasers will show considerable overlap, such as imagination soft skills. }\end{array}$ \\
\hline Innovation & $\begin{array}{l}\text { Purchasers successful in the objective 'innovation' from and with suppliers typically } \\
\text { rely, as necessary conditions, on an adequate level of sellership, process and } \\
\text { project skills and the soft skill factor 'imagination', which is also a differentiator, } \\
\text { i.e. creativity, inventiveness and holistic thinking. This type further requires process } \\
\text { \& project skills to succeed in innovation. Another necessary skill is sellership, for } \\
\text { any novelty needs to be 'sold' in the organisation. The more supplier relationship } \\
\text { management and innovation sourcing skills a purchaser have, the better they } \\
\text { perform. Parts of the advanced skills are innovation sourcing and innovation } \\
\text { implementation planning. Interestingly, a negative relation between cost and } \\
\text { innovation skills has been found. }\end{array}$ \\
\hline $\begin{array}{l}\text { Supplier } \\
\text { satisfaction }\end{array}$ & $\begin{array}{l}\text { With this target, } 12 \text { out of } 15 \text { skills factors are necessary conditions. A purchaser } \\
\text { who achieves satisfied suppliers has the right level in almost all skills. No single } \\
\text { target is as demanding. Effectively this means that supplier satisfaction seems to } \\
\text { be more a question of the purchaser's maturity level (Schiele, 2007). Put it the } \\
\text { other way around: a poorly trained purchaser is likely to generate unsatisfied } \\
\text { suppliers. }\end{array}$ \\
\hline
\end{tabular}


In this study, indeed, it is found that different foci exist amongst purchasers. However, this does not automatically imply that cost reduction is just transactional and a disappearing operational activity (Giunipero et al., 2006; Legenvre \& Gualandris, 2018). When comparing the different skillsets and associated training requirements, the evidence becomes apparent that there is not just one standard profile of a purchaser as applied in the traditional skills models such as Giunipero and Pearcy (2000) or Tassabehji and Moorhouse (2008). However, it strongly depends on the targets and roles the purchaser has.

Consequently, firms establishing a purchasing training programme would benefit from, first, clearly establishing the target priorities their purchasing function would follow. Then, a tailor-made training programme could be offered. This programme is different from firm to firm. Likewise, universities or universities of applied sciences that teach purchasing would also have to define their targeted education and decide for respective course portfolios. The sub-question was, which particular skills would benefit which objectives, which is answered with the overview in Table 8.1.

\section{Table 8.2 - Three management recommendations coming forth from Chapter 6}

Establish a
purchasing skills
training
programme

Identify and
prioritise the
seven purchasing
objectives as
input for a
training plan

This research's first significant contribution is identifying an empirically backed skills model; firms could establish a training programme oriented alongside the 15 skill factors. Depending on the firm's size, either a training programme of its own or the reliance on external purchasing skills training programmes is required. For the latter, their training system would be matched to the skill system developed here and train employees according to the firm's targets.

Another contribution of this research was identifying and empirical verifying seven purchasing targets and their link to dedicated skills models. The clear empirical evidence that there is no such person as 'the' purchaser, but that the skills profile has to match the objectives of the purchasing organisation has substantial implications for firms, the first of which would be that corporate actors need to know which targets they follow in which order. If the purchasing department does not have a clear set of objectives, it is impossible to train (or recruit) people supportive of achieving them.

Establish a
purchasing skill
controlling
system

This research's third significant contribution was to link the previous two findings - the skills model and the seven targets generate a targetspecific model of necessary and sufficient success skills. This model can serve as a blueprint for a corporate skills development scheme proposed in the HR literature by Mansfield (1996) and Campion et al. (2011). Skills can be measured, their development monitored and managed with the help of KPIs. 
In a non-specified, short programme that would offer the most prominent accessibility, the following three skills would stand central: supplier relationship management, innovation sourcing and cost management. These three competences are more often necessary or sufficient conditions for success regarding the different targets. Such a programme would introduce the classical sourcing process, starting with market analysis, category strategy development, pooling planning and innovation sourcing, supplier evaluation, development and risk management. In addition to that, quoting, cost analysis, negotiation, and global sourcing issues would round up the 'survival package'. If more time were available, analytics, sellership, and process skills would follow. Remarkably, the often in classical education neglected sellership skill stands out very prominently. Reflecting the number of interfaces, successful purchasers can convince suppliers and cross-functional partners. Three main contributions translated into managerial propositions generated in Chapter 6 are displayed in Table 8.2.

\subsubsection{Chapter 7 - finding modes of how to educate knowledge, skills and traits}

Section 1.3 introduces a historical overview of the development of competences. The ancient Greek philosophers proposed the transfer of knowledge, professional and personal skills, and attitudes. This idea was rediscovered and further developed in Europe in the post-Enlightenment era. Most striking examples are Von Humboldt in Prussia, Mill in Scotland and Blanqui in France (see: §1.3). Recently, within the Bologna Process, the European Ministers of Education proposed that students need to "develop the competences they need in a changing labour market and empower them to become active and responsible citizens' in the future" (Leuven/Louvain-laNeuve Declaration, 2009, p. 1). It refers to the Aristotelian conception of virtues to become 'better citizens' and Humboldtian Bildung. The Bildung ideal is described in Section 1.3.4. Though, it is questionable whether Von Humboldt would have supported this kind of declaration. Imposed Bildung would obstruct conscious self-development (De Hert et al., 2015).

PSM personnel requirements have changed due to the turbulence caused by digitisation and focus on sustainability issues. Machines are taking over processes, and humans' contribution to the new era is to act like a human. Machines can only support humans in their 'creativity' and 'strategic thinking' but cannot replace humans' soft skills in this role. However, learning objectives in PSM courses in higher education are evaluated for not covering soft skills. Therefore, this study presents an educational soft skills experiment that provides evidence that soft skills learning can successfully involve existing courses. 
Because of the experimental character of the study, Chapter 7 differs from the other chapters. The PSM skills literature is mainly focused on presenting important skills and has overlooked to test, experiment and describe how future PSM education should be organised. Chapter 7 aims the bridge this gap by presenting an educational experiment. The student-centred, learning-by-doing approach of Scholten and Dubois (2017) is adopted as part of this experiment.

The research questions in Chapter 7 are whether interpersonal skills and intrapersonal traits can be developed within a ten-week course and which. The answer is positive; 26 of the 36 analysed soft skills could be improved significantly. Although hardly described in learning objectives, the experiment-sample students already had developed their competence levels of specific soft skills. Ten competence levels could not be increased significantly. Contrary, as shown in Figure 7.3, those soft skills with lower self-rated competence levels at the course's beginning increased significantly. In this research, the evidence is given that in a time frame of eight weeks, with a study load of 140 hours, interpersonal skills and intrapersonal traits can be developed within the context of a real-life case. In conclusion, master students are easily influenced in their soft skills development.

A significant difference was found with 'strategic thinking,' which is a relatively lower-ranked item in the students' sample mean. The students' mean in $\mathrm{O}_{1}$ was 2.70, and in $\mathrm{O}_{2}$, it increased to 3.21 , on a 5 -point Likert scale. The impact of the course is substantial but should not be overstated. The course developed these students from a lower level towards a more average strategic thinking level and certainly not towards an excellent level. The listing of 36 competence items 'strategic thinking' was ranked 29 in $\mathrm{O}_{1}$ and $\mathrm{O}_{2}$. It increased to rank 15 (see: Appendix 9.23). 'Sellership skills' and 'negotiation' remained at respectively rank 35 and 36.

Indeed, the originally lower-ranked competences improved. Logically, the survey items with a higher self-rated competence level cannot be improved as those items with lower self-ratings since the first set of items are developed, and the latter are underdeveloped (See: Figure 7.3 and Table 7.2). Lecturers that replicate this study could analyse the outcomes of the first survey and determine which crucial skills could be best focused on and best developed.

Further, Chapter 7 elaborates the questions of whether academia 'could', 'should' and 'would' adopt soft skills learning objectives. This research shows that it is possible and desirable that academia adopts soft skills learning objectives; hence, academia 'could' and 'should'. The remaining question is if academia 'would'. Soft skills education needs another approach than the teacher-centred frontal and classical didactics that can be considered the dominant design in higher education for 'transferring' knowledge and theory (Hoidn, 2017). Multiple obstacles cause the reason why universities are dominantly teacher-centred and not shift to student-centred 
approaches. Teacher-centred methods are highly efficient since dozens or even hundreds of students can attend the same lecture, though not as effective as studentcentred methods (Hannafin \& Land, 2000).

Moreover, it is questionable whether a professional activity, such as education, can be efficient when effectiveness levels are lower. According to Drucker (1977), it is doubtful that a state of efficiency can be reached before effectiveness is established: "Effectiveness is the foundation of success - efficiency is a minimum condition for survival after success has been achieved. Efficiency is concerned with doing things right. Effectiveness is doing the right things" (Drucker, 1977, p. 33).

Soft skills education is less attractive to students, academic staff, trainees, and management who prefer hard skills over soft skills education (Anthony \& Kadir, 2012; Laker \& Powell, 2011) and lecturers feel guilty when shifting student-centred methods (Anthony \& Kadir, 2012). Nevertheless, from the student evaluations in the experiment, it became clear that the course was mostly positively evaluated and was experienced as 'different from other courses'. Remarkably, the students in the cohort 2020-2021 that, due to the Covid-measurements, followed most of the course online, appreciated the course better than preceding cohorts.

In the discourse on teacher vs student centred approached, the unsourced quote that Socrates is often associated with resounds: "I cannot teach anybody anything, I only can make them think" (Adelung \& Fitzsimons, 2015, p. 241). Plato's original quote is: "Education is not in reality what some people proclaim it to be in their profession. What they aver is that they can put true knowledge into a soul that does not possess it, as if they were inserting vision into blind eyes" (Plato, 1992 [375 BC], Book $7,518 b-c)$.

Socrates means that the learning process consists of reconstructing bits of knowledge by students themselves; the learning process is not a 'transfer' of information from a lecturer directed towards the student (Land \& Hannafin, 2000). De Houwer et al. (2013, p. 633) define learning as 'ontogenetic adaption', i.e. "as changes in the behavior of an organism that are the result of regularities in the environment of that organism". Lecturers should remember Seneca's complaint "non vitæ sed scholæ discimus," meaning: "we learn our lessons, not for life, but for the lecture-room" (Seneca, 1925 [65 AD], p. 223). In general, Seneca's plea is seen as for other than cognitive, theoretical lectures in education (on literature at that time). 


\subsection{Reply to the overarching research objective}

\subsubsection{The first part: which competences lead to success in the PSM function?}

This dissertation's overarching research objective is to determine which competences lead to success in the PSM function and the eventual focus is on the most distinct strategic activity in purchasing, which is innovation sourcing. Firstly, the main objective, which competences lead to success in the PSM function, will be addressed and eventually, the scope will be on innovation sourcing.

In Appendix 9.24, a summary of the competences found per chapter is categorised into three groups: (1) knowledge and professional skills; (2) interpersonal skills; and (3) intrapersonal character traits. These competences are scored, listed in a top-ranking and displayed in Appendix 9.25. A selection of the most mentioned competences is presented in Table 8.3. A more or less balanced distribution of knowledge, skills and traits has been found. 'Hard skills' or knowledge and professional skills count for about 40 per cent of all founds competences and the soft skills consequently 60 per cent; about 28 per cent are interpersonal, human-to-human skills and about 32 per cent are intrapersonal character traits (see: Appendix 9.24).

The findings seem to be in line with Ahmed et al. (2012), who found evidence, that soft skills (interpersonal skills and especially intrapersonal traits) are necessary and supportive to carry out hard skills (knowledge and professional tasks). It aligns with the findings in Chapter 6 that soft skills are the most crucial necessary factors.

Interestingly, in all five research chapters, are found 'creativity, innovative, out-of-the-box thinking', 'add value to the organisation with PSM / understand corporate governance and the organisational context of PSM / PSM best practice intelligence' and 'conflict resolution/diplomacy, social manners and political sensitivity / organisational sensitivity'. Indeed, a purchaser needs PSM knowledge. However, the higher objective is to add value with PSM tools for the organisation.

The purchaser is a boundary spanner and a bridge-builder between the internal partner and the (potential) suppliers in the market. The purchaser needs persuasive skills to 'sell' PSM advantages within the organisation to establish early procurement involvement and early supplier involvement (or maybe not 'early', but 'extensive supplier involvement,' as proposed by Suurmond, Wynstra, \& Dul, 2020).

Purchasers tend to work in inter-disciplinary project teams and know about finance, marketing and sales, R\&D, operations and quality management, legal and human resources. The supporting soft skills to reach these aims are strategic thinking, translating vision in plans, organisational sensitivity and conflict resolution, flexibility, creativity and inventiveness, effectiveness, integrity, entrepreneurial and sellership skills, to name a selection. 


\section{Outcomes per chapter}

\begin{tabular}{|c|c|c|c|c|c|c|}
\hline Knowledge and professional skills & 2 & 3 & 4 & 5 & 6 & $\#$ \\
\hline $\begin{array}{l}\text { add value to the organisation with PSM / understand corporate } \\
\text { governance and the organisational context of PSM / PSM best practice } \\
\text { intelligence }\end{array}$ & $x$ & $x$ & $x$ & $x$ & $x$ & 5 \\
\hline $\begin{array}{l}\text { customer-oriented / being a strategic business partner for the internal } \\
\text { customer / enabling early procurement involvement }\end{array}$ & $x$ & $\mathrm{x}$ & $\mathrm{x}$ & & $x$ & 4 \\
\hline change management & $\mathrm{x}$ & $\mathrm{x}$ & & $x$ & $x$ & 4 \\
\hline $\begin{array}{l}\text { early supplier involvement/supplier and supply chain management / } \\
\text { establish an open dialogue with the market }\end{array}$ & $\mathrm{x}$ & $x$ & & $x$ & $x$ & 4 \\
\hline eProcurement / IT skills / computer literacy & $x$ & $x$ & $\mathrm{x}$ & & $x$ & 4 \\
\hline $\begin{array}{l}\text { innovation sourcing (approaches) and implementation / strategic } \\
\text { sourcing }\end{array}$ & $\mathrm{x}$ & $\mathrm{x}$ & & $x$ & $x$ & 4 \\
\hline project management / organisational skills & $x$ & & $\mathrm{x}$ & $x$ & $x$ & 4 \\
\hline sustainability and circular economy (CSR) & $x$ & $x$ & & $x$ & $x$ & 4 \\
\hline Interpersonal Skills & 2 & 3 & 4 & 5 & 6 & \# \\
\hline $\begin{array}{l}\text { conflict resolution / diplomacy, social manners and political sensitivity / } \\
\text { organisational sensitivity }\end{array}$ & $x$ & $\mathrm{x}$ & $\mathrm{x}$ & $x$ & $x$ & 5 \\
\hline $\begin{array}{l}\text { communication skills / interpersonal communication techniques / social } \\
\text { skills }\end{array}$ & $x$ & $x$ & $\mathrm{x}$ & & $x$ & 4 \\
\hline $\begin{array}{l}\text { collaborative skills / work in multi-disciplinary teams / cross-functional } \\
\text { cooperation (with HRM, legal, logistics, marketing, production, quality, } \\
\text { R\&D) }\end{array}$ & $x$ & $x$ & & $x$ & $x$ & 4 \\
\hline networking & $x$ & $x$ & & & $x$ & 3 \\
\hline $\begin{array}{l}\text { internal business partner orientation / effective questioning / distinguish } \\
\text { the 'real need' behind the demand (emphatic, i.e. listening and } \\
\text { understanding) / profound and curious questioning the internal partner }\end{array}$ & $x$ & $x$ & & & $x$ & 3 \\
\hline $\begin{array}{l}\text { persuasion / create commitment/support challenge suppliers to be } \\
\text { innovative / 'sell' procurement's advantages in an organisation. }\end{array}$ & & $x$ & $\mathrm{x}$ & & $x$ & 3 \\
\hline $\begin{array}{l}\text { teamwork / being a team player / having team spirit/ability to be on a } \\
\text { team }\end{array}$ & $\mathrm{x}$ & & $\mathrm{x}$ & & $\mathrm{x}$ & 3 \\
\hline Intrapersonal character traits & 2 & 3 & 4 & 5 & 6 & \# \\
\hline creative and innovative handling skills / 'out-of-the-box' thinking & $x$ & $\mathrm{x}$ & $x$ & $x$ & $x$ & 5 \\
\hline $\begin{array}{l}\text { entrepreneurial or sellership skills / courage / willingness to take risks / } \\
\text { deal with ambiguity }\end{array}$ & $x$ & $\mathrm{x}$ & $\mathrm{x}$ & $\mathrm{x}$ & $\mathrm{x}$ & 5 \\
\hline flexibility / mobility / willingness to travel / adaptive to change & $\mathrm{x}$ & $\mathrm{x}$ & $\mathrm{x}$ & & $x$ & 4 \\
\hline integrity, honesty, loyalty & $x$ & $x$ & & $\mathrm{x}$ & $x$ & 4 \\
\hline $\begin{array}{l}\text { result-orientated action-taking - being result-driven / being efficient and } \\
\text { effective / being persistent / being pragmatic - having a hands-on } \\
\text { mentality }\end{array}$ & $\mathrm{x}$ & $x$ & $\mathrm{x}$ & & $x$ & 4 \\
\hline comprehension of complexity / complex problems / problem solving & & & $x$ & $\mathrm{x}$ & $x$ & 3 \\
\hline $\begin{array}{l}\text { critical thinking, strategic thinking and holistic thinking/vision translation } \\
\text { into practical plans }\end{array}$ & $x$ & $x$ & & & $x$ & 3 \\
\hline
\end{tabular}

(See: Appendix 9.25 for the complete list) 
In creativity research, there are two directions: "everyday creativity (also called "little$\left.c^{\prime \prime}\right)$, which can be found in nearly all people, and eminent creativity (also called "Big- $C^{\prime \prime}$ ), which is reserved for the great" (Kaufman \& Beghetto, 2009, p. 1). Examples of little-c given are: "creative activities in which the average person may participate each day," such as "coming up with a creative solution to a complex scheduling problem at work" (Kaufman \& Beghetto, 2009, p. 1) or active participation "in innovation projects or heads cross-functional sourcing teams" (Kiratli et al., 2016, p. 202)

\subsubsection{The second part: which competences lead to success in innovation sourcing?}

Chapter 3, 5 and 6 are mainly focused on the competences of innovation buyers in the public and the private sector. Table 8.4 displays the innovation sourcing 'success' skills found in these three chapters.

. Chapter 3 is focused on the public procurement of innovations. This research showed that public procurers for innovations need the know-how to get involved early in the procurement process. A condition for that is to understand the own organisation, to be persuasive and to be able to 'sell' procurement, which means that the advantages of cooperating with procurement are made explicit for the internal partner and needs to stay visible for the internal partner. To be visible and to understand the organisation better, the participants suggested job rotations.

Further, it is crucial for public procurers for innovations to be connective and to stay in touch with the market by having an open dialogue with the market and by establishing relationships with innovative suppliers. The aim is to challenge potential suppliers to be experimental and to come up with innovative solutions. The procurer needs to listen carefully to the internal partner and raise critical questions to distinguish the 'real need' behind the demand and ask supplementary questions since internal partners in public organisations may use technical specification instead of describing the functional outcome. Moreover, the public procurer for innovations brings in knowledge of procurement laws.

Chapter 3 underlined the need for public procurers for innovation to show entrepreneurial behaviour by thinking 'out-of-the-box' and having courage. Further, the procurer needs to be confident to innovate, create a commitment, and advocate innovations in the internal organisation. The procurer is creative, proactive and persistent and has excellent communication, presentation and networking abilities. 
Table 8.4 - Schematic overview of the competences for innovation sourcing found in chapters 3,5 and 6

\begin{tabular}{|c|c|c|c|c|}
\hline Knowledge and professional skills & 3 & 5 & 6 & \# \\
\hline $\begin{array}{l}\text { add value to the organisation with PSM/understand corporate governance and } \\
\text { the organisational context of PSM/PSM best practice intelligence }\end{array}$ & $x$ & $\mathrm{x}$ & $\mathrm{x}$ & 3 \\
\hline innovation sourcing (approaches) and implementation/strategic sourcing & $x$ & $x$ & $\mathrm{x}$ & 3 \\
\hline $\begin{array}{l}\text { early supplier involvement/supplier and supply chain management/establish an } \\
\text { open dialogue with the market/supplier relations management/supply risk } \\
\text { management }\end{array}$ & $x$ & $x$ & $\mathrm{x}$ & 3 \\
\hline change management & $x$ & $\mathrm{x}$ & & 2 \\
\hline $\begin{array}{l}\text { customer-oriented/being a strategic business partner for the internal } \\
\text { customer/enabling early procurement involvement }\end{array}$ & $x$ & & $\mathrm{x}$ & 2 \\
\hline project management/process management/organisational skills & & $x$ & $\mathrm{x}$ & 2 \\
\hline sustainability and circular economy (CSR) & $x$ & $\mathrm{x}$ & & 2 \\
\hline eProcurement/IT skills/computer literacy & $x$ & & & 1 \\
\hline Interpersonal Skills & 3 & 5 & 6 & \# \\
\hline $\begin{array}{l}\text { collaborative skills/work in multi-disciplinary teams/cross-functional } \\
\text { cooperation (with HRM, legal, logistics, marketing, production, quality, R\&D) }\end{array}$ & $x$ & $x$ & $\mathrm{x}$ & 3 \\
\hline $\begin{array}{l}\text { conflict resolution/diplomacy, social manners and political } \\
\text { sensitivity/organisational sensitivity }\end{array}$ & $x$ & $\mathrm{x}$ & & 2 \\
\hline $\begin{array}{l}\text { internal business partner orientation/effective questioning/distinguish the 'real } \\
\text { need' behind the demand (emphatic, i.e. listening and understanding)/profound } \\
\text { and curious questioning the internal partner }\end{array}$ & $x$ & & $\mathrm{x}$ & 2 \\
\hline communication skills / interpersonal communication techniques/social skills & $x$ & & & 1 \\
\hline cross-cultural awareness & & & $x$ & 1 \\
\hline networking & $x$ & & & 1 \\
\hline $\begin{array}{l}\text { persuasion/create commitment/support challenge suppliers to be innovative/'sell' } \\
\text { procurement's advantages in the organisation. }\end{array}$ & $\mathrm{x}$ & & & 1 \\
\hline teamwork/being a team player/having team spirit/ability to be on a team & & & $\mathrm{x}$ & 1 \\
\hline Intrapersonal character traits & 3 & 5 & 6 & \# \\
\hline creative and innovative handling skills/'out-of-the-box' thinking & $\mathrm{x}$ & $\mathrm{x}$ & $\mathrm{x}$ & 3 \\
\hline $\begin{array}{l}\text { entrepreneurial or sellership skills/courage/willingness to take risks/deal with } \\
\text { ambiguity }\end{array}$ & $x$ & $\mathrm{x}$ & $\mathrm{x}$ & 3 \\
\hline $\begin{array}{l}\text { critical thinking, strategic thinking and holistic thinking/vision translation } \\
\text { into practical plans/curiosity and willingness to learn }\end{array}$ & $\mathrm{x}$ & & $\mathrm{x}$ & 2 \\
\hline integrity, honesty, loyalty & $\mathrm{x}$ & $x$ & & 2 \\
\hline comprehension of complexity/complex problems/problem solving & & $x$ & & 1 \\
\hline flexibility/mobility/willingness to travel/adaptive to change & $x$ & & & 1 \\
\hline $\begin{array}{l}\text { result-orientated action-taking - being result-driven/being efficient and } \\
\text { effective/being persistent/being pragmatic - having a hands-on mentality }\end{array}$ & $x$ & & & 1 \\
\hline
\end{tabular}

In Chapter 5, the survey respondents with an innovation sourcing focus were isolated, and with a $t$-test and in total, 23 significant competences were identified. These 23 significant competences are found in a set of 17 competences with a positive sign (see: Appendix 9.12) and a set of six competences with a negative sign (see: Appendix 9.13). The discovery of the competences with a negative, significant relation was not preconceived and surprisingly revealed what an innovation purchaser is not. 
The 17 positively related competence items are found, ended up in three factors that have been titled:

1. 'Soft Skills' consisting of the intrapersonal attitudes 'creativity'; 'inventiveness'; 'honesty'; 'conflict resolution';' willingness to take risks'; and 'comprehension of complexity'11.

2. 'Managerial Skills' positively related are: 'change management'; 'corporate governance'; 'project management'; 'consultancy skills'; and 'cooperation with the HRM department'.

3. 'Innovation Competences' consists of 'Early Supplier Involvement in NPD'; 'Innovation Sourcing'; 'Innovation Implementation in the own product or process'; 'cooperation with the R\&D department'; and 'cooperation with Marketing'.

Negative associations are found for innovation sourcing in combination with the following six transactional competences:

4. 'Cost analyses'; 'cost reduction techniques'; 'negotiation'; 'solicit offers'; 'evaluate offers \& supplier selection'; and 'global sourcing/supplier acquisition'.

The conclusion drawn from Chapter 5 is that the typical innovation purchasers seem to take a strategic perspective and does not fit in a transactional, operational role.

Interestingly, a negative relation between cost and innovation skills has been found in Chapter 6. With a different methodology applied on another sample of the same dataset, the negative association is confirmed for innovation sourcing in combination with 'cost analyses'; 'cost reduction techniques'; 'negotiation'; 'solicit offers'; 'evaluate offers \& supplier selection'; and 'global sourcing/supplier acquisition', moreover (primary) 'purchasing knowledge' is grouped in that factor. Table 8.5 displays the outcomes

Purchasers successful in the 'innovation' objective typically rely, as necessary conditions, on an adequate level of sellership, process and project skills and the soft skill factor 'imagination', which is also a differentiator. The latter is not surprising, as this skill comprises elements like creativity, inventiveness and holistic thinking. Business innovation is mainly a project and process-driven activity. Hence, purchasers need to acquire process and project skills to succeed in innovation. Another necessary skill is sellership, for any novelty needs to be 'sold' in the organisation. The more supplierrelationship-management skills and innovation sourcing skills a purchaser has, the better the performance will be. Parts of the advanced skills are innovation sourcing and innovation implementation planning.

${ }^{11} \mathrm{~A}$ weaker association with this factor is found for the ability to apply sustainable sourcing in the era of circular economy. 
Table 8.5 - Competence factors positively related to innovation sourcing objectives

\begin{tabular}{|c|c|}
\hline Factors & Competences / items \\
\hline 3 Soft skills - Imagination & $\begin{array}{l}\text { Creativity; Inventiveness; Willingness to Learn; Holistic } \\
\text { Thinking }\end{array}$ \\
\hline 4 Sellership & $\begin{array}{l}\text { Sellership skills and Salesperson skill; Personality } \\
\text { Characteristics Development (e.g. entrepreneurial); Cross- } \\
\text { cultural Awareness; Customer orientation }\end{array}$ \\
\hline $\begin{array}{l}9 \text { Supplier relationship } \\
\text { management }\end{array}$ & $\begin{array}{l}\text { Supplier Relationship Management; Supply Risk } \\
\text { management; Supplier Evaluation; Supplier Development; } \\
\text { Early Supplier Involvement; Strategic Business Partner; } \\
\text { Sustainability }\end{array}$ \\
\hline 10 Innovation sourcing & $\begin{array}{l}\text { Innovation Sourcing; Innovation implementation; Category } \\
\text { Strategy Development; Stakeholder Relationship } \\
\text { Management; Pooling Planning \& Demand; Supply Market } \\
\text { Analysis }\end{array}$ \\
\hline 13 Process and Project skills & $\begin{array}{l}\text { Project Management Skills; Team Ability Skills; Optimisation } \\
\text { of Purchasing Processes; Process Management; (Know how } \\
\text { to) add value to the organisation; Corporate Governance; } \\
\text { Position of Purchasing in Organisation }\end{array}$ \\
\hline
\end{tabular}

Note: NCA confirmed the factors 3, 4 and 13; OLS the factors 3, 9 and 10 (and factor 7 'cost focus' negatively)

\subsubsection{The implications for PSM education and training}

The fourth research objective differs from the others due to the how-toelement: Research objective 4 determines how to develop the PSM knowledge, professional and interpersonal skills and intrapersonal traits.

The first chapter of this dissertation refers to the definition of competence by Delamare-Le Deist and Winterton (2005) as a triangular construct of knowledge, skills and attitudes, which has been shown before to be similar to the ancient Greek philosophy as expressed by Aristotle: knowledge, skills and virtues (Aristotle, 2013 [350 B.C.]). In chapters 2 to 6 indeed a mix of knowledge ( 40 per cent) and professional skills (or 'hard skills'), and interpersonal skills (28 per cent) and of intrapersonal traits or attitudes (32 per cent) (or 'soft skills') are found (see: Appendix 9.24).

Regarding the design of purchasing and supply chain management curricula in institutions for higher education and company training sessions, the recommendation, mainly based upon the findings in Chapter 6, is to offer a fundament that includes PSM knowledge and process management. Subsequently, the learners need to clearly understand the position of purchasing in the firm to add value with the purchasing function. Moreover, portfolio analysis skills are needed.

More general business administration skills are necessities, i.e. process management, process optimisation, setting KPIs, performing statistical analyses and 
(complex) problem-solving. Since PSM education mainly occurs within the context of business administration tracks in higher education (Birou et al., 2016; Wong et al., 2014), it is assumable that students' learning in general business skills can be facilitated. Additionally, there is a task to develop entrepreneurial skills and interpersonal humanto-human skills with students.

Consequently, these research outcomes hold that higher education institutions need to anticipate in their curricula to facilitate graduates with the necessary knowledge, skills and attitudes following the definition of Delamare-Le Deist and Winterton (2005). It is in line with the European ministers of education declaration in 2009, who stated that fostering innovation and creativity in society is a task for higher education (Leuven/Louvain-la-Neuve Declaration, 2009).

When analysing PSM curricula in academia in literature, often one and, in some cases, two of the three pillars seem to be present. Traditionally, lecturers at European universities are focused on just the transfer of knowledge and theory only (Hoidn, 2017). It also counts for universities in the USA, as concluded by Birou et al. (2016).

The learning and teaching of knowledge and professional skills and interpersonal skills (mostly limited to presenting, communication and teamwork) are recognised. However, most academic purchasing, logistics and supply (chain) management courses and tracks have been evaluated for not or almost not learning and developing intrapersonal skills (Birou et al., 2016; Wong et al., 2014). In a Project PERFECT, the same image is found: there is a gap between the job requirements and learning objectives in academic PSM courses due to the lack of soft skills learning objectives (Stinenbosch \& Stek, 2017a).

Nevertheless, interpersonal skills and intrapersonal attitude development seems to be as important as cognitive skills or are even more essential for gaining professional success. Universities are primarily focused on learning and developing knowledge and professional skills and a lower extent on developing interpersonal skills. Employers notably value intrapersonal abilities, but they seldom explicitly emerge in academic curricula (Hoidn, 2017).

To apply knowledge and cognitive skills in daily practice, interpersonal skills and intrapersonal traits have an essential role (Ahmed et al., 2012). Literature states that interpersonal skills and intrapersonal traits are as critical or even more important than cognitive skills for a professional (Ahmed et al., 2012). The presence of interpersonal skills and intrapersonal traits seems to be an excellent forecaster to success in life, and an absence of interpersonal skills and intrapersonal traits appears to be causing the ending of a labour relationship rather than a lack of cognitive skills (Ahmed et al., 2012; Heckman \& Kautz, 2012; Zunk \& Sadei, 2015). 
Still, the research objective of how to educate or to train is not answered yet. Above is referred to what is and should be taught. Nevertheless, Chapter 2 underlines that student-centred teaching methods should replace traditional, frontal teachercentred methods "as current training and teaching methods are not necessarily suitable for developing all types of competencies, and the pedagogy needs to be adapted to reflect these requirements". The suggestion is: "in-class training formats such as roleplays and the potential for online courses and more interactive formats, e.g. blended learning or flipped classroom approaches" (Bals et al., 2019, p. 11).

Still, teacher-centred, frontal, and classical lectures can be considered the dominant design in higher education for 'transferring' knowledge and theory (Hoidn, 2017). Multiple barriers cause the reason why universities are dominantly teachercentred. Firstly, since dozens or even hundreds of students can attend the same lecture, teacher-centred methods are highly efficient, however not so practical as studentcentred methods (Hannafin \& Land, 2000). Effective learning is a genuine studentcentred process since learning consists of reconstructing bits of knowledge by students themselves. The learning process is not a 'transfer' of information from a lecturer directed towards the student (Land \& Hannafin, 2000).

Secondly, the shift from frontal, classical teaching towards student-centred didactics is a profound change in the working modus (Anthony \& Kadir, 2012). Thirdly, traditional lecturers who change their didactics to student-centred approaches report 'feelings of guilt' because the student-centred method seems to be initially "just guiding and supporting the students in the learning processes", and knowledge is no longer 'transferred' in a classical, frontal mode (Anthony \& Kadir, 2012, p. 57). The guilt-feeling is caused by the wrongly expected loss of the lecturers' authority in the classroom when the lecture leaves behind the frontal, classical method (Anthony \& Kadir, 2012).

An often-heard question is whether entrepreneurial behaviour, creativity, inventiveness and strategic or holistic thinking can be developed. Kiratli et al. (2016) confirm and provide evidence that establishing a team creative climate in purchasing departments is supportive. Laker and Powell (2011) also acknowledge that soft skills can be influenced. Yet, they argue that compared with the learning of hard skills, soft skills learning encounters higher resistance levels from both, the trainees and the management. Managerial support is less for soft skills training. The reasons for the higher levels of resistance are the direct applicability to the job, which are all less in soft skill training compared to hard skill training, the degree of achieved self-efficacy, the degree of achieved proficiency and the preciseness of the identification of training objectives (Laker \& Powell, 2011).

In their study, Feisel et al. (2011) found that these intrapersonal traits of experienced professionals and their strategic behaviour are difficult to influence. Yet, in purchasing and supply chain management higher education, Scholten and Dubois 
(2017) found evidence that their student-centred method is developing cognitive and professional as well as interpersonal and intrapersonal skills of the students:

"Our results show that students who are actively involved in the learning process by taking responsibility, engaging in collaborative learning and by taking the chance to learn from practice are able to develop higher-order learning in relation to content as well as skills that are needed in today's job environment" (Scholten \& Dubois, 2017, p. 1696).

Hence, learning-by-doing seems to be a key factor and apparently, this task fits best to institutions for higher education, which is a concept that was also promoted by Aristotle, who emphasised learning-by-doing:

"the virtues we get by first exercising them, as also happens in the case of the arts as well. For the things we gave to learn before we can do them, we learn by doing them, e.g. men become builders by building and lyre players by playing the lyre; so too we become just by doing just acts, temperate by doing temperate acts, brave by doing brave acts" (Aristotle, 2013 [350 B.C.], p. 20).

The fourth research objective on training and learning the PSM knowledge, professional and interpersonal skills, and intrapersonal traits cannot be fully addressed with the previous chapters' research. However, it became clear that the design of modernistic, frontal teaching methods might be cost-efficient, but that effectiveness neither guaranteed nor is considered. The learning process consists of reconstructing bits of knowledge by students themselves; the learning process is not a 'transfer' of information from a lecturer directed towards the student (Land \& Hannafin, 2000).

Biggs (1996, p. 347) proposes 'Constructive alignment' to create meaning of the learner's activities and to align between a course's learning objectives and the assessment methods of the student's performance curriculum objectives "in terms of performances that represent a suitably high cognitive level, in deciding teaching/learning activities judged to elicit those performances, and to assess and summatively report student performance" (Biggs, 1996, p. 347).

Since in PSM education research only Scholten and Dubois (2017) have published results, the conclusion is that more research in this field is needed. Therefore, in the next chapter, quasi-experiment results (Campbell \& Stanley, 1966) are shown. In three cohorts of master students enrolled in a PSM introductory course, the individual students' soft skills levels were measures in a pre-test and a post-test and were compared with each other. The course consisted of a purchasing case study, workshops, frontal instructions, evaluation lectures and an academic paper writing project that helped construct a book entitled State of the Art in Purchasing \& Supply Management, inspired by Scholten and Dubois (2017).

In line with Biggs (2011), when changing the course's intended learning objectives, the content, the didactics, the teaching and learning activities were 
modified, and subsequently, the assessment tasks and testing of the learning objectives were altered within the 'constructive alignment'. Thus, introducing soft skills learning outcomes will affect the course's content, didactics, and testing. Concluding, soft skills like strategic thinking, negotiation and sellership skills cannot be assessed with a regular, written exam.

Contrary, the strategic management, negotiation and sellership theory and knowledge can be described explicitly and tested in a written exam or an assignment. For the course that served as an example in this study, a mix of assessments was designed. The knowledge and theory were tested with multiple-choice, open and essay questions in a regular, written exam. A scientific paper and a case study report formed the assessment of two project outputs that covered professional skills, knowledge and theory. The soft skills development was measured with two surveys on which the individual students reflected with a written personal development plan.

Lecturers that intend to apply the outcomes of this study to modify an existing course are can follow these steps: (1) select a suitable course and create a team of colleagues and practitioners with whom to cooperate and to modify the course; (2) compare the old and new intended learning outcomes and assess whether the new intended learning outcomes would fit in the curriculum; (3) based on the new intended learning objectives, design the course content and the case study and define the teaching and learning activities; (4) align the assessment methods with the learning outcomes, and the teaching and learning activities; (5) communicate the new approach with the students and manage their expectations.

The ancient Greek educational philosophy is built upon three pillars: the learning of (cognitive) knowledge, (practical) skills and (character) virtues (Bitros \& Karayiannis, 2011). The construct of a 'competence' or of 'being competent' seems, in general, to fit the closest to these ancient educational objectives, and it is mainly defined as a cluster of three elements, knowledge, skills, abilities and other characteristics as defined by Boyatzis (1982), Campion et al. (2011), Delamare-Le Deist and Winterton (2005).

In ancient Athens, the classical education of young Athenians was not primary aimed at preparing students to earn "higher incomes and amass more wealth, but to become better citizens" (Bitros \& Karayiannis, 2011, p. 211). In the $19^{\text {th }}$ century, Von Humboldt and Mill strived for creating better citizens. Mill stated:

"At least there is a tolerably general agreement about what an (sic!) University is not. It is not a place of professional education. Universities are not intended to teach the knowledge required to fit men for some special mode of gaining their livelihood. Their object is not to make skilful lawyers, or physicians, or engineers, but capable and cultivated human beings" (Mill, 1867, p. 4). 
Von Humboldt's Bildung ideal focused on personal development and creating 'better citizens'. The Bildung movement initially achieved success. However, Sanderse (2019, p. 411) warns that the "history of the Bildung idea offers an all too potent reminder of the fact that such ideals are vulnerable within a strong education system that focuses on turning young people into 'currency', to use Nietzsche's phrase," although the Bildung ideal is often initiated with the best intentions.

Those best intentions are also visible in the $21^{\text {st }}$ century in the current structure for higher education in Europe. The Bologna Process declaration issued at the meeting of the European ministers of education in Leuven and Louvain-la-Neuve, Belgium on April 28 and 29, 2009, is entirely in line with the Germanic Bildung ideal and Anglo-Saxon character-education. The Leuven/Louvain-la-Neuve Declaration (2009, p. 1) of the European ministers stated that students need to "develop the competences they need in a changing labour market and empower them to become active and responsible citizens' in the future".

Here, the Aristotelian conception of virtues to become 'better citizens' is gaining importance. However, Nietzsche's alerting resounds and raises the question of whether governments are applying Bildung again to turn students into a form of 'currency'. It is questionable whether Von Humboldt would have supported this kind of declaration. Imposed Bildung would obstruct conscious self-development (De Hert et al., 2015). Mill states, "Human nature is not a machine to be built after a model, and set to do exactly the work prescribed for it, (...)" (Mill, 1859, p. 107). The development lies in humans' nature, and slowing down that development would be unnatural (De Hert et al., 2015).

When applying the two concepts of liberties, as explained by Berlin (1958), the plea in the Declaration to create "active and responsible citizens" is an example of violating positive freedom (De Hert et al., 2015). Berlin warns that the positive concept can easily be misused by those who reason about what is right for others, to dictate to others how to live. Berlin concludes that at best, the positive conception of freedom leads to paternalism and, in the worst case, to despotism (De Hert et al., 2015):

"This is why paternalism is 'the greatest despotism imaginable', not because it oppresses more than naked, brutal, unenlightened tyranny, but because it is an insult to my conception of myself as a human being entitled to make my own life in accordance with my own purposes, and above all to be recognised as such by others (...)" (Berlin, 1958, p. 28)

Therefore, educators should remember that calls from politicians, policymakers and other stakeholders to create "better citizen" or "responsible citizen" would violate positive freedom. The government must exercise restraint and allow citizens to develop as they like. Imposed Bildung would obstruct conscious selfdevelopment. The ancient Greek education might serve as an example: it "sought to 
mold the individual in the hard and inflexible matrix of a dominant society" (Meyer, 1939, p. 1). A government that aims to develop society will, if that society is not prepared to develop, only reap conformity and dependence (Lansing, 2010). Von Humboldt disapproved of the political fashioning of private life for it has a harmful effect by manipulating human's "inneres Dasein" (or: "inmost being") (Sorkin, 1983, p. 60). 


\section{References}




\section{REFERENCES}

Adelung, M., \& Fitzsimons, V. (2015). Socrates: Making us Think. International Journal of Nursing.

Ahmed, F., Fernando Capretz, L., Bouktif, S., \& Campbell, P. (2012). Soft skills requirements in software development jobs: a cross-cultural empirical study. Journal of Systems and Information Technology, 14(1), 58-81.

Ahsan, K., \& Rahman, S. (2017). Green public procurement implementation challenges in Australian public healthcare sector. Journal of Cleaner Production, 152, 181-197.

Almeida, A. A. M. d., \& Sano, H. (2018). Purchasing function in the public sector: challenges to promote agility in electronic reverse auctions. Revista de Administração Pública, 52(1), 89-106.

Alvarez, S., \& Rubio, A. (2015). Carbon footprint in Green Public Procurement: a case study in the services sector. Journal of Cleaner Production, 93, 159-166.

Alves, A. (2019). A Tradição Alemã do Cultivo de si (Bildung) e sua Significação Histórica. Educação \& Realidade, 44. Retrieved from http://www.scielo.br/scielo.php?script=sci_arttext\&pid=S2175$62362019000200606 \&$ nrm=iso

Amann, M., \& Essig, M. (2015). Public procurement of innovation: empirical evidence from EU public authorities on barriers for the promotion of innovation. Innovation: The European Journal of Social Science Research, 28(3), 282-292. doi:10.1080/13511610.2014.998641

Ammer, D. S. (1983). Purchasing and Materials Management for Health-Care Institutions. (Second and Revised Edition ed.). Lexington, Mass: Lexington Books.

Anderson, M. G., \& Katz, P. B. (1998). Strategic sourcing. The International Journal of Logistics Management, 9(1), 1-13.

Andreasen, P. H., \& Gammelgaard, B. (2018). Change within purchasing and supply management organisations-Assessing the claims from maturity models. Journal of Purchasing and Supply Management, 24(2), 151-163.

Andrews, J., \& Higson, H. (2008). Graduate employability,' soft skills' versus 'hard' business knowledge: A European study. Higher Education in Europe, 33(4), 411-422.

Andriesse, F. (2019). Op naar een toekomstbestendig competentieprofiel. NEVI Deal!, April 2019, 16-19.

Anthony, E. M., \& Kadir, Z. A. (2012). A road not taken: a breakthrough in English for specific purposes via problem-based learning. Journal of Technical Education and Training, 4(1).

Antonson, H., \& Åkerskog, A. (2015). "This is what we did last time". Uncertainty over landscape analysis and its procurement in the Swedish road planning process. Land Use Policy, 42, 48-57.

Arcodia, C., \& Barker, T. (2003). The employability prospects of graduates in event management: Using data from job advertisements. CAUTHE 2003: Riding the Wave of Tourism and Hospitality Research, 19.

Aristotle. (2013 [350 B.C.]). Nicomachean ethics (W. D. Ross, Trans.). Moscow, Idaho: Alex Catalogue; NetLibrary.

Arjoon, S. (2000). Virtue theory as a dynamic theory of business. Journal of Business Ethics, 28(2), 159-178.

Autio, E., Pathak, S., \& Wennberg, K. (2013). Consequences of cultural practices for entrepreneurial behaviors. Journal of International Business Studies, 44(4), 334-362.

Azadegan, A., \& Dooley, K. J. (2010). Supplier innovativeness, organizational learning styles and manufacturer performance: An empirical assessment. Journal of Operations Management, 28(6), 488-505.

Babbage, C. (1832). On the Economy of Machinery and Manufactures. London: Charles Knight, Pall Mall East.

Baer, M. (2012). Putting creativity to work: The implementation of creative ideas in organizations. Academy of Management Journal, 55(5), 1102-1119.

Baer, M., \& Oldham, G. R. (2006). The curvilinear relation between experienced creative time pressure and creativity: moderating effects of openness to experience and support for creativity. Journal of Applied Psychology, 91(4), 963.

Bailly, F., \& Léné, A. (2013). The personification of the service labour process and the rise of soft skills: a French case study. Employee Relations.

Baily, P., Farmer, D., Crocker, B., Jessop, D., \& Jones, D. (2008). Procurement principles and management (10 ed.). Harlow: Pearson Education.

Baker, E. (2012). Social Contract, Essays by Locke, Hume and Rousseau: Read Books Ltd. 
Bals, L., Kelly, S., Schulze, H., \& Stek, K. (2017). The role of explicit and tacit knowledge in Purchasing and Supply Management (PSM) today and in future. Paper presented at IPSERA 2017, Balatonfüred, Hungary.

Bals, L., Schulze, H., Kelly, S., \& Stek, K. (2018). Purchasing and Supply Management (PSM) competencies today and in future: Taking stock and moving forward. Paper presented at IPSERA 2018, Athens, Greece.

Bals, L., Schulze, H., Kelly, S., \& Stek, K. (2019). Purchasing and supply management (PSM) competencies: Current and future requirements. Journal of Purchasing and Supply Management, 25(5), 100572.

Banai, M. (2010). From Comparative Management to Supranational Management. International Studies of Management \& Organization, 40(4), 10-24.

Bapeer, S., Stek, K., \& Schiele, H. (2018). 5 Megatrends binnen inkoop. NEVI Deal!, October 2018, 46-47.

Barnes, J., \& Liao, Y. (2012). The effect of individual, network, and collaborative competencies on the supply chain management system. International Journal of Production Economics, 140(2), 888-899.

Barney, J. B. (1991). Firm resources and sustained competitive advantage. Journal of Management, 17(1), 99120.

Barney, J. B. (2012). Purchasing, supply chain management and sustained competitive advantage: The relevance of resource-based theory. Journal of Supply Chain Management, 48(2), 3-6.

Bartlett, M. S. (1950). Tests of significance in factor analysis. British Journal of Statistical Psychology, 3(2), $77-$ 85.

Baskerville, R. F. (2003). Hofstede never studied culture. Accounting, Organizations and Society, 28(1), 1-14.

Bazeley, P. (2013). Qualitative data analysis: Practical strategies: Sage.

Bazeley, P., \& Jackson, K. (2013). Qualitative data analysis with NVivo: Sage Publications Limited.

Beasley, T. M., \& Schumacker, R. E. (1995). Multiple regression approach to analyzing contingency tables: Post hoc and planned comparison procedures. The Journal of Experimental Education, 64(1), 79-93.

Benitez, J., Henseler, J., Castillo, A., \& Schuberth, F. (2019). How to perform and report an impactful analysis using partial least squares: Guidelines for confirmatory and explanatory IS research. Information \& Management, 103168.

Berger, L., Kelly, S., Stek, K., \& Zunk, B. M. (2018). European Higher Education Landscape-Analysis of existing purchasing study programmes. Paper presented at IPSERA 2018, Athens, Greece.

Berlin, I. (1958). Two Concepts of Liberty. In O. University (Ed.). Oxford: Oxford University Press.

Beugelsdijk, S., Kostova, T., \& Roth, K. (2017). An overview of Hofstede-inspired country-level culture research in international business since 2006. Journal of International Business Studies, 48(1), 30-47.

Bienhaus, F., \& Haddud, A. (2018). Procurement 4.0: factors influencing the digitisation of procurement and supply chains. Business Process Management Journal.

Biggs, J. B. (1996). Enhancing teaching through constructive alignment. Higher education, 32(3), 347-364.

Biggs, J. B. (2011). Teaching for quality learning at university: What the student does: McGraw-Hill Education (UK).

Bijl, T., Stek, K., \& Sigurđardóttir, A. G. (2020). De Feminisering van de Inkoop: het Nieuwe Normaal. NEVI Deal!, September 2020 (5)(5).

Birou, L., Lutz, H., \& Zsidisin, G. A. (2016). Current state of the art and science: a survey of purchasing and supply management courses and teaching approaches. International Journal of Procurement Management, 9(1), 71-85.

Bitros, G. C., \& Karayiannis, A. D. (2011). Character, Knowledge and Skills in Ancient Greek Paideia: Some Lessons for Today's Policy Makers. The Journal of Economic Asymmetries, 8(1), 193-219.

Blanqui, A.-J. (1837). Histoire de l'économie politique en Europe, depuis les anciens jusqu'à nos jours. Paris: Guillaumin, Libraire.

Blanqui, A.-J. (1880). History of Political Economy in Europe, translated from the fourth French edition (E. J. Leonard, Trans.). New York.: G.P. Putnam's Sons.

Bloom, B. S. (1956). Taxonomy of educational objectives. Vol. 1: Cognitive domain. New York: McKay, $20,24$.

Boer, J., \& Drukker, J. (2011). High Tech, Human Touch: een beknopte geschiedenis van de Universiteit Twente-a concise history of the University of Twente, 1961-2011. Enschede: Lecturis Printing Company.

Bollinger, A. S., \& Smith, R. D. (2001). Managing organizational knowledge as a strategic asset. Journal of Knowledge Management, 5(1), 8-18.

Bonwell, C. C., \& Eison, J. A. (1991). Active Learning: Creating Excitement in the Classroom. 1991 ASHE-ERIC Higher Education Reports: ERIC.

Box, G. E., Jenkins, G. M., \& Reinsel, G. (1970). Time Series Analysis Forecasting and Control. San Francisco: Holden-Day. 
Boyatzis, R. E. (1982). The competent manager: A model for effective performance. New York: John Wiley \& Sons, Ltd.

Boyatzis, R. E. (2008). Competencies in the 21st century. Journal of Management Development, 27(1), 5-12.

Brennan, L., \& Crowe, D. (2012). IFPSM - Global Standard in Purchasing \& Supply Management (GSPSM) Assessors' Guide. Retrieved from www.ifpsm.org

Brenton, B., \& Levin, D. (2012). The softer side of innovation: The people. Journal of Product Innovation Management, 29(3), 364-366.

Bresnahan, T. F., Brynjolfsson, E., \& Hitt, L. M. (2002). Information technology, workplace organization, and the demand for skilled labor: Firm-level evidence. The Quarterly Journal of Economics, 117(1), 339-376.

Brimhall, K. C. (2019). Are We Innovative? Increasing Perceptions of Nonprofit Innovation Through Leadership, Inclusion, and Commitment. Review of Public Personnel Administration, in press(0), 0734371X19857455. doi:10.1177/0734371x19857455

Briscoe, G., Dainty, A. R., \& Millett, S. (2001). Construction supply chain partnerships: skills, knowledge and attitudinal requirements. European Journal of Purchasing \& Supply Management, 7(4), 243-255.

Brooks, A. S., Yellen, J. E., Potts, R., Behrensmeyer, A. K., Deino, A. L., Leslie, D. E., . . Zipkin, A. M. (2018). Long-distance stone transport and pigment use in the earliest Middle Stone Age. Science, 360(6384), 9094.

Brotton, J. (2006). The Renaissance: a very short introduction: OUP Oxford.

Brown, J., \& Isaacs, D. (2005). The World Café: Shaping our futures through conversations that matter: BerrettKoehler Publishers.

Bruford, W. H. (1975). The German tradition of self-cultivation: 'Bildung' from Humboldt to Thomas Mann: Cambridge University Press.

Burt, D. N., Dobler, D. W., \& Starling, S. L. (2003). World class supply management: The key to supply chain management. Boston: McGraw-Hill Irwin.

Cagliano, R., Caniato, F., Golini, R., Longoni, A., \& Micelotta, E. (2011). The impact of country culture on the adoption of new forms of work organization. International Journal of Operations \& Production Management, 31(3), 297-323.

Campbell, D. T., \& Stanley, J. C. (1966). Experimental and quasi-experimental designs for research. Dallas, Geneva, III., Hopewell, N.J., Palo Alto, London: Houghton Mifflin Company Boston.

Campion, M. A., Fink, A. A., Ruggeberg, B. J., Carr, L., Phillips, G. M., \& Odman, R. B. (2011). Doing competencies well: Best practices in competency modeling. Personnel Psychology, 64(1), 225-262.

Caniëls, M. C., \& Veld, M. (2016). Employee ambidexterity, high-performance work systems and innovative work behaviour: How much balance do we need? The International Journal of Human Resource Management, 1-21.

Cannon, J. P., Doney, P. M., Mullen, M. R., \& Petersen, K. J. (2010). Building long-term orientation in buyersupplier relationships: The moderating role of culture. Journal of Operations Management, 28(6), 506521.

Carr, A. S., \& Smeltzer, L. R. (2000). An empirical study of the relationships among purchasing skills and strategic purchasing, financial performance, and supplier responsiveness. Journal of Supply Chain Management, 36(3), 40.

Carter, C. R., Rogers, D. S., \& Choi, T. Y. (2015). Toward the theory of the supply chain. Journal of Supply Chain Management, 51(2), 89-97.

Carter, J. R., \& Narasimhan, R. (1996). Is purchasing really strategic? International Journal of Purchasing and Materials Management, 32(4), 20-28.

Cavinato, J. L. (1987). Purchasing performance: what makes the magic? Journal of Purchasing and Materials Management, 23(3), 10-16.

Chen, J., Reilly, R. R., \& Lynn, G. S. (2012). New product development speed: Too much of a good thing? Journal of Product Innovation Management, 29(2), 288-303.

Chicksand, D., Watson, G., Walker, H., Radnor, Z., \& Johnston, R. (2012). Theoretical perspectives in purchasing and supply chain management: an analysis of the literature. Supply Chain Management: An International Journal, 17(4), 454-472.

Chipulu, M., Ojiako, U., Gardiner, P., Williams, T., Mota, C., Maguire, S., . . Marshall, A. (2014). Exploring the impact of cultural values on project performance: The effects of cultural values, age and gender on the perceived importance of project success/failure factors. International Journal of Operations \& Production Management, 34(3), 364-389. 
Cho, M., Bonn, M. A., Giunipero, L., \& Divers, J. (2019). Restaurant purchasing skills and the impacts upon strategic purchasing and performance: The roles of supplier integration. International Journal of Hospitality Management, 78, 293-303. doi:10.1016/j.ijhm.2018.09.012

CIA. (2019). The World Factbook. Retrieved from https://www.cia.gov/library/publications/the-worldfactbook/

Clark, G., Huberman, M., \& Lindert, P. H. (1995). A British food puzzle, 1770-1850 1. The Economic History Review, 48(2), 215-237.

Coase, R. H. (1937). The Nature of the Firm. Economica(4 (16), ), 386-405.

Cohen, J. (1988). The effect size index: $d$ (Vol. 2). New York: Lawrence Erlbaum Associates, Publishers.

Constant, B. (1988 [1819]). The Liberty of the Ancients Compared with that of the Moderns. Political writings, 325.

Cooper, R. G. (2019). The drivers of success in new-product development. Industrial Marketing Management, 76, 36-47. doi:10.1016/j.indmarman.2018.07.005

Cousins, P. D., Lamming, R., Lawson, B., \& Squire, B. (2008). Strategic supply management: principles, theories and practice: Pearson Education.

Cousins, P. D., Lawson, B., \& Squire, B. (2006). An empirical taxonomy of purchasing functions. International Journal of Operations \& Production Management, 26(7), 775-794. doi:doi:10.1108/01443570610672239

Cousins, P. D., \& Spekman, R. (2003). Strategic supply and the management of inter-and intra-organisational relationships. Journal of Purchasing and Supply Management, 9(1), 19-29.

Cronbach, L. J. (1951). Coefficient alpha and the internal structure of tests. Psychometrika, 16(3), 297-334.

Crossley, J. N. (2018). Dominican and Jesuit Formal Education in the First Years of Spanish Manila (c. 15711621). Journal of Religious History, 42(2), 181-199.

Cruz, C., \& Murphy, E. (1996). Purchasing's new importance requires a broader education. Purchasing, 12(9), 46-49.

Cubberley, E. P. (1920). The history of education: Educational practice and progress considered as a phase of the development and spread of western civilization: Houghton Mifflin.

Culot, G., Nassimbeni, G., Orzes, G., \& Sartor, M. (2020). Behind the definition of industry 4.0: Analysis and open questions. International Journal of Production Economics, 107617.

Cvetić, B., Vasiljević, D., \& Danilović, M. (2017). Competence requirements for logistics managers in the Republic of Serbia. Management: Journal of Sustainable Business and Management Solutions in Emerging Economies, 22(2), 37-46.

Czarnitzki, D., Huenermund, P., \& Moshgbar, N. (2018). Public procurement as policy instrument for innovation. Paper presented at the Academy of Management, Briarcliff Manor, NY.

Darby, J. L., Fugate, B. S., \& Murray, J. B. (2019). Interpretative research: a complementary approach to seeking knowledge in supply chain management. International Journal of Logistics Management.

Davis, H. L., Eppen, G. D., \& Mattsson, L.-G. (1974). Critical factors in worldwide purchasing. Harvard Business Review, 52(6), 81.

De Hert, P., Kinneging, A., \& Colette, M. (2015). Benjamin Constant. Ontdekker van de moderne vrijheid. Kalmthout: Pelckmans

De Houwer, J., Barnes-Holmes, D., \& Moors, A. (2013). What is learning? On the nature and merits of a functional definition of learning. Psychonomic bulletin \& review, 20(4), 631-642.

De Stobbeleir, K. E., De Clippeleer, I., Caniëls, M. C., Goedertier, F., Deprez, J., De Vos, A., \& Buyens, D. (2018). The inside effects of a strong external employer brand: how external perceptions can influence organizational absenteeism rates. The International Journal of Human Resource Management, 29(13), 2106-2136.

De Veaux, R. D., Velleman, P. F., Bock, D. E., Vukov, A. M., \& Wong, A. C. (2005). Stats: data and models: Pearson/Addison Wesley Boston.

Delamare-Le Deist, F., \& Winterton, J. (2005). What is competence? Human Resource Development International, 8(1), 27-46.

Delgosha, M. S., Saheb, T., \& Hajiheydari, N. (2020). Modelling the Asymmetrical Relationships between Digitalisation and Sustainable Competitiveness: A Cross-Country Configurational Analysis. Information Systems Frontiers. doi:10.1007/s10796-020-10029-0

Delke, V., Karttunen, E., Kelly, S., Stek, K., \& Tkáč, M. (2021). Exploring Industry 4.0 Professional Roles and Skills within Purchasing and Supply Management. Paper presented at IPSERA 2021, online conference.

Delke, V., Schiele, H., Buchholz, W., \& Stek, K. (2021). Defining Industry 4.0 skills in Purchasing and Supply Management. Paper presented at the EurOMA, Berlin. 
Deloitte. (2013). Charting the course - Why procurement must transform itself by 2020. Retrieved from https://www2.deloitte.com/us/en/pages/operations/articles/procurement-transformation-chartingthe-course.html

Deming, W. E. (1986). Out of the Crisis. Cambridge, Mass: Massachusetts Institute of Technology - Center for Advanced Engineering Studies.

Derwik, P., \& Hellström, D. (2017). Competence in supply chain management: a systematic review. Supply Chain Management: An International Journal, 22(2), 200-218. doi:10.1108/SCM-09-2016-0324

Deslandes, G. (2019). European management teaching and research: Reflections on the life and work of A. Blanqui. European Management Journal. doi:https://doi.org/10.1016/j.emj.2019.10.005

DeVries, R. (2000). Vygotsky, Piaget, and Education: a reciprocal assimilation of theories and educational practices. New ldeas in Psychology, 18(2), 187-213.

Dowd, K. O., \& Liedtka, J. (1994). What corporations seek in MBA hires - A survey. The Magazine of the Graduation management Admission Council, 2.

Doyle, M. (1990). Fundamentals of strategic supply management. Purchasing World, 32(12), 40-41.

Drake, M. (2012). Global supply chain management: Business Expert Press.

Drucker, P. F. (1977). People and performance: The best of Peter Drucker on management. New York: Harper \& Row, Publishers, Inc.

Du Sautoy, M. (2019). The Creativity Code: Art and Innovation in the Age of Al. Cambridge, MA, London: Harvard University Press.

Dubey, R., Bag, S., Ali, S. S., \& Venkatesh, V. (2013). Green purchasing is key to superior performance: an empirical study. International Journal of Procurement Management, 6(2), 187-210.

Dubey, R., Gunasekaran, A., Childe, S. J., \& Papadopoulos, T. (2018). Skills needed in supply chain-human agency and social capital analysis in third party logistics. Management Decision, 56(1), 143-159.

Dublin Descriptors, J. Q. I. (2004). Dublin descriptors. The Joint Quality Initiative Working document. Shared Dublin descriptors for the Bachelor's, Master's and Doctoral awards.

Dudić, Ž. (2015). Controlling as a support tool for generating savings in procurement. International Journal of Industrial Engineering and Management, 7(2), 98-102.

Dul, J. (2016a). Identifying single necessary conditions with NCA and fsQCA. Journal of Business Research, 69(4), 1516-1523.

Dul, J. (2016b). Necessary condition analysis (NCA) logic and methodology of "Necessary but Not Sufficient" causality. Organizational Research Methods, 19(1), 10-52.

Dul, J. (2018a). Necessary Condition Analysis - R Package Version 3.0.

Dul, J. (2018b). Necessary condition analysis (NCA) with R (version 3.0. 1): A quick start guide. Organizational Research Methods, 19(1), 10-52.

Dul, J., Vis, B., \& Goertz, G. (2018). Necessary Condition Analysis (NCA) does exactly what it should do when applied properly: a reply to a comment on NCA. Sociological Methods \& Research, 0049124118799383.

Durach, C. F., Kembro, J., \& Wieland, A. (2017). A new paradigm for systematic literature reviews in supply chain management. Journal of Supply Chain Management, 53(4), 67-85.

Dyer, J. H. (1996). Specialized supplier networks as a source of competitive advantage: Evidence from the auto industry. Strategic Management Journal, 271-291.

Edwards, J. R. (2001). Multidimensional constructs in organizational behavior research: An integrative analytical framework. Organizational Research Methods, 4(2), 144-192.

Edwards, J. R., \& Parry, M. E. (1993). On the use of polynomial regression equations as an alternative to difference scores in organizational research. Academy of Management Journal, 36(6), 1577-1613.

EF EPI. (2020). Education First - English Proficiency Index 2020. Retrieved from ef.nl/epi/

Elias, J., \& Scarbrough, H. (2004). Evaluating human capital: an exploratory study of management practice. Human Resource Management Journal, 14(4), 21-40.

Eltantawy, R. A., Giunipero, L. C., \& Fox, G. L. (2009). A strategic skill-based model of supplier integration and its effect on supply management performance. Industrial Marketing Management, 38(8), 925-936.

Engels, F. (1845). Die Lage der arbeitenden Klasse in England, Nach eigner Anschauung und authentischen Quellen. Leipzig: Otto Wigand.

Ennis, R. H. (1993). Critical thinking assessment. Theory into Practice, 32(3), 179-186.

Erpenbeck, J., \& Scharnhorst, A. (2005). Modellierung von Kompetenzen im Licht der Selbstorganisation. In T. Meynhardt \& E. J. Brunner (Eds.), Selbstorganisation Managen - Beiträge zur Synergetik der Organisation. Münster, Deutschland: Waxmann Verlag GmbH. 
ESG Report. (2015). Standards and Guidelines for Quality Assurance in the European Higher Education Area (ESG). Retrieved from http://www.enqa.eu/index.php/home/esg/

Estacio, E. V., \& Karic, T. (2016). The World Café: An innovative method to facilitate reflections on internationalisation in higher education. Journal of Further and Higher Education, 40(6), 731-745.

Etymonline. (2020). www.etymonline.com. Retrieved from www.etymonline.com

European Commission. (2014). The EU Customs Competency Framework Retrieved from https://ec.europa.eu/taxation_customs/eu-training/eu-customs-competency-framework_en

European Commission. (2017). Strategic public procurement - Stimulate innovation through procurement Retrieved from Brussels: ec.europa.eu/regional_policy/sources/good_practices/GP_fiche_30.pdf

European Commission. (2018a). Commission notice: Guidance on Innovation Procurement. Retrieved from Brussels: c.europa.eu/docsroom/documents/29261

European Commission. (2018b). International public procurement. Retrieved from http://ec.europa.eu/growth/single-market/public-procurement/international/

Faes, W., Knight, L., \& Matthyssens, P. (2001). Buyer profiles: an empirical investigation of changing organizational requirements. European Journal of Purchasing \& Supply Management, 7(3), 197-208.

Fawcett, S. E., \& Rutner, S. M. (2014). A longitudinal view of supply chain education: Assessing the challenge of retaining relevance in today's dynamic marketplace. The International Journal of Logistics Management, 25(1), 180-201.

Feisel, E., Hartmann, E., \& Giunipero, L. C. (2011). The importance of the human aspect in the supply function: Strategies for developing PSM proficiency. Journal of Purchasing and Supply Management, 17(1), 54-67.

Feisel, E., Hartmann, E., \& Schober, H. (2007). Purchasing skills-Developing the purchasing professional of the future. Paper presented at the 23rd Industrial Marketing \& Purchasing Group (IMP), Manchester.

Fereday, J., \& Muir-Cochrane, E. (2006). Demonstrating rigor using thematic analysis: A hybrid approach of inductive and deductive coding and theme development. International Journal of Qualitative Methods, 5(1), 80-92.

Fernandes, A. C., Sampaio, P., Sameiro, M., \& Truong, H. Q. (2017). Supply chain management and quality management integration: A conceptual model proposal. International Journal of Quality \& Reliability Management, 34(1), 53-67.

Field, A. (2009). Discovering statistics using SPSS (Vol. 3). Los Angeles, London: Sage publications.

Flöthmann, C., Hoberg, K., \& Gammelgaard, B. (2018). Disentangling supply chain management competencies and their impact on performance: A knowledge-based view. International Journal of Physical Distribution \& Logistics Management, 48(6), 630-655.

Flöthmann, C., Hoberg, K., \& Wieland, A. (2018). Competency requirements of supply chain planners \& analysts and personal preferences of hiring managers. Supply Chain Management: An International Journal, in press.

Foerstl, K., Hartmann, E., Wynstra, F., \& Moser, R. (2013). Cross-functional integration and functional coordination in purchasing and supply management: Antecedents and effects on purchasing and firm performance. International Journal of Operations \& Production Management, 33(6), 689-721.

Forker, L. B., Mendez, D., \& Hershauer, J. C. (1997). Total quality management in the supply chain: what is its impact on performance? International Journal of Production Research, 35(6), 1681-1702.

Fredrich, V., Bouncken, R. B., \& Kraus, S. (2018). The race is on: Configurations of absorptive capacity, interdependence and slack resources for inter-organizational learning in coopetition alliances. Journal of Business Research.

Freeman, C., \& Soete, L. (1997). The economics of industrial innovation. Cambridge, Massachusetts: The MIT Press.

Gammelgaard, B., \& Larson, P. D. (2001). Logistics skills and competencies for supply chain management. Journal of Business Logistics, 22(2), 27-50.

García-Pérez, M. A., \& Núñez-Antón, V. (2003). Cellwise residual analysis in two-way contingency tables. Educational and Psychological Measurement, 63(5), 825-839.

Geertz, C. (1973). The interpretation of cultures - selected essays: New York: Basic Books.

Georgia Tech. (2018). Deliberate Innovation Lifetime Education. Retrieved from Atlanta, GA: provost.gatech.edu/commission-creating-next-education

Girard, J., \& Girard, J. (2015). Defining knowledge management: Toward an applied compendium. Online Journal of Applied Knowledge Management, 3(1), 1-20.

Giunipero, L. C. (2000). A Skills-Based Analysis of the World Class Purchaser, Center for Advanced Purchasing Studies, Tempe, Arizona. 
Giunipero, L. C., Dawley, D., \& Anthony, W. (1999). The impact of tacit knowledge on purchasing decisions. Journal of Supply Chain Management, 35(4), 42-49.

Giunipero, L. C., Denslow, D., \& Eltantawy, R. (2005). Purchasing/supply chain management flexibility: Moving to an entrepreneurial skill set. Industrial Marketing Management, 34(6), 602-613.

Giunipero, L. C., \& Handfield, R. B. (2004). Purchasing Education and Training II: CAPS Research Tempe, AZ.

Giunipero, L. C., Handfield, R. B., \& Eltantawy, R. (2006). Supply management's evolution: key skill sets for the supply manager of the future. International Journal of Operations \& Production Management, 26(7), 822-844. doi:doi:10.1108/01443570610672257

Giunipero, L. C., Hooker, R. E., \& Denslow, D. (2012). Purchasing and supply management sustainability: Drivers and barriers. Journal of Purchasing and Supply Management, 18(4), 258-269.

Giunipero, L. C., \& Pearcy, D. H. (2000). World-class purchasing skills: an empirical investigation. Journal of Supply Chain Management, 36(3), 4-13.

Glas, A. H., \& Kleemann, F. C. (2016). The Impact of Industry 4.0 on Procurement and Supply Management: A Conceptual and Qualitative Analysis. International Journal of Business and Management Invention, 5(6), 55-66.

Gobble, M. M. (2013). Outsourcing innovation. Research-Technology Management, 56(4), 64-67.

Goldberg, J. M., \& Schiele, H. (2020). Innovating with dominant suppliers: Lessons from the race for laser light. International Journal of Innovation Management, 24(01), 2050008.

Gonzalez-Padron, T., Hult, G. T. M., \& Calantone, R. (2008). Exploiting innovative opportunities in global purchasing: An assessment of ethical climate and relationship performance. Industrial Marketing Management, 37(1), 69-82.

Gordon, M. J. (2009). Improving the validity of public procurement research. International Journal of Public Sector Management, 22(2), 91-103. doi:doi:10.1108/09513550910934501

Grant, R. M. (1996). Toward a knowledge-based theory of the firm. Strategic Management Journal, 17(S2), 109-122.

Gries, J. M. (1919). Principles of Government Purchasing. By Arthur. G. Thomas. Institute for Government Research. (New York: D. Appleton and Company. Pp. xiii, 275.). American Political Science Review, 13(4), 685-685. Retrieved from www.cambridge.org

Groeneveld, B., Kartoidjojo, S., Kuiper, P., Reineman, D., \& Stek, K. (2021). Suppliers' roles in sustainability in early product development phases. Paper presented at IPSERA 2021, online conference.

Gross, H. (1966). Make or buy decisions in growing firms. The Accounting Review, 41(4), 745-753.

Günther, K.-H. (1988). Profiles of educators: Wilhelm von Humboldt (1767-1835). Prospects, 18(1), 127-136.

Gupta, V., Hanges, P. J., \& Dorfman, P. (2002). Cultural clusters: Methodology and findings. Journal of World Business, 37(1), 11-15.

Gushée, E. T., \& Boffey, L. F. (1928). Scientific Purchasing: McGraw-Hill Book Company, Incorporated.

Hackett, R. D., \& Wang, G. (2012). Virtues and leadership: An integrating conceptual framework founded in Aristotelian and Confucian perspectives on virtues. Management Decision, 50(5), 868-899.

Hacking, I. (1984). Experimentation and scientific realism. In Science and the Quest for Reality (pp. 162-181): Springer.

Hair, J., Black, W., Babin, B., \& Anderson, R. (2010). Multivariate Data Analysis. A Global Perspective (Seventh Edition ed.): Pearson.

Hampden-Turner, C., \& Trompenaars, F. (2006). Cultural intelligence: is such a capacity credible? Group \& Organization Management, 31(1), 56-63.

Hannafin, M. J., \& Land, S. M. (2000). Technology and student-centered learning in higher education: Issues and practices. Journal of Computing in Higher Education, 12(1), 3-30.

Hansen, V. (2012). The Silk Road: a new history: Oxford University Press.

Harari, Y. N. (2014). Sapiens: A brief history of humankind: Random House.

Harland, C., Telgen, J., \& Callender, G. (2013). International research study of public procurement. In The SAGE Handbook of Strategic Supply Management (pp. 374-401).

Harper, R. F. (1904). Assyrian and Babylonian Literature: Selected Translations: D. Appleton.

Hartley, J. L., Brodke, M., Wheeler, J. V., Wu, Z., \& Steward, M. D. (2014). Exploring supply management status, internal collaboration and operating performance. Operations Management Research, 7(1-2), 24-35.

Hauff, S., Guerci, M., Dul, J., \& van Rhee, H. (2019). Exploring necessary conditions in HRM research: Fundamental issues and methodological implications. Human Resource Management Journal. 
Haugbølle, K., Pihl, D., \& Gottlieb, S. C. (2015). Competitive dialogue: Driving innovation through procurement? Procedia Economics and Finance, 21, 555-562.

Hauser, J., Tellis, G. J., \& Griffin, A. (2006). Research on innovation: A review and agenda for marketing science. Marketing Science, 25(6), 687-717.

Hawkins, T. G., \& Gravier, M. J. (2014). Individual manager experience influences on reverse auction use. International Journal of Procurement Management, 7(6), 719-749.

Hayes, J. L. (1979). A new look at managerial competence: the AMA model of worthy performance. Management Review, 68(11), 2-3.

Hecht, T. D., \& Allen, N. J. (2005). Exploring links between polychronicity and well-being from the perspective of person-job fit: Does it matter if you prefer to do only one thing at a time? Organizational Behavior and Human Decision Processes, 98(2), 155-178.

Heckman, J. J., \& Kautz, T. (2012). Hard evidence on soft skills. Labour Economics, 19(4), 451-464.

Hedenstierna, P., Hilletofth, P., \& Hilmola, O.-P. (2011). Integrative purchasing and inventory control at sawnwood retailer-case study. International Journal of Procurement Management, 4(2), 139-155.

Heine, H. (1986 [1834]). Religion and Philosophy in Germany (J. Snodgrass, Trans.). Albany, NY: State University of New York Press.

Heisenberg, W. (1973). Schritte über Grenzen, Rede zur 100-Jahrfeier des Max-Gymnasiums. In: Gesammelte Reden und Aufsätze: München, Piper.

Henseler, J., Hubona, G., \& Ray, P. A. (2016). Using PLS path modeling in new technology research: updated guidelines. Industrial Management \& Data Systems.

Hermann, M., Pentek, T., \& Otto, B. (2016). Design principles for Industrie 4.0 scenarios. Paper presented at the 2016 49th Hawaii International Conference on System Sciences (HICSS).

Hesping, F. H., \& Schiele, H. (2015). Purchasing strategy development: A multi-level review. Journal of Purchasing and Supply Management, 21(2), 138-150.

Hesping, F. H., \& Schiele, H. (2016). Sourcing tactics to achieve cost savings: developing a formative method of measurement. International Journal of Procurement Management, 9(4), 473-504.

Heyse, V., Erpenbeck, J., \& Max, H. (2004). Kompetenzen erkennen, bilanzieren und entwickeln: Münster, Deutschland: Waxmann Verlag $\mathrm{GmbH}$.

Hitt, M., Ireland, R., \& Hoskisson, R. (2013). Strategic Management Cases: Competitiveness and Globalization. In: US: Cengage Learning.

Hoezen, M., van Rutten, J., Voordijk, H., \& Dewulf, G. (2010). Towards better customized service-led contracts through the competitive dialogue procedure. Construction Management and Economics, 28(11), 11771186.

Hofstede, G. (1980a). Culture and organizations. International Studies of Management \& Organization, 10(4), $15-41$.

Hofstede, G. (1980b). Motivation, leadership, and organization: do American theories apply abroad? Organizational Dynamics, 9(1), 42-63.

Hofstede, G. (1983a). Cultural dimensions for project management. International Journal of Project Management, 1(1), 41-48.

Hofstede, G. (1983b). The cultural relativity of organizational practices and theories. Journal of International Business Studies, 14(2), 75-89.

Hofstede, G. (1984). Culture's Consequences: International Differences in Work-Related Values (Vol. 5). Newbury Park, London, New Dehli: Sage Publications, Inc.

Hofstede, G. (1994). The business of international business is culture. International Business Review, 3(1), 114.

Hofstede, G. (2001). Culture's Consequences: Comparing Values, Behaviors, Institutions, and Organizations Across Nations (Vol. second edition). Thousand Oaks, London, New Dehli: Sage Publication.

Hofstede, G. (2006). What did GLOBE really measure? Researchers' minds versus respondents' minds. Journal of International Business Studies, 882-896.

Hofstede, G. (2010). The GLOBE debate: Back to relevance. Journal of International Business Studies, 41(8), 1339-1346.

Hofstede, G. (2011). Dimensionalizing cultures: The Hofstede model in context. Online Readings in Psychology and Culture, 2(1), 8.

Hofstede, G., Hofstede, G. J., \& Minkov, M. (2010). Cultures and Organizations: Software of the Mind (Vol. 3). New York: McGraw Hill. 
Hofstede, G., \& Minkov, M. (2010). Long-versus short-term orientation: new perspectives. Asia Pacific business review, 16(4), 493-504.

Hohenstein, N.-O., Feisel, E., \& Hartmann, E. (2014). Human resource management issues in supply chain management research: a systematic literature review from 1998 to 2014. International Journal of Physical Distribution \& Logistics Management, 44(6), 434-463.

Hoidn, S. (2017). Student-centered learning environments in higher education classrooms. New York, NY: Palgrave Macmillan.

Homburg, C., Cannon, J. P., Krohmer, H., \& Kiedaisch, I. (2009). Governance of international business relationships: A cross-cultural study on alternative governance modes. Journal of International Marketing, 17(3), 1-20.

Homfeldt, F., Rese, A., Brenner, H., Baier, D., \& Schäfer, T. F. (2017). Identification and Generation of Innovative Ideas in the Procurement of the Automotive Industry: The Case of AUDI AG. International Journal of Innovation Management, 21(07), 1750053.

Hong, P., \& Kwon, H.-B. (2012). Emerging issues of procurement management: a review and prospect. International Journal of Procurement Management 4, 5(4), 452-469.

Hoorn, S. v., \& Stek, K. (2018). Vaardigheden die leiden tot inkoopsucces. NEVI Deal!, December, 34-35.

Horan, R. D., Bulte, E., \& Shogren, J. F. (2005). How trade saved humanity from biological exclusion: An economic theory of Neanderthal extinction. Journal of Economic Behavior \& Organization, 58(1), 1-29.

Horn, P., Schiele, H., \& Werner, W. (2013). The "ugly twins": Failed low-wage-country sourcing projects and their expensive replacements. Journal of Purchasing and Supply Management, 19(1), 27-38.

Horrell, S., \& Oxley, D. (2012). Bringing home the bacon? Regional nutrition, stature, and gender in the industrial revolution 1. The Economic History Review, 65(4), 1354-1379.

House, R. J. (1998). A brief history of GLOBE. Journal of Managerial Psychology, 13(3/4), 230-240.

House, R. J., Hanges, P. J., Javidan, M., Dorfman, P. W., \& Gupta, V. (2004). Culture, Leadership, and Organizations: The GLOBE study of 62 societies. Thousand Oaks, London, New Dehli: Sage Publications.

House, R. J., Hanges, P. J., Ruiz-Quintanilla, S. A., Dorfman, P. W., Javidan, M., Dickson, M., \& Gupta, V. (1999). Cultural influences on leadership and organizations: Project GLOBE. Advances in Global Leadership, 1(2), 171-233.

House, R. J., Javidan, M., Hanges, P., \& Dorfman, P. (2002). Understanding cultures and implicit leadership theories across the globe: an introduction to project GLOBE. Journal of World Business, 37(1), 3-10.

Howie, S. J., Combrinck, C., Roux, K., Tshele, M., Mokoena, G., \& McLeod Palane, N. (2017). PIRLS Literacy 2016: Progress in International Reading Literacy Study (PIRLS) 2016: South African Children's Reading Literacy Achievement: Centre for Evaluation and Assessment (CEA).

Huizinga, J. (1924). The Waning of the Middle Ages: A Study of the Forms of Life, Thought and Art in France and the Netherlands in the XIVth and XVth Centuries: Gower Publishing Company, Limited.

Inglehart, R., \& Welzel, C. (2010). Changing mass priorities: The link between modernization and democracy. Perspectives on Politics, 8(2), 551-567.

IPP (2019). Innovation Procurement Platform. National Competence Centres. Retrieved from http://innovation-procurement.org/national-competence-centres/

Jasimuddin, S. M., Klein, J. H., \& Connell, C. (2005). The paradox of using tacit and explicit knowledge: strategies to face dilemmas. Management Decision, 43(1), 102-112.

Jauch, L. R., \& Wilson, H. K. (1979). A strategic perspective for make or buy decisions. Long Range Planning, 12(6), 56-61.

Javidan, M., \& House, R. J. (2002). Leadership and cultures around the world: findings from GLOBE: An introduction to the special issue. Journal of World Business, 37(1), 1-2.

Johnsen, T. E., Calvi, R., \& Phillips, W. (2012). Discontinuous Innovation: A challenge for purchasing. Journal of Purchasing and Supply Chain Management.

Johnsen, T. E., Howard, M., \& Miemczyk, J. (2014). Purchasing and supply chain management: A sustainability perspective: Routledge.

Kagermann, H., Wahlster, W., \& Helbig, J. (2013). Securing the future of German manufacturing industry: Recommendations for implementing the strategic initiative INDUSTRIE 4.0. Final report of the Industrie, $4(0)$.

Kaiser, H. F. (1970). A second generation little jiffy. Psychometrika, 35(4), 401-415.

Kaiser, H. F. (1974). An index of factorial simplicity. Psychometrika, 39(1), 31-36.

Kale, S. H. (1995). Grouping Euroconsumers: a culture-based clustering approach. Journal of International Marketing, 3(3), 35-48. 
Kaplan, A. (2014). European management and European business schools: Insights from the history of business schools. European Management Journal, 32(4), 529-534.

Karttunen, E., Hallikas, J., \& Stek, K. (2017). An Empirical Study of the Relationships among Purchasing Skills and Supplier Integration, Internal Integration, and Customer Focus. Paper presented at IPSERA 2017, Balatonfüred, Hungary.

Karwowski, M., Kaufman, J. C., Lebuda, I., Szumski, G., \& Firkowska-Mankiewicz, A. (2017). Intelligence in childhood and creative achievements in middle-age: The necessary condition approach. Intelligence, 64, 36-44. doi:10.1016/j.intell.2017.07.001

Kaufman, J. C., \& Beghetto, R. A. (2009). Beyond big and little: The four c model of creativity. Review of General Psychology, 13(1), 1-12.

Kaufmann, L. (2002). Purchasing and supply management-A conceptual framework. In Handbuch Industrielles Beschaffungsmanagement (pp. 3-33): Springer.

Kaufmann, L., \& Carter, C. R. (2006). International supply relationships and non-financial performance-a comparison of US and German practices. Journal of Operations Management, 24(5), 653-675.

Keinänen, M., Ursin, J., \& Nissinen, K. (2018). How to measure students' innovation competences in higher education: Evaluation of an assessment tool in authentic learning environments. Studies in Educational Evaluation, 58, 30-36.

Kelly, S., Bals, L., Schulze, H., \& Stek, K. (2020). The role of knowledge conversion in developing operational capabilities: An organisational routines perspective. Paper presented at IPSERA 2020, Knoxville, TN, USA.

Kelly, S., Vangorp, P., Stek, K., \& Delke, V. (2020). Opportunities for Gamified Learning in Purchasing and Supply Management Education. Paper presented at the ECGBL 2020 - 14th European Conference on Games Based Learning, Brighton

Kennan, M. A., Cole, F., Willard, P., Wilson, C., \& Marion, L. (2006). Changing workplace demands: what job ads tell us. Paper presented at the Aslib conference.

Keough, M. (1993). Buying your way to the top. The McKinsey Quarterly, 1993(3), 41-63.

Kern, D., Moser, R., Sundaresan, N., \& Hartmann, E. (2011). Purchasing Competence: A Stakeholder-Based Framework for Chief Purchasing Officers. Journal of Business Logistics, 32(2), 122-138.

Kibbeling, M. I., Gelderman, C. J., Ulijn, J. M., Van Weele, A. J., \& Calvi, R. (2009). A Dutch-French comparison of dependence, trust and commitment in buyer-supplier relationships: a purchasing portfolio approach. International Journal of Business and Globalisation, 3(4), 353-373.

Killen, K. H., \& Kamauff, J. W. (1995). Managing purchasing: Making the supply team work. Homestead, IL: Irwin Publishing.

Kilpi, V., Lorentz, H., Solakivi, T., \& Malmsten, J. (2018). The effect of external supply knowledge acquisition, development activities and organizational status on the supply performance of SMEs. Journal of Purchasing and Supply Management, 24(3), 247-259.

Kim, S. K., \& Hsieh, P.-H. (2003). Interdependence and its consequences in distributor-supplier relationships: a distributor perspective through response surface approach. Journal of Marketing Research, 40(1), 101112.

Kiratli, N., Rozemeijer, F., Hilken, T., de Ruyter, K., \& de Jong, A. (2016). Climate setting in sourcing teams: Developing a measurement scale for team creativity climate. Journal of Purchasing and Supply Management, 22(3), 196-204.

Kirkman, M. M. (1887). The handling of railway supplies: their purchase and disposition: CN Trivess, printer.

Knight, L., Meehan, J., Tapinos, E., Menzies, L., \& Pfeiffer, A. (2020). Researching the future of purchasing and supply management: The purpose and potential of scenarios. Journal of Purchasing and Supply Management, 100624. doi:https://doi.org/10.1016/j.pursup.2020.100624

Knight, L., Tu, Y.-H., \& Preston, J. (2014). Integrating skills profiling and purchasing portfolio management: An opportunity for building purchasing capability. International Journal of Production Economics, 147(2014), 271-283.

Knol, W. H., Slomp, J., Schouteten, R. L., \& Lauche, K. (2018). Implementing lean practices in manufacturing SMEs: testing 'critical success factors' using Necessary Condition Analysis. International Journal of Production Research, 56(11), 3955-3973. doi:10.1080/00207543.2017.1419583

Knol, W. H., Slomp, J., Schouteten, R. L., \& Lauche, K. (2019). The relative importance of improvement routines for implementing lean practices. International Journal of Operations \& Production Management, 39(2), 214-237. 
Knutsson, H., \& Thomasson, A. (2014). Innovation in the Public Procurement Process: A study of the creation of innovation-friendly public procurement. Public Management Review, 16(2), 242-255. doi:10.1080/14719037.2013.806574

Koch, A., Brierley, C., Maslin, M. M., \& Lewis, S. L. (2019). Earth system impacts of the European arrival and Great Dying in the Americas after 1492. Quaternary Science Reviews, 207, 13-36.

Koch, V., Stek, K., \& Picaud-Bello, K. (2021). Purchasing in the area of Innovation and Sustainability: A Study into Current and Future Competences. Paper presented at IPSERA 2021, online conference.

Koch, V., Zunk, B. M., \& Stek, K. (2018). Purchasers' Personality Profile. Paper presented at IPSERA 2018, Athens, Greece.

Koebner, R. (1959). Adam Smith and the Industrial Revolution. The Economic History Review, 11(3), 381-391. doi:10.2307/2591461

Kogut, B., \& Zander, U. (1992). Knowledge of the firm, combinative capabilities, and the replication of technology. Organization Science, 3(3), 383-397.

Kolchin, M. G., \& Giunipero, L. C. (1993). Purchasing education and training: Requirements and resources. Tempe, AZ: Center for Advanced Purchasing Studies.

Kothari, A., Rudman, D., Dobbins, M., Rose, M., Sibbald, S., \& Edwards, N. (2012). The use of tacit and explicit knowledge in public health: a qualitative study. Implementation Science, 7(1), 1-12.

Kotzab, H., Teller, C., Bourlakis, M., \& Wünsche, S. (2018). Key competences of logistics and SCM professionals-the lifelong learning perspective. Supply Chain Management: An International Journal, 23(1), 50-64.

Kraljic, P. (1983). Purchasing must become supply management. Harvard Business Review, 61(5), 109-117.

Krause, D. R., Pagell, M., \& Curkovic, S. (2001). Toward a measure of competitive priorities for purchasing. Journal of operations management, 19(4), 497-512.

Krause, D. R., Vachon, S., \& Klassen, R. D. (2009). Special topic forum on sustainable supply chain management: introduction and reflections on the role of purchasing management. Journal of Supply Chain Management, 45(4), 18-25.

Kretzmann, N., Kenny, A., Pinborg, J., \& Stump, E. (1988). The Cambridge history of later medieval philosophy: from the rediscovery of Aristotle to the disintegration of scholasticism, 1100-1600: Cambridge University Press.

Kristeller, P. O. (1979). The Aristotelian Tradition. id., Renaissance Thought and Its Sources, ed. Michael Mooney (New York: Columbia University Press, 1979).

Kristof, A. L. (1996). Person-organization fit: An integrative review of its conceptualizations, measurement, and implications. Personnel Psychology, 49(1), 1-49.

Kruger, J., \& Dunning, D. (1999). Unskilled and unaware of it: how difficulties in recognizing one's own incompetence lead to inflated self-assessments. Journal of personality and social psychology, 77(6), 1121.

Lacey, A. R. (1971). Our knowledge of Socrates. In The philosophy of Socrates (pp. 22-49): Springer.

Lachs, J. (1992). Mill and Constant: A Neglected Connection in the History of the Idea of Liberty. History of Philosophy Quarterly, 9(1), 87-96.

Laker, D. R., \& Powell, J. L. (2011). The differences between hard and soft skills and their relative impact on training transfer. Human Resource Development Quarterly, 22(1), 111-122.

Land, S., \& Hannafin, M. (2000). Student-Centered Learning Environments. In D. Jonassen \& S. Land (Eds.), Theoretical foundations of learning environments (pp. 1-24). Mahwah, NJ / London: Lawrence Erlbaum Associates, Inc. Publishers.

Landman, T., \& Silverman, B. W. (2019). Globalization and modern slavery. Politics and Governance, 7(4), 275290.

Lansing, C. B. (2010). From Nazism to Communism: German schoolteachers under two dictatorships (Vol. 170): Harvard University Press.

Large, R. O., \& Giménez, C. (2006). Oral communication capabilities of purchasing managers: measurement and typology. Journal of Supply Chain Management, 42(2), 17-32.

Larkin, G. L., Iserson, K., Kassutto, Z., Freas, G., Delaney, K., Krimm, J., . . . Adams, J. (2009). Virtue in emergency medicine. Academic Emergency Medicine, 16(1), 51-55.

Larson, P. D., \& Halldórsson, Á. (2002). What is SCM? And, where is it? Journal of Supply Chain Management, $38(3), 36-44$.

Lau, A. K. (2010). Training needs of purchasing and supply management personnel in Hong Kong. Journal of European Industrial Training, 34(5), 400-415. 
Lave, J., \& Wenger, E. (1991). Situated learning: Legitimate peripheral participation: Cambridge university press.

Lee, K., Woo, H.-G., \& Joshi, K. (2017). Pro-innovation culture, ambidexterity and new product development performance: Polynomial regression and response surface analysis. European Management Journal, 35(2), 249-260.

Lee, W., \& Jeong, C. (2019). Beyond the correlation between tourist eudaimonic and hedonic experiences: necessary condition analysis. Current Issues in Tourism, 1-13.

Leenders, M. R., \& Blenkhorn, D. L. (1988). Reverse marketing: The new buyer-supplier relationship: New York: Free Press; London: Collier Macmillan.

Legenvre, H., \& Gualandris, J. (2018). Innovation sourcing excellence: Three purchasing capabilities for success. Business Horizons, 61(1), 95-106.

Leger, A., Oueslati, W., \& Salanié, J. (2013). Public tendering and green procurement as potential drivers for sustainable urban development: Implications for landscape architecture and other urban design professions. Landscape and Urban Planning, 116, 13-24.

Leiponen, A. (2005). Skills and innovation. International Journal of Industrial Organization, 23(5-6), 303-323.

Leischnig, A., Kasper-Brauer, K., \& Thornton, S. C. (2018). Spotlight on customization: An analysis of necessity and sufficiency in services. Journal of Business Research, 89, 385-390.

Leoni, R. (2014). Graduate employability and the development of competencies. The incomplete reform of the "Bologna Process". International Journal of Manpower, 35(4), 448-469.

Leuven/Louvain-la-Neuve Declaration. (2009). The Bologna Process 2020: the European Higher Education Area in the new decade. Communiqué of the Conference of European Ministers Responsible for Higher Education, Leuven and Louvain-la-Neuve, 28-29 April. In.

Lewis, H. (1932). Purchasing in relation to industrial marketing. Harvard Business Review, 10(2), 181-191.

Lewis, H. (1933). Industrial purchasing: Principles and practice: RD Irwin.

Lewis, H. (1935a). The industrial buyer. National Marketing Review, 19-25.

Lewis, H. (1935b). Problems in industrial purchasing: New York, London.

Lewis, H. (1936). Standards of purchasing performance. Harvard Business Review, 14(4), 480-493.

Lincoln, Y. S., \& Guba, E. G. (1985). Naturalistic Inquiry (Vol. 75): Sage.

Ling, L. (2007). Supply Chain Management: Concepts, Techniques and Practices: Enhancing the Value through Collaboration: World scientific publishing company.

Lintukangas, K. (2010). Supplier relationship management capability in global supply management. International Journal of Procurement Management, 4(1), 1-19.

Liu, Y., Srai, J. S., \& Evans, S. (2016). Environmental management: the role of supply chain capabilities in the auto sector. Supply Chain Management: An International Journal, 21(1), 1-19.

Logan, J. (2011). The new Chinese city: globalization and market reform (Vol. 52): John Wiley \& Sons.

Lonsdale, C., Hoque, K., Kirkpatrick, I., \& Sanderson, J. (2017). Knowing the price of everything? Exploring the impact of increased procurement professional involvement on management consultancy purchasing. Industrial Marketing Management, 65, 157-167.

Lumsden, C. J. (1999). Evolving creative minds: Stories and mechanisms. In R. J. Sternberg (Ed.), Handbook of Creativity (Vol. 1, pp. 153-168). Cambridge: Cambridge University Press.

Luther, L., Bonfils, K. A., Firmin, R. L., Buck, K. D., Choi, J., Dimaggio, G., . . Lysaker, P. H. (2017). Metacognition is necessary for the emergence of motivation in people with schizophrenia spectrum disorders: $A$ Necessary Condition Analysis. Journal of Nervous and Mental Disease, 205(12), 960-966.

Luzzini, D., Amann, M., Caniato, F., Essig, M., \& Ronchi, S. (2015). The path of innovation: purchasing and supplier involvement into new product development. Industrial Marketing Management, 47, 109-120.

Luzzini, D., \& Ronchi, S. (2011). Organizing the purchasing department for innovation. Operations Management Research, 4(1-2), 14-27.

Luzzini, D., \& Ronchi, S. (2016). Cinderella purchasing transformation: linking purchasing status to purchasing practices and business performance. Production Planning \& Control, 27(10), 787-796.

Machlup, F. (1980). Knowledge-Its Creation, Distribution, and Economic Significance: Vol. i-Knowledge and Knowledge Production: Princeton University Press.

Mahamadu, A.-M., Manu, P., Booth, C., Olomolaiye, P., Coker, A., Ibrahim, A., \& Lamond, J. (2018). Infrastructure procurement skills gap amongst procurement personnel in Nigeria's public sector. Journal of Engineering, Design and Technology, 16(1), 2-24.

Mangan, J., \& Christopher, M. (2005). Management development and the supply chain manager of the future. The International Journal of Logistics Management, 16(2), 178-191. 
Mansfield, R. S. (1996). Building competency models: Approaches for HR professionals. Human Resource Management, 35(1), 7-18.

Mansi, M., \& Pandey, R. (2016). Impact of demographic characteristics of procurement professionals on sustainable procurement practices: Evidence from Australia. Journal of Purchasing and Supply Management, 22(1), 31-40.

Martels, Z. R. (2011). non scholæ sed vitæ: het Latijn aan de Rijksuniversiteit Groningen (H. Borg \& N. van Schaik Eds.): Rijksuniversiteit Groningen.

Martínes-González, J. L. (2015). Did Climate Change Influence English Agricultural Development? (1645-1740). Working Papers 0075, European Historical Economics Society (EHES).

Marx, K., \& Engels, F. (2010). Collected Works (Letters 1860-64), vol. 41.

Masters, K. (2013). Edgar Dale's Pyramid of Learning in medical education: A literature review. Medical Teacher, 35(11), e1584-e1593.

Mathews, B. P., \& Redman, T. (2001). Recruiting the wrong salespeople: are the job ads to blame? Industrial marketing management, 30(7), 541-550.

Maxwell, J. (1997). Designing a Qualitative Study. In L. Bickman \& D. Rog (Eds.), Handbook of Applied Social Research Methods (Vol. 2, pp. 214-253). Newbury Park, Ca: Sage Publications.

Mazzucato, M. (2018). Mission-oriented innovation policies: challenges and opportunities. Industrial and Corporate Change, 27(5), 803-815.

McCall, D. F. (1973). Prehistory as a Kind of History. [Prehistoric Agriculture, Stuart Struever; The Carbon-14 Dating of Iron, Nicolaas J. van der Merwe; Prehistory: An Introduction, Derek Roe]. The Journal of Interdisciplinary History, 3(4), 733-739. doi:10.2307/202691

McKeefry, H. (1998). Opportunity Knocks-Education and Technical Skills Will Open the Door to Lucrative Job Offers. CMP Net, August, 3.

McKevitt, D., Davis, P., Woldring, R., Smith, K., Flynn, A., \& McEvoy, E. (2012). An exploration of management competencies in public sector procurement. Journal of Public Procurement, 12(3), 333-355.

McLachlan, N. H., Eastwood, L., \& Friedberg, R. D. (2016). Socratic questions with children: Recommendations and cautionary tales. Journal of Cognitive Psychotherapy, 30(2), 105-119.

McLeod, A. I. (1993). Parsimony, model adequacy and periodic correlation in time series forecasting. International Statistical Review/Revue Internationale de Statistique, 387-393.

McSweeney, B. (2002a). The essentials of scholarship: A reply to Geert Hofstede. Human Relations, 55(11), 1363-1372.

McSweeney, B. (2002b). Hofstede's model of national cultural differences and their consequences: A triumph of faith-a failure of analysis. Human Relations, 55(1), 89-118.

Mensah, Y. M., \& Chen, H.-Y. (2014). Global clustering of countries by culture - an extension of the GLOBE study. The Business \& Management Review, 5(2), 143.

Meyer, A. E. (1939). The Development of Education in the Twentieth Century. New York: Prentice-Hall, Inc.

Michaelis, T. L., \& Markham, S. K. (2017). Innovation Training: Making Innovation a Core Competency A study of large companies shows that, although managers see human capital as central to innovation success, most aren't providing innovation training. Research-Technology Management, 60(2), 36-42.

Miemczyk, J., Johnsen, T. E., \& Macquet, M. (2012). Sustainable purchasing and supply management: a structured literature review of definitions and measures at the dyad, chain and network levels. Supply Chain Management: An International Journal, 17(5), 478-496.

Mill, J. S. (1859). On liberty. London: John W. Parker and Son.

Mill, J. S. (1867). Inaugural Address: Delivered to the University of St. Andrews, Feb. 1st 1867: Longmans, Green, Reader, and Dyer.

Miller, R. A., \& Collier, E. W. (2010). Redefining entrepreneurship: A virtues and values perspective. Journal of Leadership, Accountability and Ethics, 8(2), 80-89.

Mingay, G. E. (1977). The Agricultural Revolution: Changes in Agriculture, 1650-1880: London: A. and C. Black.

Mintzberg, H. (1994). The fall and rise of strategic planning. Harvard Business Review, January-February, 116.

Miocevic, D. (2011). Organizational buying effectiveness in supply chain context: Conceptualization and empirical assessment. Journal of Purchasing and Supply Management, 17(4), 246-255.

Mirabile, R. J. (1997). Everything you wanted to know about competency modeling. Training \& Development, 51(8), 73-78. 
Mogre, R., Lindgreen, A., \& Hingley, M. (2017). Tracing the evolution of purchasing research: future trends and directions for purchasing practices. Journal of Business \& Industrial Marketing, 32(2), 251-257. doi:doi:10.1108/JBIM-01-2016-0004

Monczka, R. M., Handfield, R. B., Giunipero, L. C., \& Patterson, J. L. (2016). Purchasing and Supply Chain Management: Boston, MA, Cengage Learning.

Montabon, F., Pagell, M., \& Wu, Z. (2016). Making sustainability sustainable. Journal of Supply Chain Management, 52(2), 11-27.

Muir, C. (2004). Learning soft skills at work: An interview with Annalee Luhman. In B. D. Davis (Ed.), Business Communication Quarterly (Vol. 67, pp. 95-101).

Mulder, M., Wesselink, R., \& Bruijstens, H. C. (2005). Job profile research for the purchasing profession. International Journal of Training and Development, 9(3), 185-204.

Muller, E. W. (2001). Report on the job analysis to update the certified purchasing manager and accredited purchasing practitioner examinations. Tempe, AZ: Center for Advanced Purchasing Studies.

Murphy, E. (1995). Half the battle is knowing what skills to acquire. Purchasing, 119(9), 49-54.

Nambisan, S., Lyytinen, K., Majchrzak, A., \& Song, M. (2017). Digital Innovation Management: Reinventing innovation management research in a digital world. Mis Quarterly, 41(1).

Narlikar, A. (2003). International Trade and Developing Countries: bargaining coalitions in the GATT \& WTO (Vol. 13): Taylor \& Francis.

Nemo, P. (2006). A. Destutt de Tracy critique de Montesquieu: le libéralisme économique des idéologues. Romantisme, 3, 25-34.

Neumann, H. (1994). Beer as a means of compensation for work in Mesopotamia during the Ur III period.

Nietzsche, F. W. ([1872] 2016). Anti-Education: On the future of our educational institutions (D. Searls, Trans. P. Reitter \& C. Wellmon Eds.). New York, NY: New York Review of Books.

Nijboer, K., Senden, S., \& Telgen, J. (2017). Cross-country learning in public procurement: An exploratory study. Journal of Public Procurement, 17(4), 449-482.

Nollet, J., Ponce, S., \& Campbell, M. (2005). About "strategy" and "strategies" in supply management. Journal of Purchasing and Supply Management, 11(2), 129-140.

Nonaka, I., \& Takeuchi, H. (1995). The Knowledge-Creating Company: How Japanese Companies Create the Dynamics of Innovation. New York: Oxford University Press.

Nonaka, I., \& Von Krogh, G. (2009). Perspective-tacit knowledge and knowledge conversion: Controversy and advancement in organizational knowledge creation theory. Organization Science, 20(3), 635-652.

O'Connor, G. C., \& Veryzer, R. W. (2001). The nature of market visioning for technology-based radical innovation. Journal of Product Innovation Management, 18(4), 231-246.

O'Connor, G. C., \& McDermott, C. M. (2004). The human side of radical innovation. Journal of Engineering and Technology Management, 21(1-2), 11-30.

Obwegeser, N., \& Müller, S. D. (2018). Innovation and public procurement: Terminology, concepts, and applications. Technovation.

OECD. (2017a). Government at a Glance 2017. Paris: OECD Publishing.

OECD. (2017b). Public Procurement for Innovation; Good Practices and Strategies. Retrieved from Paris:

OECD. (2020). OECD Data. Retrieved from data.oecd.org/austria.htm; data.oecd.org/belgium.htm; data.oecd.org/netherlands.htm

Ogden, J. A., Rossetti, C. L., \& Hendrick, T. E. (2007). An exploratory cross-country comparison of strategic purchasing. Journal of Purchasing and Supply Management, 13(1), 2-16.

Orlikowski, W. J. (2002). Knowing in practice: Enacting a collective capability in distributed organizing. Organization Science, 13(3), 249-273.

Orwell, G. (1945). Animal Farm: A Fairy Story. London: Secker and Warburg

Paesbrugghe, B., Rangarajan, D., Sharma, A., Syam, N., \& Jha, S. (2017). Purchasing-driven sales: Matching sales strategies to the evolution of the purchasing function. Industrial marketing management, 62, 171184.

Paesbrugghe, B., Sharma, A., Rangarajan, D., \& Syam, N. (2018). Personal selling and the purchasing function: where do we go from here? Journal of Personal Selling \& Sales Management, 38(1), 123-143.

Pagell, M., Das, A., Curkovic, S., \& Easton, L. (1996). Motivating the purchasing professional. Journal of Supply Chain Management, 32(3), 27.

Pagell, M., Katz, J. P., \& Sheu, C. (2005). The importance of national culture in operations management research. International Journal of Operations \& Production Management, 25(4), 371-394. 
Pagell, M., \& Sheu, C. (2001). Buyer behaviours and the performance of the supply chain: an international exploration. International Journal of Production Research, 39(13), 2783-2801.

Patrucco, A. S., Luzzini, D., \& Ronchi, S. (2016). Evaluating the Effectiveness of Public Procurement Performance Management Systems in Local Governments. Local Government Studies, 42(5), 739-761. doi:10.1080/03003930.2016.1181059

Patrucco, A. S., Luzzini, D., \& Ronchi, S. (2017). Research perspectives on public procurement: Content analysis of 14 years of publications in the journal of public procurement. Journal of Public Procurement, 17(2), 229-269. doi:doi:10.1108/JOPP-17-02-2017-B003

Patrucco, A. S., Luzzini, D., Ronchi, S., Essig, M., Amann, M., \& Glas, A. H. (2017). Designing a public procurement strategy: lessons from local governments. Public Money \& Management, 37(4), 269-276. doi:10.1080/09540962.2017.1295727

Pemer, F., Sieweke, J., Werr, A., Birkner, S., \& Mohe, M. (2014). The cultural embeddedness of professional service purchasing-A comparative study of German and Swedish companies. Journal of Purchasing and Supply Management, 20(4), 273-285.

Perry-Smith, J. E., \& Mannucci, P. V. (2017). From creativity to innovation: The social network drivers of the four phases of the idea journey. Academy of Management Review, 42(1), 53-79.

Pettigrew, A. M. (2001). Management research after modernism. British journal of management, 12, S61-S70.

Phillips, W., Noke, H., Bessant, J., \& Lamming, R. (2006). Beyond the steady-state: managing discontinuous product and process innovation. International Journal of Innovation Management, 10(02), 175-196.

Picaud-Bello, K., Johnsen, T., Calvi, R., \& Giannakis, M. (2019). Exploring early purchasing involvement in discontinuous innovation: A dynamic capability perspective. Journal of Purchasing and Supply Management, 25(4), 100555.

Plato. (1903 [375 BC]). Platonis Opera. Oxford: Oxford University Press.

Plato. (1992 [375 BC]). The Republic (G. Grube \& C. Reeve Eds.). Indianapolis: Hackett Classics.

Poh, M.-Z., Swenson, N. C., \& Picard, R. W. (2010). A wearable sensor for unobtrusive, long-term assessment of electrodermal activity. IEEE transactions on Biomedical Engineering, 57(5), 1243-1252.

Pohl, M., \& Förstl, K. (2011). Achieving purchasing competence through purchasing performance measurement system design-A multiple-case study analysis. Journal of Purchasing and Supply Management, 17(4), 231-245.

Polanyi, M. (1966). The Tacit Dimension. Garden City, NY: Doubleday \& Company, Inc.

Porter, M. E. (1980). Competitive Strategy. New York: The Free Press.

Prahalad, C. K., \& Hamel, G. (1990). The core competence of the corporation. Harvard Business Review, 68(3), 79-91.

Prajogo, D., \& Sohal, A. (2013). Supply chain professionals: A study of competencies, use of technologies, and future challenges. International Journal of Operations \& Production Management, 33(11/12), 15321554.

Pulles, N. J., Ellegaard, C., Schiele, H., \& Kragh, H. (2019). Mobilising supplier resources by being an attractive customer: Relevance, status and future research directions. Journal of Purchasing and Supply Management, 25(3), 100539.

Pulles, N. J., Schiele, H., Veldman, J., \& Hüttinger, L. (2016). The impact of customer attractiveness and supplier satisfaction on becoming a preferred customer. Industrial Marketing Management, 54, 129140.

Pulles, N. J., Veldman, J., \& Schiele, H. (2016). Winning the competition for supplier resources: The role of preferential resource allocation from suppliers. International Journal of Operations \& Production Management, 36(11), 1458-1481.

Quesada, G., González, M. E., Mueller, J., \& Mueller, R. (2010). Impact of e-procurement on procurement practices and performance. Benchmarking: An International Journal, 17(4), 516-538.

Quintilian. (1922 [95 AD]). Institutio Oratoria, Book 11. Cambridge, Mass: Harvard University Press.

Rademaker, M., \& Schuberth, F. (2020). cSEM: Composite-Based Structural Equation Modeling. Software, CRAN. Retrieved from https://CRAN.R-project.org/package=cSEM.

Radovilsky, Z., \& Hegde, V. (2012). Trends in supply chain management job requirements: A longitudinal study. Journal of Supply Chain and Operations Management, 10(1), 168-181.

Radovilsky, Z., Hegde, V., \& Kandasamy, G. (2007). Development of supply chain management through job market requirements. California Journal of Operations Management, 5(1), 52-59.

Rafaeli, A., \& Oliver, A. L. (1998). Employment ads: A configurational research agenda. Journal of Management Inquiry, 7(4), 342. 
Ragin, C. C. (1987). The comparative method: moving beyond qualitative and quantitative strategies, Berkeley, Los Angeles, London: University of California Press.

Redtmann, C. (1910). Das moderne Einkaufsbureau im Fabrikbetriebe. Zeitschrift für Handelswissenschaft und Handelspraxis, 2(1910), 55-62.

Riege, A. (2009). Gültigkeit und Zuverlässigkeit von Fallstudien. In Qualitative Marktforschung (pp. 285-296): Springer.

Ringle, C. M., Wende, S., \& Becker, J.-M. (2015). SmartPLS 3. Boenningstedt: SmartPLS GmbH, http://www. smartpls.com.

Rinne, T., Steel, G. D., \& Fairweather, J. (2013). The role of Hofstede's individualism in national-level creativity. Creativity Research Journal, 25(1), 129-136.

Rolfstam, M. (2012). An institutional approach to research on public procurement of innovation. Innovation: The European Journal of Social Science Research, 25(3), 303-321.

Rolfstam, M. (2015). Public procurement of innovation for a better world: a consolidation or a new beginning? Innovation: The European Journal of Social Science Research, 28(3), 211-219.

Rossetti, C. L., \& Dooley, K. J. (2010). Job types in the supply chain management profession. Journal of Supply Chain Management, 46(3), 40-56.

Roth, M. S., Money, R. B., \& Madden, T. J. (2004). Purchasing processes and characteristics of industrial service buyers in the US and Japan. Journal of World Business, 39(2), 183-198.

Rottenburger, J. R., Carter, C. R., \& Kaufmann, L. (2018). It's alright, it's just a bluff: Why do corporate codes reduce lying, but not bluffing? Journal of Purchasing and Supply Management.

Rousseau, J.-J. (1762). Émile, ou De l'Éducation. Amsterdam: Jean Néaulme, Libraire.

Roy, S., Sivakumar, K., \& Wilkinson, I. F. (2004). Innovation generation in supply chain relationships: A conceptual model and research propositions. Journal of the Academy of Marketing Science, 32(1), 6179.

Rubenstein, R. E. (2004). Aristotle's Children: How Christians, Muslims, and Jews rediscovered ancient wisdom and illuminated the middle ages: Orlando, Austin, New York, San Diego, Toronto, London: Harcourt, Inc.

Rüßmann, M., Lorenz, M., Gerbert, P., Waldner, M., Justus, J., Engel, P., \& Harnisch, M. (2015). Industry 4.0: The future of productivity and growth in manufacturing industries.

Saad, G., Cleveland, M., \& Ho, L. (2015). Individualism-collectivism and the quantity versus quality dimensions of individual and group creative performance. Journal of Business Research, 68(3), 578-586.

Saint Thomas Aquinas. ([1274] 1989). Summa Theologiae: A concise translation (T. McDermott, Trans.). Notre Dame: Christian Classics.

Salzberger, T., \& Sinkovics, R. R. (2006). Reconsidering the problem of data equivalence in international marketing research: Contrasting approaches based on CFA and the Rasch model for measurement. International Marketing Review, 23(4), 390-417.

Salzberger, T., Sinkovics, R. R., \& Schlegelmilch, B. B. (1999). Data equivalence in cross-cultural research: A comparison of classical test theory and latent trait theory-based approaches. Australasian Marketing Journal (AMJ), 7(2), 23-38.

Sanderse, W. (2019). Does neo-Aristotelian character education maintain the educational status quo? Lessons from the 19th-Century Bildung tradition. Ethics and Education, 14(4), 399-414. doi:10.1080/17449642.2019.1660456

Sass, D. A., \& Schmitt, T. A. (2010). A comparative investigation of rotation criteria within exploratory factor analysis. Multivariate Behavioral Research, 45(1), 73-103.

Saunders, M., Mann, R., \& Smith, R. (2008). Implementing Strategic initiatives: A framework of leading practices. International Journal of Operations \& Production Management.

Sawilowsky, S. S. (2009). New Effect Size Rules of Thumb. Journal of Modern Applied Statistical Methods, 8(2), 26.

Schaffar, B., \& Uljens, M. (2015). Paradoxical Tensions Between Bildung and Ausbildung in Academia. In On the Facilitation of the Academy (pp. 1-15): Springer.

Schiele, H. (2007). Supply-management maturity, cost savings and purchasing absorptive capacity: Testing the procurement-performance link. Journal of Purchasing and Supply Management, 13(4), 274-293.

Schiele, H. (2010). Early supplier integration: the dual role of purchasing in new product development. $R \& D$ Management, 40(2), 138-153.

Schiele, H. (2012). Accessing supplier innovation by being their preferred customer. Research-Technology Management, 55(1), 44-50. 
Schiele, H. (2019). Purchasing and supply management. In Operations, Logistics and Supply Chain Management (pp. 45-73): Springer.

Schiele, H., Horn, P., \& Vos, B. (2011). Estimating cost-saving potential from international sourcing and other sourcing levers: Relative importance and trade-offs. International Journal of Physical Distribution \& Logistics Management, 41(3), 315-336.

Schiele, H., Veldman, J., \& Hüttinger, L. (2011). Supplier innovativeness and supplier pricing: The role of preferred customer status. International Journal of Innovation Management, 15(01), 1-27.

Schneider, L., \& Wallenburg, C. M. (2012). Implementing sustainable sourcing-Does purchasing need to change? Journal of Purchasing and Supply Management, 18(4), 243-257.

Schoenherr, T. (2010). Outsourcing decisions in global supply chains: an exploratory multi-country survey. International Journal of Production Research, 48(2), 343-378.

Schoenherr, T., Griffith, D. A., \& Chandra, A. (2014). Knowledge management in supply chains: The role of explicit and tacit knowledge. Journal of Business Logistics, 35(2), 121-135.

Scholten, K., \& Dubois, A. (2017). Advancing the skill set of SCM graduates-An active learning approach. International Journal of Operations \& Production Management, 37(11), 1683-1699.

Schulze, H., \& Bals, L. (2020). Implementing sustainable purchasing and supply management (SPSM): A Delphi study on competences needed by purchasing and supply management (PSM) professionals. Journal of Purchasing and Supply Management, 100625.

Schulze, H., Bals, L., \& Johnsen, T. E. (2019). Individual competences for sustainable purchasing and supply management (SPSM) A literature and practice perspective. International Journal of Physical Distribution \& Logistics Management, in press.

Schuman, R. (1950). La Déclaration Schuman. Paris: Ministère fédéral des Affaires étrangères.

Schumpeter, J. (1942). Creative destruction. In Capitalism, socialism and democracy (pp. 145-150). New York: Harper \& Bros.

Schwab, K. (2016a). The 4th Industrial Revolution New York: Crown Business.

Schwab, K. (2016b). The Fourth Industrial Revolution: what it means, how to respond. 2016. Paper presented at the World Economic Forum, Davos.

Schwandt, T. A. (1994). Constructivist, interpretivist approaches to human inquiry. Handbook of qualitative research, 1, 118-137.

Schwartz, S. H. (1992). Universals in the content and structure of values: Theoretical advances and empirical tests in 20 countries. Advances in Experimental Social Psychology, 25(1992), 1-65.

Schwartz, S. H. (1994). Are there universal aspects in the structure and contents of human values? Journal of Social Issues, 50(4), 19-45.

Schwartz, S. H. (1999). A theory of cultural values and some implications for work. Applied Psychology, 48(1), 23-47.

Schwartz, S. H. (2008). A theory of cultural value orientations: Explication and applications. In New Frontiers in Comparative Sociology (pp. 171-220): Brill.

Schwartz, S. H. (2014). National culture as value orientations: Consequences of value differences and cultural distance. In Handbook of the Economics of Art and Culture (Vol. 2, pp. 547-586): Elsevier.

Seneca, L. A. (1925 [65 AD]). Moral letters to Lucilius (R. Gummere, Trans. Vol. III). Cambridge: Harvard University Press.

Serrat, O. (2017). Critical thinking. In Knowledge Solutions (pp. 1095-1100). Singapore: Springer.

Servajean-Hilst, R., \& Calvi, R. (2018). Shades of the innovation-purchasing function-the missing link of open innovation. International Journal of Innovation Management, 22(1).

Shanock, L. R., Baran, B. E., Gentry, W. A., Pattison, S. C., \& Heggestad, E. D. (2010). Polynomial regression with response surface analysis: A powerful approach for examining moderation and overcoming limitations of difference scores. Journal of Business and Psychology, 25(4), 543-554.

Shanock, L. R., Baran, B. E., Gentry, W. A., Pattison, S. C., \& Heggestad, E. D. (2014). Erratum to: Polynomial regression with response surface analysis: A powerful approach for examining moderation and overcoming limitations of difference scores. Journal of Business and Psychology, 29(1), 161-161.

Shaw, J. (1995). A schema approach to the formal literature review in engineering theses. System, 23(3), 325335.

Shaw, J. D., \& Gupta, N. (2004). Job complexity, performance, and well-being: when does supplies-values fit matter? Personnel Psychology, 57(4), 847-879.

Shi, X., \& Wang, J. (2011). Interpreting Hofstede model and GLOBE model: which way to go for cross-cultural research? International journal of business and management, 6(5), 93. 
Shin, H., Collier, D. A., \& Wilson, D. D. (2000). Supply management orientation and supplier/buyer performance. Journal of Operations Management, 18(3), 317-333.

Shou, Y., \& Wang, W. (2015). Multidimensional competences of supply chain managers: an empirical study. Enterprise Information Systems, 11(1), 58-74.

Sinha, A., Millhiser, W. P., \& He, Y. (2016). Matching supply with demand in supply chain management education. The International Journal of Logistics Management, 27(3), 837-861.

Sinkovics, R. R., Penz, E., \& Ghauri, P. N. (2005). Analysing textual data in international marketing research. Qualitative Market Research: An International Journal, 8(1), 9-38.

Sivasubramaniam, N., Liebowitz, S. J., \& Lackman, C. L. (2012). Determinants of new product development team performance: A meta-analytic review. Journal of Product Innovation Management, 29(5), 803-820.

Slowinski, G., Hummel, E., Gupta, A., \& Gilmont, E. R. (2009). Effective practices for sourcing innovation. Research-Technology Management, 52(1), 27-34.

Smit, L., Bright, C., McCorquodale, R., Bauer, M., Deringer, H., Baeza-Breinbauer, D., . . Salinier, C. (2020). Study on due diligence requirements through the supply chain: FINAL REPORT. Luxembourg: European Commission

Smith, A. (1776). An inquiry into the Nature and Causes of the Wealth of Nations: Strahan and Cadell, London.

Smith, A. (1843). Recherches sur la Nature et les Causes de la Richesse des Nations (G. Garnier, Trans. A. Blanqui Ed. Vol. 1). Paris: Guillaumin et Cie, Libraires.

Smith, E. (2001). The role of tacit and explicit knowledge in the workplace. Journal of Knowledge Management, 5(4), 311-321.

Smith, G. (2002). Are there domain-specific thinking skills? Journal of Philosophy of Education, 36(2), $207-227$.

Smith, P. B. (2006). When elephants fight, the grass gets trampled: The GLOBE and Hofstede projects. Journal of international business studies, 37(6), 915-921.

Socha, D., Razmov, V., \& Davis, E. (2003). Teaching Reflective Skills in an Engineering Course. AGE, 8, 2.

Sodhi, M. S., Son, B.-G., \& Tang, C. S. (2008). ASP, the Art and Science of Practice: What employers demand from applicants for MBA-level supply chain jobs and the coverage of supply chain topics in MBA courses. Interfaces, 38(6), 469-484.

Sohal, A. S. (2013). Developing competencies of supply chain professionals in Australia: collaboration between businesses, universities and industry associations. Supply Chain Management: An International Journal, 18(4), 429-439.

Sorescu, A. (2017). Data-driven business model innovation. Journal of Product Innovation Management, 34(5), 691-696.

Sorjonen, K., \& Melin, B. (2019). Predicting the Significance of Necessity. Frontiers in Psychology, 10(283). doi:10.3389/fpsyg.2019.00283

Sorkin, D. (1983). Wilhelm Von Humboldt: The Theory and Practice of Self-Formation (Bildung), 1791-1810. Journal of the History of Ideas, 44(1), 55-73.

Spiller, S. A., Fitzsimons, G. J., Lynch Jr, J. G., \& McClelland, G. H. (2013). Spotlights, floodlights, and the magic number zero: Simple effects tests in moderated regression. Journal of marketing research, 50(2), 277288.

Spina, G., Caniato, F., Luzzini, D., \& Ronchi, S. (2013). Past, present and future trends of purchasing and supply management: An extensive literature review. Industrial marketing management, 42(8), 1202-1212.

Sporrong, J., \& Bröchner, J. (2009). Public procurement incentives for sustainable design services: Swedish experiences. Architectural Engineering and Design Management, 5(1-2), 24-35.

Steinle, C., \& Schiele, H. (2008). Limits to global sourcing?: Strategic consequences of dependency on international suppliers: Cluster theory, resource-based view and case studies. Journal of Purchasing and Supply Management, 14(1), 3-14.

Stek, K. (2016). Purchasing skills: Comparing Dutch and Austrian industrial job advertisements with the help of $K O D E^{\circledR} X$. University of Twente.

Stek, K. (2017a). 4 Scenario's voor inkoop in 2035 - Hoogleraar supply chain kijkt naar de toekomst. NEVI Deal!, December 2017, 45-47.

Stek, K. (2017b). European Survey on Purchasing Competences-3rd White Paper: purchasing skills leading to success-outcomes, results and outlooks. In European Survey on Purchasing Competences-3rd White Paper. Project PERFECT

Stek, K. (2017c). Future of Purchasing and Supply Management Skills: An Outlook Based on Project PERFECT. Paper presented at the LIMEN 2017, Belgrade, Serbia. 
Stek, K. (2017d). Procurement in the future - where will procurement be in 2035? In-procurement, December 2017, 25-27.

Stek, K. (2018a). Inkoopvaardigheden die wél tot succes leiden. NEVI Deal!, February 2018, 42-43.

Stek, K. (2018b). A look into the Future of Procurement - Where will we be in 2035? WINGBusiness, April 2018(1).

Stek, K. (2021). A soft skills experiment in an academic course - Developing interpersonal skills and intrapersonal traits Purchasing \& Supply Management course. Paper presented at IPSERA 2021, online conference.

Stek, K., Bijl, T., \& Sigurđardóttir, A. G. (2021). Self-perceived Gender Differences in Purchasing Paper presented at IPSERA 2021, online conference.

Stek, K., Hoorn, S. v., \& Schiele, H. (2019). Public procurement skills - Requirements of innovation, strategic partnership and future proof competencies. Paper presented at IPSERA 2019, Milan, Italy.

Stek, K., Koch, V., Zunk, B. M., \& Schiele, H. (2017). Challenges for Educators in PSM-Curricula - Quest for closing the gap with employers' requirements. Paper presented at IPSERA 2017, Balatonfüred, Hungary.

Stek, K., \& Wieland, A. (2019). The Art and Science of Procurement Education - Using Ancient Greek Philosophy to Drive Future Procurement Skills. Paper presented at IPSERA 2019, Milan, Italy.

Stek, K., Wisniewski, R., van Dun, D., \& Schiele, H. (2020). The human aspect in Purchasing \& Supply Management - Traits as a proxy for personal skills development. Paper presented at IPSERA 2021, online conference.

Stek, K., Zhang, H., Koch, V., Zunk, B. M., \& Schiele, H. (2018). Comparing Purchasing and Supply Management Job Advisements in Europe and Confucian Chinese Society. Paper presented at IPSERA 2018, Athens, Greece.

Stek, K., Zunk, B. M., Berg, J. v. d., Delke, V., Berger, L., \& Schiele, H. (2018). Addressing the Gap between Employers' Needs and Learning Objectives in Purchasing \& Supply Management Study Programs: Towards a Student-Centred Learning Approach. Paper presented at the INTED 2018, Valencia.

Stek, K., Zunk, B. M., Koch, V., \& Schiele, H. (2021). Culture's Consequences for Purchasing: Comparing Purchasing Job Ad Requirements from Different European Countries with Cultural Models. International Journal of Procurement Management.

Stek, K., Zunk, B. M., \& Schiele, H. (2018). Purchasing skills leading to success - A contingency approach for industry, service and public procurement. Paper presented at IPSERA 2018, Athens, Greece.

Stek, K., Zunk, B. M., Vos, F., \& Schiele, H. (2018). Individual Innovation Sourcing Success - Combining Crucial Skills with Top Management Support. Paper presented at IPSERA 2018, Athens, Greece.

Stentoft Arlbjørn, J., \& Vagn Freytag, P. (2012). Public procurement vs private purchasing: Is there any foundation for comparing and learning across the sectors? International Journal of Public Sector Management, 25(3), 203-220.

Stephan, U., Andries, P., \& Daou, A. (2019). Goal Multiplicity and Innovation: How Social and Economic Goals Affect Open Innovation and Innovation Performance. Journal of Product Innovation Management, 36(6), 721-743.

Steward, M. D., Wu, Z., \& Hartley, J. L. (2010). Exploring Supply Managers' Intrapreneurial Ability and Relationship Quality. Journal of Business-to-Business Marketing, 17(2), 127-148.

Stinenbosch, M. (2017). Analysis of represented purchasing skills in academic literature and in current Dutch education provision. University of Twente.

Stinenbosch, M., \& Stek, K. (2017a). The gap between academic purchasing education and the market needs. In-procurement, July / August, 24-25.

Stinenbosch, M., \& Stek, K. (2017b). Kloof tussen Inkooponderwijs en Marktbehoefte. Deal!, 2017-4(4 (June)), 46-50.

Strauss, A., \& Corbin, J. (1994). Grounded theory methodology. Handbook of Qualitative Research, 17, 273285.

Sun, H., Wong, S. Y., Zhao, Y., \& Yam, R. (2012). A systematic model for assessing innovation competence of Hong Kong/China manufacturing companies: A case study. Journal of Engineering and Technology Management, 29(4), 546-565.

Suurmond, R., Wynstra, F., \& Dul, J. (2020). Unraveling the Dimensions of Supplier Involvement and their Effects on NPD Performance: A Meta-Analysis. Journal of Supply Chain Management, jscm.12221

Swobodnik, S., Stek, K., \& Zunk, B. M. (2018). Key Competences and Core Skills of Young Professionals in Purchasing in the Era of Industry 4.0: Research Concept and Framework for Higher Education Institutions 
to face Future Challenges. Paper presented at the Euro-Asia Forum in Politics, Economics and Business 2018, Zagreb, Croatia.

Tamer Cavusgil, S., Calantone, R. J., \& Zhao, Y. (2003). Tacit knowledge transfer and firm innovation capability. Journal of Business \& Industrial Marketing, 18(1), 6-21.

Tassabehji, R. (2010). Understanding e-auction use by procurement professionals: motivation, attitudes and perceptions. Supply Chain Management: An International Journal, 15(6), 425-437.

Tassabehji, R., \& Moorhouse, A. (2008). The changing role of procurement: Developing professional effectiveness. Journal of Purchasing and Supply Management, 14(1), 55-68.

Tate, W. L., \& Ellram, L. M. (2012). Service supply management structure in offshore outsourcing. Journal of Supply Chain Management, 48(4), 8-29.

Tate, W. L., Ellram, L. M., \& Kirchoff, J. F. (2010). Corporate social responsibility reports: a thematic analysis related to supply chain management. Journal of Supply Chain Management, 46(1), 19-44.

Tatham, P., Wu, Y., Kovács, G., \& Butcher, T. (2017). Supply chain management skills to sense and seize opportunities. The International Journal of Logistics Management, 28(2), 266-289.

Tchokogué, A., Nollet, J., \& Robineau, J. (2017). Supply's strategic contribution: An empirical reality. Journal of Purchasing and Supply Management, 23(2), 105-122.

Tchokogué, A., Paché, G., Nollet, J., \& Stoleru, R.-M. (2017). Intra-organizational legitimization strategies used by purchasing managers. Journal of Purchasing and Supply Management, 23(3), 163-175.

Telgen, J., Harland, C., \& Knight, L. (2007). Public procurement in perspective. In L. Knight, C. Harland, J. Telgen, K. V. Thai, G. Callender, \& K. McKen (Eds.), Public procurement: international cases and commentary (pp. 16-24). New York: Routledge.

Terlutter, R., Diehl, S., \& Mueller, B. (2006). The GLOBE study-applicability of a new typology of cultural dimensions for cross-cultural marketing and advertising research. In International Advertising and Communication (pp. 419-438): Springer.

Terpend, R., Krause, D. R., \& Dooley, K. J. (2011). Managing buyer-supplier relationships: empirical patterns of strategy formulation in industrial purchasing. Journal of Supply Chain Management, 47(1), 73-94.

Thai, K. V. (2001). Public procurement re-examined. Journal of Public Procurement, 1(1), 9-50.

Thai, K. V. (2008). International Public Procurement: Concepts and Practices. In International Handbook of Public Procurement (pp. 2-22): Routledge.

Thiem, A. (2018). The Logic and Methodology of "Necessary but Not Sufficient Causality" A Comment on Necessary Condition Analysis (NCA). Sociological Methods \& Research(in press).

Thomas, A. G. (1919). Principles of Governmental Purchasing. New York: D. Appleton and Co.

Tkáč, M., Kelly, S., \& Stek, K. (2020). Smart Supply Chain: Are the Procurers Ready for Industry 4.0. Paper presented at the 28th Interdisciplinary Information Management Talks - Digitalized Economy, Society and Information Management, Kutná Hora, Czech Republic.

Tomino, T., Park, Y., \& Hong, P. (2012). Strategic procurement through build to order system: an analysis of Japanese auto-manufacturers. International Journal of Procurement Management 4, 5(4), 413-429.

Torn, R.-J., \& Schiele, H. (2020). Cyber-physical systems with autonomous machine-to-machine communication: Industry 4.0 and its particular potential for purchasing and supply management. International Journal of Procurement Management, 1(1), doi:10.1504/IJPM.2020.10024638

Tracey, M., \& Neuhaus, R. (2013). Purchasing's role in global new product-process development projects. Journal of Purchasing and Supply Management, 19(2), 98-105.

Trent, R. J., \& Monczka, R. M. (2003a). International Purchasing and Global Sourcing-What are the Differences? Journal of Supply Chain Management, 39(3), 26-36.

Trent, R. J., \& Monczka, R. M. (2003b). Understanding integrated global sourcing. International Journal of Physical Distribution \& Logistics Management, 33(7), 607-629.

Tribe, K. (1981). 'Industrialisation' as a Historical Category. In Genealogies of Capitalism (pp. 101-120). London: Palgrave Macmillan UK.

Trompenaars, F. (1996). Resolving international conflict: Culture and business strategy. Business Strategy Review, 7(3), 51-68.

Tsao, L., Behr-Heyder, P. A., \& Ma, L. (2015) Preliminary study: Influence of cultural differences on the innovation process between Chinese and Germans. In: Vol. 9180. Lecture Notes in Computer Science (including subseries Lecture Notes in Artificial Intelligence and Lecture Notes in Bioinformatics) (pp. 381391).

Tung, R. L., \& Verbeke, A. (2010). Beyond Hofstede and GLOBE: Improving the quality of cross-cultural research. Journal of International Business Studies, 41(8), 1259-1274. 
UNIDO. (2017). Independent Thematic evaluation UNIDO's Staff Competency Development. Retrieved from www.unido.org

United Nations Capacity Development Centre. (2010). Public Procurement Capacity Development Guide. New York. Retrieved from: www.undp.org/content/undp/en/home/librarypage/capacity-building/undpprocurement-capacity-assessment-users-guide.html

Uyarra, E., Edler, J., Garcia-Estevez, J., Georghiou, L., \& Yeow, J. (2014). Barriers to innovation through public procurement: A supplier perspective. Technovation, 34(10), 631-645.

Van der Valk, W., Sumo, R., Dul, J., \& Schroeder, R. G. (2016). When are contracts and trust necessary for innovation in buyer-supplier relationships? A necessary condition analysis. Journal of Purchasing and Supply Management, 22(4), 266-277.

Van Weele, A. J. (2009). Purchasing and Supply Chain Management: Analysis, Strategy, Planning and Practice. Andover, UK: Cengage Learning EMEA.

Van Weele, A. J., \& Van Raaij, E. M. (2014). The Future of Purchasing and Supply Management Research: About Relevance and Rigor. Journal of Supply Chain Management, 50(1), 56-72.

Velasquez, M. G. (1988). Business Ethics: Concepts and Cases. Englewood Cliffs, NJ: Prentice-Hall.

Venkatesh, V., \& Goyal, S. (2010). Expectation disconfirmation and technology adoption: polynomial modeling and response surface analysis. Mis Quarterly, 281-303.

VerSteeg, R. (1998). Early Mesopotamian Commercial Law. University of Toledo Law Review, 30, 183. Retrieved from https://heinonline.org/HOL/

Vincent, K. S. (2000). Benjamin Constant, the french revolution, and the origins of French romantic liberalism. French Historical Studies, 23(4), 607-637.

Vis, B., \& Dul, J. (2018). Analyzing Relationships of Necessity Not Just in Kind But Also in Degree: Complementing fsQCA With NCA. Sociological Methods \& Research, 47(4), 872-899.

Von der Gracht, H., \& Darkow, I.-L. (2013). The future role of logistics for global wealth-scenarios and discontinuities until 2025. Foresight, 15(5), 405-419.

Von der Gracht, H., Giunipero, L. C., \& Schueller, M. (2016). Future-proof procurement; Now or never: the big procurement transformation. Retrieved from https://advisory.kpmg.us/articles/2017/future-proofprocurement.html

Von der Gracht, H., Huber-Straßer, A., Schueller, M., Müller, N., Lichtenau, P. E., \& Zühlke, H. (2018). Rethinking the value chain. A study on Al, humanoids and robots - Artificial Intelligence: Possible business application and development scenarios to 2040 . Retrieved from https://assets.kpmg/content/dam/kpmg/xx/pdf/2018/09/rethinking-the-value-chain.pdf

Von Humboldt, W. (1851). Ideen zu einem Versuch, die Gränzen der Wirksamkeit des Staats zu bestimmen. Breslau: Verlag von Eduard Trewendt.

Von Humboldt, W. (1854). Sphere and Duties of Government (The Limits of State Action) (J. Coulthard, Trans.). London: John Chapman.

Von Humboldt, W. (1999). On Language: On the Diversity of Human Language Construction and its Influence on the Mental Development of the Human Species: Cambridge University Press.

Von Tunzelmann, N. (2003). Historical coevolution of governance and technology in the industrial revolutions. Structural Change and Economic Dynamics, 14(4), 365-384.

Vos, F. G., Schiele, H., \& Hüttinger, L. (2016). Supplier satisfaction: Explanation and out-of-sample prediction. Journal of business research, 69(10), 4613-4623.

Wageningen, J., \& Muller, F. (1929). Latijnsch woordenboek (4 ed.). Groningen: Wolters.

Wagner, S. M., \& Kemmerling, R. (2014). Supply chain management executives in corporate upper echelons. Journal of Purchasing and Supply Management, 20(3), 156-166.

Walker, G., \& Weber, D. (1984). A transaction cost approach to make-or-buy decisions. Administrative science quarterly, 373-391.

Walker, M. P. (2009). The role of slow-wave sleep in memory processing. Journal of Clinical Sleep Medicine, 5(2 Suppl), S20-S26. Retrieved from https://pubmed.ncbi.nlm.nih.gov/19998871

Waller, M. A., \& Fawcett, S. E. (2013). Data science, predictive analytics, and big data: a revolution that will transform supply chain design and management. Journal of Business Logistics, 34(2), 77-84.

Walter, G. (1961). Robespierre, L'œuvre, part III. (Vol. 2). Paris: Gallimard.

Wang, X., Su, Y., Cheung, S., Wong, E., \& Kwong, T. (2013). An exploration of Biggs' constructive alignment in course design and its impact on students' learning approaches. Assessment \& Evaluation in Higher Education, 38(4), 477-491.

WEF. (2015). Unlocking the potential of technology. Geneva: World Economic Forum. 
WEF. (2016). Fostering social and emotional learning through technology. Retrieved from Geneva, $\mathrm{CH}$ : www.weforum.org

Welch, C., Marschan-Piekkari, R., Penttinen, H., \& Tahvanainen, M. (2002). Corporate elites as informants in qualitative international business research. International Business Review, 11(5), 611-628.

Wieland, A. (2021). Dancing the Supply Chain: Toward Transformative Supply Chain Management. Journal of Supply Chain Management, 57(1), 58-73.

Wieland, A., Handfield, R. B., \& Durach, C. F. (2016). Mapping the Landscape of Future Research Themes in Supply Chain Management. Journal of Business Logistics, 37(3), 205-212.

Wieland, A., \& Wallenburg, C. M. (2012). Dealing with supply chain risks: Linking risk management practices and strategies to performance. International Journal of Physical Distribution \& Logistics Management, 42(10), 887-905.

Wijen, F., Zoeteman, K., Pieters, J., \& van Seters, P. (2012). A handbook of globalisation and environmental policy: National government interventions in a global arena: Edward Elgar Publishing.

Wilding, R., Wagner, B., Miemczyk, J., Johnsen, T. E., \& Macquet, M. (2012). Sustainable purchasing and supply management: a structured literature review of definitions and measures at the dyad, chain and network levels. Supply Chain Management: An International Journal, 17(5), 478-496.

Williamson, O. E. (1981). The economics of organization: The transaction cost approach. American journal of sociology, 87(3), 548-577.

Willingham, D. T. (2008). Critical thinking: Why is it so hard to teach? Arts Education Policy Review, 109(4), 21-32.

Wong, C. Y., Grant, D. B., Allan, B., \& Jasiuvian, I. (2014). Logistics and supply chain education and jobs: a study of UK markets. The International Journal of Logistics Management, 25(3), 537-552.

Wootton, D. (2018). Power, Pleasure, and Profit: Insatiable Appetites from Machiavelli to Madison. Cambridge and London: Harvard University Press.

Yeow, J., \& Edler, J. (2012). Innovation procurement as projects. Journal of Public Procurement, 12(4), 472504.

Yeow, J., \& Edler, J. (2016). Connecting demand and supply: The role of intermediation in public procurement of innovation. Research Policy, 45(2), 414-426.

Yeung, A. K. (1996). Competencies for HR professionals: An interview with Richard E. Boyatzis. Human Resource Management (1986-1998), 35(1), 119.

Yin, R. K. (2018). Case study research and applications: Design and methods (6 ed.). Los Angeles, CA: Sage Publications, Inc.

Yu, W., Chavez, R., \& Feng, M. (2017). Green supply management and performance: a resource-based view. Production Planning \& Control, 28(6-8), 659-670.

Yuvaraj, R. (2011). Competency Mapping. International Journal of Scientific \& Engineering Research, 2(8), 17.

Zauli, B. E. (2019). For a new Bildung: Nietzsche's critique between education and "spirituality". Journal of the CIPH(1), 154-163.

Zawawi, N. A. W. A., Umar, A. A., Aziz, A. R. A., Crouzier, O., Khamidi, M. F., \& Idrus, A. (2014). PFI procurement skills: a cross-sector survey of practitioners. Procedia Engineering, 77, 170-178.

Zha, P., Walczyk, J. J., Griffith-Ross, D. A., Tobacyk, J. J., \& Walczyk, D. F. (2006). The impact of culture and individualism-collectivism on the creative potential and achievement of American and Chinese adults. Creativity Research Journal, 18(3), 355-366.

Zimmer, K. (2002). Supply chain coordination with uncertain just-in-time delivery. International Journal of Production Economics, 77(1), 1-15.

Zsidisin, G. A., Hartley, J. L., Bernardes, E. S., \& Saunders, L. W. (2015). Examining supply market scanning and internal communication climate as facilitators of supply chain integration. Supply Chain Management: An International Journal, 20(5), 549-560.

Zunk, B. M., Koch, V., Stek, K., \& Schiele, H. (2018). Purchasing Professionals' Performance: Literature-driven Research Model and Empirical Test. Paper presented at IPSERA 2018, Athens, Greece.

Zunk, B. M., \& Sadei, C. (2015). Sharpening the Industrial Engineering and Management qualification profile: Research findings from Austria. International Journal of Industrial Engineering and Management, 6(3), 109-120.

Zunk, B. M., \& Stek, K. (2018). Detection of Differences of the Purchasing Culture in the Confucian Chinese Society. Paper presented at the Euro-Asia Forum in Politics, Economics and Business 2018, Zagreb, Croatia. 


\section{Appendices}




\section{APPENDICES}

Appendix 9.1 - PSM competences literature 1987-2020 (all chapters) .......................309 Appendix 9.2 - PSM requirements mentioned in the scientific PSM job requirements

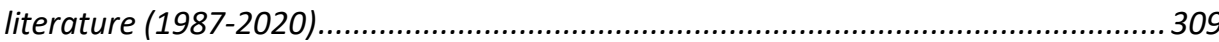

Appendix 9.3 - IFPSM Golden Standard.......................................................................... 310 Appendix 9.4 - Introduction of a new taxonomy of procurement skills, adapted from Tassabehji and Moorhouse (2008)

Appendix 9.5 - Previous literature with competence clusters, adapted from Tassabehji and Moorhouse (2008, p. 58).

Appendix 9.6 - Subjects cited from Tassabehji and Moorhouse (2008) by other scholars

Appendix 9.7 - Relation of PSM skills articles not citing Tassabehji and Moorhouse (2008)

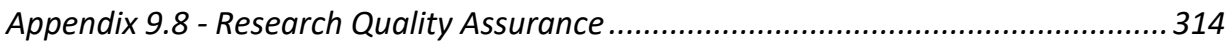

Appendix 9.9 - Interview Guide Main Parts and Introductory Texts ......................... 315 Appendix 9.10 - Additional competences to the competence clusters of Tassabehji and Moorhouse (2008)

Appendix 9.11 - PSM job requirements in the total set of the 300 Austrian, Belgian and Dutch PSM job advertisements

Appendix 9.12 - Significant distinct competences of innovation-focused purchasing professionals

Appendix 9.13 - Significant distinct absent competences of innovation-focused purchasing professionals (t-test).....

Appendix 9.14 - Factors in the questionnaire of competence items ..... 320

Appendix 9.15 - Result of exploratory factor analysis on the 17 competences

significantly associated with PSM professionals with an innovation focus. 324

Appendix 9.16 - Constructs of the three axes in the polynomial regression ................ 325

Appendix 9.17 - Level of agreement in z-value levels of the independent variables... 325

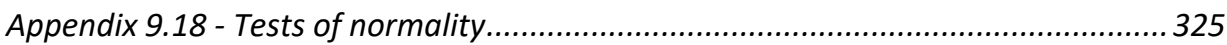

Appendix 9.19 - Necessary condition analyses outcomes per factor .............................326

Appendix 9.20 - Necessary condition analyses outcomes: effect sizes per factor on each

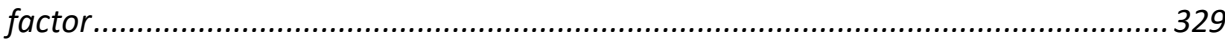

Appendix 9.21 - Invitation to the purchasing skills survey of Project PERFECT ............ 330

Appendix 9.22 - Results of the Paired-Samples or Dependent T-Test $\mathrm{O}_{1}$ and $\mathrm{O}_{2} \ldots \ldots . . .331$

Appendix 9.23 - Rankings of the items in the two student surveys.............................333

Appendix 9.24 - Summary of the competences found in chapters $2-6$.....................334

Appendix 9.25 - Schematic overview of the competences found in chapters $2-6 \ldots . .336$

Appendix 9.26 - Effectiveness statements on seven PSM objectives.......................... 338 
methodology

Anderson and Katz (1998)

Baily et al. (2008)

Bals et al. (2019)

Burt et al. (2003)

Carr and Smeltzer (2000)

J. R. Carter and Narasimhan (1996)

Cavinato (1987)

Cousins and Spekman (2003)

Cruz and Murphy (1996)

Dowd and Liedtka (1994)

Eltantawy et al. (2009)

Faes et al. (2001)

Flöthmann, Hoberg, and Wieland (2018)

Giunipero and Pearcy (2000)

Giunipero et al. (2005)

Giunipero and Handfield (2004)

Giunipero et al. (2006)

Kern et al. (2011)

Keough (1993)

Killen and Kamauff (1995)

Kolchin and Giunipero (1993)

McKeefry (1998)

Knight et al. (2014)

Mulder et al. (2005)

Muller (2001)

Murphy (1995)

Pagell et al. (1996)

Schulze et al. (2019)

Trent and Monczka (2003b)

Tassabehji and Moorhouse (2008)

Tatham et al. (2017)

Zawawi et al. (2014)
Conceptual paper

Qualitative, interview-based $(n=46)$

Qualitative, interview-based $(n=46)$

PSM textbook

Quantitative, survey-based $(n=85)$

Quantitative, survey-based $(n=302)$

Qualitative, interview-based $(n=50)$

Mixed, interview-based $(n=23)$ and survey-based $(n=310)$

Practitioners article

Quantitative, survey-based

Quantitative, survey-based $(n=152)$

Quantitative, survey-based $(n=183)$

Quantitative, survey-based $(n=243)$

Mixed, interview-based $(n=23)$ and survey-based $(n=310)$

Mixed, interview-based $(n=41)$ and survey-based $(n=73)$

Mixed, interview-based $(n=41)$ and survey-based $(n=73)$

Qualitative, focus group meeting $(n=53)$

Quantitative, survey-based $(n=148)$

Conceptual paper

PSM textbook

Quantitative, survey-based $(n=131)$

Practitioners article

Quantitative, survey-based $(n=72)$

Quantitative, survey-based $(n=261)$

Quantitative, survey-based $(n=2,416)$

Practitioners article

Qualitative, interview-based $(n=14)$

Qualitative, interview-based $(n=46)$

Quantitative, survey-based $(n=216)$

Qualitative, interview-based $(n=18)$

Quantitative, survey-based $(n=216)$

Quantitative, survey-based $(n=43)$

Appendix 9.2 - PSM requirements mentioned in the scientific PSM job requirements literature (1987-2020)

\begin{tabular}{|c|c|c|c|c|c|}
\hline PSM knowledge & $80 \%$ & Curiosity / the will to learn & $37 \%$ & Entrepreneurial attitude & $10 \%$ \\
\hline Business knowledge & $73 \%$ & Industry knowledge & $33 \%$ & Result-driven & $10 \%$ \\
\hline Negotiation skills & $73 \%$ & Creativity & $37 \%$ & Consultancy Advisory skills & $10 \%$ \\
\hline Leadership skills & $70 \%$ & Legal knowledge & $30 \%$ & Power handling & $10 \%$ \\
\hline Relationship & $63 \%$ & Quality management & $30 \%$ & Discipline & $10 \%$ \\
\hline Analytical thinking & $63 \%$ & Process management & $30 \%$ & Conscientiousness & $10 \%$ \\
\hline Holistic thinking & $63 \%$ & Blueprint reading & $33 \%$ & Will to compromise & $7 \%$ \\
\hline Computer literacy & $63 \%$ & Logistic knowledge & $27 \%$ & Self-confidence & $7 \%$ \\
\hline Team ability & $63 \%$ & Project management & $33 \%$ & Perseverance & $7 \%$ \\
\hline Communication skills & $57 \%$ & Written proficiency & $27 \%$ & CAD & $3 \%$ \\
\hline Problem solving skills & $57 \%$ & Tactfulness & $27 \%$ & Own initiative & $3 \%$ \\
\hline Strategic thinking & $50 \%$ & Motivate skills & $27 \%$ & Empathy & $3 \%$ \\
\hline Decisiveness / decision & $50 \%$ & Time management & $23 \%$ & ERP & $3 \%$ \\
\hline Organisational skills & $43 \%$ & Information management & $20 \%$ & Patience & $3 \%$ \\
\hline Risk management & $40 \%$ & Presentation skills & $20 \%$ & Common sense & $3 \%$ \\
\hline Persuasive skills & $43 \%$ & Assertiveness & $20 \%$ & Conference skills & $3 \%$ \\
\hline Conflict resolution & $43 \%$ & Flexibility & $20 \%$ & Loyalty & $3 \%$ \\
\hline Customer orientation & $37 \%$ & Mathematics/numeral & $13 \%$ & Pro-activity & $3 \%$ \\
\hline
\end{tabular}

Note: PSM requirements mentioned at least once per article in the scientific PSM job requirements literature

(1987-2020) (see: Appendix 9.1) 


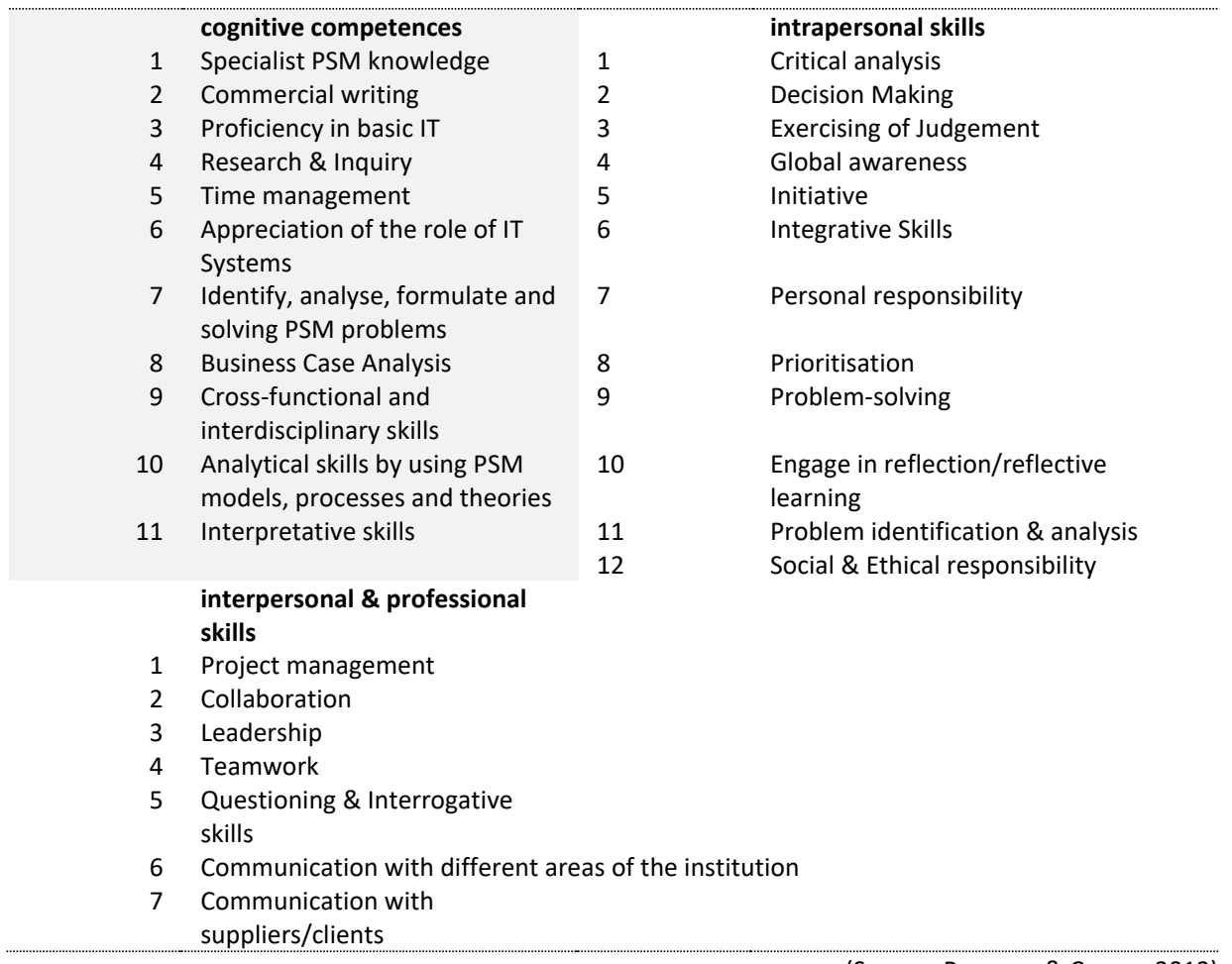

(Source: Brennan \& Crowe, 2012)

\section{Appendix 9.4 - Introduction of a new taxonomy of procurement skills, adapted from Tassabehji and Moorhouse (2008)}

\section{Technical skills (TS):}

Fundamental and basic administrative skills necessary for any procurement professional in the $21^{\text {st }}$ century. They include product knowledge, computer literacy, total quality management and government legislation. The sub-category 'Advanced procurement process skills (APP)' includes category management, project planning and e-procurement.

2 Interpersonal skills (IS):

Necessary for interaction with people in teams and on an individual level, including written and oral communication, conflict resolution, influencing and persuasion, group dynamics, leadership, problem-solving and interpersonal and cultural awareness.

3 Internal enterprise skills (IE):

These skills relate to the overall business and the interaction of the different functions.

$4 \quad$ External enterprise skills (EE):

These skills relate to the supply chain/network and its stakeholders.

$5 \quad$ Strategic business skills (SB):

These skills relate to broader strategic issues and how procurement can affect overall organisational value, such as planning and managing strategic partnerships and alliances, risk management and adding value to the organisation. 


\begin{tabular}{|c|c|}
\hline Source & $\begin{array}{l}\text { Categorisation of } \\
\text { Procurement Skills }\end{array}$ \\
\hline $\begin{array}{l}\text { Kolchin and } \\
\text { Giunipero } \\
\text { (1993), based } \\
\text { on the } \\
\text { division of } 18 \\
\text { skills }\end{array}$ & $\begin{array}{l}\text { 2. Management } \\
\text { 2. Interpersonal / } \\
\text { group } \\
\text { 2. Individual }\end{array}$ \\
\hline $\begin{array}{l}\text { Giunipero and } \\
\text { Pearcy (2000) } \\
\text { based on a } \\
\text { total of } 29 \\
\text { skills, } \\
\text { including } \\
\text { Kolchin and } \\
\text { Giunipero } \\
\text { (1993) skills }\end{array}$ & $\begin{array}{l}\text { 1. Strategic } \\
\text { 1. Quantitative } \\
\text { 2. Process } \\
\text { management } \\
\text { 2. Team skills } \\
\text { 2. Decision-making } \\
\text { 2. Behavioural } \\
\text { 2. Negotiation skills }\end{array}$ \\
\hline
\end{tabular}

$\begin{array}{ll}\text { Carr and } & \text { 1. Technical skills } \\ \text { Smeltzer } & \\ \text { (2000), based } & \\ \text { on a total of } & \text { 2. Skills techniques } \\ \text { 35 skills } & \end{array}$

2. Behaviour skills

\section{Individual sills}

- Cost analysis, product knowledge, computer literacy, total quality management and government legislation global sourcing development

- Market analysis, negotiating with partners, managing internal and external relationships, change management and planning and organisational skills, risk-taking, written and oral communication, conflict resolution, influence and persuasion, group dynamics, leadership, problem solving and international and cultural awareness

- 'Strategic thinking', supply base research

- Structuring supplier relationships, technology (planning), supplier cost targeting, risk-taking/entrepreneurship,

salesmanship, computational, technical, blueprint reading, specification development

- Market analysis, negotiating with partners, managing internal and external relationships, change management and planning and organisational skills

- Risk-taking, written and oral communication, conflict resolution, influence and persuasion, group dynamics, leadership, problem-solving, and international and cultural awareness

- Drafting CAD/computer skills, math skills, technical business writing, blueprint reading, forecasting

- Understanding: tool capability, manufacturing processes, MRP, materials, inventory systems

- Analytical, communication, presentation, coordination, negotiating (cost) and issues, cost analysis, problem-solving, quality management, programme management, organisational (paperwork), time management

- People skills (suppliers), internal customers and functions, detail orientation, proactivity, ability to follow up, flexibility, stress management, team working, patience, multi-tasking

Other sources not cited by Tassabehji and Moorhouse (2008):

Killen and 1 . Product

Kamauff Knowledge

(1995)

characteristics

of a buyer
2. Principles of Purchasing and Management

\section{Personal} Attributes 2. Interpersonal skills

$\begin{array}{ll}\begin{array}{l}\text { Killen and } \\ \text { Kamauff } \\ \text { (1995) } \\ \text { characteristics } \\ \text { of a }\end{array} & \begin{array}{l}\text { 1. Technical } \\ \text { Knowledge }\end{array} \\ \begin{array}{l}\text { purchasing } \\ \text { manager }\end{array} & \begin{array}{l}\text { 2. Anterpersical Ability } \\ \text { skills }\end{array}\end{array}$

2. Managerial Skills
- Knows major facets of product or materials; market prices; major sources; quality requirements; external customer requirements $\&$ impact of that on internal customers and suppliers.

- Knows purchasing's role in the organisation; quality \& pricing theory; to negotiate; inventory control; to time; value analysis; capital equipment buying; apply make-or-buy theory; apply SCM concepts; marketing, accounting, MIS, operations, organisational behaviour and finance.

- Integrity; accuracy; research skills; careful decision-making; appropriate risk-taking; high self-esteem \& taking the initiative. - Is good at team working; communicating; listening; persuasive speaking; writing \& reporting; dealing with opposing views. Understanding product aspects; purchasing principles; organisation knowledge; current trends; marketing, accounting, MIS, operations, organisational behaviour and finance. - Can identify a problem, solve problems, make fast decisions; thinking in the abstract; analysing strategic options, and understanding the potential and impact.

- Can cooperate with department members, other departments and suppliers; making compromises; handling conflicts; handling organisational politics; maintaining a positive attitude; aligning purchasing with the organisation. 
Shou and

Wang (2015)

Tatham et al.

- Knows to plan materials, budget, work etc.; organise work and people; be a good leader; communicate to top management and subordinates; motivate people; monitor according to the plans; set objectives; participate in new product/service development, firms growth and strategies.

2. Generic soft skills

2. Generic analytical skills 2. Functional soft skills

2. Functional technical skills 1. SCM leadership characteristics (1) 1. SCM qualifications 1. SCM expertise 2. Industry-specific skills

2. Senior management skills

2. General management skills

2. Problem-solving skills

2. Interpersonal skills

1. Functional logistic skills
- Coordination, time-management, communication, negotiation, and problem-solving

- Analytical skills, data processing, forecasting skills, and evaluation ability

- Interpersonal skills, organise skills, stakeholder management, and decision-making.

- KPI management, contract management, risk management, and project management.

- Requirements regarding accountability, driveability, teamwork, team building, commercial awareness, strategy management and leadership.

- SCM certification, requirements regarding the management of purchasing, warehousing, logistics, targets, and SC specific requirements

- Requirements regarding product launch, operations, production, warehousing, logistics, pricing, delivery, customer service, resource management, change management, and regulations knowledge.

- Industry-specific requirements

- Demand management, order management, control ability, execution ability, budget management, financial acumen, staff management, learning ability, and making recommendations.

- Supplier Relationship Management (SRM), Customer Relationship Management (CRM), Strategic Management, Marketing, Written Communication,

Risk Management, Project Management, Information Technology \& Financial Accounting

- Information Gathering, Problem Solving, Problem Identification, Problem Analysis \& Information Sharing - Change Management, Leadership, Negotiation, Personnel Management, Listening, Oral Communication, Stress Management \& Meeting Facilitation

- Forecasting, Inventory Management, Logistics Information Systems, Transport Management, Purchasing, Warehousing, Reverse Logistics, Import/Export, Legal Specification \& Port/Airport Management. 
Cited subject:

I 'PSM is (evolving to be) a strategic function'

II 'Developing individual PSM skills combined with top management support for the PSM function leads to strategic advantage' 'Developing individual PSM skills leads to strategic advantage' (without 'top management support') 'Top management support for the PSM function leads to strategic advantage' (without 'developing skills')

III 'Developing communication skills for internal use leads to excellence'

IV Referring to the PSM skills taxonomy

V 'PSM function faces an internal politico-cultural glass ceiling'
Cited by:

Almeida and Sano (2018); Feisel et al. (2011);

Hedenstierna, Hilletofth, and Hilmola (2011); Homfeldt, Rese, Brenner, Baier, and Schäfer (2017); Kern et al. (2011); Knight et al. (2014); Leger, Oueslati, and Salanié (2013); Paesbrugghe, Rangarajan, Sharma, Syam, and Jha (2017); Paesbrugghe, Sharma, Rangarajan, and Syam (2018); Pohl and Förstl (2011); Quesada, González, Mueller, and Mueller (2010); Schneider and Wallenburg (2012); Sporrong and Bröchner (2009); Tassabehji (2010); Tomino, Park, and Hong (2012); and Wagner and Kemmerling (2014)

Dubey et al. (2018); Feisel et al. (2011); Hawkins and Gravier (2014); Lau (2010); McKevitt et al. (2012); and Miocevic (2011)

Hong and Kwon (2012); Sinha et al. (2016); Tchokogué, Nollet, et al. (2017); and Tchokogué, Paché, Nollet, and Stoleru (2017)

Kilpi, Lorentz, Solakivi, and Malmsten (2018)

Feisel et al. (2011); Hartley, Brodke, Wheeler, Wu, and Steward (2014); Hong and Kwon (2012); Lonsdale, Hoque, Kirkpatrick, and Sanderson (2017); Schneider and Wallenburg (2012); Steward et al. (2010) Ahsan and Rahman (2017); Dubey, Bag, Ali, and Venkatesh (2013); Feisel et al. (2011); Hohenstein et al. (2014); Mahamadu et al. (2018); and Mansi and Pandey (2016)

Andreasen and Gammelgaard (2018); Antonson and Åkerskog (2015); Feisel et al. (2011); Hartley et al. (2014); and Zsidisin, Hartley, Bernardes, and Saunders (2015)

\section{Appendix 9.7 - Relation of PSM skills articles not citing Tassabehji and Moorhouse (2008)}

\begin{tabular}{|c|c|c|c|}
\hline $\begin{array}{l}\text { Authors of articles that } \\
\text { are not citing Tassabehji } \\
\text { \& Moorhouse (2008) ... }\end{array}$ & $\begin{array}{l}\text {...of which are citing } \\
\text { the references (i.e. } \\
\text { sources) of the } \\
\text { taxonomy of } \\
\text { Tassabehji \& } \\
\text { Moorhouse (2008). }\end{array}$ & $\begin{array}{l}\text {...of which are } \\
\text { citing articles that } \\
\text { are citing } \\
\text { Tassabehji \& } \\
\text { Moorhouse (2008). }\end{array}$ & $\begin{array}{l}\text {...of which are citing } \\
\text { articles that did not } \\
\text { cite Tassabehji and } \\
\text { Moorhouse (2008). }\end{array}$ \\
\hline $\begin{array}{l}\text { Flöthmann, Hoberg, and } \\
\text { Gammelgaard (2018) } \\
\text { Lintukangas (2010) } \\
\\
\text { Liu et al. (2016) } \\
\text { Rottenburger, Carter, and } \\
\text { Kaufmann (2018) } \\
\text { Schoenherr et al. (2014) } \\
\text { Scholten and Dubois } \\
\text { (2017) } \\
\text { Yu et al. (2017) }\end{array}$ & $\begin{array}{l}\text { Giunipero and Pearcy } \\
(2000) \\
\text { Carr and Smeltzer } \\
(2000) \\
\text { Giunipero et al. (2006) } \\
\text { Giunipero and Pearcy } \\
\text { (2000) }\end{array}$ & $\begin{array}{l}\text { Hohenstein et al. } \\
\text { (2014) } \\
\text { Eltantawy et al. } \\
\text { (2009) }\end{array}$ & $\begin{array}{l}\text { Schoenherr et al. } \\
\text { (2014) }\end{array}$ \\
\hline
\end{tabular}


Phase

\section{Credibility (internal validity)}

Transferability/
Generalisability
(external validity)

\author{
Dependability/ \\ Reliability
}

\section{Confirmability/ Objectivity}

\begin{tabular}{|c|c|c|c|c|}
\hline $\begin{array}{l}\text { Preparation } \\
\text { Methodology \& } \\
\text { approach, } \\
\text { interview guide, } \\
\text { company } \\
\text { selection }\end{array}$ & $\begin{array}{l}\text { Built on } \\
\text { established } \\
\text { theory: } \\
\text { competences, } \\
\text { skills and } \\
\text { knowledge } \\
\text { Pre-test of an } \\
\text { interview } \\
\text { guide }\end{array}$ & $\begin{array}{l}\text { Stringent decision } \\
\text { tree for research } \\
\text { methodology } \\
\text { Pre-testing } \\
\text { definition of the } \\
\text { concept } \\
\text { Sampling } \\
\text { strategy: } \\
\text { Adequate \# of } \\
\text { interviewees } \\
\text { within one } \\
\text { industry sector } \\
\text { and cross-industry }\end{array}$ & $\begin{array}{l}\text { Decision tree for } \\
\text { research approach } \\
\text { Sample for different } \\
\text { industries according } \\
\text { to the external } \\
\text { depth of value- } \\
\text { added }\end{array}$ & $\begin{array}{l}\text { Contextualised } \\
\text { theories: } \\
\text { competences, } \\
\text { skills and } \\
\text { knowledge } \\
\text { Literature } \\
\text { review as a } \\
\text { basis } \\
\text { A systematic } \\
\text { and rigorous } \\
\text { approach }\end{array}$ \\
\hline $\begin{array}{l}\text { Sample \& } \\
\text { context }\end{array}$ & $\begin{array}{l}\text { Ethi } \\
\text { con } \\
\text { Con } \\
\text { Con } \\
\text { Sub } \\
\text { Res } \\
\text { ema }\end{array}$ & \multicolumn{3}{|c|}{$\begin{array}{l}\text { Ethics: the way the participants were treated in general }->\text { written } \\
\text { consent before the interviews } \\
\text { Communication with participants -> documented how often we had to } \\
\text { contact to convince them (field notes) } \\
\text { Subject selection -> theoretical sampling along the purchasing process } \\
\text { Researchers rapport before, during and after }->\text { delivered approach } \\
\text { email, summaries and results report }\end{array}$} \\
\hline $\begin{array}{l}\text { Implementation } \\
\text { Contact } \\
\text { participants, } \\
\text { conduct } \\
\text { interviews, } \\
\text { document } \\
\text { interviews }\end{array}$ & $\begin{array}{l}\text { Establish a } \\
\text { chain of } \\
\text { evidence } \\
\text { Peer review } \\
\text { within the } \\
\text { research team }\end{array}$ & $\begin{array}{l}\text { A common } \\
\text { approach of } \\
\text { interviewers } \\
\text { ensured }\end{array}$ & $\begin{array}{l}\text { Semi-structured } \\
\text { interview guide } \\
\text { Audio Recording of } \\
\text { interviews (all in } \\
\text { English) } \\
\text { Data collection and } \\
\text { analysis in } \\
\text { alternating } \\
\text { sequences -> pre- } \\
\text { test analysis served } \\
\text { to adapt a guide }\end{array}$ & $\begin{array}{l}\text { Transcription } \\
\text { of interviews } \\
\text { (only English to } \\
\text { English) }\end{array}$ \\
\hline $\begin{array}{l}\text { Follow-up } \\
\text { Analysis of } \\
\text { interviews }\end{array}$ & $\begin{array}{l}\text { A coding } \\
\text { system in } \\
\text { NVivo Peer } \\
\text { discussion of } \\
\text { evaluation } \\
\text { results }\end{array}$ & $\begin{array}{l}\text { Coding and nodes } \\
\text { in NVivo }\end{array}$ & $\begin{array}{l}\text { Coding and nodes in } \\
\text { NVivo following } \\
\text { steps organising, } \\
\text { coding, searching } \\
\text { and modelling } \\
\text { Peer review with } \\
\text { the research team } \\
\text { Research invites } \\
\text { replication }\end{array}$ & $\begin{array}{l}\text { Had probing } \\
\text { countercheck } \\
\text { (audit) by } \\
\text { someone } \\
\text { outside of the } \\
\text { research team }\end{array}$ \\
\hline
\end{tabular}

Note: adapted from Lincoln and Guba (1985); Sinkovics, Penz, and Ghauri (2005); Yin (2018); Salzberger et al. (1999); Maxwell (1997); Strauss and Corbin (1994); Welch et al. (2002) 
Interview Guide Part 1. General Data

2.Organisational structure $\&$ performance

3. Current knowledge requirements

4. Learning in and for PSM

5. Future skill requirements

6 . Is there anything you would like to add or emphasise?

7. Can we get back to you if clarification needs should arise?
Introductory text

"At first, we need some general data about the company and the participants of this interview. We need this information to evaluate if certain knowledge is related to specific industries or roles within PSM. We will now list the data for the recording."

"Now we would like to get some information about the PSM organisation and performance measurement. We need this information to evaluate if certain knowledge is related to specific roles within PSM. Also, performance measures give an indicator of the knowledge that is needed to perform accordingly."

"The following section deals with the knowledge that you apply when performing the individual tasks of your job. It helps us to evaluate which knowledge to include in the curriculum."

"The following section deals with the training programme and knowledge management system provided by your company for PSM. Getting information on this helps us to identify the efforts of your organisation to either train specific skills or capture specific knowledge."

"The following section deals with challenges in PSM that might also become more evident in the future. We try to evaluate the knowledge that is needed to cope with these challenges in the future."

"Is there anything you would like to add or emphasise? (...)

Thank you again that we were able to record the interview to facilitate the analysis. To comply with research ethics, we also need that in written format. Therefore, we sent in advance the consent form. It is just about the recording; the results are treated confidentially, as mentioned."

"Can we get back to you if clarification needs should arise? (...) Thank you very much for your valuable input and your time!"

\section{Appendix 9.10 - Additional competences to the competence clusters of Tassabehji and Moorhouse (2008)}

\begin{tabular}{|c|c|c|}
\hline $\begin{array}{c}\text { Competence } \\
\text { Cluster } \\
\text { (based on } \\
\text { Tassabehji } \\
\text { and } \\
\text { Moorhouse, } \\
\text { 2008) }\end{array}$ & $\begin{array}{c}\text { Additional } \\
\text { competences resulting } \\
\text { out of the study } \\
\text { (marked as 'additional } \\
\text { competences' in table } \\
\text { 2.7.) }\end{array}$ & Quotes from interviews with practitioners \\
\hline $\begin{array}{l}\text { Technical } \\
\text { skills }\end{array}$ & $\begin{array}{l}\text { Big Data Analytics, } \\
\text { Automation, } \\
\text { Innovation Sourcing, } \\
\text { Innovative Sourcing } \\
\text { Approaches }\end{array}$ & $\begin{array}{l}\text { "In the past, it was difficult to get information about the } \\
\text { market. Now the question is how to make use of this overflow } \\
\text { of information. Being able to filter, prioritise and decide which } \\
\text { are the right and useful information." (Interviewee, CHEM2) } \\
\text { "If the procurement function is set up correctly, the strategic } \\
\text { procurement guys have the time to focus on market } \\
\text { developments, can bring insights into the business and can get } \\
\text { a really solid understanding of what is going on and which } \\
\text { innovation we can get in." (Interviewee, CONSU1) } \\
\text { "I try to come up with new ideas. I mean new processes, how } \\
\text { we approach the market, new tools that we implemented that } \\
\text { increased the team's efficiency very much or released them } \\
\text { from operational work to focus on strategic work." } \\
\text { (Interviewee, CHEM2) }\end{array}$ \\
\hline
\end{tabular}


Interpersonal Curiosity,

skills
Deal with Ambiguity, Humbleness,

Mobility, Openness, Openminded, Passion, Resilience, Self-Confidence Self-Reflection Self-Reliance
Strategic business skills
Critical Thinking, Holistic Supply Chain Thinking, Sustainability
"Being able to work in different cultures and different environments I think is important." (Interviewee, FOOD1)

"(Being able to) implement a project together with the supplier that drives value and there along the way you start to understand more about the actual realities on the grounds and where you can improve." (Interviewee, TECH1)

"Scenario-based thinking and making your views and mind up of all of the opinions you hear on multiple scenarios and the trigger point as to what you have to do here." (Interviewee, CHEM2)

"Being able to adapt your style, whether it is in communication or how you contact with people personally." (Interviewee, FOOD1)

"That you are able and feel comfortable with making decisions if you only know 60 per cent of what could be known." (Interviewee, CONST1)

"Also, when you have people employing at companies like (...) who are big branding, and they are very proud of having that title or something like that. They must also be still very humble." (Interviewee, FOOD1)

"Mobility means that you can do your job when you are not sitting in your office." (Interviewee, CHEM1)

"(...) have worked in different geographies or different segments" (Interviewee, FOOD1)

"Flexibility in the thinking and also in writing and in speaking with new persons (...) like suppliers or internal functions." (Interviewee, AUTO1)

"(be able to) drive people to go more for their ideas." (Interviewee, PHARM1)

"This traceability is something, and that is why it is so important that when a purchaser comes that they have a winner mentality, but on a team level, which means we can win this on the team because, together with suppliers, together with internal people and so on; you can succeed to build something like that, you cannot win by doing it on your own." (Interviewee, FOOD1 Supplier)

"You sit alone in a plane all through the week you speak with suppliers. You must discuss with 5 or 10 different companies. Can you handle it?" (Interviewee, AUTO1)

"... (the ability to) execute and run and drive, a certain ambition and hunger". (Interviewee, CONSU2)

"I think it is important to ask yourself some questions about your work, but first you have to see the result of your work after 2, 3 or 4 months." (Interviewee, CHEM2)

"(...) our people have to be able to work in agile teams, so the higher share of responsibility (...) means that the team sets targets by themselves and also tracks the target achievement." (Interviewee, AUTO1)

"Being able to ask the right questions and set the right hypotheses I think is quite important." (Interviewee, CHEM2) "(... the ability) to pick up quickly an understanding of the whole supply chain related to the good or the service that (buyers) are dealing with. And it is not just the first-level supplier but also the second, third, fourth, and fifth-level suppliers. We teach them the skills to understand how to sort of think through and map and come to some ideas around the whole supply chain and how that supply chain can be influenced to be of value to our company, be it in a cost perspective be it in an innovation perspective be it in an environmental or sustainability perspective, so they see the whole supply chain and understand what happens. "(Interviewee, CONSU1) 
"(...) buying chemicals it probably makes sense to understand the full picture of this product, of the whole value chain, the whole supply chain, the whole the supply chain part, which is also services that you buy with the product."(Interviewee, CHEM1 Supplier)

"Also doing supplier assessments and audits and is something that needs to be made aware to the buyers." (Interviewee, CHEM2)

"It's more about how you include sustainability in your sourcing strategy". (Interviewee, FOOD1)

"Having some basic knowledge and understanding of (sustainability) is important. It would be great if people have the chance to think for themselves what does that mean for themselves and their future life and role." (Interviewee, FOOD1)

Appendix 9.11 - PSM job requirements in the total set of the 300 Austrian, Belgian and Dutch PSM job advertisements

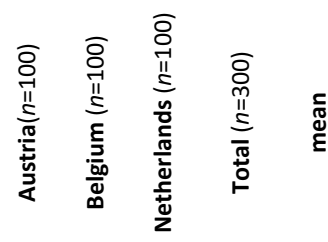

Requirement

\begin{tabular}{|c|c|c|c|c|c|c|}
\hline 1 & $\begin{array}{l}\text { English language proficiency (Erpenbeck \& Scharnhorst, 2005; Heyse } \\
\text { et al., 2004) }\end{array}$ & 94 & 80 & 66 & 240 & 80.0 \\
\hline 2 & $\begin{array}{l}\text { PSM job experience and knowledge (Schiele, 2007; Tassabehji \& } \\
\text { Moorhouse, 2008) }\end{array}$ & 72 & 86 & 78 & 236 & 78.7 \\
\hline 3 & Having at least a bachelor's (BSc/BASc) degree (new) & 70 & 45 & 79 & 194 & 64.7 \\
\hline 4 & $\begin{array}{l}\text { Communication skills (Erpenbeck \& Scharnhorst, 2005; Heyse et al., } \\
\text { 2004) }\end{array}$ & 39 & 47 & 56 & 142 & 47.3 \\
\hline 5 & $\begin{array}{l}\text { Negotiation skills (Giunipero \& Pearcy, 2000; Tassabehji \& } \\
\text { Moorhouse, 2008) }\end{array}$ & 66 & 41 & 33 & 140 & 46.7 \\
\hline 6 & $\begin{array}{l}\text { Result-orientated action-taking - being result driven (Erpenbeck \& } \\
\text { Scharnhorst, 2005; Heyse et al., 2004) }\end{array}$ & 40 & 47 & 46 & 133 & 44.3 \\
\hline 7 & $\begin{array}{l}\text { Computer literacy (Giunipero \& Pearcy, 2000; Tassabehji \& } \\
\text { Moorhouse, 2008) }\end{array}$ & 56 & 42 & 34 & 132 & 44.0 \\
\hline 8 & Persistence (Erpenbeck \& Scharnhorst, 2005; Heyse et al., 2004) & 62 & 23 & 32 & 117 & 39.0 \\
\hline 9 & $\begin{array}{l}\text { Team player - team spirit - ability to be on a team (Bals et al., } \\
\text { 2019; Erpenbeck \& Scharnhorst, 2005; Giunipero, Hooker, \& } \\
\text { Denslow, 2012; Heyse et al., 2004) }\end{array}$ & 39 & 40 & 27 & 106 & 35.3 \\
\hline 10 & Flexibility (Erpenbeck \& Scharnhorst, 2005; Heyse et al., 2004) & 71 & 16 & 17 & 104 & 34.7 \\
\hline 11 & $\begin{array}{l}\text { Analytical skills (Bals et al., 2019; Erpenbeck \& Scharnhorst, 2005; } \\
\text { Giunipero et al., 2012; Heyse et al., 2004) }\end{array}$ & 11 & 49 & 33 & 93 & 31.0 \\
\hline 12 & $\begin{array}{l}\text { Experience in the focal industry (Erpenbeck \& Scharnhorst, 2005; } \\
\text { Heyse et al., 2004) }\end{array}$ & 25 & 39 & 23 & 87 & 29.0 \\
\hline 13 & $\begin{array}{l}\text { Business and trade knowledge and experience (Giunipero \& Pearcy, } \\
\text { 2000; Tassabehji \& Moorhouse, 2008) }\end{array}$ & 36 & 16 & 30 & 82 & 27.3 \\
\hline 14 & Discipline (Giunipero et al., 2006; Giunipero \& Pearcy, 2000) & 61 & 8 & 12 & 81 & 27.0 \\
\hline 15 & Devotedness (Erpenbeck \& Scharnhorst, 2005; Heyse et al., 2004) & 65 & 0 & 3 & 68 & 22.7 \\
\hline 16 & Technical education (BSc or MSc degree) (new) & 42 & 13 & 9 & 64 & 21.3 \\
\hline 17 & $\begin{array}{l}\text { Creativity, innovativeness and handle complex situations - (Bals et } \\
\text { al., 2019; Erpenbeck \& Scharnhorst, 2005; Giunipero et al., 2012; } \\
\text { Heyse et al., 2004) }\end{array}$ & 0 & 32 & 31 & 63 & 21.0 \\
\hline 18 & $\begin{array}{l}\text { Customer-oriented (Giunipero \& Pearcy, 2000; Tassabehji \& } \\
\text { Moorhouse, 2008) }\end{array}$ & 10 & 30 & 23 & 63 & 21.0 \\
\hline 19 & $\begin{array}{l}\text { Technical knowledge and experience (Giunipero \& Pearcy, 2000; } \\
\text { Tassabehji \& Moorhouse, 2008) }\end{array}$ & 31 & 20 & 12 & 63 & 21.0 \\
\hline
\end{tabular}


Proactive - taking initiative (Erpenbeck \& Scharnhorst, 2005; Heyse et al., 2004)

21 Legal knowledge (Giunipero \& Pearcy, 2000; Tassabehji \& Moorhouse, 2008)

22 Willingness to travel (new)

23 Stress avoidance - the ability to handle stress (Erpenbeck \& Scharnhorst, 2005; Heyse et al., 2004)

24 Accuracy and precision (Erpenbeck \& Scharnhorst, 2005; Heyse et al., 2004)

25 Pragmatic - hands on mentality (new)

26 Energy drive (Erpenbeck \& Scharnhorst, 2005; Heyse et al., 2004)

27 Organisational skills (Bals et al., 2019; Erpenbeck \& Scharnhorst, 2005; Giunipero et al., 2012; Heyse et al., 2004)

Independency - sole-responsibility (Erpenbeck \& Scharnhorst, 2005; Heyse et al., 2004)

29 Responsibility (Erpenbeck \& Scharnhorst, 2005; Heyse et al., 2004)

30 Having at least a MSc degree (new)

31 Problem-solving skills (Bals et al., 2019; Flöthmann, Hoberg, \& Wieland, 2018; Tassabehji \& Moorhouse, 2008)

32 Persuasiveness (Erpenbeck \& Scharnhorst, 2005; Heyse et al., 2004)

Personnel management/Leadership Skills (Schiele, 2007)

Trustworthiness/Honesty/Reliability (Bals et al., 2019; Flöthmann,

Hoberg, \& Gammelgaard, 2018)

35 Multidisciplinary/Knowledge of Multiple disciplines (Erpenbeck \&

Scharnhorst, 2005; Heyse et al., 2004)

36 Having a degree in Business study (new)

37 Decisiveness (Erpenbeck \& Scharnhorst, 2005; Heyse et al., 2004)

38 Building Relations/Networking Skills (Erpenbeck \& Scharnhorst,

2005; Heyse et al., 2004; Schiele, 2007)

39 Project management (Schiele, 2007)

40 Assertiveness/poise (Erpenbeck \& Scharnhorst, 2005; Heyse et al., 2004)

41 Diplomacy, social manners and political sensitivity (Bals et al., 2019; Erpenbeck \& Scharnhorst, 2005; Giunipero \& Pearcy, 2000; Heyse et al., 2004)

42 Holistic Thinking/Having Overview (Giunipero \& Pearcy, 2000; Kolchin \& Giunipero, 1993; Tassabehji \& Moorhouse, 2008)

43 Proceed in a systematic-methodical manner (Erpenbeck \& Scharnhorst, 2005; Heyse et al., 2004)

44 Strategic thinking (Bals et al., 2019; Giunipero \& Pearcy, 2000)

45 Calculation/numeral skills (Giunipero \& Pearcy, 2000; Kolchin \& Giunipero, 1993)

46 Open communication/openness/accessible (Erpenbeck \& Scharnhorst, 2005; Heyse et al., 2004)

47 Process management (Bals et al., 2019; Tassabehji \& Moorhouse, 2008)

48 Consultancy or advisory skills (Bals et al., 2019; Faes et al., 2001)

49 Will to learn or learning ability (Bals et al., 2019

50 Stakeholder Relation Management (Bals et al., 2019)

51 Curiosity (Bals et al., 2019; Erpenbeck \& Scharnhorst, 2005;

Giunipero \& Pearcy, 2000; Heyse et al., 2004)

52 Motivating/inspiring others (Killen \& Kamauff, 1995)

53 Change management (Giunipero \& Pearcy, 2000; Tassabehji \& Moorhouse, 2008)

54 Change driven attitude (Erpenbeck \& Scharnhorst, 2005; Heyse et al., 2004)

55 International Mind-set and Intercultural Sensibility (Erpenbeck \& Scharnhorst, 2005; Heyse et al., 2004)

56 Presentation Skills \& Talent for Presentations (Erpenbeck \& Scharnhorst, 2005; Heyse et al., 2004)

57 Humour (Erpenbeck \& Scharnhorst, 2005; Heyse et al., 2004)

$\begin{array}{lcccc}19 & 12 & 28 & 59 & 19.7 \\ 32 & 7 & 18 & 57 & 19.0 \\ 34 & 13 & 10 & 57 & 19.0 \\ 29 & 12 & 14 & 55 & 18.3\end{array}$

$\begin{array}{lllll}12 & 23 & 19 & 54 & 18.0\end{array}$

$\begin{array}{lllll}6 & 20 & 27 & 53 & 17.7\end{array}$

$\begin{array}{lllll}7 & 16 & 27 & 50 & 16.7\end{array}$

$\begin{array}{lllll}19 & 24 & 5 & 48 & 16.0\end{array}$

$\begin{array}{lllll}0 & 27 & 20 & 47 & 15.7\end{array}$

$\begin{array}{lllll}32 & 8 & 5 & 45 & 15.0\end{array}$

$\begin{array}{lllll}0 & 38 & 7 & 45 & 15.0\end{array}$

$\begin{array}{lllll}7 & 25 & 10 & 42 & 14.0\end{array}$

$\begin{array}{lllll}4 & 14 & 23 & 41 & 13.7\end{array}$

$\begin{array}{lllll}13 & 11 & 17 & 41 & 13.7\end{array}$

$\begin{array}{lllll}16 & 13 & 10 & 39 & 13.0\end{array}$

$\begin{array}{ccccc}11 & 18 & 8 & 37 & 12.3 \\ 4 & 15 & 17 & 36 & 12.0 \\ 9 & 12 & 14 & 35 & 11.7\end{array}$

$\begin{array}{lllll}0 & 16 & 18 & 34 & 11.3\end{array}$

$\begin{array}{lllll}7 & 13 & 11 & 31 & 10.3\end{array}$

$\begin{array}{lllll}18 & 11 & 2 & 31 & 10.3\end{array}$

$\begin{array}{lllll}3 & 3 & 21 & 27 & 9.0\end{array}$

$\begin{array}{lllll}10 & 8 & 9 & 27 & 9.0\end{array}$

$\begin{array}{lllll}0 & 17 & 9 & 26 & 8.7\end{array}$

$\begin{array}{ccccc}6 & 6 & 13 & 25 & 8.3 \\ 0 & 10 & 9 & 19 & 6.3\end{array}$

$\begin{array}{lllll}2 & 4 & 13 & 19 & 6.3\end{array}$

$\begin{array}{ccccc}6 & 4 & 9 & 19 & 6.3 \\ 0 & 4 & 10 & 14 & 4.7 \\ 0 & 6 & 5 & 11 & 3.7 \\ 0 & 5 & 5 & 10 & 3.3 \\ 2 & 5 & 2 & 9 & 3.0\end{array}$

$\begin{array}{lllll}0 & 5 & 4 & 9 & 3.0 \\ 0 & 4 & 5 & 9 & 3.0\end{array}$

$\begin{array}{llllll}0 & 0 & 8 & 8 & 2.7\end{array}$

$\begin{array}{lllll}1 & 5 & 2 & 8 & 2.7 \\ 1 & 4 & 0 & 5 & 1.7\end{array}$

$\begin{array}{llll}0 & 0 & 5 & 5\end{array}$

Note: Common grounds are displayed in bold font - significant dissimilarities are displayed in standard font 


\begin{tabular}{|c|c|c|c|c|}
\hline & What is the importance of this task for your function? & $\begin{array}{c}\Delta \\
\text { means }\end{array}$ & $\begin{array}{c}F- \\
\text { value }\end{array}$ & Sign. \\
\hline \multirow{7}{*}{ 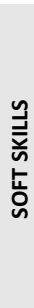 } & PSa120_Inventiveness - Being imaginativeness & +.27 & 7.463 & .006 \\
\hline & PSa220_Complexity - Comprehension of Complexity & +.19 & 4.562 & .033 \\
\hline & PSa040_Honesty - Being trustworthy in professional life & +.23 & 6.237 & .013 \\
\hline & PSa110_Will2TakeRisks - Willingness to take risks & +.23 & 4.953 & .026 \\
\hline & PSa030_Creativity - Being creative in professional life & +.40 & 15.032 & .000 \\
\hline & $\begin{array}{l}\text { POa070_Sustainable - Sustainability - Sustainable purchasing: } \\
\text { considering environmental, social, ethical and economic issues in } \\
\text { managing the organisation's external resources. }\end{array}$ & +.31 & 6.847 & .009 \\
\hline & $\begin{array}{l}\text { PSa140_ConflictResolution - Ability to Resolve Conflicts - Being able to } \\
\text { avoid and resolve conflicts }\end{array}$ & +.24 & 6.086 & .014 \\
\hline \multirow{5}{*}{ 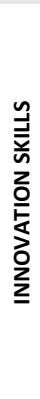 } & $\begin{array}{l}\text { POa170_ESI - Early Supplier Involvement - Inviting the supplier in the } \\
\text { NPD process from a very early stage. }\end{array}$ & +.39 & 8.762 & .003 \\
\hline & $\begin{array}{l}\text { PLa100_InnoSourcing - Innovation Sourcing - This requires a } \\
\text { systematic scan of the solutions available on the supply market. }\end{array}$ & +.40 & 11.689 & .001 \\
\hline & $\begin{array}{l}\text { PLa110_Innolmplement - Innovation Implementation - Implementing } \\
\text { suppliers' innovations in the own organisation. }\end{array}$ & +.50 & 17.239 & .000 \\
\hline & $\begin{array}{l}\text { SOa120_CoopRD - Working together with the department Research } \\
\text { and Development - Knowing basics about Research \& Development } \\
\text { and establishing/maintaining the relationship. }\end{array}$ & +.31 & 4.996 & .026 \\
\hline & $\begin{array}{l}\text { SOa100_CoopMarketing - Working together with the department } \\
\text { Marketing Management - Knowing basics about Marketing } \\
\text { Management (or Public Relations) and knowing how to } \\
\text { establish/maintain the relationship. }\end{array}$ & +.36 & 7.804 & .005 \\
\hline \multirow{5}{*}{ 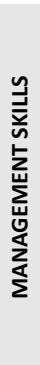 } & $\begin{array}{l}\text { HRa070_ChangeMngt - Managing change processes - The ability to } \\
\text { lead a team or group through a change process. }\end{array}$ & +.31 & 5.042 & .025 \\
\hline & $\begin{array}{l}\text { SOa060_CorpGov - Corporate Governance - Knowledge on how } \\
\text { organisations are governed, including board, the role of the advisory } \\
\text { board, stakeholders etc. }\end{array}$ & +.47 & 14.092 & .000 \\
\hline & $\begin{array}{l}\text { HRa080_ProjMngtSkills - Project Management Skills - The discipline of } \\
\text { initiating, planning, executing, controlling, and closing a team's work } \\
\text { to meet specific goals. }\end{array}$ & +.35 & 8.696 & .003 \\
\hline & PSa130_AdviceSkills - Capacity to Advice - Having consultancy skills & +.34 & 11.387 & \\
\hline & $\begin{array}{l}\text { SOa130_CoopHRM - Working together with the department Human } \\
\text { Resources Management - Knowing basics about Human Resources } \\
\text { Management and knowing how to establish/maintain the relationship }\end{array}$ & +.25 & 4.147 & .042 \\
\hline
\end{tabular}




\section{Appendix 9.13 - Significant distinct absent competences of innovation-focused purchasing}

professionals (t-test)

\begin{tabular}{|c|c|c|c|}
\hline What is the importance of this task for your function? & $\begin{array}{c}\Delta \\
\text { means }\end{array}$ & $\begin{array}{c}\text { F- } \\
\text { value }\end{array}$ & Sign. \\
\hline $\begin{array}{l}\text { Making cost analyses - For example, calculation of the total costs of } \\
\text { ownership or other cost calculations. }\end{array}$ & -.38 & 9.460 & .002 \\
\hline $\begin{array}{l}\text { Cost Reduction Techniques - Act of cutting costs to improve profitability } \\
\text { (e.g. by analysis and statistics) }\end{array}$ & -.35 & 7.636 & .006 \\
\hline $\begin{array}{l}\text { Negotiation of the Specific Terms - To make a contract, the specific } \\
\text { commercial and legal terms need to be settled in a satisfactory way for } \\
\text { your organisation. }\end{array}$ & -.28 & 5.340 & .021 \\
\hline $\begin{array}{l}\text { Solicit Offers (RfQ / RfP / RfI) Request for Quotation (RfQ) / Proposal (RfP) } \\
\text { / Information (RfI) - Inviting suppliers to submit a bid, which meets the } \\
\text { requirements as laid down in the request. }\end{array}$ & -.27 & 4.315 & .038 \\
\hline $\begin{array}{l}\text { Evaluate Offers \& Supplier Selection - Knowledge on how to ensure that } \\
\text { purchasing plays an adequate role in the organisation }\end{array}$ & -.24 & 4.286 & .039 \\
\hline $\begin{array}{l}\text { Global Sourcing / Supplier Acquisition - Sourcing materials, processes, } \\
\text { designs, technologies and suppliers from the global market / acquiring } \\
\text { new global suppliers. }\end{array}$ & -.28 & 3.908 & .049 \\
\hline
\end{tabular}

Appendix 9.14 - Factors in the questionnaire of competence items

Capacity to be empathetic - Capacity to listen and understand - (Erpenbeck \& Scharnhorst,

Social Manners - Being tactful, diplomatic and having organizational sensitivity - (Erpenbeck \&

Scharnhorst, 2005; Heyse et al., 2004)

Loyalty - Being loyal in professional life - (Erpenbeck \& Scharnhorst, 2005; Heyse et al., 2004)

Conscientiousness - Having environmental awareness; understanding what is going on -

(Erpenbeck \& Scharnhorst, 2005; Heyse et al., 2004)

Honesty - Being trustworthy in professional life - (Erpenbeck \& Scharnhorst, 2005; Heyse,

Erpenbeck, \& Max, 2004)

Comprehension of Complexity - The ability to understand complex problems - (Erpenbeck \&

Scharnhorst, 2005; Heyse et al., 2004)

Building Relations - Networking and relations management (Erpenbeck \& Scharnhorst, 2005;

Heyse et al., 2004; Schiele, 2007)

Ability to Solve Problems (Erpenbeck \& Scharnhorst, 2005; Heyse et al., 2004; Schiele, 2007)

Customer-oriented (Erpenbeck \& Scharnhorst, 2005; Heyse et al., 2004; Schiele, 2007)

\section{Factor 2 Result orientation}

Self-assurance - Being assertive and having self-esteem - (Erpenbeck \& Scharnhorst, 2005; Heyse et al., 2004)

Poise - Being (self)confident - (Erpenbeck \& Scharnhorst, 2005; Heyse et al., 2004)

Result-orientated action-taking - Aiming on effectiveness - (Erpenbeck \& Scharnhorst, 2005;

Ability to Resolve Conflicts - Being able to avoid and resolve conflicts - (Erpenbeck \&

Proactivity - Being anticipatory, change-oriented and self-initiated behaviour in situations -

(Erpenbeck \& Scharnhorst, 2005; Heyse et al., 2004)

Power of Persuasion - Having influential skills without using power - (Erpenbeck \& Scharnhorst, 2005; Heyse et al., 2004)

Willingness to take risks - (Erpenbeck \& Scharnhorst, 2005; Heyse et al., 2004)

Capacity to Advice - Having consultancy skills - (Erpenbeck \& Scharnhorst, 2005; Heyse et al., 2004) 
Creativity - Being creative in professional life (Erpenbeck \& Scharnhorst, 2005; Heyse et al.,

2004)

Inventiveness - Being imaginativeness (Erpenbeck \& Scharnhorst, 2005; Heyse et al., 2004) $\quad .605$

Willingness to Learn - Being professionally curious, motivation to learn continuously $\quad .529$

(Erpenbeck \& Scharnhorst, 2005; Heyse et al., 2004)

Holistic Thinking - Ability to think and act holistically (Erpenbeck \& Scharnhorst, 2005; Heyse et al., 2004)

Salesperson skills - Having acquisition strength and having canvassing ability (Erpenbeck \& Scharnhorst, 2005; Heyse et al., 2004)

Sellership Skills - Having the drive to sell and establish trust with a customer - (Schiele, 2007)

Personality Characteristics Development - The ability to develop the own soft skills

continuously, qualities and traits (e.g. persuasiveness, creativeness, entrepreneurial, adaptability) - (Schiele, 2007)

Cross-cultural Awareness - The ability to become aware of cultural values, beliefs and perceptions of the own and other one's cultures - (Schiele, 2007)

Customer orientation - Being focussed on the internal customer or internal user group -

(Giunipero \& Pearcy, 2000; Mulder et al., 2005; Tassabehji \& Moorhouse, 2008)

Factor 5 Cross-functional cooperation

Cooperating with department Research \& Development - Knowing basics about Research \& Development and knowing how to establish/maintain relationships - (Schiele, 2007)

Cooperating with the department Quality Management - Knowing basics about Quality

Management and knowing how to establish/maintain relationships - (Schiele, 2007)

Cooperating with the department Marketing Management - Knowing basics about Marketing

Management (or Public Relations) and knowing how to establish/maintain relationships -

(Schiele, 2007)

Cooperating with the Logistics and Storage departments - Knowing basics about Logistics and Storage and knowing how to establish/maintain relationships - (Schiele, 2007)

Cooperating with the department Production/Operations - Knowing basics about

Production/Operations and knowing how to establish/maintain relationships - (Schiele, 2007)

\section{Factor 6 Forecasting skills}

Forecasting of the demand - Planning of annual demands, based on the sales forecast and experience as input for annual negotiations - (Schiele, 2007; Tassabehji \& Moorhouse, 2008) Enterprise Resource Planning / Material Requirements Planning / Advanced Planning and Scheduling - Material Requirements Planning / Advanced Planning and Scheduling / IT skills necessary to extract planning data from employed ERP system - (Schiele, 2007)

Supply Chain Analysis and Planning - Analysis and planning not only of the immediate supply market but consideration of the entire supply chain - (Giunipero \& Pearcy, 2000; Mulder et al., 2005; Schiele, 2007; Tassabehji \& Moorhouse, 2008)

\section{Factor 7 Cost focus}

Solicit Offers (RfQ / RfP / Rfl) - Request for Quotation (RfQ) / Proposal (RfP) / Information (RfI) Inviting suppliers to submit a bid, which meets the requirements as laid down in the request (Schiele, 2007)

Making cost analyses - E.g. the calculation of the total costs of ownership or other cost calculations - (Giunipero \& Pearcy, 2000; Mulder et al., 2005; Tassabehji \& Moorhouse, 2008) Cost Reduction Techniques - Act of cutting costs to improve profitability (e.g. by analysis and statistics) - (Schiele, 2007)

Purchasing knowledge - Knowledge on purchasing in an organisation, e.g. Systems, organisational agility and best practice knowledge - (Schiele, 2007)

Global Sourcing / Supplier Acquisition - Sourcing materials, processes, designs, technologies and suppliers from global market / acquiring new global suppliers - (Schiele, 2007)

Negotiation the specific terms - Negotiating considers all commercial and legal terms that need to be settled satisfactorily with the supplier - pre-study outcome - (Giunipero \& Pearcy, 2000; Mulder et al., 2005; Schiele, 2007; Tassabehji \& Moorhouse, 2008)

\section{Factor 8 Contracting skills}

Working together with the Legal department - Knowing basics about legal aspects, like

contracts, compliance and legal consequences and knowing how to establish/maintain the 
Contract Development - Designing of contracts, application of standard vs customised contracts - (Giunipero \& Pearcy, 2000; Mulder et al., 2005; Schiele, 2007; Tassabehji \& Moorhouse, 2008)

Contract Management - Monitoring and enforcing the contracts after they have been signed -

(Schiele, 2007)

Claims Management - Claims management deals with opportunistic suppliers who tend to increase their margin with extra work apart from the contract. The negotiated price is too low, and the suppliers" margin comes from subsequent extra charges - (Schiele, 2007)

Evaluate Offers \& Supplier Selection - Evaluating the offers and selecting a supplier (or more) with whom the delivery of the product will be negotiated, including the tendering process (diversity, ethical issues, and cost/price) - (Schiele, 2007; Van Weele, 2009)

Corporate Social Responsibility - A business model that requires active compliance with the spirit of the law, ethical standards and national or international norms - (Schiele, 2007) Developing specifications for supplies - Specifying the requirements and needs for supplies (Giunipero \& Pearcy, 2000)

\section{Factor 9 Supplier relationship management}

Supplier Development - Cooperation with suppliers to improve their processes and product capabilities - (Schiele, 2007)

Supply Risk management - The implementation of strategies to manage both everyday and exceptional risks along the supply chain to deal with risks and uncertainties caused by, or impact on, logistics related resources or activities in the supply chain - (Schiele, 2007; Wieland \& Wallenburg, 2012)

Supplier Evaluation - Process of measuring and monitoring the performance of current suppliers - (Schiele, 2007)

Supplier Relationship Management - The ongoing management of the suppliers after contracting / strategically planning for, and managing, all interactions with suppliers - (Schiele, 2007)

Early Supplier Involvement - Involving the supplier in the new product development process from a very early stage - (Schiele, 2007)

Strategic Business Partner - The process of becoming a preferred strategic business partner with your supplier - (Schiele, 2007)

Sustainability - Sustainable purchasing: considering environmental, social, ethical and economic issues in the management of the organisation's external resources - (Miemczyk, Johnsen, \& Macquet, 2012; Schulze \& Bals, 2020; Schulze et al., 2019)

Factor 10 Innovation sourcing

Pooling Planning \& Organising - to bundle the entire demands of the organisation(s). Pooling

requires careful planning, demand identification and the application of organisational solutions (lead buyer concept, centralisation, purchasing councils) - (Schiele, 2007)

Supply Market Analysis - Analysing the supply market. Who are the possible suppliers? What is the competition level between suppliers, and what is their market power? - (Giunipero \&

Pearcy, 2000; Mulder et al., 2005; Schiele, 2007; Tassabehji \& Moorhouse, 2008)

Innovation Sourcing - a systematic scan of the solutions available on the supply market -

(Giunipero \& Pearcy, 2000)

Category Strategy Development - Development of the sourcing strategy for a category or family of purchasing goods, including strategic analysis and category classification/portfolio management (e.g. Kraljic) - (Schiele, 2007)

Stakeholder Relationship Management - Being focussed on all internal and external

stakeholders - (Tate, Ellram, \& Kirchoff, 2010)

Innovation implementation - Implementing suppliers innovations in the own organization (Luzzini \& Ronchi, 2011)

\section{Factor 11 Analytics}

Statistical Analyses - Applying statistical analyses methods - (Schiele, 2007)

Big Data Analyses - Uncovering hidden patterns, correlations and other insights from large amounts of data using specific statistical big data analyses methods - (Waller \& Fawcett, 2013) Performance Measurement and Follow-up - Continuous monitoring of target achievement, incl. project controlling (Performance of suppliers is part of supplier evaluation) - (Schiele, 2007)

Set key performance indicators (KPI"s) - Defining key performance indicators / objectives / targets and implementing them - (Schiele, 2007)

Portfolio Analysis Support - Analysing the purchasing portfolio, describing a classification of purchases, and supporting the portfolio management - (Schiele, 2007) 
Employee Performance Measurement - Monitoring and evaluating employees: knowledge on

employee performance measurement - (Schiele, 2007)

Employee Integration and Development Plan - Knowledge about the HR process of employee

integration and its development plan - (Schiele, 2007)

Personnel Selection Process - Knowledge about the HR process of selecting new personnel -

(Schiele, 2007)

Training personnel - Actively giving structured training and education to improve the

knowledge and skills of colleagues - (Schiele, 2007)

Leadership / managing personnel - Managing employees in teams - (Schiele, 2007)

Purchasing Roles and Job Profiles - Defining and designing different roles and job profiles of

purchasers - (Schiele, 2007)

Managing change processes - The ability to lead a team or group successfully through a change

process - (Giunipero \& Pearcy, 2000; Tassabehji \& Moorhouse, 2008)

Working together with the Department of Human Resources Management - Knowing basics

about Human Resources Management and knowing how to establish/maintain relationships -

(Schiele, 2007)

Factor 13 Organisational insight and governance

Project Management Skills - Initiating, planning, executing, controlling and closing the work of a project team - (Schiele, 2007)

Add value to the organisation - Knowledge on the added value of purchasing to the organisation and the importance of purchasing to the organisation - (Schiele, 2007)

Process Management - The design of processes and the updating as well as reading and

understanding processes - (Schiele, 2007)

Team Ability Skills - Having the ability to cooperating with others in a team - (Schiele, 2007)

Corporate Governance - Knowledge on how organisations are governed, including board, the role of an advisory board, stakeholders et cetera - (Schiele, 2007)

Optimisation of Purchasing Processes - Purchasing Process Improvement - (Schiele, 2007)

Position of Purchasing in Organisation - Knowledge on how to ensure that purchasing plays an

Automation - Working on the automation of purchasing processes - (Schiele, 2007)

Procurement IT Systems/e-procurement applications - Knowing the working of a computerized

Technical knowledge of products and production systems - Understanding the technical 
Appendix 9.15 - Result of exploratory factor analysis on the 17 competences significantly associated with PSM professionals with an innovation focus

Soft skills - construct

PSa120_Inventiveness - Being imaginativeness (Erpenbeck \& Scharnhorst, 2005; Heyse et al., 2004)

PSa220_Complexity - Comprehension of Complexity The ability to understand complex problems - (Erpenbeck \& Scharnhorst, 2005; Heyse et

PSa040_Honesty - Being trustworthy in professional life (Erpenbeck \& Scharnhorst, 2005; Heyse et al., 2004)

PSa110_Will2TakeRisks - Willingness to take risks (Erpenbeck \& Scharnhorst, 2005; Heyse et al., 2004)

PSa030_Creativity - Being creative in professional (Erpenbeck \& Scharnhorst, 2005; Heyse et al., 2004)

POa070_Sustainable - Sustainability - Sustainable purchasing: considering environmental, social, ethical and economic issues in the management of the organisation's external resources (Miemczyk et al., 2012, p. 489)

PSa140_ConflictResolution - Ability to Resolve Conflicts - Being able to avoid and resolve conflicts (Erpenbeck \& Scharnhorst, 2005; Heyse et al., 2004)

Innovation competences - construct

POa170_ESI - Early Supplier Involvement - Inviting the supplier in the NPD process from a very early stage (Schiele, 2007)

PLa100_InnoSourcing - Innovation Sourcing - This requires a systematic scan of the solutions available on the supply market. (Giunipero \& Pearcy, 2000)

PLa110_Innolmplement - Innovation Implementation - Implementing suppliers innovations in their organisation Luzzini and Ronchi (2011)

SOa120_CoopRD - Working together with the R\&D department - Knowing basics about R\&D how to establish/maintain the relationship (Schiele, 2007)

SOa100_CoopMarketing - Working together with the department Marketing

Management - Knowing basics about Marketing Management (or Public

Relations) and knowing how to establish/maintain the relationship (Schiele,

Management competences - construct

HRa070_ChangeMngt - Managing change processes - The ability to lead a team or group through a change process. (Giunipero \& Pearcy, 2000;

Tassabehji \& Moorhouse, 2008)

SOa060_CorpGov - Corporate Governance - Knowledge on how organisations are governed, including board, the role of the advisory board, stakeholders

HRa080_ProjMngtSkills - Project Management Skills - The discipline of initiating, planning, executing, controlling, and closing a team's work to meet specific goals. (Schiele, 2007)

PSa130_AdviceSkills - Capacity to Advice - Having consultancy skills (Erpenbeck \& Scharnhorst, 2005; Heyse et al., 2004)

SOa130_CoopHRM - Working together with the department Human Resources Management - Knowing basics about Human Resources Management and knowing how to establish/maintain the relationship (Schiele, 2007)

Extraction Method: Principal Component Analysis. Rotation Method: Equamax with Kaiser Normalisation. Rotation converged in 10 iterations. 
Appendix 9.16 - Constructs of the three axes in the polynomial regression

\begin{tabular}{|c|c|c|}
\hline $\begin{array}{l}\text { Innovation } \\
\text { Competences }\end{array}$ & (1) & $\begin{array}{l}\text { ESI - Early Supplier Involvement - Inviting the supplier in the NPD process from } \\
\text { a very early stage (Schiele, 2007) }\end{array}$ \\
\hline $\begin{array}{l}\text { Competences } \\
\text { (x-axis) }\end{array}$ & (4) & $\begin{array}{l}\text { a very early stage (Schiele, 2007) } \\
\text { Innovation Sourcing - This requires a systematic scan of the solutions available } \\
\text { on the supply market. (Giunipero \& Pearcy, 2000) } \\
\text { Innovation Implementation - Implementing suppliers innovations in their } \\
\text { organisation Luzzini and Ronchi (2011) } \\
\text { Cooperation with R\&D department - Implementing suppliers innovations in the } \\
\text { own organisation Luzzini and Ronchi (2011) }\end{array}$ \\
\hline $\begin{array}{l}\text { Innovation } \\
\text { Organisation } \\
\text { (y-axis) }\end{array}$ & $\begin{array}{l}\text { (2) } \\
\text { (3) }\end{array}$ & $\begin{array}{l}\text { 'Innovation is part of the purchasers' objectives' (based upon Johnsen et al., } \\
\text { 2012; Legenvre \& Gualandris, 2018; Luzzini et al., 2015); } \\
\text { 'Purchasing is organising innovation workshops to which the supplier is required } \\
\text { to contribute' (based upon Legenvre \& Gualandris, 2018); } \\
\text { 'Purchasing is measuring suppliers' contribution to innovation' (based upon } \\
\text { Gobble, 2013; Sun, Wong, Zhao, \& Yam, 2012). }\end{array}$ \\
\hline $\begin{array}{l}\text { Innovation } \\
\text { Sourcing Success } \\
\text { (z-axis) }\end{array}$ & $\begin{array}{l}\text { (1) } \\
(2) \\
\text { (3) }\end{array}$ & $\begin{array}{l}\text { Due to my actions, product and process improvements have been implemented; } \\
\text { Due to my actions, we achieved more product and process improvements than } \\
\text { average; } \\
\text { Due to my actions, we identified more ideas that are useful with suppliers than } \\
\text { the benchmark; } \\
\text { The product and process improvements achieved in my department/company } \\
\text { are considerably better than expected } \\
\text { (derived from Azadegan and Dooley (2010), Schiele, Veldman, and Hüttinger } \\
\text { (2011) and Terpend et al. (2011)) }\end{array}$ \\
\hline
\end{tabular}

\section{Appendix 9.17 - Level of agreement in z-value levels of the independent variables}

\begin{tabular}{ccccrr} 
& \multicolumn{2}{c}{ Frequency } & Per cent & Valid Percent & Cumulative Percent \\
\hline Valid & $<-0.5$ & 32 & 31.1 & 31.1 & 31.1 \\
& -0.49 to 0.49 & 41 & 39.8 & 39.8 & 70.9 \\
& 0.5 & 30 & 29.1 & 29.1 & 100.0 \\
Total & 103 & 100.0 & 100.0
\end{tabular}

Appendix 9.18 - Tests of normality

Tests of Normality

Kolmogorov-Smirnov

Shapiro-Wilk

\begin{tabular}{|c|c|c|c|c|c|c|}
\hline & Statistic & $\mathrm{df}$ & Sig. & Statistic & $\mathrm{df}$ & Sig. \\
\hline $\begin{array}{l}\text { Standardised } \\
\text { Residual }\end{array}$ & .057 & 103 & $.200^{*}$ & .978 & 103 & .077 \\
\hline
\end{tabular}

Note: *. This is a lower bound of true significance. a. Lilliefors Significance Correction 


\begin{tabular}{|c|c|c|c|}
\hline Necessary conditions & for: & effect size & $p$-value \\
\hline \multirow{16}{*}{ Factor 1 Networking } & Supplier satisfaction objective & .183 & .044 \\
\hline & Quality improvement objective & .250 & .036 \\
\hline & Factor 2 Soft skills - Result driven & .457 & .000 \\
\hline & Factor 3 Soft skills - Imagination & .432 & .000 \\
\hline & Factor 4 Sellership & .451 & .000 \\
\hline & Factor 5 Cross functional cooperation & .407 & .000 \\
\hline & Factor 6 Forecasting skills & .400 & .000 \\
\hline & Factor 7 Cost focus & .395 & .000 \\
\hline & Factor 8 Contracting skills & .411 & .000 \\
\hline & Factor 9 Supplier relationship management & .412 & .000 \\
\hline & Factor 10 Innovation sourcing & .387 & .000 \\
\hline & Factor 11 Analytics & .374 & .000 \\
\hline & Factor 12 Leadership and Personnel & .465 & .000 \\
\hline & Factor 13 Organisational insight and value-adding & .395 & .000 \\
\hline & Factor 14 Automation & .396 & .000 \\
\hline & Factor 15 Technical skills & .427 & .000 \\
\hline \multirow[t]{16}{*}{ Factor 2 Result driven } & Supplier satisfaction objective & .156 & .012 \\
\hline & Quality improvement objective & .191 & .038 \\
\hline & Competitive advantage objective & .156 & .052 \\
\hline & Factor 3 Soft skills - Imagination & .285 & .000 \\
\hline & Factor 4 Sellership & .394 & .000 \\
\hline & Factor 5 Cross functional cooperation & .333 & .000 \\
\hline & Factor 6 Forecasting skills & .362 & .000 \\
\hline & Factor 7 Cost focus & .323 & .000 \\
\hline & Factor 8 Contracting skills & .346 & .000 \\
\hline & Factor 9 Supplier relationship management & .330 & .000 \\
\hline & Factor 10 Innovation sourcing & .344 & .000 \\
\hline & Factor 11 Analytics & .350 & .000 \\
\hline & Factor 12 Leadership and Personnel & .421 & .000 \\
\hline & Factor 13 Organisational insight and value-adding & .328 & .000 \\
\hline & Factor 14 Automation & .258 & .004 \\
\hline & Factor 15 Technical skills & .347 & .000 \\
\hline \multirow[t]{14}{*}{ Factor 3 Imagination } & Innovation sourcing objective & .133 & .042 \\
\hline & Supplier satisfaction objective & .141 & .010 \\
\hline & Factor 4 Sellership & .353 & .000 \\
\hline & Factor 5 Cross functional cooperation & .331 & .000 \\
\hline & Factor 6 Forecasting skills & .370 & .000 \\
\hline & Factor 7 Cost focus & .312 & .000 \\
\hline & Factor 8 Contracting skills & .324 & .000 \\
\hline & Factor 9 Supplier relationship management & .342 & .000 \\
\hline & Factor 10 Innovation sourcing & .339 & .000 \\
\hline & Factor 11 Analytics & 270 & .000 \\
\hline & Factor 12 Leadership and Personnel & .363 & .000 \\
\hline & Factor 13 Organisational insight and value-adding & .315 & .000 \\
\hline & Factor 14 Automation & .281 & .000 \\
\hline & Factor 15 Technical skills & .318 & .000 \\
\hline Factor 13 & Innovation sourcing objective & .129 & .010 \\
\hline \multirow{14}{*}{$\begin{array}{l}\text { Organisational insight } \\
\text { and value-adding } \\
\text { skills }\end{array}$} & Supplier satisfaction objective & .149 & .000 \\
\hline & Cost reduction objective & .113 & .000 \\
\hline & Competitive advantage objective & .164 & .000 \\
\hline & Sustainability improvement objective & .158 & .022 \\
\hline & Factor 4 Sellership & .345 & .000 \\
\hline & Factor 5 Cross functional cooperation & .327 & .000 \\
\hline & Factor 6 Forecasting skills & .342 & .000 \\
\hline & Factor 7 Cost focus & .326 & .000 \\
\hline & Factor 8 Contracting skills & .374 & .000 \\
\hline & Factor 9 Supplier relationship management & .380 & .000 \\
\hline & Factor 10 Innovation sourcing & .344 & .000 \\
\hline & Factor 11 Analytics & .265 & .000 \\
\hline & Factor 12 Leadership and Personnel & 401 & 000 \\
\hline & Factor 14 Automation & 295 & .000 \\
\hline
\end{tabular}




\begin{tabular}{|c|c|c|c|}
\hline & Factor 15 Technical skills & .367 & .002 \\
\hline \multirow[t]{15}{*}{ Factor 4 Sellership } & Innovation sourcing objective & .091 & .034 \\
\hline & Supplier satisfaction objective & .121 & .002 \\
\hline & Cost reduction objective & .079 & .016 \\
\hline & Competitive advantage objective & .113 & .006 \\
\hline & Sustainability improvement objective & .117 & .052 \\
\hline & Factor 5 Cross functional cooperation & .255 & .000 \\
\hline & Factor 6 Forecasting skills & .258 & .000 \\
\hline & Factor 7 Cost focus & .242 & .000 \\
\hline & Factor 8 Contracting skills & .254 & .000 \\
\hline & Factor 9 Supplier relationship management & .279 & .000 \\
\hline & Factor 10 Innovation sourcing & .290 & .000 \\
\hline & Factor 11 Analytics & .211 & .000 \\
\hline & Factor 12 Leadership and Personnel & .344 & .000 \\
\hline & Factor 14 Automation & .188 & .000 \\
\hline & Factor 15 Technical skills & .232 & .000 \\
\hline \multirow[t]{11}{*}{ Factor 7 Cost focus } & Supplier satisfaction objective & .090 & .040 \\
\hline & Delivery improvement objective & .139 & .004 \\
\hline & Factor 5 Cross functional cooperation & .196 & .000 \\
\hline & Factor 6 Forecasting skills & .243 & .000 \\
\hline & Factor 8 Contracting skills & .292 & .000 \\
\hline & Factor 9 Supplier relationship management & .329 & .000 \\
\hline & Factor 10 Innovation sourcing & .274 & .000 \\
\hline & Factor 11 Analytics & .175 & .010 \\
\hline & Factor 12 Leadership and Personnel & .219 & .000 \\
\hline & Factor 14 Automation & .250 & .000 \\
\hline & Factor 15 Technical skills & .314 & .000 \\
\hline \multirow{9}{*}{$\begin{array}{l}\text { Factor } 8 \text { Contracting } \\
\text { skills }\end{array}$} & Supplier satisfaction objective & .073 & .050 \\
\hline & Sustainability improvement objective & .125 & .008 \\
\hline & Factor 5 Cross functional cooperation & .180 & .000 \\
\hline & Factor 6 Forecasting skills & .196 & .000 \\
\hline & Factor 9 Supplier relationship management & .256 & .000 \\
\hline & Factor 11 Analytics & .167 & .000 \\
\hline & Factor 12 Leadership and Personnel & .194 & .000 \\
\hline & Factor 14 Automation & .174 & .000 \\
\hline & Factor 15 Technical skills & .253 & .000 \\
\hline \multirow{10}{*}{$\begin{array}{l}\text { Factor } 5 \text { Cross- } \\
\text { functional } \\
\text { cooperation }\end{array}$} & Supplier satisfaction objective & .092 & .002 \\
\hline & Cost reduction objective & .087 & .016 \\
\hline & Competitive advantage objective & .054 & .024 \\
\hline & Quality improvement objective & .110 & .008 \\
\hline & Factor 6 Forecasting skills & .263 & .000 \\
\hline & Factor 9 Supplier relationship management & .227 & .000 \\
\hline & Factor 10 Innovation sourcing & .235 & .000 \\
\hline & Factor 11 Analytics & .174 & .000 \\
\hline & Factor 14 Automation & .113 & .026 \\
\hline & Factor 15 Technical skills & .255 & .000 \\
\hline \multirow[t]{11}{*}{ Factor 11 Analytics } & Supplier satisfaction objective & .101 & .000 \\
\hline & Cost reduction objective & .083 & .008 \\
\hline & Competitive advantage objective & .048 & .014 \\
\hline & Quality improvement objective & .111 & .000 \\
\hline & Delivery improvement objective & .079 & .006 \\
\hline & Factor 6 Forecasting skills & .167 & .000 \\
\hline & Factor 9 Supplier relationship management & .242 & .000 \\
\hline & Factor 10 Innovation sourcing & .224 & .000 \\
\hline & Factor 12 Leadership and Personnel & .204 & .000 \\
\hline & Factor 14 Automation & .184 & .000 \\
\hline & Factor 15 Technical skills & .177 & .000 \\
\hline \multirow{7}{*}{$\begin{array}{l}\text { Factor } 9 \text { Supplier } \\
\text { relationship } \\
\text { management }\end{array}$} & Supplier satisfaction objective & .125 & .000 \\
\hline & Competitive advantage objective & .104 & .000 \\
\hline & Quality improvement objective & .093 & .038 \\
\hline & Sustainability improvement objective & .125 & .000 \\
\hline & Factor 6 Forecasting skills & .182 & .000 \\
\hline & Factor 10 Innovation sourcing & .263 & .000 \\
\hline & Factor 12 Leadership and Personnel & .260 & .000 \\
\hline
\end{tabular}


Factor 14 Automation $\quad .192 \quad .000$

Factor 15 Technical skills $\quad .221 \quad .000$

\begin{tabular}{|c|c|c|c|}
\hline \multirow{8}{*}{$\begin{array}{l}\text { Factor } 10 \text { Innovation } \\
\text { sourcing }\end{array}$} & Supplier satisfaction objective & .104 & .000 \\
\hline & Cost reduction objective & .069 & .000 \\
\hline & Quality improvement objective & .117 & .006 \\
\hline & Delivery improvement objective & .087 & .006 \\
\hline & Factor 8 Contracting skills & .228 & .000 \\
\hline & Factor 12 Leadership and Personnel & .194 & .000 \\
\hline & Factor 14 Automation & .115 & .022 \\
\hline & Factor 15 Technical skills & .261 & .000 \\
\hline \multirow{7}{*}{$\begin{array}{l}\text { Factor } 12 \text { Leadership } \\
\text { and Personnel }\end{array}$} & Supplier satisfaction objective & .049 & .000 \\
\hline & Cost reduction objective & .039 & .000 \\
\hline & Quality improvement objective & .063 & .000 \\
\hline & Delivery improvement objective & .042 & .000 \\
\hline & Factor 5 Cross functional cooperation & .153 & .000 \\
\hline & Factor 6 Forecasting skills & .172 & .000 \\
\hline & Factor 15 Technical skills & .148 & .000 \\
\hline Factor 14 & Delivery improvement objective & .042 & .054 \\
\hline \multirow{3}{*}{ Automation } & Factor 6 Forecasting skills & .156 & .000 \\
\hline & Factor 12 Leadership and Personnel & .086 & .016 \\
\hline & Factor 15 Technical skills & .080 & .014 \\
\hline \multirow[t]{4}{*}{ Factor 6 Forecasting } & Cost reduction objective & .028 & .022 \\
\hline & Delivery improvement objective & .049 & .03 \\
\hline & Factor 10 Innovation sourcing & .156 & .000 \\
\hline & Factor 15 Technical skills & .144 & \\
\hline
\end{tabular}

$(0<d<0.1$ "small effect"; $0.1 \leq d<0.3$ "medium effect"; $0.3 \leq d<0.5$ "large effect"; $d \geq 0.5$ "very large effect" (Dul, 2018b); DV stands for 'dependent variable') 


\begin{tabular}{|c|c|c|c|c|c|c|c|c|c|c|c|c|c|c|c|c|}
\hline & 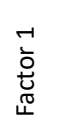 & 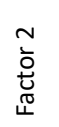 & 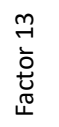 & 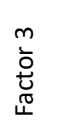 & 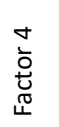 & 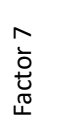 & 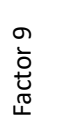 & 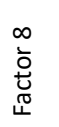 & 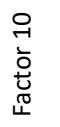 & 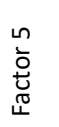 & 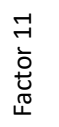 & 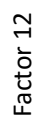 & 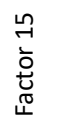 & $\begin{array}{l}6 \\
\vdots \\
\stackrel{+}{0} \\
\stackrel{0}{\leftarrow}\end{array}$ & 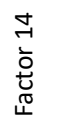 & $\begin{array}{l}\delta \\
\grave{\delta}\end{array}$ \\
\hline Factor 1 - Networking & & .457 & .395 & .432 & .451 & .395 & .412 & .411 & .387 & .407 & .374 & .465 & .427 & .400 & .396 & .415 \\
\hline $\begin{array}{l}\text { Factor } 2 \text { - Result } \\
\text { orientation } \\
\text { Factor } 13 \text { - }\end{array}$ & .310 & & .328 & .285 & .394 & .323 & .330 & .346 & .344 & .333 & .350 & .421 & .347 & .362 & .258 & .338 \\
\hline $\begin{array}{l}\text { Organisational insight } \\
\text { and value-adding skills }\end{array}$ & .155 & .244 & & .288 & .345 & .326 & .380 & .374 & .344 & .327 & .265 & .401 & .367 & .342 & .295 & .318 \\
\hline Factor 3 - Imagination & .134 & .219 & .315 & & .353 & .312 & .342 & .324 & .339 & .331 & .270 & .363 & .318 & .370 & .281 & .305 \\
\hline Factor 4 - Sellership & .096 & .192 & .182 & .197 & & .242 & .279 & .254 & .290 & .255 & .211 & .344 & .232 & .258 & .188 & .230 \\
\hline Factor 7 - Cost focus & .127 & .182 & .228 & .156 & .210 & & .329 & .292 & .274 & .196 & .175 & .219 & .314 & .243 & .250 & .228 \\
\hline $\begin{array}{l}\text { Factor } 9 \text { - Supplier } \\
\text { relationship } \\
\text { management }\end{array}$ & .085 & .144 & .138 & .105 & .245 & .240 & & .241 & .263 & .141 & .126 & .260 & .221 & .182 & .192 & .185 \\
\hline $\begin{array}{l}\text { Factor } 8 \text { - Contracting } \\
\text { skills }\end{array}$ & .084 & .121 & .145 & .118 & .189 & .256 & .256 & & .186 & .180 & .167 & .194 & .253 & .196 & .174 & .180 \\
\hline $\begin{array}{l}\text { Factor } 10 \text { - Innovation } \\
\text { sourcing }\end{array}$ & .079 & .159 & .198 & .128 & .202 & .208 & .237 & .228 & & .175 & .162 & .194 & .261 & .142 & .115 & .178 \\
\hline $\begin{array}{l}\text { Factor } 5 \text { - Cross- } \\
\text { functional cooperation }\end{array}$ & .086 & .103 & .171 & .106 & .155 & .154 & .227 & .163 & .235 & & .174 & .125 & .255 & .263 & .113 & .166 \\
\hline Factor 11 - Analytics & .085 & .105 & .128 & .102 & .189 & .171 & .242 & .152 & .224 & .126 & & .204 & .177 & .167 & .184 & .161 \\
\hline $\begin{array}{l}\text { Factor } 12 \text { - Leadership } \\
\text { and Personnel }\end{array}$ & .078 & .117 & .134 & .088 & .205 & .129 & .151 & .155 & .145 & .153 & .146 & & .148 & .172 & .082 & .136 \\
\hline $\begin{array}{l}\text { Factor } 15 \text { - Technical } \\
\text { skills }\end{array}$ & .076 & .094 & .107 & .108 & .141 & .193 & .175 & .156 & .182 & .127 & .105 & .142 & & .136 & .045 & .128 \\
\hline $\begin{array}{l}\text { Factor } 6 \text { - Forecasting } \\
\text { skills }\end{array}$ & .065 & .073 & .071 & .057 & .108 & .076 & .104 & .125 & .156 & .092 & .101 & .120 & .144 & & .104 & .100 \\
\hline Factor 14 - Automation & .056 & .047 & .054 & .031 & .069 & .042 & .062 & .076 & .052 & .031 & .125 & .086 & .080 & .156 & & .069 \\
\hline $\begin{array}{l}\text { This table shows the eff } \\
0.1 \leq d<0.3 \text { "medium ef } \\
\text { are ranked based on the } \\
\text { largest effect sizes on th } \\
\text { Automation" is not a ne } \\
\text { relations are displayed ir } \\
\text { This table is the underlyi }\end{array}$ & 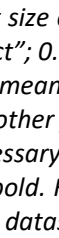 & . & . & -4 & 1 & 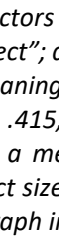 & 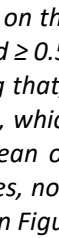 & 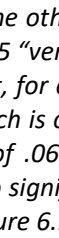 & (2) & & EJJ & & & & $\| l e$ & $\begin{array}{l}\text { tot } \\
\text { tors } \\
\text { the } \\
\text { ant } \\
\text { ant }\end{array}$ \\
\hline
\end{tabular}




\section{English version:}

Dear $\langle<N A M E \gg>$, Thanks for accepting the invitation. I need your help in our survey on successful purchasing skills. Purchasing is changing. For this reason, on behalf of www.project-perfect.eu. I invite you to participate in our survey and benchmark your answers with other professionals. «<SURVEY LINK〉>. The goal of project PERFECT is to align learning objectives in higher education with the purchasing practice in organisations.

Can I count on you? Thanks in advance!

Regards, Klaas Stek / klaas.stek@utwente.nl

\section{French version:}

Cher/Chère $<<N A M E>>$, Je vous remercie d'avoir accepté l'invitation. J'ai besoin votre aide dans notre sondage sur les compétences d'achat réussies. Achat évolue. Pour cette raison au nom de www.project-perfect.eu je vous invite à participer à notre sondage et de comparer vos réponses avec d'autres professionnels. «<SURVEY LINK〉>. L'objectif du projet PERFECT est d'aligner les objectifs d'apprentissage dans les universités avec les pratiques d'achat des organisations.

Puis-je compter sur vous? Merci d'avance!

Cordialement, Klaas Stek / klaas.stek@utwente.nl

\section{German version:}

Sehr geehrte( $r$ ) $<<N A M E \gg>$, Vielen Dank, dass Sie die Einladung angenommen haben. Ich brauche Hilfe in unserer Umfrage über erfolgreichen Einkauf Fähigkeiten. Einkauf ist im Wandel. Aus diesem Grund lade ich im Namen www.project-perfect.eu ihnen ein zur Teilnahme an unserer Umfrage und um Ihre Antworten mit anderen Fachleuten zu vergleichen. <<SURVEY LINK〉>. Das Ziel des Projekts PERFECT: Lernziele im Bereich der Hochschulbildung abstimmen mit der Einkauf Praxis in Organisationen.

Kann ich auf Sie zählen? Vielen Dank im Voraus!

Viele Grüße, Klaas Stek / klaas.stek@utwente.nI

\section{Dutch version:}

Beste $\langle<N A M E>>$, Dank voor het aannemen van de uitnodiging. Ik heb je hulp nodig in ons onderzoek naar succesvolle purchasing skills. Omdat de inkoop verandert, nodig ik je namens www.project-perfect.eu uit om deel te nemen en je antwoorden te benchmarken. $\langle\langle$ SURVEY LINK〉>. Het doel van PERFECT is om de leerdoelen in het hoger onderwijs af te stemmen op de praktijk.

Kan ik op je deelname rekenen? Bij voorbaat dank!

Groet, Klaas Stek / klaas.stek@utwente.nl 


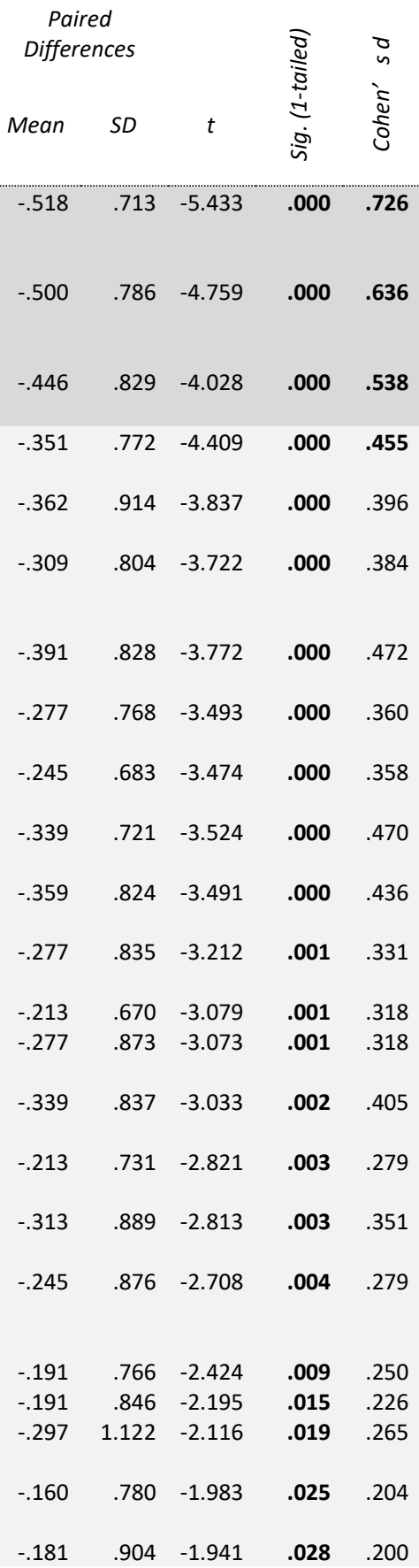


24 Holistic Thinking - Holistic thinking involves understanding a system by sensing its large-scale patterns and reacting to them

25 Poise - Being (self) confident

6 Task management - being able to make prioritisation in business-related tasks

27 Power of Persuasion - Having influential skills

28 Result-orientated action-taking - Aiming on effectiveness

29 Self-assurance - Being assertive and having self-esteem

30 Inter-generation skills - Being aware of and able to work with people from different generations

31 Honesty - Being trustworthy in professional life

32 Conscientiousness - Conscientiousness implies a desire to do a task well and to take obligations to others seriously

33 Social Manners - Being tactful. Diplomatic and having organisational sensitivity

34 Ability to Resolve Conflicts - Being able to avoid and resolve conflicts

35 Critical thinking - the ability to think critically

36 Loyalty - Being loyal in professional life

$-.149$

$-.219$

$.747 \quad-1.933$

$.917-1.909$

$-143$

$\begin{array}{llll}.699 & -1.530 & .066 & .204\end{array}$

$-.128$

$.688-1.422$

$.079 \quad .147$

$-.106$

$\begin{array}{llll}.809 & -1.274 & .103 & .131\end{array}$

$-.156$

$.996-1.256$

$.107 \quad .156$

$\begin{array}{lllll}-.096 & .804 & -1.154 & .126 & .119\end{array}$

$\begin{array}{lllll}-.125 & .833 & -1.124 & .133 & .150\end{array}$

$\begin{array}{lllll}-.096 & .081 & -1.054 & .057 & .108\end{array}$

$\begin{array}{lllll}-.096 & .928 & -1.000 & .160 & .103\end{array}$

$\begin{array}{lllll}-.107 & .867 & -0.925 & .180 & .124\end{array}$

$\begin{array}{lllll}-.053 & .884 & -0.583 & .281 & .060\end{array}$

The sample consists of Business Administration and Industrial Engineering and Management master students $(n=94)$ in the cohorts 2018-2019 $(n=30), 2019-2020(n=26)$, and 2020-2021 $(n=38)$ of the introductory course Purchasing Management at the University of Twente. Used method: Paired t-test; Confidence Interval Percentage: 95\%; Missing Values: Exclude cases analysis by analysis; The students filled out the first survey before the end of the first week of the ten-week course. The same students filled out the second survey before the end of the last week of the course. The 'Mean' results are found by subtracting the different items' outcomes in the second survey from those in the first survey. Both surveys were measured on a 5-point-Likert scale from "fully disagree" to "fully agree". Cohen's d effect sizes: 'small' $(.2<d<.5)$; 'medium' (.5<d<.8); and 'large' (.8<d<1.2) (Cohen, 1988, pp. 25-26; Sawilowsky, 2009). 
Mean Mean

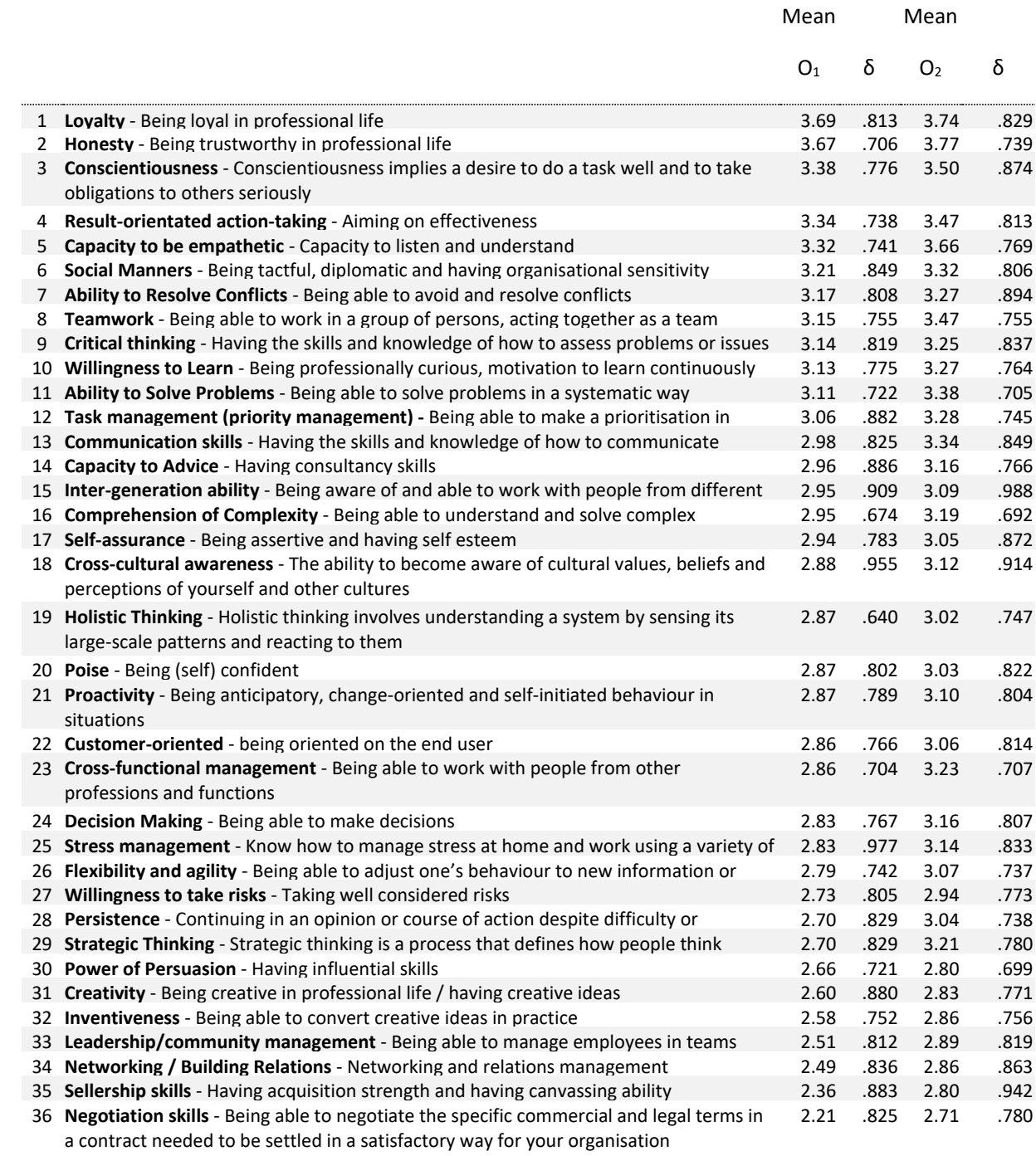

Notes: $O_{1}$ is the first survey that was held in the first week of the course; $O_{2}$ is the second survey, taken after the course; the items were measured on a 5-point Likert scale (fully disagree to fully agree) 


\author{
Knowledge and Professional \\ Skills \\ analytical skills; eProcurement; big \\ data analytics; business and financial \\ acumen; change management; \\ contract management; cost savings; \\ customer focus; innovation sourcing \\ (approaches) and implementation; \\ PSM best practice intelligence \\ scouting; risk management; \\ prioritisation; remote virtual \\ working; supply chain; sales; \\ negotiation; process management \\ and optimisation; product \\ knowledge; project management; \\ quality assurance; stakeholder \\ relationship management; supplier \\ management; strategic sourcing; \\ tools and systems implementation; \\ sustainability ( $n=25 ; 42.4 \%$ in Ch. 2)
}

Outcomes Chapter 2 - PSM Competences: Current and Future Requirement

communication skills; cross-

functional cooperation (with logistics, production, marketing, quality, R\&D); conflict resolution; cross-functional abilities \& knowledge; cultural awareness; decision making; effective questioning; interpersonal communication techniques; languages; leadership; networking; teamwork-working in teams $(n=16$; $27.1 \%$ in Ch. 2)

\section{Intrapersonal Character} Traits

creativity; critical thinking; curiosity; deal with ambiguity; holistic supply chain thinking; humility; integrity; learning agility; mobility; openness / open-minded; passion; resilience; results focus driving for results; selfconfidence; self-reflection; selfreliance; strategic thinking; a structured way of working ( $n=18$; $30.5 \%$ in Ch. 2)

Outcomes Chapter 3 - Public Procurement of Innovation Skills Requirements analytical skills; add value to the organisation with PSM; change management; corporate governance; contract development; early procurement involvement; early supplier involvement; innovation implementation; innovation sourcing; IT skills; legal knowledge; strategic business partner behaviour; vision translation into practical plans; sustainability and circular economy (CSR) $(n=14 ; 34.1 \%$ in Ch. 3$)$

adaptive to change; challenge suppliers to be innovative; collaborative skills/work in multidisciplinary teams; communicative skills; create commitment/support for innovations; distinguish the 'real need' behind the demand / profound and curious questioning the internal partner; emphatic; establish an open dialogue with the market; working together with the legal department; networking skills, i.e. create and sustain relationships; organisational sensitivity; persuasive; social skills; willing 'to leave the office', (e.g. frequently visit the internal partner, to do job rotations and internship within the company); visible as procurement officer to the internal partner; 'sell' procurement's advantages in an organisation ( $n=$ $16 ; 39.0 \%$ in Ch. 3 ) creativity / 'out-of-the-box' thinking; critical thinking; courage; efficient and effective way; entrepreneurial skills; loyalty; proactive attitude; Sellership skills; showing/taking the initiative; decisiveness; being riskcontrolling rather than risk-avoiding $(n=11 ; 26.8 \%)$

\footnotetext{
Outcomes Chapter 4 - Is there a "European Purchaser"? Comparing Requirements in Job Ads from different European Countries with cultural models analytical skills; business and trade knowledge and experience; computer literacy; experience in the focal industry; legal knowledge; negotiation skills; organisational skills; technical higher education; technical knowledge and experience $(n=9 ; 27.3 \%$ in Ch. 4$)$

communication skills; customeroriented; English language proficiency; diplomacy, social manners and political sensitivity; persuasiveness; team player - having team spirit - ability to be on a team $(n=7 ; 21.2 \%$ in Ch. 4)

accuracy and precision; complexity handling skills; creativity; devotedness; discipline; energy drive; flexibility; independency sole-responsibility; innovativeness; persistence; pragmatic - hands-on mentality; proactive - taking the initiative problem-solving skills; result-orientated action-taking being result-driven; responsibility; stress avoidance - ability to handle stress; willingness to travel $(n=17$; $51.5 \%$ in Ch. 4)
} 
Outcomes Chapter 5 - The Purchaser for Innovation: Innovation, Management and Soft Skills and the Importance of Organisational Support

change management; corporate governance; early supplier involvement; innovation sourcing and implementation; project management; sustainable purchasing (CSR) $(n=6 ; 37.5 \%$ in Ch. 5$)$ conflict resolution; consultancy skills; cooperation with the departments HRM, Marketing Management and $\operatorname{R\& D}(n=5 ; 31.3 \%$ in Ch. 5$)$ comprehension of complexity / complex problems; creativity; honesty; inventiveness / imagination; willingness to take risks $(n=5 ; 31.3 \%$ in Ch. 5$)$

\section{Outcomes Chapter 6 - Purchasing Skills leading to Success: A Necessary Condition Analysis}

add value to the organisation with PSM (know-how); change management; corporate governance; big data analyses; category strategy development; cost analyses; cost reduction techniques; early supplier involvement; employee Integration and development plan; employee performance measurement; global sourcing; innovation implementation; innovation sourcing; key performance indicators defining (KPI's); negotiation; performance measurement and follow-up; personnel selection process; pooling planning \& demand; portfolio analysis support; process management; project management skills; purchasing knowledge; purchasing processes optimisation; purchasing roles and job profiles design; solicit offers; stakeholder relationship management; statistical analyses; strategic business partner; supplier development; supplier evaluation; supplier relationship management; supply risk management; supply market analysis; sustainability; understanding the position of PSM in an organisation $(n=35 ; 55.6 \%$ in Ch. 6) advice skills; building relations/networking; conflict resolution; empathy; comprehension of complexity; conscientiousness; cooperation with the department HRM; cross-cultural awareness; customer orientation; honesty; leadership/managing personnel; persuasion; social manners; team ability skills; training personnel $(n=$ $15 ; 23.8 \%$ in Ch. 6 ) creativity; inventiveness; holistic thinking; loyalty; personality characteristics development (e.g. entrepreneurial); poise; proactivity; problem-solving; salesperson skills/sellership skills; self-assurance; result-orientated action-taking; willingness to learn; willingness to take risks ( $n=13 ; 20.6 \%$ in Ch. 6 ) 
Outcomes per chapter

\begin{tabular}{|c|c|c|c|c|c|c|}
\hline Knowledge and professional skills & 2 & 3 & 4 & 5 & 6 & \# \\
\hline $\begin{array}{l}\text { add value to the organisation with PSM / understand corporate } \\
\text { governance and the organisational context of PSM / PSM best practice } \\
\text { intelligence }\end{array}$ & $x$ & $\mathrm{x}$ & $\mathrm{x}$ & $\mathrm{x}$ & $x$ & 5 \\
\hline $\begin{array}{l}\text { customer-oriented / being a strategic business partner for the internal } \\
\text { customer / enabling early procurement involvement }\end{array}$ & $x$ & $x$ & $x$ & & $\mathrm{x}$ & 4 \\
\hline $\begin{array}{l}\text { early supplier involvement/supplier and supply chain management / } \\
\text { establish an open dialogue with the market }\end{array}$ & $x$ & $\mathrm{x}$ & & $\mathrm{x}$ & $x$ & 4 \\
\hline eProcurement / IT skills / computer literacy & $\mathrm{x}$ & $x$ & $x$ & & $x$ & 4 \\
\hline $\begin{array}{l}\text { innovation sourcing (approaches) and implementation / strategic } \\
\text { sourcing }\end{array}$ & $x$ & $\mathrm{x}$ & & $\mathrm{x}$ & $x$ & 4 \\
\hline project management / organisational skills & $x$ & & $x$ & $x$ & $x$ & 4 \\
\hline sustainability and circular economy (CSR) & $\mathrm{x}$ & $x$ & & $x$ & $x$ & 4 \\
\hline analytical skills / big data analytics & $\mathrm{x}$ & & $\mathrm{x}$ & & $x$ & 3 \\
\hline $\begin{array}{l}\text { business and financial acumen/business and trade knowledge and } \\
\text { experience/experience in the focal industry }\end{array}$ & $x$ & & $\mathrm{x}$ & & & 2 \\
\hline contract management / contract development & $x$ & $x$ & & & & 2 \\
\hline legal knowledge & & $\mathrm{x}$ & $x$ & & & 2 \\
\hline negotiation & $x$ & & $x$ & & & 2 \\
\hline $\begin{array}{l}\text { process management and optimisation/tools and systems } \\
\text { implementation }\end{array}$ & $x$ & & & & $\mathrm{x}$ & 2 \\
\hline technical knowledge, experience or higher education & $x$ & & $x$ & & & 2 \\
\hline stakeholder relationship management & $\mathrm{x}$ & & & & $x$ & 2 \\
\hline cost savings & $\mathrm{x}$ & & & & $x$ & 2 \\
\hline multi-disciplinary knowledge (quality assurance, risk management, sales) & $x$ & & & & $x$ & 2 \\
\hline Interpersonal Skills & 2 & 3 & 4 & 5 & 6 & $\begin{array}{l}41 \\
\#\end{array}$ \\
\hline $\begin{array}{l}\text { conflict resolution / diplomacy, social manners and political sensitivity / } \\
\text { organisational sensitivity }\end{array}$ & $\mathrm{x}$ & $\mathrm{x}$ & $\mathrm{x}$ & $\mathrm{x}$ & $\mathrm{x}$ & 5 \\
\hline $\begin{array}{l}\text { communication skills / interpersonal communication techniques / social } \\
\text { skills }\end{array}$ & $x$ & $\mathrm{x}$ & $\mathrm{x}$ & & $\mathrm{x}$ & 4 \\
\hline change management & $\mathrm{x}$ & $\mathrm{x}$ & & $\mathrm{x}$ & $\mathrm{x}$ & 3 \\
\hline $\begin{array}{l}\text { collaborative skills / work in multi-disciplinary teams / cross-functional } \\
\text { cooperation (with HRM, legal, logistics, marketing, production, quality, } \\
\text { R\&D) }\end{array}$ & $\mathrm{x}$ & $\mathrm{x}$ & & $\mathrm{x}$ & $x$ & 4 \\
\hline networking & $x$ & $x$ & & & $\mathrm{x}$ & 3 \\
\hline $\begin{array}{l}\text { internal business partner orientation / effective questioning / distinguish } \\
\text { the 'real need' behind the demand (emphatic, i.e. listening and } \\
\text { understanding) / profound and curious questioning the internal partner }\end{array}$ & $x$ & $x$ & & & $\mathrm{x}$ & 3 \\
\hline $\begin{array}{l}\text { persuasion / create commitment/support challenge suppliers to be } \\
\text { innovative / 'sell' procurement's advantages in an organisation. }\end{array}$ & & $\mathrm{x}$ & $x$ & & $x$ & 3 \\
\hline $\begin{array}{l}\text { teamwork / being a team player / having team spirit/ability to be on a } \\
\text { team }\end{array}$ & $\mathrm{x}$ & & $\mathrm{x}$ & & $x$ & 3 \\
\hline cross-cultural awareness & $x$ & & & & $x$ & 2 \\
\hline advising/consultancy skills & & & & $x$ & $x$ & 2 \\
\hline cross-functional abilities \& knowledge & $x$ & & & & $x$ & 2 \\
\hline languages / English language proficiency & $x$ & & $\mathrm{x}$ & & & 2 \\
\hline leadership & $\mathrm{x}$ & & & & $x$ & 2 \\
\hline
\end{tabular}




\begin{tabular}{|c|c|c|c|c|c|c|}
\hline Intrapersonal character traits & 2 & 3 & 4 & 5 & 6 & \# \\
\hline creative and innovative handling skills / 'out-of-the-box' thinking & $x$ & $x$ & $x$ & $\mathrm{x}$ & $x$ & 5 \\
\hline $\begin{array}{l}\text { entrepreneurial or sellership skills / courage / willingness to take risks / } \\
\text { deal with ambiguity }\end{array}$ & $\mathrm{x}$ & $\mathrm{x}$ & $\mathrm{x}$ & $x$ & $\mathrm{x}$ & 5 \\
\hline flexibility / mobility / willingness to travel / adaptive to change & $\mathrm{x}$ & $\mathrm{x}$ & $\mathrm{x}$ & & $\mathrm{x}$ & 4 \\
\hline integrity, honesty, loyalty & $\mathrm{x}$ & $x$ & & $\mathrm{x}$ & $x$ & 4 \\
\hline $\begin{array}{l}\text { result-orientated action-taking - being result-driven / being efficient and } \\
\text { effective / being persistent / being pragmatic - having a hands-on } \\
\text { mentality }\end{array}$ & $\mathrm{x}$ & $\mathrm{x}$ & $\mathrm{x}$ & & $\mathrm{x}$ & 4 \\
\hline comprehension of complexity / complex problems / problem solving & & & $\mathrm{x}$ & $x$ & $\mathrm{x}$ & 3 \\
\hline $\begin{array}{l}\text { critical thinking, strategic thinking and holistic thinking/vision translation } \\
\text { into practical plans }\end{array}$ & $\mathrm{x}$ & $\mathrm{x}$ & & & $\mathrm{x}$ & 3 \\
\hline decisiveness & $x$ & $\mathrm{x}$ & & & & 2 \\
\hline inventiveness / imagination & & & & $\mathrm{x}$ & $\mathrm{x}$ & 2 \\
\hline proactive attitude/showing/taking initiative & & $\mathrm{x}$ & $\mathrm{x}$ & & $x$ & 2 \\
\hline energy drive / passion & $x$ & & $\mathrm{x}$ & & & 2 \\
\hline accuracy and precision / structured way of working/prioritisation & $x$ & & $x$ & & & 2 \\
\hline curiosity and learning agility & $x$ & & & & & 1 \\
\hline discipline and devotedness & & & $\mathrm{x}$ & & & 1 \\
\hline independency - (sole)-responsibility & & & $\mathrm{x}$ & & & 1 \\
\hline openness / open-minded & $x$ & & & & & 1 \\
\hline self-confidence / self-reflection / self-reliance / resilience & $\mathrm{x}$ & & & & & 1 \\
\hline stress avoidance - ability to handle stress & & & $\mathrm{x}$ & & & $\begin{array}{c}1 \\
40\end{array}$ \\
\hline
\end{tabular}


Statements focussed on cost reductions $-\alpha=.783$

(Nollet et al., 2005; Schiele, 2007; Schiele, Horn, et al., 2011; Schulze et al., 2019; Shin et al., 2000)

Due to my actions, we achieved higher than average cost reductions.

Compared with other departments, my department achieved higher than average reductions in costs.

The reductions in costs achieved in my department are considerably higher than our goals.

Statements focussed on quality $-\alpha=.761$

(Fernandes et al., 2017; Forker et al., 1997; Nollet et al., 2005; Schulze et al., 2019; Shin et al., 2000)

Due to my actions, we achieved a higher-than-average level of quality.

Compared with other departments, my department achieved higher quality goals.

The improvements in quality achieved in my department are considerably higher than our goals.

Statements focussed on sustainability $-\alpha=.872$

(Johnsen et al., 2014; Schulze \& Bals, 2020; Schulze et al., 2019; Wilding et al., 2012)

Due to my actions, we achieved a higher-than-average level of sustainability.

Compared with other departments, my department achieved higher sustainability goals.

The improvements in sustainability achieved in my department are considerably higher than our goals.

Statements focussed on the delivery of supplies $-\alpha=.755$

(Giunipero, 2000; Nollet et al., 2005; Schulze et al., 2019; Shin et al., 2000; Zimmer, 2002)

Due to my actions, we improved the supply delivery process.

We outperform the benchmark with other departments; my department achieved higher supply delivery

goals.

The improvements in the delivery performance of suppliers achieved in our department are considerably higher than our goals.

Statements focussed on innovation $-\alpha=.850$

(Azadegan \& Dooley, 2010; Foerstl et al., 2013; Hesping \& Schiele, 2015; Johnsen et al., 2012; Krause et al., 2009; Legenvre \& Gualandris, 2018; Nollet et al., 2005; Schiele, Horn, et al., 2011; Schulze et al., 2019; Terpend et al., 2011)

Due to my actions, product and process improvements have been implemented.

Due to my actions, we achieved more product and process improvements than average.

Due to my actions, we identified more useful ideas with suppliers than the benchmark.

The product and process improvements achieved in my department/company are considerably better than expected.

Statements focussed on long-term competitive advantages? $-\alpha=.812$

(Barney, 1991, 2012; Dyer, 1996; Nollet et al., 2005)

Due to my actions, my organisation obtained a long-term competitive advantage.

The long-term competitive advantage of my organisation is considerably better than those of competitors.

We do better than expected: the improvements in obtaining the long-term competitive advantage of my organisation are considerably higher than expected.

Statements focussed on supplier satisfaction? $-\alpha=.757$

(Nollet et al., 2005; Pulles, Schiele, et al., 2016; Vos et al., 2016)

Due to my actions, the suppliers see the importance of cooperating with my company/department Due to my actions, the relationship with our most important supplier(s) is (are) improved significantly Due to my actions, my company has become a preferred customer of our most important supplier(s)

The form and wording of the 'cost reduction' and 'innovation' statements are based upon Azadegan and Dooley (2010); Hesping and Schiele (2016); Krause et al. (2001); Schiele, Horn, et al. (2011); and Terpend et al. (2011). The quality, sustainability, delivery, competitive advantage and supplier satisfaction items are based on the literature and stated in the exact wordings. Note: $\alpha$ is Cronbach's Alpha for the construct. 


\section{Chapter 10}

\section{Future Research for PSM}




\section{FUTURE RESEARCH FOR PSM}

\subsection{Project PERSIST - towards PSM competences in the era of Industry 4.0}

In section 1.4, Project PERFECT is explained. This project lasted from 2015 to 2018. Project PERSIST (Purchasing Education Research Syndicate: Industry 4.0 Skills Transfer) builds further on Project PERFECT and is carried out in almost the same constellation. The newcomer to the action is EUBA in Košice, Slovakia. After the first attempt in 2018, the project was awarded in 2019 after the second submission.

Project PERSIST is an initiative of the University of Twente in Enschede (NL), TU Dortmund (Technische Universität Dortmund) in Dortmund (D), LUT University (Lappeenrannan-Lahden Teknillinen Yliopisto) in Lappeenranta (FIN), Edge Hill University in Ormskirk (UK) and the Economic University of Bratislava with a seat in Košice - EUBA (Ekonomickej univerzity v Bratislave so sídlom v Košiciach) in Košice (SK). Whereas TU Dortmund led Project PERFECT, Project PERSIST is submitted in the Netherlands by the project lead, the University of Twente.

The project concerns a new development that gained unpreceded momentum, i.e. the Fourth Industrial Revolution (Industry 4.0). Cyber-physical systems with autonomous machine-to-machine communication are re-shaping parts of our economy. The PSM is amongst the areas that are most strongly affected. Hence, the competence set that purchasers need to manage and organise such systems and to prevail efficiently in an Industry 4.0 world is changing, too.

There is a strong demand for directions on managing this change in general and educating and preparing the purchasing workforce within education and industry. The aim and innovation of this proposal, therefore, lies in a) identifying those skills which are likely to prevail and those who are newly added to the profile of a European purchaser to develop an Industry 4.0 PSM Skill framework and b) developing a modulebased course for higher education to teach these skills and c) to develop new, 
gamification and playful interaction oriented didactical elements for purpose studentcentred teaching approach, including a gamified course.

The challenge is that very little knowledge is currently available on how to react to Industry 4.0 induced change from an educational perspective. The following questions have been formulated:

How will the purchaser in Industry 4.0 have to act?

Which skills and knowledge are purchasers likely to need in Industry 4.0?

How to train current students as purchasers of the future in an efficient, modern way (i.e. student-centred), i.e. already reflecting the new technologies?

The project started in September 2019 and will end in August 2020. The White Papers are downloadable from the website www.project-persist.eu.

\subsection{Project PERISCOPE - towards PSM competences in the era of the circular economy}

The Project PERISCOPE (Purchasing Education Research with an Innovative Sustainability Scope) is an initiative of the University of Twente, ESSCA (École supérieure des sciences commerciales d'Angers) in Angers (F) and Audencia (Ecole Supérieure de Commerce Audencia Nantes) in Nantes (F), CBS - Copenhagen Business School (Handelshøjskolen $i$ København) in Copenhagen (DK) and TU Graz (Technische Universität Graz) in Graz (A).

Project PERISCOPE is similar to Project PERSIST, building further on the outcomes of Project PERFECT. The project management plan and structure of Project PERISCOPE are similar to the sister-project PERSIST. Project PERSIST was handed in with the Dutch National Agency for Erasmus+ EU-funding in The Hague, and Project PERISCOPE was parallel submitted to the French National Agency in Bordeaux.

The project aims to prepare students in acquiring future PSM competences and key competences towards innovative and sustainable solutions. In the fastchanging world, PSM employers need to keep pace with the occurring developments. Institutes for higher education need to be a step ahead of the future's employer needs and have to face the future and prepare students for the upcoming developments, i.e. sustainable developments. There is a strong demand for directions on managing this change in general and educating and preparing the purchasing workforce, particularly within education and industry.

Project PERISCOPE's objective is to address this demand by identifying those competences that are likely to prevail and those who are newly added to the profile of 
a European purchaser and develop a course-set to teach these competences. Moreover, PERISCOPE will develop open student-centred learning in a digital space with educational materials and simulation games. The challenge is that currently, very little knowledge is available on how purchasing managers, together with their suppliers, can develop sustainable and innovative solutions to face the environmental changes and requirements from an educational perspective. The following research questions are arising

How will the purchasing and supply managers select and evaluate sustainable suppliers?

What skills and knowledge are managers likely to need to develop sustainable and innovative solutions together with their suppliers?

How to train current students as employees of the future in an efficient, modern way (i.e. student-centred), i.e. already reflecting innovative and integrated methods?

The project started in September 2019 and will end in August 2020. The White Papers are downloadable from the website http://eu-periscope.essca.fr/.

\subsection{Future projects for academic and lifelong learning in PSM}

In the coming years, higher education institutions may expect an unprecedented, parallel stream of students. Experienced PSM practitioners will follow courses and workshops in lifelong learning programmes (see: Georgia Tech, 2018). This parallel stream of students needs another approach by didactics, content and even testing. The questions about "what" and "how" will be answered in possible new projects.

Public procurement and health care procurement are possible future topics. Public procurement is increasingly used as a tool to promote innovativeness and sustainability. Health care spends are increasing due to an ageing population. Which competences need to be taught at universities, and how to develop practitioners? Moreover, the digital era and Al may cause onshoring activities and the return of production in the region supported by the need to mitigate supply chain risks experienced during the covid-crisis and the block of the Suez canal. How can public and private organisations benefit from a regional network, and which competences are needed? The PERFECT research showed gender inequality in PSM (Bijl et al., 2020; Stek, Bijl, \& Sigurđardóttir, 2021) 


\section{Chapter 11}

\section{Publications Coming Forth from this Dissertating}




\section{PUBLICATIONS COMING FORTH FROM THIS DISSERTATION}

\subsection{Academic output per chapter}

The texts of all chapters, including parts of the introduction, are based on papers submitted, peer-reviewed, accepted and presented at scientific conferences and partly published in scientific journals. However, the activities in the context of this dissertation provided additional publications in proceedings of peer-reviewed conferences (see: §11.2), at a practitioners conference and in articles for practitioners magazines (see: §11.3).

Parts of Chapters 1 and 7 were presented at INTED 2019 in Valencia. Spain in March 2018 (Stek, Zunk, Berg, et al., 2018) and at IPSERA 2019 in Milan, Italy, in April 2019 (Stek \& Wieland, 2019).

In developing stages, Chapter 2 was presented at IPSERA 2017 in Balatonfüred. Hungary in April 2017 (Bals, Kelly, Schulze, \& Stek, 2017) and at IPSERA 2018 in Athens. Greece (Bals, Schulze, Kelly, \& Stek, 2018) in March 2018 and is published in the special $25^{\text {th }}$-anniversary edition of the Journal for Purchasing and Supply Management (Bals et al., 2019).

Chapter 3 was presented at WION 2019 in Lunteren, the Netherlands, in January 2019 and IPSERA 2019 in Milan, Italy, in April 2019 (Stek et al., 2019).

Chapter 4 was presented at IPSERA 2017 in Balatonfüred, Hungary, in April 2017 (Stek et al., 2017) and is published in the International Journal of Procurement Management (Stek, Zunk, et al., 2021).

Chapter 5 was presented at IPSERA 2018 in Athens, Greece, in April 2018 (Stek, Zunk, Vos, \& Schiele, 2018) and is ready to be submitted for publication.

Chapter 6 was presented at IPSERA 2018 in Athens, Greece, in April 2018 (Stek, Zunk, \& Schiele, 2018). It is subjected to a novel methodology, i.e. necessary condition analysis 
was rewritten and presented at WION 2020 in Lunteren, the Netherlands. An altered version is accepted and submitted to IPSERA 2020 in Knoxville, TN, USA, and is under review for the IPSERA 2020 edition of the Journal of Purchasing and Supply Management.

Chapter 7, "Developing Soft Skills of PSM Graduates", is accepted and submitted to IPSERA 2021 (Stek, 2021). The chapter proposal is accepted for the upcoming book "Training Engineering Students for Modern Technological Advancement", published by IGI Global, an international publisher of advanced academic research.

\subsection{Other peer-reviewed publications coming forth from the dissertation}

"An Empirical Study of the Relationships among Purchasing Skills and Supplier Integration, Internal Integration and Customer Focus" was presented at IPSERA 2017 in Balatonfüred, Hungary, in April 2017 (Karttunen et al., 2017)

"European Higher Education Landscape - Analysis of existing purchasing study programmes" was presented at IPSERA 2018 in Athens, Greece, in March 2018 (Berger et al., 2018)

"Purchasers' Personality Profile" was presented at IPSERA 2018 in Athens, Greece, in March 2018 (V. Koch, Zunk, \& Stek, 2018)

"Comparing Purchasing and Supply Management Job Advisements in Europe and Confucian Chinese Society" was presented at IPSERA 2018 in Athens, Greece, in March 2018 (Stek, Zhang, et al., 2018)

"Purchasing Professionals' Performance: Literature-driven Research Model and Empirical Test" was presented at IPSERA 2018 in Athens, Greece, in March 2018 (Zunk, Koch, Stek, \& Schiele, 2018)

"Detection of Differences of the Purchasing Culture in the Confucian Chinese Society" was presented at Euro-Asia Forum in Politics, Economics and Business 2018 in Zagreb, Croatia, in July 2018 (Zunk \& Stek, 2018)

"Key Competences and Core Skills of Young Professionals in Purchasing in the Era of Industry 4.0: Research Concept and Framework for Higher Education Institutions to face Future Challenges" was presented at Euro-Asia Forum in Politics, Economics and Business 2018 in Zagreb, Croatia in July 2018 (Swobodnik, Stek, \& Zunk, 2018)

"The human aspect in Purchasing \& Supply Management - Traits as a proxy for personal skills development" would have been presented at IPSERA 2020 in Knoxville, TN, USA in April 2020; however, due to the COVID-19 virus, the conference is postponed to 2021 (Stek et al., 2020). The paper is resubmitted for IPSERA 2021 and has been invited for 
the IPSERA 2021 edition of the Journal of Purchasing and Supply Management.

"The role of knowledge conversion in developing operational capabilities: An organisational routines perspective" would have been presented at IPSERA 2020 in Knoxville, TN, USA in April 2020; however, due to the COVID-19 virus, the conference is postponed to 2021 (Kelly, Bals, et al., 2020). The paper is presented at IPSERA 2021 and has been invited for the IPSERA 2021 edition of the Journal of Purchasing and Supply Management.

"Smart Supply Chain: Are the Procurers Ready for Industry 4.0" presented at the 28th Interdisciplinary Information Management Talks - Digitalized Economy, Society and Information Management in Kutná Hora, Czech Republic in September 2020 (Tkáč et al., 2020).

"Opportunities for Gamified Learning in Purchasing and Supply Management Education" is presented at the 14th European Conference on Games Based Learning in Brighton, UK, in September 2020 (Kelly, Vangorp, et al., 2020).

"Suppliers' roles in sustainability in early product development phases" has been presented at the online IPSERA 2021 in March 2021 (Groeneveld, Kartoidjojo, Kuiper, Reineman, \& Stek, 2021). This working paper is the result of the student-centred approach as described in Chapter 7.

"Gender differences in purchasing" is presented at the online WION 2021 in January 2021 and the online IPSERA 2021 in March 2021 (Stek, Bijl, et al., 2021).

"Purchasing in the area of Innovation and Sustainability: A Study into Current and Future Competences" is presented at the online IPSERA 2021 in March 2021 (V. Koch, Stek, \& Picaud-Bello, 2021) and is the winner of the Best Paper Award IPSERA 2021. The paper has been invited for the IPSERA 2021 edition of the Journal of Purchasing and Supply Management.

"Exploring Industry 4.0 Professional Roles and Skills within Purchasing and Supply Management" is submitted for the online IPSERA 2021 in March 2021 (Delke, Karttunen, Kelly, Stek, \& Tkáč, 2021). The paper has been invited for the IPSERA 2021 edition of the Journal of Purchasing and Supply Management.

"Defining Industry 4.0 skills in Purchasing and Supply Management" is accepted for the EurOMA 2021 conference in Berlin in July 2021 (Delke, Schiele, Buchholz, \& Stek, 2021).

\subsection{Non-peer-reviewed publications}

"Kloof tussen inkooponderwijs en marktbehoefte" (Gap between purchasing education and market needs) - NEVI Deal! June 2017 (Stinenbosch \& Stek, 2017b).

"The gap between academic purchasing education and the market needs" - Inprocurement, July / August 2017 (Stinenbosch \& Stek, 2017a). 
"European Survey on Purchasing Competences-3rd White Paper: purchasing skills leading to success-outcomes, results and outlooks - European Survey on Purchasing Competences-3rd White Paper" - Project PERFECT - November 2017 (Stek, 2017b).

"4 Scenario's voor inkoop in 2035 - Hoogleraar supply chain management kijkt naar de toekomst" - (4 Scenario's for procurement in 2035 - Professor supply chain management looks into the future" - NEVI Deal! December 2017 (Stek, 2017a).

"Procurement in the future - Where will procurement be in 2035" - In-procurement. December 2017 (Stek, 2017d).

"Future of Purchasing and Supply Management Skills: An Outlook Based on Project PERFECT" was presented at LIMEN 2017 in Belgrade, Serbia, in December 2017 (Stek, 2017c).

"Inkoopvaardigheden die wél tot succes leiden" (Purchasing skills leading to success" NEVI Deal! February 2018 (Stek, 2018a).

"A look into the Future of Procurement - Where will we be in 2035?" - WINGBusiness April 2018 (Stek, 2018b).

"5 Megatrends binnen inkoop" (5 Megatrends for procurement) - NEVI Deal! October 2018 (Bapeer et al., 2018).

"Vaardigheden die leiden tot inkoopsucces" (Skills leading to purchasing success) - NEVI Deal! December 2018 (Hoorn \& Stek, 2018).

"Op naar een toekomstig competentieprofiel - mismatch tussen onderwijs en praktijk" (interview) (Towards a future proof competence profile - mismatch between education and practice) - NEVI Deal! April 2019 (Andriesse, 2019).

"De Feminisering van de Inkoop: het Nieuwe Normaal" (The Feminisation of Purchasing - the New Normal) - NEVI Deal! September 2020 (Bijl et al., 2020). 


\section{Chapter 12}

\section{Summary and Red Thread}




\section{SUMMARY AND RED THREAD}

\subsection{Summary in English}

This dissertation's overarching research objective is to determine which competences lead to success in the purchasing and supply (chain) management function, and the eventual focus is on the most distinct strategic activity in purchasing, which is innovation sourcing.

In the past decades, the purchasing and supply chain management discipline changed from an operational function to a strategic function. Innovations are increasingly purchased from suppliers or are co-developed. It places the purchasers in the so-called 'boundary spanner' role, meaning that they became virtual bridgebuilders between the partners in the internal organisation and the possible suppliers somewhere in the global market.

Purchasers fulfil a vital role as 'boundary spanner', and a precondition for purchasing's success is a high level of top managerial support. With quantitative methods, evidence is shown that investing in purchasers' competence development is useless without acknowledging the importance of the purchasing function in innovation sourcing. In an excellent organisational atmosphere, purchasers can develop and apply their competences.

This study measured purchasers' levels of success or effectiveness per specific purchasing focus (i.e. cost reduction, quality improvement, delivery improvement, sustainability improvement, innovation sourcing, increasing supplier satisfaction and competitive advantage), and purchasers' competences are revealed that are either sufficient or necessary. Primarily hard skills are associated with success or effectiveness, but soft skills are necessary for hard skills.

The outcomes show that purchasers need knowledge and understanding about their product and process but highlight the essence of soft skills. With 
quantitative methodologies, a hierarchy in competences is revealed; soft skills are necessary conditions to carry out professional hard skills. A successful purchaser for innovations possesses networking skills, complex problem solving, proactivity, resultdriven, conflict-resolution, creativity, persuasion, curiosity and an entrepreneurial attitude. These soft skills are necessary to perform well in hard skills as supplier relationship management, innovation management, analytical skills, process and project management and personnel leadership skills that characterise the successful purchaser of innovations.

Purchasers need to align the purchasing strategy with the organisation's strategy and carry out a strategic purchasing plan. To execute these professional hard skills, soft skills, attitudes or traits are needed as strategic thinking, inventiveness, and creativity. However, the literature shows that universities are focused on the learning outcomes regarding hard skills and theory. Therefore, soft skills are mostly absent in courses' learning objectives.

This dissertation's recommendation for higher education is to include soft skills learning objectives. However, the question is whether these attitudes or traits are innate or can be developed. Therefore an educational experiment is executed demonstrating how soft skills could be developed with three cohorts of master students via a student-centred approach within a timeframe of ten weeks. The educational construct is differentiating between didactics, learning outcomes and assessment of 'knowledge', 'skills' and 'traits' with a book writing project, a real-life purchasing case and personality development workshops.

Moreover, this dissertation provides a historical context of purchasing and education in the era of the Internet-of-Thing or Industry 4.0 (i.e. the $4^{\text {th }}$ Industrial Revolution). A parallel is drawn with the challenges during the $1^{\text {st }}$ Industrial Revolution, about two centuries ago. Soft skills development is highly associated with the $19^{\text {th }}$. century "Bildung" ideals to create 'better citizens'. Recently, a similar call resounded in the European ministers for education meeting: students need "to become active and responsible citizens in the future". This thesis alerts that imposed Bildung would obstruct conscious self-development; soft skills development can be influenced by external stimuli but is nevertheless a personal effort.

The conclusion could very well be made that the necessity of soft skills for purchasers is forming this dissertation's red thread. The absence of attention for soft skills development in purchasing curricula in higher education is the other side of the same coin. In Chapter 7 is demonstrated that soft skills can be developed in a short time frame. 


\subsection{The red thread of the dissertation}

In Figure 12.1, the red thread is graphically displayed. As described in Chapter 1 , the literature suggests that PSM success is reached with a highly competent staff and a high level of top managerial support for the PSM function (e.g. Cousins et al., 2006; Tassabehji \& Moorhouse, 2008); Chapter 5 is providing empirical evidence for this statement based upon an extensive survey data set and with polynomial regression techniques.

In Chapter 1 is shown that the literature agrees that a competent purchaser possesses the right set of hard skills (i.e. knowledge and professional skills) and soft skills (interpersonal skills and intrapersonal traits and behaviour) (e.g. Bals et al., 2019; Giunipero \& Pearcy, 2000). Despite the high importance of hard skills, the even higher importance of intrapersonal traits and behaviour form a red thread in this dissertation.

The importance of soft skills has been increasing over the last decade and will further increase, as described in Chapter 2 and 3. Chapter 4 shows that half of the job advertisements' requirements can be categorised as soft skills, of which two-thirds are intrapersonal traits and behaviour and one-third interpersonal, human-to-human skills. Moreover, the soft skills requirements are exposed to the cultural context; employers in various countries demand other soft skills, and due to structural differences (service versus industry), employers demand other hard skills.

Although employers demand a substantial volume of soft skills (see: Chapters 2 and 4), learning objectives in higher education are mainly focused on the learning of hard skills and some occasions on soft skills and more precisely on interpersonal, human-to-human communication, mostly limited to presentation skills and teamwork (see: Chapter 1). Hence there is a gap between what institutions for higher education 'deliver' and what employers demand.

Soft skills are not just 'important' for purchasing but are indispensable and therefore necessary, as suggested in the literature, as described in Chapter 1 . Chapter 6 contributes to the literature and provides empirical evidence that soft skills are necessary conditions for carrying out hard skills. Another contribution of Chapter 6 is that it demonstrates that for different PSM foci, different competence sets are required (see: Figure 12.1).

As noted before, in higher education, soft skills learning objectives are rarely found in general (Hoidn, 2017) or in the specific PSM, logistics and SCM curricula (e.g. Birou et al., 2016; Stinenbosch, 2017; Wong et al., 2014). The absence of these soft skills learning objectives is described, although the literature is clear that soft skills can be developed and highly appreciated by employers. Therefore, an experiment was set up in Chapter 7 to demonstrate how soft skills can be developed in a cohort of master students. 


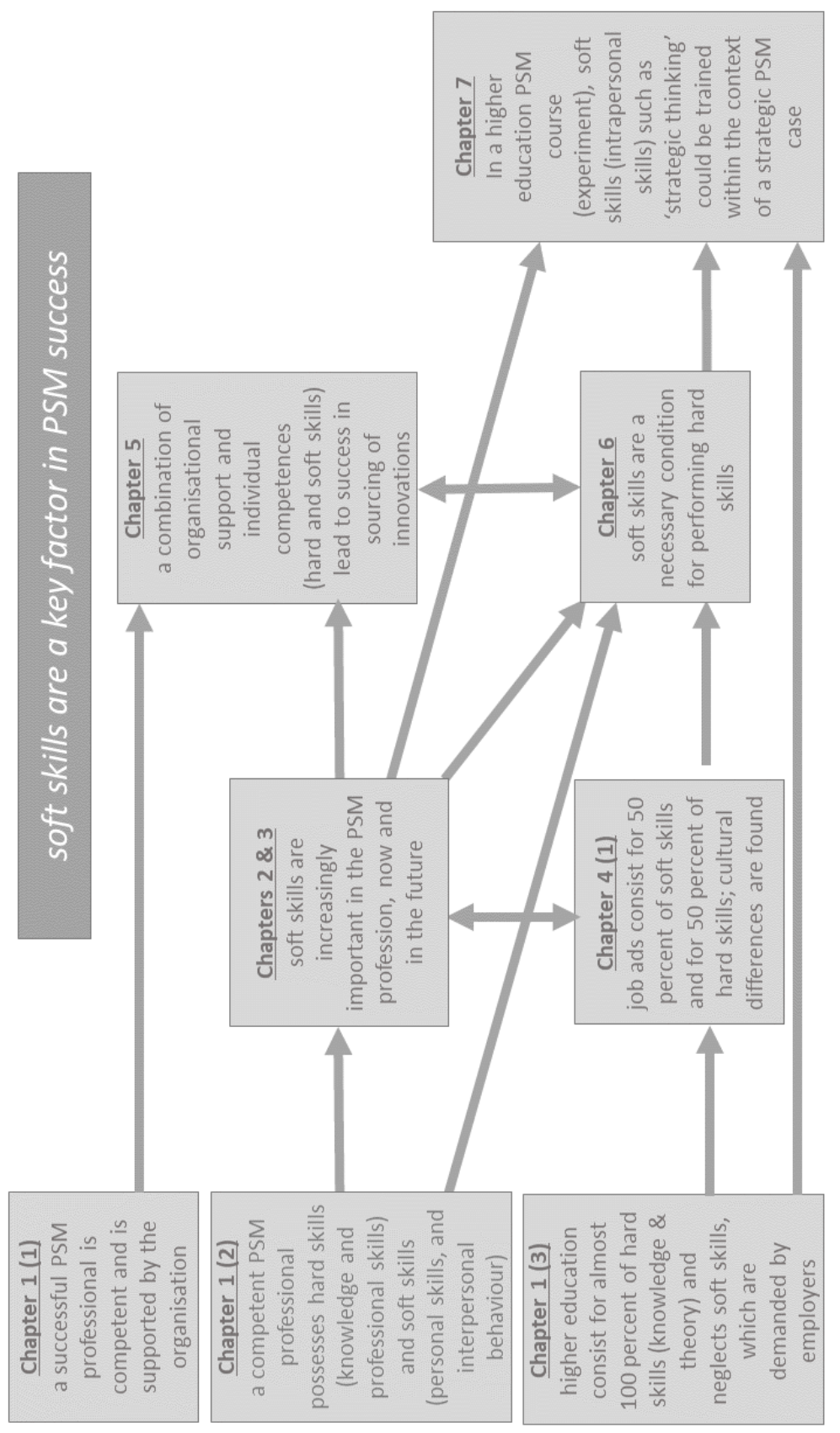

Figure 12.1 - Red thread in the dissertation: soft skills are key factors in PSM success 


\subsection{Samenvatting (Summary in Dutch)}

De hoofddoelstelling van het onderzoek in dit proefschrift is om uit te zoeken welke competenties tot succes leiden in de inkoop-en leveranciersmanagementfunctie (PSM) en de uiteindelijke focus ligt op de meest uitgesproken strategische activiteit bij inkoop, namelijk de acquisitie van innovaties.

In de afgelopen decennia is het inkoop- en leveranciersmanagement (PSM purchasing and supply management) veranderd van een operationele functie tot een strategische functie. Innovaties worden steeds vaker bij leveranciers ingekocht of mede met hen ontwikkeld. Dit plaatst de inkopers in de zogenaamde 'boundary spanner'-rol, wat betekent dat ze virtuele bruggenbouwers zijn geworden tussen de partners in de interne organisatie en de mogelijke leveranciers ergens op de wereldmarkt.

Inkopers vervullen een cruciale rol als 'boundary spanner', en een voorwaarde voor het succes van de inkoop is een hoge mate van top-managementondersteuning. Met kwantitatieve methoden wordt aangetoond dat investeren in de competentieontwikkeling van kopers zinloos is zonder het belang van de inkoopfunctie bij innovatiesourcing te erkennen. In een goede organisatorische omgeving kunnen inkopers hun competenties ontwikkelen en toepassen. In dit onderzoek werd het succes- of effectiviteitsniveau van kopers gemeten per specifieke inkoopfocus (d.w.z. kostenreductie, verbetering van kwaliteit, levering, duurzaamheid, innovatie-inkoop, leverancierstevredenheid en competetief voordeel) en de competenties van de kopers worden onthuld die ofwel voldoende ofwel noodzakelijk zijn. Veelal worden hard skills geassocieerd met succes of effectiviteit, maar soft skills zijn noodzakelijk voor het uitvoeren van hard skills.

De resultaten laten zien dat inkopers kennis en begrip van hun product en proces nodig hebben, maar vooral de essentie van soft skills komt duidelijk naar voren. Met kwantitatieve methodologieën werd een hiërarchie in competenties onthuld; soft skills vormen een noodzakelijke voorwaarde om professionele hard skills uit te oefenen. Een succesvolle inkoper van innovaties beschikt over vaardigheden als het kunnen netwerken, complexe probleemoplossing, proactiviteit, resultaatgerichtheid, conflictoplossing, creativiteit, overtuigingskracht, nieuwsgierigheid en een ondernemende houding. Deze soft skills zijn, zoals gezegd, nodig om hard skills goed uit te voeren zoals leveranciersrelatiebeheer, innovatiemanagement, analytische vaardigheden, proces- en projectmanagement en personeelsleiderschapsvaardigheden die de succesvolle inkoper van innovaties kenmerken.

Kopers moeten de inkoopstrategie afstemmen op de strategie van de organisatie en een strategisch inkoopplan uitvoeren. Om deze professionele hard skills uit te voeren, zijn soft skills, attitudes of eigenschappen nodig zoals strategisch denken, inventiviteit en creativiteit. Uit de literatuur blijkt echter dat universiteiten gericht zijn 
op het aanleren van hard skills en theorie. Daarom ontbreken soft skills meestal in de universitaire leerdoelen.

De aanbeveling van dit proefschrift voor het hoger onderwijs is om leerdoelen voor soft skills op te nemen. De vraag is niettemin of deze soft skills, d.w.z. attitudes of eigenschappen aangeboren zijn of ontwikkeld kunnen worden. Daarom werd een onderwijsexperiment uitgevoerd dat aantoonde hoe soft skills op eenvoudige wijze kunnen worden getraind met een studentgerichte benadering. Er werd onderscheid gemaakt tussen didactiek, leerresultaten en beoordeling van 'kennis', 'vaardigheden' en 'eigenschappen' met een boekschrijfproject, een real-life inkoopcasus en workshops ter bevordering van de persoonlijkheidsontwikkeling.

Bovendien wordt in dit proefschrift de historische context van de inkoopdiscipline en het onderwijs in het tijdperk van het Internet-of-Things of Industry 4.0 (d.w.z. de $4^{\mathrm{e}}$ Industriële Revolutie) verschaft. Er wordt een parallel getrokken met de uitdagingen tijdens de $1^{\mathrm{e}}$ Industriële Revolutie, ongeveer twee eeuwen geleden. De ontwikkeling van soft skills wordt sterk geassocieerd met de 19de-eeuwse "Bildung" idealen om 'betere burgers' te creëren. Onlangs klonk een soortgelijke oproep in de bijeenkomst van de Europese ministers van onderwijs: studenten moeten "in de toekomst actieve en verantwoordelijke burgers worden". Dit proefschrift waarschuwt dat gedwongen Bildung de bewuste zelfontwikkeling in de weg staat; de ontwikkeling van soft skills kan weliswaar worden beïnvloed met externe prikkels maar is een persoonlijke inspanning.

De conclusie die getrokken mag worden is dat de noodzaak van soft skills voor inkopers de rode draad vormt van dit proefschrift. Het gebrek aan aandacht voor de ontwikkeling van soft skills in PSM-curricula in het hoger onderwijs is de keerzijde van de medaille.

\subsection{Rode draad in het proefschrift}

In figuur 12.1 wordt deze rode draad grafisch weergegeven. Zoals beschreven in hoofdstuk 1, stelt de literatuur dat PSM-succes bereikt wordt met een combinatie van enerzijds competent personeel en anderzijds een hoog niveau van topmanagementondersteuning en erkenning voor de PSM-functie (bijv. Cousins et al., 2006; Tassabehji \& Moorhouse, 2008); hoofdstuk 5 geeft cijfermatig, empirisch bewijs voor deze stelling op basis van een groot aantal onderzoeksgegevens en met een polynoomregressietechniek.

In hoofdstuk 1 wordt de literatuur aangehaald dat een competente inkoper over de juiste set hard skills (d.w.z. kennis en professionele vaardigheden) en soft skills (interpersoonlijke vaardigheden en intra-persoonlijke eigenschappen en attitudes) 
beschikt (bijv. Bals et al., 2019; Giunipero \& Pearcy, 2000). Ondanks het grote belang van hard skills, vormt het nog grotere belang van intra-persoonlijke eigenschappen en attitudes een rode draad in dit proefschrift.

Het belang van soft skills is het afgelopen decennium toegenomen en zal in de nabije toekomst verder toenemen zoals beschreven in hoofdstuk 2 en 3 . In hoofdstuk 4 wordt aangetoond dat de helft van de vereisten in personeelsadvertenties kan worden gecategoriseerd als soft skills, waarvan twee derde intra-persoonlijke eigenschappen en attitudes en één derde interpersoonlijke, mens-tot-mens-vaardigheden. Bovendien worden de soft skills-eisen tegen het licht gehouden van de culturele context; werkgevers in verschillende landen vragen andere soft skills en vanwege structurele verschillen (service ten opzichte van industrie) worden andere hard skills verlangd.

Hoewel werkgevers een aanzienlijke hoeveelheid soft skills vereisen (zie: hoofdstukken 2 en 4), zijn de leerdoelen in het hoger onderwijs vooral gericht op het aanleren van hard skills en in enkele gevallen op soft skills en dan meer specifiek op slechts interpersoonlijke, mens-tot-mens communicatie (hoofdstuk 1). Er is dus een kloof tussen wat instellingen voor hoger onderwijs 'leveren' en wat werkgevers verlangen.

Soft skills zijn niet alleen 'belangrijk' voor het inkoopvak, maar zijn onmisbaar en daarom noodzakelijk, zoals in de literatuur wordt gesuggereerd en beschreven is in hoofdstuk 1. Hoofdstuk 6 draagt bij aan de literatuur en levert cijfermatig, empirisch bewijs dat soft skills noodzakelijke voorwaarden zijn voor het uitvoeren van harde vaardigheden. Een andere bijdrage van hoofdstuk 6 is dat het duidelijk aantoont dat voor verschillende PSM-focuspunten verschillende competentiesets nodig zijn (zie: figuur 12.1).

Zoals eerder werd opgemerkt, worden leerdoelen voor soft skills zelden aangetroffen in het hoger onderwijs in het algemeen (Hoidn, 2017) en in de specifieke gevallen van PSM, logistiek en supply chain management-curricula (bijv. Birou et al., 2016; Stinenbosch, 2017; Wong et al., 2014). De redenen voor het ontbreken van deze leerdoelen voor soft skills werden met name in de hoofstukken 1 en 6 beschreven. Deze leerdoelen ontbreken ondanks dat uit de literatuur duidelijk is dat soft skills kunnen worden ontwikkeld en dat deze door werkgevers zeer worden gewaardeerd. Daarom werd voor hoofdstuk 7 een experiment opgezet om aan te tonen hoe soft skills op eenvoudige wijze kunnen worden ontwikkeld in drie cohorten van master-studenten, telkens in een beperkte tijdspanne van tien weken. 


\subsection{Zusammenfassung in deutscher Sprache (Summary in German)}

Das übergeordnete Forschungsziel dieser Dissertation besteht darin, festzustellen, welche Kompetenzen zum Erfolg in der Einkaufs- und Lieferkettenmanagementfunktion (PSM) führen. Der Schwerpunkt liegt schließlich auf der ausgeprägtesten strategischen Aktivität im Einkauf, der Innovationsbeschaffung.

In den letzten Jahrzehnten hat sich die Einkauf- und Lieferkettenmanagementdisziplin von einer operativen zu einer strategischen Funktion gewandelt. Innovationen werden zunehmend von Lieferanten gekauft oder gemeinsam entwickelt. Dadurch werden die Einkäufer in die sogenannte „Boundary Spanner“-Rolle versetzt, was bedeutet, dass sie zu virtuellen Brückenbauern zwischen den Partnern in der internen Organisation und den möglichen Lieferanten auf dem Weltmarkt wurden.

Einkäufer spielen eine wichtige Rolle als „Boundary Spanner“. Voraussetzung für den Erfolg des Einkaufs ist ein hohes Maß an Unterstützung durch das TopManagement. Mit quantitativen Methoden wird gezeigt, dass Investitionen in die Kompetenzentwicklung der Einkäufer nutzlos sind, ohne die Bedeutung der Einkaufsfunktion für die Beschaffung von Innovationen anzuerkennen. In einer guten organisatorischen Atmosphäre können Einkäufer ihre Kompetenzen entwickeln und anwenden. In dieser Studie wurde der Erfolg oder die Effektivität der Einkäufer pro spezifischem Einkaufsfokus (z.B. Kostenreduzierung, Qualitätsverbesserung, Beschaffung von Innovationen) gemessen, und es wurden die Kompetenzen der Käufer ermittelt, die entweder ausreichend oder notwendig sind. Meistens sind Hard Skills mit Erfolg oder Effektivität verbunden, aber Soft Skills sind für Hard Skills erforderlich.

Die Ergebnisse zeigen, dass Einkäufer Wissen und Verständnis über ihr Produkt und ihren Prozess benötigen, aber die Essenz von Soft Skills hervorheben. Mit quantitativen Methoden wurde eine Hierarchie der Kompetenzen aufgedeckt; Soft Skills sind notwendige Bedingungen, um professionelle, Hard Skills auszuführen. Ein erfolgreicher Einkäufer für Innovationen verfügt über Netzwerkfähigkeiten, komplexe Problemlösungsfähigkeiten, Proaktivität, Ergebnisorientiertheit, Konfliktlösung, Kreativität, Überzeugungskraft, Neugier und eine unternehmerische Haltung. Diese Soft Skills sind erforderlich, um in Hard Skills wie Lieferantenbeziehungsmanagement, Innovationsmanagement, analytischen Fähigkeiten, Prozess- und Projektmanagement und Personalführungsfähigkeiten, die den erfolgreichen Einkäufer von Innovationen auszeichnen, gute Leistungen zu erbringen.

Einkäufer müssen die Einkaufsstrategie an der Strategie der Organisation ausrichten und einen strategischen Einkaufsplan erstellen. Um diese professionellen Hard Skills, Soft Skills, Einstellungen oder Eigenschaften auszuführen, sind strategisches Denken, Erfindungsreichtum und Kreativität erforderlich. Die Literatur zeigt jedoch, dass sich die Universitäten auf die Lernergebnisse in Bezug auf Hard Skills und Theorie konzentrieren. Daher fehlen in den Lernzielen der Kurse meistens Soft Skills. 
Die Empfehlung dieser Dissertation für die Hochschul- und Universitätbildung lautet, Lernziele für Soft Skills aufzunehmen. Die Frage ist jedoch, ob diese Einstellungen oder Eigenschaften angeboren sind oder entwickelt werden können. Daher würde ein pädagogisches Experiment durchgeführt, das zeigt, wie Soft Skills mit einem studentzentrierten Ansatz einfach trainiert werden können. Das Edukationskonstrukt unterscheidet zwischen Didaktik, Lernergebnissen und der Bewertung von "Wissen“, „Fähigkeiten“ und „Merkmalen“ mit einem Buchschreibprojekt, einem realen Einkauffall und Workshops zur Persönlichkeitsentwicklung.

Darüber hinaus wird der historische Kontext von Einkauf und Edukation im Zeitalter des Internet-of-Things oder der Industrie 4.0 (d.h. der 4. Industriellen Revolution) dargestellt. Es wird eine Parallele zu den Herausforderungen während der 1. Industriellen Revolution vor etwa zwei Jahrhunderten gezogen. Die Entwicklung von Soft Skills ist in hohem Maße mit den Bildung-Idealen im 19. Jahrhundert verbunden, um „bessere Bürger" zu schaffen. Kürzlich ertönte in den Bildungstreffen der europäischen Minister ein ähnlicher Aufruf: die Studenten müssen „in Zukunft aktive und verantwortungsbewusste Bürger werden". Diese These weist darauf hin, dass auferlegte Bildung die bewusste Selbstentwicklung behindern würde. Die Entwicklung von Soft Skills kann durch externe Reize beeinflusst werden; est ist aber eine persönliche Anstrengung.

Die Schlussfolgerung könnte sehr gut gezogen werden, dass die Notwendigkeit von Soft Skills für Einkäufer den roten Faden dieser Dissertation bildet. Das Fehlen von Aufmerksamkeit für die Entwicklung von Soft Skills in PSM-Lehrplänen im Universitätbereich ist sprichwörtlich die andere Seite derselben Medaille. In Kapitel 7 wird gezeigt, dass Soft Skills in kurzer Zeit entwickelt werden können.

\subsection{Der rote Faden der Dissertation}

In Abbildung 12.1 wird dieser rote Faden grafisch dargestellt. Wie in Kapitel 1 beschrieben, deutet die Literatur darauf hin, dass der Erfolg von PSM mit einem hochkompetenten Personal und einem hohen Maß an Unterstützung durch das TopManagement für die PSM-Funktion erreicht wird (z. B. Cousins et al., 2006; Tassabehji \& Moorhouse, 2008); Kapitel 5 liefert empirische Belege für diese Aussage auf der Grundlage eines umfangreichen Umfragedatensatzes und mit polynomiellen Regressionstechniken.

In Kapitel 1 wird gezeigt, dass die Literatur der Ansicht ist, dass ein kompetenter Einkäufer über die richtigen Hard Skills (d.h. Kenntnisse und berufliche Fähigkeiten) und Soft Skills (zwischenmenschliche Fähigkeiten und intrapersonale Merkmale und Verhaltensweisen) verfügt (z.B. Bals et al., 2019; Giunipero \& Pearcy, 2000). Trotz der hohen Bedeutung von Hard Skills bildet die noch höhere Bedeutung 
von intrapersonalen Eigenschaften und Verhaltensweisen einen roten Faden in dieser Dissertation.

Die Bedeutung von Soft Skills hat in die letzten Jahrzehnte zugenommen und wird weiter zunehmen, wie in Kapitel 2 und 3 beschrieben. Kapitel 4 zeigt, dass die Hälfte der Anforderungen an Stellenanzeigen als Soft Skills eingestuft werden können, von denen zwei Drittel intrapersonale Merkmale sind und ein Drittel zwischenmenschliche Fähigkeiten von Person zu Person. Darüber hinaus sind die Anforderungen an Soft Skills dem kulturellen Kontext ausgesetzt. Arbeitgeber in verschiedenen Ländern fordern andere Soft Skills, und aufgrund struktureller Unterschiede (Dienstleistung gegenüber Industrie) fordern Arbeitgeber andere Hard Skills.

Obwohl Arbeitgeber ein beträchtliches Volumen an Soft Skills fordern (siehe: Kapitel 2 und 4), konzentrieren sich die Lernziele in der Universität- und Hochschulbildung hauptsächlich auf das Erlernen von Hard Skills und gelegentlich auf Soft Skills und genauer auf die zwischenmenschliche Kommunikation von Person zu Person, meist beschränkt auf Präsentationsfähigkeiten und Teamwork (siehe: Kapitel 1). Daher besteht eine Lücke zwischen den Leistungen der Hochschulen und Universitäten und den Anforderungen der Arbeitgeber. Soft Skills sind nicht nur für den Einkauf „wichtig“, sondern unverzichtbar und daher notwendig, wie in der Literatur vorgeschlagen und in Kapitel 1 beschrieben. Kapitel 6 trägt zur Literatur bei und liefert empirische Belege dafür, dass Soft Skills notwendige Bedingungen für die Durchführung von Hard Skills sind. Ein weiterer Beitrag von Kapitel 6 besteht darin, dass gezeigt wird, dass für verschiedene PSM-Schwerpunkte unterschiedliche Kompetenzsätze erforderlich sind (siehe: Abbildung 12.1).

Wie bereits erwähnt, werden in der Hochschul- und Universitätsbildung Lernziele für Soft Skills im Allgemeinen (Hoidn, 2017) oder in den spezifischen Lehrplänen für PSM, Logistik und Lieferkettenmanagement (z. B. Birou et al., 2016; Stinenbosch, 2017; Wong et al. 2014) selten gefunden. Das Fehlen dieser Soft Skills Lernziele wird beschrieben, obwohl in der Literatur klar ist, dass Soft Skills von Arbeitgebern hochgeschätzt werden können. Daher wurde in Kapitel 7 ein Experiment durchgeführt, um zu demonstrieren, wie Soft Skills in drei Kohorten von Masterstudenten entwickelt werden können.

\subsection{Roadmap for Practitioners - How to use the outcomes of this dissertation in the Human Resources practice}

Project PERFECT's research ideas inspired this dissertation, i.e. to translate the competences that lead to successful performances in the PSM profession into PSM learning objectives of higher education institutions. Chapter 8 addressed the overall 
research aim, and the question of how PSM in higher education could be designed is answered in Chapter 7. What also was brought to the surface is how practitioners, especially those involved in HRM and PSM leadership, could benefit from the insights that come forth from the project and this thesis. In this section, practical guidance is given for those who are responsible for HRM practices in PSM

Presuming that the PSM strategy in the focal organisation is aligned with the organisational strategy as is depicted in Figure 12.2, the first takeaway is that the PSM has to define the PSM objective or objectives in line with the strategy of the employing organisation. In this thesis, the following PSM objectives are covered: reducing cost and improving quality, sustainability, delivery, innovation sourcing, competitive advantage and supplier satisfaction. Once the main objectives are made clear, the PSM competences important for the organisation have to be identified, as elaborated in Chapter 6 . The distinction should be made between the essential competences that should be covered by the whole team of PSM professionals and those held by the subsequent individuals.

The Project PERFECT assessment tool (http://supplycompetence.com) or the listing in Appendix 9.14 could be applied to estimate the individual competence levels. Preferably, a 360-degree method should be employed, meaning that an individual professional is not self-rating the own competence levels, but that peers and the individual manager fill out the same questionnaire regarding that individual's competence levels. The differences in the individual's perceived competence levels, the peers and the manager, and the previous stated desired competence level can identify those underdeveloped per individual. It would lead to an agreement on an individual personal development plan or an alternative job career agreement. 


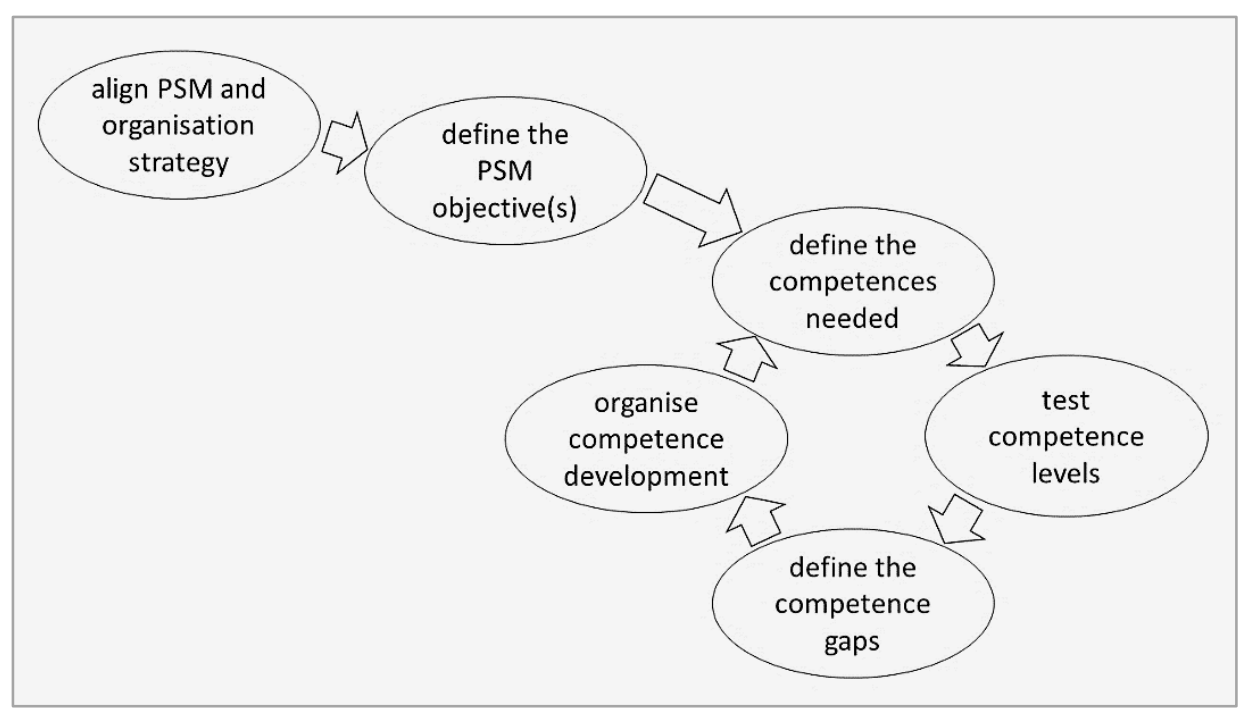

Figure 12.2 - Graphical outline: the organisation of PSM competence development

After the individual competence gaps are identified, the total gap between the desired and existing competences can be defined for the whole PSM organisation, which would lead to an educational and possibly to a recruitment plan that could be joined in a PSM competence development strategy. Figure 12.2 shows the subsequent steps that eventually lead to a cycle in which periodically is checked whether the required competences are still sufficient.

\subsection{Routekaart voor professionals - Hoe de resultaten van dit proefschrift te gebruiken in de Human Resources-praktijk}

Dit proefschrift is gebaseerd op de onderzoeksideeën van Project PERFECT, namelijk het vertalen van de competenties die leiden tot succesvolle prestaties in het PSM-beroep naar PSM-leerdoelen van instellingen voor hoger onderwijs. Het antwoord op het overkoepelende onderzoeksdoel wordt behandeld in hoofdstuk 8 en de vraag hoe PSM in het hoger onderwijs vormgegeven kan worden, wordt beantwoord in hoofdstuk 7. Wat ook aan de oppervlakte kwam is hoe beoefenaars, vooral degenen die betrokken zijn bij HRM- en PSM-leiderschap, kunnen profiteren van de inzichten die uit het project en dit proefschrift naar voren komen. In deze paragraaf worden praktische richtlijnen gegeven voor degenen die verantwoordelijk zijn voor HRMpraktijken in PSM. 
Ervan uitgaande dat de PSM-strategie in de betreffende organisatie in lijn is met de organisatiestrategie zoals weergegeven in Figuur 12.2, is het eerste aandachtspunt dat de PSM-functie de doelstellingen moet definiëren waar de organisatie in kwestie naar streeft. In dit proefschrift komen de volgende PSMdoelstellingen aan bod: het verlagen van kosten en het verbeteren van kwaliteit, duurzaamheid, levering, innovatie-sourcing, concurrentievoordeel en leverancierstevredenheid. Zodra de belangrijkste doelstellingen helder zijn, moeten de PSM-competenties die belangrijk zijn voor de organisatie worden geïdentificeerd zoals uitgewerkt in hoofdstuk 6. Op dit punt moet het onderscheid worden gemaakt tussen de cruciale competenties die moeten worden vervuld door het hele PSM-team en de afzonderlijke individuen in het team.

Om de individuele competentieniveaus te meten, zou het Project PERFECT assessment tool (http://supplycompetence.com) of de lijst in bijlage 9.14 kunnen worden gebruikt. Bij voorkeur wordt een 360-graden methode gehanteerd, wat betekent dat een individuele professional niet zelf de eigen competentieniveaus beoordeelt, maar dat ook peers en de manager van het individu dezelfde vragenlijst invullen over de competentieniveaus van dat individu. De verschillen in de zelf-ervaren competentieniveaus van het individu, de peers en de manager plus het eerdergenoemde gewenste competentieniveau kunnen worden gebruikt om per individu te identificeren welke competenties onderontwikkeld zijn. Dit zou leiden tot overeenstemming om tot een individueel persoonlijk ontwikkelingsplan of zelfs een alternatieve beroepsloopbaan te komen.

Nadat de individuele competentiegaten zijn geïdentificeerd, kan de totale kloof tussen de gewenste en bestaande competenties worden gedefinieerd voor de hele PSM-organisatie, wat bij voorkeur zou leiden tot een educatie- en eventueel een wervingsplan, dat zou kunnen worden samengevoegd in een PSMcompetentieontwikkelingsstrategie. In figuur 12.2 zijn de vervolgstappen afgebeeld die uiteindelijk leiden tot een cyclus waarin periodiek wordt getoetst of de benodigde competenties nog voldoende zijn.

\subsection{Roadmap für Praktiker - Verwendung der Ergebnisse dieser Dissertation in der Personalpraxis}

Die Forschungsideen von Project PERFECT haben diese Dissertation inspiriert, d.h. die Kompetenzen, die zu erfolgreichen Leistungen im PSM-Beruf führen, in PSMLernziele von Universitäten und Hochschuleinrichtungen umzusetzen. Kapitel 8 befasste sich mit dem allgemeinen Forschungsziel, und die Frage, wie PSM in der Universitäts- und Hochschulbildung gestaltet werden könnte, wird in Kapitel 7 beantwortet. Es wurde auch an die Oberfläche gebracht, wie Praktiker, insbesondere diejenigen, die an HRM- und PSM-Führung beteiligt sind, davon profitieren könnten 
Erkenntnisse, die aus dem Projekt und dieser These hervorgehen, anzuwenden. In diesem Abschnitt werden praktische Anleitungen für diejenigen gegeben, die für HRMPraktiken in PSM verantwortlich sind.

Unter der Annahme, dass die PSM-Strategie in der Schwerpunktorganisation, mit der in Abbildung 12.2 dargestellten Organisationsstrategie übereinstimmt, muss der PSM zunächst die PSM-Ziele im Einklang mit der Strategie der beschäftigenden Organisation definieren. In dieser Arbeit werden die folgenden PSM-Ziele behandelt: Kostensenkung und Verbesserung von Qualität, Nachhaltigkeit, Lieferung, Innovationsbeschaffung, Wettbewerbsvorteil und Lieferanten-zufriedenheit. Sobald die Hauptziele klargestellt sind, müssen die für die Organisation wichtigen PSMKompetenzen identifiziert werden, wie in Kapitel 6 erläutert. Es sollte unterschieden werden zwischen den wesentlichen Kompetenzen, die vom gesamten Team der PSMFachkräfte abgedeckt werden sollten, und denen von den nachfolgenden Personen.

Das Project PERFECT-Bewertungstool (http://supplycompetence.com) oder die Auflistung in Anhang 9.14 können zur Schätzung der einzelnen Kompetenzstufen verwendet werden. Vorzugsweise sollte eine 360-Grad-Methode angewendet werden, was bedeutet, dass ein einzelner Fachmann oder Fachfrau die eigenen Kompetenzstufen nicht selbst bewertet, sondern dass Kollegen und der einzelne Manager denselben Fragebogen bezüglich der Kompetenzstufen dieser Person ausfüllen. Die Unterschiede in den wahrgenommenen Kompetenzniveaus des Einzelnen, der Kollegen und dem Manager sowie dem zuvor angegebenen gewünschten Kompetenzniveau zeigen die unterentwickelten Kompetenzen der einzelnen Individuen. Dies würde zu einer Einigung über einen individuellen persönlichen Entwicklungsplan oder eine alternative Berufsvereinbarung führen.

Nachdem die einzelnen Kompetenzlücken identifiziert wurden, kann die Gesamtlücke zwischen den gewünschten und den vorhandenen Kompetenzen für die gesamte PSM-Organisation definiert werden, was zu einem Bildungs- und möglicherweise zu einem Einstellungsplan führen würde, der in eine PSMKompetenzentwicklungsstrategie eingebunden werden könnte. Abbildung 12.2 zeigt die nachfolgenden Schritte, die schließlich zu einem Zyklus führen, in dem regelmäßig überprüft wird, ob die erforderlichen Kompetenzen noch ausreichen.

\subsection{Propositions}

A maximum of ten propositions is be appended to the dissertation. The first four propositions are based on the findings in this dissertation. The second four propositions have an academic and scientific nature related to one or several subjects in the thesis, and the last two propositions have a general character. 


\section{propositions related to the dissertation}

1) The ideal PSM competence set does not exist; it depends on focus and culture.

2) Individual PSM competences and organisational or top-managerial support and recognition for PSM are related in a complementary form.

3) Interpersonal skills and intrapersonal traits are necessary to carry out professional skills.

4) Master students are easily influenced in their soft skills development.

\section{propositions of an academic/scientific nature relate to one or several subjects}

5) In PSM recruitment procedures, Neanderthal applicants should be neglected.

6) Knowledge, skills and attitudes form an indivisible competence 'triangle'.

7) "Everyday creativity (also called "little-c")" is regarding: "creative activities in which the average person may participate each day," such as "coming up with a creative solution to a complex scheduling problem at work" (Kaufman \& Beghetto, 2009, p. 1).

8) "At least there is a tolerably general agreement about what an (sic!) University is not. It is not a place of professional education. Universities are not intended to teach the knowledge required to fit men for some special mode of gaining their livelihood. Their object is not to make skilful lawyers, or physicians, or engineers, but capable and cultivated human beings" (Mill, 1867, p. 4).

\section{general propositions}

9) "Quemadmodum omnium rerum, sic litterarum quoque intemperantia laboramus; non vitæ sed scholæ discimus" ("Just as we suffer from excess in all things, so we suffer from excess in literature; thus we learn our lessons, not for life, but for the lecture-room"; Seneca, 1925 [65 AD], p. 223).

10) "Education is not in reality what some people proclaim it to be in their profession. What they aver is that they can put true knowledge into a soul that does not possess it, as if they were inserting vision into blind eyes" (Plato, 1992 [375 BC], Book 7,

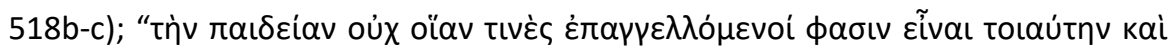

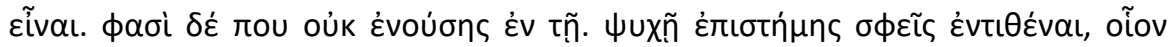

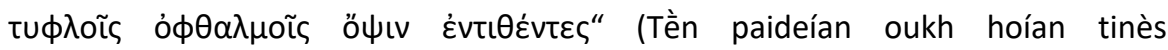
epangellómenoí phasin eĩnai toiaútēn kaì eĩnai. Phasì dé pou ouk enoúsēs en tẹ̃. Psukhẹ̃ epistếmēs spheĩs entithénai, hoĩon tuphloĩs ophthalmoĩs ópsin entithéntes) (Plato, 1903 [375 BC], Book 7, 518ß-६). 


\section{About the Author and Acknowledgements}




\section{ABOUT THE AUTHOR AND ACKNOWLEDGEMENTS}

When I enrolled at the University of Twente in the master track Purchasing and Supply Management, I was already in my late forties. From the mid-1980s until the early 1990s, I studied economic science and law at the University of Applied Sciences NHL teacher training in Groningen (NL). I participated in student exchanges with the then Karl Marx University in Budapest, Hungary (now Corvinus University) and the University of Northern Colorado Greeley, Colorado, USA.

Next, I graduated from the University of Groningen (Netherlands) in Central and East-European studies at the Faculty of Economic Sciences, the Law Faculty, the Faculties of Philosophy, Theology and Sociology, and the Arts Faculty. It explains the historical and philosophical foci in this dissertation. After graduation, I worked as a secondary education teacher, a paralegal in the financial sector, and as a lecturer and thesis supervisor at a university of applied sciences for tourism, hospitality, and event management.

In 2015, I decided to enrol again. I chose for the PSM master track at the University of Twente, where I met Holger Schiele and Niels Pulles, who eventually supervised my master thesis. Niels suggested writing my master thesis in Project PERFECT and continuing as a PhD candidate. After some sleepless nights, I decided to join the project. In February 2016, I was invited for the first transnational meeting of Project PERFECT at the Fraunhofer Institute at TU Dortmund. A few months later, in August 2016, I graduated on cultural differences in PSM job advertisements and got employed at Holger Schiele's Technology Management and Supply (TMS) department by September 2016.

TMS is known for its warm atmosphere, and during the start of my research, I always found an open door with my closest colleague and fellow PhD-student Frederik Vos. I could benefit from his unlimited knowledge of statistical trivia, and we discussed the methodologies of the research papers. Moreover, we made fun at joyful events or 
daily lunch breaks. We developed a never fulfilled plan to establish the University of Ibiza, which would have been located at a white Mediterranean beach. Our finest hour came when Holger appointed us as volunteers to be paranymphs for a doctoral defence of our external PhD-candidate Justus Eggers in autumn 2016. In penguin suits, we presented the best simultaneous speech ever performed by two Laurel-and-Hardylook-a-like paranymphs.

Besides Holger, Niels and Frederik, I would express my thanks to the staff members Petra Hoffmann, Erwin Hofman, Louise Knight, Matthias de Visser, Remco Siebelink, Aldís Sigurðardóttir, Jan Telgen, Fabio Cerquinho, Henrike Fitschen, Paul Scheffler, Srikanta Routroy, Matteo di Domenico, Georg Mohr and Phillip Horn; and to my fellow PhD-students in the past years: Vincent Delke, Justus Eggers, Tobias Bohnekamp, Franz Simon, Ines Schulze Horn, Antonia Kappel, Janina Goldberg, Madelon Wind, Juliano Tessaro, Bita Mirzaei, Thomas Körber and André Grothus; and of course the supporting staff over the past years: Jeannette Visser, Monique Zuithof and Marie-Christine Prédéry. Further, I owe thanks to Desirée van Dun (CM\&OB), Martin Stienstra (NIKOS), Tanya Bondarouk, Jeroen Meijerink, Maarten Renkema and Milou Habraken (HRM) for their help and expertise.

I have experienced a cooperative and friendly atmosphere with my colleagues in the European Project PERFECT. I would express my gratefulness to the team members from the Technical University of Dortmund, Germany: Michael Henke, Natalia Straub, Laura Berger, Philipp Asterios Ioannidis and Dennis Meyer, from Lappeenranta, Finland: Jukka Hallikas and Elina Karttunen, from Staffordshire University and Edge Hill University, UK: Stephen Kelly, Tom Ward and Peter Vangorp, and from Mainz University for Applied Sciences: Lydia Bals and Heike Schulze. Moreover, I would like to thank my qualifier exam committee that approved my research proposal at the IFPSM Summer School at UTwente in June 2017: Mats Bergmann (Södertön University, Sweden), Christoph Bode (University of Mannheim, Germany), Chris Ellegaard (Aarhus University, Denmark), and Larry Giunipero (Florida State University, USA).

From October 2017 to May 2018 and from May 2020 to August 2020, I was employed at the Graz University of Technology (TU Graz) at the chair of Business Economics and Industrial Sociology (BWL - Betriebswirtschafstlehre) of the Faculty of Mechanical Engineering. I am thankful for BWL's chairholder Ulrich Bauer and staff members Bernd Zunk and Volker Koch, whom I cooperated with from 2016 in the research on job requirements and competences in PSM. Bernd contributed to the development of my dissertation and research ideas. A unique friendship grew over time when discussing purchasing and supply educational issues, but also elaborating about art, music and literature, while having a couple of beers (ein Paar Bier, oder ein paar Bier) at Kaiser-Josef-Platz, in Stadtpark, at Gösser Bräu, at Geidorfstub'n or his place in Franckstraße in Graz. 
A special memory was attending the LIMEN 2017 conference with my TU Graz colleagues Stephan Grbenic, Amila Omazic and Sigrid Weller in Belgrade, Serbia, in December 2017. In February 2018, we carried out a plan to establish another exchange between UTwente and TU Graz, thanks to the kind willingness of UTwente Prof. Rezaul Kabir, chair of Corporate Finance and Risk Management. In May and June 2018, Stephan visited UTwente and was followed by Amila in February 2019.

In the meanwhile, in 2018, Project PERFECT came to its completion and ideas were formed to apply for a follow-up project on PSM competences in the era of Industry 4.0 and machine-to-machine-communication, entitled Project PERSIST. The first attempt in March 2018 failed, and we made a new strategy in Dortmund in November 2018. In December 2018, we met at the campus of UTwente, and in early March 2019, we finalised the application idea in Dortmund. In the following two weeks, the complete application for Project PERSIST was settled by the TU DortmundUTwente-team. In Summer 2019, the Dutch National Agency informed us that the project was awarded. Most of the PERFECT members are now cooperating in PERSIST. Newcomer to the action is Michal Tkáč of the University of Economics in Bratislava with a seat in Košice, Slovakia, whose hospitality we enjoyed in early March 2020, just some days before Europe went in lockdown due to the Covid measurements.

In Autumn 2018, within the IPSERA particular interest group Purchasing \& Product Innovation, an idea for another successor of Project PERFECT was developed. Together with Katia Picaud-Bello of ESSCA (École Supérieure des Sciences Commerciales d'Angers) in Angers, France, an idea was worked out to deepen PSM competences in the process of sourcing innovations from suppliers. In our extensive meetings via the almost forgotten application Skype, we agreed to add sustainable purchasing, and we named it Project PERISCOPE. Bernd and Volker at TU Graz joined, and so did Katia's promoter Thomas Johnsen and his staff member François Constant (Audencia, Nantes, France), and Andreas Wieland and Philip Beske-Janssen of Copenhagen Business School (CBS) in Denmark.

Meanwhile, the PERISCOPE application was already written based on the PERSIST application, and we were happy to have Audencia and CBS at PERISCOPE. Our invitation came at concise notice and created a pressure-cooker-situation in Nantes and Copenhagen. It worked surprisingly well. PERISCOPE was handed in with the French agency and was also awarded and started successful, and in the meanwhile, we welcomed ESSCA's Murielle Francillette in PERISCOPE and UTwente's Gaby Maris in PERSIST. I thank all PERSIST and PERISCOPE members for their trust and willingness to cooperate and also the supporting staff of legal advisors and financial controllers.

Many PERFECT, PERSIST, and PERISCOPE papers were handed in for the IPSERA conferences. IPSERA is a unique community, and I am thankful for the friendly feedback I got at the presentations of PERFECT and the paper presentations at the conferences 
in Dortmund (2016), Budapest and Balatonfüred (2017), Athens (2018), Milan (2019) and online in 2021. The online 2021 version is very special to me. In 2021, I received with Katia Picaud-Bello and Volker Koch the best paper award IPSERA 2021. Further, I would like to thank my master students who graduated within the context of PERFECT: Haoqing Zhang (European and Chinese PSM job ads), Shannon van Hoorn (public procurement competences; i.e. the basis for Chapter 3), Tess Bijl (gender differences in PSM competences) and Rafal Wisniewski (PSM competence development in a crosssectional sample).

The outcomes of the projects drew third parties' attention, giving me a platform to disseminate the project's outcomes. My gratitude goes out to the following persons: Freek Andriesse, deputy editor in chief of Purchasing and Supply Management Magazine Deal! of the Dutch purchasing management association NEVI for accepting half a dozen articles; Anne Staal, lecturer at Hanzehogeschool for inviting me as a keynote speaker for their North Netherlands Purchasing Conference in Groningen in January 2019; Heinz Pechek, director of BMÖ (Austrian association for logistics and purchasing, Vienna, Austria) for his invitation to address the BMÖ-Austrian Purchasing Forum in Vienna in October 2018; Richard Calvi (Université Savoie Mont-Blanc, Chambéry, France) and Nathalie Leroy (managing director of Conseil National des Achats - CNA, Paris, France) for inviting Vincent Delke and me for their webinar on Procurement 4.0 competences.

As described in Chapter 7, this dissertation's outcomes are applied in the elective introductory course Purchasing Management for the master Industrial Engineering and Management at UTwente, which I coordinate. The learning objectives are divided into explicit PSM knowledge and theory, second in professional skills and interpersonal, human-to-human skills, and third in intrapersonal attitudes. The course provides classical lectures, workshop, tutoring, guest lectures and student presentation. It is built upon three pillars: writing a scientific paper, solving a case study and developing personal skills. I express my gratitude to the 95 students in the three cohorts who agreed to use their survey data for scientific use.

Designing a course from scratch has been an effort or even a quest. I would not have succeeded without the help of Hans van den Berg, educational consultant at the Centre of Expertise in Learning and Teaching (CELT) at UTwente. Content-wise, I could exchange and develop ideas with sparring partner and public procurer Sander Vaneker (Dutch Tax Authorities). My inspirator for the student-centred approach is my lecturer in Groningen, Geert Hoevers, whom I count as a close friend. Geert is a Bildung adept, who educated and formed me, and he was very helpful in designing the didactics of my courses at UTwente. We discussed and evaluated the course many times in his house in the Groningen countryside. 
Together with Sander, the idea originated to introduce a real-life case study from the purchasing practice, and we contacted the purchasing department of UTwente. Thanks to its manager, Geert-Jan Westhof cooperation, was established with purchasers Linda Pariënte in 2019 and Bert Kloppers in 2020. Linda provided us with the ins and outs of tendering the design of an on-campus building for ITC, the Faculty of Geo-Information Science and Earth Observation. A year later, Bert suggested introducing the tender for hot beverage vending machines.

Linda and Bert were involved at the kick-offs and the evaluation of the cases. Moreover, they introduced other UTwente colleagues involved in the cases. In 2019, Annemarie Arets, Secretary to the Board of ITC and Rob Nengerman, building project manager, were part of the team. In 2020, the team was formed with Anouk van der Wal (contract manager), Brechje Maréchal (sustainability officer) and Chantal Hilgeholt (contract responsible). The case study assignments were deliberately written in a limited form. Students are supposed to interview these team members. The title we gave the real-life case study is talking with 'real people'.

This dissertation's outcome is that students can understand and learn more effectively and efficiently thanks to listening and talking to real people. In the course, many professionals contributed to sharing professional knowledge and personal experiences. I want to thank Vincent Delke, Aldís Sigurđardóttir, Jan Telgen, Fredo Schotanus and Leentje Volker (fellow UTwente-lecturers), Wolter van der Vlist (policymaker), Frank Oort, Norbert Romeijn, and Bert Timmer (CPOs), Paul Maatman (marketing manager \& tenders), Nick Provoost, Nienke Ebbers, Mark Plate and Sevim Garip (purchasing consultants) and Mirjam Bult, who as the vice-president of the Executive Board of UTwente addressed the 2019-cohort.

I want to thank my parents Marga and Tjabering Stek, for the loving upbringing they gave my younger brother Martin and me. Further, I am sure my children Wouter, Maarten and Friso, not only saw me working on this dissertation. I like to thank my exwife Yvonne, who encouraged me to take up a study again. Next, I thank my friends Steven, Jent, Johan and Reinier, whom I know since we were studying economics in Groningen (that was indeed in another century) and who are happy to let me theorise in our chat group. A special word of thank is for my partner Sylvia, who was very patient with me, even when I was working during our holidays in Spain in Summer 2017 (recruiting Project PERFECT survey participants via LinkedIn), writing a working paper during our stay at our holidays in France in 2018, and working in Graz in the academic year 2017-2018 and the summer of 2020.

I feel privileged. Thank you all! 




\section{PURCHASING SKILLS LEADING TO}

\section{SUCCESS \\ RIAAS STEK}

"All animals are equal, but some animals are more equal than others," George Orwell (1945, p. 51) wrote in Animal Farm. The starting point of PURCHASING SKILLS LEADING TO SUCCESS is that humans or Homo Sapiens are more equal than other creatures. Homo Sapiens became world champions in task specialisation, trade, sales, and purchasing and therefore did survive archaic humans, like the Neanderthals. Homo Sapiens combined creativity with curiosity and social networking skills, which led to continuous development in technology and science, demonstrated in organisations and businesses. Eventually, Homo Sapiens' way of cooperating ran to increasingly complex supply chains in which purchasers are responsible for a multitude of challenges.

Supply or value chains became complex since make-or-buy decisions in organisations led to more buying activities due to globalisation and global sourcing. In an average industrial company, 60 to 80 per cent of the total value is transferred to suppliers. In the $1960 \mathrm{~s}$, this was just 10 to 20 per cent. A challenge for the modern purchaser is to fulfil the 'bridge-builder'-role to connect the internal organisational partners with possible suppliers on the global market. The quest for Purchasing and Supply Management (PSM) is to maintain a staff of competent purchasers. PURCHASING SKILLS LEADING TO SUCCESS focuses on those competences that lead to success in the most strategic PSM activity: innovation sourcing. PURCHASING SKILLS LEADING TO SUCCESS is dedicated to those competences that are important and necessary, and that will lead to success, whereas previous research wrongly assumed that important competences are de facto necessary and always lead to success. Both, competence sets and professional success levels of purchasers are carefully measured and analysed to determine which competences lead to which successes; ranging from reducing costs to innovation sourcing.

An important finding is that soft skills are necessary conditions to carry out professional hard skills. A successful purchaser for innovations possesses networking skills, complex problem solving, proactivity, result-drive, conflict-resolution, creativity, persuasion, curiosity and an entrepreneurial attitude. These soft skills are necessary to perform well in hard skills such as supplier relationship management and innovation management skills, analytical skills, process and project management skills and personnel leadership skills.

Although purchasers first need these soft skills to carry out hard skills, surprisingly, PSM curricula in academia are exclusively focused on learning hard skills (knowledge, theory and professional and communication skills). In contrast, employers highly appreciate the abovementioned soft skills. PURCHASING SKILLS LEADING TO SUCCESS shows educators and students how soft skills can be trained and assessed, and it gives guidance to employers on which competences are necessary in which case and how to develop individual purchasers successfully. Concluding, purchasers who have read PURCHASING SKILLS LEADING TO SUCCESS have an advantage and will be more equal than others. 